UNIVERSIDADE DE SÃO PAULO

ESCOLA DE ENGENHARIA DE SÃO CARLOS

DEPARTAMENTO DE ENGENHARIA DE ESTRUTURAS

\title{
ANÁLISE TEÓRICA E EXPERIMENTAL DE PERFIS DE AÇO FORMADOS A FRIO SUBMETIDOS À COMPRESSÃO
}

\section{Gustavo Monteiro de Barros Chodraui}

Orientador: Prof. Associado Maximiliano Malite

Tese apresentada à Escola de Engenharia de São Carlos da Universidade de São Paulo, como parte dos requisitos para obtenção do Título de Doutor em Engenharia de Estruturas.

São Carlos 

Tese de Doutorado - Gustavo Monteiro de Barros Chodraui

"Nunca ande pelo caminho traçado, pois ele conduz somente até onde os outros foram"

Alexander Graham Bell

"A força não provém da capacidade física e sim de uma vontade indomável"

"Seja você mesmo as mudanças que quer ver no mundo"

Mahatma Gandhi

"Procure ser uma pessoa de valor, em vez de ser uma pessoa de sucesso"

"A mente que se abre a uma nova idéia jamais volta ao seu tamanho original"

Albert Einstein

"Não há nada como um sonho para criar o futuro"

Victor Hugo

Aos meus pais, Carlos Alberto Chodraui e Regina Helena Monteiro de Barros Chodraui. À minha irmã, Juliana. 
Tese de Doutorado - Gustavo Monteiro de Barros Chodraui 


\section{AGRADECIMENTOS}

A Deus, que sempre me deu forças para percorrer meu caminho corretamente.

À minha família, mais uma vez, que é a base de tudo na minha vida.

À querida Fer, e aos meus parentes e amigos, que sempre me incentivaram e apoiaram, em todos os momentos.

Ao professor Maximiliano Malite, pela imensa orientação, amizade e incentivo desde o período de graduação. Sua orientação foi essencial para a qualidade deste e de outros trabalhos.

Ao professor Benjamin W. Schafer, da The Johns Hopkins University, Baltimore, E.U.A., pela valiosa ajuda, em especial durante o período em que morei nos Estados Unidos e com ele e sua equipe pude conviver via minha bolsa sanduíche.

Aos professores Roberto Martins Gonçalves, José Jairo de Sales e Jorge Munaiar Neto, pela atenção e amizade, e também aos demais professores que me ajudaram ao longo deste percurso.

Aos professores Roger LaBoube e Wei-Wen Yu, da University of Missouri-Rolla (EUA), que me acolheram com muito carinho durante minha breve estada na cidade de Rolla, conversando comigo sobre este trabalho e permitindo livre acesso à biblioteca da UMR, onde existe um acervo imenso sobre perfis formados a frio.

Aos colegas do Departamento, por todos os momentos compartilhados, dentro e fora da Universidade. Especial agradecimento aos colegas que me ajudaram especificamente com a elaboração da Tese (em ordem alfabética): Adilson Takeuti, Alex Sander Souza, Cilmar Baságlia, Daniela David, Gustavo Tristão, Ricardo Carrazedo, Tatianne Kotinda, Yuri Maggi, entre outros.

Aos funcionários do Departamento, pela constante ajuda.

Ao pessoal do Laboratório de Estruturas, todos muito importantes para que eu obtivesse sucesso nos ensaios.

Ao engenheiro civil José Carlos D’Ambrósio da Silva, pela amizade e ensinamentos relacionados aos aspectos mais variados da engenharia.

À USIMINAS, pelos recursos que foram utilizados para a compra dos perfis, chapas e demais necessidades para os ensaios.

À FAPESP - Fundação de Amparo à Pesquisa do Estado de São Paulo, pela concessão da bolsa de estudos. 
Tese de Doutorado - Gustavo Monteiro de Barros Chodraui 


\section{SUMÁRIO}

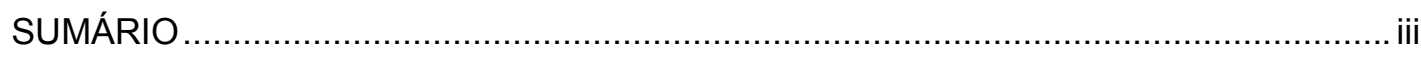

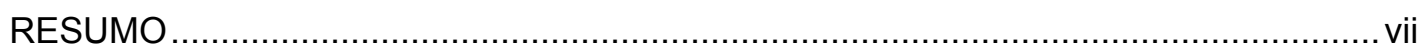

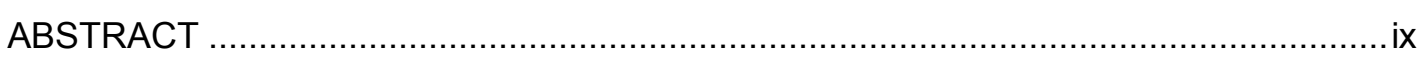

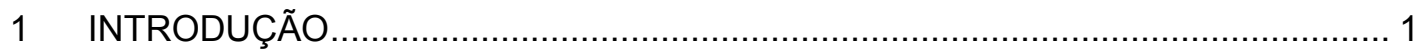

2 FATORES QUE INFLUENCIAM NA RESISTÊNCIA DAS BARRAS SUBMETIDAS

À COMPRESSÃO

2.1 Propriedades mecânicas .................................................................... 7

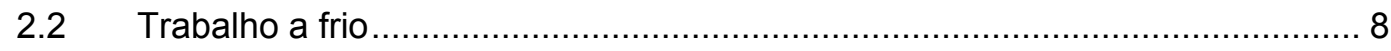

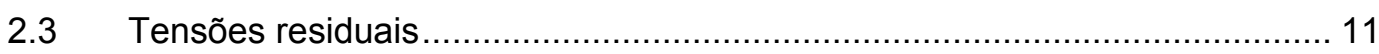

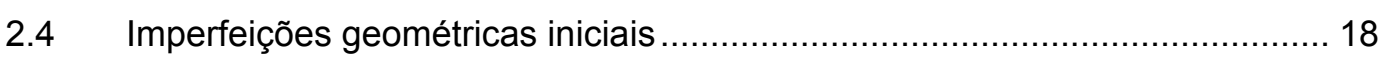

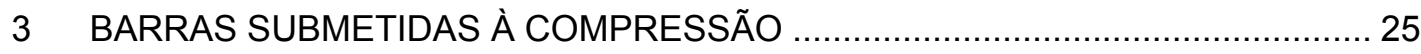

3.1 Instabilidade: conceitos e definições importantes......................................... 25

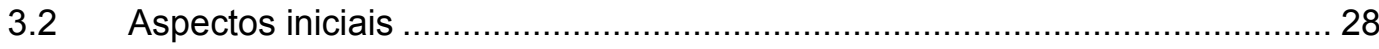

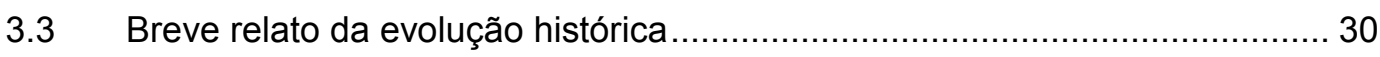

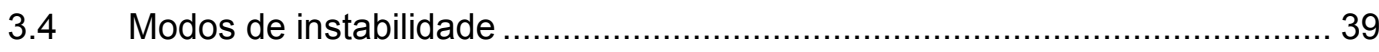

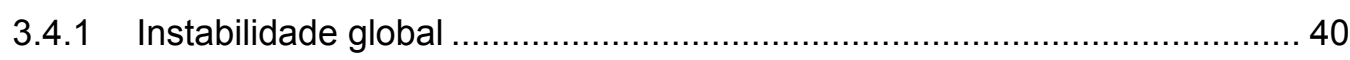

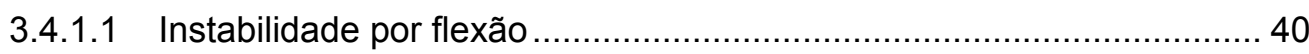

3.4.1.1.1 Flambagem elástica ............................................................ 40

3.4.1.1.2 Flambagem elasto-plástica (ou inelástica) …………………....... 41

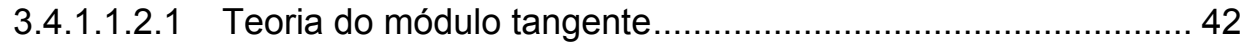

3.4.1.1.2.2 Teoria do módulo reduzido ou duplo módulo .......................... 43

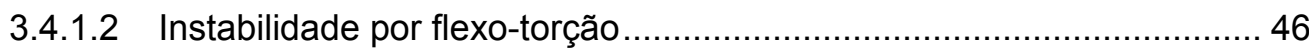

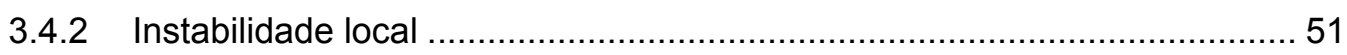

3.4.2.1 Tensão crítica de flambagem elástica de chapas ............................... 53

3.4.2.2 Flambagem de chapa em regime elasto-plástico ............................... 55

3.4.2.3 Resistência pós-flambagem e largura efetiva....................................... 56

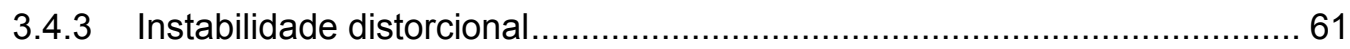

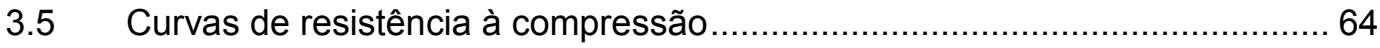

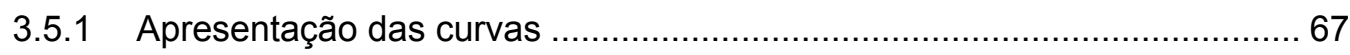

3.6 Interação entre modos de instabilidade ...................................................... 70

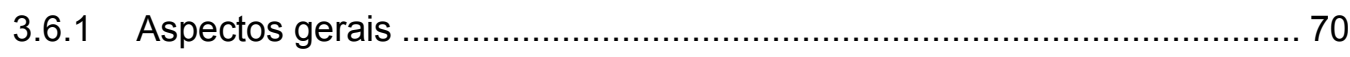

3.6.2 Método da Erosão da Força Crítica - ECBL............................................. 72

3.6.2.1 Adaptação da fórmula de Ayrton-Perry para o ECBL ……………….... 79

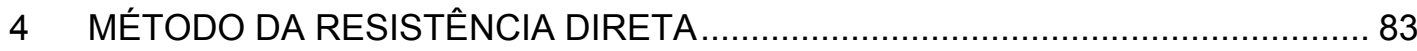

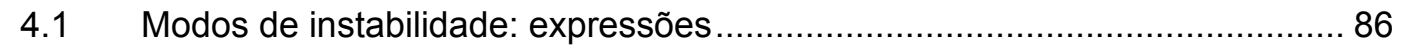




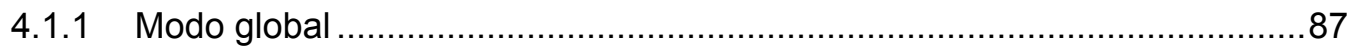

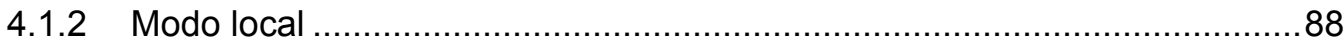

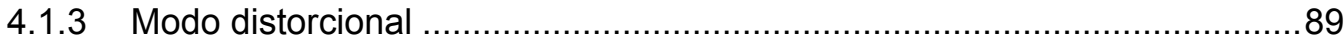

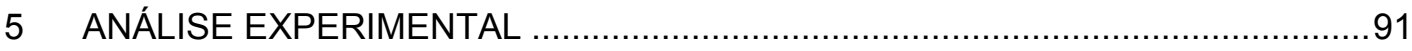

5.1 Descrição das barras ensaiadas .......................................................... 91

5.1.1 Análises via NBR 14762:2001 .......................................................

5.2 Procedimento da análise experimental ....................................................101

5.3 Resultados da análise experimental...................................................... 102

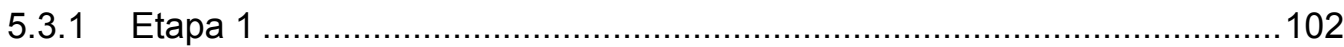

5.3.1.1 Imperfeições geométricas iniciais................................................102

5.3.1.2 Análise de conformidade segundo a NBR 6355:2003......................106

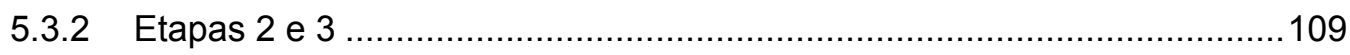

5.3.2.1 Resultados dos ensaios das barras ..............................................116

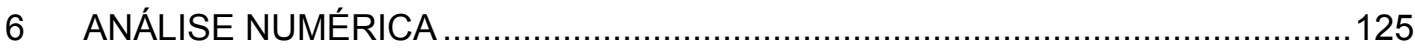

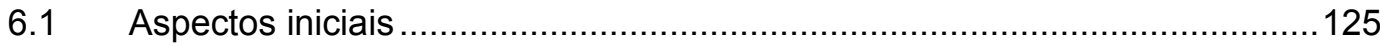

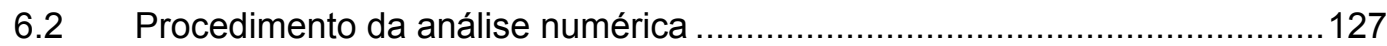

6.2.1 Programa via faixas finitas CUFSM ................................................. 127

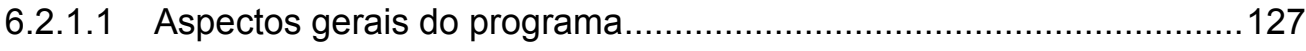

6.2.2 Programa via elementos finitos ANSYS ............................................ 131

6.2.2.1 Aspectos gerais da modelagem ................................................131

6.2.2.2 Imperfeições geométricas iniciais...................................................138

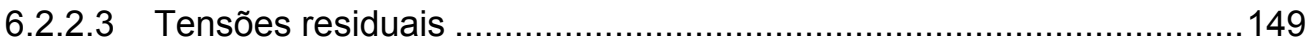

6.2.2.4 Modelo reológico .................................................................... 152

6.2.2.5 Parâmetros da análise não-linear geométrica...................................155

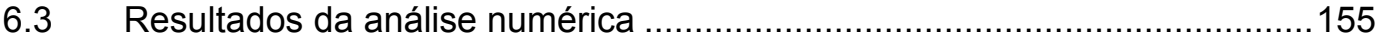

7 ANÁLISE E DISCUSSÃO DOS RESULTADOS ........................................... 163

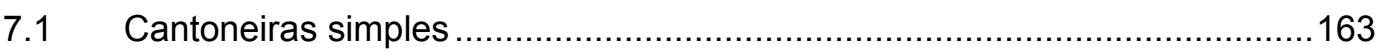

7.1.1 Comparação com o Método da Resistência Direta .................................169

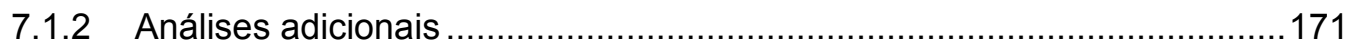

7.2 Discussão dos resultados em geral..................................................... 173

7.2.1 Comparação com o Método da Resistência Direta ..................................183

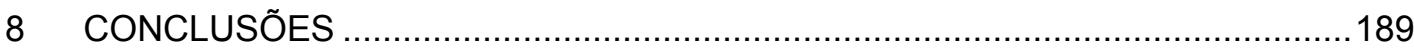

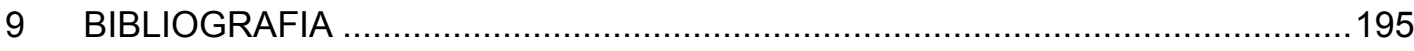

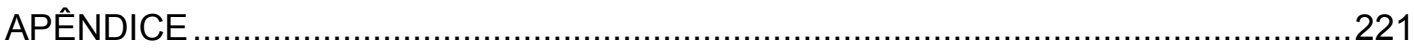

Apêndice A - Modelos reológicos (true values): Ansys............................................22

Apêndice B - Imperfeições geométricas medidas no laboratório....................................233

Apêndice C - Ensaios das barras curtas (stub columns) ........................................245 


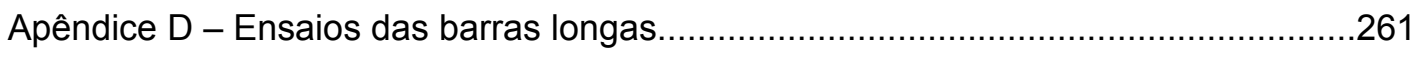

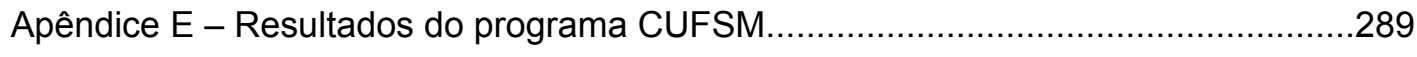

Apêndice F - Expressões: flexo-compressão.....................................................293 


\section{RESUMO}

\section{CHODRAUI, G.M.B. Análise teórica e experimental de perfis de aço formados a}

frio submetidos à compressão. São Carlos, 2006. Tese (Doutorado) - Escola de Engenharia de São Carlos, Universidade de São Paulo.

Os perfis de aço formados a frio apresentam, em geral, maior esbeltez local (relação largura-espessura dos elementos) em relação aos clássicos perfis laminados, acentuando a instabilidade local. Além disso, em se tratando de seções abertas com paredes muito delgadas, a rigidez à torção resulta muito pequena, o que torna os modos globais de torção e flexo-torção muitas vezes dominantes em relação aos modos de flexão. Outro modo de instabilidade que pode se manifestar é o modo distorcional, característico nos perfis com enrijecedores de borda.

Com relação à análise do modo global, as normas para cálculo de perfis formados a frio têm adotado as mesmas curvas de resistência à compressão desenvolvidas para os perfis laminados e soldados, como a curva do SSRC (Structural Stability Research Council), adotada pela NAS (North American Specification), e as curvas européias, adotadas pela norma brasileira. Embora alguns estudos indiquem que as citadas curvas sejam aceitáveis para os perfis formados a frio, há também referências explícitas quanto à necessidade de um maior aprofundamento na investigação sobre o comportamento estrutural destes perfis, uma vez que apresentam particularidades quanto às tensões residuais, imperfeições geométricas e interação entre modos de instabilidade.

Nesse trabalho é apresentada uma análise experimental em perfis usualmente empregados no Brasil (perfis $U, U$ enrijecidos e cantoneiras simples e duplas), e uma estratégia de análise numérica não-linear, considerando os efeitos das imperfeições geométricas globais e localizadas (de chapa e distorcional), bem como das tensões residuais, de modo a se obter teoricamente um valor confiável da força normal de compressão resistente da barra. Os resultados permitiram constatar a viabilidade do emprego das atuais curvas de resistência à compressão para os perfis formados a frio.

Complementando, foi analisada a aplicação do Método da Resistência Direta (MRD) a todos os perfis estudados, confirmando bons resultados. Especial atenção foi dada ao estudo da estabilidade elástica de cantoneiras, com foco principal na coincidência entre o modo localchapa e o modo global-torsional, o que tem gerado controvérsias na aplicação dos métodos de cálculo. Além disso, como as cantoneiras não são pré-qualificadas para aplicação do MRD, foram analisadas várias opções para emprego do método, onde pode-se concluir que desconsiderar a torção na análise do modo global conduz a resultados contra a segurança.

Palavras-chave: perfis de aço formados a frio, curvas de resistência à compressão, análise numérica não-linear, imperfeições geométricas, tensões residuais, método da resistência direta. 


\section{ABSTRACT}

\section{CHODRAUI, G.M.B. Theoretical and experimental analysis of cold-formed steel} members under compression. São Carlos, 2006. Thesis - School of Engineering of Sao Carlos, University of Sao Paulo.

Cold-formed steel members present, in general, higher local slenderness than classical hot-rolled ones, which make them more prone to local buckling. Besides, thin-walled open sections have small torsional stiffness, and hence global torsional and flexural-torsional instability modes are many times more critical than global flexural ones. Also, distortional mode can happen in sections with lips (edge stiffener).

Concerning on global buckling for members under compression, curves used in coldformed steel design are based on hot-rolled and welded members. For example, the SSRC (Structural Stability Research Council) buckling curve, adopted by NAS (North American Specification), and Eurocode buckling curves, adopted by Brazilian codes. Although some papers indicate these curves are acceptable for cold-formed steel members, others claim for a deeper analysis on their unique structural behavior, specially on residual stress, geometric imperfections and coupled buckling modes.

It is presented in this Thesis an experimental analysis of sections usually used in Brazil (simple and lipped channels, and also single and built-up angles). Moreover, it is developed a strategy for numerical non-linear analysis, considering the effects of global and local (also distortional) geometric imperfections and residual stress as well, in order to obtain a trustable theoretical value for the axial member stength. Results show the viability of the current buckling curves for cold-formed steel members.

Finally, Direct Strength Method (DSM) was analysed for all studied members, showing good results. Special attention to angle's elastic stability, focusing on the coincidence between local-plate and global-torsional mode, which still causes confusion in design methods. Also, due to the fact angles are not pre-qualified sections for using DSM, many options on its application were studied, where it was concluded that negleting torsion in global analysis leeds to unconservative results.

Keywords: cold-formed steel members, buckling curves, numerical non-linear analysis, geometric imperfections, residual stresses, direct strength method. 


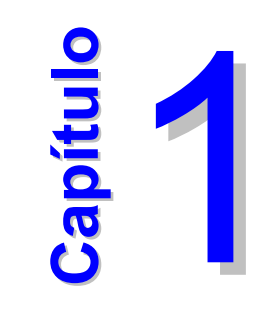

\section{INTRODUÇÃO}

A efetiva participação da EESC-USP (Escola de Engenharia de São Carlos da Universidade de São Paulo) no campo das estruturas de aço constituídas por perfis de aço formados a frio teve início em 1990, ocasionada principalmente pela forte demanda induzida de empresas de pequeno e médio porte do interior do Estado que passaram a consumir em larga escala os perfis formados a frio em substituição aos clássicos perfis laminados nas chamadas "estruturas leves".

O motivo dessa mudança foi a escassez de laminados leves no mercado, pois a CSN (Companhia Siderúrgica Nacional) iniciava a desativação dos seus laminadores de perfis, além evidentemente das vantagens que os perfis formados a frio traziam: maior disponibilidade no mercado para pequenas e elevadas quantidades, e maior possibilidade de otimização de perfis nos projetos, resultando em perfis de maior relação inércia/peso que os laminados, cuja conseqüência imediata é o menor consumo de material.

Por outro lado, percebia-se na ocasião uma carência básica de informações técnicas mais consistentes por parte do corpo técnico das empresas, quer na área de projetos ou de execução, devido principalmente ao desconhecimento de normas técnicas específicas, inclusive das normas brasileiras em vigência, a NB 143:1967 e a NBR 6355:1980. A obsolescência da NB 143:1967, vinculada à antiga NB-14 (tensões admissíveis), praticamente obrigava os projetistas a adotarem normas estrangeiras, como as do AISI (American Iron and Steel Institute), CSA (Canadian Standards Institute) e outras.

Além do suporte dado pela EESC-USP às empresas em questões "emergenciais" nos campos teórico e experimental, iniciou-se um processo de formação de mão-de-obra especializada para o setor, com a implementação de uma disciplina optativa voltada aos alunos de graduação em Engenharia Civil (SET 618 - Estruturas de aço em perfis formados a frio), 
além da inclusão do assunto nos programas das disciplinas do curso de Arquitetura e da pósgraduação em Estruturas.

Em 1990 foi iniciado o primeiro trabalho de pós-graduação em perfis formados a frio e em 1993 o tema foi classificado como uma Linha de Pesquisa na Área de Estruturas Metálicas. A partir dessa data, vários trabalhos teóricos e experimentais de mestrado e doutorado foram desenvolvidos ou estão em desenvolvimento, alguns em parcerias com empresas, visando melhor entender o comportamento e o conseqüente aprimoramento do emprego dos perfis formados a frio nas estruturas.

Outra atividade relevante e que tem merecido destaque é o intercâmbio com pesquisadores estrangeiros pertencentes a instituições com forte tradição em pesquisas sobre estruturas em perfis formados a frio. Em 1996, 1998 e 2001 o Departamento de Engenharia de Estruturas da EESC-USP recebeu a visita do Prof. Duane Ellifritt, da University of Florida e membro do AISI, entidade responsável pela edição da norma norte-americana. Em 1998, 2000, 2002, 2004, e possivelmente agora em 2006, professores e/ou alunos de pós-graduação do Departamento participaram da International Specialty Conference on Cold-Formed Steel Structures, realizada nos Estados Unidos e promovida pelo W.W. Yu Center for Cold-Formed Steel Structures da University of Missouri-Rolla, proporcionando importantes contatos com os principais pesquisadores do mundo.

Vale ressaltar ainda que a experiência acumulada no período foi um fator fundamental para que a EESC-USP participasse do processo de revisão da NB 143:1967, iniciado em 1997, que a rigor constituiu-se na elaboração de uma nova norma, assumindo então a coordenação dos trabalhos. Nos últimos anos houve intensa pesquisa sobre normas estrangeiras e trabalhos que deram origem aos seus procedimentos, buscando o necessário embasamento teórico que, aliado ao levantamento das particularidades da construção metálica brasileira, permitiram elaborar a NBR 14762:2001 - Dimensionamento de estruturas de aço constituídas por perfis formados a frio, que traz procedimentos atualizados e compatíveis com as principais normas estrangeiras em vigor.

Mais recentemente foi concluída também a revisão da NBR 6355:2003, no âmbito do CB-28 (Comitê Brasileiro de Siderurgia), que trata da padronização dos perfis formados e frio. A coordenação dos trabalhos também foi de responsabilidade dos representantes da EESCUSP, havendo satisfatória participação do meio acadêmico, das usinas siderúrgicas e de empresas fabricantes de perfis.

Por fim, o autor complementou este trabalho de doutorado durante um estágio de 3 meses na The Johns Hopkins University com o professor Benjamin W. Schafer, atualmente referência mundial na área de formados a frio, o que contribuiu muito em vários fatores, especialmente quanto ao desenvolvimento da estratégia de análise numérica não-linear. 
Passando agora para o assunto específico deste trabalho, quanto à história dos perfis de aço formados a frio em particular, estes são amplamente empregados na construção civil por apresentarem uma relação inércia/peso maior que os perfis laminados e soldados. Entretanto, por sua própria natureza, apresentam elevada relação largura-espessura, fazendo com que no cálculo devam ser considerados os modos de instabilidade local, global, e quando aplicável, o distorcional, analisando-os não somente como modos isolados mas com possibilidade de ocorrerem acoplados.

WINTER (1940) iniciou nos Estados Unidos os ensaios em barras na Cornell University, e anos mais tarde, na Inglaterra, CHILVER (1953) resumiu as descobertas teóricas e experimentais, sendo estes entre outros pesquisadores grandes colaboradores quanto ao início dos estudos dos perfis de aço formados a frio. Isto foi citado meramente para que o leitor tenha uma idéia de mais ou menos quando começaram as investigações quanto aos perfis de aço formados a frio, pois a continuação destes estudos sobre alguns aspectos será abordada no decorrer deste trabalho.

Vale comentar, logo na introdução, que DUBINA \& UNGUREANU (2002) relatam que a diferente natureza das imperfeições geométricas iniciais e dos fenômendos de interação entre os modos de instabilidade, e a associação deste fato à esbeltez das chapas dos perfis de aço formados a frio induzem a um comportamento de instabilidade diferente do verificado nos perfis laminados e soldados. Portanto, curvas de resistência específicas para estes perfis deveriam ser propostas, em vez da utilização, por exemplo, das curvas do Eurocode e SSRC (Structural Stability Research Council) - propostas para os perfis laminados e soldados e utilizadas também para os formados a frio.

SCHAFER (1997) ressalta em sua Tese de Doutorado que devido ao fato dos perfis de aço formados a frio possuirem esbeltez elevada não é raro o fato das tensões de flambagem elásticas serem muito inferiores a $\mathrm{f}_{\mathrm{y}}$.

Vale ressaltar que os perfis de aço formados a frio possuem características peculiares, por exemplo:

$>\quad$ Pode-se obter estruturas mais econômicas para pequenos vãos (maior relação inércia/peso), sendo que no Brasil uma grande quantidade de obras se enquadra nesta categoria;

$>\quad$ Configurações não usuais da seção transversal podem ser utilizadas quando necessário, devido à facilidade de dobramento das chapas;

$>\quad$ Apresentam elevadas relações largura-espessura, o que exige considerações sobre a flambagem local e distorcional, além da resistência pós-flambagem;

$>\quad$ Elevada possibilidade de interação entre os modos de instabilidade; 
$>\quad$ A distribuição das tensões residuais, proveniente do efeito do trabalho a frio, difere daquelas causadas pelo resfriamento nos perfis laminados;

$>\quad$ As ligações devem ser cuidadosamente analisadas devido à pequena espessura das chapas;

Além destas diferenças supracitadas entre os perfis de aço formados a frio e os laminados e soldados, outras são citadas por YU (2000):

$>\quad$ Rigidez à torção nos formados a frio normalmente é baixa pois está relacionada com $\mathrm{t}^{3}$, sendo que normalmente o centro de gravidade não coincide com o centro de torção, pois em geral os perfis são monossimétricos;

$>\quad$ Método das larguras efetivas para análise da instabilidade local nos perfis formados a frio conduz a possíveis recálculos das propriedades geométricas da seção transversal, com translações do centro de gravidade, o que não é previsto nos procedimentos de cálculo para perfis laminados e soldados;

$>$ Enrugamento da alma (web crippling), devido ao fato de não ser comum o uso de enrijecedores de alma nos perfis formados a frio;

$>\quad$ Análise plástica não usual nos perfis formados a frio devido à elevada relação larguraespessura b/t, o que normalmente conduz à ocorrência de algum modo de instabilidade localizado antes da plastificação da seção;

Por fim, embora as curvas de resistência à compressão do Eurocode e SSRC, adotadas pela NBR 14762:2001 e pela NAS:2004 (suplemento atual da NAS:2001) respectivamente, tenham sido desenvolvidas para perfis laminados e soldados, as mesmas têm sido utilizadas para os formados a frio. Este fato se ampara em alguns estudos que aceitam essa utilização, enquanto que existem indicações explícitas na literatura quanto a necessidade de estudos mais aprofundados para os formados a frio, especialmente pelas características únicas destes quanto à tensões residuais, imperfeições geométricas iniciais e possível interação entre os modos de instabilidade.

Entendeu-se, portanto, ser importante este trabalho para a realização de uma análise teórica, numérica (faixas finitas e elementos finitos) e experimental de perfis de aço formados a frio usualmente empregados no Brasil (tipo $U, U$ enrijecido, cantoneira simples e dupla) submetidos à compressão, com o objetivo geral de avaliar, entre outros fatores, a interação entre os modos de instabilidade e a adequação das curvas de resistência adotadas pelas normas atuais, verificando-se a possível necessidade de novas curvas.

Quanto às cantoneiras, o fato da análise elástica para este tipo de seção indicar a coincidência do modo local de chapa com o modo global de torção (a rigor trata-se do modo 
global de flexo-torção) - como pode ser explicitamente observado em RASMUSSEN (2003) causa dúvidas quanto à consideração da interação entre esses modos nos procedimentos de cálculo. Neste trabalho foram realizadas análises em conjunto com o Dr. Benjamin W. Schafer para melhor esclarecer o tema, entre elas algumas variações do Método da Resistência Direta (MRD) propostas aqui como opções de cálculo.

Assim, os objetivos específicos do presente trabalho são:

- definir uma estratégia de análise numérica não-linear para perfis formados a frio, incluindo as imperfeições geométricas globais e localizadas (de chapa e distorcional), bem como as tensões residuais, de modo a se obter teoricamente um valor confiável da força normal de compressão resistente da barra. Trata-se da chamada análise de resistência máxima, que juntamente com a análise experimental, é a base das atuais curvas de resistência à compressão adotadas pelas normas.

- analisar a resposta estrutural de perfis de aço formados a frio produzidos no Brasil e a adequação das curvas de resistência à compressão, desenvolvidas para os perfis laminados e soldados, mas também adotadas pelas normas de perfis formados a frio. Trata-se de um estudo confirmatório, pois alguns trabalhos similares já foram realizados e publicados. Entretanto, foi de fundamental importância para a definição da estratégia de análise numérica não-linear citada anteriormente.

- analisar a sensibilidade da força normal de compressão resistente em função da amplitude das imperfeições geométricas globais e localizadas, atuando isoladamente ou acopladas, bem como das tensões residuais.

- estudo da estabilidade elástica de cantoneiras, com foco principal na coincidência entre o modo local-chapa e o modo global-torsional, o que tem gerado controvérsias na aplicação dos métodos de cálculo. Além disso, como as cantoneiras não são pré-qualificadas para aplicação do Método da Resistência Direta (MRD), o objetivo estendeu-se à análise de viabilidade de seu emprego.

Portanto, espera-se que este trabalho contribua para o esclarecimento de dúvidas quanto ao comportamento estrutural dos perfis de aço formados a frio e também quanto ao dimensionamento destes quando submetidos à compressão. 
Tese de Doutorado - Gustavo Monteiro de Barros Chodraui 


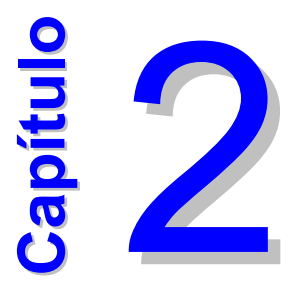

\section{FATORES QUE INFLUENCIAM NA RESISTÊNCIA DAS BARRAS SUBMETIDAS À COMPRESSÃO}

Todas as estruturas são na realidade "imperfeitas". Para o caso particular das barras analisadas, as imperfeições nas chapas que constituem a seção e no eixo da barra ocorrem tanto na seção transversal quanto ao longo do comprimento, e referem-se, entre outras, às imperfeições geométricas e também às físicas (do material). Neste capítulo são apresentados e discutidos alguns dos fatores que influenciam na resistência das barras submetidas à compressão, tendo por objetivo esclarecer vários aspectos que serão apresentados ao longo do trabalho.

\subsection{Propriedades mecânicas}

Algumas das propriedades mecânicas que exercem influência na resistência dos perfis de aço formados a frio, afetando desde o processo de conformação até o dimensionamento da barra são, entre outras, a resistência ao escoamento do aço $f_{y}$, a resistência à ruptura do aço na tração $f_{u}$, e a ductilidade, esta última que é a capacidade do material se deformar antes de ocorrer a ruptura.

Estas propriedades mecânicas são determinadas por meio de ensaios de tração simples de onde se obtém - assim como foi feito para as chapas e perfis utilizados na análise experimental deste trabalho - o diagrama tensão-deformação, no qual o comportamento linear (Lei de Hooke) é válido até um determinado valor de tensão, com sua inclinação definindo o módulo de elasticidade do material, E. Cabe salientar que para todos os aços o valor do módulo de elasticidade é admitido convencionalmente pelas normas NBR 8800:1986 e NBR 14762:2001 como $205.000 \mathrm{MPa}$. 
É importante frisar - pode ser melhor visto, por exemplo, em BJORHOVDE (2004) que atualmente existe o crescente desenvolvimento no mundo de aços estruturais com elevada resistência mecânica e propriedades especiais relativas à corrosão, ductilidade e soldabilidade. Por exemplo, nos Estados Unidos pode ser observada a crescente utilização de aços ASTM A992 e de aços denominados HPS (high performance steel), enquanto que no Brasil há uma crescente utilização do aço ASTM A572 ( $\left.f_{y}=345 \mathrm{MPa}\right)$ em substituição ao ASTM A36 $\left(f_{y}=250\right.$ MPa), além da crescente utilização do ASTM A588 e aços similares de especificação própria das usinas brasileiras ( $\mathrm{f}_{\mathrm{y}} \approx 345 \mathrm{MPa}$, resistente à corrosão).

Estas melhoras nas propriedades, como por exemplo, o aumento da resistência ao escoamento, conduz a seções ainda mais esbeltas, e por consequência eleva a relação inércia/peso dos perfis. Se por um lado isso é bom para a redução de peso de material necessário para resistir ao mesmo esforço (redução de custo), por outro faz com que os problemas de instabilidade se agravem e devam ser cautelosamente avaliados.

\subsection{Trabalho a frio}

Os dois processos utilizados para se realizar a conformação a frio dos perfis de aço são por meio de prensas dobradeiras e mesas de roletes (perfiladeiras).

O dobramento é executado devido ao impacto produzido por uma barra biselada superior em uma chapa - cortada previamente em guilhotina - a qual é posicionada entre uma base (ou matriz) inferior fixa e uma ferramenta superior móvel. Este processo é empregado, por exemplo, na fabricação de cantoneiras, perfis do tipo $U, U$ enrijecido, $Z$ e $Z$ enrijecido. $A$ perfilação, por outro lado, é feita por calandragem em rolos dispostos em linha de produção, por exemplo utilizada na fabricação de calhas, tubos, telhas, painéis de fechamento, pisos, e também de perfis quando a produção é elevada.

As propriedades mecânicas dos perfis de aço formados a frio não são as mesmas das chapas de aço antes do dobramento (aço virgem), pois a operação de conformação a frio eleva a resistência ao escoamento do aço $f_{y}$ para a resistência ao escoamento do aço modificada considerando o trabalho a frio $f_{y a}$, elevando também a resistência à ruptura do aço na tração $f_{u}$, e diminuindo a ductilidade.

Esses efeitos acima mencionados dependem do tipo de aço, do tipo de tensão (tração ou compressão), da direção da tensão com relação à direção do trabalho a frio, da relação $f_{u} / f_{y}$, da relação entre o raio de dobramento e a espessura $r_{i} / t$, e de quanto trabalho a frio foi executado. Pelo fato do material dos cantos da seção transversal ser mais afetado durante o processo de conformação a frio, as propriedades mecânicas destes também diferem das partes planas da seção. Como informação adicional, pesquisas indicam que as propriedades mecânicas devido ao trabalho a frio têm como causa principal o encruamento e o efeito 
Bauschinger (resistência longitudinal à compressão do aço estirado é menor que a resistência longitudinal à tração).

Como exemplo, a Figura 2.1 ilustra a variação das propriedades mecânicas em vários pontos da seção transversal em um perfil do tipo $U$ simples devido ao trabalho de conformação a frio. Pode-se obervar a elevação da resistência na região dos cantos, com aumento de $28 \%$ para $f_{u}$ e de $70 \%$ para $f_{y}$ para este caso em particular. Portanto, nota-se que definitivamente as propriedades mecânicas são alteradas quando do trabalho a frio para a conformação da seção transversal, e o projetista deve - mesmo que não tome partido de tais ganhos de resistência estar ciente deste fato durante o dimensionamento.
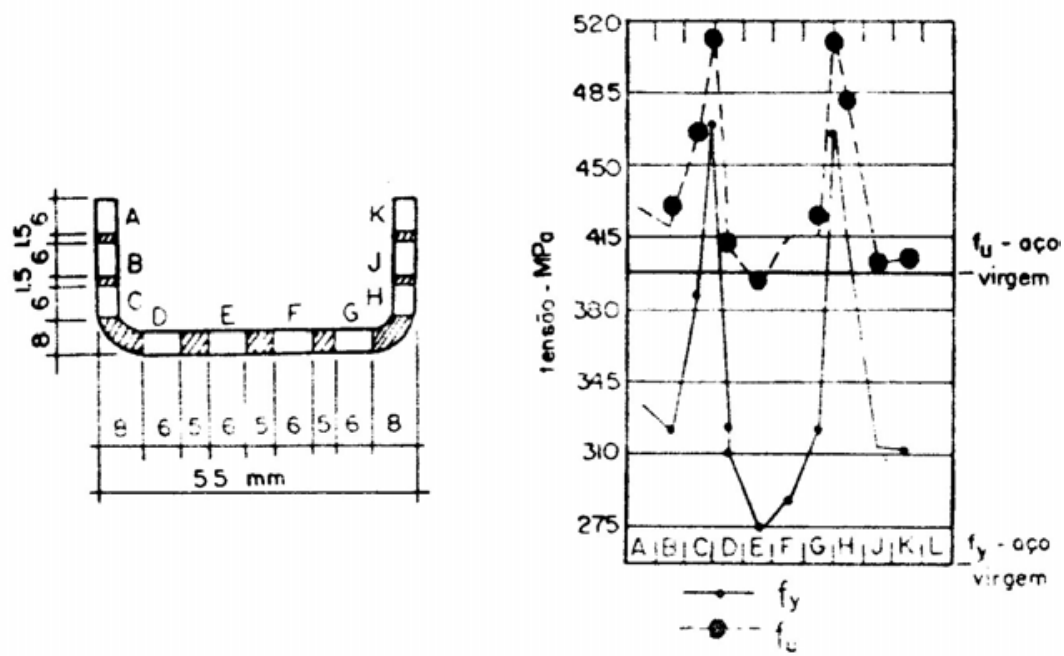

Figura 2.1 Efeito do trabalho a frio: perfil do tipo U simples [JAVARONI (1993)]

YU (2000) cita que resultados de um estudo realizado por Winter e Uribe indicam que a consideração dos efeitos do trabalho a frio nas regiões dos cantos conduziu a uma elevação do momento resistente entre 4 e $22 \%$, em relação aos perfis nos quais estes efeitos foram negligenciados. Por outro lado, quando a consideração deste efeito foi feita tanto para as regiões dos cantos como para as regiões planas (a região plana da seção também sofre alteração de propriedades, ainda que menor do que ocorre nos cantos), o aumento ficou entre 17 e $41 \%$. Entretanto, conforme será discutido mais adiante, estas considerações podem implicar na consideração das tensões residuais nestas regiões de canto, o que reduz a resistência dos perfis, e portanto os efeitos seriam opostos e possivelmente quase que se equilibrariam.

Por outro lado, BATISTA (1986) verificou em ensaios realizados na Universidade de Liège, em barras submetidas à compressão constituídas por perfis do tipo $U$ e $U$ enrijecido, que $f_{y a}$ é somente 2 a $7 \%$ superior a $f_{y}$. 
Percebe-se então que não há um consenso quanto à real importância da utilização das propriedades oriundas do trabalho a frio para o dimensionamento, nem quanto às implicações que devem ser feitas para outros fatores quando do seu uso.

Algumas formulações, apresentadas por KARREN (1967) na expressão (2.1), por LIND \& SCHROFF (1975) na expressão (2.5), e a do EUROCODE 3 - Parte 1.3 na expressão (2.6), são utilizadas para representar a relação entre $\mathrm{f}_{\text {ya }}$ (considerada na região dos cantos da seção) e $\mathrm{f}_{\mathrm{y}}$ (aço virgem). Entretanto, existem algumas limitações quanto ao uso destas expressões que devem ser melhor analisadas em cada caso.

KARREN (1967) - adotada pela norma americana NAS:2004 e também pela norma brasileira NBR 14762:2001

$$
\frac{f_{y c}}{f_{y}}=\frac{B_{c}}{\left(r_{i} / t\right)^{m}}
$$

Sendo:

$$
\begin{aligned}
& B_{c}=3,69 \frac{f_{u}}{f_{y}}-0,819\left(\frac{f_{u}}{f_{y}}\right)^{2}-1,79 \\
& m=0,192 \frac{f_{u}}{f_{y}}-0,068
\end{aligned}
$$

$f_{y c}$ : resistência ao escoamento do aço modificada, considerando o trabalho a frio;

$f_{y}$ : resistência ao escoamento do aço virgem;

$\mathrm{f}_{\mathrm{u}}$ : resistência à ruptura do aço na tração;

$r_{i}$ : raio interno de dobramento;

t: espessura da chapa ou do elemento;

Uma possibilidade para um ajuste mais real quanto às propriedades da seção transversal é o cálculo da média ponderada entre a resistência ao escoamento do aço dos cantos (representada por $f_{y c}$ ) e dos elementos planos (representada por $f_{y f}$ ), apresentada na expressão (2.4):

$$
f_{y a}=C f_{y c}+(1-C) f_{y f}
$$

Sendo:

$\mathrm{f}_{\mathrm{ya}}$ : resistência ao escoamento do aço, devido à média ponderada; 
$f_{y f:}$ resistência ao escoamento do aço nas partes planas, podendo ser adotado igual a $f_{y}$ (aço virgem);

C: para o caso da compressão é a relação entre a área dos cantos e área total da seção transversal;

LIND \& SCHROFF (1976) - adotada pela norma canadense CSA CAN3-S136-M84:1984

$$
f_{y a}=f_{y f}+\frac{5 D}{W^{*}}\left(f_{u}-f_{y f}\right)
$$

Sendo:

D: soma dos ângulos de dobramento dividida por $90^{\circ}$;

$W^{*}$ : relação entre o comprimento da linha do esqueleto (referente à mesa da seção transversal para o caso de barra submetida à flexão, ou à seção transversal total para o caso de barra submetida à compressão ou tração) e a espessura;

$f_{y a}, f_{y f}, f_{u}$ conforme descrito no caso anterior.

\section{EUROCODE 3 - PARTE 1.3:1996}

$$
f_{y a}=f_{y f}+\left(\frac{C \cdot n \cdot t^{2}}{A}\right) \cdot\left(f_{u}-f_{y f}\right)
$$

Sendo:

$f_{y a}, f_{y f}, f_{u}$ conforme descrito no caso anterior.

$\mathrm{t}$ : espessura da chapa;

A: área bruta da seção transversal da barra

C: função do tipo de trabalho a frio:

$C=7$ para perfis oriundos de conformação em mesa de roletes;

$C=5$ para outros métodos de conformação a frio;

$\mathrm{n}$ : número de dobras a $90^{\circ}$ na seção transversal com raio interno $r_{i}<5$ t.

\subsection{Tensões residuais}

Tensões residuais são as existentes nos perfis e chapas antes mesmo destes serem colocados em uso, pois o elemento estrutural apresenta um estado inicial de tensões ao qual superpõem-se as tensões originárias das ações externas. Algumas causas do aparecimento destas tensões residuais são o resfriamento desigual das chapas de aço após a laminação a quente e também as operações de fabricação, como conformação a frio, soldagem e 
puncionamento. Sabe-se também que o valor e a distribuição das tensões residuais dependem basicamente da geometria da seção transversal, tipo de aço e dos processos utilizados na fabricação dos perfis.

É interessante saber que dentre alguns métodos para avaliação das tensões residuais destacam-se o método de seccionamento em tiras e também métodos não-destrutivos como raio $\mathrm{X}$ e abertura de pequenos furos associados a extensômetros específicos.

Nos perfis laminados, as tensões residuais são especialmente de natureza térmica. Após o processo de laminação as partes mais expostas dos perfis (por exemplo, extremidades das mesas e meio da alma) se resfriam mais rápido e posteriormente, para "conter" o resfriamento do restante do perfil essas partes automaticamente resultam comprimidas e as demais por conseguinte tracionadas. Além disso, vale ressaltar que mesas e almas, usualmente espessas quando comparadas à dos perfis formados a frio, apresentam uma variação significativa do valor das tensões residuais ao longo da espessura, o que não ocorre nos formados a frio.

Nos perfis soldados e formados a frio, respectivamente, as soldas causam um gradiente térmico adicional às tensões de fabricação das chapas, e a conformação a frio causa tensões residuais de natureza mecânica.

Como se pôde observar, os diferentes modos de inserção das tensões residuais nos perfis laminados, soldados e formados a frio geram obviamente comportamentos diferentes, o que é uma das causas do comportamento estrutural diferenciado dos perfis formados a frio.

As tensões residuais $\left(\sigma_{r}\right)$ causam a redução da tensão de proporcionalidade $\left(\sigma_{p}\right)$ tensão máxima referente ao trecho linear do diagrama tensão-deformação $\left(\sigma_{p}=\sigma_{y}-\sigma_{r}\right)-$ sendo que o regime elástico sofre transição para o patamar de escoamento de maneira gradual, sendo que para tensões acima da tensão de proporcionalidade o regime elástico passa para o elasto-plástico (inelástico), como ilustrado na Figura 2.2.

De acordo com HUBER (1954), a presença de tensões residuais é a principal causa da não-linearidade do trecho do diagrama tensão-deformação para tensões superiores à tensão de proporcionalidade $\sigma_{p}$ (Figura 2.2). Para perfis sem tensão residual o comportamento tensãodeformação tenderia para o elasto-plástico perfeito. 


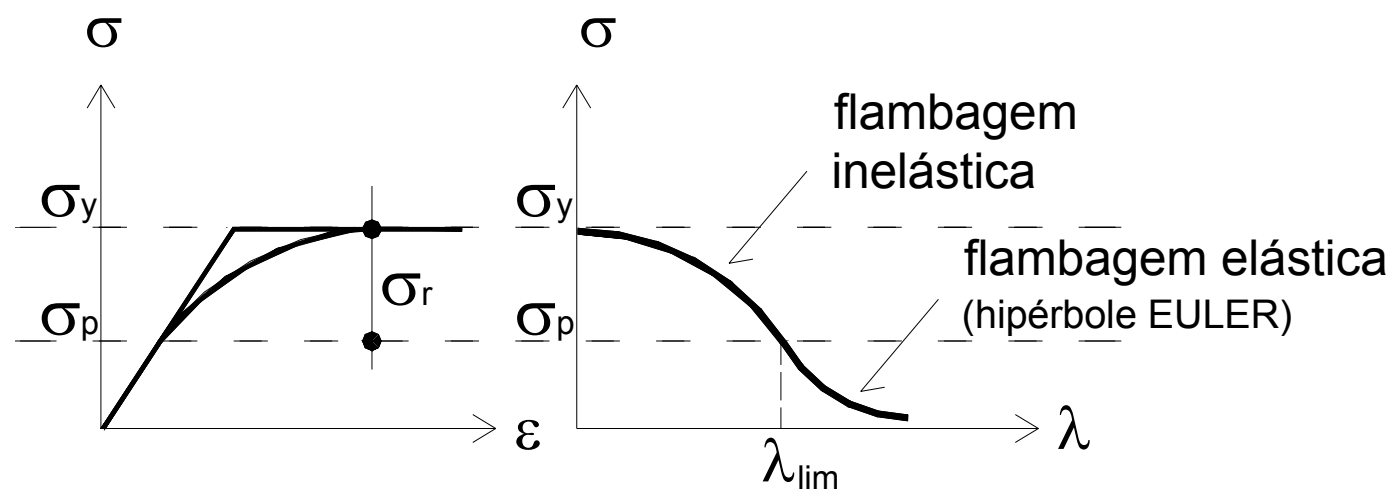

Figura 2.2 Influência típica da tensão residual no diagrama tensão-deformação

- Flambagem elástica e elasto-plástica (inelástica) -

WENG \& PEKÖZ (1990) concluiram a partir de resultados experimentais em perfis de aço formados a frio do tipo $U$ simples (um dos tipos de perfil estudado neste trabalho) que a distribuição das tensões residuais apresenta algumas particularidades:

- Existem tensões residuais de tração na superfície externa e de compressão na superfície interna dos perfis;

- As tensões residuais nas regiões dos cantos da seção transversal devido ao trabalho a frio podem ser negligenciadas no cálculo, pois são "compensadas" pelo inerente aumento da resistência ao escoamento;

- Os valores das tensões residuais estão entre $25 \%$ e $75 \%$ da resistência ao escoamento do aço virgem, $\mathrm{f}_{\mathrm{y}}$;

- A forma geral de distribuição das tensões residuais segue um mesmo padrão para todas as seções transversais;

Adicionalmente, WENG (1991) apresenta estudo baseado em ensaios de 93 barras constituídas por perfis formados a frio submetidas à compressão, com a medição de tensões residuais, a fim de avaliar o efeito das tensões residuais na resistência destas barras. Mostra que tanto a magnitude quanto a distribuição destas tensões é bem diferente da que aparece nos perfis laminados, fato também já verificado por outros autores. Isto pode ser uma possível explicação, dentre outras causas, para a curva do CRC (calibrada para perfis laminados) fornecer resultados às vezes não conservadores quando utilizadas para os perfis formados a frio. 
Para um melhor entendimento do assunto, é importante explicar que SCHAFER \& PEKÖZ (1998) e SCHAFER (1997) enfatizam que as tensões residuais são constituídas por duas parcelas: de membrana e de flexão (Figura 2.3). Esta convenção foi estabelecida, entre outros motivos, pelo fato de que no laboratório os extensômetros são colocados na superfiície dos perfis (face externa e interna), fornecendo duas leituras. Estas leituras fornecem normalmente um valor de tensão residual de compressão na superfície interna e de tração na externa, com magnitudes diferentes.

Foi idealizada então tal convenção para melhor se entender o conceito destas leituras. A situação mais razoável para esta explicação é o fato destes resultados serem oriundos de uma superposição entre uma tensão de compressão constante ao longo da espessura (denominada de membrana) e um gradiente simétrico de tensão ao longo da espessura com tração na parte externa e compressão na parte interna (denominada de flexão), como visualizado também na Figura 2.3.

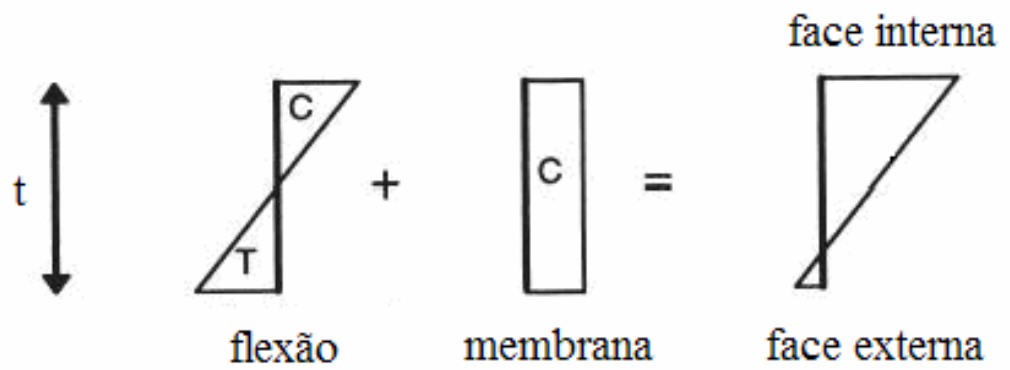

Figura 2.3 Tensões residuais nos perfis de aço formados a frio: de membrana e de flexão [adaptada de SCHAFER \& PEKÖZ (1998)]

É importante lembrar que ao efeito das tensões residuais pode ser superposto o efeito do aumento da resistência ao escoamento devido ao trabalho a frio, compensando o efeito das tensões residuais de certa forma, fato este que fez com que SCHAFER \& PEKÖZ (1998) e SCHAFER (1997) alertassem que deve haver coerência ao se assumir nos modelos numéricos o efeito do trabalho a frio nas regiões dos cantos da seção (aumento de $f_{y}$ ), a fim de se considerar também a elevação das tensões residuais nesses locais, ou não se considerar nenhum dos efeitos.

Para uma explicação mais técnica do assunto sobre as tensões residuais, tem-se que:

- A tensão residual de membrana é mais pronunciada nos perfis laminados e soldados, sendo muito baixa nos formados a frio. Como informação em SCHAFER (1997), para 95\% das medidas relatadas na literatura, foram encontrados valores inferiores a 0,13. $f_{y}$ para perfis oriundos de prensas dobradeiras e inferiores a 0,25. $\mathrm{f}_{\mathrm{y}}$ para perfis oriundos de mesas de roletes. Esta tensão é constante ao longo da espessura da seção, é de compressão, e é mais 
proeminente devido ao processo de fabricação por mesas de roletes do que por prensas dobradeiras. Além disso, ocorre especialmente nas regiões das dobras do perfil, o que torna justificável sua adoção nos modelos numéricos somente se for considerado também o efeito do trabalho a frio nestas regiões (aumento de $f_{y}$ );

- A tensão residual de flexão, por outro lado, é normalmente mais elevada em relação à de membrana para os perfis de aço formados a frio. De acordo com SCHAFER (1997), para 95\% das medidas relatadas na literatura o panorama foi o seguinte: para perfis oriundos de prensas dobradeiras foram encontrados valores inferiores a 0,56. $f_{y}$ nos cantos, 0,40. $f_{y}$ nos enrijecedores de borda e 0,53.f nos elementos enrijecidos; para perfis oriundos de mesas de roletes, foram encontrados valores inferiores a 0,67. $\mathrm{f}_{\mathrm{y}}$ nos cantos, 0,43. $\mathrm{f}_{\mathrm{y}}$ nos enrijecedores de borba e $0,71 . f_{y}$ nos elementos enrijecidos. Como se pôde ver, este tipo de tensão residual também é mais proeminente devido ao processo de fabricação por mesas de roletes do que por prensas dobradeiras. Finalmente, este tipo de tensão residual deve ser considerado segundo SCHAFER (1997) nos modelos numéricos por exemplo pelos valores médios da Figura 2.4, como explicado adiante ainda neste item.

Para exemplificar como esse assunto de tensões residuais não é um consenso, por exemplo, vale dizer que COSTA FERREIRA \& RONDAL (1986) relatam que as tensões residuais de flexão influenciam menos na resistência da barra do que as de membrana, de certo modo contradizendo o explicado anteriormente.

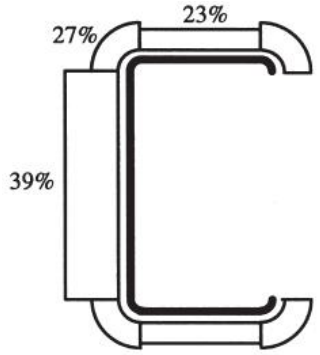

Mesa de roletes

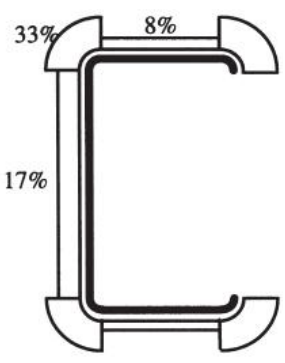

Prensa dobradeira

Figura 2.4 Tensão residual por flexão média: porcentagem de $\mathrm{f}_{\mathrm{y}}$ [SCHAFER \& PEKÖZ (1998)]

Como alternativa para a utilização aproximada das tensões residuais de flexão, SCHAFER (1997) apresenta um modelo bilinear para o diagrama de tensão-deformação, com valores apresentados na Figura 2.5, e ilustrado na Figura 2.6, para ser usado quando as tensões residuais não forem modeladas explicitamente. Entretanto, deve ficar claro que o escoamento prematuro das faces dos elementos no modelo numérico não será observado se 
não forem modeladas as tensões residuais de flexão explicitamente, pois este diagrama aproximado sugere valores do modelo reológico para a seção como um todo, enquanto que as tensões residuais de flexão sugerem variação de magnitude ao longo da espessura conforme visto na Figura 2.3.

\begin{tabular}{|c|c|c|c|}
\hline \multicolumn{4}{|c|}{$15 \% f y$} \\
\hline$\sigma$ & $\varepsilon \mathrm{p}$ & $\varepsilon e$ & Etot. \\
\hline 310 & 0.00000 & 0.00153 & 0.00153 \\
\hline 338 & 0.00008 & 0.00167 & 0.00175 \\
\hline 347 & 0.00034 & 0.00171 & 0.00205 \\
\hline \multicolumn{4}{|c|}{$30 \% f y$} \\
\hline$\sigma$ & $\varepsilon \mathrm{p}$ & $\varepsilon \mathrm{e}$ & Etot. \\
\hline 260 & 0.00000 & 0.00128 & 0.00128 \\
\hline 328 & 0.00013 & 0.00162 & 0.00175 \\
\hline 347 & 0.00059 & 0.00171 & 0.00230 \\
\hline \multicolumn{4}{|c|}{$45 \% f y$} \\
\hline$\sigma$ & $\varepsilon p$ & $\varepsilon \mathrm{e}$ & Etot. \\
\hline 220 & 0.00000 & 0.00108 & 0.00108 \\
\hline 320 & 0.00022 & 0.00158 & 0.00180 \\
\hline 347 & 0.00079 & 0.00171 & 0.00250 \\
\hline
\end{tabular}

$\sigma: \mathrm{MPa} \quad ; \quad \varepsilon:$ admensional

Figura 2.5 Modelos reológicos bilineares propostos por SCHAFER (1997)

Resumindo-se o fato mencionado anteriormente quanto à aplicação de tensões residuais de flexão nos modelos numéricos sugerido por SCHAFER \& PEKÖZ (1998) e SCHAFER (1997), estes recomendam a distribuição média de tensões residuais de flexão para um perfil de aço formado a frio. Entretanto, enfatizam que não há um consenso sobre a distribuição e magnitude das tensões residuais a serem adotadas nos modelos numéricos, e por isso estas são usualmente negligenciadas. Propõem então a utilização de médias dos valores, como apresentado na Figura 2.4. Vale dizer ainda que SCHAFER (1997) lista vários trabalhos de análise experimental de tensões residuais que foram realizados em todo o mundo, os quais podem servir para um melhor entendimento do assunto.

Para que se deixe claro o fato de que muitas são as sugestões na literatura para a adoção de tensões residuais nos modelos numéricos, e que entretanto não existe um consenso, algumas outras referências são apresentadas a seguir. 


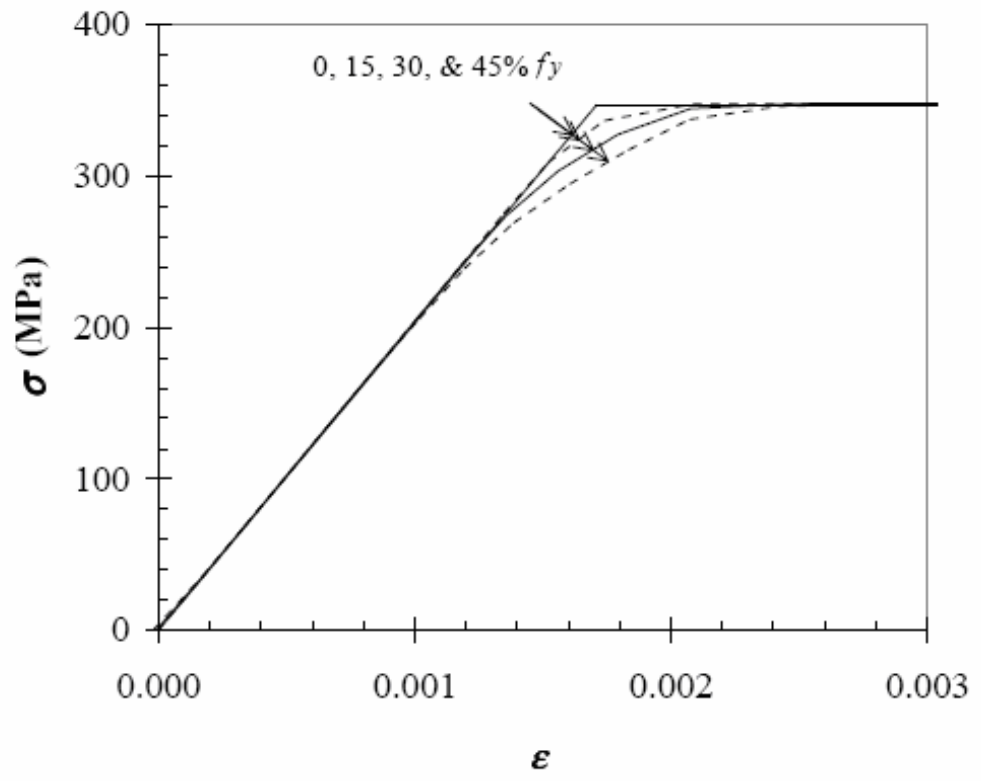

Figura 2.6 Influência da tensão residual de flexão no diagrama tensão-deformação [SCHAFER (1997)]

Por exemplo, NARAYANAN \& MAHENDRAN (2003) utilizam em seu trabalho um valor médio de $0,17 . \mathrm{f}_{\mathrm{y}}$ (tensão residual de flexão) aplicado uniformemente em todos os elementos da seção transversal. Relatam que os valores de resistência das barras praticamente não se alteraram quando comparados com a não utilização de tensões residuais.

Por outro lado, YOUNG \& RASMUSSEN (1997) apresentam medições de tensões residuais em perfis de aço formados a frio do tipo $U$ e $U$ enrijecido. As tensões residuais de membrana e de flexão foram inferiores a 3\% e 7\%, respectivamente, à tensão de escoamento, fazendo com que fossem negligenciadas nas análises.

Alertando mais uma vez para o fato de que ainda não existe um consenso quanto a este aspecto de tensões residuais, o trabalho de NARAYANAN \& MAHENDRAN (2003), sobre a resistência de perfis de aço formados a frio com seções transversais "inovadoras", i.e., seções transversais com geometria não usual, submetidos à compressão, mostra que a inclusão dos efeitos da tensão residual nas análises numéricas via ABAQUS não altera significativamente a capacidade resistente da barra.

Em resumo, e concordando com o exposto por DUBINA \& UNGUREANU (2002), entende-se que a inclusão de tensões residuais na análise numérica é geralmente complicada devido à falta de dados experimentais para embasar os valores a serem adotados tanto quanto à magnitude como quanto à distribuição adequada. Adicionalmente, os panoramas destas tensões sugeridos na literatura indicam muita divergência.

Por fim, considerando-se o efeito "contrário" às tensões residuais provocado pelo aumento da resistência ao escoamento devido ao trabalho a frio, percebe-se que as tensões 
residuais são geralmente negligenciadas nas simulações numéricas ou é adotado um valor uniforme para toda a seção conforme alguma das propostas apresentadas anteriormente.

Em virtude de tudo isso, o procedimento proposto neste trabalho, definido em conjunto com o Dr. Benjamin W. Schafer será apresentado e comentado no capítulo 6.

\subsection{Imperfeições geométricas iniciais}

As imperfeições geométricas, assim como as tensões residuais, são normalmente oriundas do processo de fabricação dos perfis, e por isso a hipótese de chapas retilíneas e barras perfeitamente retas ao longo do seu eixo não é tecnicamente correta.

Portanto, as barras submetidas à compressão centrada ficam na verdade submetidas à flexo-compressão desde o início do carregamento devido aos esforços de flexão oriundos destas imperfeições iniciais - para não se falar das possíveis excentricidades - e a rigor o problema deveria ser analisado como sendo um problema de $2^{a}$ espécie, como explicado mais adiante.

Existe então um acréscimo gradual no esforço de flexão quando existem imperfeições na barra e/ou excentricidade na aplicação da força de compressão, o que pode ser melhor entendido pela análise de equilíbrio de uma barra biapoiada na posição deslocada ilustrada na Figura 2.7.

Em 1807 Young propôs uma função senoidal para representar a imperfeição inicial global do eixo da barra, obviamente de modo aproximado, mas aceitável em muitos casos em virtude da variação das imperfeições verificada na prática (vale lembrar que esta função aproximada é para representar a imperfeição global do eixo da barra, e não aborda as imperfeições localizadas dos elementos/chapas que compõem a barra e são importantes para uma representação mais real, estas últimas discutidas logo adiante).

Esta aproximação de Young foi tão importante para se prever as imperfeições geométricas das barras que foi utilizada como base para as curvas de resistência americanas e européias.

As curvas americanas (SSRC) e européias (ECCS), elaboradas para perfis laminados e soldados, adotam para representar a imperfeição inicial da barra uma senóide com o valor de $\mathrm{v}_{0}=\mathrm{L} / 1000$ para amplitude no meio do comprimento da barra, como resultado da média estatística das imperfeições para barras de aço submetidas à compressão, o que é conservador, sendo que também pode ser utilizado $v_{0}=L / 1500$, sugerido por BJORHOVDE (1972), e adotado nas curvas 1P, 2P e 3P do SSRC. Vale ressaltar que estes valores foram idealizados para considerar também outras excentricidades, como, por exemplo, as oriundas da aplicação do carregamento. 
Para se ter uma idéia da complexidade desta representação de imperfeições, YU (2000) diz que a instabilidade da barra pode ser bastante influenciada pela presença das imperfeições geométricas iniciais, especialmente se estas forem periódicas e possuirem comprimento de meia-onda próximo ao do modo de instabilidade resultante da análise de autovalor da barra em questão.
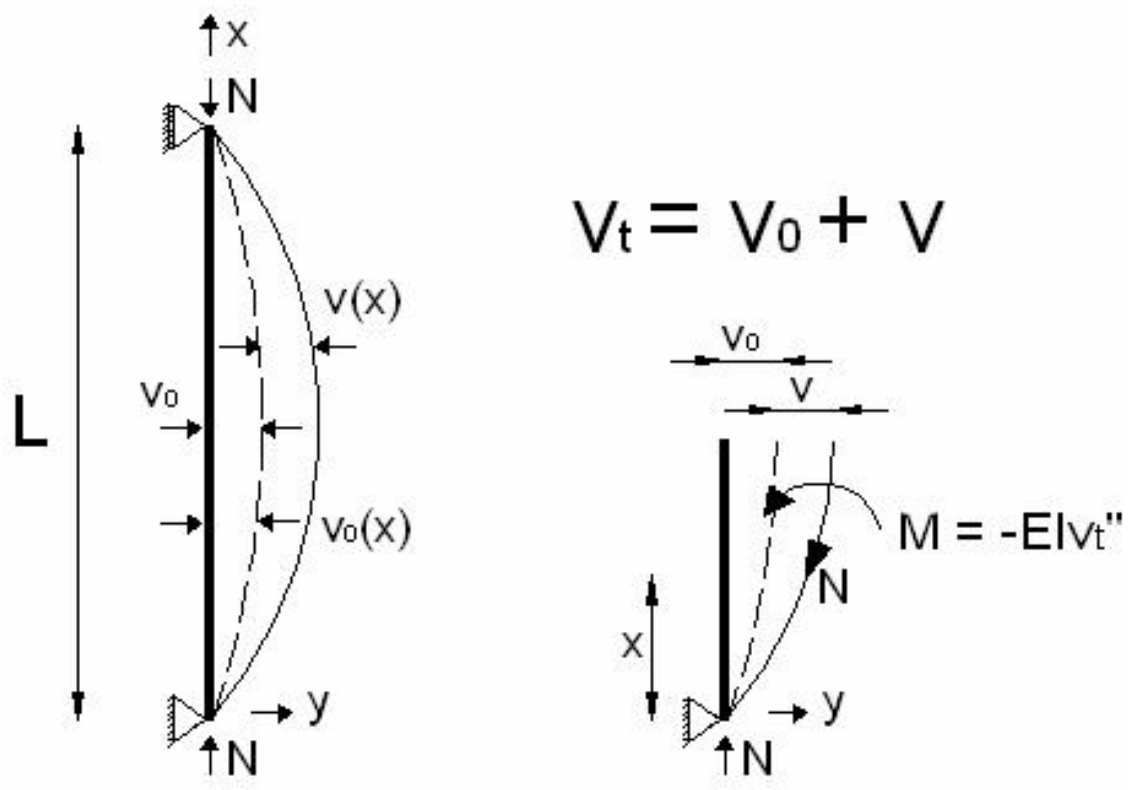

Figura 2.7 Barra com imperfeição geométrica inicial via aproximação de Young: equilíbrio na posição deslocada

Além disso, DUBINA \& UNGUREANU (2002a) relatam que diferentes formas adotadas para imperfeições geométricas iniciais decorrentes da instabilidade local (imperfeições das chapas que formam a seção) conduzem a variação na resistência da barra, ressaltando-se ainda que a utilização da forma senoidal (imperfeição global, do eixo da barra) nem sempe é a melhor opção. Mencionam ainda que a interação entre os modos de instabilidade distorcional e global geralmente se mostra bastante sensível às imperfeições locais, e que o modo distorcional tem muito mais sensibilidade às imperfeições do que o modo local.

Retomando à proposição de Young, tem-se as expressões (2.7) e (2.8) relativas à Figura 2.7, sendo que o equilíbrio na posição deslocada fornece o momento fletor na seção central da barra, conforme expressão (2.9). 


$$
\begin{aligned}
& v_{0}(x)=v_{0} \operatorname{sen}\left(\frac{\pi x}{L}\right) \\
& v(x)=v \operatorname{sen}\left(\frac{\pi x}{L}\right)
\end{aligned}
$$

$\mathrm{M}=\mathrm{N} \cdot \mathrm{v}_{\mathrm{t}}$

Calculando-se o equilíbrio na posição deslocada e, com expressões oriundas da resistência dos materiais resolvendo-se a equação diferencial do problema, a expressão para a flecha (deslocamento transversal ao eixo da barra no meio do comprimento desta) é fornecida pela expressão (2.10). Pode-se verificar que $\mathrm{v}_{\mathrm{T}}$ tende ao infinito quando $\mathrm{N}$ se aproxima de $\mathrm{N}_{\mathrm{e}}$.

$$
v_{T}=v_{0}\left(\frac{1}{1-N / N_{e}}\right)
$$

Sendo:

$\mathrm{v}_{\mathrm{T}}$ : flecha (deslocamento transversal ao eixo da barra no meio do comprimento desta);

$\mathrm{V}_{0}$ : imperfeição inicial máxima no meio do comprimento da barra ou excentricidade de aplicação da força de compressão em relação ao centro de gravidade;

$\mathrm{N}$ : força normal de compressão;

$\mathrm{N}_{\mathrm{e}}$ : força normal de flambagem elástica (Euler).

Efetuando-se a substituição de (2.10) em (2.9), tem-se a expressão para o momento fletor máximo de $2^{\mathrm{a}}$ ordem conforme a expressão (2.11). Percebe-se, portanto, que a rigor a flexão deveria ser considerada mesmo nas análises de compressão centrada.

$$
M=N v_{0}\left(\frac{1}{1-N / N_{e}}\right)
$$

Mesmo enfatizando novamente que não há um consenso sobre a distribuição e magnitude das imperfeições iniciais a serem adotadas nos modelos, assim como não há para as tensões residuais, SCHAFER \& PEKÖZ (1998) sugerem a utilização da imperfeição geométrica inicial oriunda da "superposição" de imperfeições referentes a mais de um modo de instabilidade, sendo normalmente definidas a partir das deformadas da análise de autovalor da barra. 
Outra opção proposta por SCHAFER \& PEKÖZ (1998), agora especificamente com relação às imperfeições geométricas localizadas, referentes aos modos local e distorcional, é a utilização da amplitude do modo, ressaltando-se que a sugestão sublinhada é mais recomendada. Vale dizer que quanto ao modo distorcional esta recomendação foi confirmada por KWON \& HANCOCK (1992), e que NARAYANAN \& MAHENDRAN (2003) utilizam em seu trabalho a opção sublinhada para imperfeições iniciais localizadas.

$\begin{array}{llll}\text { Modo local: } & \mathrm{d}_{1}=6 \mathrm{te}^{-2 \mathrm{t}} & \text { ou } & \underline{\mathrm{d}}_{1}=0,006 \mathrm{~b} \\ \text { Modo distorcional: } & \mathrm{d}_{2}=0,014 \mathrm{~b}+0,5 \mathrm{t} & \text { ou } & \underline{\mathrm{d}}_{2} \approx \mathrm{t}\end{array}$

$\left(d_{1}\right.$ e $d_{2}$ - vide Figura 2.8)

Sendo:

b: largura do elemento em questão;

t: espessura;

$\mathrm{d}_{1}$ : máximo deslocamento da deformada da alma do perfil, relativo ao modo local [denominado tipo 1 em SCHAFER (1997)];

$\mathrm{d}_{2}$ : máximo deslocamento da deformada da mesa do perfil, relativo ao modo distorcional [denominado tipo 2 em SCHAFER (1997)].

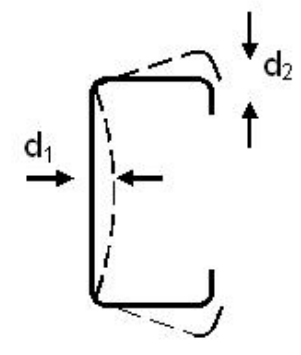

Figura 2.8 Parâmetros de imperfeições geométricas da seção transversal

Ainda quanto às imperfeições localizadas, SCHAFER (1997) e SCHAFER \& PEKÖZ (1998) apresentam uma análise dos dados existentes medidos e colhidos em todo o mundo referentes às imperfeições em elementos do tipo AA conforme nomenclatura da NBR 14762:2001 (poderiam ser aplicadas como sendo imperfeições para modos locais), e referentes às imperfeições em elementos do tipo $A L$ conforme também nomenclatura da NBR 14762:2001 (poderiam ser aplicadas como sendo imperfeições para modos distorcionais), sendo ilustrados respectivamente como imperfeições tipo 1 e tipo 2 na Figura 2.8 anteriormente apresentada.

SCHAFER \& PEKÖZ (1998) apresentam uma análise estatística ressaltando que as imperfeições tipo 1 e tipo 2 apresentam grande dispersão, e realizam uma análise CDF (função 
de distribuição cumulativa estimada) elegendo quantis de probabilidade de excedência das imperfeições a serem adotadas nos modelos. É importante lembrar desde já que este procedimento citado neste parágrafo foi adotado no presente trabalho, e será explicado no capítulo 6.

RONDAL (1988) analisou as diferenças entre perfis laminados/soldados e formados a frio quanto às imperfeições geométricas iniciais. Percebeu que a diferença da natureza das imperfeições aliada à elevada esbeltez conduz a comportamentos de instabilidade diferentes. Portanto, curvas de resistência específicas para os perfis de aço formados a frio deveriam ser utilizadas, ao invés de se utilizar as curvas que foram elaboradas para os perfis laminados e soldados (curvas do Eurocode e SSRC, por exemplo) como se tem feito atualmente.

Quanto ao parágrafo anterior, uma das maneiras de se adaptar estas curvas para uso dos perfis formados a frio é por meio da utilização do ECBL (Erosion of Critical Bifurcation Load) com calibração do novo coeficiente de imperfeição $\alpha$, como será explicado em um capítulo específico sobre tal método.

Entre as várias alternativas para a adoção de imperfeições iniciais nos modelos teóricos, vale apresentar também a proposta de SIVAKUMARAN \& ABDEL-RAHMAN (1998). Para um perfil de aço formado a frio do tipo $U$ enrijecido são admitidas imperfeições geométricas iniciais somente na alma, constituídas por semi-ondas senoidais, como ilustrado na Figura 2.9. É utilizada somente metade da amplitude $\delta_{0}$ recomendada pela norma Britânica BS 5950:1987, apresentada na expressão (2.12).

$$
\frac{\delta_{0}}{t}=0,145\left(\frac{b_{w}}{t}\right) \sqrt{\frac{f_{y}}{E}}
$$

Sendo:

$\delta_{0}$ : imperfeição inicial;

$b_{\mathrm{w}}$ : largura nominal da alma;

$\mathrm{E}$ : módulo de elasticidade do aço.

$\mathrm{f}_{\mathrm{y}}$ : resistência ao escoamento do aço; 


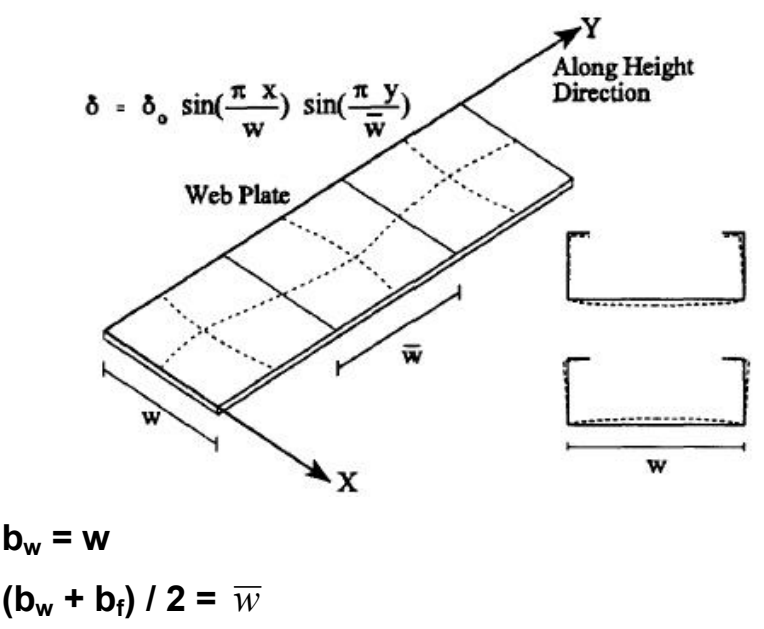

Figura 2.9 Imperfeições iniciais adotadas para a alma: perfil do tipo $U$ enrijecido [SIVAKUMARAN \& ABDEL-RAHMAN (1998)]

Adicionalmente, YANG \& HANCOCK (2004) apresentam a expressão (2.13), sugerida por WALKER (1975) para imperfeição geométrica, estabelecendo como amplitude do modo de flambagem da análise de autovalor uma porcentagem da espessura do perfil.

$$
0,3\left(\frac{N_{y}}{N_{c r}}\right)^{1 / 2} t
$$

Sendo:

$\mathrm{N}_{\mathrm{y}}: \mathrm{Af}_{\mathrm{y}}$

$\mathrm{N}_{\mathrm{cr}}$ : força crítica de flambagem elástica

t: espessura do perfil

Após tantas variações e possibilidades apresentadas, vale ressaltar que PEKÖZ et al. (2003) apresentam 3 possíveis procedimentos a serem adotados para a modelagem numérica de barras constituídas por perfis de aço formados a frio quando não há dados precisos quanto à distribuição nem magnitude das imperfeições geométricas iniciais:

1) superposição dos modos de instabilidade oriundos de prévia análise de autovalor, controlando a magnitude dos valores máximos, o que pode ser exemplificado na Figura 2.10, sendo que este conceito foi utilizado no presente trabalho;

2) aproximação por meio da medição em laboratório de imperfeições geométricas, o que tem que ser avaliado com cautela pela dificulade de se separar a quais modos pertencem as 
deformadas, que quando são lidas estão acopladas. Aproveitando-se esta idéia, as imperfeições geométricas das barras de aço podem também ser medidas em laboratório por meio de laser, conforme apresentado em LECCE \& RASMUSSEN (2004);

3) utilização de processo estocástico com o intuito de gerar sinais aleatórios para a deformada da seção, o que pode ser feito por uma rotina de computador, e daí passar-se a várias análises verificando os resultados.

Por fim, MAQUOI et al. (2002) advertem que a magnitude pode ser menos importante do que a forma e direção das imperfeições iniciais adotadas para os modelos numéricos no que diz respeito à resistência das barras. Diz também que deve ser considerada a superposição de imperfeições iniciais localizadas e globais (pois às vezes a inserção de imperfeições devido a somente 1 modo de instabilidade conduz a resultados errôneos, superestimando a resistência da barra, ou seja, contra a segurança). Entretanto, no caso particular do trabalho de MAQUOI et al. (2002) este fato não reduziu significativamente a resistência das barras com relação ao caso da inserção de imperfeições globais somente.
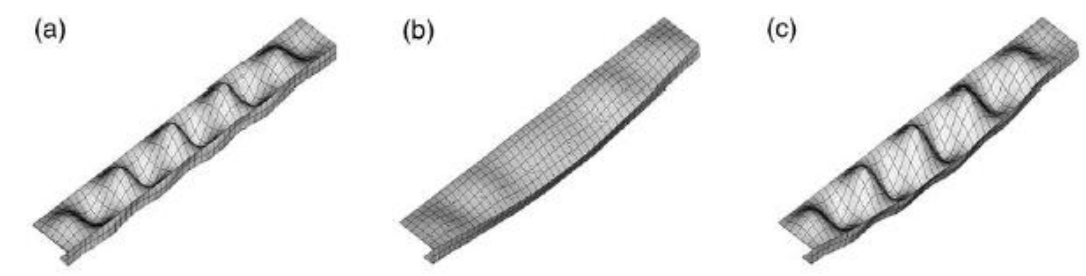

Figura 2.10 Imperfeições geométricas iniciais: (a) instabilidade local, (b) instabilidade por distorção, (c) imperfeição devido à superposição de (a) e (b) [PEKÖZ et al. (2003)]

Finalizando-se este capítulo, RODRIGUES (1993) realizou medições de imperfeições iniciais para perfis formados a frio do tipo $U$, sendo que o valor máximo encontrado para a relação imperfeição/comprimento da barra foi $10^{-3}$, ou seja, L/1.000. Com relação a medições de imperfeição geométrica relativa ao modo global de flexão em torno do eixo de menor inércia para cantoneiras, POPOVIC et al. (1999) apresentam resultados de L/1.305, PRABHU (1982) entre L/2.000 e L/500, e YOUNG (2004) valores médios de L/2.360. Pode-se perceber a grande variabilidade de medidas, e as consequências serão melhor entendidas mais adiante neste trabalho.

A falta de consenso quanto à imperfeições iniciais e tensões residuais a serem adotadas faz com que sua utilização na análise numérica não tenha uma estratégia clara. No intuito de contribuir para a proposição de uma estratégia satisfatória, é proposta neste trabalho uma estratégia para a inserção destes fatores nos modelos numéricos, cujos resultados são comparados a resultados experimentais. 


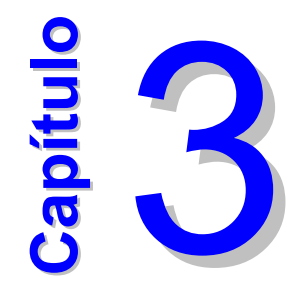

\section{BARRAS SUBMETIDAS À COMPRESSÃO}

\subsection{Instabilidade: conceitos e definições importantes}

A capacidade de uma estrutura suportar um carregamento sem que ocorra mudança significativa na configuração de seu equilíbrio é definido como estabilidade da mesma, sendo que a instabilidade é a transição entre configurações de equilíbrio estáveis e instáveis ao longo de uma trajetória de equilíbrio. Deve-se entender desde já que o termo flambagem está associado a um problema de bifurcação do equilíbrio, o que na prática não acontece, ocorrendo normalmente o fenômeno mais amplo denominado instabilidade, pois o fenômeno teórico de flambagem ocorre em problemas de primeira espécie (explicado a seguir). Entretanto, o termo flambagem ainda tem sido utilizado frequentemente para se designar qualquer fenômeno de instabilidade.

Apresentando-se agora algumas definições referentes ao fenômeno de instabilidade, vale dizer que a teoria de análise de estruturas considera algumas particularidades quanto à posição de equilíbrio e grandeza dos deslocamentos RACHID (1983):

\section{Teoria de $1^{\mathrm{a}}$ ordem:}

Considera o equilíbrio da estrutura na posição indeslocada, isto é, "confunde" a posição deslocada com a posição inicial, e admite simplificações introduzidas pela geometria dos pequenos deslocamentos: $\operatorname{sen}(\theta)=\theta ; \cos (\theta)=1 ; \mathrm{v}^{\prime \prime}=-(\mathrm{M} / \mathrm{El})$. Além disso, vale a superposição de efeitos desde que seja válida a Lei de Hooke (relação tensão-deformação no regime elástico linear). 


\section{Teoria de $2^{\mathrm{a}}$ ordem:}

Considera agora o equilíbrio da estrutura na posição deslocada, mas ainda admite como na teoria de $1^{\text {a }}$ ordem as simplificações introduzidas pela geometria dos pequenos deslocamentos: $\operatorname{sen}(\theta)=\theta ; \cos (\theta)=1 ; v^{\prime \prime}=-(\mathrm{M} / \mathrm{EI})$.

\section{Teoria de $3^{\mathrm{a}}$ ordem:}

Considera o equilíbrio da estrutura na posição deslocada, não admite simplificações introduzidas pela geometria dos pequenos deslocamentos. Neste caso, a expressão exata da curvatura deve ser utilizada, sendo representada por $\left.\mathrm{v}^{\prime \prime} /\left[1+\left(\mathrm{v}^{\prime}\right)^{2}\right]^{3 / 2}\right]=-(\mathrm{M} / \mathrm{EI})$.

A Figura 3.1 e a Figura 3.2 ilustram as trajetórias de equilíbrio para o caso de barras, chapas e cascas submetidas à compressão.

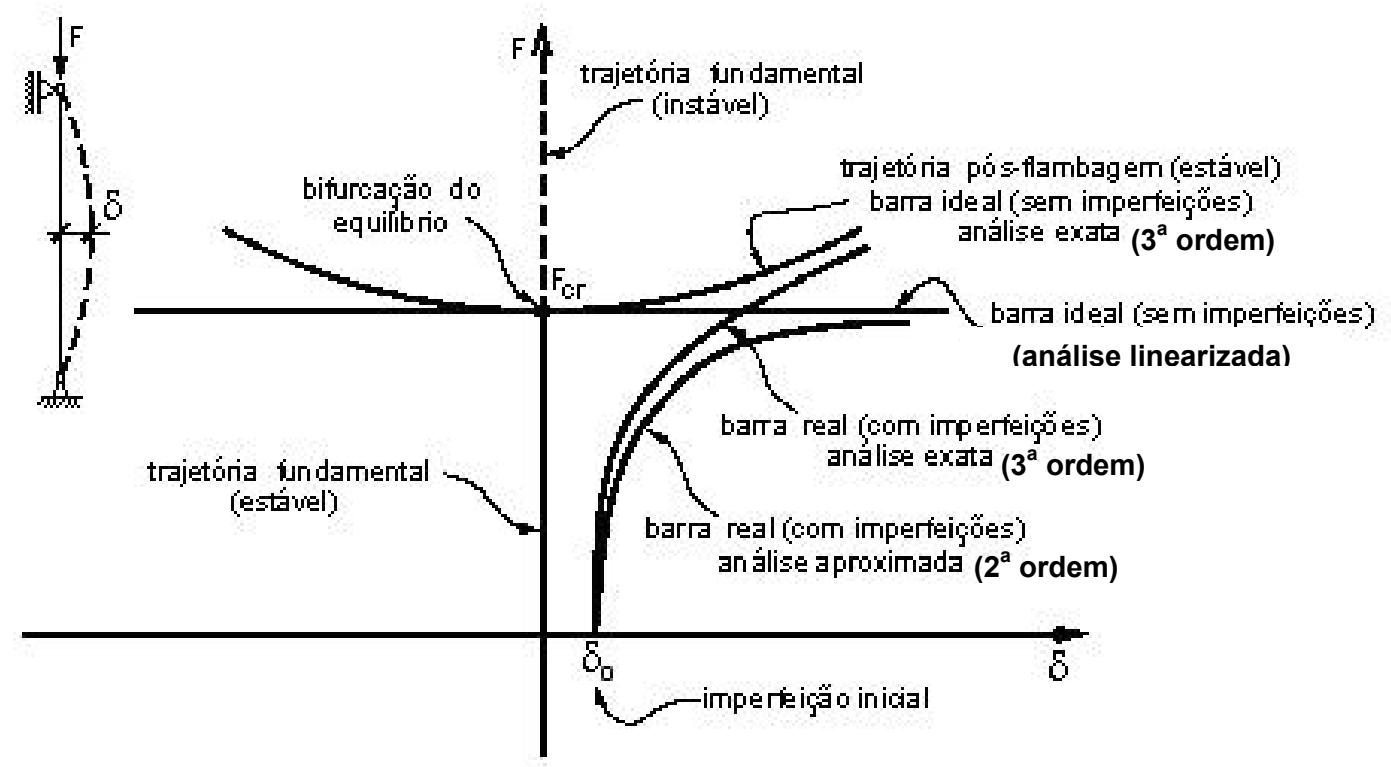

Figura 3.1 Trajetórias de equilíbrio: barras submetidas à compressão 


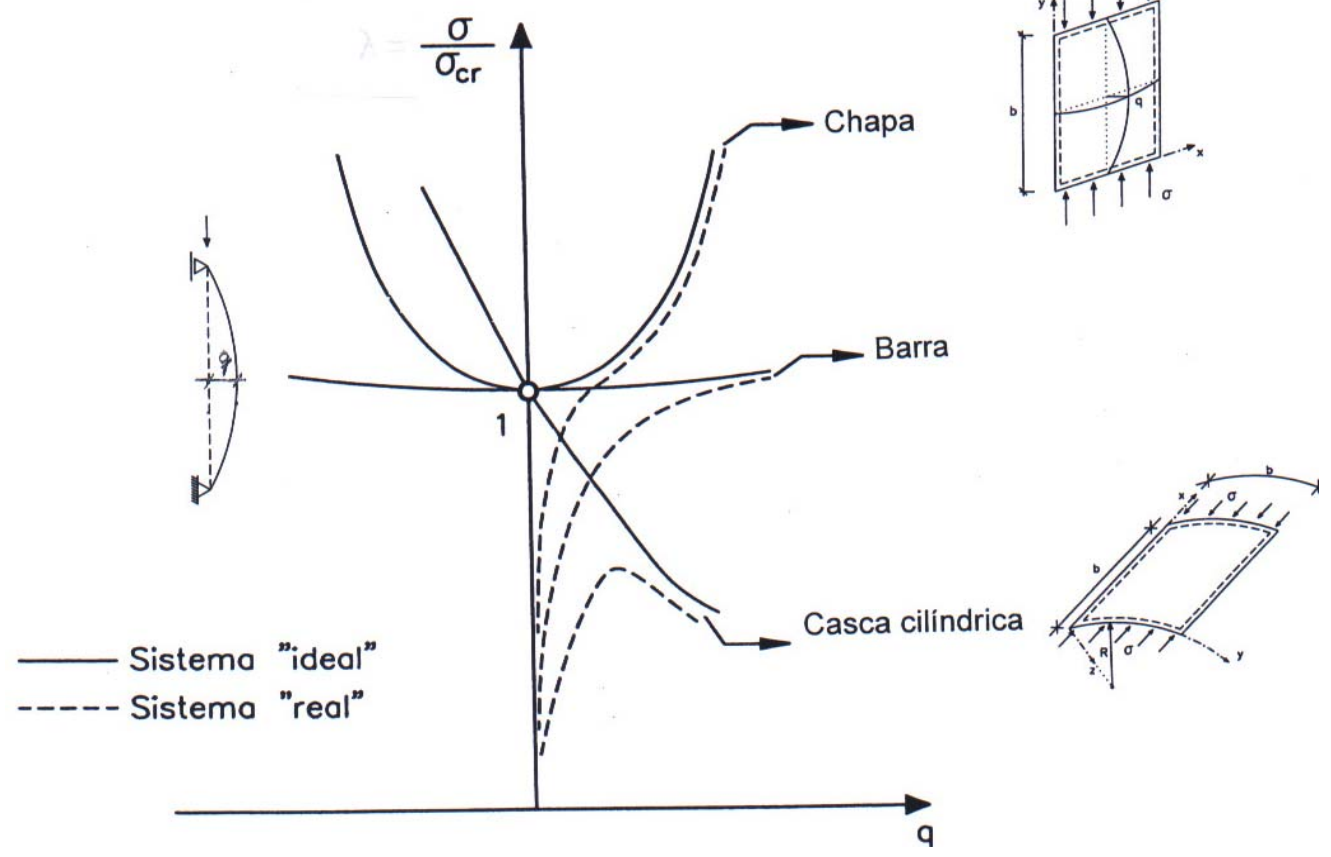

Figura 3.2 Trajetórias de equilíbrio: barras, chapas e cascas submetidas à compressão [adaptado de REIS \& CAMOTIM (2001)]

Há também uma definição bastante usada quanto à espécie do problema a ser avaliado:

\section{Problemas de $1^{\text {a }}$ espécie:}

Chamados de problemas de autovalor ou bifurcação do equilíbrio (barra perfeitamente reta, sem imperfeições iniciais nem tensões residuais, força aplicada com resultante atuando no C.G., seções planas permanecendo planas, teoria dos pequenos deslocamentos, etc.). $\mathrm{Na}$ iminência de se atingir o carregamento crítico, qualquer perturbação provoca a flambagem. É o caso, por exemplo, de sistemas ideais (sem imperfeição) submetidos à compressão centrada. As trajetórias de equilíbrio estão anotadas em traço cheio na Figura 3.2.

\section{Problemas de $2^{a}$ espécie:}

Nesse caso, a mudança no equilíbrio ocorre de maneira gradual, com deslocamentos crescentes para acréscimos do carregamento, até que os deslocamentos cresçam muito para um pequeno incremento de carregamento. É o caso, por exemplo, de sistemas reais (com imperfeições) ou mesmo sistemas ideais com carregamento excêntrico. As trajetórias de equilíbrio estão anotadas em traço pontilhado na Figura 3.2. 
Problemas de $3^{\mathrm{a}}$ espécie:

Chamados de problemas de ponto limite. Nesse caso, a mudança no equilíbrio ocorre de maneira gradual com deslocamentos crescentes para acréscimos do carregamento somente até se atingir o ponto limite, verificando-se logo após uma brusca variação na configuração deformada (snap through) - ilustrado na Figura 3.3 - e consequente estabilização do equilíbrio em uma posição distante da inicial. Este caso não se trata de um problema de bifurcação do equilíbrio pois não é verificada a opção de caminhos diferentes de equilíbrio após a ocorrência do fenômeno de instabilidade. Ex.: arcos e cascas abatidas.

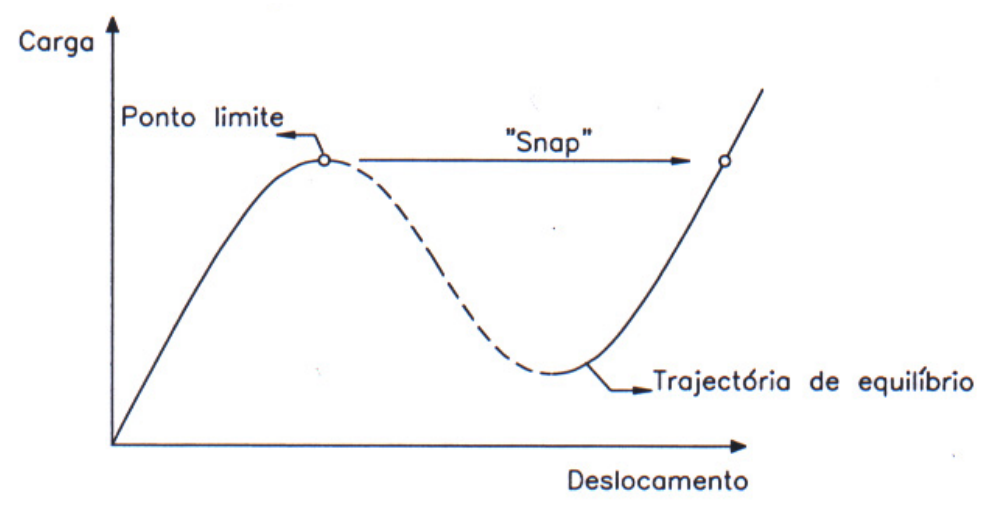

Figura 3.3 Instabilidade por ponto limite (snap-through) [REIS \& CAMOTIM (2001)]

\subsection{Aspectos iniciais}

De acordo com BALLIO \& MAZZOLANI (1983) - e ilustrado na Figura 3.4 - os estudos teóricos de barras sumetidas à compressão remontam ao ano de 75 (a.C.) com Erone d'Alexandria, havendo similares descrições encontradas em desenhos de Leonardo da Vinci (1452-1519) e estudos de P. Van Musschenbroek (1693-1761) e de Bernoulli (1700-1782).

Obviamente, não cabe aqui discorrer sobre toda esta história tão distante em detalhes, mas é fato que toda esta evolução de estudos, dentre outros, contribuiu para inspirar o matemático suíço Leonard Euler (1707-1783) a propor em 1744 (publicando em 1759) a expressão da força normal crítica de flambagem elástica para uma barra submetida à compressão. Desde então o desenvolvimento teórico e experimental a respeito não cessou.

Os perfis formados a frio em geral são constituídos por seções abertas de paredes delgadas de chapas finas de aço laminadas a frio ou a quente, que são posteriormente dobradas resultando em elevadas relações largura/espessura dos elementos.

Portanto, além dos clássicos fenômenos de instabilidade global (da barra como um todo) ou local (instabilidade de chapa), há a possibilidade de ocorrência de outro modo de instabilidade, associado à distorção da seção transversal, que é especialmente característico 
nos perfis com enrijecedores de borda, por exemplo perfis $U$ e $Z$ enrijecidos, perfis cartola e perfis "rack", e esses modos podem aparecer isolados e/ou combinados. Isto quando ocorre a instabilidade nos perfis, pois estes podem, ainda que raramente, atingir o escoamento no caso de seções não tão esbeltas.

A ocorrência de um ou outro modo de instabilidade, com possível interação entre eles, depende, dentre outros fatores, da forma da seção transversal, do comprimento $L$ da barra, da espessura $t$, e consequentemente da esbeltez global $(\lambda)$ da barra e da esbeltez local $(b / t)$ dos elementos que compõem a seção transversal, e também das imperfeições geométricas iniciais, tensões residuais, relação tensão-deformação, excentricidades de carregamento, condições de vinculação, entre outros.

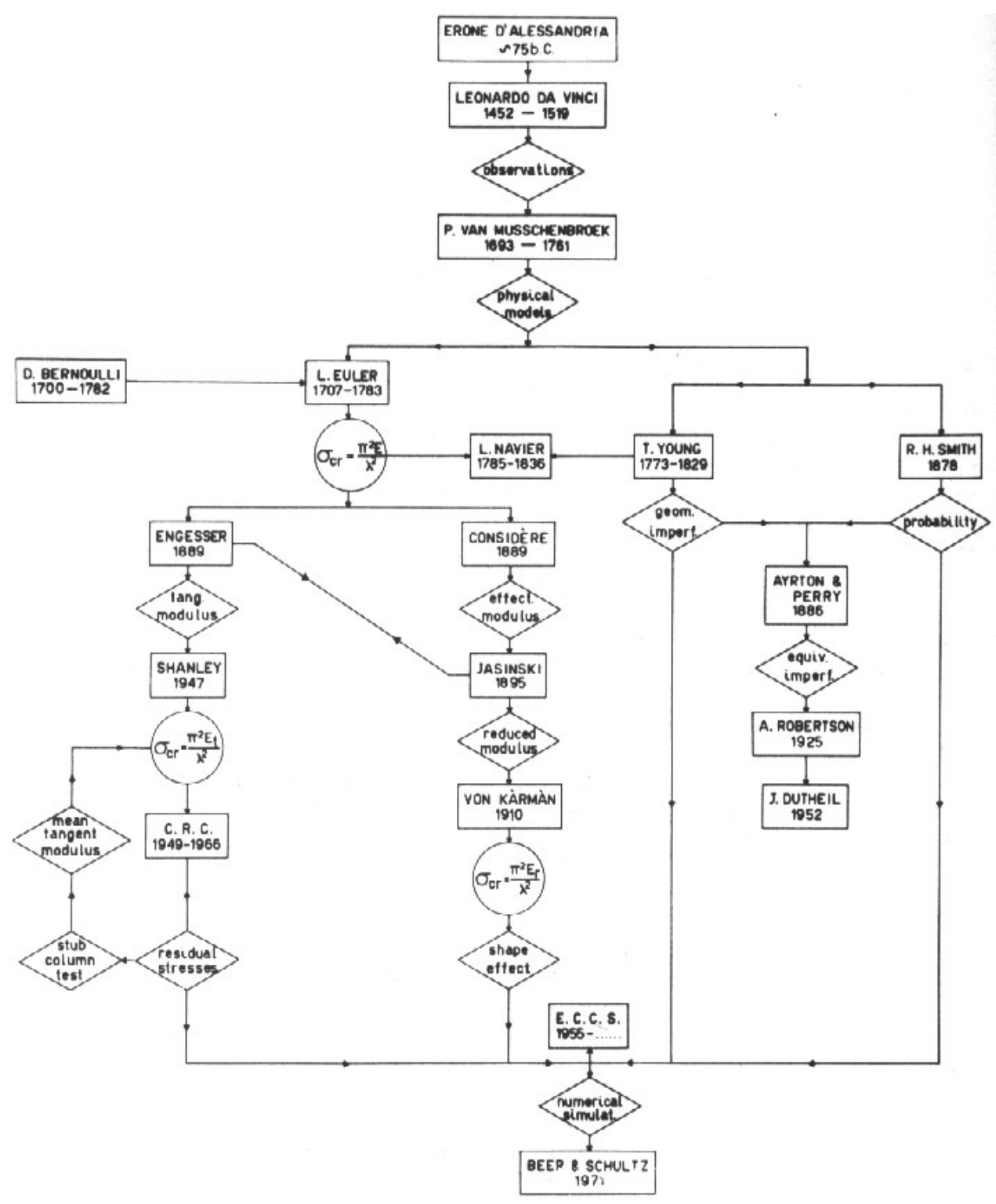

Figura 3.4 Histórico: estudo de barras e chapas submetidas à compressão 


\subsection{Breve relato da evolução histórica}

A Tabela 3.1, contendo informações atualizadas e também algumas já apresentadas por PAULA (2002), apresenta cronologicamente a evolução dos fatos e estudos referentes às barras submetidas à compressão.

Tabela 3.1 Quadro evolutivo dos principais fatos relativos às barras submetidas à compressão

\begin{tabular}{|c|c|}
\hline Ano / década & Fatos históricos \\
\hline 1744 & $\begin{array}{l}\text { Euler propõe a expressão para determinação da força normal crítica de } \\
\text { flambagem elástica para barras submetidas à compressão: } \\
\mathrm{N}_{\mathrm{e}}=\pi^{2} \mathrm{El} / \mathrm{L}^{2} \text {. A publicação ocorre em } 1759 \text {. }\end{array}$ \\
\hline 1886 & $\begin{array}{l}\text { Início das curvas de resistência à compressão baseadas no escoamento, } \\
\text { por exemplo a expressão de Ayrton-Perry. }\end{array}$ \\
\hline 1889 & $\begin{array}{l}\text { Engesser apresenta a teoria do módulo tangente para o regime inelástico, } \\
\text { substituindo na expressão de Euler o módulo de elasticidade } E \text { pelo } \\
\text { módulo de elasticidade tangente } E_{t} \text {. }\end{array}$ \\
\hline 1890 & $\begin{array}{l}\text { Considère propõe a substituição do módulo de elasticidade tangente } E_{t} \\
\text { pelo módulo de elasticidade reduzido } E_{r} \text {. }\end{array}$ \\
\hline 1895 & $\begin{array}{l}\text { Jasinsky ressalta que a teoria do módulo tangente está incorreta sob a } \\
\text { ótica da teoria da estabilidade clássica. }\end{array}$ \\
\hline 1899 & Engesser apresenta então a teoria do módulo reduzido ou duplo módulo. \\
\hline 1925 & $\begin{array}{l}\text { Robertson, com base em resultados experimentais, apresenta a relação } \\
\text { entre a amplitude das imperfeições geométricas iniciais e o índice de } \\
\text { esbeltez das barras: } \eta=0,003 \lambda \text { (Fórmula de Perry-Robertson). }\end{array}$ \\
\hline 1947 & $\begin{array}{l}\text { Shanley apresenta um modelo matemático para a determinação da força } \\
\text { normal crítica no regime inelástico, mostrando que o modelo do módulo } \\
\text { tangente representa bem a realidade do ponto de vista do valor da força } \\
\text { normal crítica. }\end{array}$ \\
\hline 1952 & $\begin{array}{l}\text { Bleich propõe uma expressão parabólica para o cálculo da tensão crítica } \\
\text { de flambagem no regime inelástico (região de tensões superiores a de } \\
\text { proporcionalidade } f_{p} \text { ) para barras sumetidas à compressão: } \\
f_{c r}=f_{y}-\left(f_{p} / \pi^{2} E\right)\left(f_{y}-f_{p}\right)(k L / r)^{2}\end{array}$ \\
\hline Década de 50 & $\begin{array}{l}\text { É publicada a curva do CRC (Column Research Council), que veio a ser } \\
\text { amplamente conhecida e adotada pelas normas de diversos países. }\end{array}$ \\
\hline
\end{tabular}




\begin{tabular}{|c|c|}
\hline Década de 60 & $\begin{array}{l}\text { Início dos estudos sobre as múltiplas curvas de resistência, na } \\
\text { Universidade de Lehigh e na ECCS (European Convention for } \\
\text { Constructional Stee/work). }\end{array}$ \\
\hline 1961 & $\begin{array}{l}\text { A norma americana AISC/ASD:1961 (método das tensões admissíveis) } \\
\text { adota a curva básica do CRC para a resistência à compressão dos perfis } \\
\text { estruturais de aço. }\end{array}$ \\
\hline 1967 & $\begin{array}{l}\text { Trabalho de Batterman \& Johnston verifica que no cálculo da resistência } \\
\text { das barras submetidas à compressão devem ser considerados os efeitos } \\
\text { das tensões residuais e imperfeições geométricas inicias. }\end{array}$ \\
\hline 1970 & $\begin{array}{l}\text { Jacquet apresenta estudo estatístico relativo a ensaios de } 1067 \text { barras de } \\
\text { aço submetidas à compressão realizados na Europa. }\end{array}$ \\
\hline 1972 & $\begin{array}{l}\text { Bjorhovde determina uma série de curvas de resistência a partir de } \\
\text { análise estatística, admitindo flecha (amplitude) no meio do comprimento } \\
\text { das barras de L/1000 para imperfeição inicial. Verificando semelhanças } \\
\text { entre as curvas, as divide em três subgrupos (curvas médias ajustadas } \\
\text { para originarem as múltiplas curvas do SSRC). Posteriormente, com base } \\
\text { nos resultados das medições das imperfeições iniciais, outras três curvas } \\
\text { - 1P, } 2 \mathrm{P} \text { e 3P - são apresentadas, oriundas de análises probabilísticas } \\
\text { com flecha (amplitude) no meio do comprimento das barras de L/1500. }\end{array}$ \\
\hline Década de 70 & $\begin{array}{l}\text { As múltiplas curvas de resistência para várias famílias de perfis são } \\
\text { apresentadas (curvas do SSRC e da ECCS), fundamentadas em análise } \\
\text { experimental e numérica. }\end{array}$ \\
\hline 1976 & $\begin{array}{l}\text { As primeiras múltiplas curvas de resistência européias recebem muitas } \\
\text { críticas. A comissão } 8 \text { da ECCS propõe então } 5 \text { novas curvas, que são } \\
\text { depois adotadas pelas recomendações da ECCS de } 1978 \text {. }\end{array}$ \\
\hline 1978 & $\begin{array}{l}\text { O trabalho de Maquoi \& Rondal apresenta formulação para as curvas } \\
\text { européias do ECCS, utilizando a fórmula adimensional de Ayrton-Perry } \\
\text { (explicada mais adiante): } \quad(1-\bar{N})\left(1-\bar{N} \bar{\lambda}^{2}\right)=\eta \bar{N} \text {, com } \\
\eta=\alpha \sqrt{\bar{\lambda}^{2}-\bar{\lambda}_{0}^{2}} \text {. Vale dizer que } \eta \text { representa as imperfeições, e que } \\
\text { as curvas apresentam patamar de escoamento para } \bar{\lambda} \leq 0,2 .\end{array}$ \\
\hline 1978 & $\begin{array}{l}\text { O Eurocode adota múltiplas curvas de resistência - baseado na análise } \\
\text { experimental de } 1067 \text { barras submetidas à compressão (previamente } \\
\text { citada) e análise numérica. }\end{array}$ \\
\hline 1979 & $\begin{array}{l}\text { O trabalho de Maquoi \& Rondal apresenta modificações na formulação } \\
\text { das curvas apresentada em } 1978 .\end{array}$ \\
\hline
\end{tabular}




\begin{tabular}{|c|c|}
\hline 1983 & $\begin{array}{l}\text { Fukumoto \& Itoh agrupa resultados de } 25 \text { anos de pesquisa - } 1665 \\
\text { ensaios, com apenas } 10 \text { tipos de perfis diferentes - realizados na Europa, } \\
\text { América do Norte e Japão, os quais são armazenados no NDSS } \\
\text { "Numerical Data-Base for Steel Structures". É proposta uma fórmula } \\
\text { múltipla de resistência para as famílias dos perfis (análise estatística). }\end{array}$ \\
\hline 1984 & $\begin{array}{l}\text { É publicada a norma canadense relativa aos perfis de aço formados a frio } \\
\text { CAN3-S136-M84:1984, adotando a curva de resistência à compressão do } \\
\text { CRC. Foi a primeira norma a adotar estados limites para perfis de aço } \\
\text { formados a frio. }\end{array}$ \\
\hline 1986 & $\begin{array}{l}\text { A versão do AISC/LRFD:1986 (estados limites) é publicada, adotando a } \\
\text { curva } 2 \mathrm{P} \text { do SSRC, porém com uma expressão mais simples que a } \\
\text { apresentada inicialmente por Bjorhovde. }\end{array}$ \\
\hline 1986 & $\begin{array}{l}\text { A norma brasileira NBR 8800:1986 - Projeto e execução de estruturas de } \\
\text { aço de edifícios (método dos estados limites) é publicada. As curvas de } \\
\text { resistência à compressão adotadas são as curvas antigas do Eurocode } 3 \\
\text { - expressões de MAQUOI \& RONDAL (1978), omitindo-se a curva } a_{0} \\
\text { (perfis de elevada resistência) e adotando-se } \alpha=0,572 \text { para a curva d } \\
\text { (perfis jumbo). }\end{array}$ \\
\hline 1989 & $\begin{array}{l}\text { É publicada a norma canadense relativa aos perfis formados a frio CAN3- } \\
\text { S136-M89:1989, que utiliza as curvas de resistência 1P e 2P do SSRC. }\end{array}$ \\
\hline 1996 & $\begin{array}{l}\text { É publicado o AISI (ASD/LRFD):1996 (tensões admissíveis e estados } \\
\text { limites), que adota a expressão do AISC/LRFD:1986 - curva 2P do SSRC } \\
\text { - unificando para todos os tipos de perfis (laminados, soldados e } \\
\text { formados a frio) a mesma curva de resistência à compressão. }\end{array}$ \\
\hline 1996 & $\begin{array}{l}\text { A norma australiana relativa aos perfis formados a frio AS/NZS } \\
\text { 4600:1996 é publicada, adotando a curva do AISC/LRFD:1986 (curva 2P } \\
\text { do SSRC). Pela primeira vez a flambagem por distorção é explicitamente } \\
\text { abordada numa norma. }\end{array}$ \\
\hline 1996 & $\begin{array}{l}\text { É publicado o Eurocode } 3 \text { - 1.3, que utiliza para as curvas de resistência } \\
\text { à compressão as expressões de MAQUOI \& RONDAL (1979), com } \\
\text { algumas alterações a serem explicadas mais adiante. }\end{array}$ \\
\hline 2001 & $\begin{array}{l}\text { A norma brasileira NBR 14762:2001 - Dimensionamento de estruturas de } \\
\text { aço constituídas por perfis formados a frio é publicada. As curvas de } \\
\text { resistência à compressão adotadas são as mesmas curvas do Eurocode } \\
\text { 3:1996, as quais possivelmente também serão adotadas na revisão (em } \\
\text { andamento) da NBR } 8800: 1986 \text {. }\end{array}$ \\
\hline
\end{tabular}




\begin{tabular}{|c|c|}
\hline 2001 & $\begin{array}{l}\text { É publicada a norma norte-americana para perfis de aço formados a frio, } \\
\text { denominada North American Specification for the Design of Cold-Formed } \\
\text { Steel Structural Members: } 2001 \text {, válida para os E.U.A., Canadá e México. } \\
\text { Mantém a mesma curva de resistência à compressão da edição do AISI } \\
\text { de 1996, que conforme mencionado anteriormente corresponde à curva } \\
\text { 2P do SSRC com uma expressão mais simples. }\end{array}$ \\
\hline 2004 & $\begin{array}{l}\text { É publicado um suplemento para a norma norte-americana anteriormente } \\
\text { citada, denominado Supplement } 2004 \text { to the North American Specification } \\
\text { for the Design of Cold-Formed Steel Structural Members } 2001 \text { Edition. No } \\
\text { Apêndice } 1 \text { deste suplemento é sugerido como procedimento alternativo } \\
\text { ao clássico método das larguras efetivas, o Método da Resistência Direta } \\
\text { (MRD), o qual será abordado no decorrer do presente trabalho. }\end{array}$ \\
\hline
\end{tabular}

As principais curvas de resistência à compressão propostas ao longo da história são apresentadas na Tabela 3.2. Optou-se nesta tabela por padronizar o máximo possível o formato e a simbologia.

Tabela 3.2 Curvas de resistência à compressão: principais expressões propostas

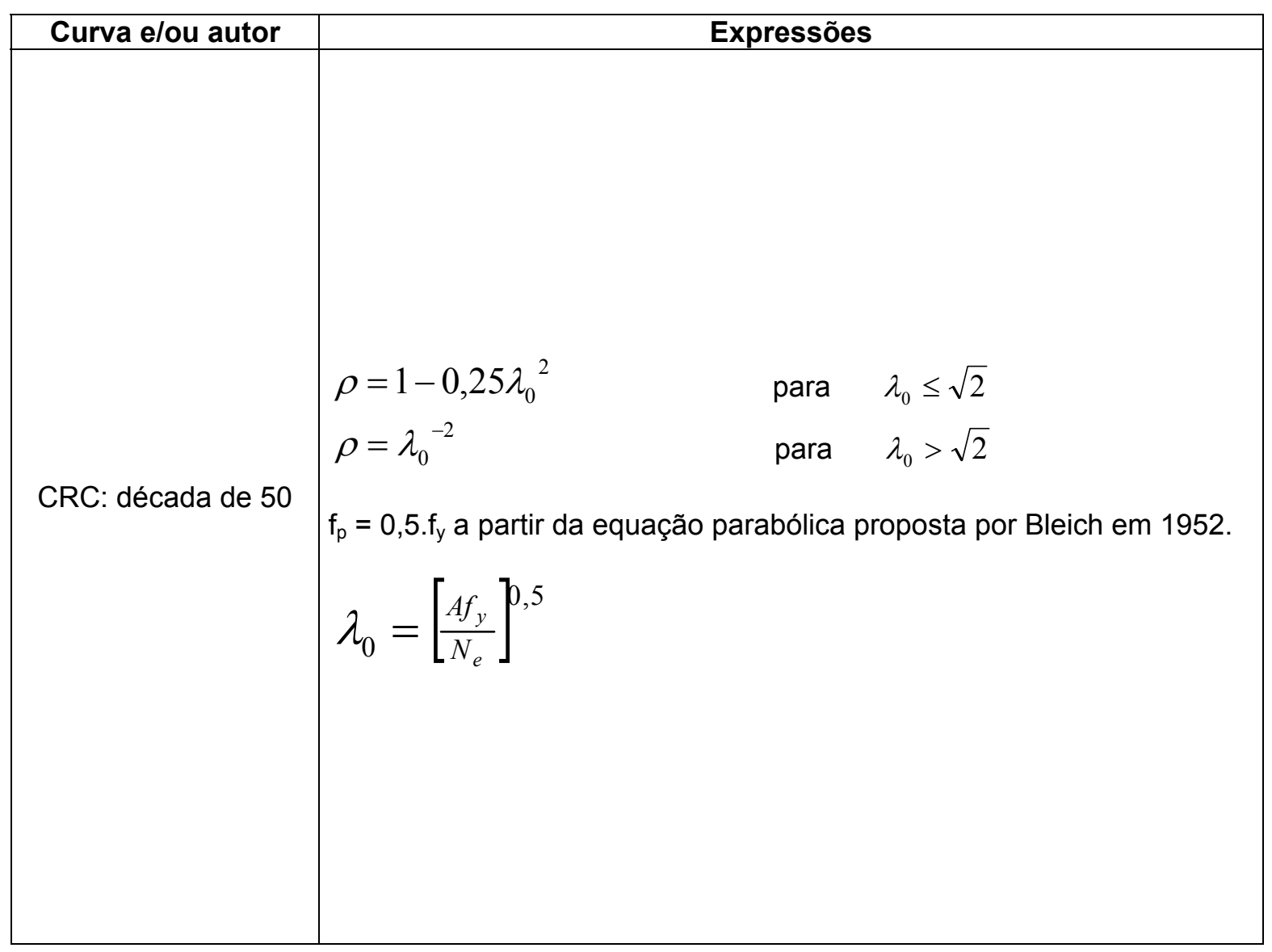




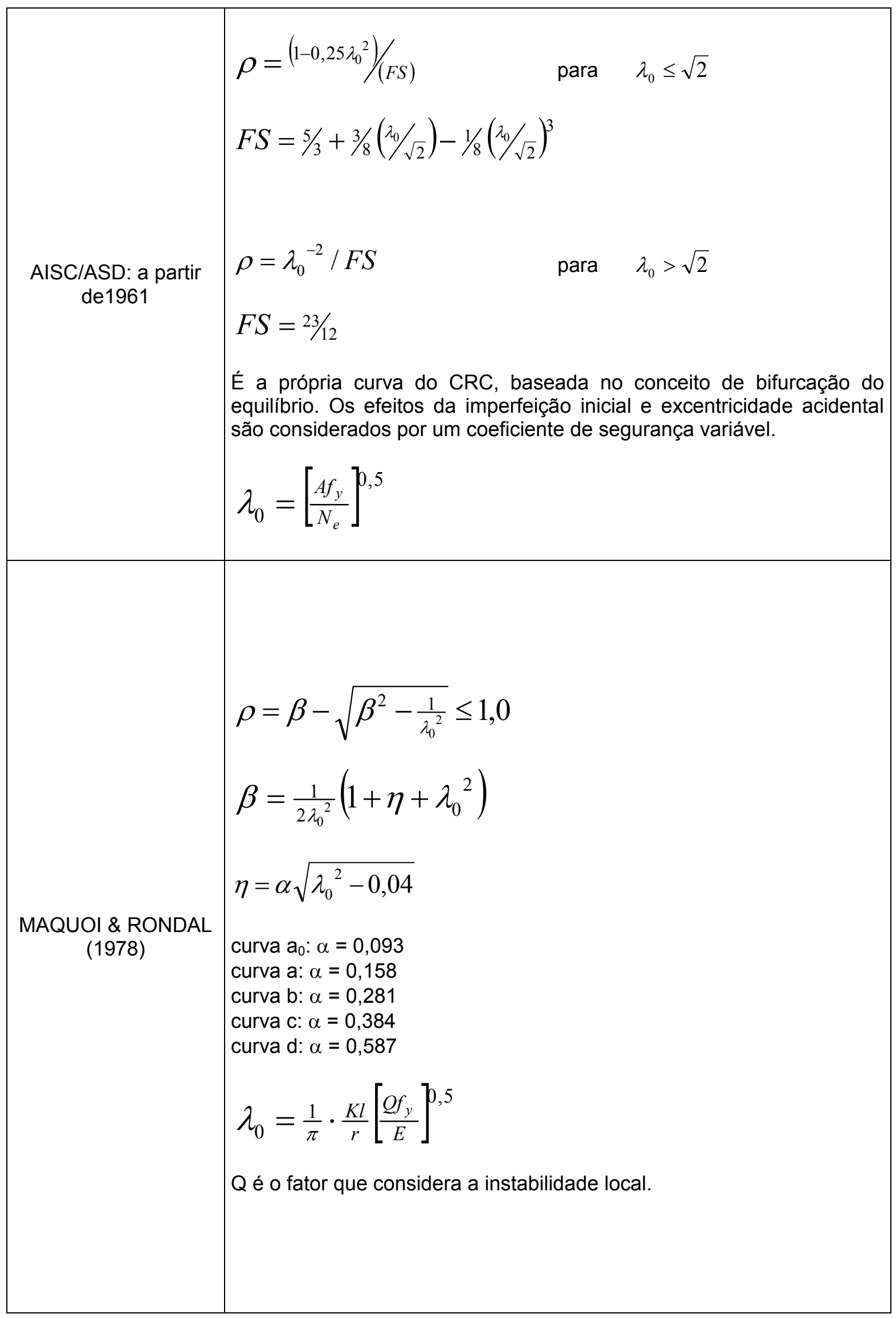




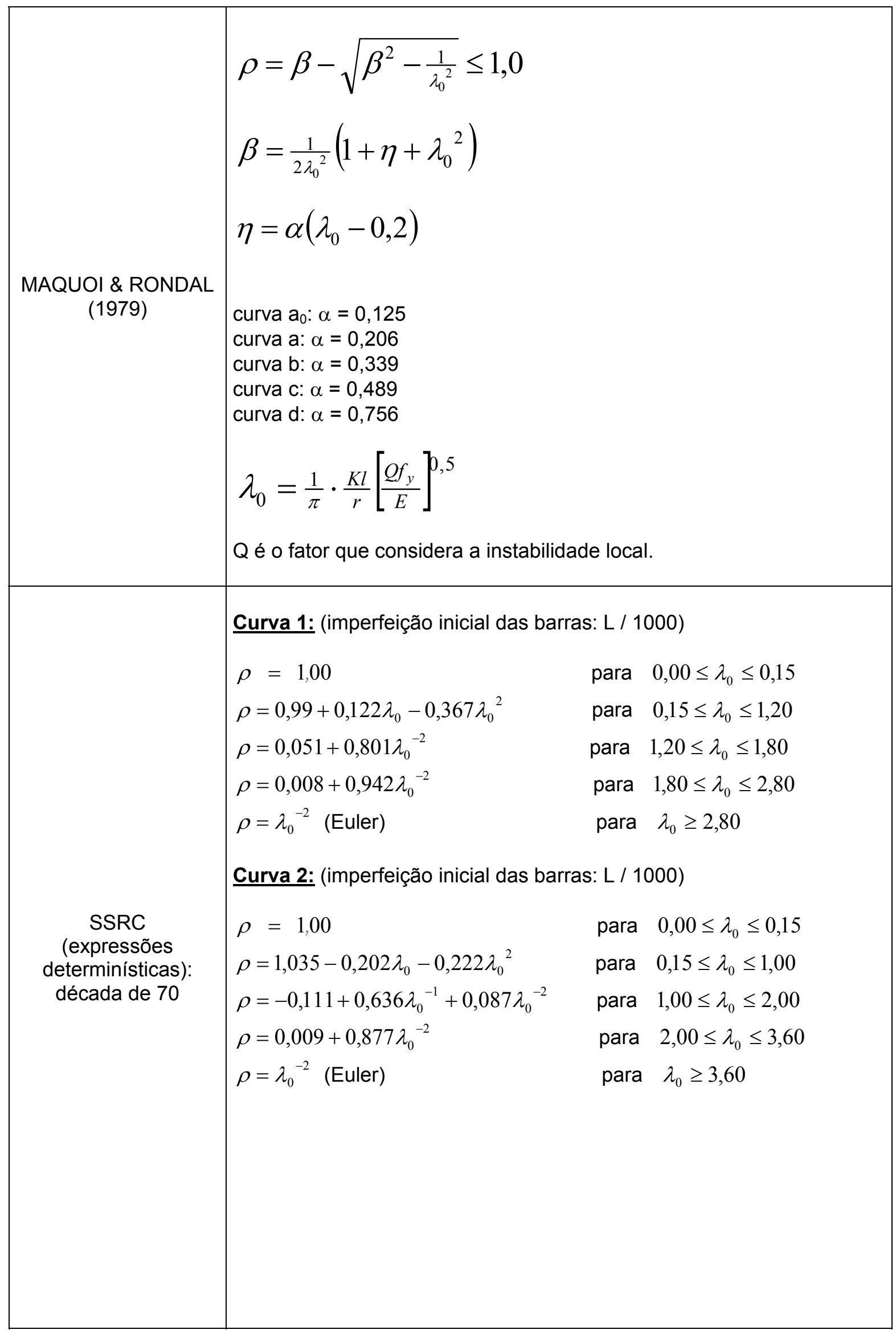




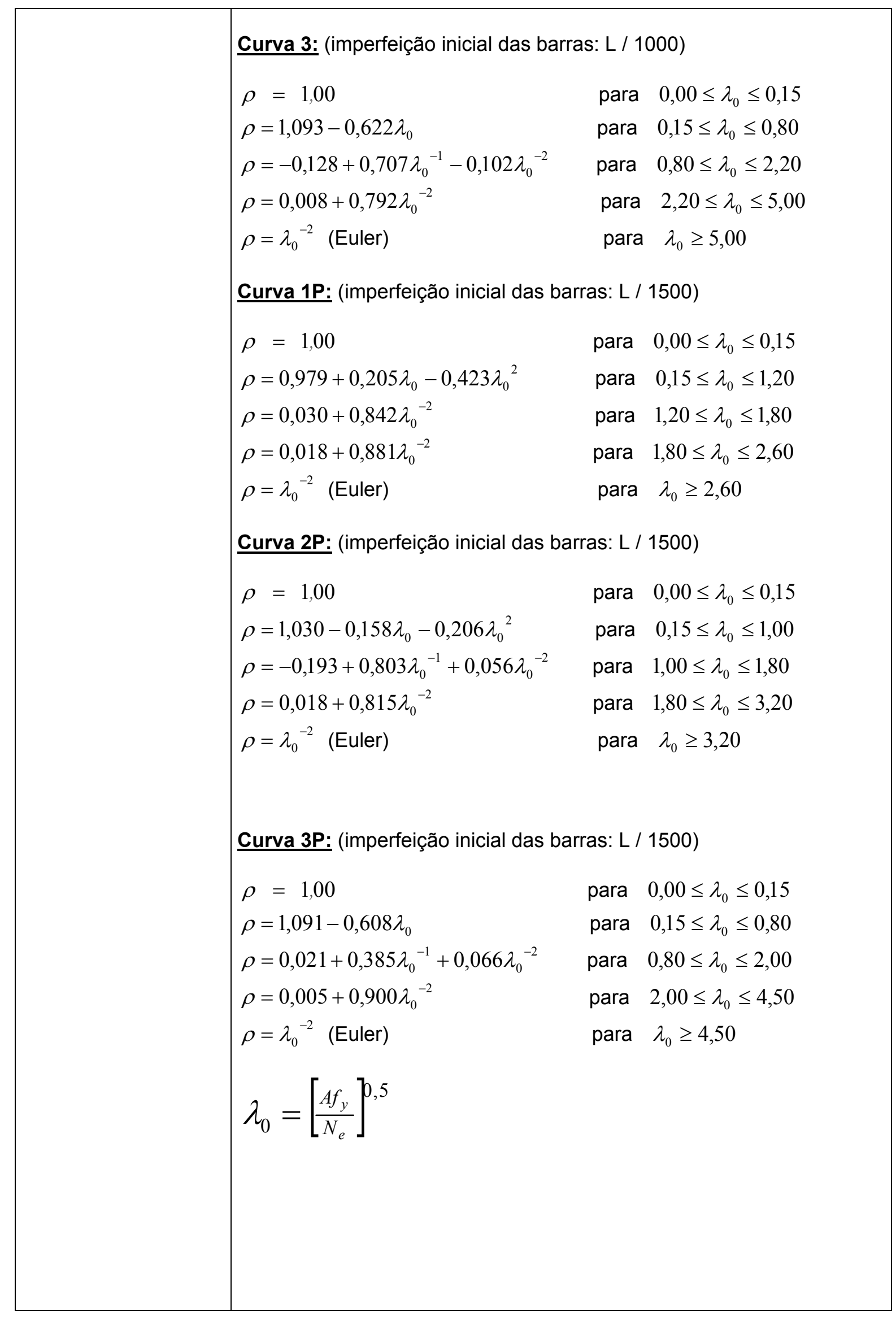




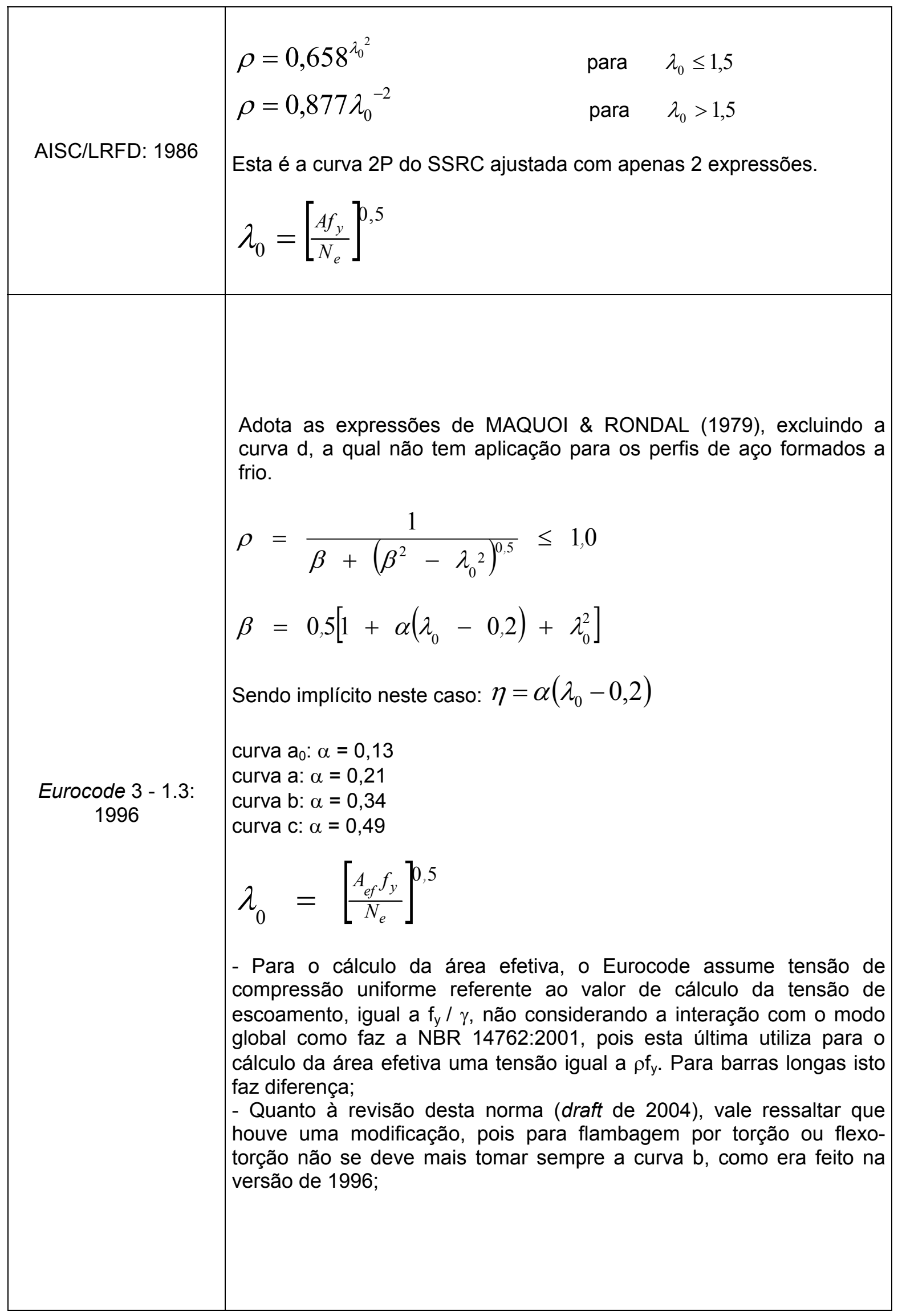




\begin{tabular}{|c|c|}
\hline NBR 14762: 2001 & $\begin{array}{l}\text { Utiliza as mesmas curvas e formato do Eurocode 3-1.3: } 1996 . \\
\rho=\frac{1}{\beta+\left(\beta^{2}-\lambda_{0}^{2}\right)^{0,5} \leq 1,0} \\
\beta=0,5\left[1+\alpha\left(\lambda_{0}-0,2\right)+\lambda_{0}^{2}\right] \\
\text { Sendo também implícito: } \eta=\alpha\left(\lambda_{0}-0,2\right) \\
\text { curva a: } \alpha=0,21 \\
\text { curva b: } \alpha=0,34 \\
\text { curva c: } \alpha=0,49 \\
\quad=\left[\frac{A_{e f} f_{y}}{N_{e}}\right] \\
\quad \begin{array}{l}\lambda, 5 \\
0\end{array} \\
\text { - Recomenda sempre a curva b para flambagem por torção ou flexo- } \\
\text { torção, conforme o EC3:1996; } \\
\text { - Não é apresentada a curva } a_{0} \text {, pois destina-se a perfis de elevada } \\
\text { resistência mecânica nem a curva d, destinada a perfis jumbo; } \\
\text { - Como explicado anteriormente, para o cálculo da área efetiva, esta } \\
\text { norma assume tensão de compressão uniforme considerando a } \\
\text { interação com o modo global, utilizando uma tensão igual a of } \mathrm{y} \text {. }\end{array}$ \\
\hline $\begin{array}{c}\text { Projeto de Revisão } \\
\text { NBR 8800: } 1986\end{array}$ & $\begin{array}{l}\text { Utiliza as mesmas curvas da norma brasileira de perfis formados a frio } \\
\text { NBR 14762: } 2001 \text {, portanto também baseada no EC3:1996. } \\
\rho=\frac{1}{\beta+\sqrt{\left(\beta^{2}-\lambda_{0}^{2}\right)}} \leq 1,0 \\
\beta=0,5\left[1+\alpha\left(\lambda_{0}-0,2\right)+\lambda_{0}^{2}\right] \\
\text { Sendo implícito também neste caso: } \eta=\alpha\left(\lambda_{0}-0,2\right) \\
\text { curva a: } \alpha=0,21 \\
\text { curva b: } \alpha=0,34 \\
\text { curva c: } \alpha=0,49 \\
\text { curva d: } \alpha=0,76 \\
\lambda_{0}=\sqrt{\frac{Q A f_{y}}{N_{e}}} \\
\text { Q é o fator que considera a instabilidade local. }\end{array}$ \\
\hline
\end{tabular}


Vale salientar que estas curvas de resistência apresentadas foram elaboradas sem a consideração de qualquer restrição à rotação nas extremidades das barras.

Deve-se também considerar o trecho das curvas relativo a baixos valores de esbeltez, onde o efeito do encruamento é significativo, resultando em um aumento da resistência. A resistência esperada para as barras nesse trecho do diagrama resulta acima do valor $\rho=1,0$, e, portanto, foram adotados platôs para se obter uma condição a favor da segurança.

\subsection{Modos de instabilidade}

Antes de se iniciar o assunto referente a modos de instabilidade propriamente dito, vale a pena discutir brevemente sobre as condições de vinculação nas extremidades das barras.

Segundo NAGAHAMA (2003), para análises de perfis de aço formados a frio de paredes delgadas e seção aberta, a restrição ao empenamento nas extremidades não altera a força crítica para os modos locais, diferentemente do caso relativo ao modo distorcional, no qual tal restrição conduz a um valor de força crítica superior. Também diz que o engastamento localizado - condição de engaste para o modo local de chapa, porém com a barra biarticulada quanto ao modo global - nas extremidades da barra eleva a força crítica para estes dois modos de instabilidade, sendo que para barras de comprimentos maiores a força crítica diminui, tendendo aos valores correspondentes às barras biarticuladas. Entretanto, não se entrará em detalhes quanto a estas variações de condições de vinculação, pois neste trabalho o empenamento foi restringido para todas as barras analisadas.

Passa-se agora a uma abordagem quanto aos diferentes modos de instabilidade, denominados instabilidade global, local e distorcional. Para uma melhor visualização inicial do assunto, a Figura 3.5 ilustra os vários modos de instabilidade simples e acoplados para um perfil do tipo $U$ enrijecido submetido à compressão.

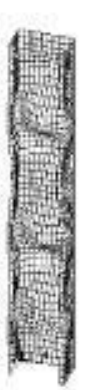

(a)

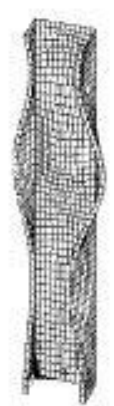

(b)

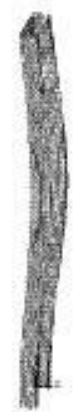

(c)

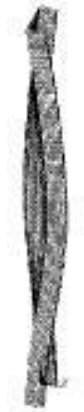

(d)

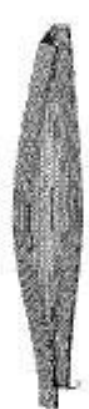

(e)

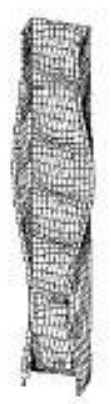

(f)

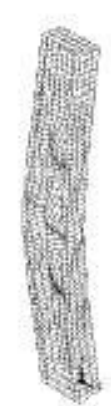

(g)

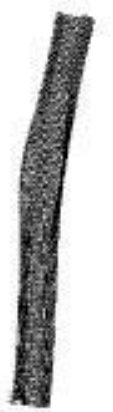

(h)

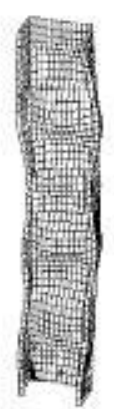

(i)

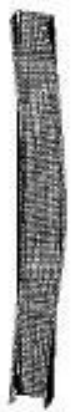

(i)

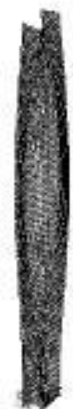

(k)

Modos simples: (a) local - L; (b) distorcional - D; (c) global por flexão - F; (d) global por torção - T; (e) global por flexo-torção - FT

Modos acoplados: (f) L + D; (g) F + L; (h) F + D; (i) FT + L; (j) FT + D; (k) F + FT

Figura 3.5 Modos de instabilidade simples e acoplados: perfil do tipo $U$ enrijecido submetido à compressão [DUBINA (2003)] 


\subsubsection{Instabilidade global}

As seções transversais dos perfis de aço formados a frio são geralmente abertas (monossimétricas), pelo menos na maioria das situações de aplicações práticas. Portanto, a condição geral de instabilidade global por flexo-torção é muito importante na análise do comportamento da barra. Os modos de instabilidade globais para as barras submetidas à compressão são discutidos a seguir.

\subsubsection{Instabilidade por flexão}

\subsection{Flambagem elástica}

Primeiramente vale salientar que o termo aqui utilizado é "flambagem" pois se trata de um modelo de primeira espécie (problema de bifurcação do equilíbrio).

A flambagem por flexão é caracterizada pela flexão em torno de um dos eixos principais de inércia da seção transversal, sendo apresentada aqui a expressão (3.1) referente à força normal de flambagem elástica (Euler).

$$
N_{e}=\frac{\pi^{2} E I}{(K L)^{2}}
$$

\section{Sendo:}

$\mathrm{N}_{\mathrm{e}}$ : força normal de flambagem elástica;

E: módulo de elasticidade do aço;

I: momento de inércia da seção bruta referente ao eixo de flambagem em questão;

KL: comprimento efetivo de flambagem da barra - introduzido por Jasinsky em 1893 - que pode ser definido como a distância entre dois pontos de curvatura nula (pontos de inflexão) na posição deslocada de uma barra;

$$
K=\sqrt{\frac{N_{e}{ }^{*}}{N_{c r}}}
$$

$\mathrm{N}_{\mathrm{e}}{ }^{*}$ : força normal crítica de Euler (barra biapoiada);

$\mathrm{N}_{\mathrm{cr}}$ : força normal crítica de Euler (barra com outras condições de vinculação nas extremidades);

Se for substituído na expressão (3.1) o termo $\left(I=A \cdot r^{2}\right)$, sendo $r$ o raio de giração da seção bruta, resulta a expressão (3.2) referente à tensão normal de flambagem elástica. Vale lembrar a definição do índice de esbeltez: $\lambda=(\mathrm{KL} / \mathrm{r})$. 


$$
\sigma_{e}=\frac{\pi^{2} E}{\lambda^{2}}
$$

A expressão (3.2) pode ser aplicada a barras "ideais", i.e., modelos de primeira espécie, e não se aplica a trechos do diagrama tensão-deformação para tensões acima da tensão de proporcionalidade $f_{p}$, no qual a flambagem ocorre no regime inelástico, vide Figura 2.2. Salienta-se que a tensão de proporcionalidade está diretamente relacionada às tensões residuais $\left(f_{p}=f_{y}-f_{r}\right)$, inerentes aos processos de fabricação dos perfis de aço, como já explicado.

A tensão de proporcionalidade está associada com a esbeltez de proporcionalidade $\left(\lambda_{\lim }\right.$ na Figura 2.2), que é obtida fazendo-se $\sigma_{e}=f_{p}$ na expressão (3.2). Consequentemente, a expressão da tensão crítica de flambagem de Euler deve ser corrigida quando apresentar valores acima da tensão de proporcionalidade, a fim de se considerar o comportamento inelástico do material.

\subsection{Flambagem elasto-plástica (ou inelástica)}

Aqui também será utilizado o termo "flambagem" pelo mesmo motivo do item anterior. Neste regime elasto-plástico, algumas fibras da seção transversal estão sob tensão acima da tensão de proporcionalidade, enquanto que outras encontram-se ainda no regime elástico. Portanto, é mais correta a utilização do termo elasto-plástico em vez do termo inelástico.

Entende-se por regime inelástico, ou elasto-plástico, o trecho do diagrama tensãodeformação para tensões superiores a tensão de proporcionalidade $f_{p}$. Acima deste trecho ocorre a perda de linearidade no traçado do gráfico entre a tensão de proporcionalidade $f_{p}$ e a resistência ao escoamento do aço $f_{y}$, fato este decorrente principalmente da existência de tensões residuais presentes nos perfis (Figura 2.2 e Figura 3.6).

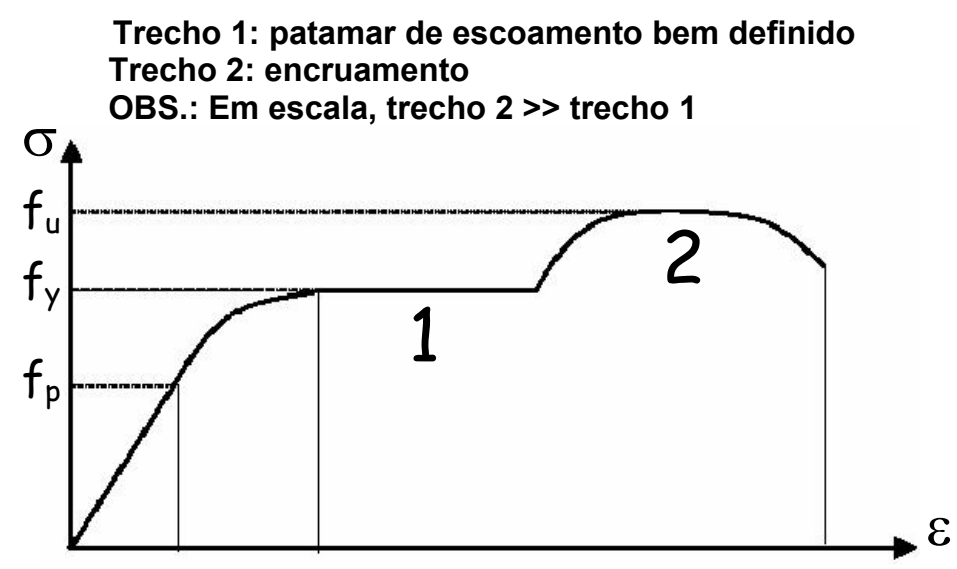

Figura 3.6 Diagrama tensão-deformação para aços com patamar de escoamento 
Para a análise do fenômeno da instabilidade neste regime existem alguns conceitos utilizados, como o módulo tangente e o módulo reduzido (duplo módulo), que podem ser melhor entendidos, por exemplo, em BLEICH (1952), GALAMBOS (1988), TIMOSHENKO (1961). Estes conceitos são aqui abordados de maneira sucinta, por serem métodos clássicos e já amplamente conhecidos, valendo lembrar que estas teorias são muito importante para o estudo de barras submetidas à compressão com imperfeições iniciais e tensões residuais, propensas ao enquadramento neste regime.

\subsection{Teoria do módulo tangente}

Conforme esta teoria, no regime elasto-plástico (Figura 2.2) não mais o módulo de elasticidade $E$, mas sim o módulo de elasticidade tangente $E_{t}$ (cujo valor varia ponto a ponto no diagrama tensão-deformação de acordo com a derivada $E_{t}=d \sigma / d \varepsilon$ ), governa 0 comportamento na flambagem, como ilustrado na Figura 3.7. Obviamente, algumas hipóteses fundamentais governam esta teoria, mas não são apresentadas aqui pois são amplamente conhecidas na literatura.

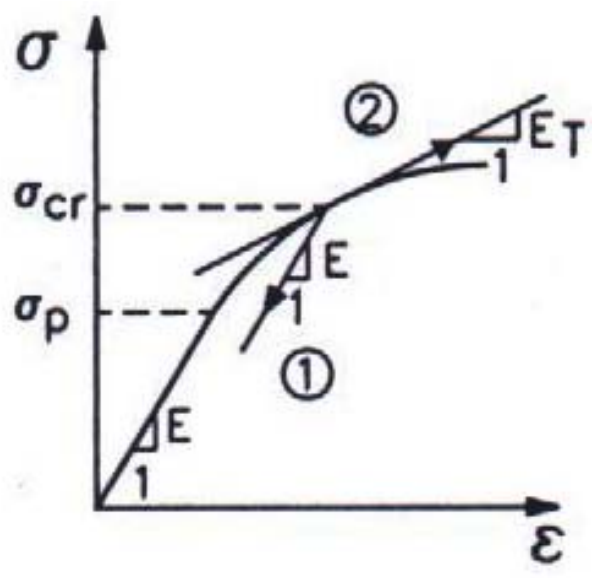

Figura 3.7 Curva típica tensão-deformação do aço

Após resolvidas as equações diferenciais inerentes a esta teoria, são obtidas as expressões relativas à força normal e à tensão crítica de flambagem elasto-plástica, respectivamente apresentadas nas expressões (3.3) e (3.4). 


$$
\begin{aligned}
& N_{T}=\frac{\pi^{2} E_{T} I}{(K L)^{2}}=\frac{E_{T}}{E} N_{e} \\
& \sigma_{c r, T}=\frac{\pi^{2} E_{T}}{\lambda^{2}}
\end{aligned}
$$

Conforme relatado na literatura, apesar das forças críticas obtidas pela teoria do módulo tangente serem próximas aos resultados de ensaios, o conceito inicial apresentado por Engesser em 1889 era incorreto, pois afirmava que no regime elasto-plástico os trechos de carregamento e descarregamento do diagrama tensão-deformação são governados pelo módulo de elasticidade tangente $\mathrm{E}_{\mathrm{t}}$.

Admitindo-se a configuração deformada por flexão, uma parte da seção transversal apresenta alívio de compresão (descarregamento) e a outra aumento. Na parte que sofre o alívio, o módulo de elasticidade volta a ser E, o que contradiz a expressão (3.3), fato que conduziu à modificação introduzida por Engesser em 1898 que resultou na proposição da teoria do módulo reduzido (duplo módulo), apresentada a seguir.

\subsection{Teoria do módulo reduzido ou duplo módulo}

De acordo com esta teoria, no regime elasto-plástico o trecho de carregamento do diagrama tensão-deformação é governado pelo módulo de elasticidade tangente $E_{t}$, enquanto que o descarregamento é governado pelo módulo de elasticidade $\mathrm{E}$, o que mostrou ser mais coerente conceitualmente, assim como apresentado na Figura 3.7.

Após resolvidas as equações diferenciais inerentes a esta teoria, são obtidas as expressões relativas à força normal e à tensão crítica de flambagem elasto-plástica, respectivamente apresentadas nas expressões (3.5) e (3.6). É importante salientar que $E_{r}>E_{T}$ e também que $\mathrm{N}_{\mathrm{r}}>\mathrm{N}_{\mathrm{T}}$.

$$
\begin{aligned}
& N_{r}=\frac{\pi^{2} E_{r} I}{(K L)^{2}}=\frac{E_{r}}{E} N_{e} \\
& \sigma_{c r, r}=\frac{\pi^{2} E_{r}}{\lambda^{2}}
\end{aligned}
$$

Algumas considerações quanto à adequação das duas teorias supracitadas são apresentadas pelo modelo de SHANLEY (1947) na Figura 3.8, sendo este um modelo 
consistente para análise do comportamento pós-flambagem no regime elasto-plástico, com análise de uma configuração de equilíbrio na vizinhança da trajetória fundamental, admitindo que a bifurcação poderá ocorrer em equilíbrio não neutro: $\Delta N \neq 0$.

Este modelo de Shanley apresenta algumas conclusões citadas a seguir, visualisadas na Figura 3.9 na qual o diagrama força normal $N$ versus deslocamento $v$ para uma barra biapoiada submetida à compressão centrada é ilustrado. Do modelo de Shanley constata-se:

- Um dos fatores quanto aos resultados dos ensaios serem mais próximos aos previstos pelo conceito do módulo tangente do que pelo conceito do duplo módulo é que na prática não existe barra sem imperfeição inicial geométrica, sendo que o ensaio reproduz na verdade uma flexo-compressão. Portanto, a flexão da barra existe desde o início do carregamento fazendo com que o alívio das tensões na seção transversal não seja tão pronunciado como admitido no conceito do módulo reduzido;

- A força normal crítica é maior que a obtida pelo módulo tangente $\left(\mathrm{N}_{T}\right)$, mas é inferior à referente ao módulo reduzido ou duplo módulo $\left(\mathrm{N}_{\mathrm{r}}\right)$;

- Quando $\mathrm{N}>\mathrm{N}_{\mathrm{T}}$ deslocamentos laterais v (perpendiculares ao eixo da barra) ocorrerão;

- $\mathrm{Na}$ prática, devido ao fato das condições reais quanto à excentricidades no carregamento e imperfeições iniciais não serem claras, a opção pela força normal crítica referente ao módulo tangente $\left(\mathrm{N}_{\mathrm{T}}\right)$ é recomendada, por ser a favor da segurança.

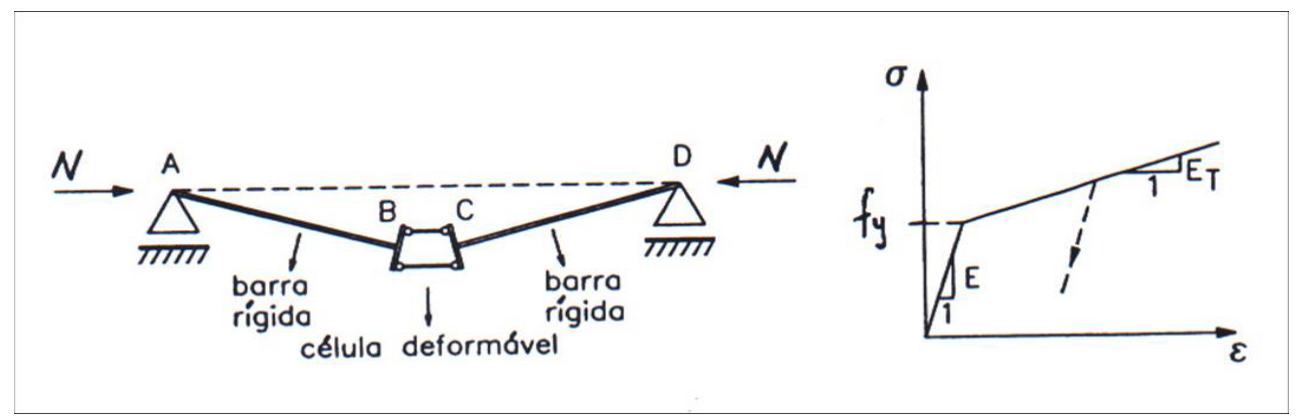

Figura 3.8 Coluna de Shanley 


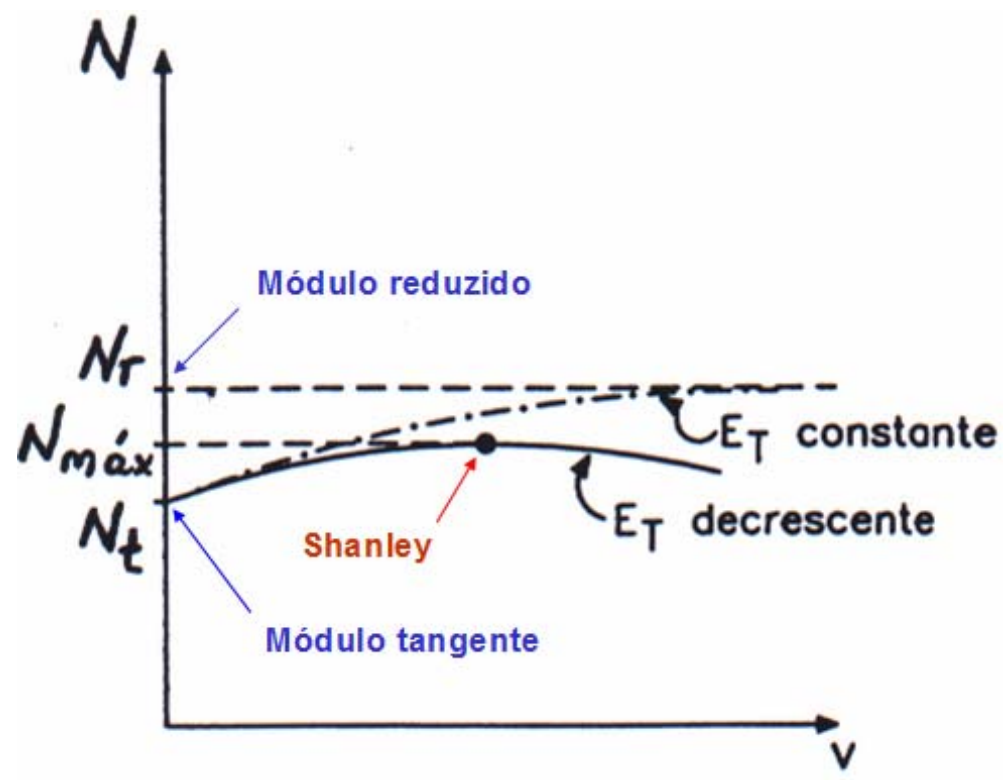

Figura 3.9 Força normal versus deslocamento: barra biapoiada submetida à compressão centrada

Como informação adicional é válido dizer que BLEICH (1952) propôs uma equação parabólica, ilustrada na Figura 2.2 no trecho denominado flambagem elasto-plástica (inelástica), para servir de aproximação para a equação da tensão crítica obtida pelo módulo tangente.

A Figura 3.10 ilustra algumas das curvas propostas para a análise da instabilidade global por flexão. Apresenta-se para o trecho elástico a curva proposta por Euler. Para o trecho elasto-plástico, as curvas propostas pelas teorias do módulo tangente, módulo reduzido, e a parábola aproximadora do módulo tangente apresentada por Bleich.

Ressalta-se que esta parábola apresentada por Bleich é uma curva conservadora aproximada do conceito do módulo tangente, representada por $\sigma=f_{y}\left(1-f_{y} / 4 \sigma_{e}\right)$, proposta pelo CRC (atual SSRC) para aços laminados a quente considerando-se $f_{p}=0,5 . f_{y}$. Foi também adotada pelas normas de perfis de aço formados a frio. 


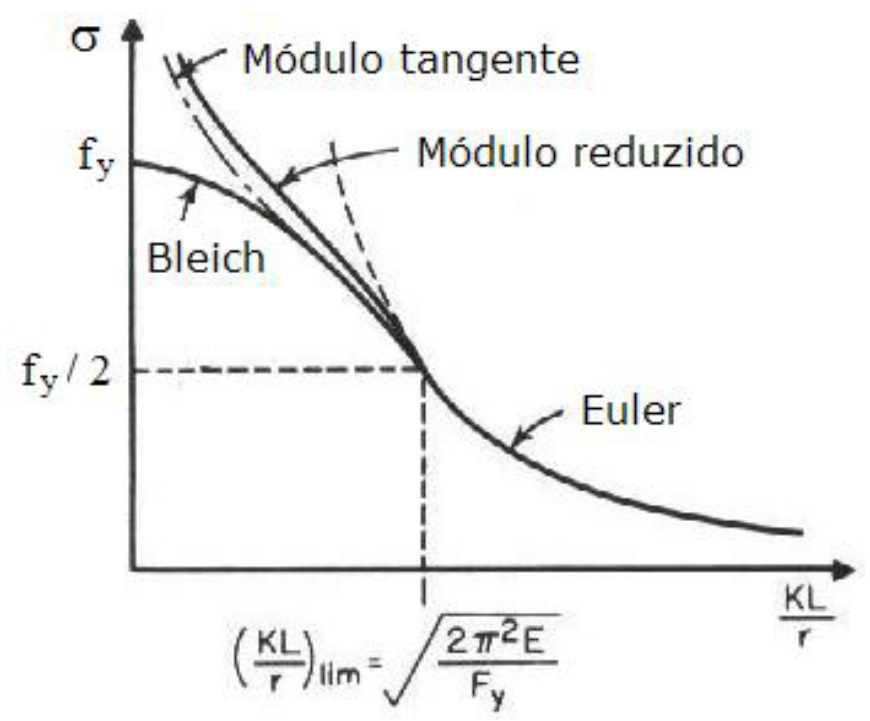

Figura 3.10 Curva tensão versus esbeltez: flambagem por flexão para barras submetidas à compressão [adaptado de YU (2000)]

\subsubsection{Instabilidade por flexo-torção}

Barras submetidas à compressão com seção transversal assimética, monossimétrica, seção cruciforme, e também as com grande comprimento livre à torção estão sujeitas à instabilidade por torção ou por flexo-torção. Portanto, as barras com seção aberta e paredes delgadas - objeto desta tese - estão inseridas neste contexto.

Ressalta-se que tanto a instabilidade por flexão como a instabilidade por torção são casos particulares do caso geral de instabilidade por flexo-torção, este caracterizado pela mudança de posição do centro de cisalhamento (centro de torção), ocorrendo na seção transversal translações $w$ e $v$ nas direções $x$ e $y$, respectivamente, e rotação $\phi$ no plano da seção xy, vide Figura 3.11. Se ocorrerem somente as translações o fenômeno será de flambagem por flexão, e se ocorrer somente a rotação o fenômeno será de flambagem por torção.

De acordo com a Teoria da Estabilidade Elástica, citada entre outros por TIMOSHENKO (1961), RACHID \& MORI (1993) e YU (2004), se uma barra for submetida a uma força de compressão atuante em seu centro de gravidade, sendo que a seção transversal desta é aberta e o centro de gravidade e o centro de torção não são coincidentes - caso dos perfis do tipo $U, U$ enrijecido, cantoneira simples e dupla estudados neste trabalho - os autovetores são relativos à movimentos característicos de flexão e torção. 


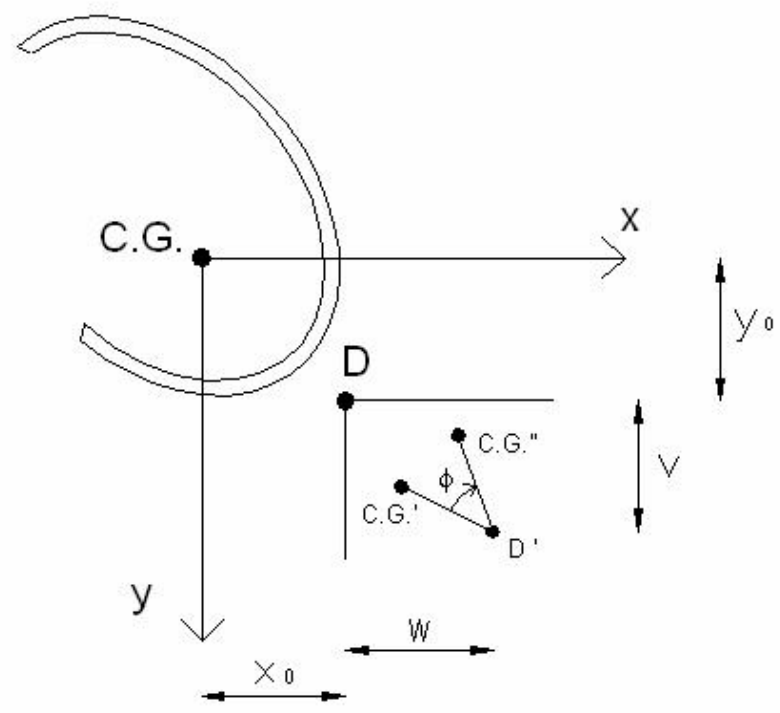

Figura 3.11 Seção transversal aberta genérica com paredes delgadas

Admitindo-se o equilíbrio na posição deslocada da seção apresentada na Figura 3.12, as três equações diferenciais que regem o problema da flexo-torção relativas ao equilíbrio de forças nas direções x e y são apresentadas a seguir nas expressões (3.7) a (3.9), e determinam a força normal crítica $\mathrm{N}$, que pode ser relativa à instabilidade por flexão, torção, ou por flexo-torção. Vale lembrar que as derivadas são em relação ao eixo z, direção ao longo do eixo da barra.

Vale aqui abrir um parênteses para explicar que as expressões (3.7) a (3.9) são para o caso de compressão centrada. Expressões mais gerais incluindo o caso da flexo-compressão não serão aqui apresentadas por não ser o tema deste trabalho.

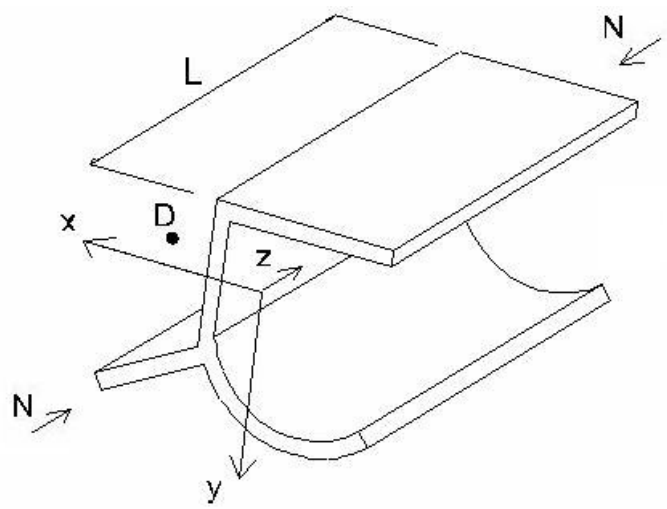

Figura 3.12 Seção transversal aberta genérica com paredes delgadas sob compressão centrada 


$$
\begin{aligned}
& E I_{x} v_{D}{ }^{i v}+N v_{D}^{\prime \prime}-N x_{0} \phi^{\prime \prime}=0 \\
& E I_{y} w_{D}^{i v}+N w_{D}^{\prime \prime}+N y_{0} \phi^{\prime \prime}=0 \\
& E C_{w} \phi^{i v}-\left(G I_{t}-N r_{0}^{2}\right) \phi^{\prime \prime}-N x_{0} v_{D}^{\prime \prime}+N y_{0} w_{D}^{\prime \prime}=0
\end{aligned}
$$

Sendo:

$\mathrm{I}_{\mathrm{x}}$ : momento de inércia da seção bruta em relação ao eixo principal $\mathrm{x}$;

$\mathrm{I}_{\mathrm{y}}$ : momento de inércia da seção bruta em relação ao eixo principal y;

w: deslocamento em $\mathrm{x}$;

v: deslocamento em y;

$\phi$ : ângulo de rotação;

$\mathrm{x}_{0}$ : coordenada $\mathrm{x}$ do centro de torção;

$\mathrm{y}_{0}$ :coordenada y do centro de torção;

E: módulo de elasticidade do aço;

G: módulo de elasticidade transversal do aço;

$\mathrm{I}_{\mathrm{t}}$ : momento de inércia à torção uniforme;

$\mathrm{C}_{\mathrm{w}}$ : constante de empenamento da seção;

$r_{0}$ : raio de giração polar da seção bruta em relação ao centro de torção;

Considerando-se na barra as mesmas condições de contorno para as duas extremidades, para $z=0$ e para $z=L$, tem-se, dependendo do caso em questão:

Se engaste: $\quad w=v=\phi=0 \quad$ e $\quad w^{\prime}=v^{\prime}=\phi^{\prime}=0$

Se apoio: $\quad w=v=\phi=0 \quad$ e $\quad w "=v "=\phi "=0$

As expressões (3.7) a (3.9) podem ser reescritas na forma da expressão (3.10), sendo a força normal crítica $\mathrm{N}_{\mathrm{cr}}$ o menor valor dentre as três raízes.

$r_{0}^{2}\left(N_{c r}-N_{x}\right)\left(N_{c r}-N_{y}\right)\left(N_{c r}-N_{z}\right)-\left(N_{c r}\right)^{2}\left(y_{0}\right)^{2}\left(N_{c r}-N_{x}\right)-\left(N_{c r}\right)^{2}\left(x_{0}\right)^{2}\left(N_{c r}-N_{y}\right)=0$

Sendo: 


$$
\begin{aligned}
& N_{x}=\frac{\pi^{2} E I_{x}}{\left(K_{x} L_{x}\right)^{2}} \\
& N_{y}=\frac{\pi^{2} E I_{y}}{\left(K_{y} L_{y}\right)^{2}} \\
& N_{z}=\left(\frac{\pi^{2} E C_{w}}{\left(K_{t} L_{t}\right)^{2}}+G I_{t}\right)\left(\frac{1}{r_{0}{ }^{2}}\right)
\end{aligned}
$$

$\mathrm{KL}=$ comprimento efetivo de flambagem da barra.

Especificando-se mais o assunto, uma particularidade para o caso de seção transversal com um único eixo de simetria - seção monossimétrica e caso dos perfis do tipo $U, U$ enrijecido, cantoneira simples e dupla, estudados no presente trabalho - é que se o eixo $x$ for tomado como o eixo de simetria, tem-se $y_{0}=0$ e $x_{0} \neq 0$. Com isso, a equação (3.10) é modificada para a equação (3.11).

$$
\left(N_{c r}-N_{y}\right)\left(r_{0}^{2}\left(N_{c r}-N_{x}\right)\left(N_{c r}-N_{z}\right)-\left(N_{c r} x_{0}\right)^{2}\right)=0
$$

Para este caso, uma das soluções representa a flambagem por flexão em torno do eixo y, apresentada na expressão (3.12). As duas outras soluções para o fenômeno da flambagem por flexo-torção podem ser obtidas resolvendo-se a equação quadrática (3.13).

Na primeira equação, (3.12), pode-se perceber que a flambagem por flexão em torno do eixo y é desacoplada das demais e pode ser tratada separadamente. A equação (3.13), por outro lado, resulta acoplada caracterizando a flambagem por flexo-torção.

$$
\begin{aligned}
& \left(N_{c r}\right)_{1}=N_{y}=\frac{\pi^{2} E I_{y}}{\left(K_{y} L_{y}\right)^{2}} \\
& r_{0}^{2}\left(N_{c r}-N_{x}\right)\left(N_{c r}-N_{z}\right)-\left(N_{c r} x_{0}\right)^{2}=0
\end{aligned}
$$

Com o intuito de facilitar a apresentação das duas soluções oriundas da resolução da equação (3.13), faz-se: $\beta=1-\left(x_{0} / r_{0}\right)^{2}$. Daí, obtém-se as expressões (3.14) e (3.15). 


$$
\begin{aligned}
& \left(N_{c r}\right)_{2}=\frac{1}{2 \beta}\left(\left(N_{x}+N_{z}\right)+\sqrt{\left(N_{x}+N_{z}\right)^{2}-4 \beta N_{x} N_{z}}\right) \\
& \left(N_{c r}\right)_{3}=\frac{1}{2 \beta}\left(\left(N_{x}+N_{z}\right)-\sqrt{\left(N_{x}+N_{z}\right)^{2}-4 \beta N_{x} N_{z}}\right)
\end{aligned}
$$

É importante salientar que devido ao fato da expressão (3.15) fornecer um valor de força crítica inferior ao proveniente da expressão (3.14), o resultado da expressão (3.15) pode ser utilizado como sendo a força crítica associada à flambagem por flexo-torção, e que será sempre inferior tanto a $N_{x}$ quanto a $N_{z}$, mas que pode ser inferior ou superior a $N_{y}$ resultante da expressão (3.12).

Será agora realizada uma análise no âmbito das tensões, para se ilustrar uma curva similar à curva já apresentada para o caso da flambagem por flexão como feito na Figura 3.10. Dividindo-se então a expressão (3.15) pela área bruta $A$ da seção, obtem-se a expressão (3.16) de tensão elástica de flambagem por flexo-torção, com a curva ilustrada na Figura 3.13.

$$
\sigma_{T F 0}=\frac{1}{2 \beta}\left(\left(\sigma_{e x}+\sigma_{t}\right)-\sqrt{\left(\sigma_{e x}+\sigma_{t}\right)^{2}-4 \beta \sigma_{e x} \sigma_{t}}\right)
$$

Sendo:

$\sigma_{\mathrm{ex}}=\mathrm{N}_{\mathrm{x}} / \mathrm{A}$

$\sigma_{\mathrm{t}}=\mathrm{N}_{\mathrm{z}} / \mathrm{A}$

Pode ser verificado que uma seção monossimétrica pode sofrer flambagem tanto por flexão em torno do eixo perpendicular ao de simetria, quanto por flexo-torção (neste último caso, flexão em torno do eixo de simetria e rotação em torno do centro de torção), isso dependendo, dentre outros fatores, da seção transversal e do comprimento efetivo da barra.

As normas têm adotado as mesmas curvas de resistência à compressão associadas à flambagem por flexão, atribuindo a elas um caráter mais geral, como por exemplo, no caso da clássica curva do CRC ilustrada na Figura 3.13, cujo trecho elasto-plástico é dado pela parábola de Bleich, vide expressão (3.17). 


$$
\sigma_{T F T}=f_{y}\left(1-\frac{f_{y}}{4 \sigma_{T F 0}}\right)
$$

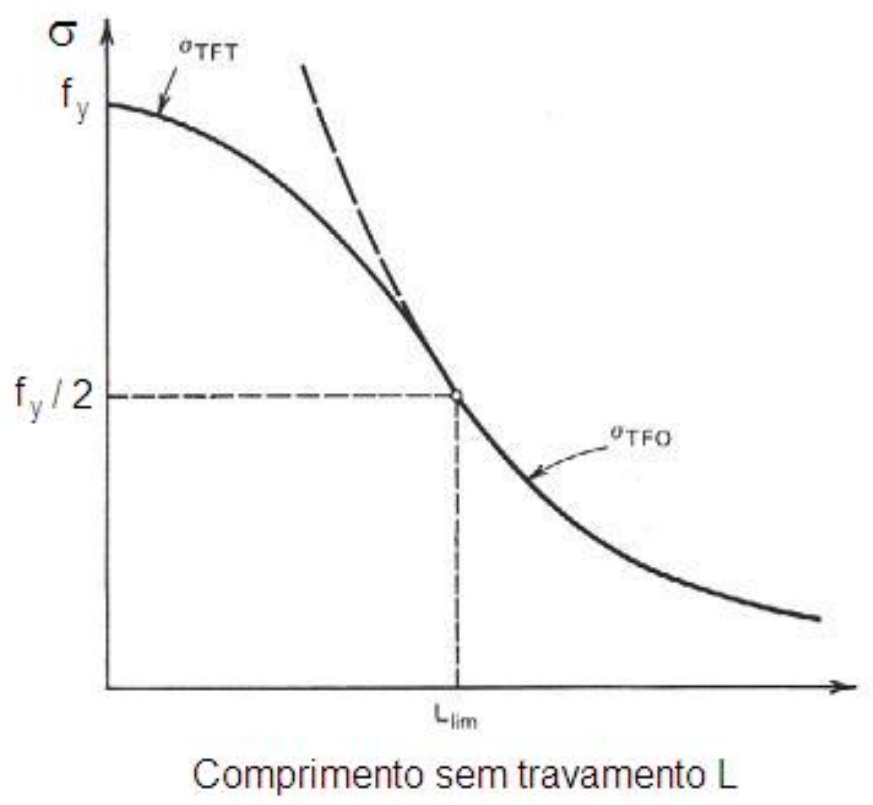

Figura 3.13 Curva tensão versus comprimento entre travamentos ao longo da barra: flambagem por flexo-torção de barras comprimidas [YU (2000)]

\subsubsection{Instabilidade local}

A instabilidade local de uma barra submetida à compressão caracteriza-se por um típico modo de instabilidade de chapa, conforme ilustrado na Figura 3.14, apresentando significativo comportamento pós-crítico. A rigor, este fenômeno pode ser analisado de dois modos: "simplificado" e "rigoroso".

Em geral, é adotado o modo "simplificado" de cálculo, em que se analisa isoladamente os elementos que compõem a seção. Resultados satisfatórios são obtidos por meio da expressão de Winter considerando-se a relação largura-espessura do elemento (b/t) para efeito da instabilidade local. Tal procedimento implica na determinação de uma largura menor que a largura total do elemento, denominada largura efetiva (método das larguras efetivas), resultando então em uma redução de área do elemento em questão.

Por outro lado, a consideração do modo "rigoroso" na análise da seção transversal implica na consideração explícita da interação entre os elementos que a constituem, modelo portanto mais próximo da situação real. Utiliza-se métodos aproximados ou métodos numéricos como, por exemplo, método dos elementos finitos ou faixas finitas. 
As condições para se equacionar o problema de instabilidade local dependem do modo como a seção está solicitada e do modo como as extremidades destes elementos se apresentam (vinculados em ambas as extremidades a outros elementos - AA, conforme indicado na Figura 3.15 ou com uma borda livre - AL, conforme Figura 3.16).

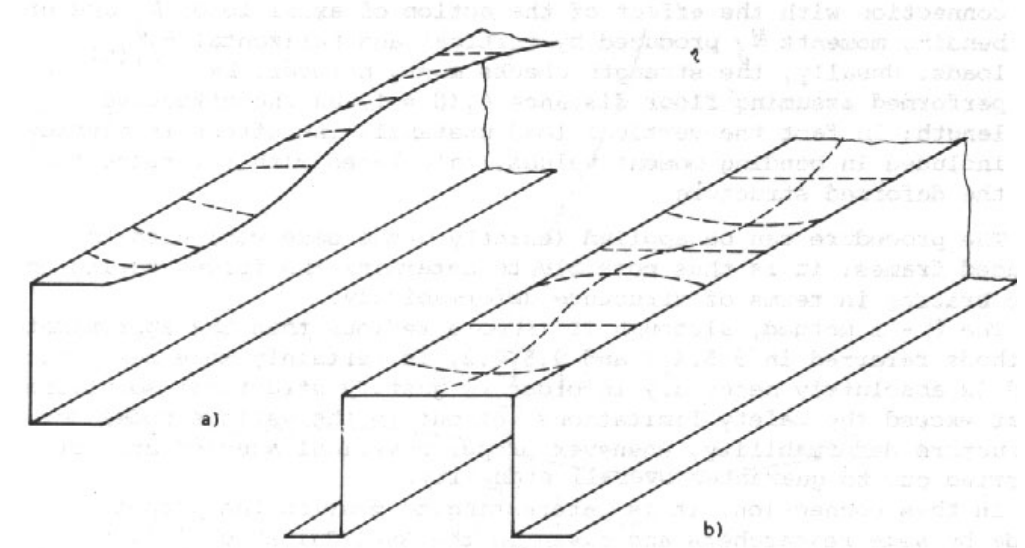

Figura 3.14 Instabilidade local em perfis do tipo U (a) e do tipo cartola (b) [YU (2000)]
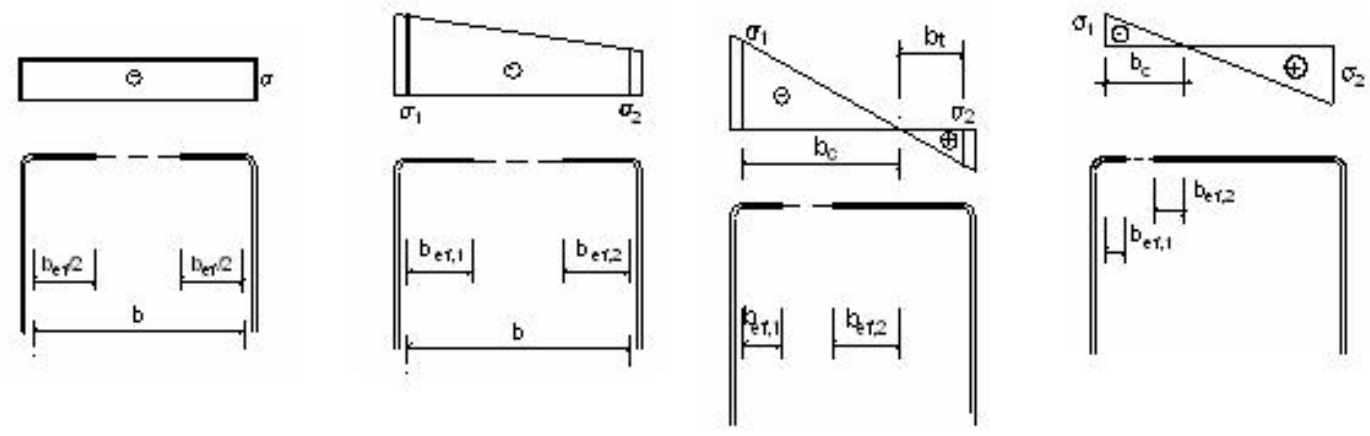

Figura 3.15 Elementos com bordas apoiadas (AA) [NBR 14762:2001]
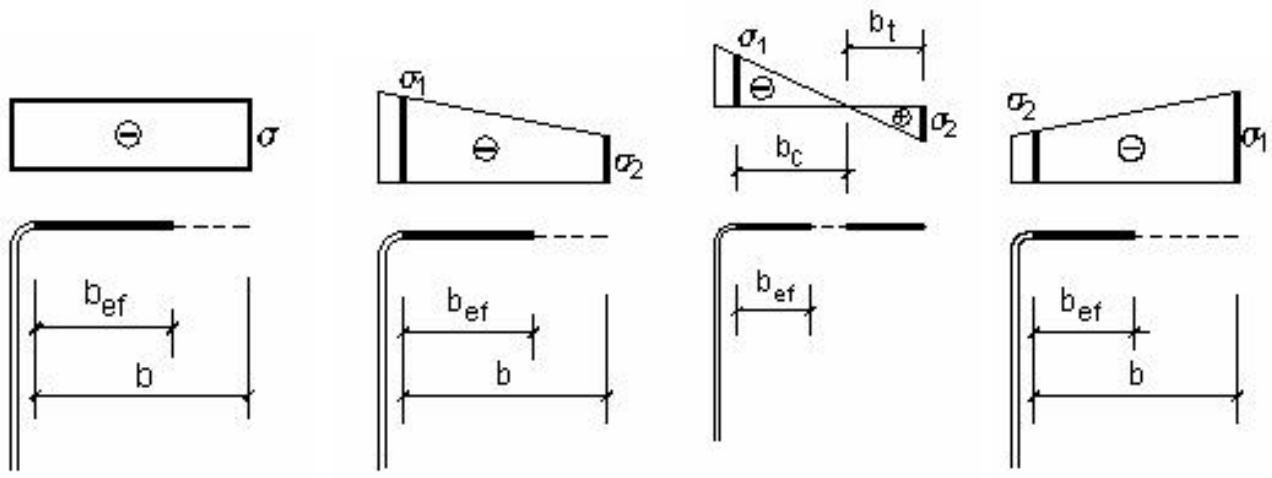

Figura 3.16 Elementos com borda livre (AL) [NBR 14762:2001] 


\subsubsection{Tensão crítica de flambagem elástica de chapas}

A tensão crítica de flambagem elástica de chapas pode ser determinada resolvendo-se a equação diferencial (3.18), proposta por Bryan em 1891, supondo-se a hipótese de pequenos deslocamentos.

$\frac{\partial^{4} w}{\partial x^{4}}+2 \frac{\partial^{4} w}{\partial x^{2} \partial y^{2}}+\frac{\partial^{4} w}{\partial y^{4}}+\frac{f_{x} t}{D} \frac{\partial^{2} w}{\partial x^{2}}=0$

Sendo:

$\mathrm{D}=\mathrm{Et} \mathrm{t}^{3} /\left[12\left(1-\mathrm{v}^{2}\right)\right]$

E: módulo de elasticidade;

v: coeficiente de Poisson;

w: deslocamento da chapa perpendicular ao seu plano;

$\mathrm{f}_{\mathrm{x}}$ : tensão de compressão na direção $\mathrm{x}$;

t: espessura da chapa.

Para $m$ e $n$ correspondendo aos números de meias ondas senoidais nas direções $\mathrm{x}$ e y respectivamente, a série dupla apresentada na expressão (3.19) representa o deslocamento w perpendicular ao plano da chapa, que satisfaz as condições de contorno para uma chapa simplesmente apoiada em todas as bordas.

$$
w=\sum_{m=1}^{\infty} \sum_{n=1}^{\infty} A_{m n} \operatorname{sen} \frac{m \pi x}{\ell} \operatorname{sen} \frac{n \pi y}{b}
$$

Sendo:

$\ell$ : comprimento da chapa;

b: largura da chapa.

Inserindo-se a expressão (3.19) na (3.18), tem-se a expressão (3.20), referente à tensão crítica de flambagem elástica de chapa. Vale ressaltar que o valor mínimo de $f_{c r}$ ocorre para $n=1$ (somente uma meia onda senoidal na direção y), resultando na expressão (3.21). A expressão do valor do coeficiente de flambagem local $k$, por sua vez, é apresentada em (3.22). 


$$
\sigma_{c r}=\frac{D \pi^{2}}{t b^{2}}\left[m\left(\frac{b}{l}\right)+\frac{n^{2}}{m}\left(\frac{l}{b}\right)\right]^{2}
$$

$$
\sigma_{c r}=\frac{D \pi^{2}}{t b^{2}} k
$$

$$
k=\left[m\left(\frac{b}{l}\right)+\frac{1}{m}\left(\frac{l}{b}\right)\right]^{2}
$$

A expressão (3.23), obtida substituindo-se o valor de D na expressão (3.21), representa a expressão geral da tensão crítica de flambagem elástica para uma chapa retangular simplesmente apoiada submetida à compressão uniforme em uma direção.

$$
\sigma_{c r}=\frac{\pi^{2} E}{12\left(1-v^{2}\right)(b / t)^{2}} k
$$

O valor de $\mathrm{k}$ (coeficiente de flambagem local) depende da relação entre o comprimento e a largura da chapa $\ell$ / b (representado por a / w na Figura 3.17), do número de meias ondas $m$, das condições de contorno e da distribuição de tensões na chapa.

A Figura 3.17, apresentada em YU (2000) para chapas simplesmente apoiadas "s.s" em todos os lados, ilustra que os pontos de mínimo associados a cada valor de $m$ correspondem a relações a/w inteiras, em $k=4$. Vale salientar também que para chapas retangulares, a tensão crítica de flambagem local é praticamente a mesma para quaisquer comprimentos a, desde que $a>4 w$. Por fim, para chapas com condição de contorno diferente desta o coeficiente $k$ varia de outra maneira para valores $\mathrm{a} / \mathrm{w}$. 


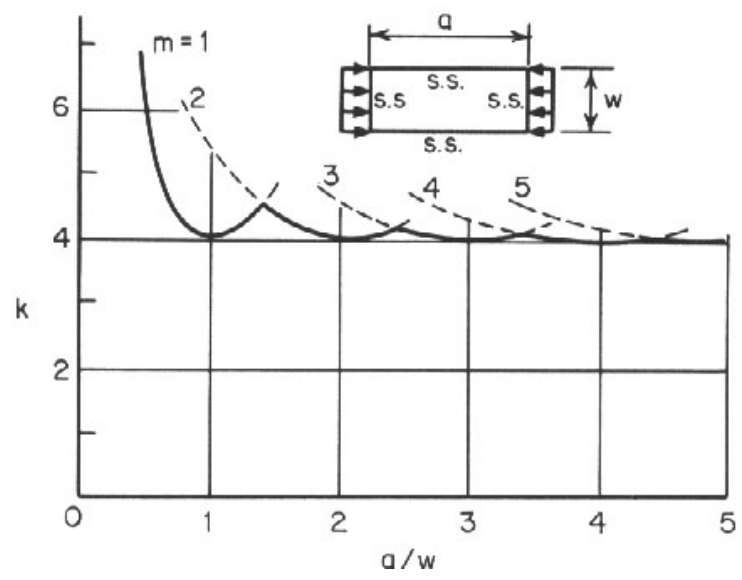

Figura 3.17 Coeficiente de flambagem local para chapas retangulares [YU (2000)]

Além disso, cabe ressaltar que os valores do coeficiente de flambagem local $\mathrm{k}$ indicados na Figura 3.17 consideram que as bordas dos elementos são simplesmente apoiadas. Portanto, o valor de $\sigma_{\mathrm{cr}}$ é conservador, pois se for considerada explicitamente a interação entre os elementos adjacentes que compõem a seção transversal do perfil (por exemplo, por meio de um programa via elementos finitos ou faixas finitas) o valor de $k$ será maior, conduzindo a valores maiores de $\sigma_{\mathrm{cr}}$.

\subsubsection{Flambagem de chapa em regime elasto-plástico}

Para os casos em que a tensão de compressão ultrapassa a tensão de proporcionalidade $f_{p}$, a expressão (3.23) não é mais válida, pois somente é aplicável para o regime elástico. BLEICH (1924) propôs então a equação diferencial (3.24) para a flambagem de chapas no regime elasto-plástico.

$$
R \frac{\partial^{4} w}{\partial x^{4}}+2 \sqrt{R} \frac{\partial^{4} w}{\partial x^{2} \partial y^{2}}+\frac{\partial^{4} w}{\partial y^{4}}+\frac{f_{x} t}{D} \frac{\partial^{2} w}{\partial x^{2}}=0
$$

Sendo:

$\mathrm{R}=\mathrm{E}_{\mathrm{t}} / \mathrm{E}$

$E_{t}:$ módulo de elasticidade tangente;

Resolvendo-se a equação diferencial (3.24), obtem-se a expressão (3.25) referente à tensão crítica de flambagem de chapa para o regime elasto-plástico. 


$$
\sigma_{c r}=\frac{\pi^{2} E \sqrt{R}}{12\left(1-v^{2}\right)(b / t)^{2}} k
$$

\subsubsection{Resistência pós-flambagem e largura efetiva}

Conforme ilustrado anteriormente na Figura 3.2, as barras normalmente não resistem a forças superiores à crítica de flambagem. Por outro lado, para as chapas, o fato de se atingir a tensão de flambagem não representa o colapso. Isto ocorre nas chapas devido especialmente às suas características bidimensionais e presença de tensões de tração de membrana que "resistem" à flexão fora do plano da chapa, pois uma redistribuição de tensões para as partes mais enrijecidas permite a absorção de acréscimos de tensão (resistência pós-flambagem). Tal fato é ilustrado na Figura 3.18 por meio da representação clássica via modelo de grelha, sendo este fenômeno mais pronunciado nos casos de chapas com relações b/t elevadas (elevada esbeltez local).

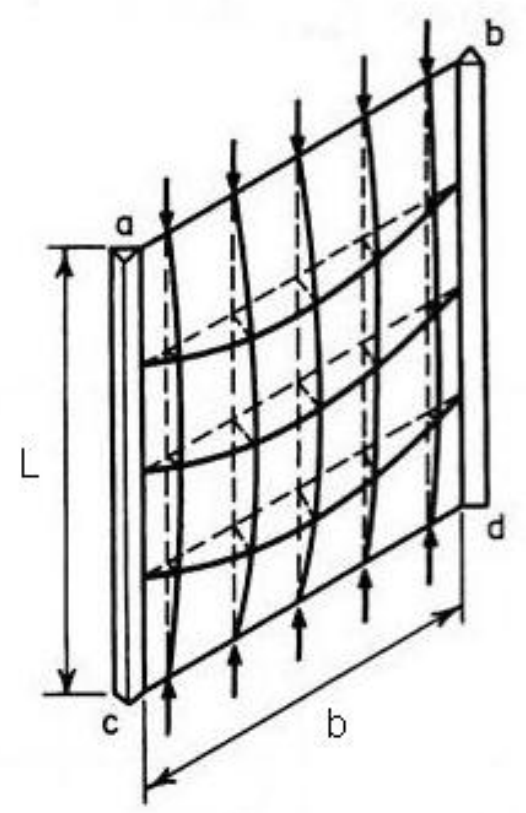

Figura 3.18 Modelo de grelha: analogia com a resistência pós-flambagem de chapas

$$
\text { [YU (2000)] }
$$

O comportamento pós-flambagem pode ser visualizado na Figura 3.19, em que a tensão na chapa permanece uniforme até se atingir a tensão crítica de flambagem $\sigma_{c r}$ (representada na figura por $\mathrm{f}_{\mathrm{cr}}$ ). Em seguida, ocorre uma redistribuição não-uniforme até que a tensão na borda da chapa (a qual é a região mais rígida da chapa se esta for enrijecida) atinja a resistência ao escoamento $f_{y}$, caracterizando o fim da capacidade resistente da chapa. 
Este fenômeno de comportamento pós-flambagem foi analisado por von Karman em 1910 por meio da consideração de grandes deslocamentos em um sistema de equações diferenciais de equilíbrio apresentado aqui na expressão (3.26), similar ao apresentado para pequenos deslocamento em (3.18), e cuja solução numérica conduz a um problema não-linear.

$$
\frac{\partial^{4} w}{\partial x^{4}}+2 \frac{\partial^{4} w}{\partial x^{2} \partial y^{2}}+\frac{\partial^{4} w}{\partial y^{4}}=\frac{t}{D}\left(\frac{\partial^{2} F}{\partial y^{2}} \frac{\partial^{2} w}{\partial x^{2}}-2 \frac{\partial^{2} F}{\partial x \partial y} \frac{\partial^{2} w}{\partial x \partial y}+\frac{\partial^{2} F}{\partial x^{2}} \frac{\partial^{2} w}{\partial y^{2}}\right)
$$

Sendo:

F: função da tensão na fibra média da chapa;

$$
\begin{aligned}
& f_{x}=\frac{\partial^{2} F}{\partial y^{2}} \\
& f_{y}=\frac{\partial^{2} F}{\partial x^{2}} \\
& \tau_{x y}=-\frac{\partial^{2} F}{\partial x \partial y}
\end{aligned}
$$

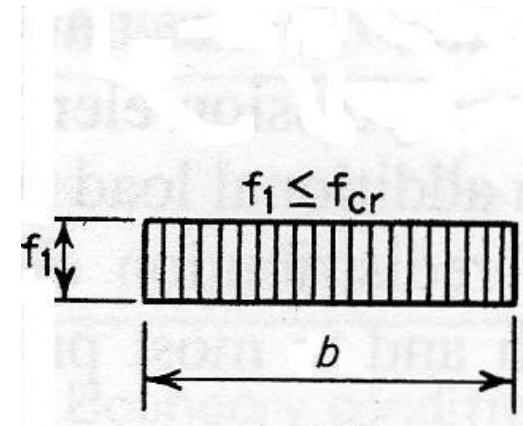

(a)

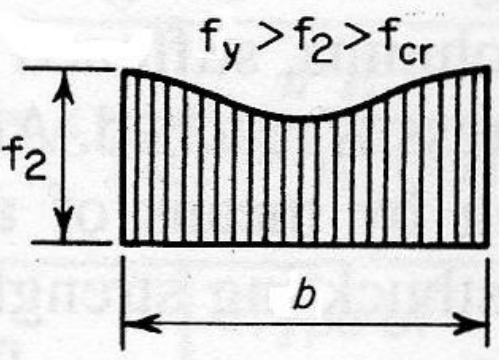

(b)

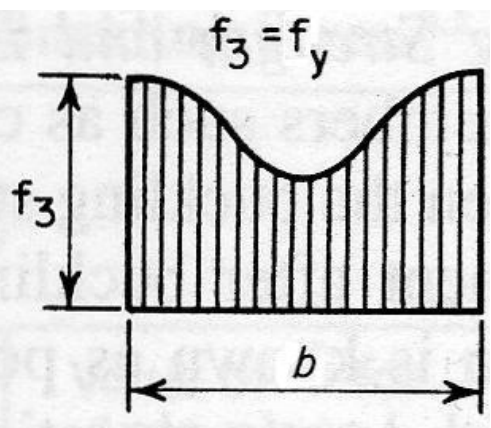

(c)

Figura 3.19 Comportamento pós-flambagem: elemento enrijecido submetido à compressão

$$
\text { [YU (2000)] }
$$

Em 1932 von Karman introduziu o conceito de largura efetiva, pois percebeu-se que a solução da expressão (3.26) é muito complexa para uso prático. Conforme este conceito, em vez de se considerar a distribuição não-uniforme de tensões sobre toda a largura da chapa b, é assumido que a resultante de tensões é absorvida por uma largura efetiva fictícia $b_{\text {ef }}$ sujeita a uma distribuição uniforme de tensões $\sigma_{\max }$ igual às das bordas (Figura 3.20).

A expressão (3.30) mostra que a largura efetiva é obtida igualando-se a área sob a curva de distribuição de tensões não-uniforme à soma das áreas equivalentes de largura $b_{\text {ef }}$ com intensidade de tensão $\sigma_{\max }$. 


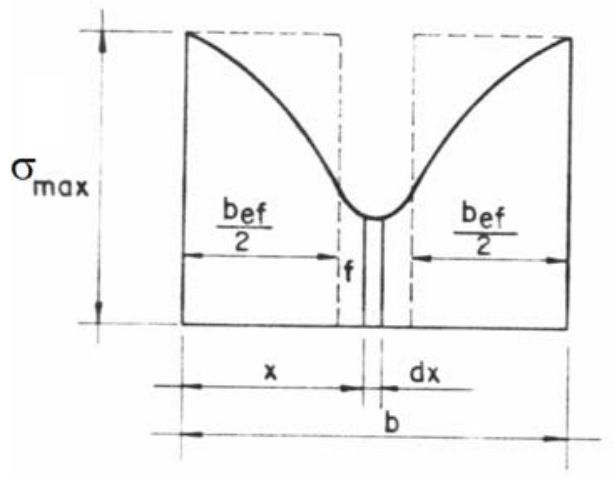

Figura 3.20 Largura efetiva: elemento enrijecido submetido à compressão

$$
\int_{0}^{b} \sigma d x=b_{e f} \sigma_{\max }
$$

Algumas expressões para a determinação da largura efetiva são apresentadas a seguir nas expressões (3.31) a (3.33). Ressalta-se que o trabalho experimental WINTER et al. (1947) conduziu à modificação da relação proposta por von KARMAN et al. (1932), relativa a larguras efetivas de elementos enrijecidos submetidos à compressão.

von Karman:

$$
b_{e f}=1,9 t \sqrt{\frac{E}{f_{y}}}
$$

Winter (von Karman modificado):

$$
b_{e f}=0,95 t \sqrt{\frac{k E}{\sigma}}\left(1-0,2075 \frac{t}{b} \sqrt{\frac{k E}{\sigma}}\right)
$$

Expressão de Winter parametrizada, adotada pela NBR 14762:2001 e pela NAS:2004:

$$
b_{e f}=b\left(\frac{1-0,22 / \lambda_{p}}{\lambda_{p}}\right) \leq b
$$


Vale lembrar que von Karman propôs a formulação das larguras efetivas para os elementos enrijecidos, extrapolando posteriormente também sua aplicação para os elementos não-enrijecidos (Figura 3.21) para os quais aparentemente também apresenta bons resultados, conforme verificado na Cornell University por KALYANARAMAN et al. (1977).

Por fim, para se fazer um desfecho na breve apresentação realizada aqui sobre o assunto de larguras efetivas, a Figura 3.22 ilustra a redução da largura plana dos elementos b para a largura efetiva $b_{\text {ef }}$, tanto para perfis enrijecidos com para os não-enrijecidos, submetidos à compressão e à flexão. Obviamente, no caso dos perfis submetidos à flexão, somente a parte comprimida da seção transversal sofre redução pois é a qual está sujeita ao fenômeno de instabilidade.

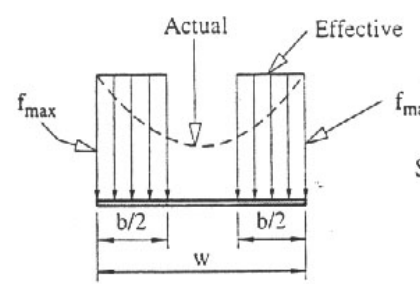

(a)

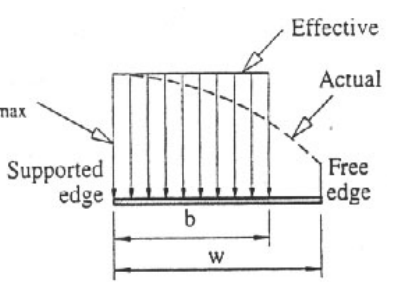

(b)

Figura 3.21 Largura efetiva: elementos enrijecidos (a) e não enrijecidos (b) submetidos à compressão [YU (2000)] 


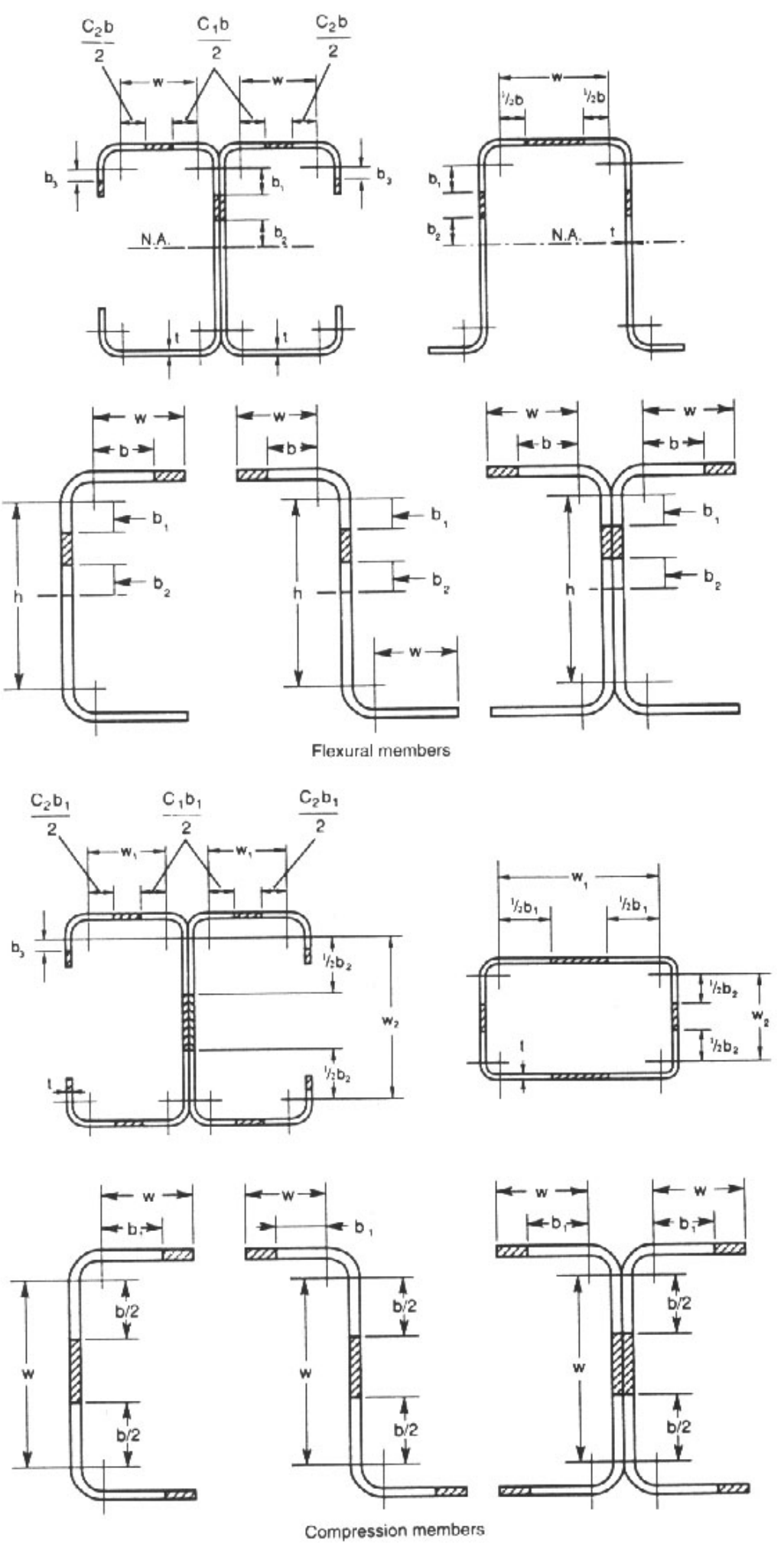

Figura 3.22 Largura efetiva: perfis submetidos à compressão e à flexão [YU (2000)] 


\subsubsection{Instabilidade distorcional}

Será feita aqui uma breve apresentação do modo de instabilidade distorcional, mesmo porque esse assunto pode ser melhor explorado, por exemplo, em CHODRAUI (2003).

Como explicado anteriormente, além dos clássicos fenômenos de instabilidade global (da barra como um todo) ou local (instabilidade de chapa), há a possibilidade de ocorrência de outro modo de instabilidade, associado à distorção da seção transversal (Figura 3.23), que é característico dos perfis com enrijecedores de borda - perfis do tipo $U$ e $Z$ enrijecido, perfis cartola e perfis "rack" - sendo ainda mais pronunciado no caso de aços com elevada resistência mecânica. Tanto o termo "por distorção" como "distorcional" são utilizados.

Perfis sem enrijecedores de borda não apresentam o modo distorcional como crítico pois a instabilidade local é preponderante pelo fato do elemento possuir apenas uma borda apoiada, conforme relatado em CHODRAUI (2003) e CHODRAUI et al. (2004b). Como informação adicional, segundo DAVIES (2000), alguns perfis laminados relativamente esbeltos também são propensos a apresentar o fenômeno da instabilidade distorcional.

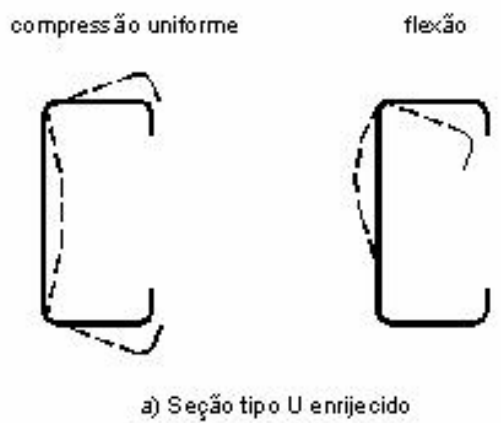

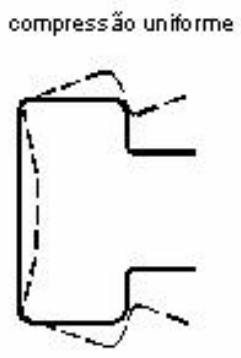

b) Seção tipo rack

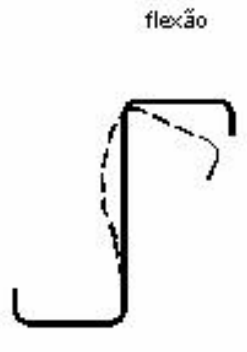

c) Seção tipo Z en rijecido

Figura 3.23 Instabilidade por distorção da seção transversal [NBR 14762:2001]

O modo distorcional caracteriza-se pela rotação e possível translação - perda de estabilidade - do conjunto formado pelo elemento comprimido e seu enrijecedor de borda, alterando a forma inicial da seção (Figura 3.23), ao contrário da instabilidade local, na qual admite-se a conservação da posição original dos cantos dobrados da seção e dos ângulos formados entre elementos adjacentes.

O modo distorcional, ilustrado para um perfil do tipo $U$ enrijecido submetido à compressão na Figura 3.24, pode ser entendido também como um modo torcional de um trecho da seção, que ocorre como meias ondas ao longo do comprimento da barra.

DESMOND et al. (1981) já alertavam para esse tipo de instabilidade, só que o denominava de "modo de instabilidade do enrijecedor", fazendo comparações com a instabilidade local, a qual denominava "modo de instabilidade local de chapa". 


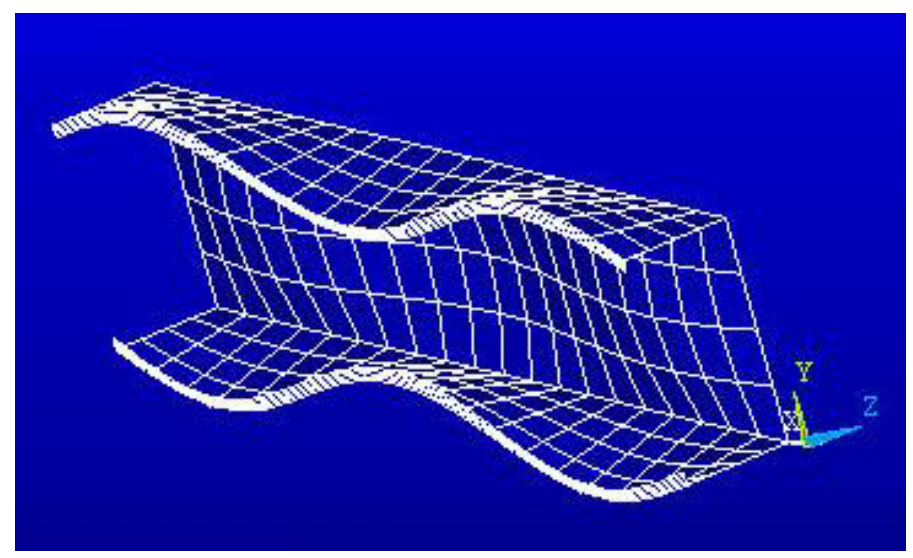

Figura 3.24 Modo distorcional: configuração deformada de perfil U enrijecido submetido à compressão [CHODRAUI (2003)]

Recentemente ocorreu a publicação da nova norma brasileira NBR 14762:2001 Dimensionamento de estruturas de aço constituídas por perfis formados a frio, que apresenta para o cálculo da instabilidade por distorção o "modelo australiano". Esse modelo simplificado, ilustrado na Figura 3.25, proposto por HANCOCK et al. (1987) e incorporado à norma australiana AS/NZS 4600:1996, analisa a estabilidade de conjuntos formados por um elemento comprimido e seu respectivo enrijecedor de borda, vinculados elasticamente à outra parte do perfil.

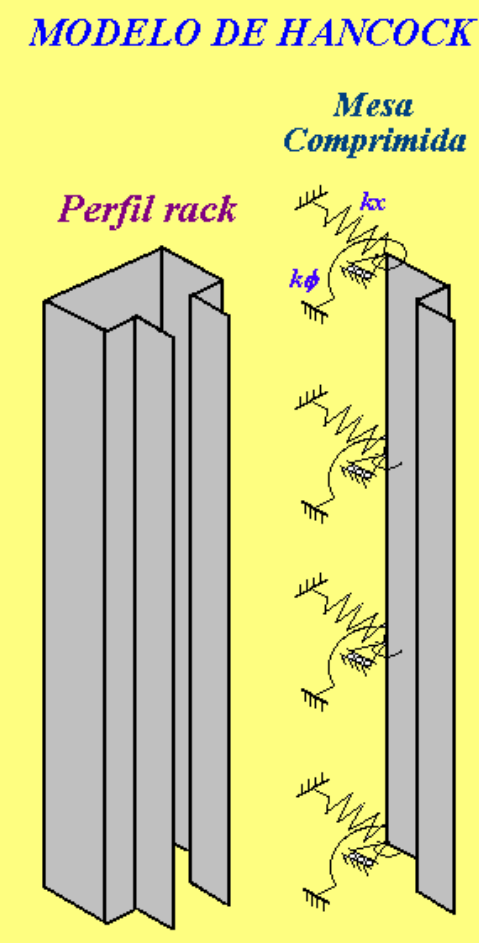

Figura 3.25 Modelo simplificado: flambagem por distorção [CHODRAUI (2003)] 
É importante dizer que com o auxílio de análise via método das faixas finitas (análise elástica), foram elaboradas tabelas de uso simples para, em função das dimensões da seção transversal do perfil, poder dispensar o cálculo da flambagem por distorção, constatando que tal modo não é crítico. Tais tabelas foram inseridas na NBR 14762:2001. Assim, torna-se possível definir, a priori, as dimensões da seção de maneira que o modo distorcional não seja dominante. Isto pode ser visto em CHODRAUI et al. (2006b).

A análise da instabilidade distorcional pode ser realizada por meio da teoria da estabilidade elástica, e também via procedimentos numéricos, como o Método dos Elementos Finitos (MEF), o Método das Faixas Finitas (MFF) e a Teoria Generalizada de Viga (GBT) vide Silvestre \& Camotim (2004). Na verdade, todos esses métodos têm sido muito utilizados, por exemplo, para a análise elástica em geral, ou seja, englobando todos os modos de instabilidade.

Para que se tenha uma idéia simples da possibilidade de ocorrência do modo distorcional, BATISTA (2000) apresentou algumas relações geométricas referentes à seção transversal que exercem grande influência no modo crítico de instabilidade (Tabela 3.3).

Tabela 3.3 Influência das relações geométricas das seções tipo U enrijecido no modo crítico [BATISTA (2000)]

\begin{tabular}{|l|c|c|}
\hline \multicolumn{1}{|c|}{ Quanto menor } & Relação geométrica & \multicolumn{1}{c|}{ Quanto maior } \\
\hline \multicolumn{1}{|c|}{ Modo Local } & $\mathrm{b}_{\mathrm{f}} / \mathrm{b}_{\mathrm{w}}$ & Modo Distorcional \\
\hline \multicolumn{1}{|c|}{ Modo Distorcional } & $\mathrm{D} / \mathrm{b}_{\mathrm{w}}$ & Modo Local \\
\hline \multicolumn{1}{|l}{} & $\mathrm{b}_{\mathrm{w}} / \mathrm{t}$ & \\
\hline $\begin{array}{l}\text { Notas: } \\
\mathrm{b}_{\mathrm{f}}: \text { largura nominal de mesa } \\
\mathrm{b}_{\mathrm{w}}: \text { largura nominal de alma } \\
\text { D: largura nominal do enrijecedor de borda } \\
\text { t: espessura }\end{array}$ & \\
\hline
\end{tabular}

Finalmente, deve ser salientado que o modo distorcional tem menor capacidade póscrítica que o modo local, o que já foi constatado em trabalhos divulgados na literatura, por exemplo, SCHAFER (2006). Entretanto, sabe-se que quanto maior o valor do índice de esbeltez reduzido referente à instabilidade distorcional $\lambda_{\text {dist }}$ maior será a reserva de resistência pós-crítica. 


\subsection{Curvas de resistência à compressão}

Neste item será abordado o assunto "curvas de compressão", um dos temas deste trabalho. Inicialmente, será apresentado brevemente o aspecto evolutivo das curvas:

- Empíricas (meados do século XIX), sendo aplicáveis somente aos casos analisados, portanto com campo limitado de aplicação;

- Baseadas no início de escoamento (propostas inicialmente em 1886), sendo denominadas expressões de Ayrton-Perry. Estas curvas são oriundas de análise elástica limite, conforme ilustrado na Figura 3.26, admitindo-se imperfeição inicial porém sem considerar tensões residuais.

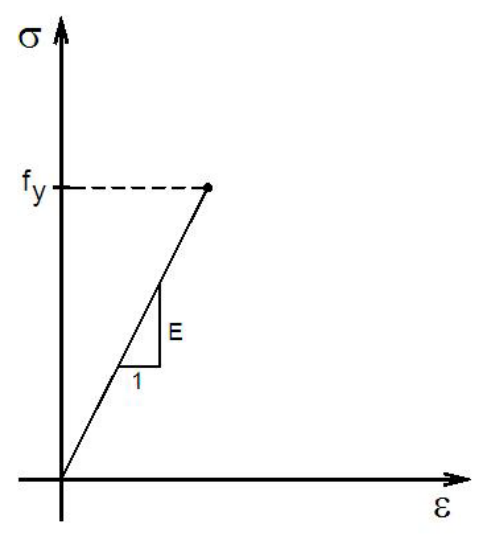

Figura 3.26 Hipótese utilizada para o diagrama tensão-deformação das curvas de resistência baseadas no escoamento

A fim de se apresentar o equacionamento desta formulação, vale dizer que para a análise do problema de $2^{\mathrm{a}}$ espécie, que na realidade sempre ocorre para o caso de barras submetidas à compressão - já foi explicado que um problema de $1^{a}$ espécie não ocorre na prática - expressões relativas à formulação do equilíbrio de uma barra submetida à flexão composta são aqui apresentadas. A expressão da flexão composta, admitindo-se a tensão normal máxima na barra referente ao escoamento, portanto igual a $f_{y}$, é dada por (3.34).

$$
\frac{N}{A}+\frac{M}{W}=f_{y}
$$

Com a substituição de (2.11), apresentada anteriormente, em (3.34), tem-se (3.35). 
$\frac{N}{A}+\frac{N v_{0}\left(\frac{1}{1-N / N_{e}}\right)}{W}=f_{y}$

Rearranjando, tem-se a expressão (3.36).

$$
\frac{N}{A}+\frac{N}{W}\left(\frac{A}{A}\right) \mathcal{N}_{0}\left(\frac{1}{1-N / N_{e}}\right)=f_{y}
$$

Modificando-se a expressão (3.36), tem-se a (3.37).

$$
\frac{N}{A}+\frac{N}{A} \eta\left(\frac{1}{1-N / N_{e}}\right)=f_{y}
$$

Sendo $\eta$ o parâmetro geométrico:

$\eta=\frac{A v_{0}}{W}$

Rearranjando-se a expressão (3.37), tem-se a expressão (3.39).

$\eta\left(\frac{N}{A}\right)=\left(f_{y}-\frac{N}{A}\right)\left(1-N / N_{e}\right)$

A expressão (3.39) sob um novo formato pode ser apresentada como (3.40).

$$
\eta \bar{N}=(1-\bar{N})\left(1-N / N_{e}\right)
$$

Sendo:

$$
\frac{N}{A f_{y}}=\frac{N}{N_{y}}=\bar{N}=\rho
$$

Com algumas modificações na expressão (3.40), tem-se a expressão (3.42), conhecida como fórmula adimensional de Ayrton-Perry. 
$\eta \bar{N}=(1-\bar{N})\left(1-\bar{N} \bar{\lambda}^{2}\right)$

Sendo:

$$
\begin{aligned}
& \frac{N}{N_{e}}=\rho \frac{N_{y}}{N_{e}}=\rho \frac{f_{y}}{\sigma_{e}} \\
& \sigma_{e}=\frac{\pi^{2} E}{\lambda^{2}} \\
& \lambda_{p_{\ell}}=\sqrt{\frac{\pi^{2} E}{f_{y}}} \\
& \lambda_{0}=\frac{\lambda}{\lambda_{p_{\ell}}}
\end{aligned}
$$

Rearranjando-se a expressão (3.42), tem-se a equação (3.47).

$$
\lambda_{0}^{2} \rho^{2}-\left(1+\eta+\lambda_{0}^{2}\right) \rho+1=0
$$

A resolução da equação (3.47) fornece o resultado de $\rho$ na expressão (3.48), propiciando o cálculo da força normal máxima ou resistente. Deve então ser analisado o menor resultado desta expressão (3.48).

$$
\boldsymbol{\rho}=\frac{\left(\lambda_{0}{ }^{2}+\eta+1\right) \pm \sqrt{\left(\lambda_{0}{ }^{2}+\eta+1\right)^{2}-4 \lambda_{0}{ }^{2}}}{2 \lambda_{0}{ }^{2}}
$$

- Baseadas na teoria do módulo tangente, com o conceito de bifurcação do equilíbrio, sendo associadas a sistemas perfeitos. Por exemplo, pode-se citar a curva do CRC;

- Baseadas na resistência máxima, são curvas ajustadas com base na análise de resistência à compressão de barras com imperfeições geométricas iniciais e tensões residuais. Este conceito é a base das múltiplas curvas do SSRC (originou as curvas do AISI, AISC e NAS) e do ECCS (originou as múltiplas curvas da NBR 8800:1986 e NBR 14762:2001). 


\subsubsection{Apresentação das curvas}

Considerando-se que a forma da seção transversal influencia a ocorrência dos aspectos de instabilidade global, foram definidas ao longo da história diferentes curvas representativas do comportamento dos perfis laminados e soldados, capazes de fornecer informações para o dimensionamento. Exceção é, por exemplo, o caso das normas americanas, em que se adotou uma curva única para todos os perfis. É aqui apresentada uma análise comparativa das curvas de resistência à compressão adotadas por algumas normas ao longo dos anos.

Inicialmente são apresentadas as múltiplas curvas das normas brasileiras, que são as mesmas curvas do Eurocode, classificadas como curvas a, b, c, d, ilustradas na Figura 3.27 e na Figura 3.28 (vale dizer que as curvas da norma brasileira de perfis formados a frio NBR 14762:2001 têm diferença quanto as de perfis laminados e soldados NBR 8800:1996, além de não utilizar a curva d, que não se aplica a perfis formados a frio), e também são apresentadas as múltiplas curvas do SSRC, ilustradas na Figura 3.29.

Posteriormente, na Figura 3.30 são apresentadas as curvas únicas, as quais são adotadas para todos os tipos de perfis (caso das normas americanas, australianas e a canadense de 1984).

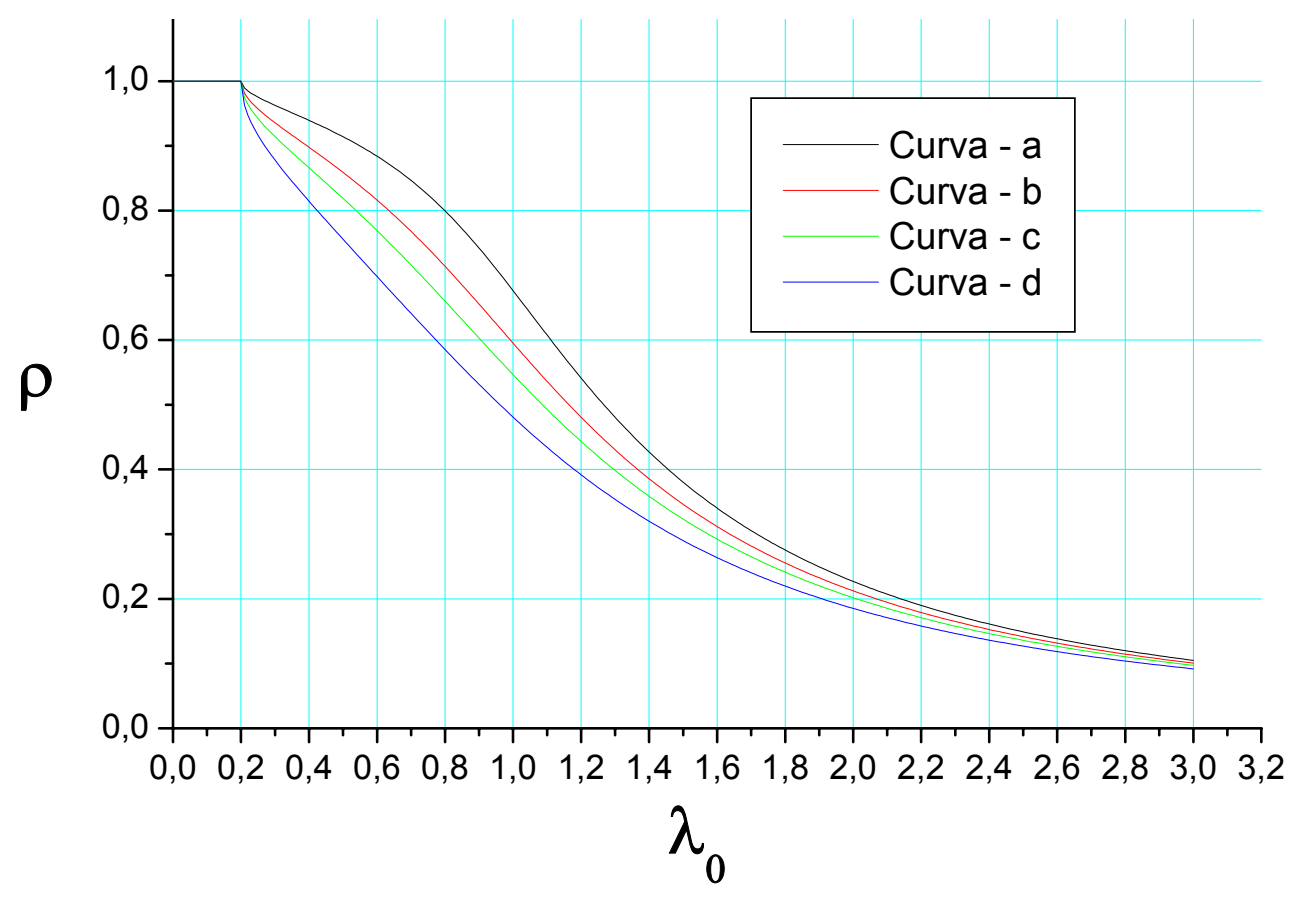

Figura 3.27 Curvas de resistência à compressão: curvas a, b, c, d - NBR 8800:1986 


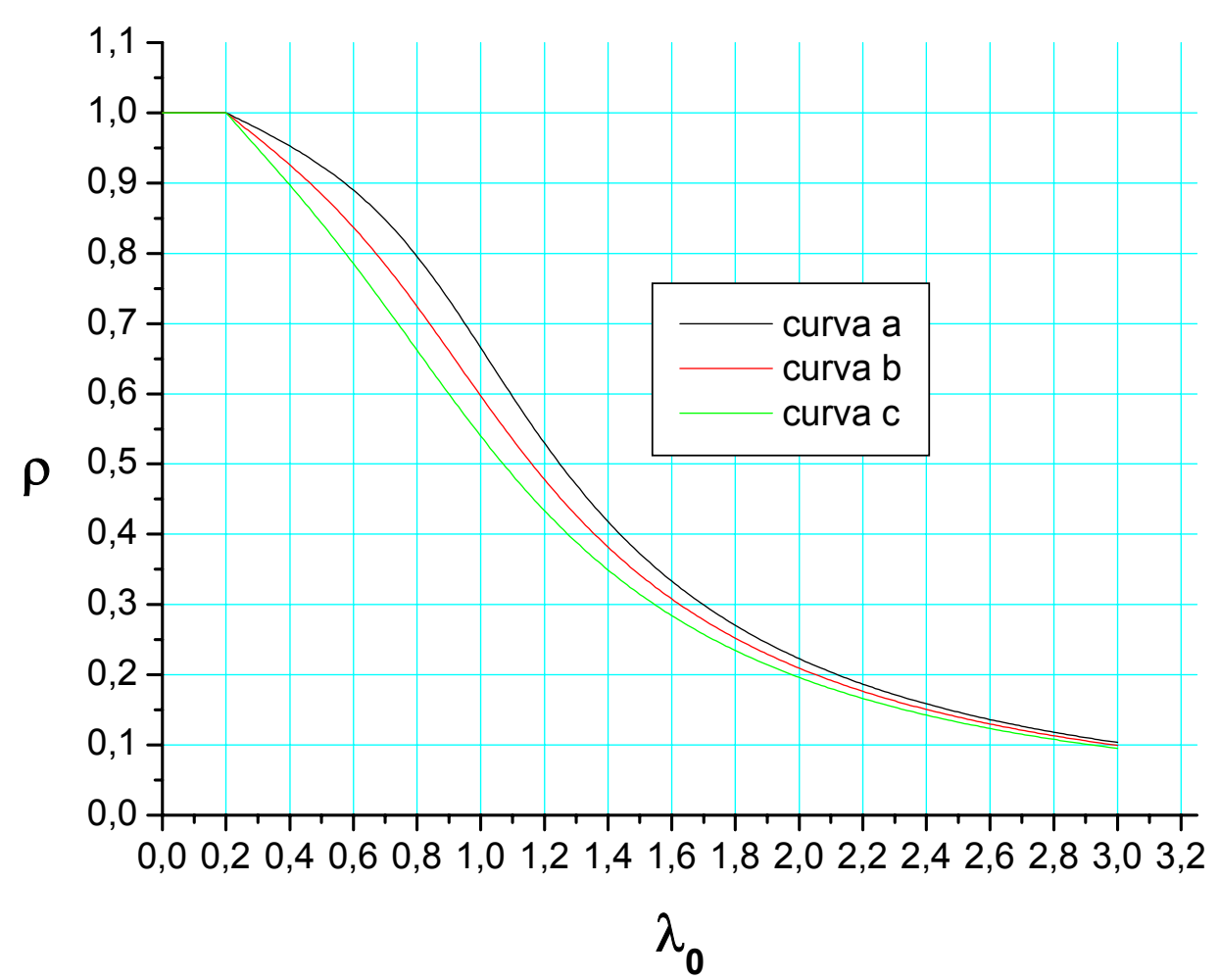

Figura 3.28 Curvas de resistência à compressão: curvas a, b, c - NBR 14762:2001

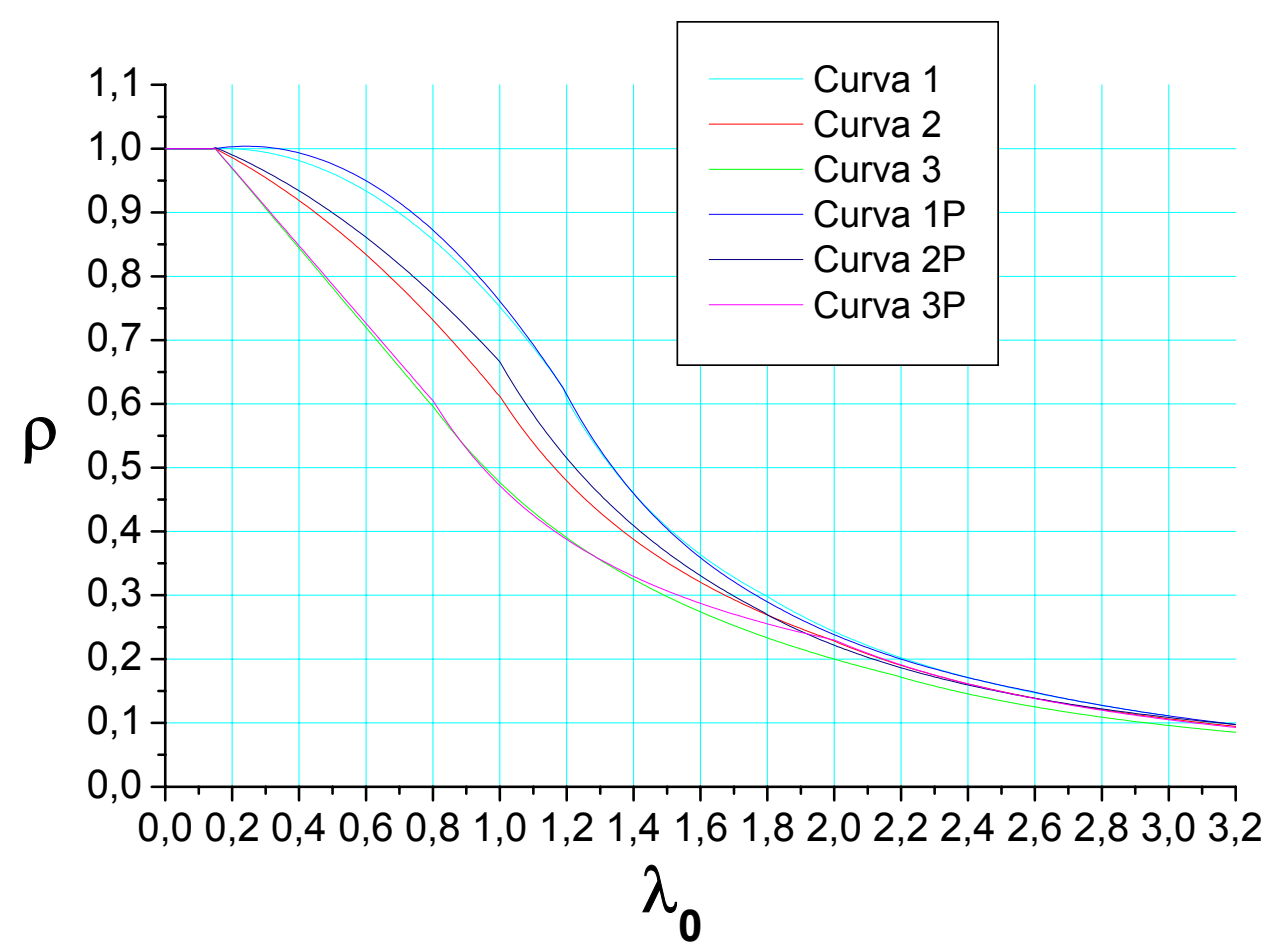

Figura 3.29 Curvas de resistência à compressão: curvas 1, 2, 3, 1P, 2P, 3P - SSRC 


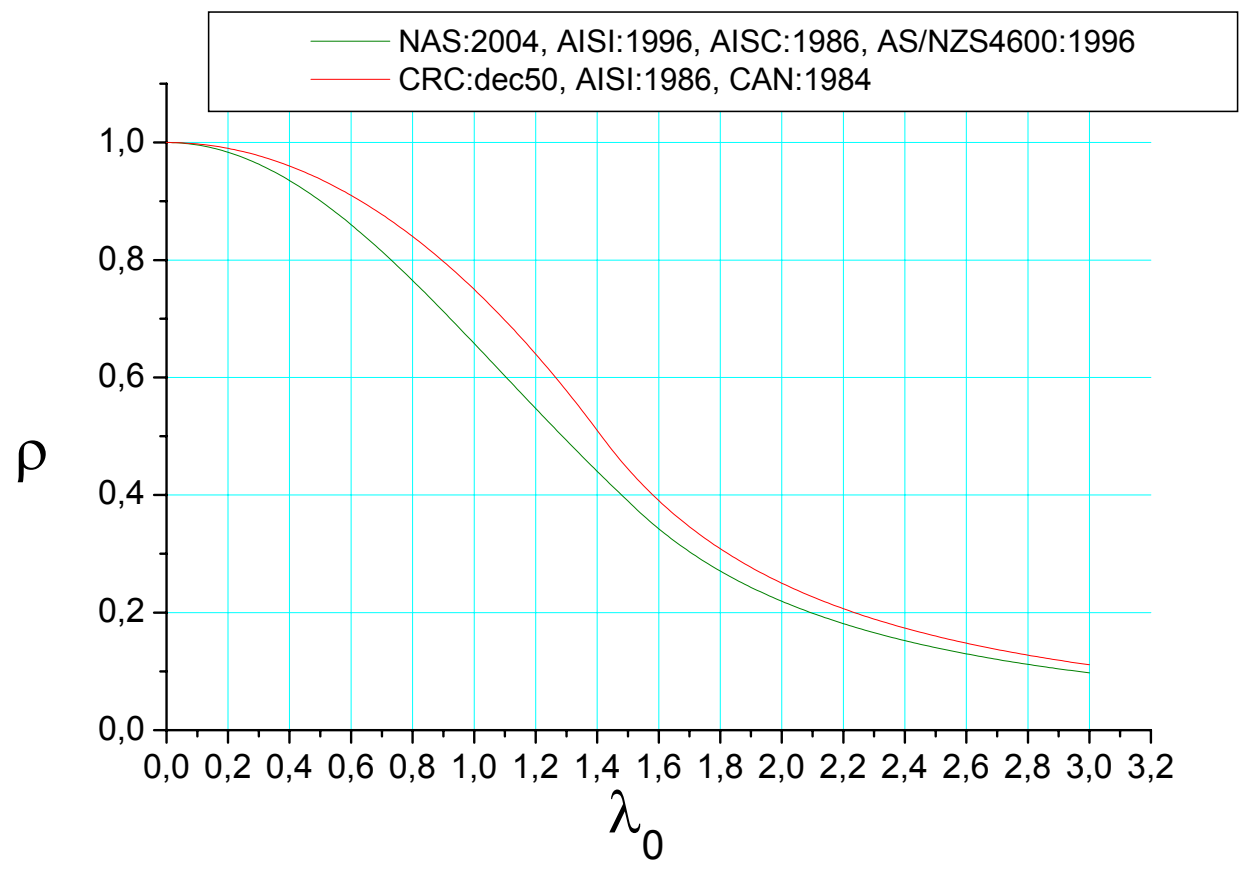

Figura 3.30 Curvas de resistência à compressão: CRC:década de 50, CAN:1984, AISI (ASD):1986, AISC/LRFD:1986, AISI (ASD/LRFD):1996, AS/NZS 4600:1996, NAS:2004

Pode-se perceber que há variações no traçado das curvas. Além disso, as normas americanas, por exemplo, adotam curva única independente do tipo de perfil analisado, contrariando uma tendência global por múltiplas curvas.

Adicionalmente, vale ressaltar que RODRIGUES (1993) propôs uma curva de resistência à compressão para perfis de aço formados a frio, que resultou muito próxima à uma das curvas propostas pela NBR 8800:1986, não tendo sido então adotada pela NBR 14762:2001.

Por fim, é importante salientar que estudos conduzidos por KARREN \& WINTER (1967) mostraram que a curva do CRC, desenvolvida para perfis de aço laminados, apresenta resultados satisfatórios para perfis formados a frio totalmente efetivos $\left(A_{\text {ef }}=A\right)$. Entretanto, DAT (1980) relata em sua tese que a curva do AISI da época apresentava valores não conservadores (contra a segurança) para alguns tipos de perfis de aço formados a frio.

Além disso, alguns trabalhos, por exemplo PEKÖZ \& WENG (1988), já alertavam que os resultados de ensaios demonstram que barras constituídas por alguns tipos de perfis de aço formados a frio submetidos à compressão apresentam resistência inferior à prevista pelo AISI em alguns casos a diferença foi superior a $15 \%$ - relatando também que quanto maiores as tensões residuais maior a dispersão de resultados entre os ensaios e o AISI. 


\subsection{Interação entre modos de instabilidade}

\subsubsection{Aspectos gerais}

A interação entre os modos de instabilidade é um fenômeno muito comum em perfis de aço formados a frio, resultando em provável redução da resistência da barra. A Figura 3.5, apresentada anteriormente, ilustra alguns casos tanto para modos de instabilidade isolados quanto acoplados.

Conforme citado em YU (2000), o fenômeno da interação entre modos localizados e o global em barras submetidas à compressão depende, entre outros fatores, da forma da seção transversal, da esbeltez global da barra $(\lambda)$ e local dos elementos (b/t), do modo de instabilidade global relativo à interação (flambagem por flexão, torção ou flexo-torção), do tipo de aço e suas propriedades mecânicas, da influência do trabalho a frio, das imperfeições geométricas iniciais e tensões residuais, de eventuais soldas, da interação entre os elementos componentes da seção transversal e do efeito de possíveis perfurações nos perfis.

Em muitos casos práticos, o intuito de se tentar otimizar o projeto de estruturas quanto à instabilidade, idealizando-se a geometria de uma determinada seção para que os modos de instabilidade ocorram para forças críticas próximas, parece interessante. Entretanto, quando se faz a análise elástica dessa seção otimizada, existe a possibilidade de ocorrência de dois ou mais modos de instabilidade com forças críticas próximas, fato denominado conceito de BleichShanley.

Esta idéia apresentada no parágrafo acima, que para alguns parecia interessante, foi contestada pela primeira vez por KOITER \& SKALOUD (1962) apud GIONCU (1994), pois percebeu-se que o acoplamento pode conduzir a uma forte sensibilidade às imperfeições geométricas. Além disso, dois modos de instabilidade estáveis podem, devido ao acoplamento, resultar em um modo pós-crítico completamente instável com forte sensibilidade às imperfeições geométricas, conduzindo à redução de resistência da barra.

$\mathrm{Na}$ mesma linha de raciocínio, alguns estudos também analisaram o fato do acoplamento de dois modos de instabilidade simétricos (em que a seção deformada é simétrica em relação à seção transversal original) resultarem em um modo assimétrico, além de causar um aumento na sensibilidade às imperfeições, por exemplo vide HUNT $(1982,1983,1986)$ apud GIONCU (1994).

Apresenta-se a seguir um breve histórico dos estudos sobre a teoria de instabilidades acopladas, sendo que um relato mais completo pode ser encontrado em GIONCU (1994).

Inicialmente, KOITER (1945) apud GIONCU (1994) elaborou a teoria moderna de instabilidade de estruturas para sistemas contínuos elásticos, seguido de BUDIANSKY (1974), 
sendo estes dois estudos os primeiros a abordarem o caso do acoplamento dos modos de instabilidade.

Segundo GIONCU (1994), após 1966 alguns trabalhos se destacaram no tema, como CHILVER (1967), que aborda o prosseguimento dos estudos desenvolvidos por JOHNS (1972,1974,1976), e também os estudos de JOHNS \& CHILVER (1971), SUPPLE (1967,1968,1969), HO $(1972,1974)$ e THOMPSON \& HUNT $(1971,1973)$.

Além destes trabalhos, ainda no tema de interação entre modos de instabilidade, vale dizer que a interação entre o modo global por flexão e o local já foi bastante estudada, por DEWOLF et al. (1974), KALYANARAMAN (1979), MULLIGAN et al. (1984), DAVIDS \& HANCOCK (1985), WENG (1991), LOUGHLAN et al. (1980), entre vários outros.

Entretanto, a interação entre o modo global por flexo-torção e o local foi menos estudada, com exceção de alguns trabalhos como CHAJES et al. (1965), PEKÖZ et al. (1969), TONEFF et al. (1987), WANG \& PAO (1980), BASU \& AKHTAR (1991), e FLESERIU \& DUBINA (1986), que apresentam ensaios de barras de aço formadas a frio constituídas por perfis do tipo $U$ enrijecido e $Z$ enrijecido, constatando que em alguns casos há uma complexa interação entre o modo global por flexo-torção e o modo local.

MOLDOVAN (1994) verificou por meio de ensaios de compressão em barras de aço de perfis formados a frio do tipo $U$ e $U$ enrijecido, com seção transversal de modo a apresentar a força normal de estabilidade elástica do modo de flexão próxima a do modo de flexo-torção, que o decréscimo de resistência devido à interação entre esses dois modos globais foi pequeno, especialmente quando comparado à perda de resistência quando do acoplamento entre o modo local e um global genérico, caso este de forte interação.

Neste momento chama-se a atenção para o fato da interação ser mais intensa, i.e., com possibilidade de maior redução da resistência da barra, se ocorrer entre modos de comprimento de meia onda diferentes entre si. Por exemplo, a interação entre um modo global e um local é mais intensa do que entre dois modos globais, um de flexão e um de flexo-torção.

Para que o leitor tenha uma idéia de como esse assunto de interação entre modos de instabilidade é tratado nas normas atuais, ressalta-se que os métodos aproximados disponíveis atualmente nas principais normas internacionais consideram somente a interação entre os modos local e global. Com relação à NBR 14762:2001, esta consideração pode ser verificada na expressão relativa à análise de instabilidade global da barra, por meio da utilização da área efetiva $A_{\text {ef }}$ considerando então o modo local. Por outro lado, a interação entre o modo local e o distorcional não é considerada nas normas. Além disso, sabe-se que o trabalho de PEKÖZ \& DRACKY (1997) já alertava que os procedimentos normativos eram inadequados para o caso de interação entre o modo global por flexo-torção e o local.

Vale dizer que algumas informações e bibliografias complementares sobre a consideração da interação entre os modos de instabilidade podem ser obtidas em DUBINA et 
al. (2000). Além disso, UNGUREANU \& DUBINA (2003) citam alguns métodos utilizados para se avaliar a interação entre modos de instabilidade para os perfis de aço formados a frio. GIONCU (1994) apresenta a Teoria Geral de Instabilidades Acopladas, que também apresenta uma idéia bem ampla sobre o assunto.

Complementando-se esta introdução quanto à interação entre os modos de instabilidade, RASMUSSEN \& YOUNG (1999) citam que nas décadas de 70 e 80 vários ensaios foram realizados em barras biarticuladas de perfis de aço formados a frio submetidas à compressão. Nos casos dos perfis do tipo $U$, foi verificada interação entre o modo local e global por flexão, enquanto que para os perfis do tipo $U$ enrijecido a interação verificada foi entre o modo local e global por flexão e por flexo-torção.

Cabe aqui dizer que uma possível justificativa para a interação entre os modos local e global é uma mudança na linha de ação das forças internas quando da ocorrência da instabilidade local, resultando em uma redistribuição assimétrica das tensões longitudinais internas, o que provoca a mudança de posição do centróide da seção transversal efetiva em relação à seção original. Esta mudança conduz à uma excentricidade adicional na aplicação da força "axial" externa, produzindo uma compressão excêntrica ou flexo-compressão, que induz por sua vez à instabilidade global nestas barras biarticuladas, como explicado em RHODES \& HARVEY (1977). Este fato não ocorre para barras engastadas como já havia sido relatado em RASMUSSEN \& HANCOCK (1993) e em YOUNG \& RASMUSSEN (1997), pois a mudança de posição da linha de ação das forças internas é "equilibrada" por uma mudança na linha de ação da força externa.

Por fim, vale a pena chamar a atenção, mesmo que sem entrar em detalhes, para o trabalho de BADAWY ABU-SENA et al. (2001), que apresenta expressões oriundas do método da energia - validadas por análise de autovalor via MEF - para a avaliação da interação entre o modo global por flexo-torção e o distorcional para perfis do tipo $U$ enrijecido submetidos à compressão. Ainda que tenha sido um trabalho específico, em alguns casos foi verificada uma redução de até $24 \%$ na tensão crítica quando comparada ao menor valor da tensão crítica referente aos modos de instabilidade isolados, o que pode ser preocupante em um dimensionamento no qual esta redução não seja considerada.

\subsubsection{Método da Erosão da Força Crítica - ECBL}

DUBINA (1990, 1993, 1998, 2001) e DUBINA et al. (1995, 2002), entre outros trabalhos citados nas referências bibliográficas deste mesmo autor, apresentam o Método da Erosão da Força Crítica - ECBL (Erosion of Critical Bifurcation Load). Este método é aqui apresentado por ser interessante, relativamente recente, e ainda não estar totalmente difundido, muito menos no Brasil. 
Segundo os propositores deste método, devido às imperfeições geométricas iniciais e elevada esbeltez dos elementos constituintes das seções transversais dos perfis de aço formados a frio, as interações entre os modos de instabilidade (local, distorcional e global) normalmente ocorrem.

Entretanto, os autores do ECBL enfatizam que essas interações não são consideradas de maneira satisfatória nas curvas de resistência existentes nas normas atuais, pois estas foram desenvolvidas para perfis laminados e soldados, que apresentam comportamento diferente dos formados a frio, como já explicado.

Portanto, o ECBL apresenta um procedimento para avaliar o comportamento de instabilidade dos perfis de aço formados a frio, considerando a interação entre os modos de instabilidade local-global e distorcional-global. Com isso, propõem uma maneira para se adequar as atuais curvas de resistência para os perfis de aço formados a frio.

Vale alertar que somente parte do método, relativo à interação entre os modos localglobal, será apresentada neste trabalho, por ser mais comum de ocorrer e, de acordo com a literatura, mais significativa.

Embasando o parágrafo acima, KWON (1992) apud PÉREZ (2003) realizou ensaios na University of Sydney com perfis do tipo $U$ com e sem enrijecedores intermediários na alma, obtendo como resultado o fato de que a interação entre a instabilidade distorcional e outros modos é muito pequena, fato este confirmado por YOUNG (1997) e também, por meio da utilização da GBT, por DAVIES \& JIANG (1996). Além disso, a utilização da teoria da GBT (Generalized Beam Theory) por DAVIES \& JIANG (1996) comprova que a instabilidade distorcional tem pouca interação com outros modos.

A propósito, mais detalhes sobre a GBT podem ser encontrados também em DAVIES \& LEACH (1994), DAVIES et al. (1994), SILVESTRE \& CAMOTIM (2002a), SILVESTRE \& CAMOTIM (2002b), SILVESTRE \& CAMOTIM (2003), e em SILVESTRE (2005).

Falando agora especificamente do método, utilizando-se as curvas de resistência adotadas pelo Eurocode 3 - parte 1.3 para os perfis laminados e soldados, aliadas à introdução do coeficiente de erosão $\psi$ que "rebaixa" as curvas (depende do modo de instabilidade associado) e, baseado no coeficiente de erosão $\psi$, calculando-se um novo coeficiente de imperfeição $\alpha$ (pode ser avaliado em função de $\psi$ e de $Q$, como explicado mais adiante), tais curvas podem ser utilizadas para se avaliar diretamente a interação entre os modos de instabilidade local-global e distorcional-global para os perfis formados a frio.

Entende-se que este procedimento parece ser interessante no sentido de ser uma ferramenta útil e relativamente simples para se avaliar a interação entre os modos de instabilidade, além de ser uma alternativa ao método das largura efetivas. Portanto, uma explicação sobre o assunto será apresentada a seguir. 
Resumidamente, pode-se ilustrar o conceito do ECBL por meio do caso de uma barra submetida à compressão sujeita a dois modos de instabilidade simultâneos. Na expressão (3.49) tem-se $\mathrm{N}_{\mathrm{u}}$ como a força crítica última (redução de resistência devido ao acoplamento entre os modos de instabilidade) e $\mathrm{N}_{\mathrm{cr}}$ como a força crítica para um modo isolado. Percebe-se claramente que quanto maior a interação entre os modos, maior será o coeficiente de erosão $\psi$, e maior será a redução de resistência separando os valores $\mathrm{N}_{\mathrm{u}}$ e $\mathrm{N}_{\mathrm{cr}}$.

$$
\mathrm{N}_{\mathrm{u}}=(1-\psi) \mathrm{N}_{\mathrm{cr}}
$$

GIONCU (1994) classificou os tipos de interação (classes) em função do coeficiente de erosão $\psi$, os quais são apresentados a seguir na Tabela 3.4. Alerta que dependendo do grau de erosão evidenciado no fenômeno de acoplamento de instabilidades pode ser prudente a adoção de critérios especiais de dimensionamento das seções. Por exemplo, a interação fraca pode ser negligenciada por estar coberta pelos coeficientes de segurança das normas, e a moderada pode ser considerada por métodos simples, mas no caso de interação forte ou muito forte métodos especiais precisam ser desenvolvidos e utilizados.

A Tabela 3.4 resume então os casos de instabilidade acoplada mais comuns para barras submetidas à compressão. Adicionalmente, a Figura 3.31 ilustra uma classificação do coeficiente de erosão mais usual para os diferentes tipos de seções transversais, onde se pode perceber que a cantoneira simples apresenta o maior fator dentre as seções ilustradas, sujeita portanto a um maior grau de erosão devido ao acoplamento entre modos de instabilidade.

É importante dizer que conforme verificações apresentadas pelo grupo do prof. Dubina, se o procedimento do Eurocode 3 - parte 1.3 (somente aborda o caso da interação entre os modos local-global, assim como a NBR 14762:2001) for utilizado para a avaliação da interação entre os modos distorcional-global, os resultados serão muito conservadores.

O prof. Dubina reforça em alguns artigos a idéia (já mencionada) de que o acoplamento de dois modos de instabilidade que possuem comprimentos de meia onda similares apresenta fraca ou moderada interação, como no caso da interação entre os modos globais de flexão e flexo-torção. Por outro lado, se há uma grande diferença dos comprimentos de meia onda entre os dois modos de instabilidade que se acoplam, como no caso entre a instabilidade local e global, a interação será moderada ou forte.

Para que o leitor entenda melhor o método quanto ao já comentado rebaixamento da curva de resistência, a Figura 3.32 ilustra a comparação entre a curva de resistência proposta pelo Eurocode e a proposta pelo ECBL (rebaixada), esta última considerando a interação entre os modos de instabilidade. 
Tabela 3.4 Modos acoplados de instabilidade mais comuns: barras submetidas à compressão [DUBINA (2001)]

\begin{tabular}{|c|c|c|}
\hline $\begin{array}{l}\text { Tipo de barras sumetidas } \\
\text { à compressão }\end{array}$ & $\begin{array}{c}\text { Modos de } \\
\text { instabilidade }\end{array}$ & Classe de interação \\
\hline $\begin{array}{l}\text { Monossimétricas } \\
\text { (compactas) }\end{array}$ & $F+F T$ & $\begin{array}{l}\text { C1 a C2 } \\
\psi \leq 0,3\end{array}$ \\
\hline Compostas & $F+L$ & $\begin{array}{c}\mathrm{C} 2 \\
0,1<\psi \leq 0,3\end{array}$ \\
\hline \multirow{2}{*}{ Paredes delgadas } & $\begin{array}{c}F+L \\
F T+L \\
F+F T+L\end{array}$ & $\begin{array}{l}\text { C3 a C4 } \\
\psi \geq 0,3\end{array}$ \\
\hline & $\begin{array}{c}F+D \\
F T+D \\
F+F T+D\end{array}$ & $\begin{array}{c}\text { C2 a C3 } \\
0,3 \leq \psi \leq 0,5\end{array}$ \\
\hline \multicolumn{3}{|c|}{$\begin{array}{l}\text { Legenda: } \\
\text { F = instabilidade por flexão } \\
\text { FT = instabilidade por flexo-torção } \\
L=\text { instabilidade local } \\
\text { D = instabilidade distortional } \\
\text { C1 - Classe 1: interação fraca }(\psi \leq 0,1) \\
\text { C2 - Classe 2: interação moderada }(0,1<\psi \leq 0,3) \\
\text { C3 - Classe } 3 \text { : interação forte }(0,3<\psi \leq 0,5) \\
\text { C4 - Classe 4: interação muito forte }(\psi>0,5)\end{array}$} \\
\hline
\end{tabular}
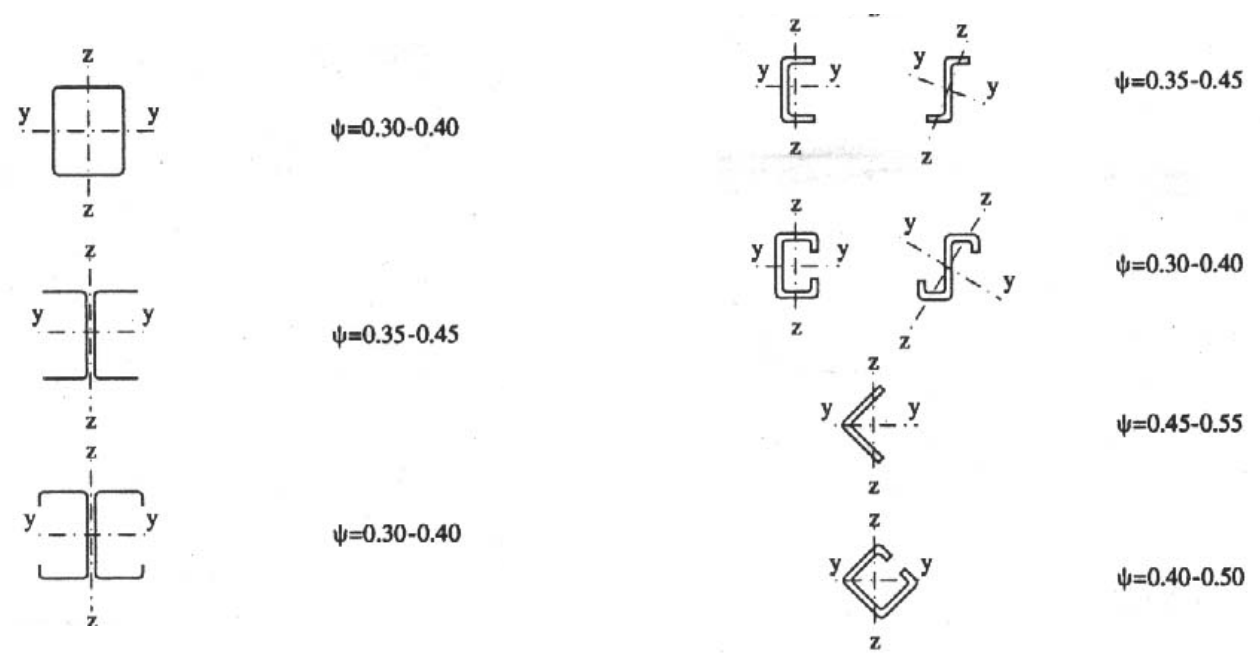

Figura 3.31 Classificação do fator de erosão $\psi$ [MOLDOVAN (1994)] 


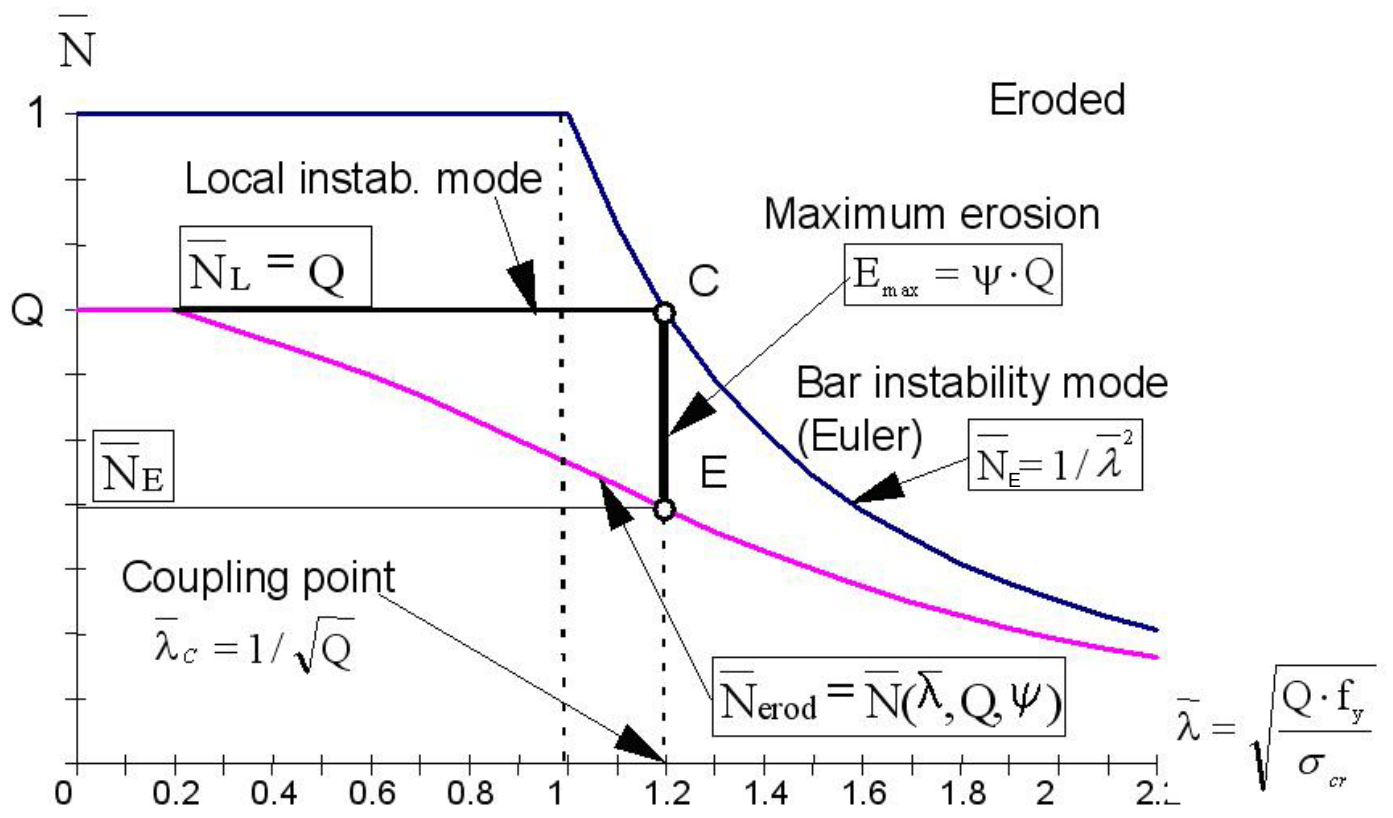

Figura 3.32 Curva de resistência: rebaixamento ECBL [DUBINA \& UNGUREANU (2002)]

Para melhor se entender a Figura 3.32, deve-se atentar para o fato de que os perfis de aço formados a frio são propensos à instabilidade local, e para se considerar tal fenômeno pode-se reduzir a área da seção transversal $A$ para $A_{\text {ef, }}$ como já explicado. Utilizando-se esta idéia, na Figura 3.32 tem-se $Q=A_{\text {ef }} / A$. Seguindo o raciocínio, o ECBL prescreve que para um perfil de aço formado a frio submetido à compressão, dois modos de instabilidade podem interagir:

- Instabilidade global, representada na Figura 3.32 pela hipérbole de Euler, $\overline{N_{E}}=\frac{1}{\lambda^{2}}$

- Instabilidade local, $\overline{N_{L}}=Q$

O ponto $\mathrm{C}\left(\overline{\lambda_{c}}=\frac{1}{\sqrt{Q}}\right)$ de interceptação destes dois modos na Figura 3.32 representa a erosão máxima de resistência, e tem-se então que a curva resultante, rebaixada na mesma abscissa do ponto $C$ para o ponto E, que descreve os modos de instabilidade acoplados, é $\bar{N}(\bar{\lambda}, Q, \psi)$. Este rebaixamento será maior ou menor dependendo de cada caso. Entretanto, é importante dizer desde já que a maior "dificuldade" para a utilização do ECBL é o cálculo do coeficiente de erosão $\psi$, como relatado adiante.

Quanto à aplicação prática do método, vale dizer que as curvas de resistência do Eurocode para perfis laminados e soldados podem ser adaptadas para perfis formados a frio 
aplicando-se o procedimento proposto pelo ECBL, por meio das expressões relativas às barras submetidas à compressão apresentadas na Tabela 3.5. Pode-se perceber que o coeficiente $\alpha$ é inovador, considerando agora o coeficiente de erosão $\psi$ e o fator $Q$. Vale dizer que a simbologia dessas expressões foi também padronizada, assim como feito para as expressões normativas no início deste trabalho. Por fim, ressalta-se que existem também expressões para o caso da flexão, que não serão aqui apresentadas por não ser o tema deste trabalho.

Tabela 3.5 ECBL para barras submetidas à compressão: adaptação da curva de resistência do Eurocode para perfis formados a frio

\begin{tabular}{c}
$N_{c, R d}=\rho A_{e f} f_{y} / \gamma_{M 1}$ \\
$\rho=\frac{1}{\beta+\left(\beta^{2}-\lambda_{0}^{2}\right)^{0,5}} \leq 1$ \\
$\beta=0,5\left[1+\alpha\left(\lambda_{0}-0,2\right)+\lambda_{0}^{2}\right]$ \\
$\lambda_{0}=\left[A_{e f} f_{y} / N_{e}\right]^{0,5}$ \\
$\alpha=\frac{\psi^{2} \sqrt{Q}}{(1-\psi)(1-0,2 \sqrt{Q})}$ \\
\hline
\end{tabular}

É válido salientar que a Tabela 3.5 apresenta o coeficiente de imperfeição inicial $\alpha$ para o caso elástico-elástico da interação entre modos de instabilidade. Adicionalmente, para o caso plástico-elástico da interação, há a teoria baseada no conceito enfatizado por DUBINA \& UNGUREANU (2000) de que a instabilidade local é relacionada com a "plastificação" localizada da seção com formação de rótulas plásticas localizadas e, portanto, a interação entre os modos de instabilidade local-global é do tipo plástico-elástico e não do tipo elástico-elástico.

Ressalta-se que BATISTA (1986) também verificou mecanismos plásticos localizados durante a realização de ensaios em barras constituídas por perfis do tipo $U$ e $U$ enrijecido submetidas à compressão, durante os ensaios em seu doutorado na Université de Liège na Bélgica.

Por fim, a Figura 3.33 ilustra o trabalho apresentado por MOLDOVAN (1994), com as curvas referentes ao ECBL propostas por Dubina para considerar a interação entre o modo local e o global. 


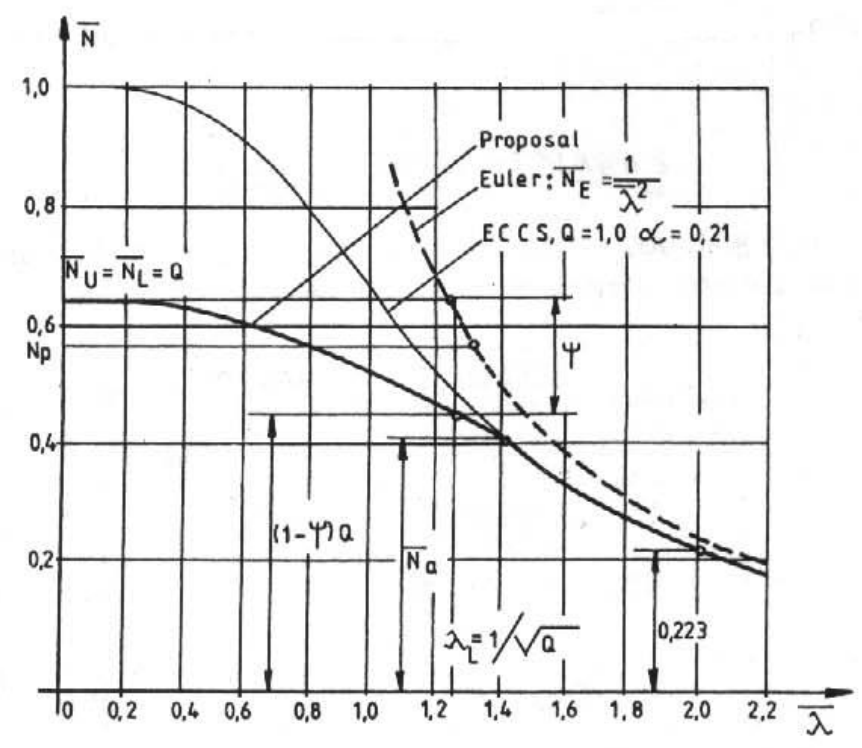

Figura 3.33 Procedimento ECBL proposto por Dubina [MOLDOVAN (1994)]

As expressões relativas à Figura 3.33 são apresentadas a seguir.

1) Se $0<\bar{\lambda}<0,2 \rightarrow \bar{N}=Q$, sendo $\mathrm{Q}=\mathrm{A}_{\text {ef }} / \mathrm{A}$, com $\mathrm{A}_{\text {ef }}$ conforme ECCS 1987 .

Portanto, $N=A_{\text {eff }} f_{y}$

2) Se $0,2 \leq \bar{\lambda} \leq 2 \rightarrow \bar{N}=a \bar{\lambda}^{2}+b \bar{\lambda}+c$, sendo $\bar{N} \leq \bar{N}_{a}$

Condição: $\bar{\lambda}=\frac{1}{\sqrt{Q}} \rightarrow \bar{N}=(1-\psi) Q$

3) Se $\bar{\lambda} \geq 2 \rightarrow \bar{N}=\bar{N}_{a}$, sendo $\bar{N}_{a}$ a força normal referente à curva a do ECCS e EC3

$$
\begin{array}{lll}
a=-\frac{\chi_{1}+\chi_{2}}{2,2-\chi_{3}} & b=-\chi_{1}+2,2 \frac{\chi_{1}+\chi_{2}}{2,2-\chi_{3}} & c=0,223+2 \chi_{1}-0,4 \frac{\chi_{1}+\chi_{2}}{2,2-\chi_{3}} \\
\chi_{1}=\frac{Q-0,223}{1,8} & \chi_{2}=\frac{(\bar{\psi} Q-0,223) \sqrt{Q}}{1-2 \sqrt{Q}} \quad \chi_{3}=\frac{1+2 \sqrt{Q}}{\sqrt{Q}}
\end{array}
$$




\subsubsection{Adaptação da fórmula de Ayrton-Perry para o ECBL}

A fórmula adimensional de Ayrton-Perry (base das curvas de resistência do Eurocode) para a análise da instabilidade global de barras submetidas à compressão pode ser expressa por (3.50), como já apresentado.

$$
(1-\bar{N})\left(1-\bar{\lambda}^{2} \bar{N}\right)=\eta \bar{N}
$$

RONDAL \& MAQUOI (1979) propõem o fator de imperfeição $\eta$ apresentado na expressão (3.51) para as curvas de resistênca à compressão do Eurocode 3 -1.3:1996.

$$
\eta=\alpha(\bar{\lambda}-0,2)
$$

Substituindo-se a expressão (3.51) na (3.50), tem-se a expressão (3.52).

$$
(1-\bar{N})\left(1-\bar{\lambda}^{2} \bar{N}\right)=\alpha(\bar{\lambda}-0,2) \bar{N}
$$

Resolvendo-se a expressão (3.52) para $\bar{N}$, é obtida a expressão (3.53), na qual somente o resultado devido à parcela negativa interessa, por ser o crítico.

$$
\bar{N}=\frac{1+\alpha(\bar{\lambda}-0,2)+\bar{\lambda}^{2}}{2 \bar{\lambda}^{2}} \pm \frac{1}{2 \bar{\lambda}^{2}} \sqrt{\left[1+\alpha(\bar{\lambda}-0,2)+\bar{\lambda}^{2}\right]^{2}-4 \bar{\lambda}^{2}}
$$

A solução de (3.53) deve ser igualada a $(1-\psi)$ no ponto $\bar{\lambda}=1$ da Figura 3.32 , originando a expressão (3.54), que corresponde ao valor máximo da erosão na curva de Euler quando não ocorre a instabilidade local, fato ilustrado na Figura 3.34.

$$
\bar{N}(\bar{\lambda}=1, \alpha)=\frac{1}{2}\left[2+0,8 \alpha-\sqrt{(2+0,8 \alpha)^{2}-4}\right]=1-\psi
$$

Sendo então na expressão (3.54) : $\bar{\lambda}=1,0 \rightarrow \bar{N}=(1-\psi)$ 


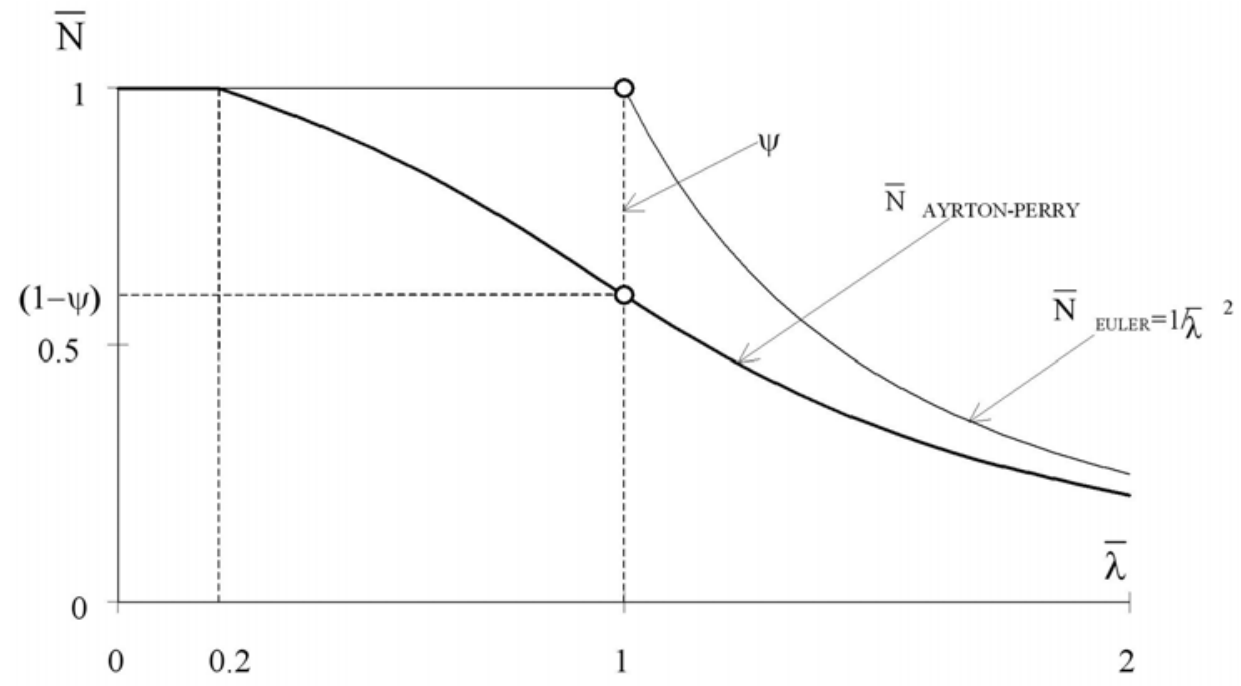

Figura 3.34 Curva de resistência a compressão de barra exemplificando a "erosão", quando não ocorre a instabilidade local [DUBINA (2001)]

A resolução da expressão (3.54), para $\bar{\lambda}=1$, fornece a (3.55).

$\alpha=\frac{\psi^{2}}{0,8(1-\psi)}$

A Figura 3.35 ilustra a variação do coeficiente de erosão $\psi$ em função do coeficiente de imperfeição $\alpha$, para melhor visualização da expressão (3.55).

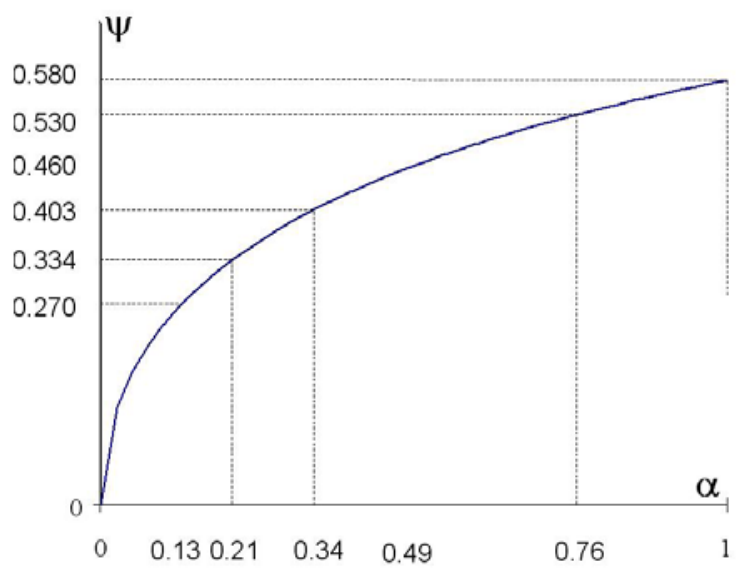

Figura 3.35 Relação: coeficiente de erosão $\psi$ vs. coeficiente de imperfeição $\alpha$ [DUBINA (2001)]

Considerando-se agora também a instabilidade local dos elementos que compõem a seção por meio do critério das larguras efetivas já apresentado, tem-se $A_{\text {ef }}=Q$.A. Feito isso, a 
expressão (3.52) passa a ser a expressão (3.56), que representa a expressão de Ayrton-Perry com a consideração da interação entre os modos de instabilidade local e global.

$$
(Q-\bar{N})\left(1-\bar{\lambda}^{2} \bar{N}\right)=\alpha(\bar{\lambda}-0,2) \bar{N}
$$

Portanto, quando a instabilidade local ocorre antes da global, a solução da expressão (3.56) no ponto de acoplamento E da Figura 3.32, pode ser apresentada como na expressão (3.57).

Continuando o raciocínio, da expressão (3.57) pode ser isolado o coeficiente de imperfeição $\alpha$, apresentado então na expressão (3.58), o qual consta da Tabela 3.5 apresentada anteriormente.

$$
\begin{aligned}
& \bar{N}=\frac{1+\alpha(\bar{\lambda}-0,2)+Q \bar{\lambda}^{2}}{2 \bar{\lambda}^{2}}-\frac{1}{2 \bar{\lambda}^{2}} \sqrt{\left[1+\alpha(\bar{\lambda}-0,2)+Q \bar{\lambda}^{2}\right]^{2}-4 Q \bar{\lambda}^{2}}=(1-\psi) Q \\
& \alpha=\frac{\psi^{2}}{1-\psi} \frac{\sqrt{Q}}{1-0,2 \sqrt{Q}}
\end{aligned}
$$

Sendo então na expressão (3.57) : $\bar{\lambda}=\sqrt{\frac{1}{Q}} \rightarrow \bar{N}=(1-\psi) Q$

A expressão (3.58) representa, portanto, o novo coeficiente de imperfeição $\alpha$ (vide Tabela 3.5), que conforme DUBINA \& UNGUREANU (2002)a pode ser introduzido nas curvas de resistência à compressão do Eurocode no intuito de adaptar as mesmas para a interação entre os modos de instabilidade local e global e com isso fazer uma melhor análise do comportamento dos perfis de aço formados a frio. A Figura 3.36 permite visualizar a variação de $\alpha$ em função de $\psi$ e $Q$ conforme expressão (3.58).
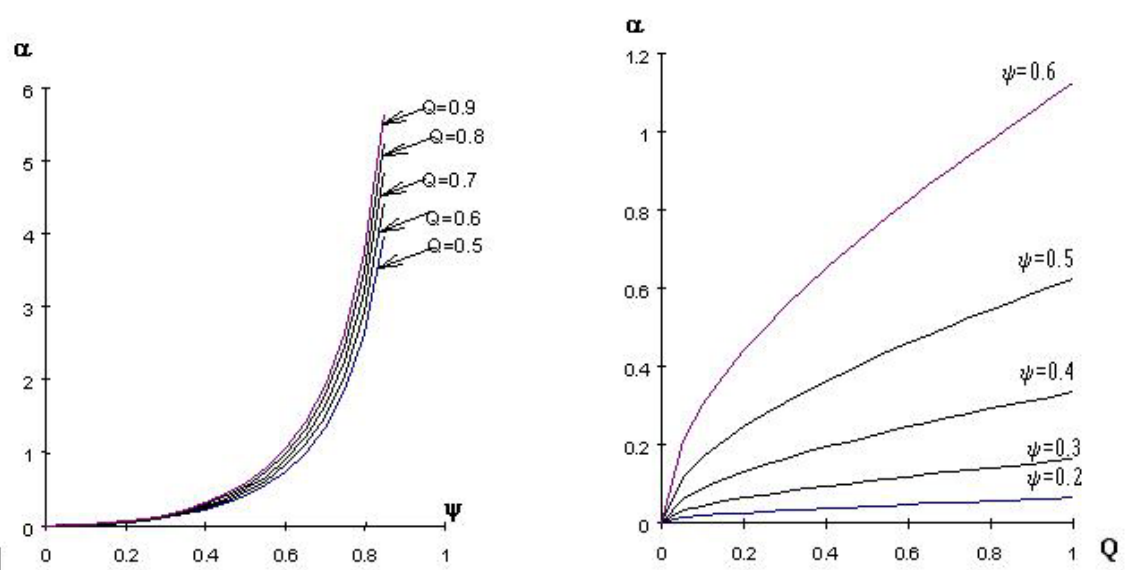

Figura 3.36 Relação entre $\alpha$, Q e $\psi$ [DUBINA (2001)] 
Vale salientar que a "erosão" total da curva de resistência à compressão - vide Figura 3.32 - que ocorre no ponto de acoplamento, não se deve somente ao coeficiente de erosão $\psi$ (referente aos efeitos da imperfeição geométrica inicial e da interação entre os modos de instabilidade), mas deve-se também à redução da resistência da barra devido à instabilidade local introduzida por meio do fator $Q$.

Por fim, é importante dizer mais uma vez que a chave do ECBL é o cálculo do coeficiente de erosão $\psi$, cálculo este que pode ser realizado por análise numérica ou experimental. Após esse cálculo, pode-se portanto utilizar a expressão (3.58) para o cálculo do novo coeficiente de imperfeição inicial $\alpha$ que deve ser utilizado nas curvas de resistência do Eurocode para adaptá-las. Estes dois procedimentos para cálculo do coeficiente de erosão $\psi$ são explicados na íntegra em DUBINA (2001).

Vale ressaltar também que este método não é uma "alternativa" ao método das largura efetivas, pois utiliza este mesmo método por meio do fator $Q=A_{\text {ef }} / A$ para rebaixar as curvas de resistência à compressão do Eurocode, como visto por exemplo na Tabela 3.5. Portanto, o procedimento como um todo é que é uma alternativa aos existentes atualmente.

Em suma, este rebaixamento das curvas considera o coeficiente de erosão $\psi$, que considera tanto o acoplamento dos modos de instabilidade como as imperfeições geométricas iniciais (em seções compactas a erosão se deve normalmente às imperfeições geométricas iniciais, enquanto que nas seções mais esbeltas uma parcela adicional é relativa ao fenômeno de acoplamento entre os modos de instabilidade), e o fator $Q$, que considera a instabilidade local. 


\section{MÉTODO DA RESISTÊNCIA DIRETA}

Tradicionalmente, o efeito da redução da resistência em perfis formados a frio devido à instabilidade local de seus elementos é computado pelo método das larguras efetivas, o que conduz ao cálculo de propriedades efetivas da seção transversal. Além disso, de acordo com os procedimentos normativos vigentes, os elementos (chapas) que constituem a seção transversal são analisados em separado, não contabilizando portanto a interação entre elementos adjacentes.

Devido ao cálculo das propriedades geométricas efetivas ser trabalhoso e também por perceber que a consideração da interação entre elementos adjacentes da seção pode otimizar o dimensionamento, SCHAFER \& PEKÖZ (1998) propuseram o Método da Resistência Direta (MRD em português, e DSM em inglês, devido ao nome original Direct Strength Method) como uma alternativa ao método das larguras efetivas.

Portanto, larguras e propriedades efetivas da seção não precisam ser calculadas, pois o método utiliza as propriedades da seção bruta. Além disso, permite que sejam consideradas as interações entre os elementos adjacentes componentes da seção - uma das principais diferenças com relação aos procedimentos usuais - sendo garantidas as condições de compatibilidade e equilíbrio entre os elementos, pois a análise elástica prévia é realizada usualmente por métodos numéricos para a seção transversal como um todo, como será explicado adiante.

Vale lembrar que esse método já está inserido como uma opção de cálculo na norma americana em sua versão de 2001 (por meio de um draft de 2004), inserido no Apêndice 1 do NAS (2004), e que o comitê responsável pela norma australiana votou favoravelmente à adoção deste método para versões futuras como uma alternativa a seus procedimentos. Este método pode ser melhor entendido no guia elaborado e denominado Design Guide for Direct 
Strength Method, vide SCHAFER (2006), e também em CHODRAUI (2003) e CHODRAUI et al. (2004a).

O objetivo do método é, portanto, a determinação da resistência de perfis submetidos à compressão ou à flexão, considerando todos os modos de instabilidade envolvidos. Entretanto, vale salientar que o método vem sendo adaptado atualmente para outros tipos de solicitações, como esforço cortante combinado com flexão, vide QUISPE \& HANCOCK (2002), e também para a flexo-compressão, vide SCHAFER (2002).

O uso deste método requer uma análise prévia de estabilidade elástica da barra, que pode ser realizada por diversos métodos. Usualmente, são utilizados métodos numéricos como faixas finitas, elementos finitos, elementos de contorno, diferenças finitas ou teoria generalizada de vigas (GBT), sendo que para tirar o máximo de proveito do MRD a seção deve ser analisada como um todo permitindo então a interação entre elementos adjacentes.

Portanto, para o uso do método é necessária a obtenção dos valores $N_{c r e}, N_{c r}, N_{c r d}, M_{c r e}$, $M_{c r}$, $M_{c r d}$, correspondentes à análise de estabilidade elástica relativos aos modos local, distorcional e global (euler), referentes, respectivamente, à força normal e ao momento fletor. Como exemplo, a Figura 4.1 ilustra para o caso da compressão o resultado da análise de estabilidade elástica do programa CUFSM para um perfil do tipo $U$ enrijecido, onde se pode observar os modos local e distorcional.

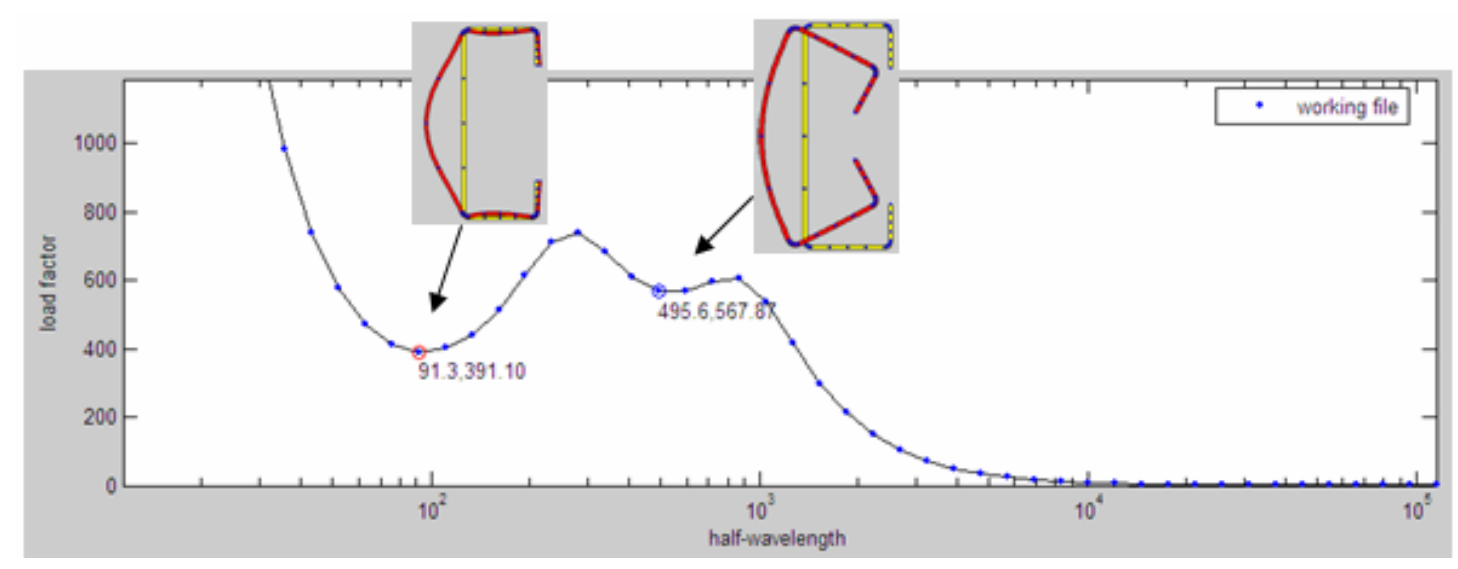

Figura 4.1 Análise de estabilidade elástica via CUFSM: perfil do tipo U enrijecido

Vale lembrar que devem ser consideradas nestes modelos de análises de estabilidade elástica prévia as corretas condições de carregamento e contorno das barras para que o resultado seja o mais correto possível. Entretanto, se a opção for pelo uso do programa CUFSM (que permite somente condição de extremidades articuladas das barras) - sugerido e desenvolvido pelo próprio prof. Ben Schafer - e a barra apresentar extremidades engastadas, o seguinte comentário é importante: 
- $\quad$ Para perfis do tipo $U$ e $U$ enrijecido por exemplo, em que a análise de estabilidade elástica via CUFSM apresenta na sua curva os mínimos dos modos de instabilidade bem definidos, por exemplo visto na Figura 4.1, não há problema. Os valores de tensão crítica devem ser obtidos para os modos localizados (local, e distorcional se aplicável) nos pontos de mínimo fornecidos pelo programa, enquanto que o modo global será obtido da teoria de estabilidade elástica (sugerido) onde a "correção" do comprimento efetivo é inerente. Entretanto, se o modo global for obtido das próprias curvas do CUFSM, deve-se utilizar $\mathrm{K}=0,5$ (metade do comprimento da barra) para o comprimento half-wavelength quando da leitura no gráfico do valor desejado;

- $\quad$ Para as cantoneiras, perfis que até o momento não são seções pré-qualificadas para o MRD - e, portanto, análises exploratórias são apresentadas mais adiante nesta tese em conjunto com o prof. Ben Schafer a fim de pré-qualificá-las - entendendo-se o primeiro trecho da curva do CUFSM (apresentado mais adiante na Figura 6.4) como um modo global (local/torsional) o valor de tensão crítica deverá ser obtido utilizando-se $\mathrm{K}=0,5$ (metade do comprimento da barra) para o comprimento half-wavelength quando da leitura no gráfico. Adicionalmente, simplesmente para se adiantar um pouco o assunto, a dúvida quanto à questão desse modo (local/torsional) ser local ou global será discutida em um capítulo mais adiante (item 7.1);

Após essas considerações, e para continuar a explicação do método, o leitor deve entender que uma vez realizada a análise elástica, os resultados são utilizados como dados de entrada para algumas curvas de resistência, no intuito de se prever a resistência da barra, i.e., determinar o valor nominal da força normal de compressão resistente $\mathrm{N}_{\mathrm{n}}$ e do momento fletor resistente $M_{n}$. Em seguida, são então aplicados para finalizar o procedimento os coeficientes de ponderação, para se obter as resistências de cálculo.

Vale salientar que as expressões do método apresentadas a seguir são somente relativas à compressão, por ser este o foco principal deste trabalho. Portanto, o valor nominal da força normal de compressão resistente $N_{n}$ é o mínimo entre os valores $N_{g}, N_{\ell}$ e $N_{\text {dist }}$, como apresentado de 4.1.1 a 4.1.3. Para o modo global, vale lembrar que as expressões (4.1) e (4.2) são as mesmas expressões da curva de resistência à compressão da norma americana atual (NAS:2004).

Quanto aos coeficientes de ponderação, existem algumas seções pré-qualificadas para o uso do método, devido ao fato de que vários ensaios foram realizados em barras de aço constituídas por perfis formados a frio, obtendo-se resultados para a calibração do método. Esse coeficiente varia, dependendo se a seção for ou não pré-qualificada, e também devido ao tipo de esforço solicitante. 
Apresentando um pouco a origem desses ensaios qualificatórios, com relação às barras submetidas à compressão centrada, com extemidades articuladas, pode-se destacar BATISTA (1986, 1988), KWON \& HANCOCK (1992), LAU \& HANCOCK (1987), LOUGHLAN (1979), MILLER \& PEKÖZ (1994), MULLIGAN (1983), POLYZOIS et al. (1993) e THOMASSON (1978). Por outro lado, dentre os ensaios de barras submetidas à flexão, destacam-se COHEN (1987), ELLIFRITT et al. (1997), LABOUBE \& YU (1978), MOREYARA (1993), PHUNG \& YU (1978), ROGERS (1995), SCHARDT \& SCHRADE (1982), SCHUSTER (1992), SHAN et al. (1994) e WILLIS \& WALLACE (1990).

Antes de se apresentar as expressões do método, algumas observações devem ser feitas:

- O modo global é calculado com base na curva do NAS:2004;

- Para o caso do modo local (item 4.1.2), em vez de usar nas expressões (4.5) e (4.6) $\mathrm{N}_{\mathrm{g}}$, para se considerar a interação entre o modo global e local, pode-se usar $\mathrm{N}_{\mathrm{y}}$, para considerar o escoamento;

- Por outro lado, para o caso do modo distorcional (item 4.1.3), a versão de 2004 do método apresentada por Schafer já utiliza na expressão somente $N_{y}$, para se considerar o escoamento, e não admite mais substituí-lo por $\mathrm{N}_{\mathrm{g}}$, para se considerar a interação entre o modo global e distorcional, como permitido anteriormente. Vale lembrar que SCHAFER (2001) já alertava para este fato, e esta mudança ocorreu devido à resultados provenientes de ensaios e análises com a norma australiana, o que constata que o modo distorcional é independente do modo global.

\subsection{Modos de instabilidade: expressões}

São aqui apresentadas as expressões do MRD para o caso de barras submetidas à compressão, aproveitando-se a oportunidade para algumas comparações, por exemplo, da curva do MRD com as múltiplas curvas da NBR 14762:2001 para o modo global (Figura 4.2), e também da curva do MRD com a curva proposta por Winter para o modo local (Figura 4.3) e com a curva da NBR 14762:2001 para o modo distorcional (Figura 4.4).

Quanto a essas comparações, percebe-se que as curvas de resistência são diferentes (para o modo global a diferença depende da curva da NBR adotada, para o modo local há uma diferença significativa, e para o modo distorcional as curvas são próximas), e têm pontos de inflexão distintos. Entretanto, não se pode dizer, por exemplo para o modo local, que a curva de Winter é mais conservadora que a curva do MRD, pois os procedimentos são diferentes, e 
portanto não se pode analizar a curva isoladamente. Haja visto, por exemplo, que o MRD não utiliza larguras efetivas e faz uma análise da seção como um todo considerando a interação entre os elementos adjacentes que constituem a seção transversal, ao contrário da metodologia proposta por Winter.

É importante frisar que, para o modo global (Figura 4.2), $\lambda_{\mathrm{c}} \neq \lambda_{0}$ se $\mathrm{A}_{\mathrm{ef}} \neq \mathrm{A}$.

\subsubsection{Modo global}

O valor nominal da força normal de compressão resistente $\mathrm{N}_{\mathrm{g}}$, para instabilidade por flexão, torção ou flexo-torção (ilustrado na Figura 4.2) é:

$$
\begin{array}{ll}
N_{g}=\left(0,658^{\lambda_{c}^{2}}\right) N_{y} & \text { para } \lambda_{c} \leq 1,5 \\
N_{g}=\left(\frac{0,877}{\lambda_{c}^{2}}\right) N_{y} & \text { para } \lambda_{c}>1,5
\end{array}
$$

Onde:

$$
\begin{aligned}
& \lambda_{c}=\sqrt{\frac{N_{y}}{N_{c r e}}} \\
& N_{y}=A \cdot f_{y}
\end{aligned}
$$

$\mathrm{N}_{\text {cre }}=$ menor valor da força normal crítica elástica entre a flexão, torção e flexo-torção. 


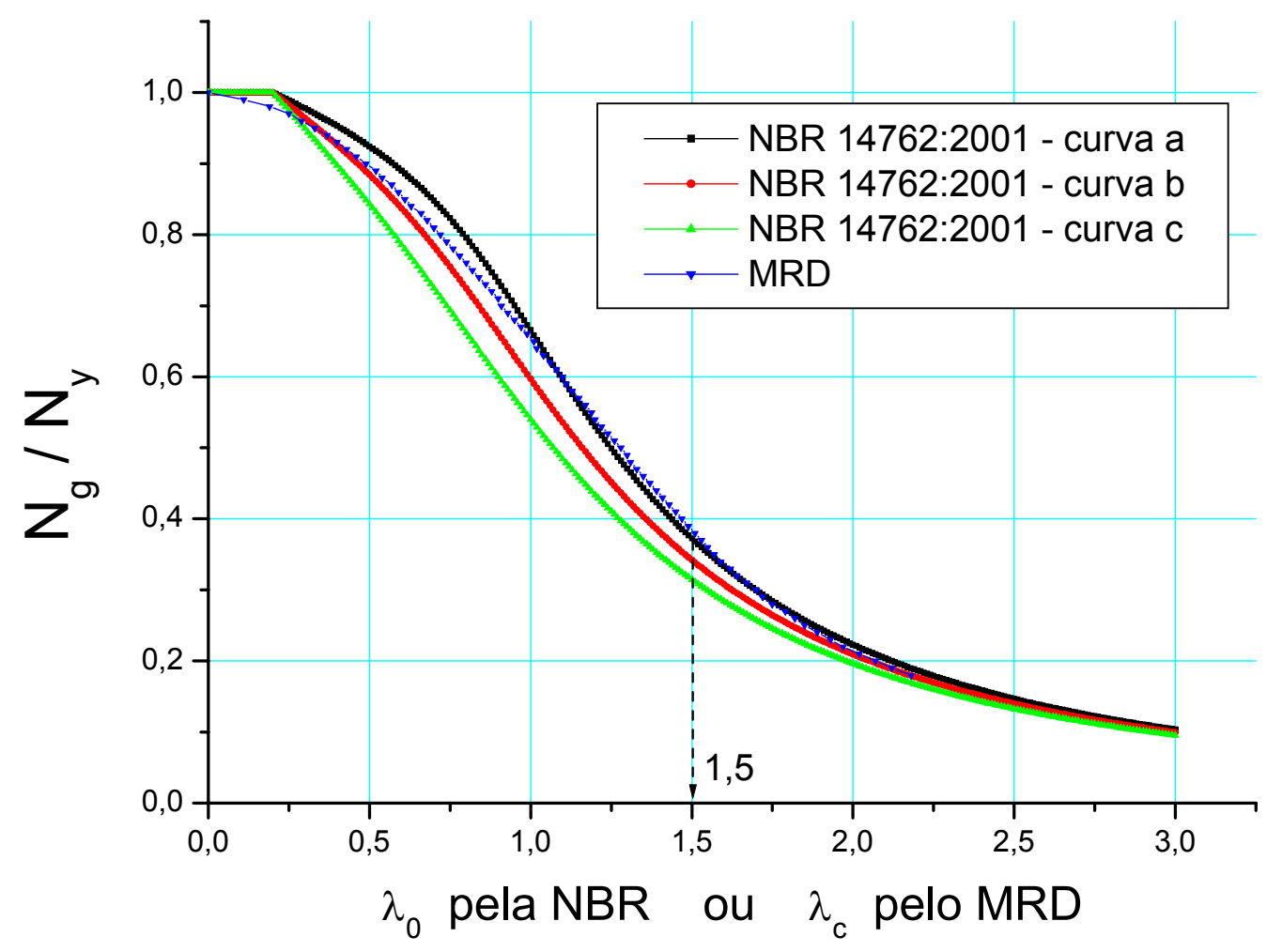

Figura 4.2 MRD e NBR 14762:2001: curva de resistência à compressão para o modo global

\subsubsection{Modo local}

O valor nominal da força normal de compressão resistente $\mathrm{N}_{\ell}$, para instabilidade local (ilustrado na Figura 4.3) é:

$$
\begin{array}{ll}
N_{\ell}=N_{g} & \text { para } \lambda_{\ell} \leq 0,776 \\
N_{\ell}=\left(1-0,15\left(\frac{N_{c r \ell}}{N_{g}}\right)^{0,4}\right)^{\left(\frac{N_{c r \ell}}{N_{g}}\right)^{0,4} N_{g}} \quad \text { para } \lambda_{\ell}>0,776
\end{array}
$$

Onde:

$$
\lambda_{\ell}=\sqrt{\frac{N_{g}}{N_{c r l}}}
$$

$\mathrm{N}_{\mathrm{cr} \ell}=$ força normal crítica elástica relativa ao modo local. 


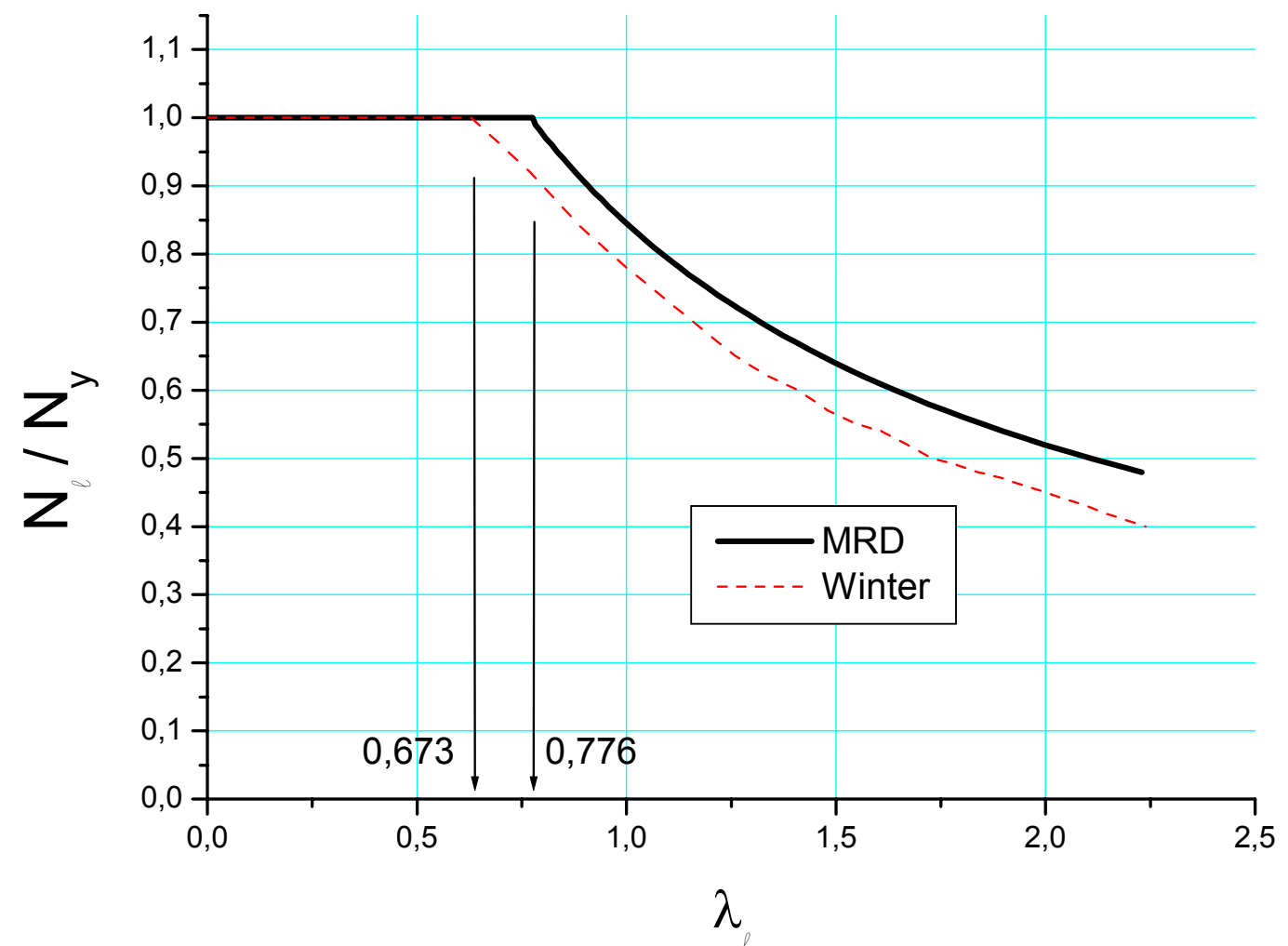

Figura 4.3 MRD e Winter: curva de resistência à compressão para modo local

\subsubsection{Modo distorcional}

O valor nominal da força normal de compressão resistente $\mathrm{N}_{\text {dist }}$, para instabilidade por distorção (ilustrado na Figura 4.4) é:

$$
\begin{aligned}
& N_{\text {dist }}=N_{y} \\
& \text { para } \lambda_{\text {dist }} \leq 0,561
\end{aligned}
$$

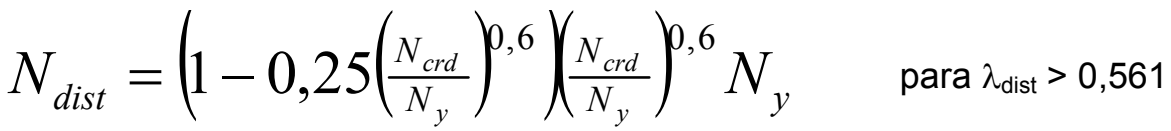

Onde:

$$
\lambda_{\text {dist }}=\sqrt{\frac{N_{y}}{N_{c r d}}}
$$

$\mathrm{N}_{\text {crd }}=$ força normal crítica elástica relativa ao modo distorcional. 


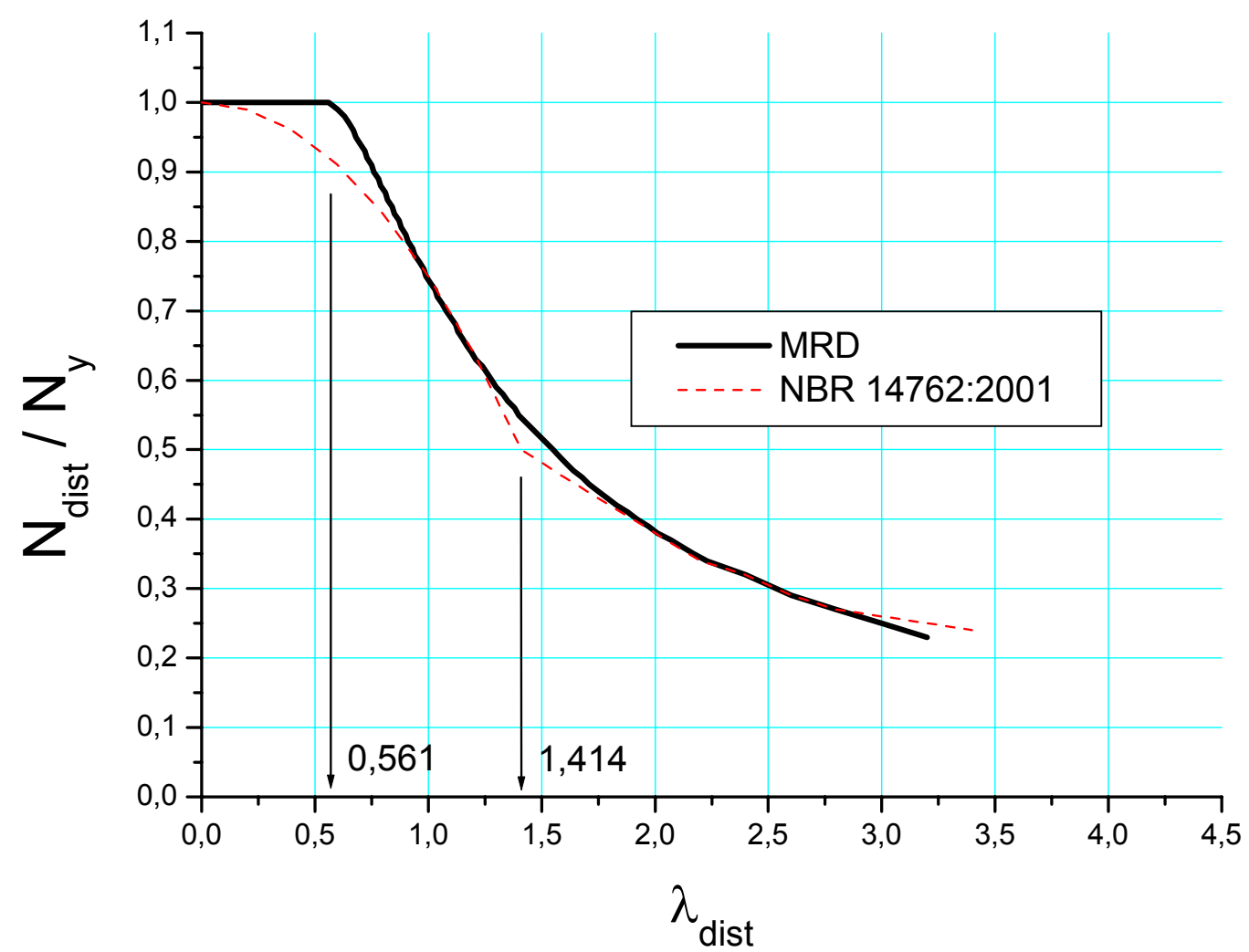

Figura 4.4 MRD e NBR 14762:2001: curva de resistência à compressão para modo distorcional 


\section{ANÁLISE EXPERIMENTAL}

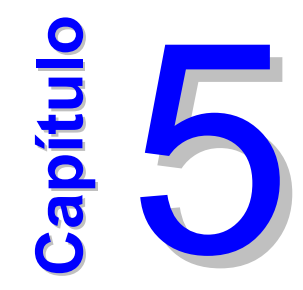

\subsection{Descrição das barras ensaiadas}

As barras utilizadas no presente trabalho foram adquiridas junto à empresa PERFILAM $S / A$ indústria de perfilados, a qual forneceu nominalmente os seguintes materiais:

- Bobina fina a quente / CSN COR 420, relativa à espessura de 2,25mm, produzida pela siderúrgica INAL/CSN;

- Bobina fina a quente / USI - SAC 300, relativa à espessura de $3,75 \mathrm{~mm}$, produzida pela siderúrgica USIMINAS;

Uma informação importante, fundamentada no item 5.3.1.2 a ser apresentado adiante, é que as espessuras reais medidas dos perfis (valores médios), referentes às espessuras nominais de $2,25 \mathrm{~mm}$ e $3,75 \mathrm{~m}$, foram respectivamente $2,38 \mathrm{~mm}$ e $3,88 \mathrm{~mm}$. Portanto, nas tabelas constarão estes valores medidos, mesmo porque estes é que foram utilizadas nos modelos numéricos e cálculos normativos ao longo deste trabalho, a fim de que a comparação com os resultados da análise experimental fosse mais correta.

Para todos os casos e análises, foram utilizadas também as resistências ao escoamento e à ruptura (valores médios) resultantes dos ensaios realizados de caracterização do aço em corpos-de-prova extraídos dos perfis, cujos valores são os apresentadas a seguir:

- Perfis $t=2,25 \mathrm{~mm}: \mathrm{f}_{\mathrm{y}}=375 \mathrm{MPa}$ e $\mathrm{f}_{\mathrm{u}}=513 \mathrm{MPa}$;

- Perfis $t=3,75 \mathrm{~mm}: \mathrm{f}_{\mathrm{y}}=288 \mathrm{MPa}$ e $\mathrm{f}_{\mathrm{u}}=429 \mathrm{MPa}$. 
Estes valores foram obtidos de ensaios de tração direta para caracterização do aço conforme norma ASTM A370:1992. Foram extraídos corpos-de-prova dos perfis (14 ensaios), como ilustrado da Figura 5.1 a Figura 5.3. Os corpos-de-prova (vide detalhe na Figura 5.4) foram extraídos da parte central dos elementos dos perfis. Os resultados (resistência ao escoamento e à ruptura, e também o alongamento dos corpos-de-prova com base de medida de $50 \mathrm{~mm}$ ) são apresentados na Tabela 5.1, onde se pode ver que o aço apresentou em todos os casos um alongamento satisfatório na faixa dos $30 \%$, lembrando-se que o valor mínimo aceitável da NBR 14762:2001 é de 10\%.

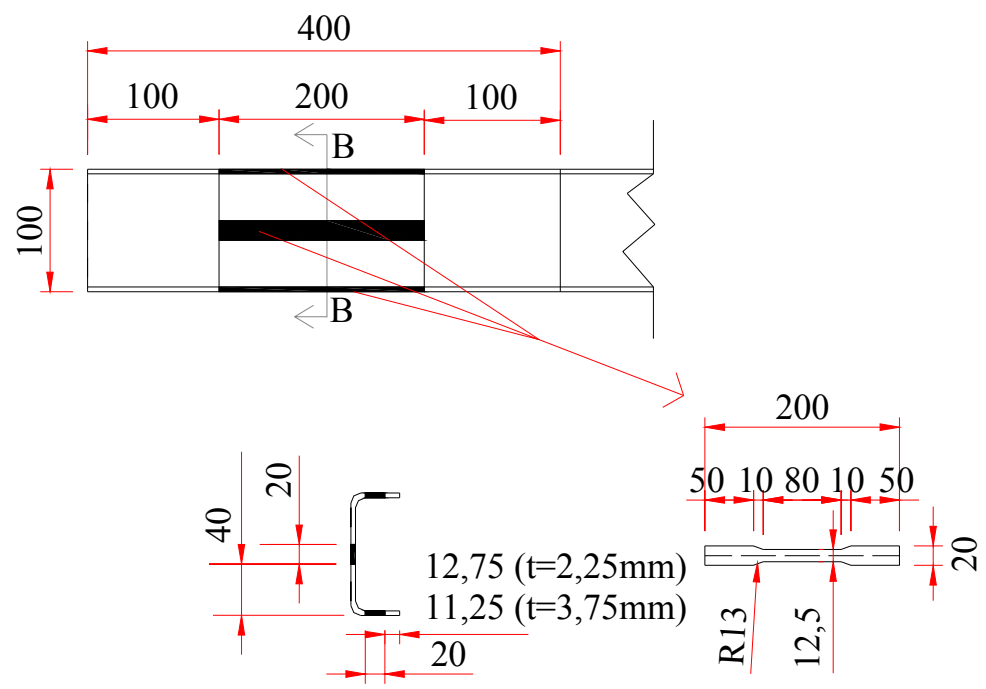

\section{Corte BB}

Figura 5.1 Corpos de prova extraídos dos perfis: perfil U
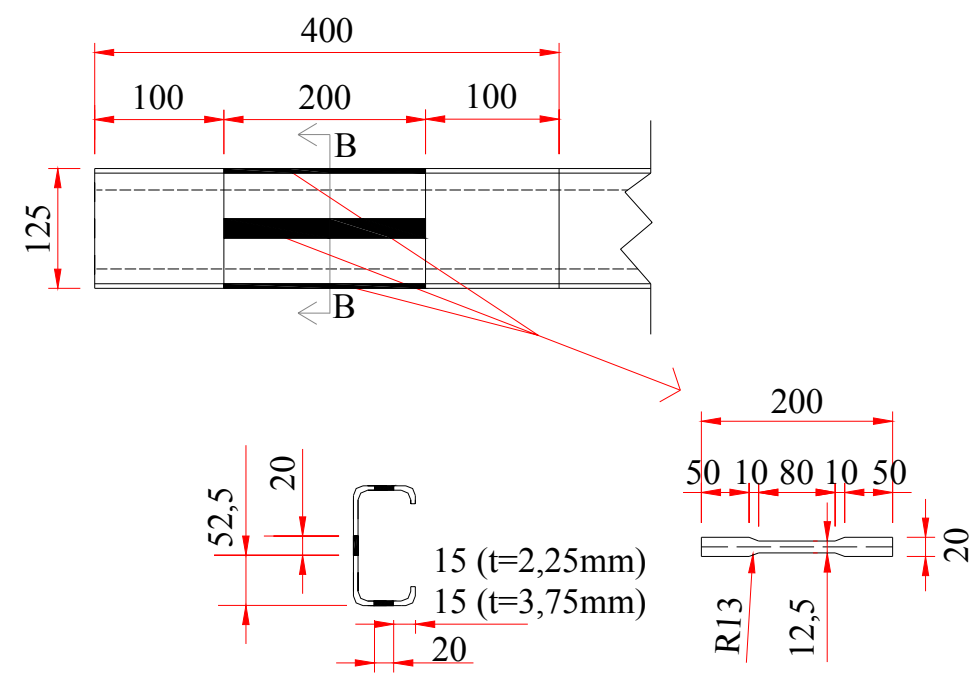

\section{Corte BB}

Figura 5.2 Corpos de prova extraídos dos perfis: perfil Ue 

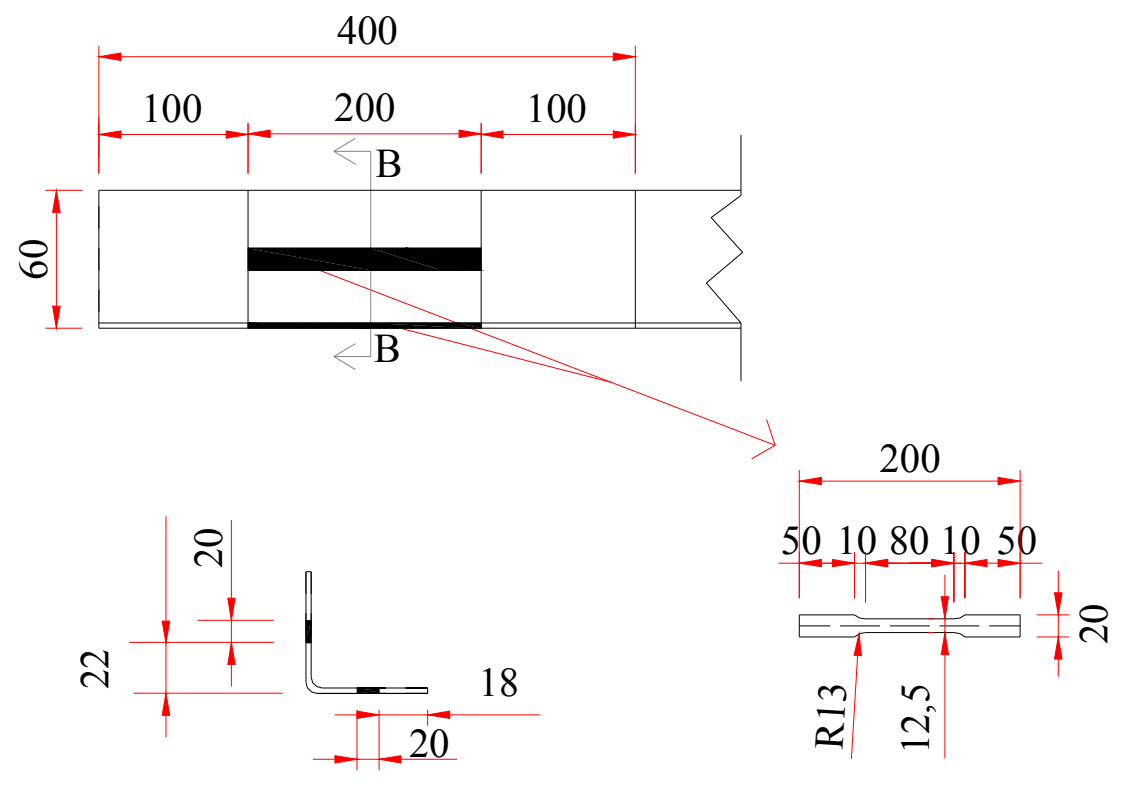

\section{Corte BB}

Figura 5.3 Corpos de prova extraídos dos perfis: perfil L

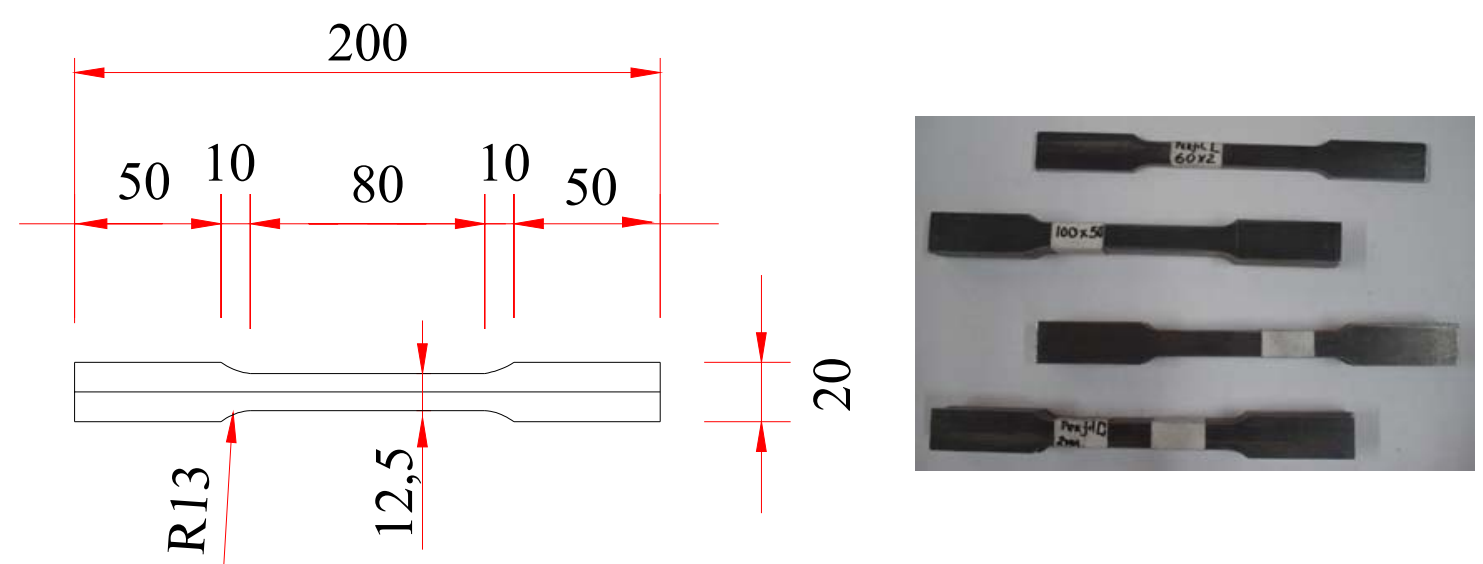

Figura 5.4 Detalhe do corpo-de-prova para ensaio de tração conforme ASTM A370:1992 
Tabela 5.1 Resultados dos ensaios de caracterização do aço

\begin{tabular}{|c|c|c|c|c|c|c|c|c|c|}
\hline PERFIL & $\begin{array}{l}\text { SIGLA } \\
\text { C.P. }\end{array}$ & $\begin{array}{c}\text { Área } \\
\text { MÉDIIA } \\
\left(\mathrm{cm}^{2}\right)\end{array}$ & $\begin{array}{c}\text { Força } \\
\text { escoam. } \\
\text { (kN) }\end{array}$ & $\begin{array}{c}\mathbf{f}_{\mathrm{y}} \\
(\mathrm{MPa})\end{array}$ & $\begin{array}{c}\text { Tensão } \\
\text { Escoam. } \\
\text { MÉDIA } \\
\text { (MPa) }\end{array}$ & $\begin{array}{l}\text { Força } \\
\text { máxima } \\
\text { (kN) }\end{array}$ & $\begin{array}{c}\mathbf{f}_{\mathrm{u}} \\
(\mathrm{MPa})\end{array}$ & $\begin{array}{c}\text { Tensão } \\
\text { máxima } \\
\text { MÉDIA } \\
\text { (MPa) }\end{array}$ & $\begin{array}{l}\text { Alongamento } \\
(\mathrm{L}=50 \mathrm{~mm})\end{array}$ \\
\hline \multirow{3}{*}{ 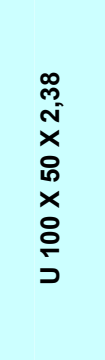 } & $\begin{array}{l}\text { U2-a } \\
\text { (alma) }\end{array}$ & 0,292 & 10,3 & 352,6 & \multirow{3}{*}{371,1} & 14,5 & 496,4 & \multirow{3}{*}{509,9} & $34,00 \%$ \\
\hline & $\begin{array}{c}\mathrm{U} 2-\mathrm{m} 1 \\
\text { (mesa 1) }\end{array}$ & 0,297 & 10,5 & 353,8 & & 14,7 & 495,3 & & $28,00 \%$ \\
\hline & $\begin{array}{c}\text { U2-m2 } \\
\text { (mesa 2) }\end{array}$ & 0,297 & 12,1 & 406,8 & & 16,0 & 537,9 & & $26,00 \%$ \\
\hline \multirow{3}{*}{ 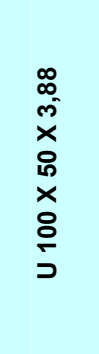 } & $\begin{array}{l}\text { U3-a } \\
\text { (alma) }\end{array}$ & 0,497 & 14,6 & 293,7 & \multirow{3}{*}{295,7} & 21,1 & 424,4 & \multirow{3}{*}{428,3} & $36,00 \%$ \\
\hline & $\begin{array}{c}\text { U3-m1 } \\
\text { (mesa 1) }\end{array}$ & 0,491 & 14,5 & 295,5 & & 21,1 & 430,1 & & $38,00 \%$ \\
\hline & $\begin{array}{c}\text { U3-m2 } \\
\text { (mesa 2) }\end{array}$ & 0,490 & 14,6 & 297,9 & & 21,1 & 430,5 & & $38,00 \%$ \\
\hline \multirow{3}{*}{ 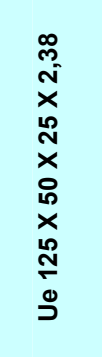 } & $\begin{array}{l}\text { Ue2-a } \\
\text { (alma) }\end{array}$ & 0,299 & 11,6 & 387,7 & \multirow{3}{*}{382,8} & 15,3 & 511,4 & \multirow{3}{*}{513,4} & $26,00 \%$ \\
\hline & $\begin{array}{l}\text { Ue2-m1 } \\
\text { (mesa 1) }\end{array}$ & 0,300 & 11,3 & 377,1 & & 15,3 & 510,6 & & $28,00 \%$ \\
\hline & $\begin{array}{c}\text { Ue2-m2 } \\
\text { (mesa 2) }\end{array}$ & 0,297 & 11,4 & 383,5 & & 15,4 & 518,1 & & $26,00 \%$ \\
\hline \multirow{3}{*}{ 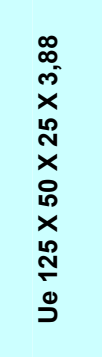 } & $\begin{array}{l}\text { Ue3-a } \\
\text { (alma) }\end{array}$ & 0,489 & 13,8 & 282,1 & \multirow{3}{*}{281,0} & 20,9 & 427,3 & \multirow{3}{*}{429,8} & $34,00 \%$ \\
\hline & $\begin{array}{l}\text { Ue3-m1 } \\
\text { (mesa 1) }\end{array}$ & 0,484 & 13,4 & 276,8 & & 20,7 & 427,5 & & $34,00 \%$ \\
\hline & $\begin{array}{l}\text { Ue3-m2 } \\
\text { (mesa 2) }\end{array}$ & 0,485 & 13,8 & 284,3 & & 21,1 & 434,6 & & $36,00 \%$ \\
\hline \multirow{2}{*}{ 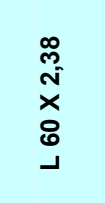 } & $\begin{array}{c}\text { L2-a1 } \\
\text { (alma 1) }\end{array}$ & 0,295 & 10,1 & 342,8 & \multirow{2}{*}{371,0} & 14,6 & 495,6 & \multirow{2}{*}{516,2} & $28,00 \%$ \\
\hline & $\begin{array}{c}\text { L2-a2 } \\
\text { (alma 2) }\end{array}$ & 0,291 & 11,6 & 399,2 & & 15,6 & 536,9 & & $22,00 \%$ \\
\hline
\end{tabular}


É necessário comentar que para os corpos-de-prova com $\mathrm{t}=3,75 \mathrm{~mm}$ era de se esperar $f_{y}>300 \mathrm{MPa}$, por ser proveniente de bobina USI - SAC 300. Entretanto, os valores obtidos nos ensaios de caracterização mostram que houve falha no fornecimento.

Vale a pena definir logo no início deste capítulo os dois tipos de barras utilizados neste trabalho:

- $\quad$ Barras curtas (stub columns): $\lambda_{0}<0,2$ (região de patamar na curva $\rho \times \lambda_{0}$ )

- $\quad$ Barras longas: $\lambda_{0}>0,2$

$\lambda_{0}$ é o índice de esbeltez reduzido conforme NBR 14762:2001

Previamente aos ensaios, foram realizados o corte das barras curtas (15 barras da Etapa 4), e as soldas das chapas de topo das barras longas (28 barras da Etapa 5). Antes do envio à Oficina Mecânica, o C.G das chapas de topo foi marcado com riscador para facilitar o posicionamento das barras durante a soldagem, de modo que o C.G. da seção transversal da barra fosse coincidente com o C.G. da chapa de topo a fim de resultar em compressão centrada nos ensaios. Alguns cuidados foram tomados nesta fase:

- Quanto à soldagem, pois as chapas de topo têm espessura de $12,5 \mathrm{~mm}$, enquanto que as barras têm espessura nominal de $2,25 \mathrm{~mm}$ e de $3,75 \mathrm{~mm}$;

- Quanto à garantia de perpendicularidade entre o eixo das barras longas e a chapa de topo, e também entre o eixo das barras curtas e o plano da seção de extremidade;

- Quanto ao paralelismo entre as duas chapas de topo das barras longas, para facilitar o correto posicionamento na máquina de ensaio.

É importante dizer que para os ensaios de barras longas, ao comprimento das barras ( $\left.L_{\text {perfil }}\right)$ deve ser somado $135 \mathrm{~mm}$ para se ter o comprimento efetivo de flambagem $\left(L_{r}\right)$ comprimento entre centro das rótulas. Este valor de $135 \mathrm{~mm}$ é a soma de duas parcelas especificadas a seguir que compõem o sistema de rótulas utilizado nos ensaios, ilustradas na Figura 5.16:

- $\quad$ espessura das duas chapas de topo de $12,5 \mathrm{~mm}$ (uma em cada extremidade) $=25 \mathrm{~mm}$;

- distância adicional ao ponto de rotação das rótulas $(55 \mathrm{~mm}$ cada $)=110 \mathrm{~mm}$. 
A Tabela 5.2 apresenta as barras longas utilizadas neste trabalho, enquanto que a Tabela 5.3 apresenta as barras curtas (stub columns), juntamente com algumas características. Além disso, com o intuito de se facilitar a apresentação dos resultados, foi criado um conjunto de siglas para a denominação dos perfis, que será utilizado quando se entender necessário. Tais siglas fazem referência ao tipo de perfil e a "padrões de referência" quanto à espessura, índice de esbeltez na menor inércia e eixo de flambagem (caso das cantoneiras duplas).

Uma informação que será explicada com detalhes no item referente aos procedimento de ensaio, mas vale a pena fazer aqui um breve comentário para melhor se entender a Tabela 5.2, é quanto à rótula utilizada nos ensaios das barras longas. Esta é cilíndrica, permitindo portanto rotação somente em torno de um eixo. Para reduzir o número de ensaios, optou-se por realizá-los somente permitindo a rotação em torno do eixo de menor inércia para todas as seções. Exceção para as cantoneiras duplas, pois um primeiro lote de barras foi ensaiado permitindo rotação em torno do eixo $\mathrm{x}$ e um segundo permitindo rotação em torno do eixo y, como se pode ver na Tabela 5.2.

\subsubsection{Análises via NBR 14762:2001}

Todas as barras utilizadas no presente trabalho foram analisadas à compressão pelo procedimento da norma brasileira de perfis de aço formados a frio NBR 14762:2001 (e também via NAS:2004, como será apresentado mais adiante), a fim de se comparar no capítulo de análise de resultados a força normal de compressão resistente $\mathrm{N}_{c, R}$ (calculada com o auxílio de planilhas desenvolvidas no EXCEL pelo autor deste trabalho) com os resultados provenientes da análise experimental e da análise numérica.

A Tabela 5.4 e a Tabela 5.5 apresentam os resultados desse cálculo conforme a norma em questão, respectivamente para as barras longas e para as barras curtas (stub columns). Apresentam, para todos os tipos de perfis e comprimentos de barras, o comprimento da barra $\left(L_{\text {perfil }}\right)$, o comprimento entre os centros das rótulas, também denominado efetivo de flambagem $\left(L_{r}\right)$, a área $A$, a área efetiva $A_{e f}$, a relação $A_{e f} / A$, os valores de força normal de flambagem elástica e força normal de compressão resistente, e também os coeficientes $\mathrm{K}$ de flambagem do modo global para os eixos em questão.

Para a Tabela 5.5, ou seja, stub columns, a força normal resistente foi calculada simplesmente como $\mathrm{N}_{c, R}=A_{\text {eff }} f_{y}$.

Pode-se perceber a disposição dos eixos e a nomenclatura das dimensões da seção transversal dos perfis por meio da Figura 5.5. 
Tabela 5.2 Barras longas utilizadas no trabalho

\begin{tabular}{|c|c|c|c|c|c|c|c|c|c|}
\hline PERFIL & SIGLA & $\begin{array}{c}\mathrm{L}_{\mathrm{r}} \\
(\mathrm{mm})\end{array}$ & $\begin{array}{l}\mathrm{L}_{\text {perfil }} \\
(\mathrm{mm})\end{array}$ & $\underset{\left(\mathrm{cm}^{2}\right)}{\mathrm{A}}$ & $\begin{array}{c}\text { Peso } \\
\text { (kgf/m) }\end{array}$ & $\begin{array}{c}r_{x} \\
(\mathrm{~cm})\end{array}$ & $\begin{array}{c}r_{y} \\
(\mathbf{c m})\end{array}$ & $\lambda_{x}$ & $\lambda_{y}$ \\
\hline \multirow[t]{4}{*}{ U $100 \times 50 \times 2,38$} & U2.60 & 850 & 715 & 4,57 & 3,59 & 3,97 & 1,58 & 11 & 54 \\
\hline & U2.90 & 1.320 & 1.185 & 4,57 & 3,59 & 3,97 & 1,58 & 17 & 84 \\
\hline & U2.120 & 1.800 & 1.665 & 4,57 & 3,59 & 3,97 & 1,58 & 23 & 114 \\
\hline & U2.150 & 2.270 & 2.135 & 4,57 & 3,59 & 3,97 & 1,58 & 29 & 144 \\
\hline \multirow[t]{4}{*}{ U $100 \times 50 \times 3,88$} & U3.60 & 850 & 715 & 7,27 & 5,71 & 3,90 & 1,56 & 11 & 55 \\
\hline & U3.90 & 1.320 & 1.185 & 7,27 & 5,71 & 3,90 & 1,56 & 17 & 85 \\
\hline & U3.120 & 1.800 & 1.665 & 7,27 & 5,71 & 3,90 & 1,56 & 23 & 116 \\
\hline & U3.150 & 2.270 & 2.135 & 7,27 & 5,71 & 3,90 & 1,56 & 29 & 146 \\
\hline \multirow[t]{4}{*}{ Ue $125 \times 50 \times 25 \times 2,38$} & Ue2.60 & 1.015 & 880 & 6,17 & 4,84 & 4,84 & 1,95 & 10 & 52 \\
\hline & Ue2.90 & 1.575 & 1.440 & 6,17 & 4,84 & 4,84 & 1,95 & 16 & 81 \\
\hline & Ue2.120 & 2.130 & 1.995 & 6,17 & 4,84 & 4,84 & 1,95 & 22 & 109 \\
\hline & Ue2.150 & 2.700 & 2.565 & 6,17 & 4,84 & 4,84 & 1,95 & 28 & 139 \\
\hline \multirow[t]{4}{*}{ Ue $125 \times 50 \times 25 \times 3,88$} & Ue3.60 & 985 & 850 & 9,68 & 7,60 & 4,75 & 1,87 & 10 & 53 \\
\hline & Ue3.90 & 1.530 & 1.395 & 9,68 & 7,60 & 4,75 & 1,87 & 16 & 82 \\
\hline & Ue3.120 & 2.070 & 1.935 & 9,68 & 7,60 & 4,75 & 1,87 & 22 & 111 \\
\hline & Ue3.150 & 2.615 & 2.480 & 9,68 & 7,60 & 4,75 & 1,87 & 28 & 140 \\
\hline PERFIL & SIGLA & $\begin{array}{c}\mathrm{L}_{\mathrm{r}} \\
(\mathrm{mm})\end{array}$ & $\begin{array}{l}L_{\text {perfil }} \\
(\mathrm{mm})\end{array}$ & $\begin{array}{c}\mathrm{A} \\
\left(\mathrm{cm}^{2}\right)\end{array}$ & $\begin{array}{l}\text { Peso } \\
\text { (kgf/m) }\end{array}$ & $\begin{array}{c}r_{1} \\
(\mathrm{~cm})\end{array}$ & $\begin{array}{c}r_{2} \\
(\mathrm{~cm})\end{array}$ & $\lambda_{1}$ & $\lambda_{2}$ \\
\hline \multirow{4}{*}{$\begin{array}{c}\mathrm{L} 60 \times 2,38 \\
\mathrm{r}_{2}=1,18 \mathrm{~cm}\end{array}$} & L2.60 & 615 & 480 & 2,76 & 2,17 & 2,42 & 1,18 & 13 & 52 \\
\hline & L2.90 & 970 & 835 & 2,76 & 2,17 & 2,42 & 1,18 & 20 & 82 \\
\hline & L2.120 & 1.330 & 1.195 & 2,76 & 2,17 & 2,42 & 1,18 & 28 & 113 \\
\hline & L2.150 & 1.685 & 1.550 & 2,76 & 2,17 & 2,42 & 1,18 & 35 & 143 \\
\hline PERFIL & SIGLA & $\begin{array}{c}L_{r} \\
(\mathrm{~mm})\end{array}$ & $\begin{array}{l}L_{\text {perfil }} \\
(\mathrm{mm}) \\
\end{array}$ & $\begin{array}{c}\mathrm{A} \\
\left(\mathrm{cm}^{2}\right)\end{array}$ & $\begin{array}{c}\text { Peso } \\
\text { (kgf/m) }\end{array}$ & $\begin{array}{c}r_{x} \\
(\mathrm{~cm})\end{array}$ & $\begin{array}{c}r_{y} \\
(\mathrm{~cm})\end{array}$ & $\lambda_{x}$ & $\lambda_{y}$ \\
\hline \multirow{4}{*}{$\begin{array}{c}2 \mathrm{~L} 60 \times 2,38 \\
\mathrm{r}_{2}=1,18 \mathrm{~cm} \\
\text { Chapa }=5 \mathrm{~mm} \\
\text { (rótula p/ flexão em "x") }\end{array}$} & 2L2.60-x & 1.045 & 910 & 5,53 & 4,34 & 1,90 & 2,66 & 55 & 20 \\
\hline & 2L2.90-x & 1.620 & 1.485 & 5,53 & 4,34 & 1,90 & 2,66 & 85 & 30 \\
\hline & 2L2.120-x & 2.190 & 2.055 & 5,53 & 4,34 & 1,90 & 2,66 & 115 & 41 \\
\hline & 2L2.150-x & 2.765 & 2.630 & 5,53 & 4,34 & 1,90 & 2,66 & 145 & 52 \\
\hline \multirow{4}{*}{$\begin{array}{c}2 \mathrm{~L} 60 \times 2,38 \\
\mathrm{r}_{2}=1,18 \mathrm{~cm} \\
\text { Chapa }=5 \mathrm{~mm} \\
\text { (rótula p/ flexão em "y") }\end{array}$} & 2L2.60-y & 1.490 & 1.355 & 5,53 & 4,34 & 1,90 & 2,66 & 39 & 56 \\
\hline & 2L2.90-y & 2.020 & 1.885 & 5,53 & 4,34 & 1,90 & 2,66 & 53 & 76 \\
\hline & 2L2.120-y & 2.550 & 2.415 & 5,53 & 4,34 & 1,90 & 2,66 & 67 & 96 \\
\hline & 2L2.150-y & 3.060 & 2.925 & 5,53 & 4,34 & 1,90 & 2,66 & 80 & 115 \\
\hline
\end{tabular}


Tabela 5.3 Barras curtas (stub columns) utilizadas no trabalho

\begin{tabular}{|c|c|c|c|c|c|c|c|c|}
\hline PERFIL & SIGLA & $\begin{array}{l}L_{\text {perfil }} \\
(\mathbf{m m})\end{array}$ & $\begin{array}{c}A \\
\left(\mathrm{~cm}^{2}\right)\end{array}$ & $\begin{array}{c}\text { Peso } \\
(\mathrm{kgf} / \mathrm{m})\end{array}$ & $\begin{array}{c}r_{x} \\
(\mathrm{~cm})\end{array}$ & $\begin{array}{c}r_{y} \\
(\mathrm{~cm})\end{array}$ & $\lambda_{x}$ & $\lambda_{y}$ \\
\hline U $100 \times 50 \times 2,38$ & U2.c & 300 & 4,57 & 3,59 & 3,97 & 1,58 & 4 & 9 \\
\hline U $100 \times 50 \times 3,88$ & U3.c & 300 & 7,27 & 5,71 & 3,90 & 1,56 & 4 & 10 \\
\hline Ue $125 \times 50 \times 25 \times 2,38$ & Ue2.c & 375 & 6,17 & 4,84 & 4,84 & 1,95 & 4 & 10 \\
\hline Ue $125 \times 50 \times 25 \times 3,88$ & Ue3.c & 375 & 9,68 & 7,60 & 4,75 & 1,87 & 4 & 10 \\
\hline PERFIL & SIGLA & $\begin{array}{l}L_{\text {perfil }} \\
(\mathrm{mm})\end{array}$ & $\begin{array}{c}A \\
\left(\mathrm{~cm}^{2}\right)\end{array}$ & $\begin{array}{c}\text { Peso } \\
\text { (kgf/m) }\end{array}$ & $\begin{array}{c}r_{1} \\
(\mathrm{~cm})\end{array}$ & $\begin{array}{c}r_{2} \\
(\mathrm{~cm})\end{array}$ & $\lambda_{1}$ & $\lambda_{2}$ \\
\hline L $60 \times 2,38$ & L2.C & 250 & 2,76 & 2,17 & 2,42 & 1,18 & 5 & 11 \\
\hline
\end{tabular}

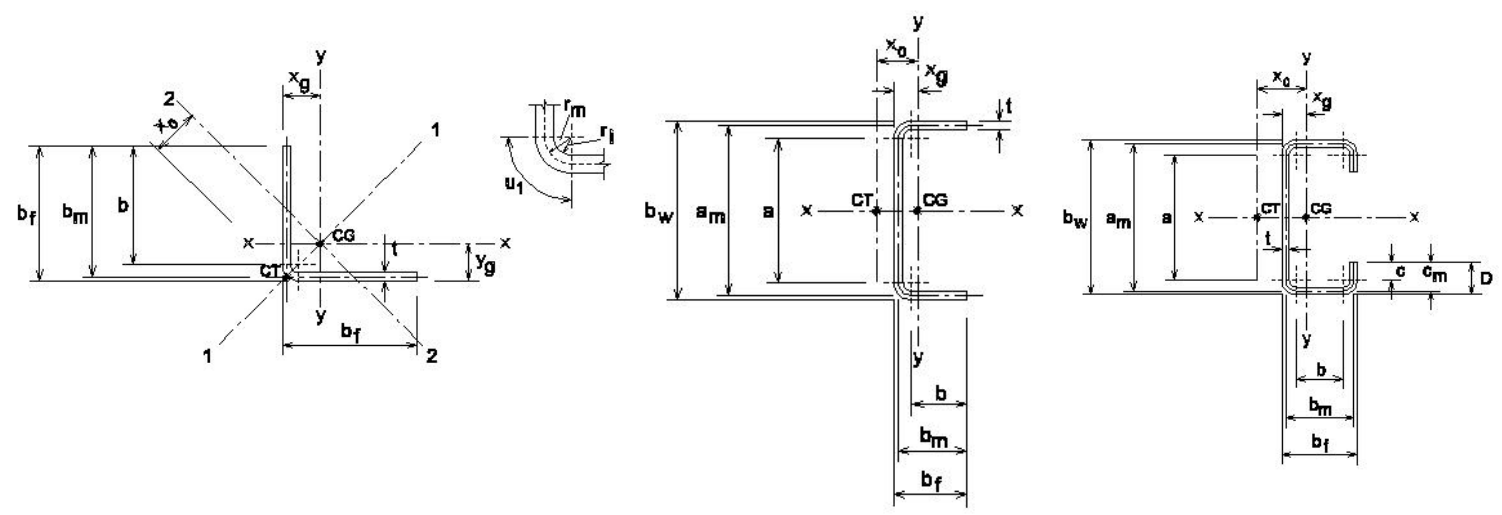

Figura 5.5 Eixos e a nomenclatura das dimensões da seção transversal dos perfis

Como observado na literatura e apresentado no item 7.1 mais adiante, tanto para o caso da cantoneira simples como para a dupla, os valores previstos pelas normas relativos à tensão elástica - que são utilizados para o cálculo da resistência das barras - de flambagem por torção e por flexo-torção são muito inferiores aos relativos à flambagem por flexão. Este fato despertou em alguns pesquisadores a idéia de que os procedimentos normativos poderiam ser muito conservadores para o caso das cantoneiras, mesmo porque alguns ensaios realizados haviam apresentado resultados diferente dos previstos por normas. Com isso, alguns trabalhos optaram para o cálculo da resistência das cantoneiras com adoção somente do valor da tensão de flambagem elástica por flexão, negligenciando a tensão de flambagem elástica por torção e por flexo-torção.

Avaliando-se essa idéia, neste trabalho a Tabela 5.6 apresenta o cálculo pela NBR 14762:2001 das mesmas cantoneiras simples e duplas apresentadas na Tabela 5.4, mas agora considerando-se no procedimento o menor valor da força normal de flambagem elástica como sempre o referente à flexão. 
Tabela 5.4 Cálculo das barras longas via NBR 14762:2001

\begin{tabular}{|c|c|c|c|c|c|c|c|c|}
\hline \multicolumn{6}{|c|}{ BARRAS LONGAS } & \multicolumn{3}{|c|}{$K_{x} \cdot L_{r}=K_{t} \cdot L_{r}=0,5 \cdot L_{r} ; K_{y} \cdot L_{r}=1,0 \cdot L_{r}$} \\
\hline PERFIL & $\begin{array}{c}\mathrm{L}_{\mathrm{r}} \\
(\mathrm{mm})\end{array}$ & $\begin{array}{l}\mathrm{L}_{\text {perfil }} \\
(\mathrm{mm})\end{array}$ & $\begin{array}{c}A \\
\left(\mathrm{~cm}^{2}\right)\end{array}$ & $\begin{array}{c}A_{\text {ef }} \\
\left(\mathrm{cm}^{2}\right)\end{array}$ & $\mathrm{A}_{\mathrm{ef}} / \mathrm{A}$ & $\begin{array}{c}\mathbf{N}_{\mathrm{ey}} \\
(\mathbf{k N})\end{array}$ & $\begin{array}{l}\mathbf{N}_{\text {ext }} \\
(\mathbf{k N})\end{array}$ & $\begin{array}{l}\mathbf{N}_{\mathbf{c}, \mathbf{R}} \\
(\mathbf{k N})\end{array}$ \\
\hline \multirow{4}{*}{ U $100 \times 50 \times 2,38$} & 850 & 715 & 4,57 & 3,92 & 0,86 & 319 & 774 & 108 \\
\hline & 1.320 & 1.185 & 4,57 & 4,24 & 0,93 & 132 & 334 & 77 \\
\hline & 1.800 & 1.665 & 4,57 & 4,51 & 0,99 & 71 & 190 & 51 \\
\hline & 2.270 & 2.135 & 4,57 & 4,57 & 1,00 & 45 & 128 & 35 \\
\hline \multirow{4}{*}{ U $100 \times 50 \times 3,88$} & 850 & 715 & 7,27 & 7,27 & 1,00 & 493 & 1.268 & 158 \\
\hline & 1.320 & 1.185 & 7,27 & 7,27 & 1,00 & 204 & 583 & 112 \\
\hline & 1.800 & 1.665 & 7,27 & 7,27 & 1,00 & 110 & 359 & 75 \\
\hline & 2.270 & 2.135 & 7,27 & 7,27 & 1,00 & 69 & 261 & 52 \\
\hline \multirow{4}{*}{ Ue $125 \times 50 \times 25 \times 2,38$} & 1.015 & 880 & 6,17 & 5,62 & 0,91 & 461 & 1.605 & 168 \\
\hline & 1.575 & 1.440 & 6,17 & 5,92 & 0,96 & 191 & 677 & 122 \\
\hline & 2.130 & 1.995 & 6,17 & 6,17 & 1,00 & 105 & 378 & 80 \\
\hline & 2.700 & 2.565 & 6,17 & 6,17 & 1,00 & 65 & 242 & 54 \\
\hline \multirow{4}{*}{ Ue $125 \times 50 \times 25 \times 3,88$} & 985 & 850 & 9,68 & 9,68 & 1,00 & 708 & 2.653 & 229 \\
\hline & 1.530 & 1.395 & 9,68 & 9,68 & 1,00 & 294 & 1.145 & 171 \\
\hline & 2.070 & 1.935 & 9,68 & 9,68 & 1,00 & 160 & 660 & 117 \\
\hline & 2.615 & 2.480 & 9,68 & 9,68 & 1,00 & 100 & 442 & 80 \\
\hline & & & & & & \multicolumn{3}{|c|}{$\mathrm{K}_{1} \cdot \mathrm{L}_{\mathrm{r}}=\mathrm{K}_{\mathrm{t}} \cdot \mathrm{L}_{\mathrm{r}}=0,5 \cdot \mathrm{L}_{r} ; \mathrm{K}_{2} \cdot \mathrm{L}_{\mathrm{r}}=1,0 \cdot \mathrm{L}_{\mathrm{r}}$} \\
\hline PERFIL & $\begin{array}{c}\mathrm{L}_{\mathrm{r}} \\
(\mathrm{mm})\end{array}$ & \begin{tabular}{|l|}
$L_{\text {perfil }}$ \\
$(\mathrm{mm})$ \\
\end{tabular} & $\begin{array}{c}\mathrm{A} \\
\left(\mathrm{cm}^{2}\right)\end{array}$ & $\begin{array}{c}A_{\text {ef }} \\
\left(\mathrm{cm}^{2}\right)\end{array}$ & $\mathbf{A}_{\text {ef }} / \mathbf{A}$ & $\begin{array}{c}\mathbf{N}_{\mathrm{e} 2} \\
(\mathbf{k N})\end{array}$ & $\begin{array}{l}\mathbf{N}_{\mathrm{e} 1 \mathrm{t}} \\
(\mathrm{kN})\end{array}$ & $\begin{array}{l}\mathbf{N}_{\mathrm{c}, \mathrm{R}} \\
(\mathbf{k N})\end{array}$ \\
\hline \multirow{4}{*}{$\begin{array}{c}L 60 \times 2,38 \\
r_{2}=1,18 \mathrm{~cm}\end{array}$} & 615 & 480 & 2,76 & 2,41 & 0,87 & 206 & 38 & 29 \\
\hline & 970 & 835 & 2,76 & 2,44 & 0,88 & 83 & 36 & 28 \\
\hline & 1.330 & 1.195 & 2,76 & 2,46 & 0,89 & 44 & 35 & 28 \\
\hline & 1.685 & 1.550 & 2,76 & 2,66 & 0,96 & 27 & 35 & 21 \\
\hline & & & & & & \multicolumn{3}{|c|}{$\mathrm{K}_{\mathrm{x}} \cdot \mathrm{L}_{\mathrm{r}}=1,0 \cdot \mathrm{L}_{\mathrm{r}} ; \mathrm{K}_{\mathrm{y}} \cdot \mathrm{L}_{\mathrm{r}}=\mathrm{K}_{\mathrm{t}} \cdot \mathrm{L}_{\mathrm{r}}=0,5 \cdot \mathrm{L}_{\mathrm{r}}$} \\
\hline PERFIL & $\begin{array}{c}\mathrm{L}_{\mathrm{r}} \\
(\mathrm{mm})\end{array}$ & $\begin{array}{l}\mathrm{L}_{\text {perfil }} \\
(\mathrm{mm})\end{array}$ & $\begin{array}{c}\mathrm{A} \\
\left(\mathrm{cm}^{2}\right)\end{array}$ & $\begin{array}{c}A_{\text {ef }} \\
\left(\mathrm{cm}^{2}\right)\end{array}$ & $\mathbf{A}_{\text {ef }} / \mathbf{A}$ & $\begin{array}{c}\mathbf{N}_{\text {ex }} \\
(\mathbf{k N})\end{array}$ & $\begin{array}{l}\mathbf{N}_{\text {eyt }} \\
(\mathbf{k N})\end{array}$ & $\begin{array}{l}\mathbf{N}_{\mathrm{c}, \mathrm{R}} \\
(\mathbf{k N})\end{array}$ \\
\hline \multirow{4}{*}{$\begin{array}{c}2 \mathrm{~L} 60 \times 2,38 \\
\mathrm{r}_{2}=1,18 \mathrm{~cm} \\
\text { Chapa }=5 \mathrm{~mm} \\
\text { (rótula p/ flexão em "x") }\end{array}$} & 1.045 & 910 & 5,53 & 5,04 & 0,91 & 370 & 63 & 51 \\
\hline & 1.620 & 1.485 & 5,53 & 5,05 & 0,91 & 154 & 63 & 51 \\
\hline & 2.190 & 2.055 & 5,53 & 5,06 & 0,92 & 84 & 63 & 51 \\
\hline & 2.765 & 2.630 & 5,53 & 5,37 & 0,97 & 53 & 62 & 41 \\
\hline & & & & & & \multicolumn{3}{|c|}{$K_{x} \cdot L_{r}=K_{t} \cdot L_{r}=0,5 \cdot L_{r} ; K_{y} \cdot L_{r}=1,0 \cdot L_{r}$} \\
\hline PERFIL & $\begin{array}{c}\mathrm{L}_{\mathrm{r}} \\
(\mathrm{mm})\end{array}$ & $\begin{array}{l}L_{\text {perfil }} \\
(\mathrm{mm}) \\
\end{array}$ & $\begin{array}{c}A \\
\left(\mathrm{~cm}^{2}\right)\end{array}$ & $\begin{array}{c}A_{\text {ef }} \\
\left(\mathrm{cm}^{2}\right)\end{array}$ & $\mathbf{A}_{\mathrm{ef}} / \mathbf{A}$ & $\begin{array}{c}\mathbf{N}_{\text {ex }} \\
(\mathbf{k N})\end{array}$ & $\begin{array}{l}\mathbf{N}_{\text {eyt }} \\
(k N)\end{array}$ & $\begin{array}{l}\mathbf{N}_{c, \mathbf{R}} \\
(\mathrm{kN})\end{array}$ \\
\hline \multirow{4}{*}{$\begin{array}{c}2 \mathrm{~L} 60 \times 2,38 \\
\mathrm{r}_{2}=1,18 \mathrm{~cm} \\
\text { Chapa }=5 \mathrm{~mm} \\
\text { (rótula } \mathrm{p} / \text { flexão em "y") }\end{array}$} & 1.490 & 1.355 & 5,53 & 5,08 & 0,92 & 728 & 62 & 50 \\
\hline & 2.020 & 1.885 & 5,53 & 5,13 & 0,93 & 396 & 59 & 48 \\
\hline & 2.550 & 2.415 & 5,53 & 5,21 & 0,94 & 249 & 56 & 46 \\
\hline & 3.060 & 2.925 & 5,53 & 5,33 & 0,96 & 173 & 51 & 42 \\
\hline
\end{tabular}


Tabela 5.5 Cálculo das barras curtas (stub columns) via NBR 14762:2001

\begin{tabular}{|c|c|c|c|c|c|c|c|}
\hline \multicolumn{5}{|c|}{ BARRAS CURTAS (STUB COLUMNS) } & \multicolumn{3}{|c|}{$\begin{array}{l}\mathrm{K}_{\mathrm{x}} \cdot \mathrm{L}_{\text {perfil }}=0,5 \cdot \mathrm{L}_{\text {perfil }} \\
\mathrm{K}_{\mathrm{v}} \cdot \mathrm{L}_{\text {perfil }}=0,5 \cdot \mathrm{L}_{\text {perfil }} \\
\mathrm{K}_{\mathrm{t} \cdot \mathrm{L}_{\text {perfil }}}=0,5 \cdot \mathrm{L}_{\text {perfil }}\end{array}$} \\
\hline PERFIL & $\begin{array}{l}L_{\text {perfil }} \\
(\mathrm{mm})\end{array}$ & $\begin{array}{c}A \\
\left(\mathrm{~cm}^{2}\right)\end{array}$ & $\begin{array}{c}A_{e f} \\
\left(\mathrm{~cm}^{2}\right)\end{array}$ & $A_{\text {ef }} / A$ & $\begin{array}{c}\mathbf{N}_{\text {ey }} \\
(\mathbf{k N})\end{array}$ & $\begin{array}{l}\mathbf{N}_{\text {ext }} \\
(\mathbf{k N})\end{array}$ & $\begin{array}{l}\mathbf{N}_{c, R} \\
(\mathbf{k N})\end{array}$ \\
\hline U $100 \times 50 \times 2,38$ & 300 & 4,57 & 3,50 & 0,77 & 10.248 & 6.056 & 132 \\
\hline U $100 \times 50 \times 3,88$ & 300 & 7,27 & 7,27 & 1,00 & 15.824 & 9.482 & 209 \\
\hline Ue $125 \times 50 \times 25 \times 2,38$ & 375 & 6,17 & 5,42 & 0,88 & 13.496 & 11.647 & 204 \\
\hline \multirow[t]{2}{*}{ Ue $125 \times 50 \times 25 \times 3,88$} & 375 & 9,68 & 9,68 & 1,00 & 19.546 & 17.848 & 279 \\
\hline & & & & & \multicolumn{3}{|c|}{$\begin{array}{l}\mathrm{K}_{1} \cdot \mathrm{L}_{\text {perfil }}=0,5 \cdot \mathrm{L}_{\text {perfil }} \\
\mathrm{K}_{2} \cdot \mathrm{L}_{\text {perfil }}=0,5 \cdot \mathrm{L}_{\text {perfil }} \\
\mathrm{K}_{\mathrm{t}} \cdot \mathrm{L}_{\text {perfil }}=0,5 \cdot \mathrm{L}_{\text {perfil }}\end{array}$} \\
\hline PERFIL & $\begin{array}{l}L_{\text {perfil }} \\
(\mathrm{mm})\end{array}$ & $\begin{array}{c}A \\
\left(\mathrm{~cm}^{2}\right)\end{array}$ & $\begin{array}{c}A_{e f} \\
\left(\mathrm{~cm}^{2}\right)\end{array}$ & $A_{\text {ef }} / A$ & $\begin{array}{c}\mathbf{N}_{\mathrm{e} 2} \\
(\mathrm{kN})\end{array}$ & $\begin{array}{l}\mathbf{N}_{\text {e1t }} \\
(\mathrm{kN})\end{array}$ & $\begin{array}{l}\mathbf{N}_{\mathrm{c}, \mathrm{R}} \\
(\mathrm{kN})\end{array}$ \\
\hline L $60 \times 2,38$ & 250 & 2,76 & 1,56 & 0,57 & 4.985 & 52 & 58 \\
\hline \multicolumn{8}{|c|}{$\begin{array}{l}\text { Para os perfis Ue a força normal resistente devido ao modo distorcional foi ligeiramente inferior à } \\
\text { aqui apresentada ( } 196 \mathrm{kN} \text { para } \mathrm{t}=2,38 \mathrm{~mm} \text { e } 260 \mathrm{kN} \text { para } \mathrm{t}=3,88 \mathrm{~mm} \text { ). Entretanto, esse não foi o } \\
\text { valor adotado, pois o comprimento das barras é muito menor que o característico da meia-onda do } \\
\text { modo distorcional, não sendo então correta a adoção de tais valores. }\end{array}$} \\
\hline
\end{tabular}

Entretanto, é importante que se deixe claro que os ensaios de cantoneiras realizados neste presente trabalho mostraram que o modo de flexo-torção (denominado para esses casos de local/torsional, como será melhor explicado no item 7.1) realmente comandou, sendo que entende-se então ser incorreta essa idéia de consideração do menor valor da força normal de flambagem elástica como sempre o referente à flexão, negligenciando-se o modo de flexotorção.

Comparando-se a Tabela $5.4 \mathrm{com}$ a Tabela 5.6, pode-se perceber que para as barras com os dois menores comprimentos para cada tipo de seção, o cálculo da resistência somente se considerando a flexão conduziu a valores de resistência 1,9 a 2,2 vezes superiores. Para os dois maiores comprimentos, por outro lado, a resistência praticamente se iguala nas duas tabelas, provavelmente porque nestes casos o modo de flexão começa a comandar (ou fica próximo) a resistência destas barras. Entretanto, isto não vale para o caso da rótula para flexão em y da dupla cantoneira, que apresenta diferença significativa de resistências entre as duas tabelas para todos os quatro comprimentos de barra, e isto é explicado pois foi verificado na Tabela 5.4 que em todos esses 4 casos o modo que comanda a resistência é o de flexo-torção. 
Tabela 5.6 Cálculo das barras longas via NBR 14762:2001 (somente modo de flexão)

\begin{tabular}{|c|c|c|c|c|c|c|c|c|}
\hline \multicolumn{6}{|c|}{ BARRAS LONGAS } & \multicolumn{3}{|c|}{$\mathrm{K}_{1} \cdot \mathrm{L}_{\mathrm{r}}=\mathrm{K}_{\mathrm{t}} \cdot \mathrm{L}_{\mathrm{r}}=0,5 \cdot \mathrm{L}_{\mathrm{r}} ; \mathrm{K}_{2} \cdot \mathrm{L}_{\mathrm{r}}=1,0 \cdot \mathrm{L}_{\mathrm{r}}$} \\
\hline PERFIL & $\begin{array}{c}\mathrm{L}_{\mathrm{r}} \\
(\mathrm{mm})\end{array}$ & $\begin{array}{l}\text { Lperfil } \\
\text { (mm) }\end{array}$ & $\underset{\left(\mathrm{cm}^{2}\right)}{\mathrm{A}}$ & $\begin{array}{c}A_{e f} \\
\left(\mathrm{~cm}^{2}\right)\end{array}$ & $\begin{array}{c}\mathbf{A}_{\mathrm{ef}} I \\
\mathrm{~A}\end{array}$ & $\begin{array}{c}\mathbf{N}_{\mathrm{e} 2} \\
(\mathbf{k N})\end{array}$ & $\begin{array}{l}\mathbf{N}_{\mathrm{e} 1 \mathrm{t}} \\
(\mathbf{k N})\end{array}$ & $\begin{array}{l}\mathbf{N}_{c, \mathbf{R}} \\
(\mathbf{k N})\end{array}$ \\
\hline \multirow{4}{*}{$\begin{array}{c}L 60 \times 2,38 \\
r_{2}=1,18 \mathrm{~cm}\end{array}$} & 615 & 480 & 2,76 & 1,76 & 0,64 & 206 & 38 & 53 \\
\hline & 970 & 835 & 2,76 & 2,05 & 0,74 & 83 & 36 & 43 \\
\hline & 1.330 & 1.195 & 2,76 & 2,38 & 0,86 & 44 & 35 & 30 \\
\hline & 1.685 & 1.550 & 2,76 & 2,66 & 0,96 & 27 & 35 & 21 \\
\hline & & & & & & \multicolumn{3}{|c|}{$K_{x} \cdot L_{r}=1,0 \cdot L_{r} ; K_{y} \cdot L_{r}=K_{t} \cdot L_{r}=0,5 \cdot L_{r}$} \\
\hline PERFIL & $\frac{\mathrm{L}_{\mathrm{r}}}{(\mathrm{mm})}$ & $\begin{array}{l}\text { Lperfil } \\
\text { (mm) }\end{array}$ & $\frac{A}{\left(\mathrm{~cm}^{2}\right)}$ & $\begin{array}{c}A_{\text {ef }} \\
\left(\mathrm{cm}^{2}\right)\end{array}$ & $\frac{A_{\text {ef }} I}{A}$ & $\begin{array}{l}\mathbf{N}_{\text {ex }} \\
(\mathbf{k N})\end{array}$ & $\begin{array}{l}\mathbf{N}_{\text {eyt }} \\
(\mathbf{k N})\end{array}$ & $\begin{array}{l}\mathbf{N}_{\mathrm{c}, \mathbf{R}} \\
(\mathbf{k N})\end{array}$ \\
\hline \multirow{4}{*}{$\begin{array}{c}2 \mathrm{~L} 60 \times 2,38 \\
\mathrm{r}_{2}=1,18 \mathrm{~cm} \\
\text { Chapa }=5 \mathrm{~mm} \\
\text { (rótula } \mathrm{p} / \text { flexão em "x") }\end{array}$} & 1.045 & 910 & 5,53 & 3,57 & 0,65 & 370 & 63 & 105 \\
\hline & 1.620 & 1.485 & 5,53 & 4,16 & 0,75 & 154 & 63 & 84 \\
\hline & 2.190 & 2.055 & 5,53 & 4,81 & 0,87 & 84 & 63 & 59 \\
\hline & 2.765 & 2.630 & 5,53 & 5,37 & 0,97 & 53 & 62 & 41 \\
\hline & & & & & & \multicolumn{3}{|c|}{$\mathrm{K}_{\mathrm{x}} \cdot \mathrm{L}_{\mathrm{r}}=\mathrm{K}_{\mathrm{t}} \cdot \mathrm{L}_{\mathrm{r}}=0,5 \cdot \mathrm{L}_{r} ; \mathrm{K}_{\mathrm{y}} \cdot \mathrm{L}_{\mathrm{r}}=1,0 \cdot \mathrm{L}_{\mathrm{r}}$} \\
\hline PERFIL & $\begin{array}{c}\mathrm{L}_{\mathrm{r}} \\
(\mathrm{mm})\end{array}$ & $\begin{array}{c}\text { Lperfil } \\
\text { (mm) }\end{array}$ & $\begin{array}{c}\mathrm{A} \\
\left(\mathrm{cm}^{2}\right)\end{array}$ & $\begin{array}{c}A_{\text {ef }} \\
\left(\mathrm{cm}^{2}\right)\end{array}$ & $\begin{array}{c}A_{\text {ef }} / \\
A\end{array}$ & $\begin{array}{c}\mathbf{N}_{\mathrm{ex}} \\
(\mathbf{k N})\end{array}$ & $\begin{array}{l}\mathbf{N}_{\text {eyt }} \\
(\mathbf{k N})\end{array}$ & $\begin{array}{l}\mathbf{N}_{c, \mathbf{R}} \\
(\mathbf{k N})\end{array}$ \\
\hline \multirow{4}{*}{$\begin{array}{c}2 \mathrm{~L} 60 \times 2,38 \\
\mathrm{r}_{2}=1,18 \mathrm{~cm} \\
\text { Chapa }=5 \mathrm{~mm} \\
\text { (rótula p/ flexão em "y") }\end{array}$} & 1.490 & 1.355 & 5,53 & 3,35 & 0,61 & 728 & 62 & 112 \\
\hline & 2.020 & 1.885 & 5,53 & 3,54 & 0,64 & 396 & 59 & 106 \\
\hline & 2.550 & 2.415 & 5,53 & 3,79 & 0,69 & 249 & 56 & 98 \\
\hline & 3.060 & 2.925 & 5,53 & 4,06 & 0,73 & 173 & 51 & 88 \\
\hline
\end{tabular}

\subsection{Procedimento da análise experimental}

A análise experimental consistiu de 3 (três) etapas, realizadas no Laboratório de Estruturas da Escola de Engenharia de São Carlos da Universidade de São Paulo. As etapas foram as seguintes:

(ETAPA 1): Medição de imperfeições geométricas iniciais (12 barras da Etapa 3) e verificação de tolerâncias conforme NBR 6355:2003 (5 barras da Etapa 3);

(ETAPA 2): Ensaios de compressão centrada em barras curtas, i.e., stub columns (15 ensaios);

(ETAPA 3): Ensaios de compressão centrada em barras longas (28 ensaios); 
Vale ressaltar que para as cantoneiras duplas foram colocadas presilhas, respeitando o espaçamento máximo sugerido pela NBR 14762:2001, como apresentado na Tabela 5.7. As fotos ilustrando essas presilhas podem ser vistas no apêndice.

Tabela 5.7 Espaçamento presilhas: cantoneiras duplas

\begin{tabular}{|c|c|c|c|c|}
\hline PERFIL & $\begin{array}{l}\mathrm{L}_{\text {perfil }} \\
(\mathrm{mm})\end{array}$ & $\begin{array}{c}l_{1} \max \\
\text { NBR 14762:2001 } \\
(\mathrm{mm}) \\
\end{array}$ & $\begin{array}{c}\mathrm{L}_{\text {perfil }} / 3 \\
(\mathrm{~mm}) \\
2 \text { presilhas } \\
\end{array}$ & $\begin{array}{c}\mathrm{L}_{\text {perfil }} / 4 \\
(\mathrm{~mm}) \\
3 \text { presilhas } \\
\end{array}$ \\
\hline \multirow{4}{*}{$\begin{array}{c}2 \mathrm{~L} 60 \times 2,38 \\
\text { (rótula p/ flexão em "x") }\end{array}$} & 910 & 326 & 303 & - \\
\hline & 1.485 & 505 & 495 & - \\
\hline & 2.055 & 682 & 685 & - \\
\hline & 2.630 & 861 & 877 & - \\
\hline \multirow{4}{*}{$\begin{array}{c}2 \mathrm{~L} 60 \times 2,38 \\
\text { (rótula p/ flexão em "y") }\end{array}$} & 1.355 & 334 & - & 339 \\
\hline & 1.885 & 453 & - & 471 \\
\hline & 2.415 & 572 & - & 604 \\
\hline & 2.925 & 687 & - & 731 \\
\hline
\end{tabular}

\subsection{Resultados da análise experimental}

\subsubsection{Etapa 1}

\subsubsection{Imperfeições geométricas iniciais}

As imperfeições geométricas medidas nas barras são apresentadas a seguir. Foram medidas para os dois maiores comprimentos de cada espessura de cada tipo de perfil a serem ensaiados, como ilustrado da Figura 5.6 a Figura 5.9. A Figura 5.10 ilustra os pontos da seção transversal onde tais medidas foram lidas.

Para tal procedimento foi utilizada uma bancada com eixo retificado (Figura 5.9) construída para o doutorado de JAVARONI (2003), como ilustrado na Figura 5.8 - em cujo eixo deslizava um transdutor de deslocamento com curso de 50mm (Figura 5.6).

As barras foram divididas em dez (10) partes ao longo do comprimento para a realização das medições, como ilustrado, por exemplo, na Tabela 5.8, sendo que os valores medidos pelo transdutor eram lidos em um indicador portátil (Figura 5.7).

Vale lembrar que todas as barras foram niveladas antes de se efetuar as leituras. Além disso, as barras foram posicionadas de modo que as duas extremidades estivessem igualmente afastadas do eixo retificado, constituindo assim um segmento de reta para referência das medidas. 
O objetivo da medição de imperfeições geométricas iniciais foi verificar se as barras atendiam às tolerâncias da norma brasileira de padronização de perfis NBR 6355:2003, pois as barras foram medidas do modo como foram recebidas, isto é, as chapas de topo ainda não haviam sido soldadas nas extremidades, fato este que pode alterar o panorama de imperfeições geométricas. Para se ter uma idéia mais correta das imperfeições geométricas iniciais - e utilizá-las como base para inserção nos modelos numéricos - é interessante que tal medição seja feita após a soldagem das chapas de topo nas extremidades das barras, se possível efetuando-se as leituras na própia máquina de ensaio momentos antes do ensaio.

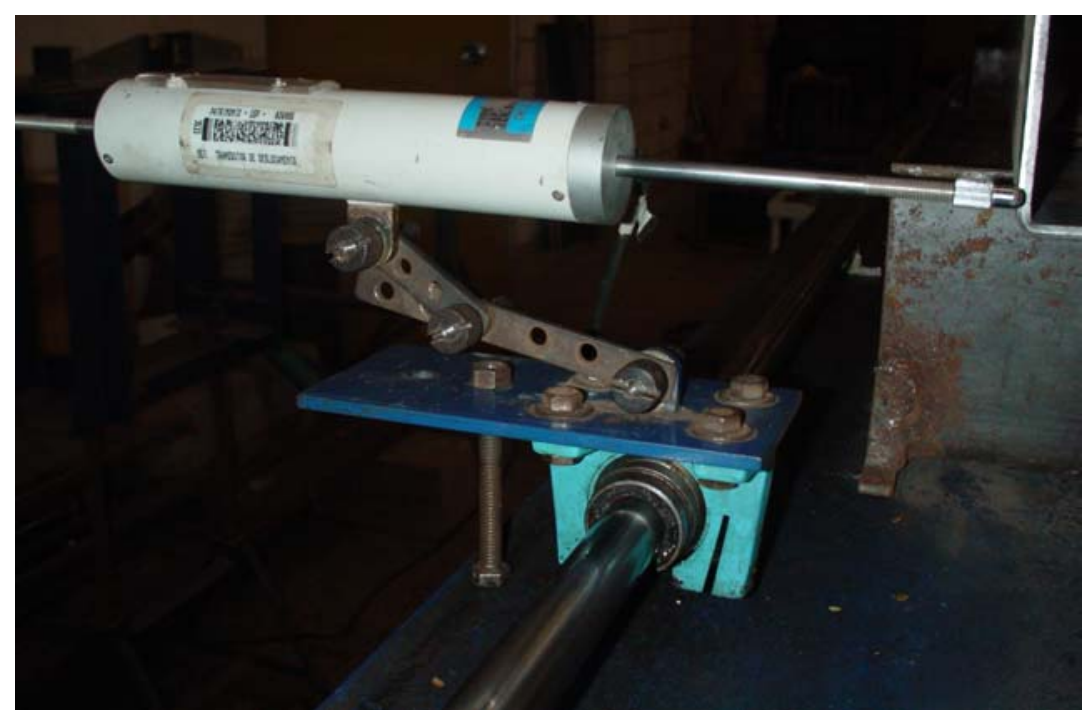

Figura 5.6 Transdutor de deslocamento: medição de imperfeições geométricas iniciais

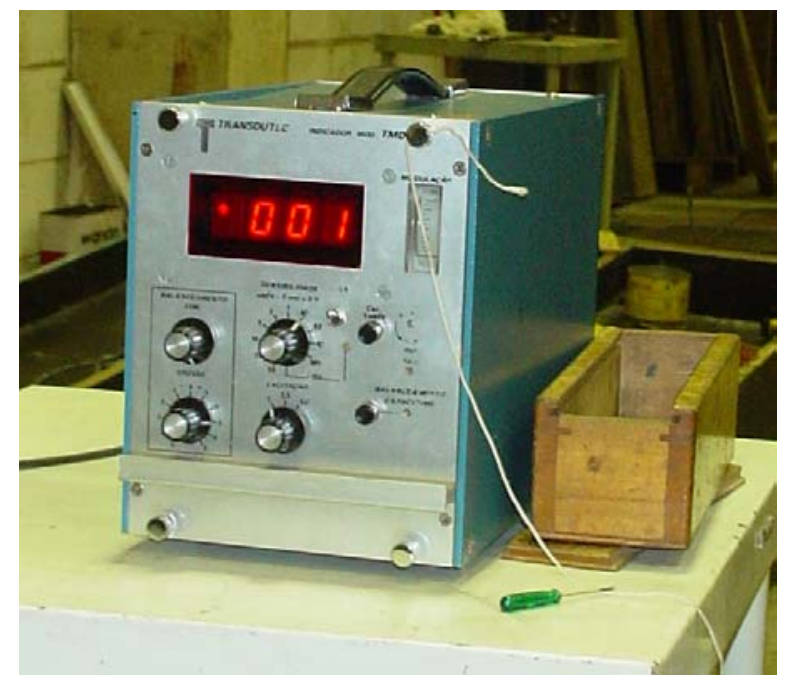

Figura 5.7 Indicador portátil interligado ao transdutor de deslocamento 


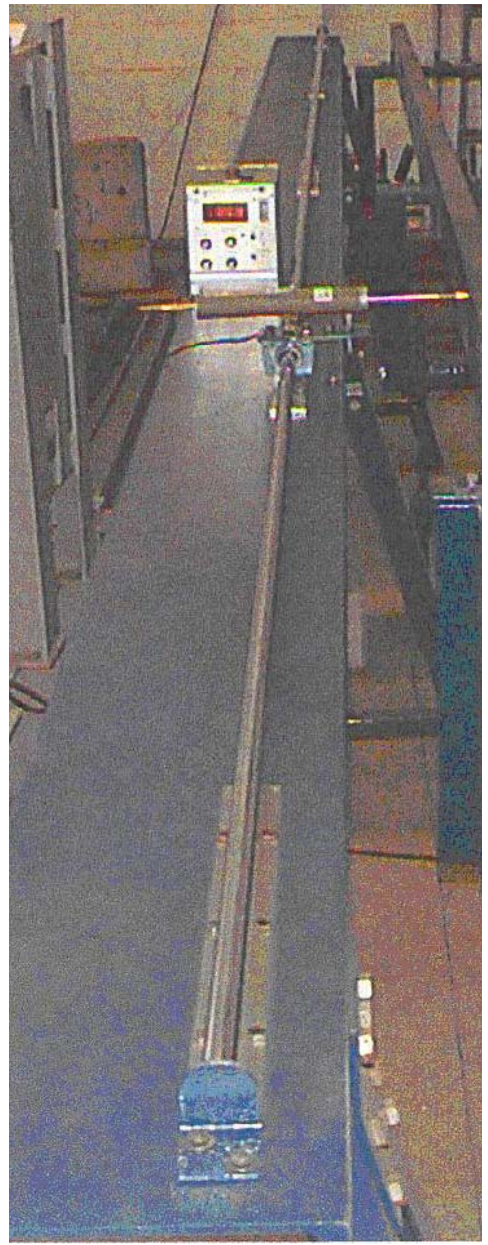

Figura 5.8 Dispositivo para leitura das imperfeições geométricas longitudinais [JAVARONI (2003)]

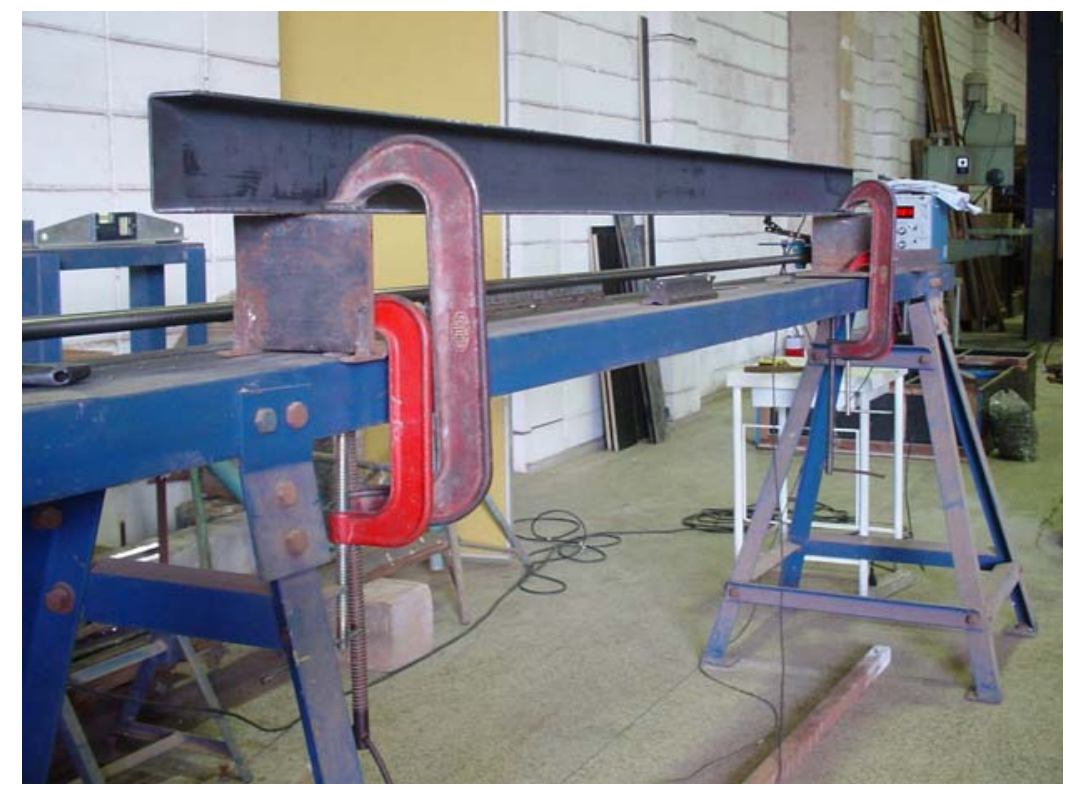

Figura 5.9 Perfil U posicionado na bancada para medição das imperfeições geométricas 


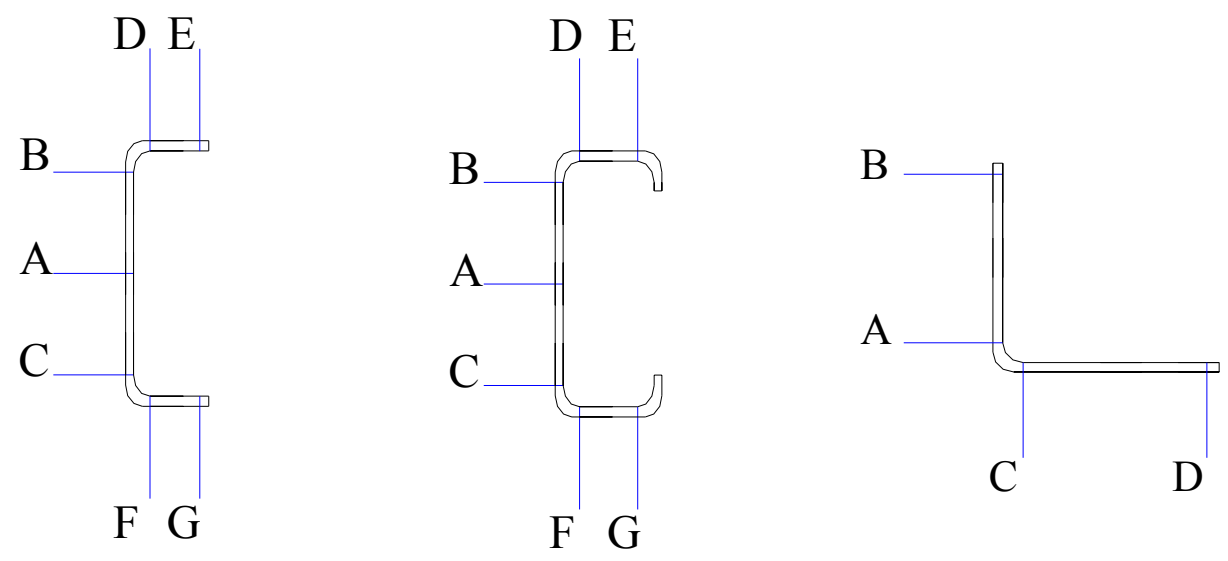

Figura 5.10 Pontos medição imperfeições geométricas iniciais: U, Ue, cantoneira

Como exemplo, a Tabela 5.8 contém os valores das imperfeições geométricas iniciais para o perfil $U 100 \times 50 \times 2,38 \mathrm{~mm}(\mathrm{~L}=1.665 \mathrm{~mm})$, e a ilustração destes valores por meio de um gráfico pode ser visualisada na Figura 5.11. As tabelas e figuras para todas as barras encontram-se no apêndice, onde se pode notar que em nenhuma das barras foi ultrapassada a tolerância de flecha (L / 500) da NBR 6355:2003. Além disso, constatou-se que este dispositivo utilizado para as medições mostrou-se adequado ao fim proposto.

Outra observação importante é que os valores de deslocamentos máximos apresentados tanto na Figura 5.11 como nas figuras similares para as demais barras apresentadas no apêndice são referentes ao deslocamento máximo de qualquer um dos pontos medidos da seção. Esses deslocamentos máximos, por sua vez, podem resultar da superposição de deslocamentos oriundos da configuração deformada do eixo da barra (global), da ondulação dos elementos (chapas) e distorção da seção transversal. Com isso, se a intenção for, por exemplo, saber qual a máxima imperfeição global medida, deve-se tentar descartar os deslocamentos lidos referentes aos modos localizados. Uma maneira é fazer a leitura desse deslocamento máximo somente nos pontos referentes aos cantos da seção transversal, que por serem partes mais rígidas da seção teoricamente sofrem menos influência de deslocamentos associados aos modos localizados.

Ainda quanto às imperfeições geométricas iniciais medidas, é importante que se diga que foi observada uma grande variação nas leituras. Por exemplo, para as cantoneiras, as medições deste trabalho indicaram valores entre $L / 2.400$ e $L / 1.650$, enquanto que outros valores foram apresentados na revisão bibliográfica. Tal fato conduziu à proposição de uma estratégia para a inserção destas nos modelos numéricos, a qual será explicada no capítulo 6 . 
Tabela 5.8 Valores das imperfeições iniciais obtidos (mm)

\begin{tabular}{|c|c|c|c|c|c|c|c|c|}
\hline Perfil & \multirow{2}{*}{$\begin{array}{c}\text { Ordenada ao longo } \\
\text { da barra } \\
(\mathrm{mm})\end{array}$} & \multicolumn{7}{|c|}{ Posição na seção transversal - vide Figura 5.11} \\
\hline \multirow{12}{*}{$\begin{array}{l}U 100 \times 50 \times 2,38 \\
L=1.665 \mathrm{~mm}\end{array}$} & & $\begin{array}{c}\mathrm{A} \\
(\mathrm{mm})\end{array}$ & $\begin{array}{c}\mathrm{B} \\
(\mathrm{mm})\end{array}$ & $\begin{array}{c}\mathrm{C} \\
(\mathrm{mm})\end{array}$ & $\begin{array}{c}\mathrm{D} \\
(\mathrm{mm})\end{array}$ & $\begin{array}{c}\mathrm{E} \\
(\mathrm{mm})\end{array}$ & $\begin{array}{c}\mathrm{F} \\
(\mathrm{mm})\end{array}$ & $\begin{array}{c}\mathrm{G} \\
(\mathrm{mm})\end{array}$ \\
\hline & 0 & 0,0 & 0,0 & 0,0 & 0,0 & 0,0 & 0,0 & 0,0 \\
\hline & 167 & $-0,4$ & $-0,6$ & $-0,5$ & 0,0 & $-0,2$ & 0,0 & 0,0 \\
\hline & 333 & $-0,6$ & $-0,8$ & $-0,7$ & 0,2 & 0,3 & 0,0 & 0,0 \\
\hline & 500 & $-0,2$ & $-0,3$ & $-0,4$ & 0,4 & 0,7 & 0,1 & 0,1 \\
\hline & 666 & $-0,2$ & $-0,3$ & $-0,4$ & 0,1 & 0,2 & 0,0 & $-0,3$ \\
\hline & 833 & $-0,1$ & $-0,2$ & $-0,3$ & 0,0 & 0,0 & $-0,2$ & $-0,4$ \\
\hline & 999 & 0,0 & $-0,2$ & $-0,3$ & 0,0 & $-0,3$ & 0,0 & 0,0 \\
\hline & 1166 & 0,0 & 0,0 & $-0,3$ & 0,1 & 0,0 & 0,1 & 0,0 \\
\hline & 1332 & 0,0 & 0,0 & $-0,3$ & 0,2 & 0,2 & 0,1 & 0,2 \\
\hline & 1499 & 0,1 & 0,1 & 0,0 & 0,2 & 0,2 & 0,1 & 0,1 \\
\hline & 1665 & 0,0 & 0,0 & 0,0 & 0,0 & 0,0 & 0,0 & 0,0 \\
\hline
\end{tabular}

U $100 \times 50 \times 2,38(L=1.665 \mathrm{~mm})$

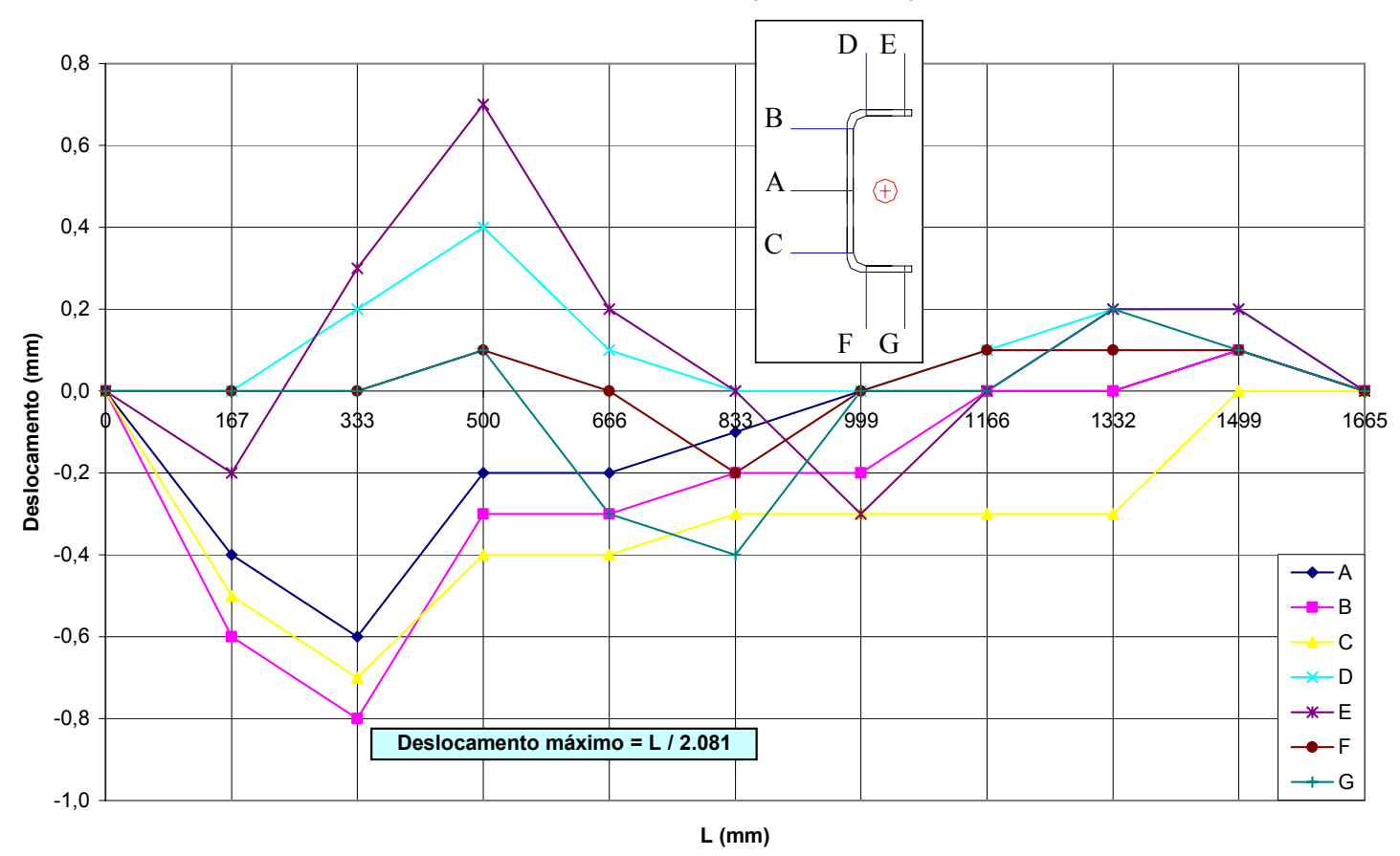

Figura 5.11 Imperfeição inicial geométrica - perfil U $100 \times 50$ × 2,38mm ( $\mathrm{L}=1.665 \mathrm{~mm})$

\subsubsection{Análise de conformidade segundo a NBR 6355:2003}

As tolerâncias exigidas pela norma de padronização de perfis de aço formados a frio NBR 6355:2003, ilustradas na sequência da Figura 5.12 até a Figura 5.15, são apresentadas a seguir. As imperfeições foram medidas para o maior comprimento de cada espessura de cada tipo de perfil a ser ensaiado, nas seções transversais das extremidades, próximas aos apoios (quarto do vão), e na seção transversal no meio do vão, utilizando-se paquímetro digital e trena 
metálica. Na sequência, a Tabela 5.9 ilustra os valores obtidos. Na maioria dos casos os valores da norma foram respeitados.
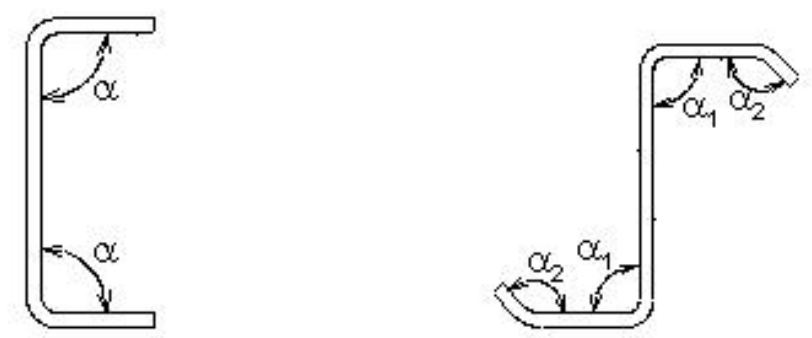

Figura 5.12 Ângulo formado por elementos adjacentes
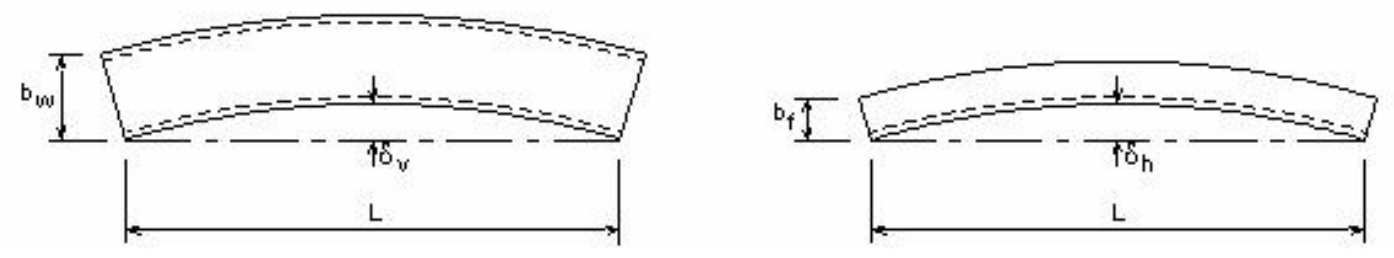

Figura 5.13 Flecha do perfil

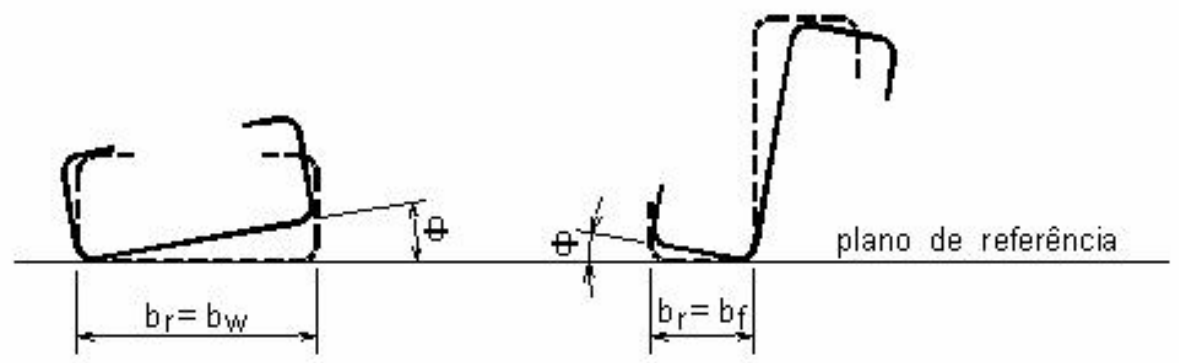

Figura 5.14 Torção do perfil

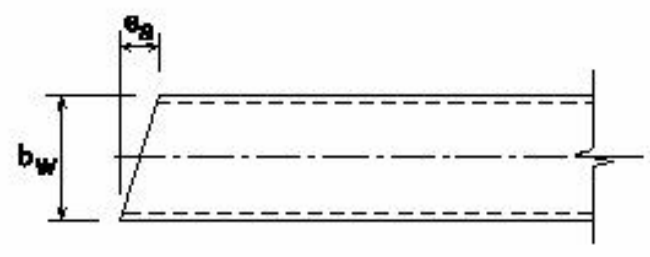

Plano da alma

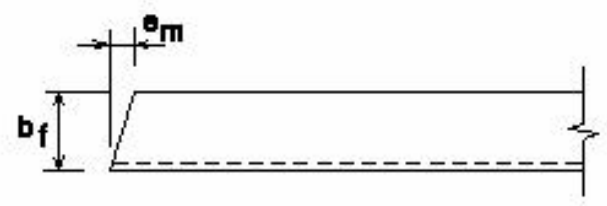

Plano da mesa

Figura 5.15 Esquadro de extremidade do perfil 
Tabela 5.9 Análise de conformidade dos perfis segundo a NBR 6355:2003

\begin{tabular}{|c|c|c|c|c|c|}
\hline Tipo & $\begin{array}{l}\text { Seção } \\
{[\mathrm{L}(\mathrm{mm})]}\end{array}$ & Variável & Parâmetro & Tolerância & $\begin{array}{l}\text { Valor medido } \\
\text { médio (mm) }\end{array}$ \\
\hline \multirow{5}{*}{$\begin{array}{l}\text { Dimensões } \\
\text { da seção } \\
\text { transversal }\end{array}$} & $\begin{array}{l}U 100 \times 50 \times 2,38 \\
(L=2.135)\end{array}$ & \multirow{5}{*}{$b_{w} / b_{f}$} & \multirow{5}{*}{$t_{n} \leq 4,75 \mathrm{~mm}$} & \multirow{5}{*}{ $\pm 1,5 \mathrm{~mm}$} & $\begin{array}{c}101,62 / 50,30 \\
\text { NA }\end{array}$ \\
\hline & $\begin{array}{c}U 100 \times 50 \times 3,88 \\
(L=2.135)\end{array}$ & & & & $\begin{array}{c}100,43 / 49,66 \\
\text { NA } \\
\end{array}$ \\
\hline & 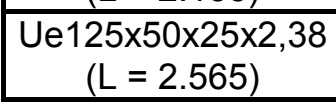 & & & & $\begin{array}{c}125,75 / 51,05 \\
24,10 \\
\end{array}$ \\
\hline & 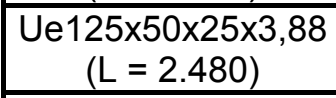 & & & & $\begin{array}{c}123,62 / 49,41 \\
25,13 \\
\end{array}$ \\
\hline & $\begin{array}{c}L 60 \times 2,38 \\
(L=2.925) \\
\end{array}$ & & & & $\begin{array}{c}61,32 \\
\text { NA } \\
\end{array}$ \\
\hline \multirow{5}{*}{$\begin{array}{c}\text { Espessura da } \\
\text { parte plana }\end{array}$} & $\begin{array}{l}\mathrm{U} 100 \times 50 \times 2,38 \\
(\mathrm{~L}=2.135)\end{array}$ & \multirow{5}{*}{$t_{n}$} & \multirow{5}{*}{\multicolumn{2}{|c|}{$\begin{array}{c}\text { Conforme norma } \\
\text { NM 144-2:1998 } \\
\text { Requisitos gerais para } \\
\text { produtos laminados } \\
\text { planos de aço-carbono e } \\
\text { aço baixa liga e alta } \\
\text { resistência. Parte 2 - } \\
\text { Produzidos em } \\
\text { laminadores de tiras a } \\
\text { quente }\end{array}$}} & 2,37 \\
\hline & $\begin{array}{l}U 100 \times 50 \times 3,88 \\
(L=2.135)\end{array}$ & & & & 3,87 \\
\hline & 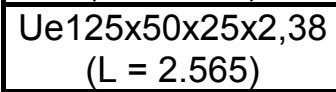 & & & & 2,38 \\
\hline & 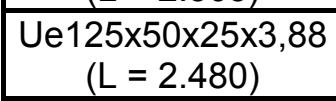 & & & & 3,88 \\
\hline & $\begin{array}{c}\mathrm{L} 60 \times 2,38 \\
(\mathrm{~L}=2.925)\end{array}$ & & & & 2,40 \\
\hline \multirow{5}{*}{$\begin{array}{c}\text { Ângulo } \\
\text { formado por } \\
\text { elementos } \\
\text { adjacentes }\end{array}$} & $\begin{array}{l}\mathrm{U} 100 \times 50 \times 2,38 \\
(\mathrm{~L}=2.135)\end{array}$ & \multirow{5}{*}{$\alpha$} & \multirow{5}{*}{ Qualquer } & \multirow{5}{*}{ $\pm 1^{\circ}$} & 1,52 \\
\hline & $\begin{array}{c}\mathrm{U} 100 \times 50 \times 3,88 \\
(\mathrm{~L}=2.135)\end{array}$ & & & & 1,00 \\
\hline & 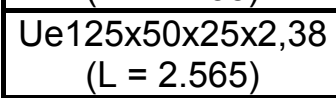 & & & & 0,61 \\
\hline & 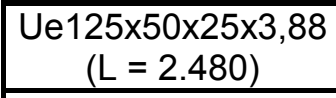 & & & & 1,23 \\
\hline & $\begin{array}{l}L 60 \times 2,38 \\
(L=2.925)\end{array}$ & & & & 1,27 \\
\hline \multirow{5}{*}{$\begin{array}{c}\text { Comprimento } \\
\text { do perfil } \\
\text { (ajustado ) }\end{array}$} & $\begin{array}{c}\mathrm{U} 100 \times 50 \times 2,38 \\
(\mathrm{~L}=2.135)\end{array}$ & \multirow{5}{*}{$L$} & \multirow{5}{*}{$\mathrm{t}_{\mathrm{n}} \leq 4,75 \mathrm{~mm}$} & \multirow{5}{*}{$\begin{array}{c}+3 \mathrm{~mm} \\
0\end{array}$} & 2.135 \\
\hline & $\begin{array}{c}\mathrm{U} 100 \times 50 \times 3,88 \\
(\mathrm{~L}=2.135)\end{array}$ & & & & 2.135 \\
\hline & 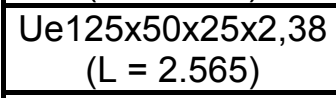 & & & & 2.565 \\
\hline & 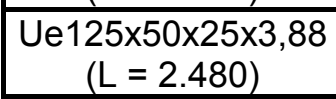 & & & & 2.479 \\
\hline & $\begin{array}{l}\mathrm{L} 60 \times 2,38 \\
(\mathrm{~L}=2.925)\end{array}$ & & & & 2.925 \\
\hline
\end{tabular}


.....continuação da Tabela 5.9:

\begin{tabular}{|c|c|c|c|c|c|}
\hline \multirow{5}{*}{$\begin{array}{c}\text { Flecha do } \\
\text { perfil }\end{array}$} & \multirow{2}{*}{$\begin{array}{c}U 100 \times 50 \times 2,38 \\
(L=2.135) \\
U 100 \times 50 \times 3,88 \\
(L=2.135)\end{array}$} & \multirow{5}{*}{$\begin{array}{l}\text { Plano da } \\
\text { alma }\left(\delta_{v}\right) \\
\text { Plano da } \\
\text { mesa ou } \\
\text { aba }\left(\delta_{h}\right)\end{array}$} & \multirow{5}{*}{ Qualquer } & \multirow{5}{*}{$\mathrm{L} / 500$} & L / 1.525 \\
\hline & & & & & L / 1.256 \\
\hline & \multirow{2}{*}{ 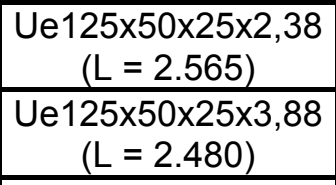 } & & & & L / 1.710 \\
\hline & & & & & L / 1.550 \\
\hline & $\begin{array}{c}\mathrm{L} 60 \times 2,38 \\
(\mathrm{~L}=2.925)\end{array}$ & & & & L / 860 \\
\hline \multirow{5}{*}{$\begin{array}{l}\text { Torção do } \\
\text { perfil }\end{array}$} & $\begin{array}{l}\mathrm{U} 100 \times 50 \times 2,38 \\
(\mathrm{~L}=2.135)\end{array}$ & \multirow{5}{*}{$\begin{array}{l}\theta_{\mathrm{f}}(\text { mesa }) \\
\theta_{\mathrm{w}}(\text { alma })\end{array}$} & \multirow{5}{*}{ Qualquer } & \multirow{5}{*}{$1^{\circ} /$ metro $^{8)}$} & $\begin{array}{l}1,07^{\circ} / \text { metro } \\
0,80^{\circ} / \text { metro }\end{array}$ \\
\hline & $\begin{array}{l}\mathrm{U} 100 \times 50 \times 3,88 \\
(\mathrm{~L}=2.135)\end{array}$ & & & & $\begin{array}{l}1,07^{\circ} / \text { metro } \\
0,94^{\circ} / \text { metro }\end{array}$ \\
\hline & 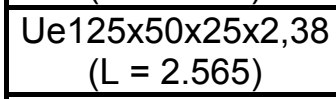 & & & & $\begin{array}{l}0,45^{\circ} / \text { metro } \\
0,18 \% \text { metro }\end{array}$ \\
\hline & 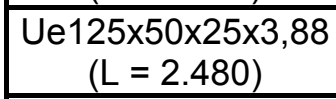 & & & & $\begin{array}{l}0,46^{\circ} / \text { metro } \\
0,09^{\circ} / \text { metro }\end{array}$ \\
\hline & $\begin{array}{c}\mathrm{L} 60 \times 2,38 \\
(\mathrm{~L}=2.925) \\
\end{array}$ & & & & $\begin{array}{l}0,98^{\circ} / \text { metro } \\
0,98^{\circ} / \text { metro }\end{array}$ \\
\hline \multirow{5}{*}{$\begin{array}{l}\text { Esquadro de } \\
\text { extremidade }\end{array}$} & $\begin{array}{c}\mathrm{U} 100 \times 50 \times 2,38 \\
(\mathrm{~L}=2.135)\end{array}$ & \multirow{5}{*}{$\begin{array}{l}\text { Plano da } \\
\text { alma }\left(\mathrm{e}_{\mathrm{a}}\right) \\
/ \\
\text { Plano das } \\
\text { mesas ou } \\
\text { abas }\left(\mathrm{e}_{\mathrm{m}}\right)\end{array}$} & \multirow{5}{*}{ Qualquer } & \multirow{5}{*}{ $\pm b_{w} / 100$} & $0,0 / 0,0$ \\
\hline & $\begin{array}{c}U 100 \times 50 \times 3,88 \\
(L=2.135)\end{array}$ & & & & $1,5 / 0,0$ \\
\hline & 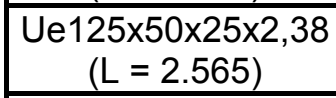 & & & & $0,0 / 0,0$ \\
\hline & 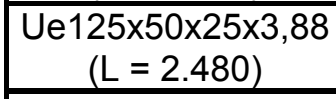 & & & & $0,0 / 0,0$ \\
\hline & $\begin{array}{l}\mathrm{L} 60 \times 2,38 \\
(\mathrm{~L}=2.925)\end{array}$ & & & & $1,0 / 0,0$ \\
\hline
\end{tabular}

\subsubsection{Etapas 2 e 3}

Neste item são apresentadas tanto a Etapa 2, referente aos ensaios de compressão centrada em barras curtas, denominadas também de stub columns (15 ensaios), como a Etapa 3 , referente aos ensaios de compressão centrada em barras longas (28 ensaios).

Os ensaios foram realizados na máquina servo-controlada Instron 8506 com capacidade para aplicação de carregamento de até $2.500 \mathrm{kN}$. Foi aplicada condição de carregamento monotônico com controle de deslocamento, utilizando-se para as leituras o sistema de aquisição de dados System 5000.

Após a realização dos ensaios piloto definiu-se a taxa de carregamento de $0,005 \mathrm{~mm} /$ segundo na fase de carregamento, e de $0,01 \mathrm{~mm} /$ segundo durante o 
descarregamento. É importante lembrar que para as stub columns, o manual do AISI recomenda taxa de carregamento inferior a $21 \mathrm{MPa} /$ minuto, o que corresponde a $0,0005 \mathrm{~mm} /$ segundo, sendo entretanto utilizada a velocidade mínima da máquina de ensaio, ou seja, $0,001 \mathrm{~mm} /$ segundo.

Para o ensaio das barras longas, vide esquema e dimensões da rótula utilizada na Figura 5.16, foi utilizado o alinhamento geométrico a fim de se garantir a aplicação da força de compressão no centróide da seção transversal. Conforme mencionado anteriormente, o alinhamento do centróide da seção transversal bruta das barras com o centróide da chapa de topo já havia sido feito antes da soldagem. Portanto, na máquina de ensaio foi feito o alinhamento deste centróide único com o centro do prato da máquina de ensaio. Para facilitar a sobreposição, foram feitas linhas (sulcos) nas chapas da rótula nas duas direções passando pelo seu centro, conforme pode ser visto na Figura 5.17.

Esse tipo de alinhamento foi satisfatório para o propósito deste trabalho, ou seja, compressão centrada nas barras, o que foi confirmado pelos resultados de deformações e deslocamentos obtidos.

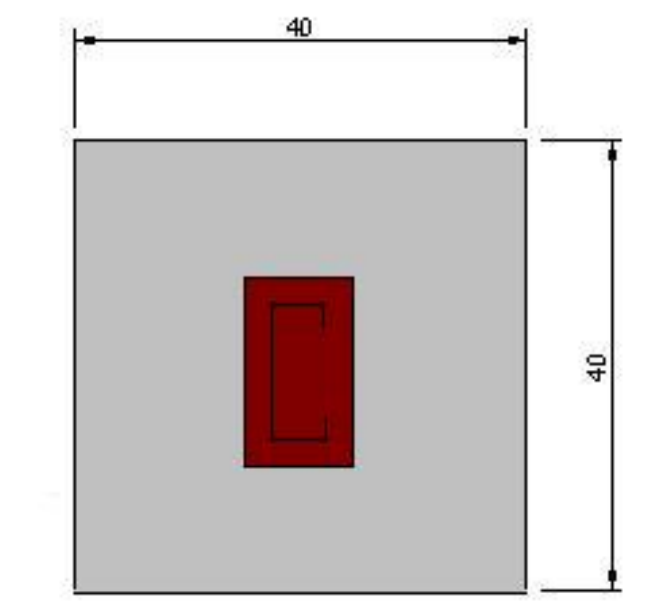

Vista Superior

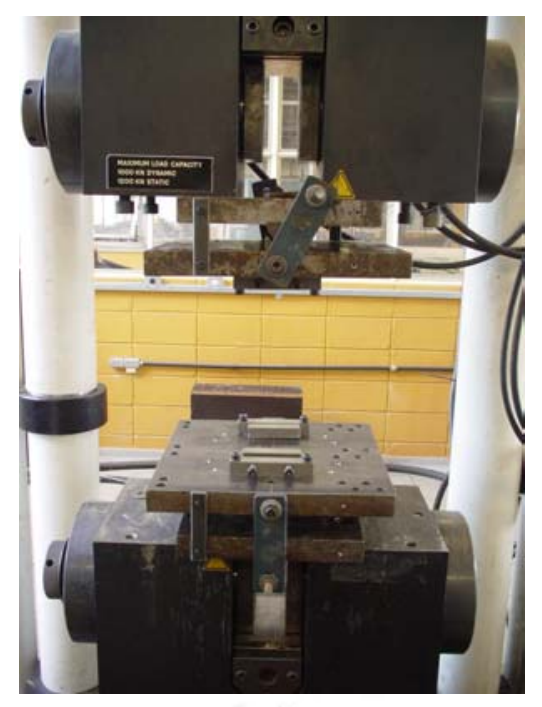

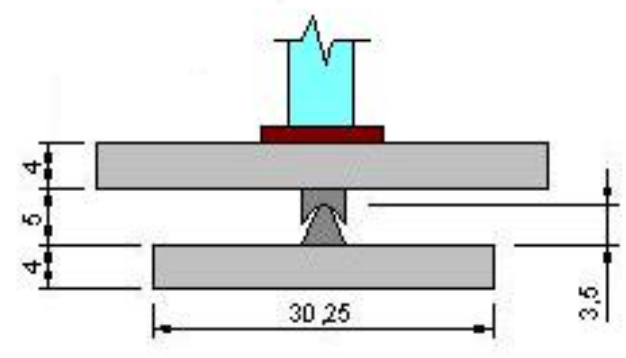

Vista Lateral

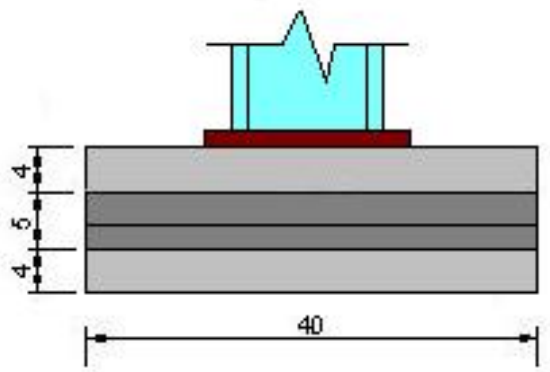

Vista Frontal

Figura 5.16 Esquema e dimensões das rótulas (medidas em centímetros) 


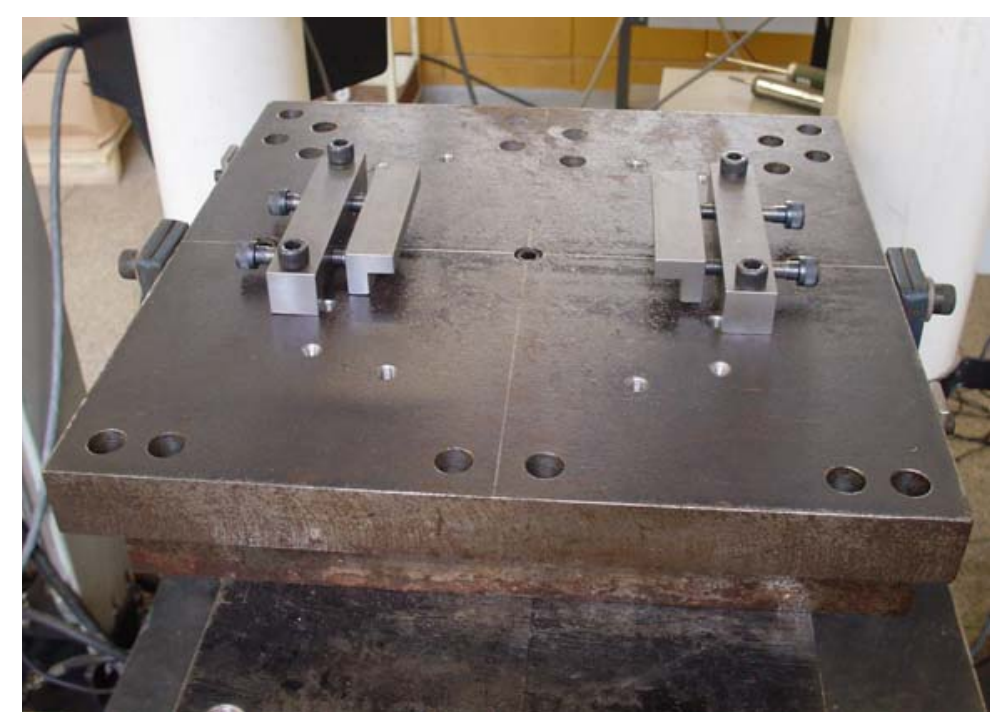

Figura 5.17 Rótula cilíndrica utilizada nos ensaios de barras longas: notar dispositivo para fixação e centragem das barras

As barras curtas (stub columns) foram colocadas diretamente no prato da máquina de ensaios, sem a utilização das rótulas nem chapas de topo soldadas. Entretanto, na fase de corte destas barras, procurou-se ter o cuidado de garantir a planicidade da seção transversal das extremidades das barras e também a perpendicularidade do plano da seção transversal das extemidades com o eixo da barra.

Para os ensaios das barras longas foram utilizadas as já mencionadas rótulas cilíndricas (pode-se ver melhor o detalhe da "faca" na Figura 5.18), que permitem, nas duas extremidades da barra, giro em torno de um dos eixos somente, restringindo torção e empenamento. Estas barras foram então posicionadas na máquina de ensaio de modo que o eixo principal de menor inércia fosse coincidente com o eixo da rótula, para haver portanto condição biapoiada em torno deste eixo, enquanto que de engaste para o perpendicular a este (maior inércia). Tais comentários podem ser melhor entendidos nos detalhes de posicionamento para o perfil do tipo $U$ enrijecido na Figura 5.19 e na Figura 5.20, e também com uma visão mais geral na Figura 5.21 onde é ilustrado o sistema de ensaio para a cantoneira simples.

Deve ser destacado o caso especial referente aos ensaios das cantoneiras duplas, em que a torção e o empenamento foram também restringidos nas extremidades, mas foram ensaiados dois lotes de barras, o primeiro com posicionamento na rótula de modo a permitir flexão em torno do eixo de menor inércia, e o segundo posicionado de modo a permitir flexão em torno do eixo de maior inércia. 


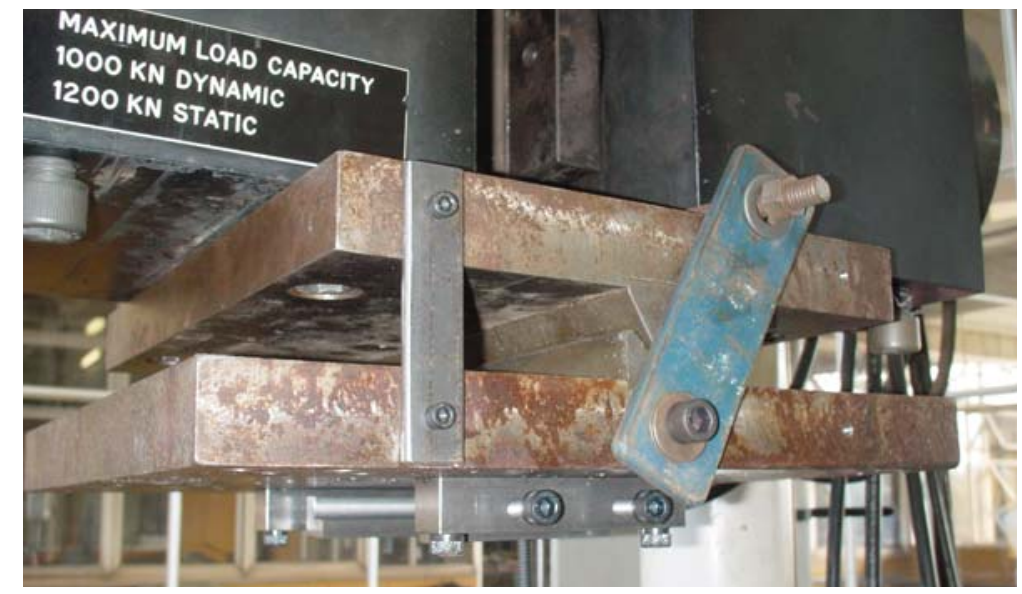

Figura 5.18 Detalhe da "faca" da rótula cilíndrica

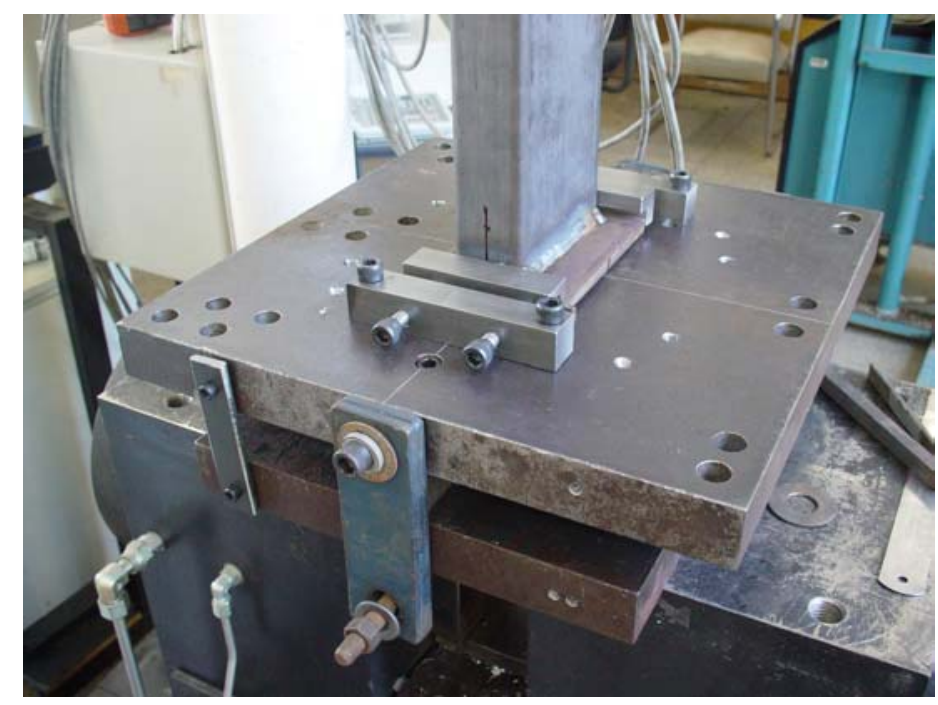

Figura 5.19 Detalhe de apoio para o perfil tipo U enrijecido: rótula inferior

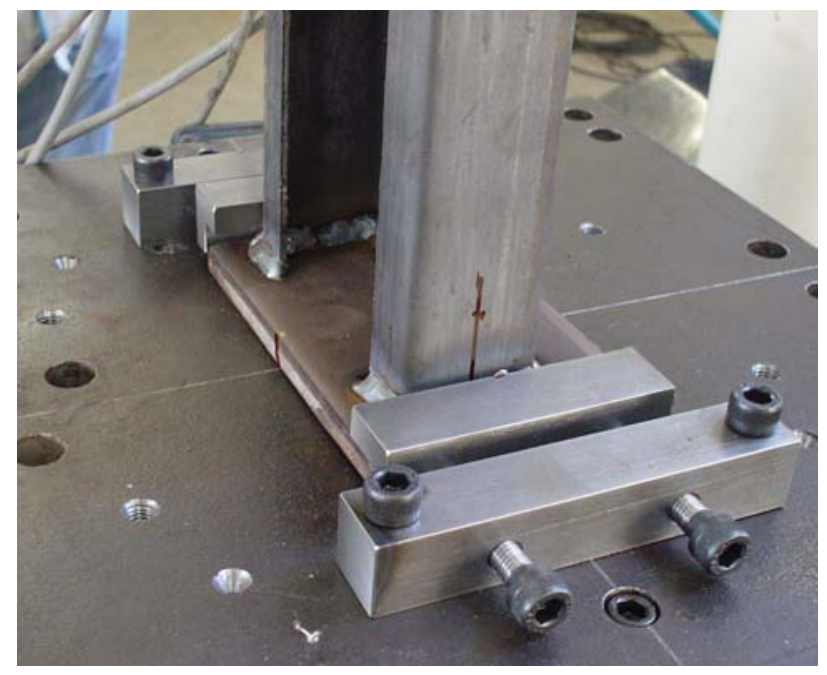

Figura 5.20 Detalhe do dispositivo de fixação da barra na rótula 


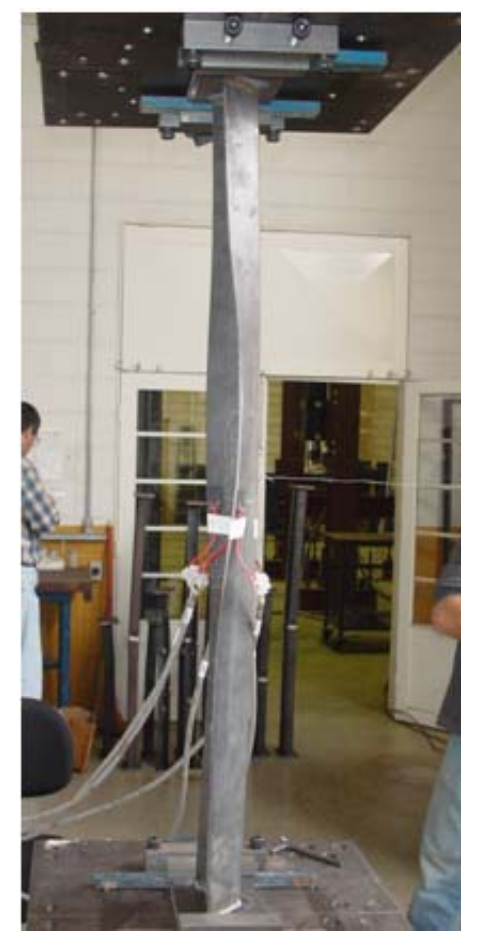

Figura 5.21 Vista geral do ensaio: cantoneira simples

Quanto à instrumentação dos ensaios, foram utilizados extensômetros com base de medida de $5 \mathrm{~mm}$ para a leitura das deformações e também transdutores de deslocamento com curso de $50 \mathrm{~mm}$, fixados na metade do comprimento das barras nas direções de maior e menor inércia dos perfis, conforme indicado da Figura 5.22 a Figura 5.26. Para as stub columns, de cada 3 ensaios (repetiu-se 3 vezes o ensaio de cada seção) somente em 1 se utilizou extensômetros e transdutores de deslocamento, caso ilustrado como exemplo para o perfil U na Figura 5.27. Por fim, a direção das setas (1 e 2) indicativas dos transdutores de deslocamento, apresentadas da Figura 5.22 a Figura 5.26, indica deslocamento positivo nos gráficos a serem apresentados relativos aos ensaios. 

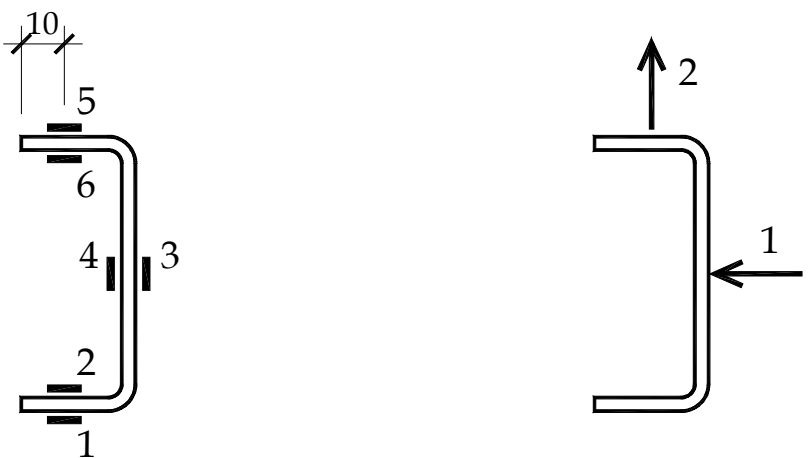

Figura 5.22 Posição dos extensômetros e transdutores de deslocamento perfil $\cup$ (medidas em $\mathrm{mm}$ )
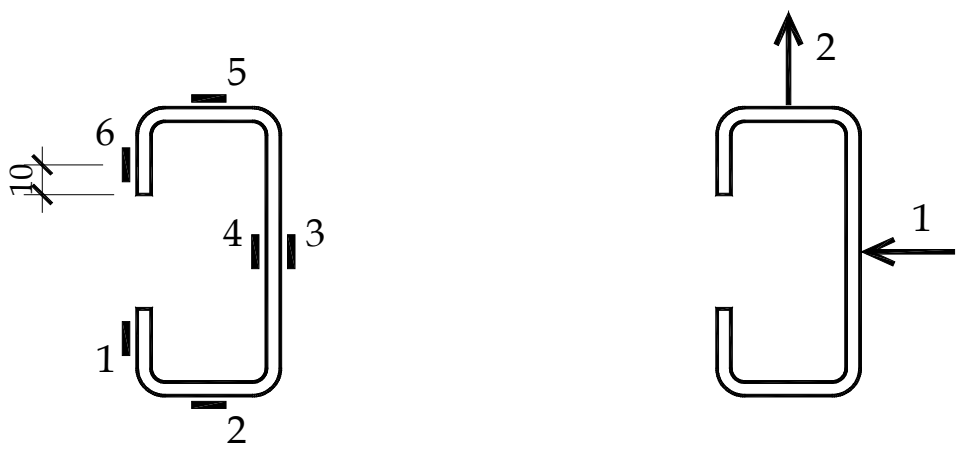

Figura 5.23 Posição dos extensômetros e transdutores de deslocamento perfil Ue (medidas em $\mathrm{mm}$ )
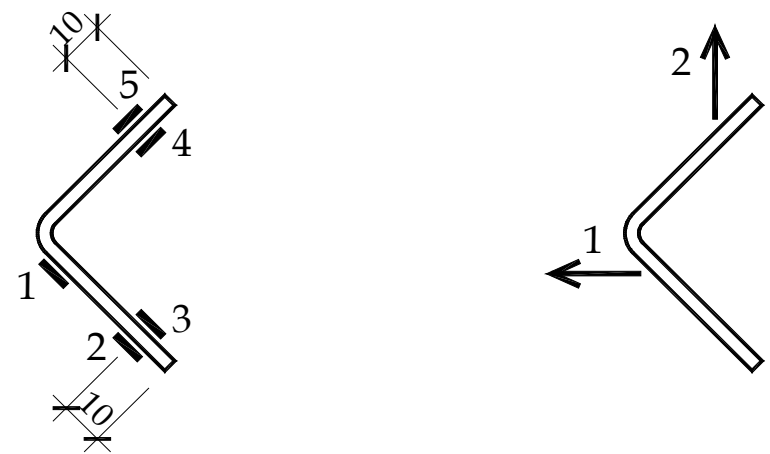

Figura 5.24 Posição dos extensômetros e transdutores de deslocamento cantoneira simples (medidas em $\mathrm{mm}$ ) 

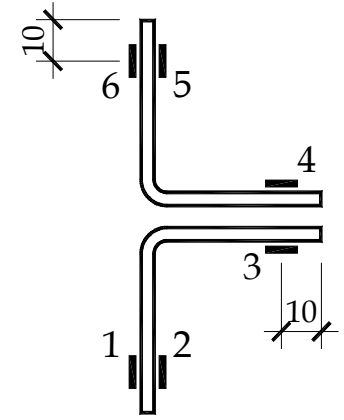

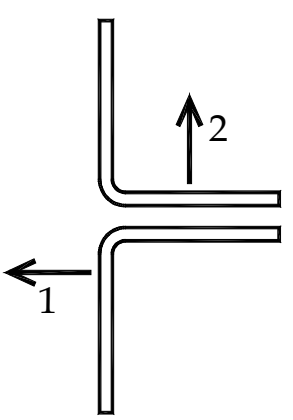

Figura 5.25 Posição dos extensômetros e transdutores de deslocamento Cantoneira dupla - ensaios com rótula para flexão em " $x$ " (medidas em mm)
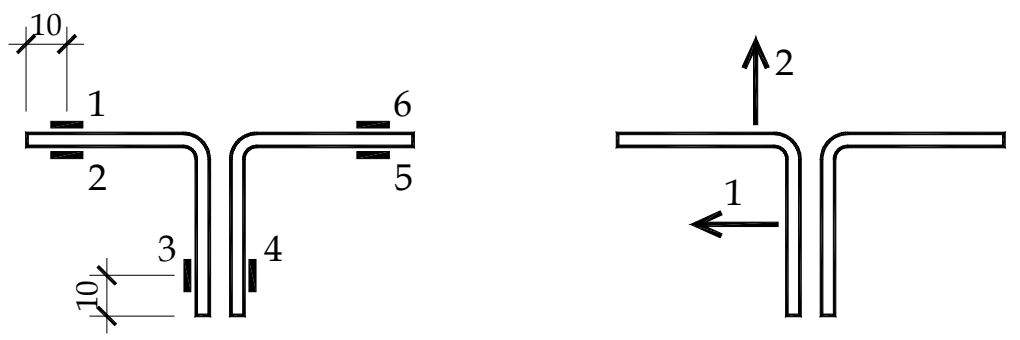

Figura 5.26 Posição dos extensômetros e transdutores de deslocamento Cantoneira dupla - ensaios com rótula para flexão em "y" (medidas em mm)

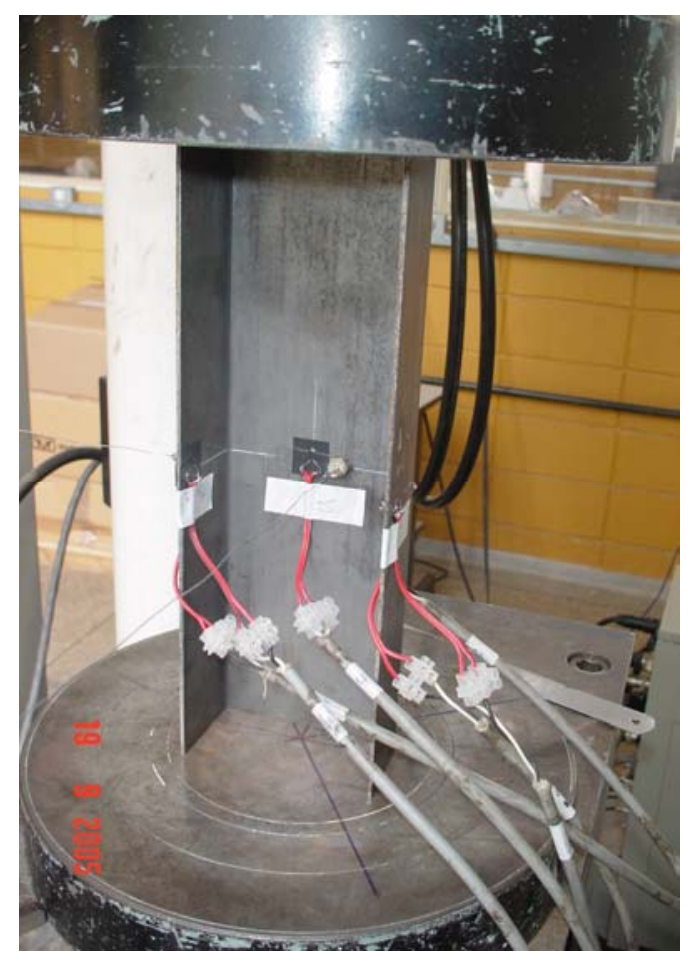

Figura 5.27 Instrumentação barra curta (stub column): exemplo de perfil do tipo U 


\subsubsection{Resultados dos ensaios das barras}

Tabela 5.10 Barras longas ensaiadas: propriedades e resultados

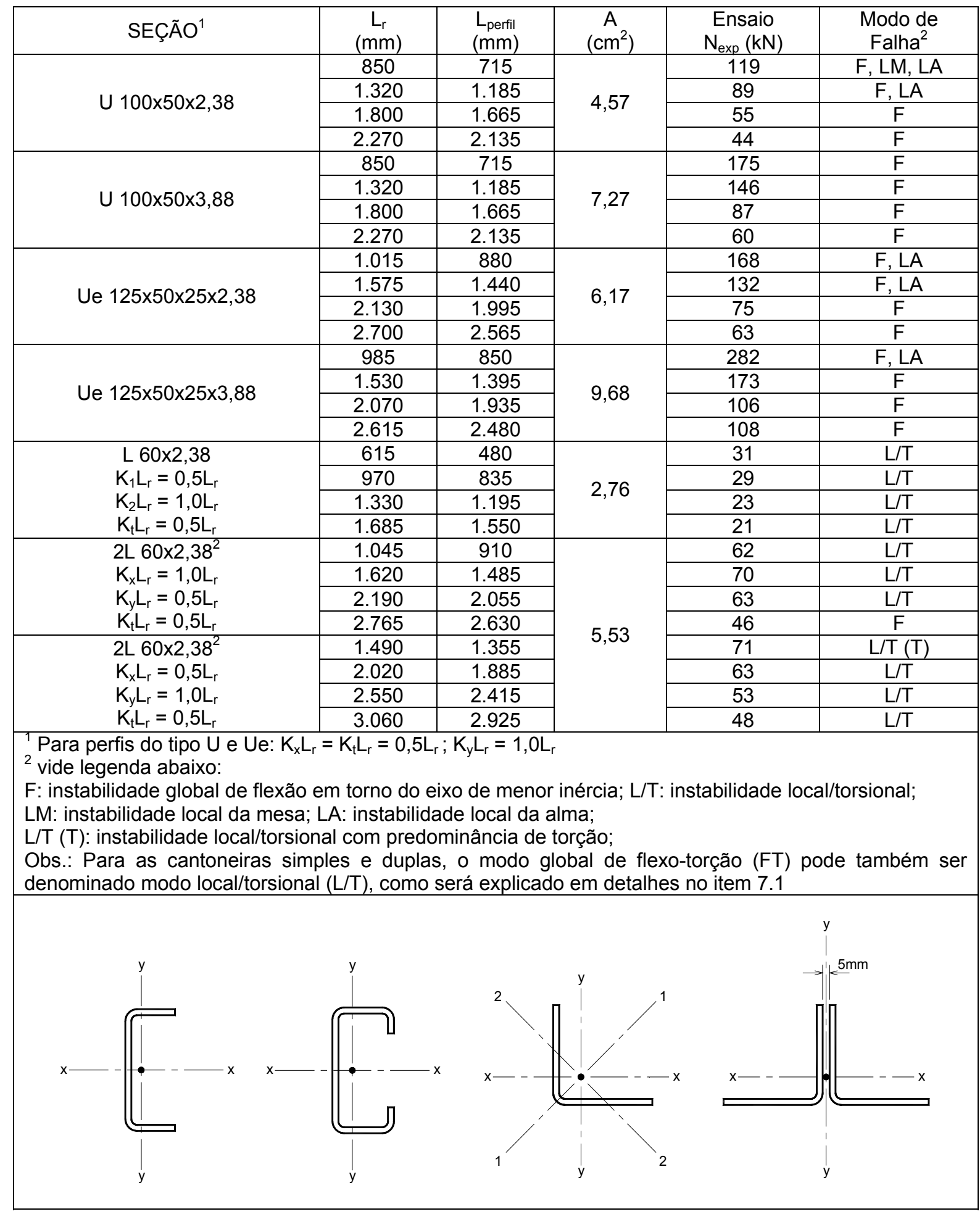


Tabela 5.11 Barras curtas (stub columns) ensaiadas: propriedades e resultados

\begin{tabular}{|c|c|c|c|c|c|}
\hline SEÇÃO ${ }^{1}$ & $\begin{array}{c}\mathrm{L}_{\mathrm{r}} \\
(\mathrm{mm})\end{array}$ & $\begin{array}{l}L_{\text {perfil }} \\
(\mathrm{mm})\end{array}$ & $\begin{array}{c}\mathrm{A} \\
\left(\mathrm{cm}^{2}\right)\end{array}$ & $\begin{array}{c}\text { Ensaio } \\
N_{\text {exp }}(k N)\end{array}$ & $\begin{array}{l}\text { Modo } \\
\text { Falha }^{2}\end{array}$ \\
\hline \multirow{3}{*}{ U $100 \times 50 \times 2,38$} & 150 & 300 & \multirow{3}{*}{4,57} & 119 & LA, LM \\
\hline & 150 & 300 & & 119 & LA, LM \\
\hline & 150 & 300 & & 120 & LA, LM \\
\hline \multirow{3}{*}{ U 100x50x3,88 } & 150 & 300 & \multirow{3}{*}{7,27} & 225 & LA, LM \\
\hline & 150 & 300 & & 227 & LA, LM \\
\hline & 150 & 300 & & 231 & LA, LM \\
\hline \multirow{3}{*}{ Ue $125 \times 50 \times 25 \times 2,38$} & 187,5 & 375 & \multirow{3}{*}{6,17} & 199 & LA \\
\hline & 187,5 & 375 & & 206 & LA \\
\hline & 187,5 & 375 & & 196 & LA \\
\hline \multirow{3}{*}{ Ue $125 \times 50 \times 25 \times 3,88$} & 187,5 & 375 & \multirow{3}{*}{9,68} & 313 & LA \\
\hline & 187,5 & 375 & & 315 & LA \\
\hline & 187,5 & 375 & & 311 & LA \\
\hline \multirow{3}{*}{ L 60x2,38 } & 125 & 250 & \multirow{3}{*}{2,76} & 51 & $\mathrm{~L} / \mathrm{T}$ \\
\hline & 125 & 250 & & 50 & $\mathrm{~L} / \mathrm{T}$ \\
\hline & 125 & 250 & & 51 & $\mathrm{~L} / \mathrm{T}$ \\
\hline \multicolumn{6}{|c|}{$\begin{array}{l}{ }^{1} \text { Para todos perfis: } \mathrm{KL}_{r}=0,5 \mathrm{~L}_{r} ; \\
{ }^{2} \text { vide legenda abaixo: } \\
\text { LM: instabilidade local da mesa; } L A \text { : instabilidade local da alma; } \\
\text { L/T: instabilidade local/torsional; }\end{array}$} \\
\hline
\end{tabular}

Os resultados dos ensaios mostram que a resistência das barras foi ligeiramente superior à esperada devido aos cálculos das normas, como será visto no capítulo de análise dos resultados, o que aponta o já esperado caráter conservador da norma e um bom aparato de ensaio.

Uma idéia interessante quanto aos ensaios das stub columns, e que deve ser analisada com cuidado em trabalhos futuros, é sobre a definição do comprimento das barras curtas (stub columns) a serem ensaiadas, que neste trabalho foi definido seguindo-se a recomendação do AISI. Uma alternativa, contribuindo no sentido de uma padronização, seria a utilização de programas numéricos simples como o CUFSM (a ser explicado no item 6.2.1) para se obter o comprimento de meia-onda referente ao modo local para a seção transversal em questão, multiplicá-lo por 3 para se garantir que a deformada referente ao modo local ocorra na região central do comprimento da barra, e daí este comprimento é o que seria o da barra a ser ensaiada.

Vale ressaltar que para as barras curtas (stub columns) pôde-se verificar que o modo de falha foi por instabilidade local, como esperado e planejado. Salienta-se que mesmo não tendo sido realizada a usinagem das extremidades das barras, os procedimentos tomados procurou-se ter o cuidado de garantir a planicidade da seção transversal das extremidades das barras e também a perpendicularidade do plano da seção transversal das extemidades com o eixo da barra - conduziram a bons resultados, vide Tabela 5.11.

Ressalta-se ainda quanto às barras curtas que as imperfeições geométricas iniciais exercem influência nos resultados, pois os perfis com paredes mais esbeltas aparecem abaixo dos mais compactos na Figura 7.18 e na Figura 7.19, apresentadas mais adiante. Além desse 
fato, essa questão também é influenciada pelo tipo de colapso verificado nos ensaios, que é diferente comparando-se os perfis mais esbeltos com os mais compactos.

Além disso, o leitor deve se lembrar do que foi dito na revisão bibliográfica desta tese quanto à questão das cantoneiras, i.e., o que alguns pesquisadores pensam sobre se negligenciar o modo de flexo-torção. Contrariando esses pesquisadores, nos ensaios de cantoneiras aqui realizados, os modos de falha foram de flexo-torção (denominado também de modo local/torsional, como será explicado no item 7.1), fazendo entender que este modo não deve ser negligenciado na análise elástica deste tipo de seção.

As fotos e os gráficos relativos aos resultados para todos os ensaios são apresentados no apêndice. Por hora, algumas fotos representativas são apresentadas. A Figura 5.28 ilustra o detalhe de fixação das barras longas nos ensaios utilizando-se a rótula cilíndrica, enquanto que a Figura 5.29 ilustra o giro da rótula ao final de um ensaio. A Figura 5.30, por sua vez, ilustra o modo global de flexão em torno do eixo de menor inércia. O conjunto de fotos (Figura 5.31 a Figura 5.33) apresenta claramente o modo global de flexo-torção (local/torsional) das cantoneiras para se ilustrar o que acabou de ser comentado.
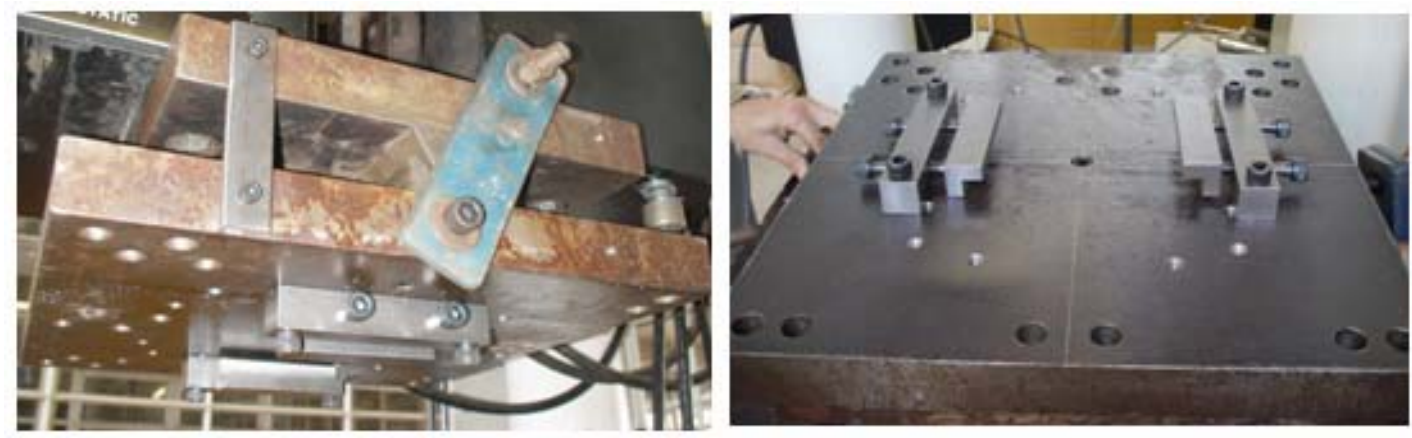

Figura 5.28 Detalhe de fixação das barras nos ensaios: rótula cilíndrica

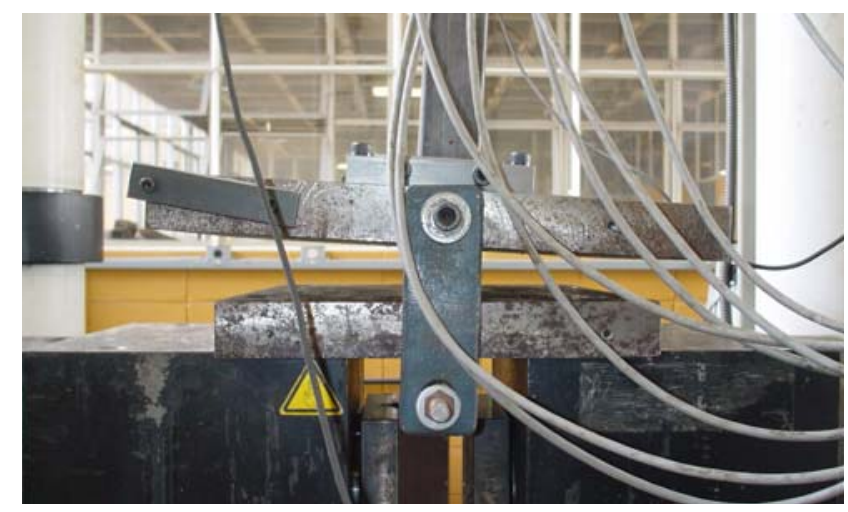

Figura 5.29 Giro da rótula 


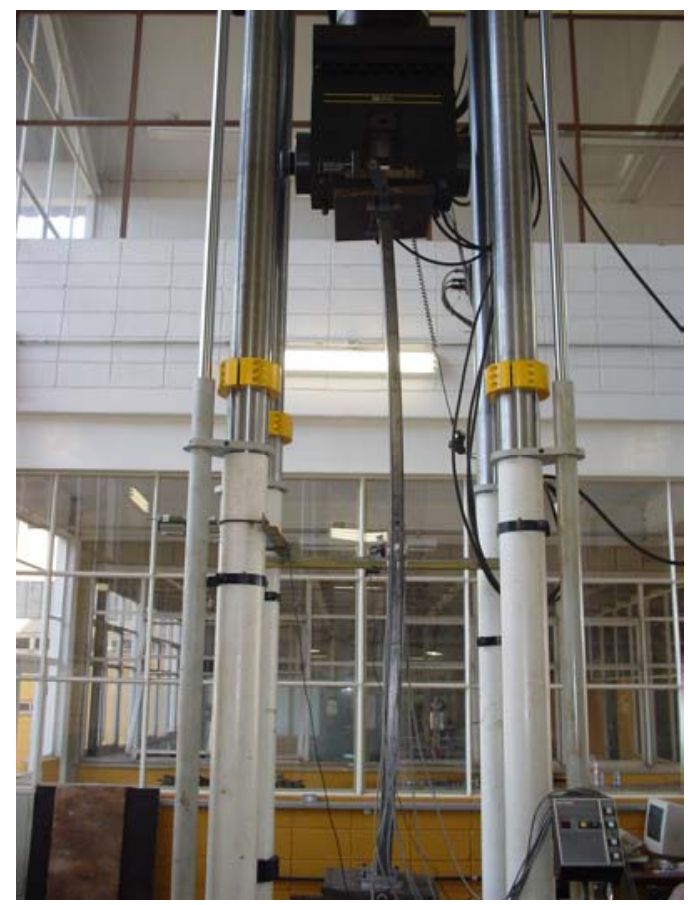

Figura 5.30 Resistência máxima: modo global de flexão em torno do eixo de menor inércia: detalhe da flexão do perfil Ue $125 \times 50 \times 25 \times 3,88 \mathrm{~mm}\left(L_{r}=2.615 \mathrm{~mm}\right)$

As figuras que estão sendo apresentadas, os gráficos e figuras do apêndice, e a comparação que será apresentada mais adiante dos resultados dos ensaios com os previstos por normas e também com os obtidos da análise numérica, demonstram a elevada eficiência das rótulas, do esquema de centragem, controle de delocamento, etc. Todo esse sistema de ensaio fez com que os resultados obtidos fossem muito interessantes e proveitosos.

O padrão dos gráficos de resultados é apresentado a seguir como exemplo para uma das cantoneiras, ilustrado da Figura 5.34 a Figura 5.36 (vide legenda na Figura 5.24 anteriormente apresentada). São apresentados e comentados os gráficos para todas as barras no apêndice e no capítulo de análise dos resultados, respectivamente. Pode-se perceber desde já o êxito do sistema de ensaio e funcionamento das rótulas.

A Figura 5.34 ilustra uma das razões de se fazer ensaio com controle de deslocamento: é possível continuar o ensaio mesmo após se atingir a resistência máxima da barra, obtendo os resultados inclusive para o trecho de descarregamento. 


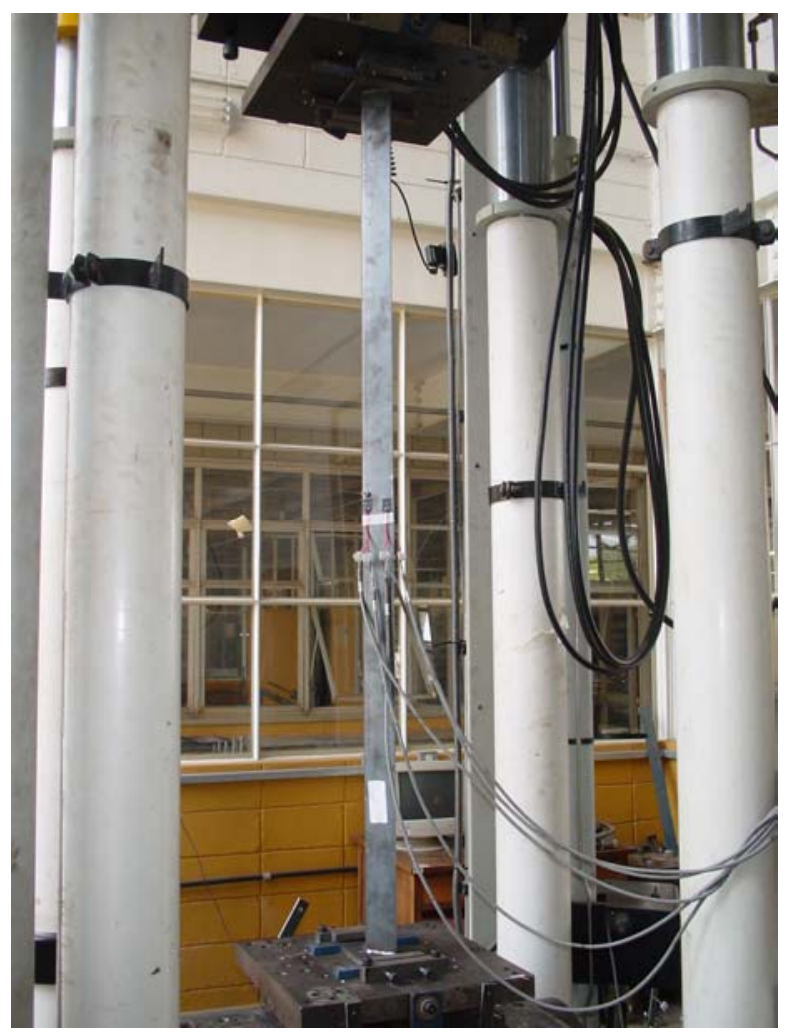

Figura 5.31 Antes do ensaio: cantoneira $60 \times 2,38 \mathrm{~mm}\left(L_{r}=1.685 \mathrm{~mm}\right)$

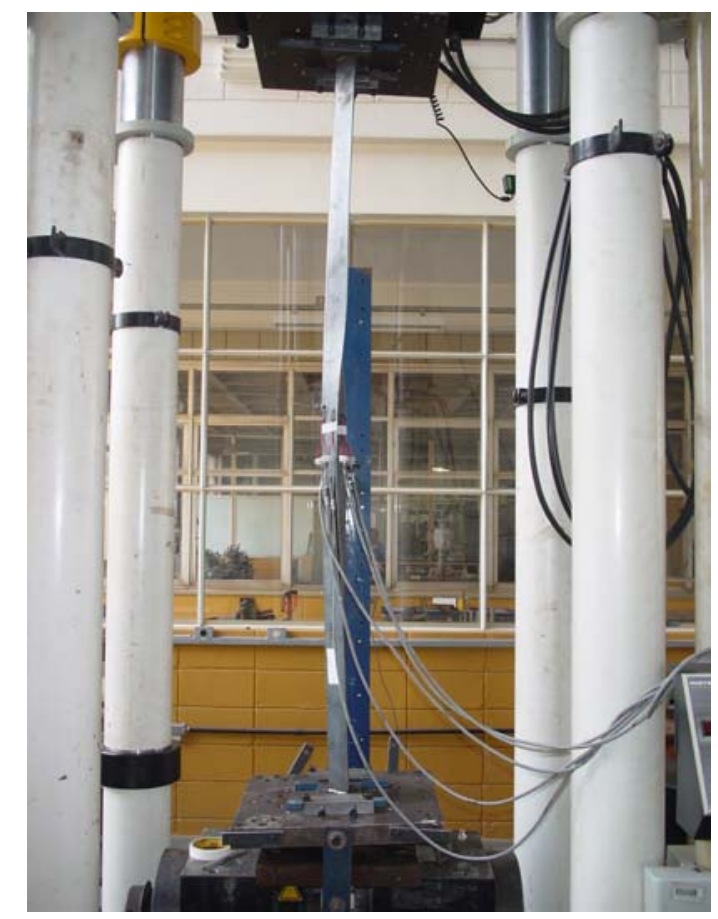

Figura 5.32 Estágio final ensaio: modo local/torsional cantoneira $60 \times 2,38 \mathrm{~mm}\left(L_{r}=1.685 \mathrm{~mm}\right)$ 


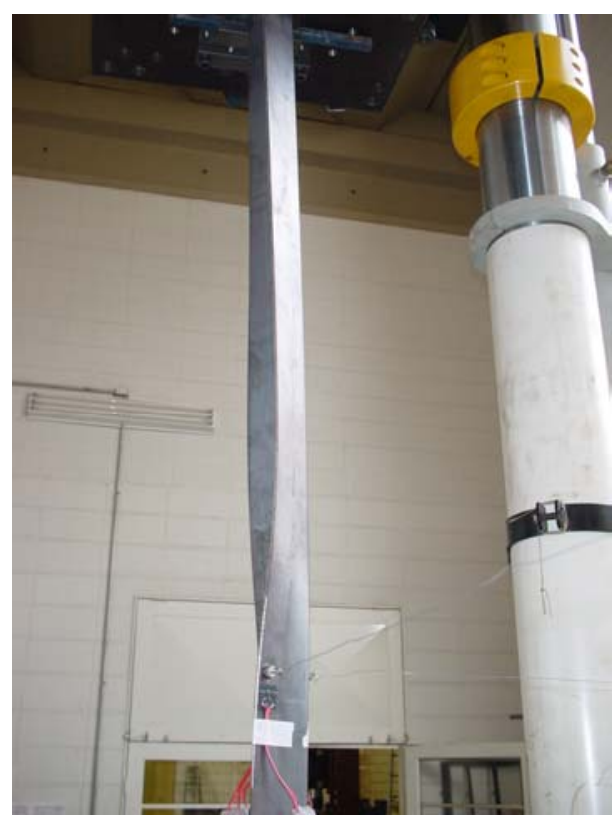

Figura 5.33 Detalhe modo local/torsional $(L / T)$ : cantoneira $60 \times 2,38 \mathrm{~mm}\left(L_{r}=1.685 \mathrm{~mm}\right)$

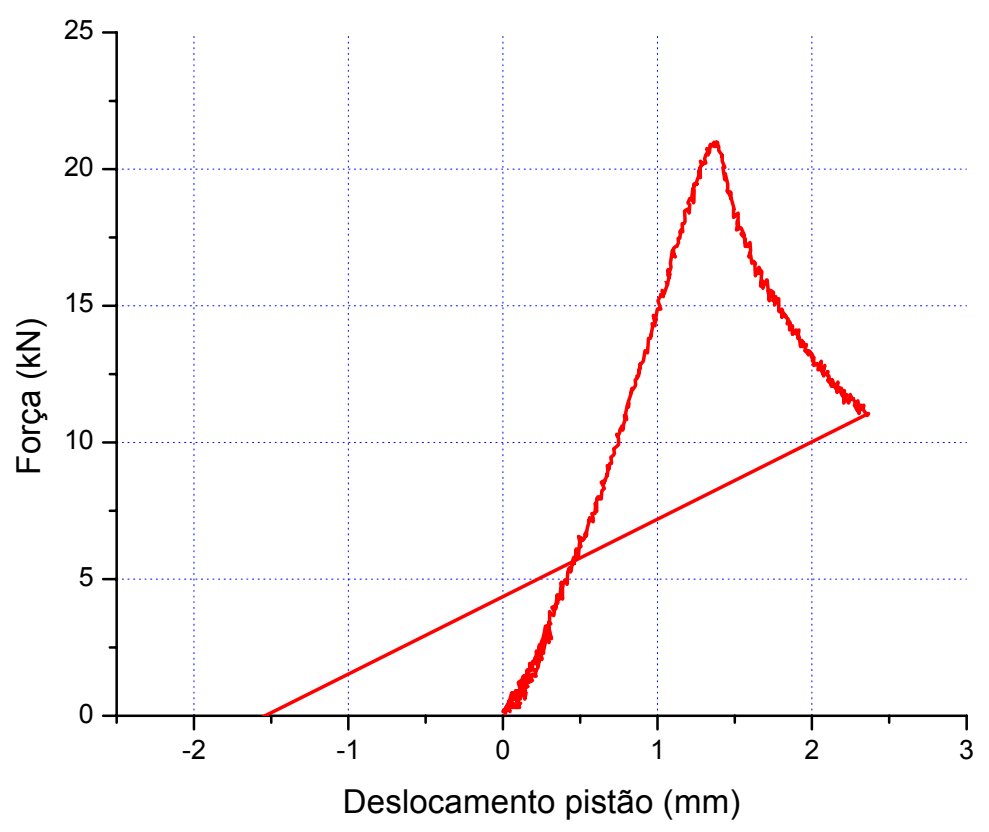

Figura 5.34 Força $x$ deslocamento pistão: cantoneira $60 \times 2,38 \mathrm{~mm}\left(L_{r}=1.685 \mathrm{~mm}\right)$

Pode-se ver na Figura 5.35 que os deslocamentos apresentados pelo transdutor 2 (flexão em torno do eixo de maior inércia) foram pequenos se comparados aos referentes ao transdutor 1. Isto era esperado, pois o posicionamento da barra no sistema de rótulas já explicado faz com que a flexão em torno do eixo de maior inércia tenha metade do comprimento de flambagem, por ambas extremidades serem engastadas nessa direção. 
Quanto às deformações ilustradas na Figura 5.36 para uma das cantoneira simples ensaiadas (vide legenda na Figura 5.24), o entendimento sobre o que ocorreu fica mais fácil se a Figura 5.32 e a Figura 5.33 forem juntamente a ela observadas. No início, todos os extensômetros apresentaram valores baixos de deformação (encurtamento), o que era esperado. Entretanto, no decorrer do ensaio os extensômetros 3 e 5 apresentaram valores maiores de encurtamento, enquanto que os extensômetros 1, 2 e 4 mudaram o sentido da deformação, de encurtamento para alongamento, proveniente de configuração deformada ilustrada nas figuras.

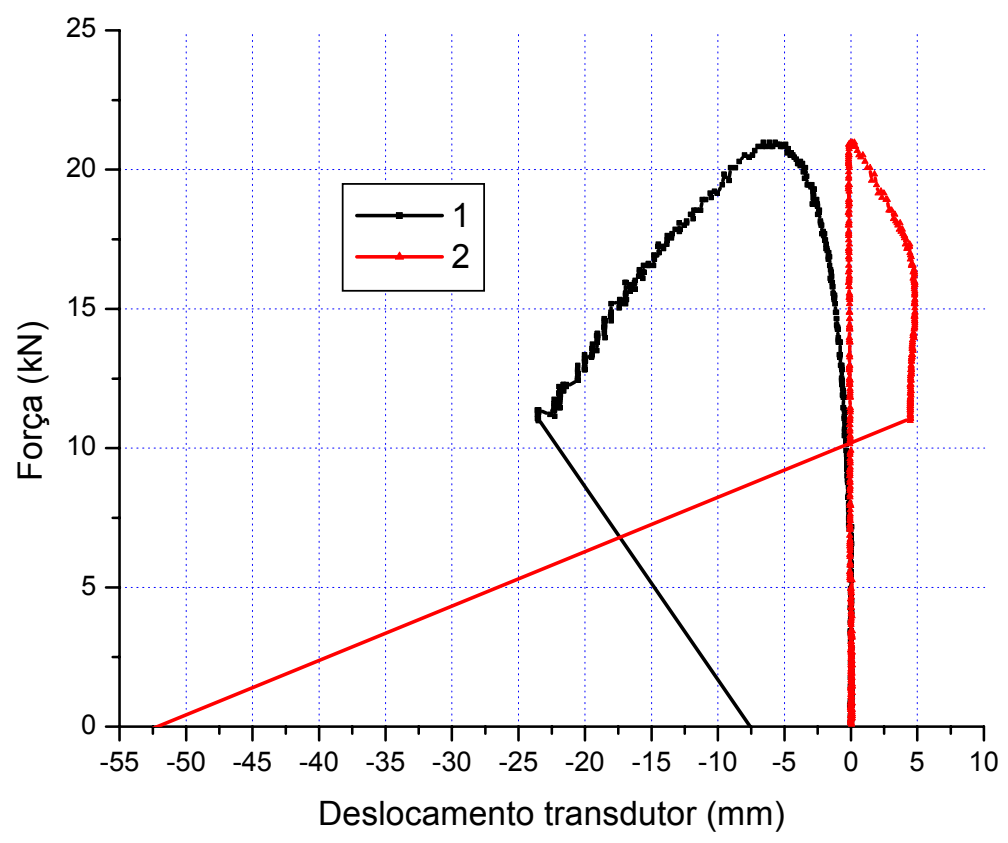

Figura 5.35 Força $x$ deslocamento transdutores: cantoneira $60 \times 2,38 \mathrm{~mm}\left(L_{r}=1.685 \mathrm{~mm}\right)$ 


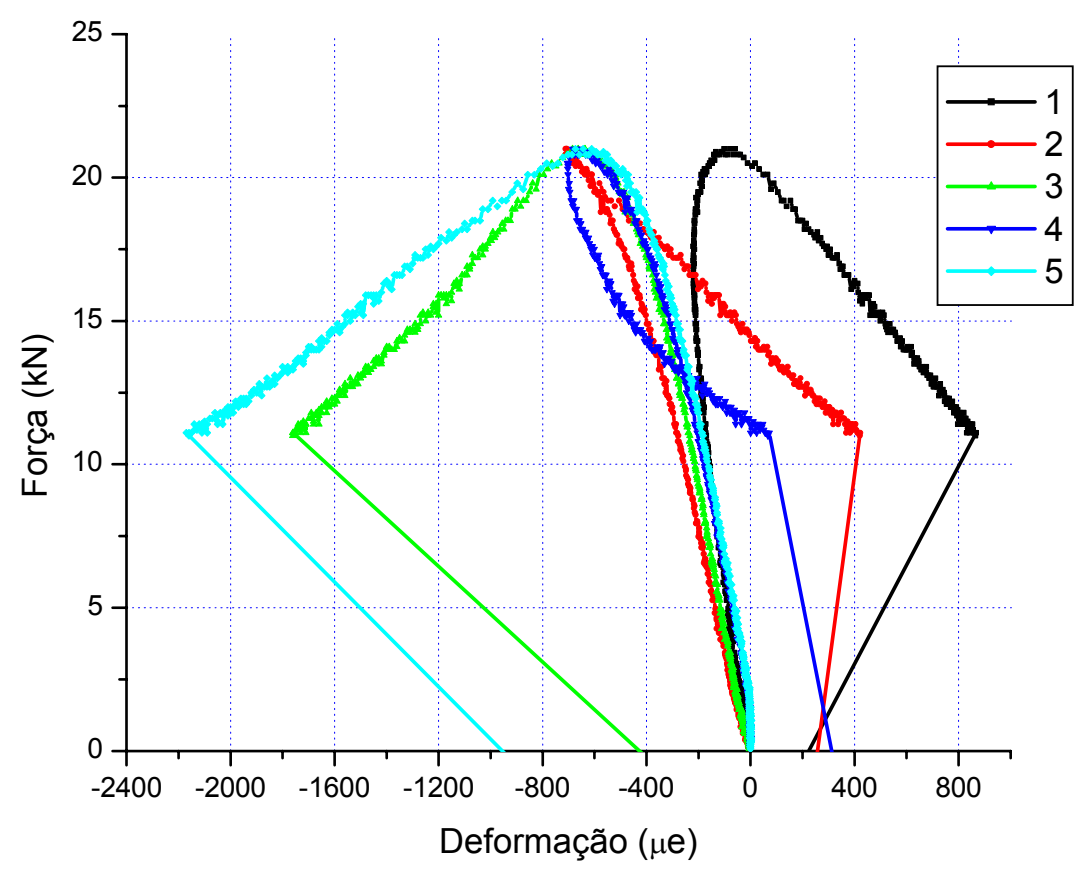

Figura 5.36 Força x deformação extensômetros: cantoneira $60 \times 2,38 \mathrm{~mm}\left(L_{r}=1.685 \mathrm{~mm}\right.$ ) 


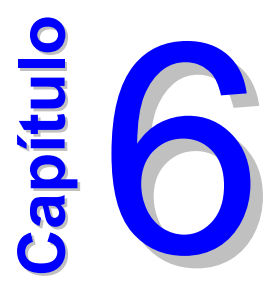

\section{ANÁLISE NUMÉRICA}

\subsection{Aspectos iniciais}

No contexto da análise numérica, e para servir de embasamento e reflexão quanto à estratégia proposta e adotada nos modelos numéricos que serão aqui apresentados, seguem informações sobre alguns procedimentos apresentados na literatura. Ao final de cada parágrafo faz-se comentários a fim de comparar tais idéias com o presente trabalho.

DAVIES \& VOUTAY (2002) não consideram nem os cantos arredondados nos perfis do tipo $U$ enrijecido nem as tensões residuais nas análises númericas em elementos finitos. Para as imperfeições geométricas iniciais, adotam somente o primeiro modo da análise de autovalor. Comentário: isto seria uma opção simplificada, mas o leitor poderá constatar logo adiante que se optou por um refinamento melhor dos modelos numéricos deste presente trabalho.

GUO \& FUKUMOTO (1996) apresentam uma análise numérica de barras constituídas por perfis do tipo $U$ submetidas à compressão centrada, para os casos considerando o raio de curvatura, $r=2 \mathrm{t}$ e $r=4 \mathrm{t}$, e também para o caso de cantos vivos. Constataram que a capacidade resistente não é muito diferente entre esses casos. Entretanto, quanto maior o raio de curvatura mais é prorrogada a ocorrência da instabilidade local, conforme visualizado na Figura 6.1, provavelmente por ser menor a largura plana do elemento e com isso menor a esbeltez local. Comentário: vale dizer que neste presente trabalho de doutorado utilizou-se cantos arredondados, e como se criou os modelos pela linha de esqueleto foi adotado $r=1,5 \mathrm{t}$, i.e., raio médio.

DUBINA \& UNGUREANU (2002) negligenciam as tensões residuais nos modelos via elementos finitos de perfis do tipo $U$ e $U$ enrijecido, pois relatam que o trabalho de YOUNG \& RASMUSSEN (1995) obteve na medição dos ensaios destes tipos de perfis valores de tensão residual de membrana e de flexão entre 15 e $40 \mathrm{MPa}$, o que é muito baixo pois consideraram 
$\mathrm{f}_{\mathrm{y}}=45 \mathrm{kN} / \mathrm{cm}^{2}$. Comentário: ainda que neste presente trabalho não se tenha medido tensões residuais, e que a resistência ao escoamento seja de $28,8 \mathrm{kN} / \mathrm{cm}^{2}$ e de $37,5 \mathrm{kN} / \mathrm{cm}^{2}$, dependendo da espessura utilizada, portanto inferior ao trabalho citado, será visto adiante que uma estratégia foi desenvolvida para a inserção de tensões residuais nos modelos numéricos.

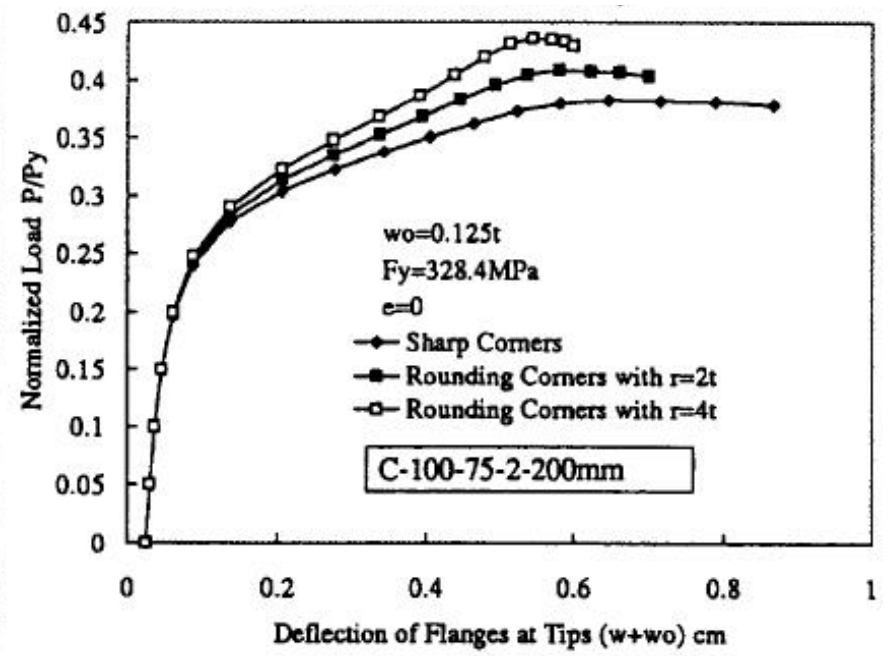

Figura 6.1 Perfis de aço formados a frio do tipo U: consideração ou não do raio de curvatura [GUO \& FUKUMOTO (1996)]

YANG \& HANCOCK (2004) adotam como procedimento para inserção de imperfeições geométricas iniciais nos modelos numéricos uma prévia análise de autovalor da barra (análise modal), obtendo as tensões e os modos de flambagem. Em seguida, fazem a atualização da geometria da barra com base em algum critério a partir da configuração deformada do primeiro modo de flambagem, ou superposição linear dos primeiros modos - provavelmente a utilização da superposição dos primeiros modos resulta mais crítica - e por último faz uma análise nãolinear física e geométrica analisando também o comportamento pós-crítico da barra. Comentário: Neste presente trabalho, utilizou-se um procedimento similar quanto às imperfeições geométricas, como será explicado. Para a resolução, optou-se pelo método de Newton-Raphson Full. Além disso, a observação deste artigo em questão quanto ao fato de que a utilização de imperfeições baseadas em um único modo de instabilidade nos modelos pode conduzir a uma resposta da estrutura não conservadora (contra a segurança, por superestimar a resistência da barra) reforçou a idéia de que neste presente trabalho fosse utilizado mais de um modo para compor a imperfeição inicial geométrica das barras, como será descrito adiante.

Ainda quanto ao artigo de YANG \& HANCOCK (2004), uma das maneiras para a inserção da imperfeição geométrica inicial nos modelos numéricos foi adotar a amplitude da forma deslocada relativa ao modo de flambagem oriundo da análise de autovalor como função de uma porcentagem da espessura do perfil, por meio da expressão de WALKER (1975), 
apresentada na expressão (2.13). Tal artigo relata que bons resultados foram obtidos. Comentário: esta opção parece ser interessante, dentre as várias encontradas na literatura. Entretanto, neste presente trabalho uma estratégia diferente, descrita adiante, foi elaborada em conjunto com o prof. Ben Schafer.

NARAYANAN \& MAHENDRAN (2003) introduzem tensões residuais de flexão nos modelos numéricos de maneira uniforme, no valor de $0,17 . f_{y}$, utilizando a sub-rotina SIGINI do ABAQUS. Foi adotada variação linear ao longo da espessura com valor nulo no centro da mesma. A comparação dos resultados de força última das análises numéricas para barras com e sem tensões residuais não apresenta resultados significativamente diferentes, sendo normalmente inferior a $5 \%$. Comentário: neste presente trabalho o procedimento proposto foi similar, e será descrito adiante. Adicionalmente, pode-se adiantar que os resultados de resistência máxima obtidos por análises prévias no presente trabalho também não apresentaram diferenças significativas quando comparados aos resultados de modelos sem tensões residuais. Portanto, a decisão foi de não se utilizar tensões residuais nos modelos.

\subsection{Procedimento da análise numérica}

Vale ressaltar que este capítulo está baseado em grande parte nas conclusões apresentadas em SCHAFER (1997), que é a Tese de Doutorado do prof. Benjamin W. Schafer. Sua Tese trata de todos os aspectos deste capítulo, pois o mesmo colheu dados de vários pesquisadores do mundo ao longo dos anos e realizou várias análises, além de ter elaborado, juntamente com o prof. Teoman Peköz, o programa de faixas finitas CUFSM (explicado a seguir) e proposto o Método da Resistência Direta (MRD) já explicado, ambos utilizados neste trabalho.

\subsubsection{Programa via faixas finitas CUFSM}

\subsubsection{Aspectos gerais do programa}

$\mathrm{Na}$ análise numérica deste trabalho, foi utilizado primeiramente o programa computacional via faixas finitas CUFSM, o qual realiza uma análise de estabilidade elástica da barra, como será aqui explicado. Isto foi feito para que tal análise pudesse contribuir para um melhor entendimento do comportamento dos perfis em questão, e fosse utilizada como uma opção para a utilização do MRD.

O CUFSM é um programa via Método das Faixas Finitas elaborado pelos profs. Benjamim W. Schafer e Teoman Peköz, vide SCHAFER \& PEKÖZ (1998). Este programa realiza a análise de estabilidade elástica de seções submetidas à distribuição qualquer de 
tensões normais nas extremidades. Examina uma variedade de comprimentos para a barra, para cada um dos quais a tensão crítica e a correspondente configuração deformada da barra, indicando o modo de flambagem, são arquivadas. Como resultado, é obtida a curva de flambagem com os modos de flambagem explicitados, como será mostrado a seguir. Essa curva fornece o fator de carga (relação entre a tensão crítica e uma tensão de referência) e correspondentes comprimento de meia-onda e configuração deformada, para todos os modos de instabilidade aplicáveis a cada seção analisada.

Devido à solução ser numérica, seções transversais com geometrias mais complexas, i.e., não usuais, não implicam em maiores dificuldades ao usuário do programa, habilitando o engenheiro a considerar quaisquer seções transversais sem complicações. Comparado com métodos manuais, a solução é muito mais direta.

Além disso, pelo fato de seções transversais como um todo (sem haver necessidade da separação dos elementos que constituem a seção transversal) poderem ser modeladas, a interação entre os elementos adjacentes que a constituem é considerada. Esta característica faz com que o CUFSM realize uma análise mais real do que, por exemplo, o método das larguras efetivas, se aproximando portanto dos programas em elementos finitos nesse aspecto. Portanto, é mais simples e requer menor tempo de processamento que programas em elementos finitos, porém é mais limitado, como será explicado logo adiante.

Para que a discretização em faixas finitas de uma barra forneça resultados com precisão satisfatória, cada elemento da seção transversal deve ser subdividido em pelo menos quatro faixas finitas. Ressalta-se que tal discretização considera os raios de dobramento, podendo inclusive considerar enrijecedores na seção, por exemplo no caso dos perfis do tipo $U$ enrijecido, com qualquer inclinação em relação à mesa do perfil.

A entrada de dados da seção transversal pode ser feita por coordenadas dos pontos de cada nó, ou então pode ser utilizada uma opção padrão do programa. Se for utilizada esta última opção, que automaticamente considera os cantos arredondados, dimensões planas da seção transversal devem ser utilizadas. Por exemplo, com relação aos perfis do tipo $U$ enrijecido, as dimensões nominais (externas) fornecidas pelos catálogos dos fabricantes, $b_{w}, b_{f}$, $\mathrm{D}, \mathrm{t}$ (vide Figura 5.5), devem ser alteradas para dimensões planas da seguinte forma (o subíndice 1 se refere às larguras requeridas pelo programa na opção padrão, para este exemplo):

$$
\begin{array}{ll}
\text { - } & \mathrm{b}_{\mathrm{w} 1}=b_{\mathrm{w}}-4 t \text { (alma) } \\
\text { - } & \mathrm{b}_{\mathrm{f} 1}=\mathrm{b}_{\mathrm{f}}-4 \mathrm{t} \text { (mesa) } \\
\text { - } & \mathrm{D}_{1}=\mathrm{D}-2 \mathrm{t} \text { (enrijecedor) } \\
\text { - } & \mathrm{r}_{1}=1,5 \mathrm{t} \text { (raio médio) }
\end{array}
$$


Para este tipo de entrada de dados, o programa escolhe automaticamente o número de faixas finitas para a discretização da seção transversal, 4 faixas em cada parte plana do perfil e 4 faixas em cada canto arredondado, o que após análises prévias se mostrou completamente satisfatório. Além disso, os comprimentos de meia onda para a execução da varredura realizada para a construção da curva de flambagem, são escolhidos conforme critério embutido no CUFSM.

Como mencionado anteriormente, há basicamente duas limitações do CUFSM que merecem destaque:

$\checkmark$ Empenamento livre nas extremidades da barra, i. e., não há restrição ao empenamento;

$\checkmark$ Seção transversal, esforços solicitantes e vinculações constantes ao longo do comprimento da barra, mesmo porque o programa é via faixas finitas (se discretiza a seção transversal, mas há somente uma faixa finita ao longo do comprimento) e não via elementos finitos. Portanto, por haver nós somente nas extremidades da barra, somente estes tem seus deslocamentos impedidos em relação aos eixos x e z, ou seja, deslocamentos no plano da seção. Somente nestes nós pode-se aplicar solicitação externa, sendo aplicada ao longo da "linha de esqueleto" da seção transversal, por força por unidade de comprimento. Como visto, há uma condição simétrica de condições de contorno.

É importante lembrar que para se utilizar o CUFSM como ferramenta de projeto, i.e., cálculo estrutural, deve-se ter em mente que como o mesmo fornece como resultado apenas tensões críticas de flambagem elástica, tais valores devem ser corrigidos por curvas de resistência para a obtenção dos esforços resistentes da barra analisada.

No caso de se optar pela utilização do programa CUFSM, por ser uma ferramenta simples para a análise de estabilidade elástica de uma seção, a fim de utilizá-lo para aplicação do Método da Resistência Direta (MRD), os valores que devem ser obtidos do programa, por exemplo para o caso de barras submetidas à compressão, são $N_{c r}, N_{c r d}, N_{c r e}$, forças normais críticas elásticas relativas aos modos local, distorcional e global (Euler), respectivamente.

Entretanto, é recomendado que o valor de $\mathrm{N}_{\text {cre }}$ não seja obtido do programa, mas pelas expressões da teoria de estabilidade elástica, de maneira a permitir considerar as várias condições de vínculo da barra. Isto é porque se houver travamentos nas barras, a abscissa a ser tomada no CUFSM para a obtenção dos resultados do programa, referente ao modo global, se desloca para a esquerda (pois nesse caso $K<1$ ), possivelmente ficando sobre a curva do modo local ou distorcional, e seria necessário solicitar do programa modos superiores para se obter resultados da curva do modo global desejado em abscissa. 
Para que o leitor entenda um pouco melhor este programa, é importante saber que a faixa finita utilizada possui 4 nós, com 4 graus de liberdade por nó, sendo 3 translações $\left(u_{x}=u\right.$, $u_{y}=v$ e $\left.u_{z}=w\right)$ e 1 rotação $\left(\phi_{y}=\theta\right)$, conforme ilustrado na Figura 6.2. Além disso, o plano da seção transversal das barras é definido pelos eixos $x$ e $z$, sendo que o eixo y é relativo ao comprimento da barra (eixo longitudinal).

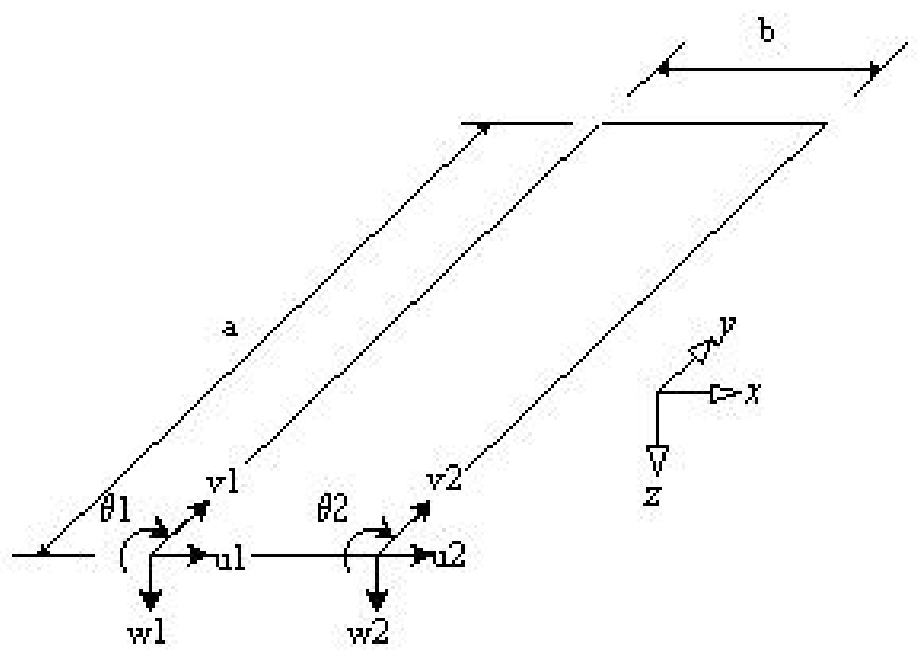

Figura 6.2 Faixa finita - programa CUFSM

Após explicações iniciais sobre o CUFSM, e passando agora a uma fase de aplicação no presente trabalho, é importante que se diga que este programa foi utilizado para analisar todas as seções ensaiadas, conforme será mostrado mais adiante. Por exemplo, a Figura 6.3 e a Figura 6.4 ilustram exemplos de saída de resultados (curva de flambagem).

Na Figura 6.3 observa-se para o perfil $U$ enrijecido a clara diferença entre as tensões críticas de flambagem elástica para o modo local e o distorcional. O modo local, que apresenta ponto de mínimo (tensão crítica elástica) de $39,11 \mathrm{kN} / \mathrm{cm}^{2}$, é crítico em relação ao modo distorcional, que apresenta ponto de mínimo (tensão crítica elástica) de $56,79 \mathrm{kN} / \mathrm{cm}^{2}$. Resumindo, ainda que seja somente uma análise elástica, essa seção é mais propensa à instabilidade via modo local do que via distorcional.

Por outro lado, a Figura 6.4 - dois modos são ilustrados, mas a curva azul é a crítica ilustra a singela diferença que ocorre na análise elástica para o caso das cantoneiras entre os modos local de chapa e global de torção. A primeira parte da curva indica uma coincidência entre o modo local e o modo global de torção (a rigor, flexo-torção, e que será denominado modo local/torsional neste trabalho conforme explicação a ser dada no item 7.1) não existindo um ponto de mínimo. A segunda parte é claramente um modo global de flexão. 
Todos os resultados das análises via CUFSM são apresentados no apêndice, sendo discutidos no capítulo 7, de análise e discussão dos resultados.

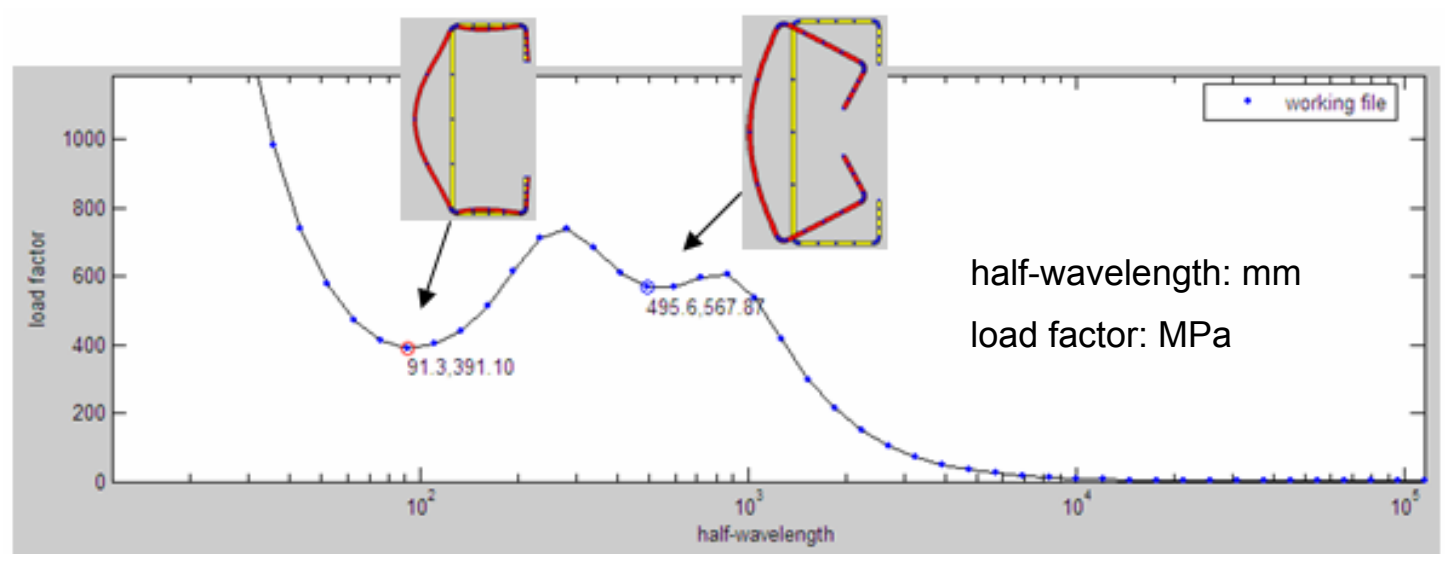

Figura 6.3 CUFSM: resultado U enrijecido $125 \times 50 \times 25 \times 2,38 \mathrm{~mm}$ submetido à compressão

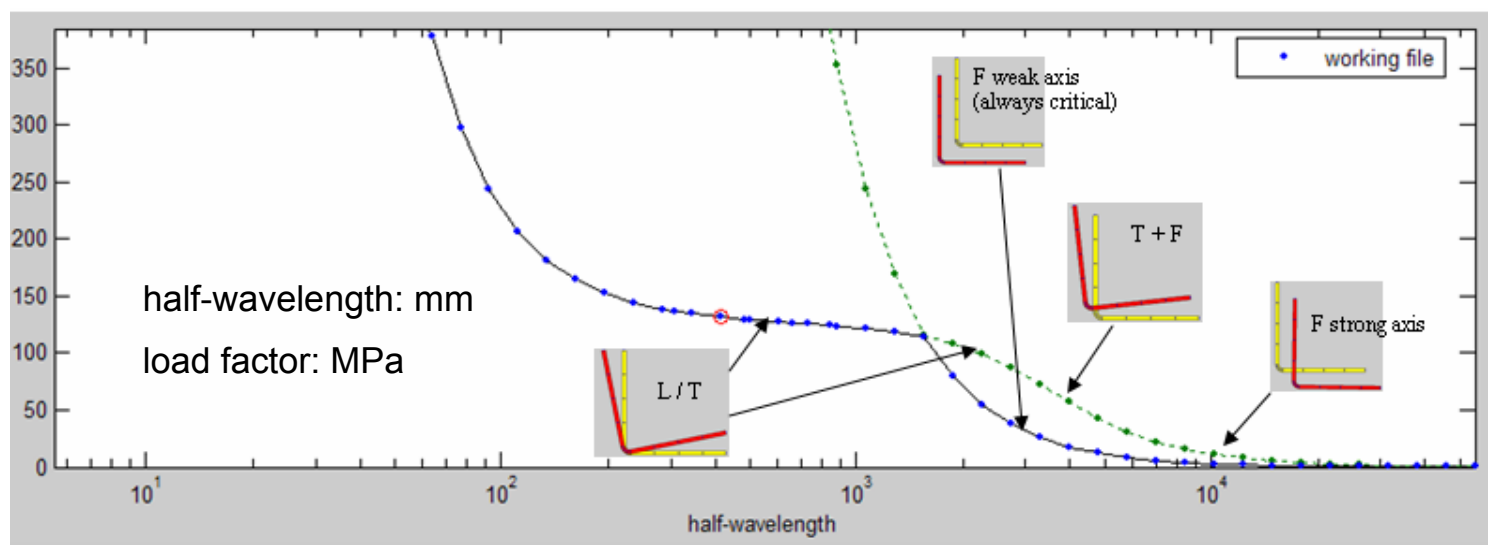

Figura 6.4 CUFSM: resultado cantoneira simples $60 \times 2,38 \mathrm{~mm}$ submetida à compressão

\subsubsection{Programa via elementos finitos ANSYS}

\subsubsection{Aspectos gerais da modelagem}

Para simular o comportamento de todas as barras da análise experimental realizada neste trabalho, e com isso poder propor uma estratégia confiável de análise numérica para perfis de aço formados a frio, foram criados modelos em elementos finitos utilizando o programa Ansys, os quais foram calibrados com os próprios resultados experimentais deste trabalho.

Inicialmente, foi realizada uma análise de autovalor, na qual solicitou-se do programa os primeiros 100 modos de instabilidade, a fim de se capturar somente os modos de interesse. Esta análise de autovalor foi realizada tanto como opção à utilização do CUFSM para emprego 
do Método da Resistência Direta (MRD), como para gerar as imperfeições geométricas iniciais para a análise não-linear física e geométrica, que foi realizada em seguida.

Os elementos finitos utilizados foram de casca e sólido. Para os perfis foi utilizado o elemento SHELL 181, com quatro nós, sendo seis graus de liberdade por nó (três translações e três rotações, com relação aos eixos $\mathrm{x}, \mathrm{y}, \mathrm{z}$ ), conforme ilustrado na Figura 6.5. Para os dispositivos de extremidade, foi utilizado o elemento SOLID 45, com oito nós, sendo três graus de liberdade por nó (três translações, com relação aos eixos $x, y, z$ ), conforme ilustrado na Figura 6.6.

Para estes modelos o plano da seção transversal adotado foi o $x-y$, sendo $z$ o eixo ao longo do comprimento das barras. As seções transversais dos perfis foram desenhadas por meio da linha de esqueleto, adotando-se para os elementos dos perfis a espessura real média medida no laboratório, e não a nominal, como explicado anteriormente. Considerou-se os cantos arredondados dos perfis (Figura 6.7).
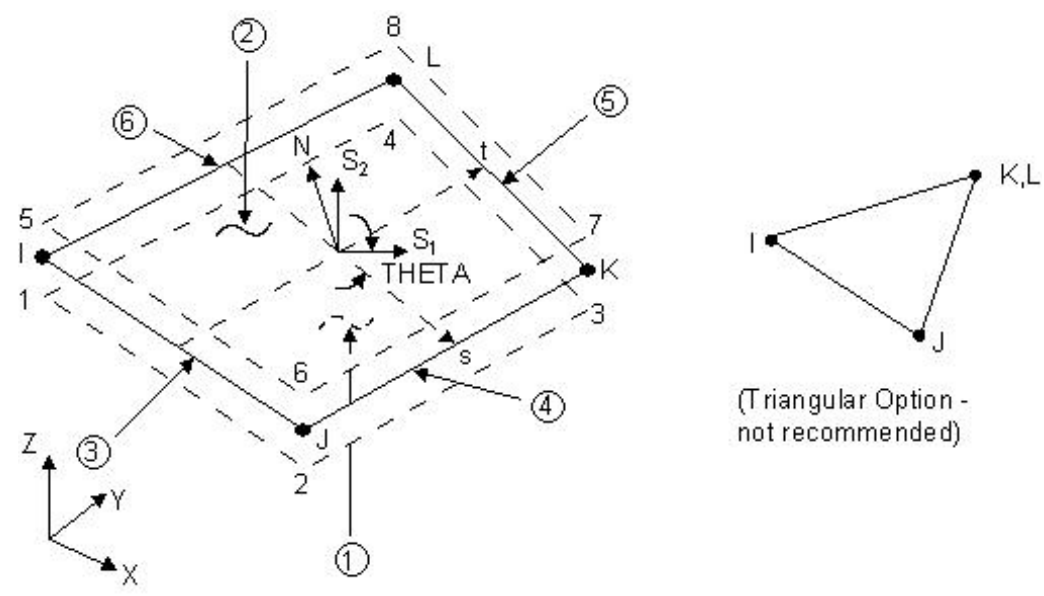

(Triangular Option not recommended)

Figura 6.5 Elemento SHELL 181 - programa ANSYS
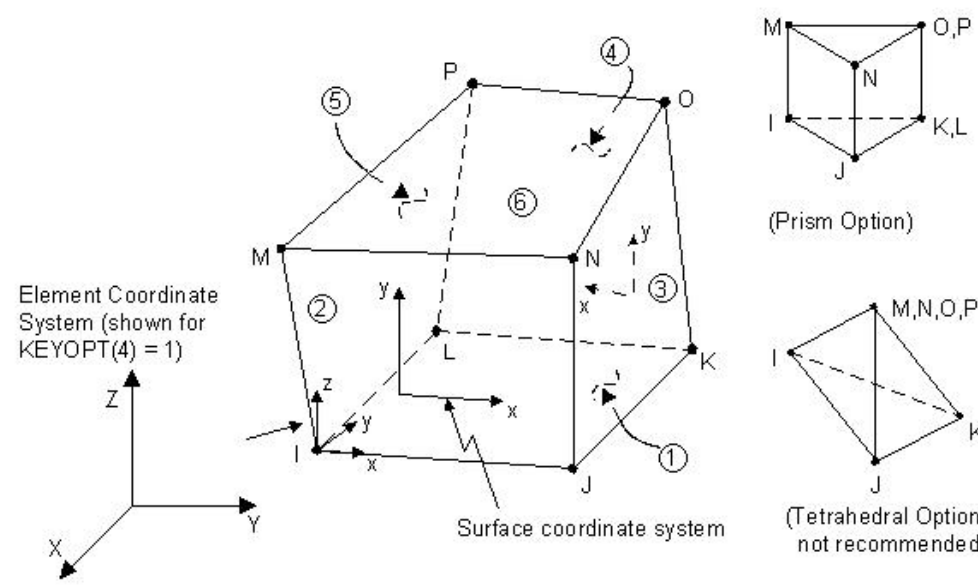

(Prism Option)

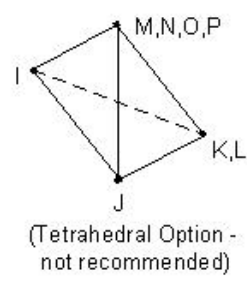

Figura 6.6 Elemento SOLID 45 - programa ANSYS 


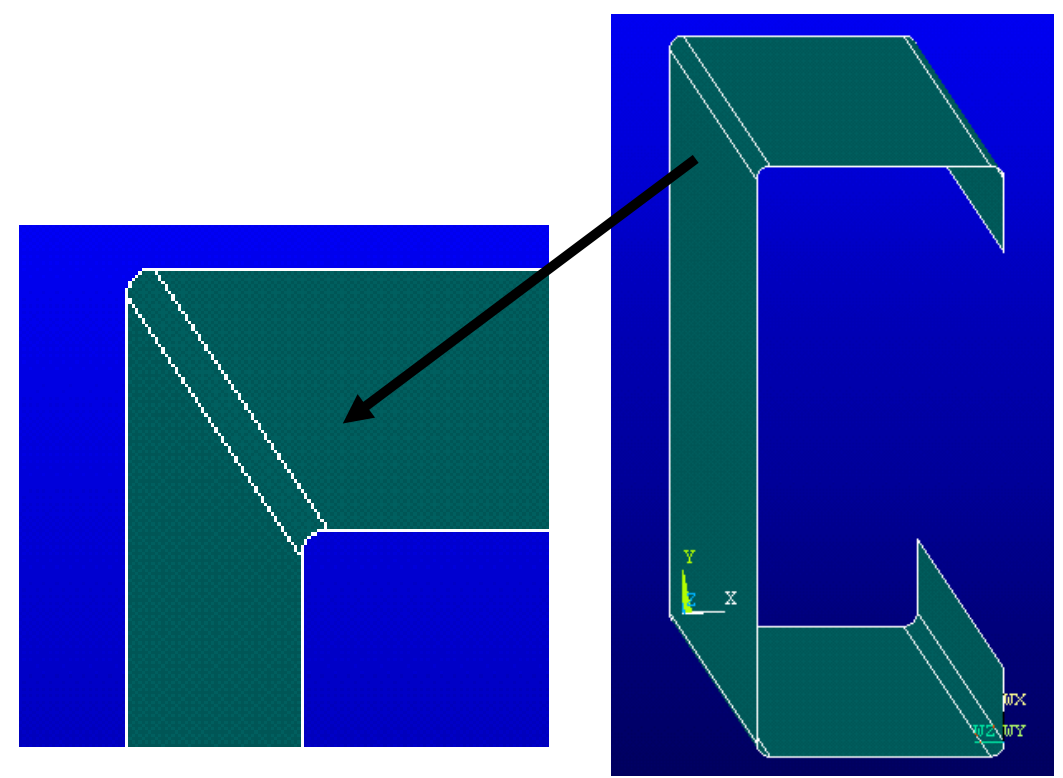

Figura 6.7 Perfil Ue analisado no ANSYS: detalhe dos cantos arredondados

Todos os elementos finitos são ou quadrados (elementos de casca) ou cúbicos (elementos sólidos), com lado de $1 \mathrm{~cm}$, sendo que esta discretização foi definida após análise prévia, em que apresentou bons resultados. A dimensão da malha da região dos cantos (curvas) na seção transversal foi exceção, utilizando 2 elementos (vide Figura 6.8).

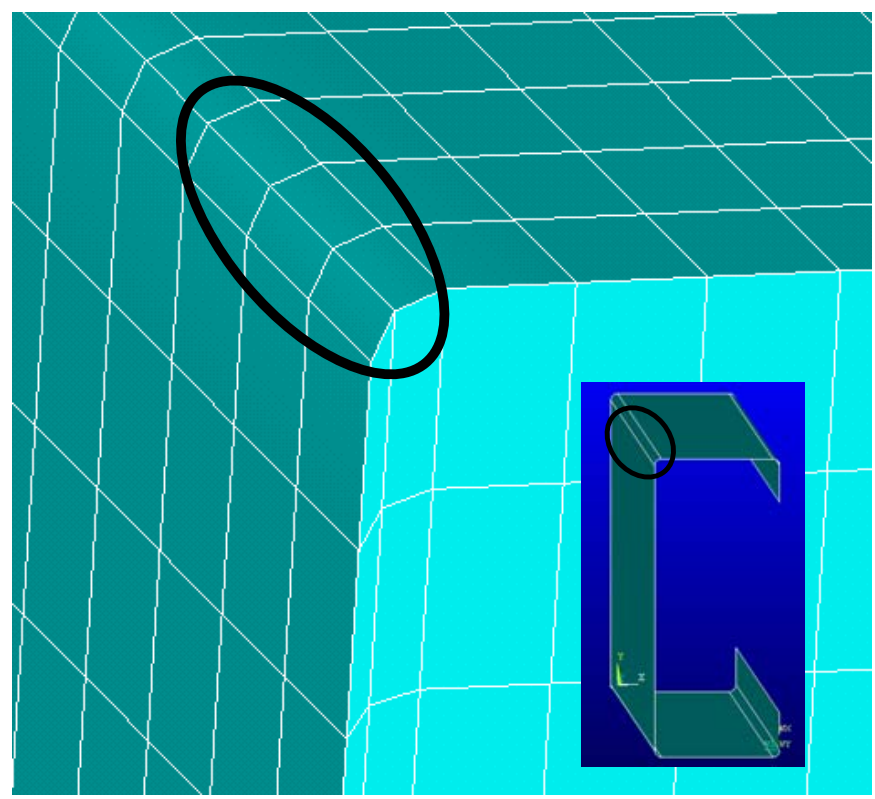

Figura 6.8 Ansys: detalhe malha região dos cantos (exemplo perfil tipo U enrijecido)

Para que o modelo fosse criado de modo a reproduzir a análise experimental, a espessura do dispositivo de extremidade, em cada extremidade das barras, foi adotada como sendo a soma da espessura da chapa do dispositivo de extremidade propriamente dito (55mm) 
mais a espessura da chapa de topo $(12,5 \mathrm{~mm})$, sendo então adotada a espessura total de $67,5 \mathrm{~mm}$ para cada extremidade. Isto foi realizado mediante a criação de um bloco de elementos sólidos com espessura de $67,5 \mathrm{~mm}$ em cada extremidade das barras, e se explica pois já foi mencionado que na análise experimental o comprimento entre as rótulas $\left(L_{r}\right)$ é o comprimento das barras ( $\left.L_{\text {perfil }}\right)$ mais $135 \mathrm{~mm}$ (duas vezes $67,5 \mathrm{~mm}$ ).

Além disso, para que a análise numérica representasse a compressão centrada realizada na análise experimental, e também o funcionamento das rótulas (Figura 6.9), os dispositivos de extremidade dos modelos foram criados de modo que uma linha de nós da sua malha passasse pelo centro de gravidade da seção transversal da barra, obviamente variando a posição e direção dessa linha de nós dependendo do tipo de seção transversal e tipo de ensaio.

Por exemplo, a Figura 6.10 ilustra tal linha para a rótula posicionada de modo a permitir flexão em torno do eixo de menor inércia no perfil do tipo $U$. Pode-se ver no modelo que a aplicação de deslocamento ocorre ao longo dessa linha, simulando a "faca" da rótula utilizada na análise experimental (Figura 6.9). Essa "faca" aplica o deslocamento da máquina de ensaio, e está em contato em uma chapa grossa, que está por sua vez em contato com a chapa de topo soldada à barra.

Para que fosse possível esse tipo de aplicação de deslocamento nos modelos, todos os nós dessa linha (procedimento realizado para os dispositivos das duas extremidades das barras) foram acoplados com relação a $U_{z}$ (deslocamento perpendicular ao plano da seção transversal, isto é, ao longo do comprimento das barras). Isto possibilitou que a linha simulando a "faca" se movesse uniformemente comprimindo a seção, como na análise experimental.

Portanto, nos dispositivos de extremidade, na face externa dos elementos sólidos, de uma das extremidades das barras foi aplicada então compressão por meio de deslocamento aplicado na direção z (eixo ao longo do comprimento das barras) em um nó denominado mestre entre os nós da linha dos dispositivos de extremidade. Com isso, toda a linha se desloca uniformemente, pois estes nós dessa linha foram acoplados segundo o grau de liberdade Uz, conforme já descrito. Por outro lado, no dispositivo de extremidade, na face externa dos elementos sólidos, da outra extremidade da barra, o deslocamento na direção z (grau de liberdade Uz) foi restringido para todos os nós da linha da malha que passa pelo CG, simulando o apoio da máquina de ensaio.

É importante salientar que o valor deste deslocamento foi adotado como aproximadamente 1,20 vezes o deslocamento máximo do prato da máquina de ensaio (deslocamento do pistão) verificado durante o ensaio realizado previamente para cada barra. Isto foi feito para se verificar se o comportamento seria de fato similar à análise experimental.

Este procedimento de aplicação de deslocamento tornou a convergência da análise não-linear mais fácil, e permitiu que as forças equivalentes fossem obtidas após o 
processamento tanto para as ações (no nó mestre de aplicação do deslocamento) quanto para as reações (no nó mestre de restrição do deslocamento), as quais apresentam os mesmos valores, com sinais contrários, verificando-se a capacidade das barras (resistência máxima, ou força máxima aplicada).

A Figura 6.10 também serve para ilustrar os elementos sólidos na extremidade da barra, utilizados para simular o sistema da rótula (dispositivo de extremidade), e o procedimento adotado quanto à restrição e acoplamento dos graus de liberdade para o caso particular do perfil do tipo $U$ a fim de simular as condições da análise experimental.

Continuando a explicação sobre a simulação do sistema de rótulas (dispositivo de extremidade), a Figura 6.11 ilustra o bom funcionamento da rótula tanto na análise experimental como nos modelos numéricos. É ilustrado o giro da rótula (flexão em torno do eixo de menor inércia) para um perfil do tipo $U$ simples para as duas situações, sendo que pode ser visto nitidamente na imagem (b) o giro em torno da linha que passa pelo centro de gravidade, representando assim a "faca" como na análise experimental.

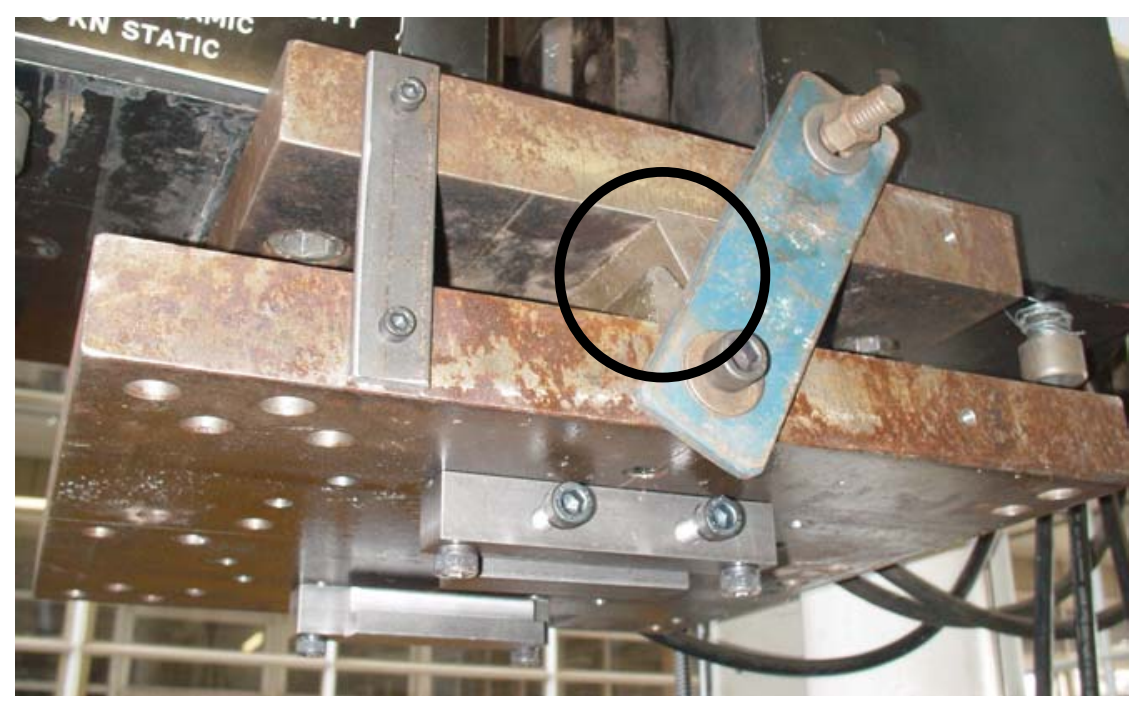

Figura 6.9 Apoio superior: detalhe da "faca" (permite rotação somente em torno de um eixo)

Em síntese, as condições de contorno utilizadas no Ansys para simular a análise experimental para todas as seções transversais são apresentadas na Tabela 6.1.

Para completar o assunto, vale dizer, como mencionado anteriormente, que para as cantoneiras duplas foram colocadas presilhas na análise experimental (e adotadas também para as análises numéricas, respeitando o espaçamento máximo sugerido pela NBR 14762:2001), como apresentado na Tabela 5.7. Portanto, na modelagem via elementos finitos essas presilhas foram simuladas por meio do acoplamento dos graus de liberdade de translação $U_{x}, U_{y}$ e $U_{z}$ de 18 nós, sendo 9 nós em cada cantoneira. Desse modo, a região das presilhas abrange 4 elementos finitos adjacentes formando um quadrado de $2 \mathrm{~cm} \times 2 \mathrm{~cm}$, 
posicionado na metade da altura da aba das cantoneiras nas posições previstas ao longo do comprimento das barras (vide Figura 6.12).

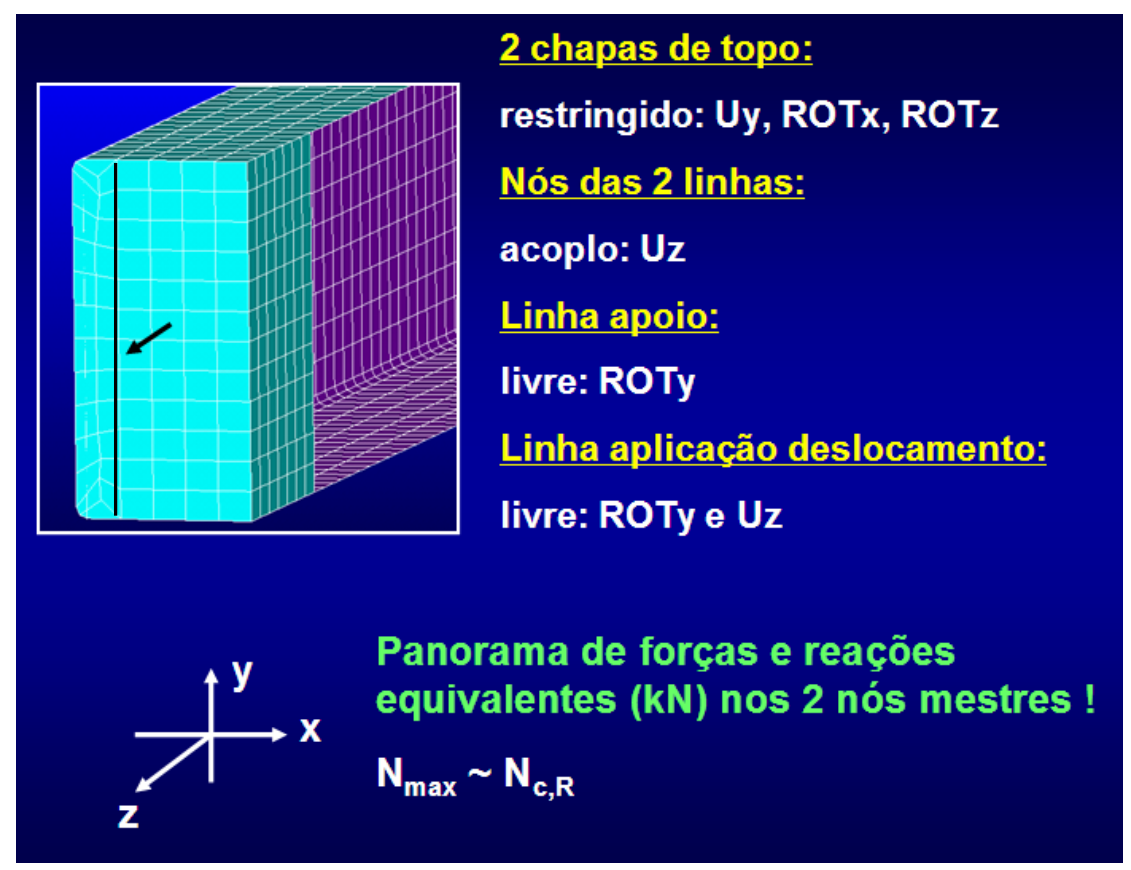

Figura 6.10 Perfil tipo U com linha vertical de nós da malha do dispositivo de extremidade, na face externa dos elementos sólidos, passando pelo C.G. da seção: condição simulando a análise experimental

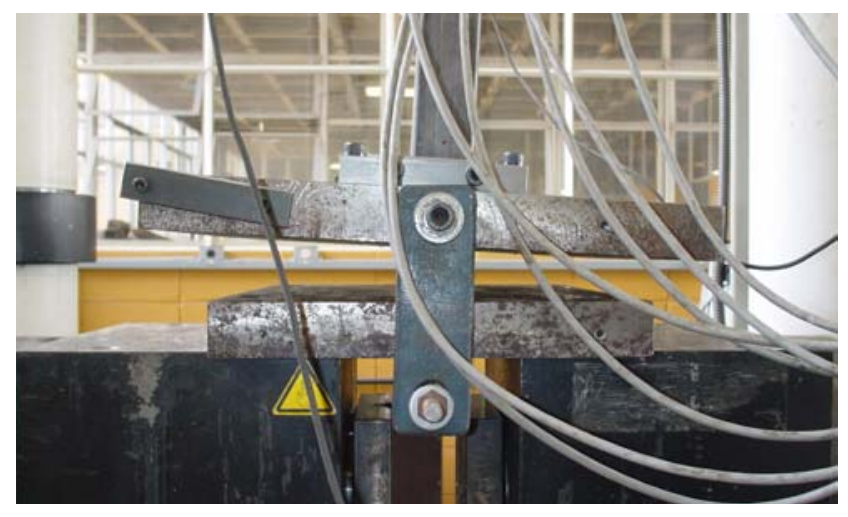

(a)

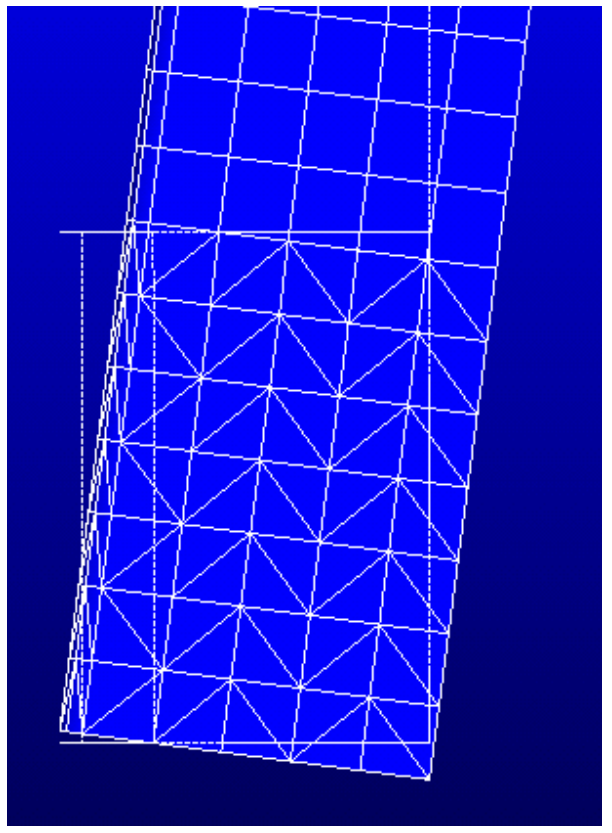

(b)

Figura 6.11 Funcionamento da rótula: perfil U simples

(a) giro em torno da "faca" (b) giro em torno da linha que passa pelo centro de gravidade 
Os itens a seguir, relativos à imperfeições geométricas iniciais, tensões residuais e modelo reológico (curva tensão-deformação), adotados nos modelos numéricos, ainda não são um consenso entre os pesquisadores no mundo. Portanto, espera-se que este trabalho possa contribuir com um avanço de idéias nesse sentido.

Tabela 6.1 Condições de contorno para simular a análise experimental: modelos via Ansys

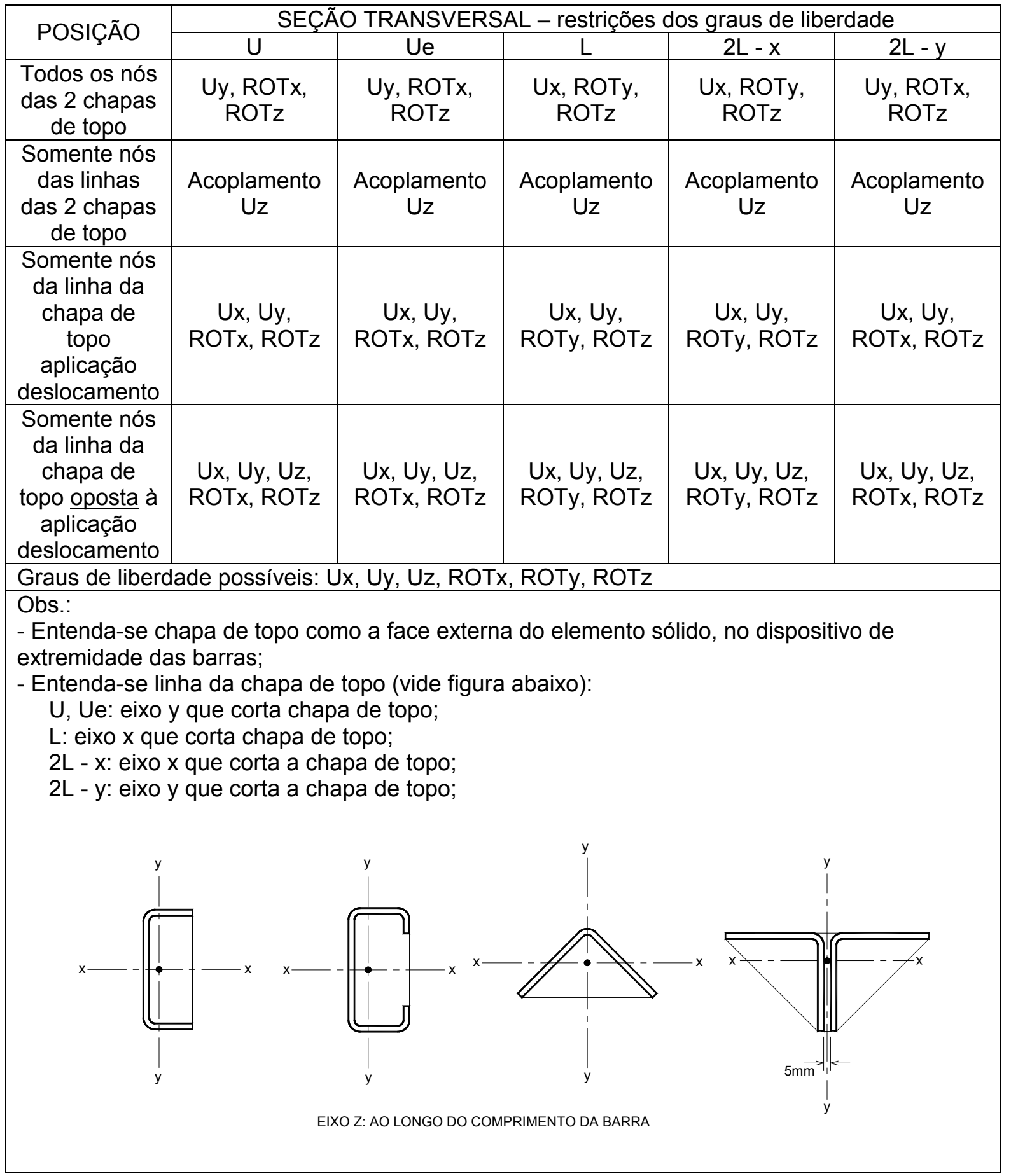




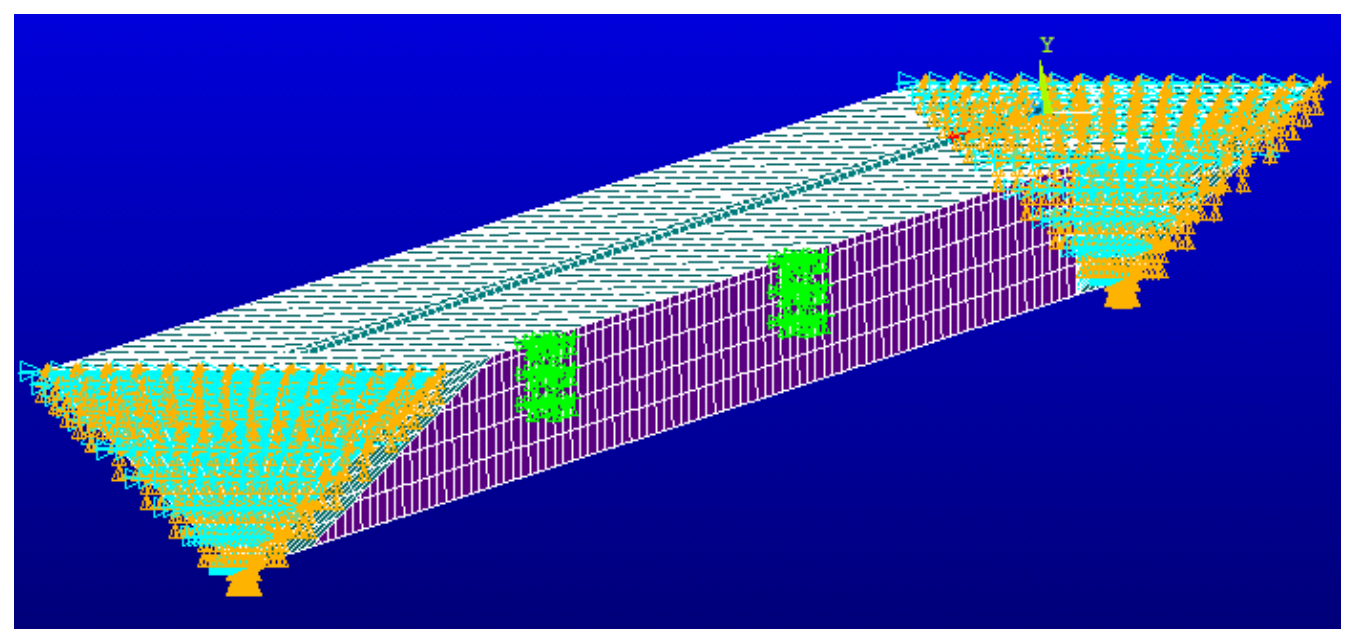

Figura 6.12 Presilhas simuladas no Ansys nas cantoneiras duplas

\subsubsection{Imperfeições geométricas iniciais}

Um aspecto muito importante quanto à análise numérica não-linear de perfis de aço formados a frio é o relativo às imperfeições geométricas iniciais. Diferentes panoramas podem mudar completamente a resposta dos modelos. Como agravante, ainda não existe um consenso dos pesquisadores quanto a magnitude, forma e modo de aplicação das imperfeições utilizadas nos modelos numéricos, conforme já explicado na revisão bibliográfica deste trabalho.

Durante o estágio de 3 meses na The Johns Hopkins University, sob orientação do Prof. Dr. Benjamin W. Schafer, inicialmente foram realizadas várias análises numéricas com nãolinearidade geométrica variando-se as imperfeições geométricas iniciais, para que se chegasse a uma decisão sobre o procedimento a ser utilizado nos modelos.

Inicialmente, pelo fato de se ter medido no laboratório as imperfeições geométricas iniciais em algumas barras, conforme apresentado no item 5.3.1.1, tentou-se utilizar desta informação para se obter um panorama de imperfeições iniciais próximo do real das barras analisadas.

Para tanto, utilizou-se o programa CUFSM para analisar as seções transversais, vide Figura 6.13, na qual a deformada do modo local é destacada. Foram anotados os números dos nós do modelo que coincidiam com as posições nas seções transversais onde se efetuaram as medidas das imperfeições iniciais no laboratório, ilustradas anteriormente na Figura 5.10.

Utilizando-se dados do CUFSM, foi elaborado um programa na plataforma MatLab (exemplo de saída gráfica de resultados ilustrada na Figura 6.14), com o qual se conseguiu obter para todas as seções transversais os modos de instabilidade de interesse (local, global, e quando aplicável o distorcional) possibilitando-se a visualização das curvas dos dois primeiros modos críticos para cada tipo de instabilidade, o que entendeu-se ser satisfatório. A curva em 
azul (primeiro modo) é a curva crítica para todos os tipos de instabilidade possíveis de acontecer para a seção analisada.

Embora a curva de flambagem deste programa via MatLab seja a mesma fornecida pelo programa CUFSM (o que pode ser notado comparando-se a curva azul da Figura $6.14 \mathrm{com}$ a curva da Figura 6.13), este programa via Matlab fornece também como resultado uma listagem com os delocamentos máximos (amplitude) no meio do comprimento das barras para as tais posições nas seções transversais em que foram medidas no laboratório as imperfeições. Obviamente, são apresentados, em tais resultados, valores relativos entre os delocamentos dos pontos da seção, que posteriormente foram comparados com os valores medidos no laboratório. É importante dizer que embora a Figura 6.14 ilustre a tela de resultados somente para o caso do perfil $U$ enrijecido, isto é um mero exemplo, pois este programa via MatLab foi feito e utilizado para todas as seções transversais analisadas neste trabalho.

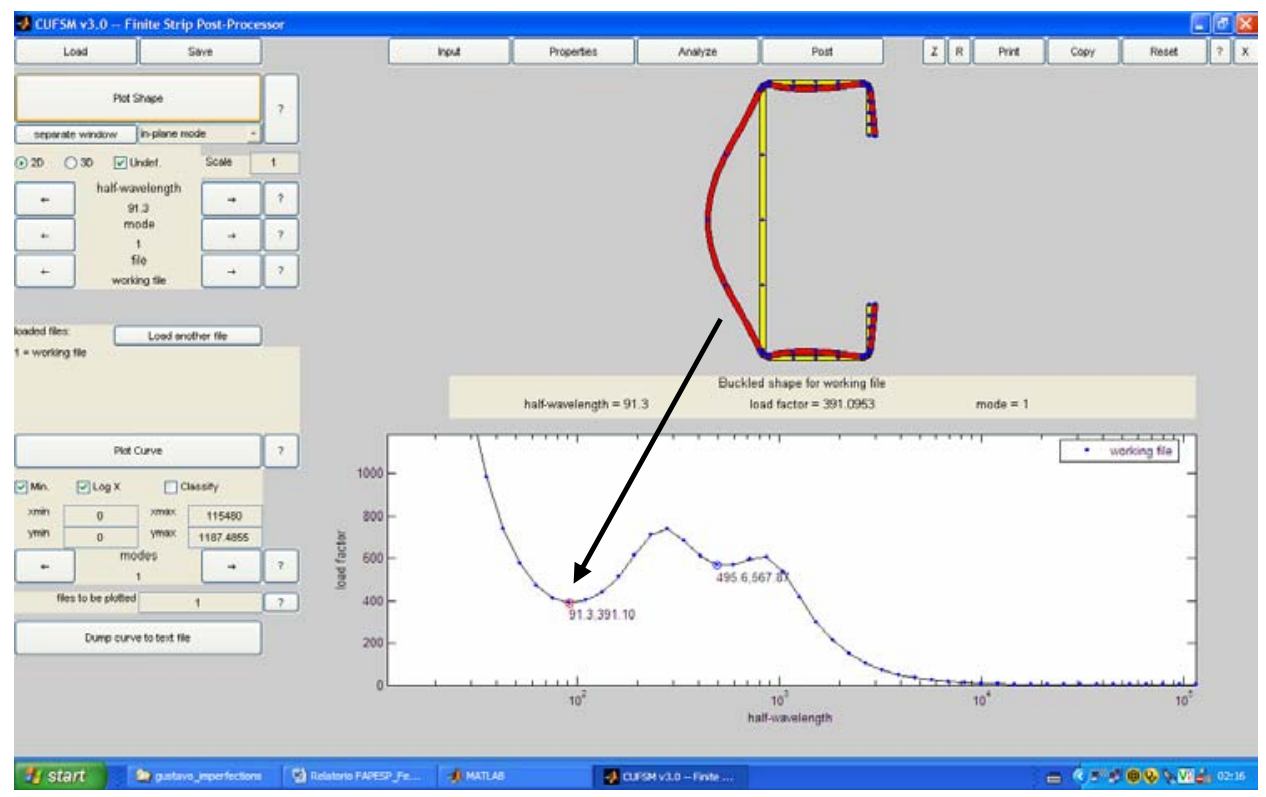

Figura 6.13 Resultado programa CUFSM: perfil Ue 125x50×25×2,38mm

Como já explicado no item 5.3.1.1, as imperfeições medidas no laboratório podem resultar da superposição de deslocamentos oriundos da configuração deformada do eixo da barra (global), da ondulação dos elementos (chapas) e distorção da seção transversal, e não há uma maneira confiável para se desmembrar tais imperfeições relativas a cada modo. Por outro lado, sabe-se que a função senoidal de Young - ilustrada na Figura 2.7 e apresentada na expressão (2.8) - é classicamente conhecida para se avaliar a imperfeição relativa ao modo global. Portanto, utilizando-se destas duas informações, foram feitas planilhas no Excel para se fazer um ajuste. 
Este ajuste foi realizado para todas as seções nas quais foram medidas imperfeições geométricas iniciais, sendo que a partir das leituras do laboratório tentou-se, para cada barra e seção transversal analisada, minimizar o erro ao longo do comprimento das barras entre os valores medidos de imperfeição e a curva senoidal clássica de Young.

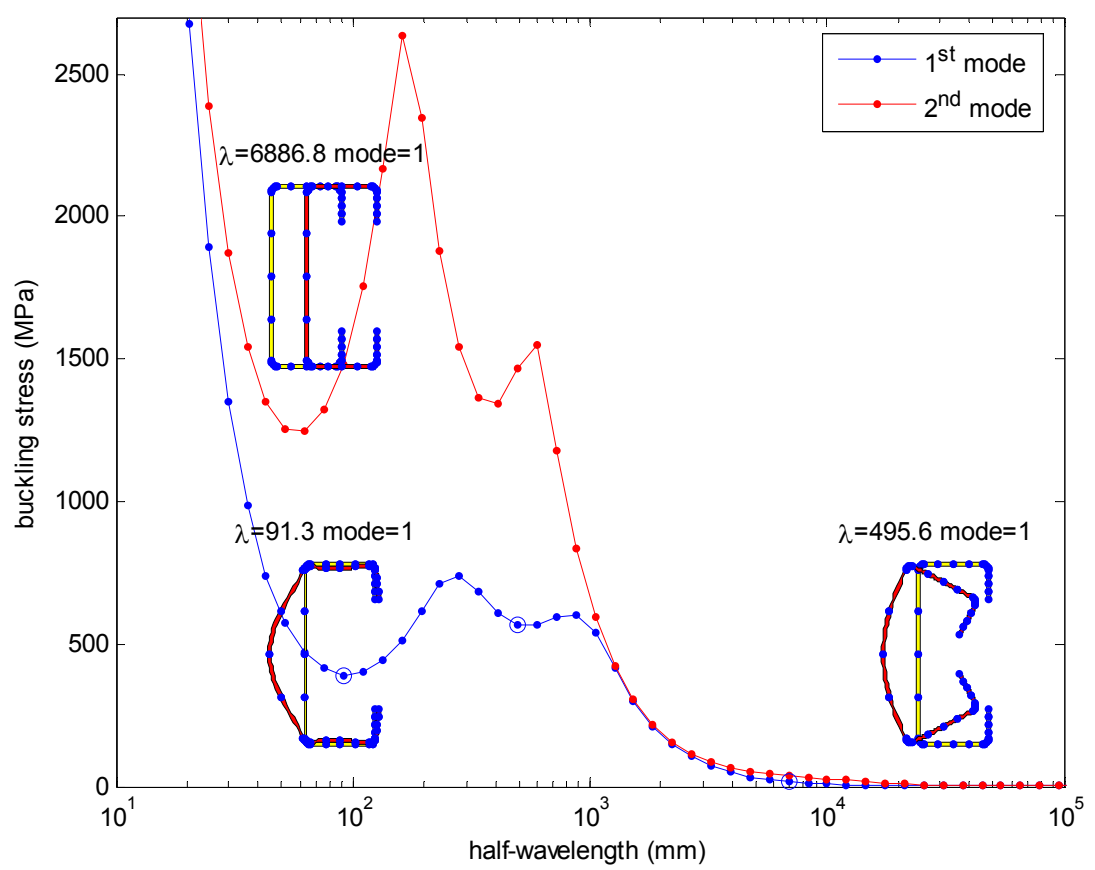

Figura 6.14 Programa via MatLab: Modos de instabilidade via faixas finitas perfil $U$ enrijecido com $t=2,38 \mathrm{~mm}$

Para tanto, utilizou-se a amplitude proveniente do programa via MatLab (que utiliza resultados do CUFSM, como explicado) para a senóide de Young em cada ponto medido da seção transversal. Vale lembrar que este ajuste foi feito para todos os modos de instabilidade pertinentes, para todas as barras em questão.

O processo de minimização do erro ao longo do comprimento das barras foi feita utilizando-se o Solver do Excel. O objetivo foi minimizar a soma dos quadrados dos erros (diferenças entre imperfeição medida e curva senoidal de Young) para todos os pontos da seção transversal para todas as 10 divisões ao longo do comprimento das barras.

Como exemplo, o gráfico gerado pelo Excel para a cantoneira de comprimento $1.195 \mathrm{~mm}$ é apresentado na Figura 6.15 , onde se pode ver que os valores originais $(A, B, C, D)$ são devido à medição das imperfeições no laboratório, enquanto que os valores "fit" são o resultado da minimização de erros. Para as outras seções e barras o procedimento foi similar. 


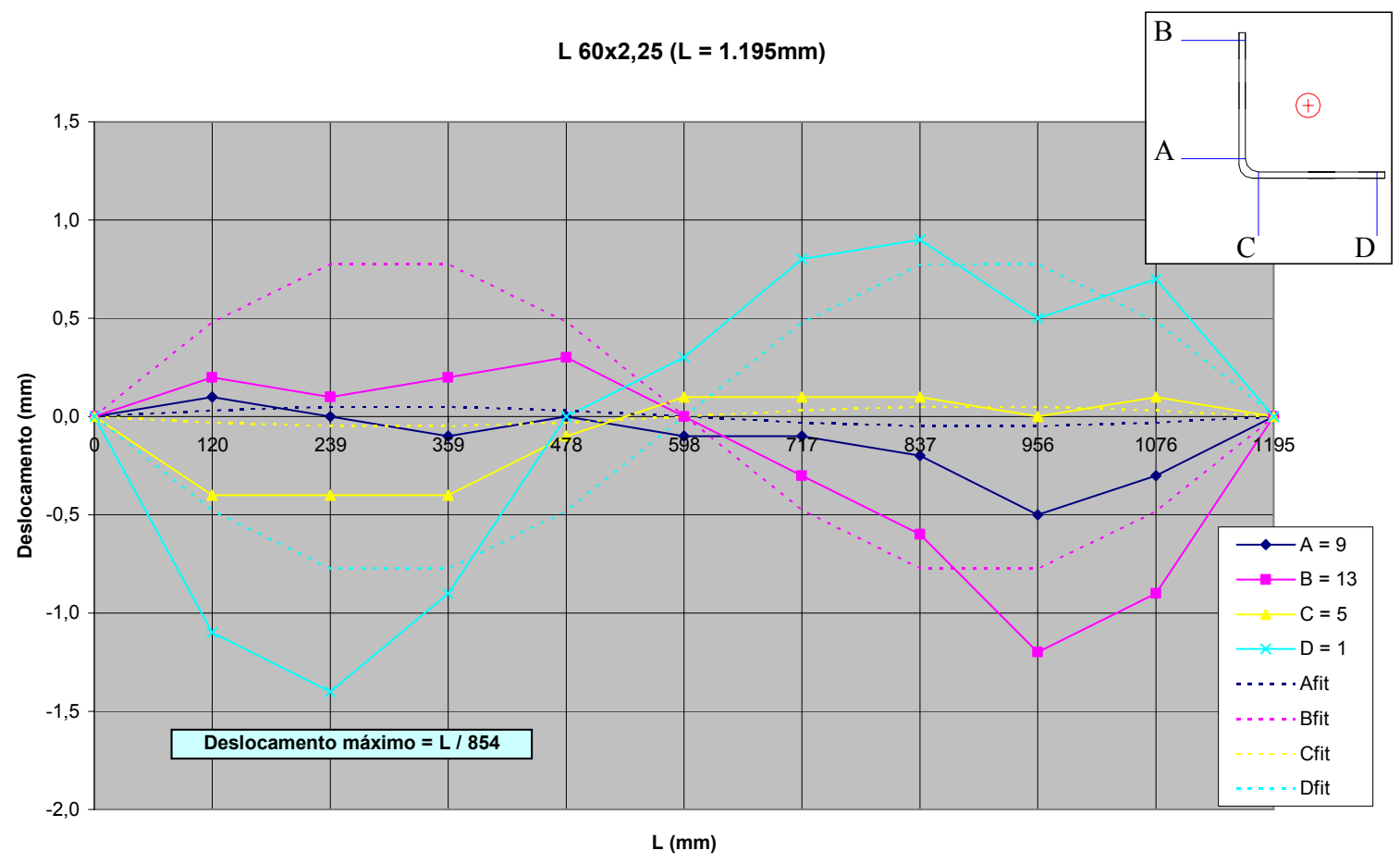

Figura 6.15 Minimização do erro entre imperfeições medidas e senóide de Young

Após esta minimização de erros, anotou-se o valor máximo de amplitude resultante dentre os pontos da seção transversal mencionados. Daí, a divisão deste valor pela espessura da seção conduziu ao valor de d/t, para cada modo de instabilidade, para cada barra analisada.

Com esse procedimento, todos os modos de instabilidade foram avaliados e forneceram os valores $\mathrm{d} / \mathrm{t}$ para todas as seções transversais em todas as barras.

Para facilitar o entendimento e reduzir a curiosidade do leitor, antes que outros critérios sejam explicados quanto à definição dos valores de imperfeição geométrica inicial, será agora apresentada uma estratégia proposta para se aplicar essas imperfeições geométricas iniciais aos modelos numéricos.

Esta estratégia partiu da idéia de se realizar a análise de autovalor utilizando-se o programa Ansys, que fornece como resultado tanto o autovalor (valor de força crítica) como o autovetor (deformada da barra) para os modelos completos, ou seja, conjunto formado pela barra e dispositivos de extremidade.

Nesta análise foram registrados os 100 primeiros modos de instabilidade, dentre os quais obviamente se tentou escolher os "modos puros", i.e, modos isolados e não combinados/acoplados de instabilidade, referentes aos modos de instabilidade local, global, e também distorcional quando aplicável. Por exemplo, o modo local (ou local/torsional, como melhor explicado no item 7.1) e o global de flexão para uma cantoneira simples são ilustrados, respectivamente, na Figura 6.16 e Figura 6.17 repectivamente. 


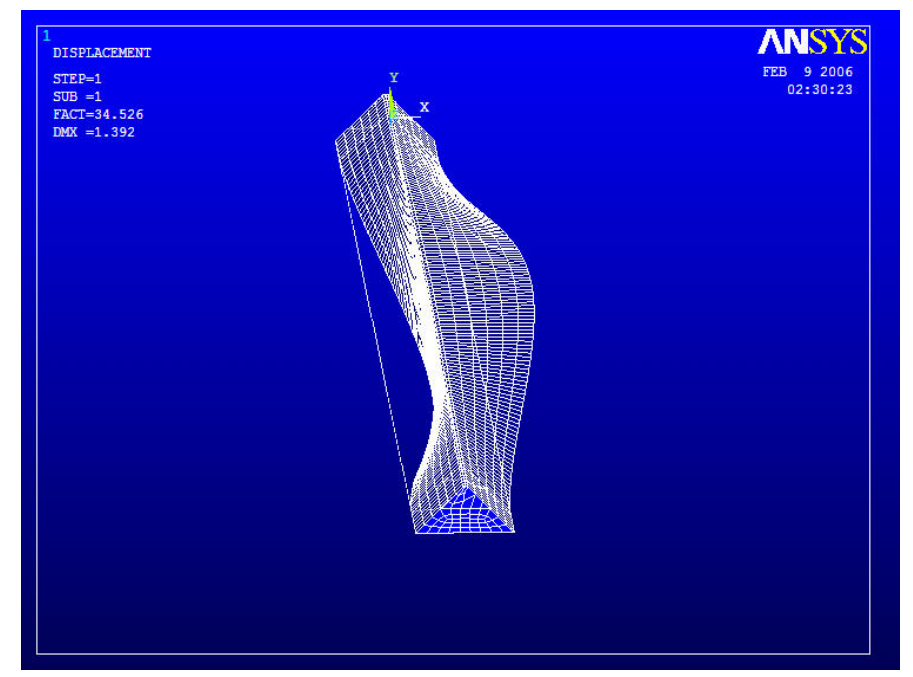

Figura 6.16 Análise de autovalor: modo local perfil $L$ 60x2,38mm $(\mathrm{Lr}=1.330 \mathrm{~mm})$

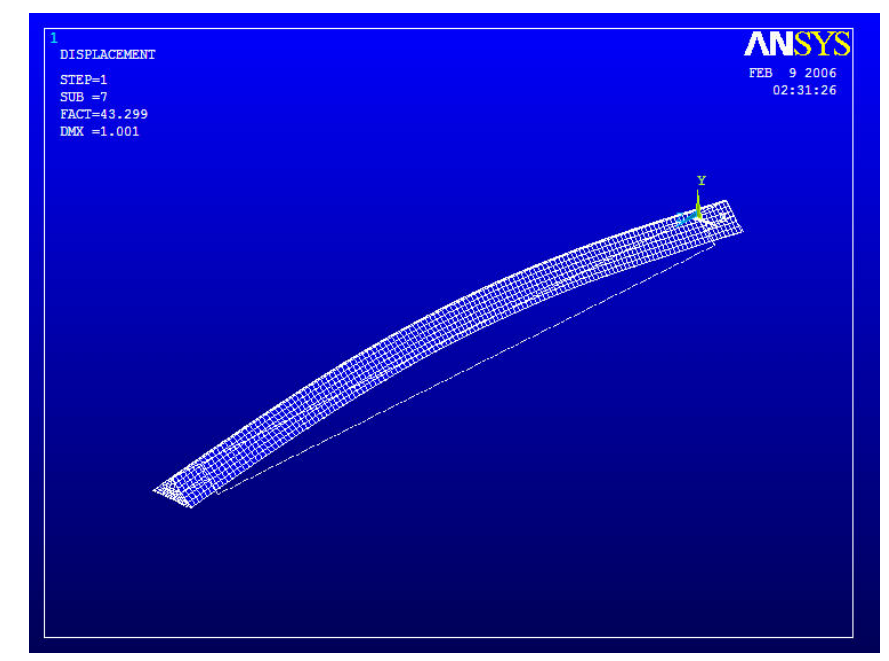

Figura 6.17 Análise de autovalor: modo global de flexão perfil L 60x2,38mm ( $\mathrm{Lr}=1.330 \mathrm{~mm})$

A partir do resultado da configuração deformada (autovetor) referente a cada um dos modos críticos escolhidos para cada caso, com base no respectivo valor da amplitude de cada configuração (deslocamento máximo entre todos os nós da malha desta configuração deformada, frente à geometria inicial), foi adotado um critério a fim de se amplificar ou reduzir esta amplitude, e com isso se obter a nova geometria de todos os nós da malha de elementos finitos da barra.

Após essa utilização do critério em questão (será logo explicado) para a geração das novas geometrias das barras referentes a cada modo de instabilidade aplicável, foi então feita a superposição destas novas geometrias para todos os nós das barras.

Feito isso, foi possível se realizar uma análise não-linear geométrica coerente, mesmo porque por meio de análises prévias e também via relatos na literatura, percebeu-se que os 
resultados das análises numéricas não-lineares são muito sensíveis à escolha das imperfeições iniciais.

Em certa fase deste trabalho já se sabia portanto um primeiro critério para se avaliar os valores d/t, ou seja, via minimização de erros anteriormente explicada. Também já se havia proposto a estratégia para a inserção destas imperfeições nos modos oriundos das análises de autovalor. Era agora necessário descobrir se este primeiro critério era razoável, e daí várias análises não-lineares prévias foram realizadas para se avaliar valores de $\mathrm{d} / \mathrm{t}$ a serem utilizados como amplitude dos modos, sendo apresentadas a seguir:

I. Primeiro critério, via minimização de erros, anteriormente explicado;

II. Uma segunda opção, que constava em multiplicar por 10 os valores de d/t do primeiro critério, portanto, de certo modo exagerando as imperfeições iniciais, a fim de se avaliar o impacto dessa variação de magnitude de imperfeições nos resultados (resistência das barras);

III. Uma terceira opção, na qual se superpõe as coordenadas de todos os nós da malha das barras oriundas de cada modo de autovalor do Ansys escolhido, obtendo-se um valor de $\mathrm{d} / \mathrm{t}$ (amplitude) parcial. Este valor de d/t parcial é comparado ao máximo valor de $\mathrm{d} / \mathrm{t}$ medido no laboratório, e é feita a partir daí uma modificação proporcional dos valores $\mathrm{d} / \mathrm{t}$ provenientes da minimização de erros para cada modo de instabilidade, que aí sim serão utilizados como um terceiro critério;

IV. Para o modo global, utilizar-se para valores de d/t a minimização de erros, com exceção das cantoneiras duplas, para as quais as imperfeições iniciais não foram medidas em laboratório e portanto adotou-se o valor da senóide de Young com amplitude de L/1.500. Para o modo local, e distorcional quando aplicável, utilizar valores tipo 1 e/ou tipo 2 respectivamente, provenientes de SCHAFER \& PEKÖZ (1998), como explicado a seguir.

Várias análises prévias foram realizadas para se avaliar os valores mais adequados de amplitude de imperfeição geométrica a ser adotada para os modos, conforme as opções I, II, III e IV anteriores. Após tais análises prévias concluiu-se que a opção IV foi a mais próxima dos resultados experimentais. Portanto, a opção IV foi adotada para todas as análises deste trabalho, e será agora melhor explicada.

Como introdução à explicação desta opção IV, os dados existentes medidos em todo o mundo referentes às imperfeições geométricas iniciais de barras constituídas por perfis de aço formados a frio podem ser definidos basicamente quanto a dois tipos de elementos da seção: 
elementos do tipo AA (sigla conforme NBR 14762:2001, para os quais poderiam ser aplicados como imperfeições para modos locais) e elementos do tipo AL (sigla conforme NBR 14762:2001, para os quais poderiam ser aplicados como imperfeições para modos distorcionais). Para um melhor entendimento, esses tipos de imperfeições foram ilustrados respectivamente como tipo 1 e tipo 2 na Figura 2.8 anteriormente apresentada. Além disso, vale dizer que esses dados foram coletados em SCHAFER (1997), sendo posteriormente apresentados também em SCHAFER \& PEKÖZ (1998).

Há uma análise estatística apresentada em SCHAFER \& PEKÖZ (1998), ressaltando-se que estas variáveis tipo 1 e tipo 2 têm grande dispersão de dados. Neste mesmo artigo é apresentada uma análise CDF (função de distribuição cumulativa estimada) elegendo quantis de probabilidade de excedência das imperfeições a serem adotadas nos modelos.

Entretanto, (ainda que para os mesmos valores de imperfeição apresentados por tal artigo) foi definida neste trabalho a idéia inversa, que é mais lógica e é apresentada na Tabela 6.2, de que o valor típico de CDF é escrito como $P(\Delta>d)$ e indica a probabilidade de que um valor de imperfeição selecionado aleatoriamente $\Delta$ exceda um valor de imperfeição discreto determinístico d, ou seja, probabilidade de que os valores de imperfeição geométrica inicial medidos e que constam desse banco de dados sejam maiores que os adotados nos modelos numéricos.

Por exemplo, $\mathrm{P}(\Delta>\mathrm{d})=0,75$ corresponde na Tabela 6.2 a um valor de $\mathrm{d} / \mathrm{t}$ de $0,14 \mathrm{e}$ 0,64 para os tipos 1 e 2 de imperfeição respectivamente, ou seja, adotando esses valores de relação d/t, que correspondem à imperfeições "baixas", existe $75 \%$ de chance de que o banco de dados de imperfeições coletados na literatura exceda os valores adotados para a análise numérica.

Tabela 6.2 Análise probabilística CDF para imperfeições tipo 1 e tipo 2 [adaptado de SCHAFER \& PEKÖZ (1998)]

\begin{tabular}{c|c|c} 
& Tipo 1 & Tipo 2 \\
\hline $\mathrm{P}(\Delta>\mathrm{d})$ & $\mathrm{d}_{1} / \mathrm{t}$ & $\mathrm{d}_{2} / \mathrm{t}$ \\
\hline 0,75 & 0,14 & 0,64 \\
0,50 & 0,34 & 0,94 \\
0,25 & 0,66 & 1,55 \\
0,05 & 1,35 & 3,44 \\
0,01 & 3,87 & 4,47 \\
média & 0,50 & 1,29 \\
desvio padrão & 0,66 & 1,07
\end{tabular}

$\mathrm{d}_{1}$ e $\mathrm{d}_{2}$ : vide Figura 2.8

Adotou-se então para todas as análises deste trabalho a opção IV, sendo superpostos os modos (autovetores) da análise de autovalor, como ilustrados na Figura 6.18. 
Vale lembrar que, adicionalmente à imperfeição geométrica referente ao modo global (aplicada para todas as seções), foram adotados com base em SCHAFER \& PEKÖZ (1998) como já mencionado: para os perfis do tipo $U$ imperfeições do tipo 1 , para as cantoneiras imperfeições do tipo 2, para os perfis do tipo Ue imperfeições tanto do tipo 1 quanto do tipo 2, e para as cantoneiras duplas imperfeições do tipo 2. Esse esquema de superposição foi pensado de modo a inserir nas barras imperfeições coerentes com as verificadas na prática.

Após se definir a estratégia, foi realizada uma análise de sensibilidade via elementos finitos para se verificar o impacto das imperfeições geométricas iniciais na resistência máxima das barras. Por exemplo, foi considerado o perfil Ue $125 \times 50 \times 25 \times 2,38$, que apresenta os três tipos de imperfeições, referentes aos modos global, local e distorcional, com dois comprimentos extremos: $L_{r}=1.015 \mathrm{~mm}$ e $L_{r}=2.700 \mathrm{~mm}$. A Figura 6.19 e a Figura 6.20 ilustram os resultados das análises com inserção de imperfeições de modos isolados (tanto global quanto local+distorcional, respectivamente), enquanto que a Figura 6.21 e a Figura 6.22 apresentam os casos de variação da imperfeição do modo global mantendo-se constante para a imperfeição local+distorcional os quantis de $75 \%$ e $25 \%$ respectivamente.

Percebe-se que as barras analizadas são, em geral, mais sensíveis à magnitude de imperfeição referente aos modos localizados (por exemplo, local+distorcional). Entretanto, para barrras longas o modo global também afeta consideravelmente os resultados.

Portanto, quanto à questão de adoção de imperfeições geométricas iniciais, entende-se como razoável se adotar para o modo global a senóide proposta por Young, com a magnitude das imperfeições seguindo os valores usuais de $L / 1.500$ (curvas $P$ do SSRC) e L / 1.000 (curvas Européias). Isto é muito útil, mesmo porque os valores medidos de imperfeições apresentam grande variabilidade na literatura mesmo após a tentativa de se fazer o ajuste realizado via minimização de erros, como apresentado na Tabela 6.3. Além disso, é uma opção interessante quando não houver disponível a medição de imperfeições geométricas como a deste trabalho para possibilitar tal procedimento de ajuste.

Finalmente, decidiu-se utilizar para a inserção de imperfeições geométricas iniciais em todas as análises o seguinte: modo global proveniente da minimização de erros já explicada com os valores apresentados na Tabela 6.3 (exceção para as cantoneiras duplas, para as quais não se mediu as imperfeições iniciais no laboratório e portanto adotou-se para o modo global o valor usual de L / 1.500), superpondo-se ao modo local (e distorcional também quando aplicável, por exemplo nos perfis do tipo Ue) tanto para os quantis $\mathrm{P}(\Delta>\mathrm{d})=0,75$ quanto para $\mathrm{P}(\Delta>\mathrm{d})=0,25$.

Vale lembrar novamente que é uma opção para novos trabalhos se adotar para a magnitude das imperfeições do modo global os valores usuais de L / 1.500 (curvas P do SSRC) ou L / 1.000 (curvas Européias). 


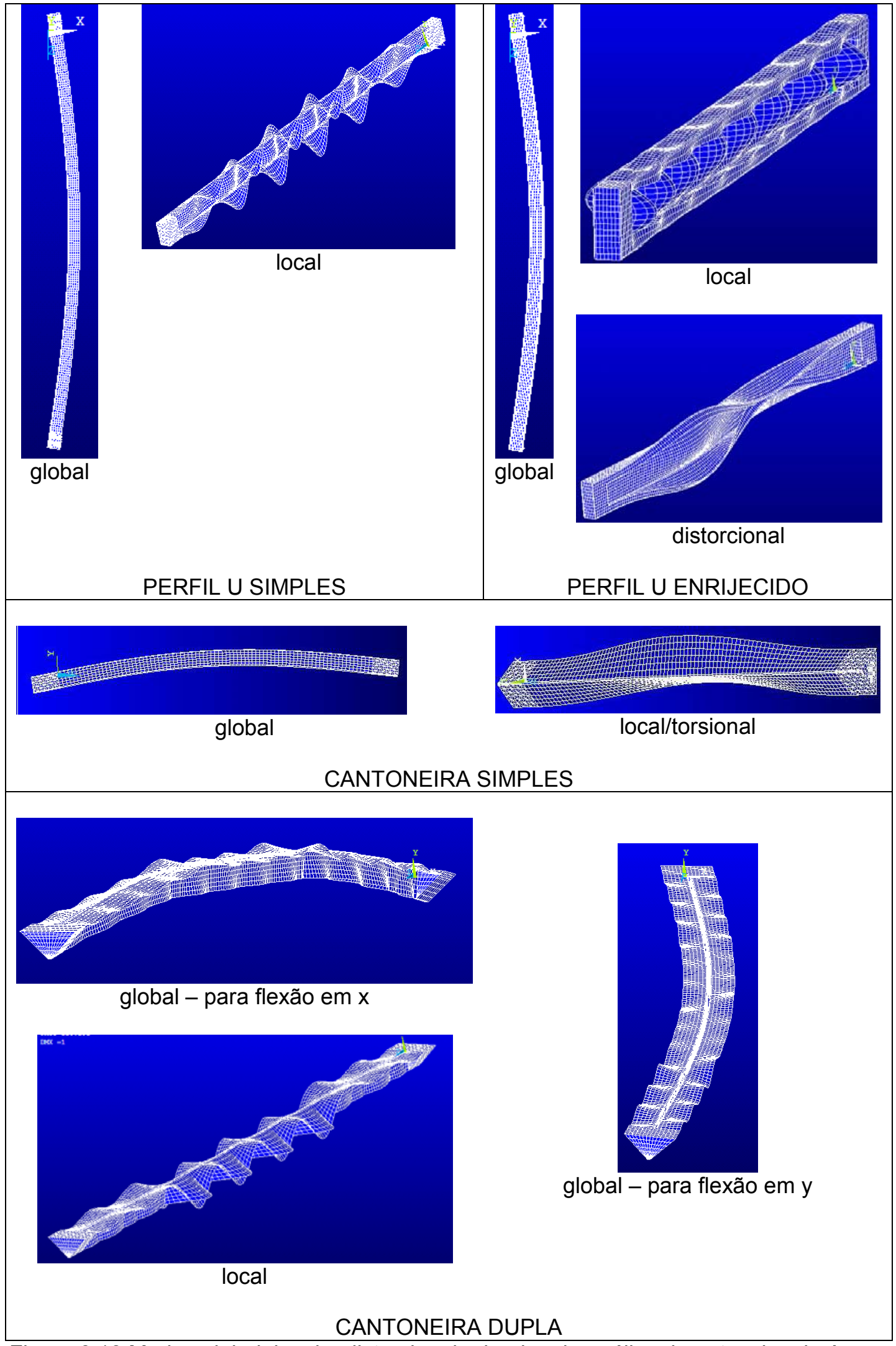

Figura 6.18 Modos global, local e distorcional oriundos da análise de autovalor via Ansys 


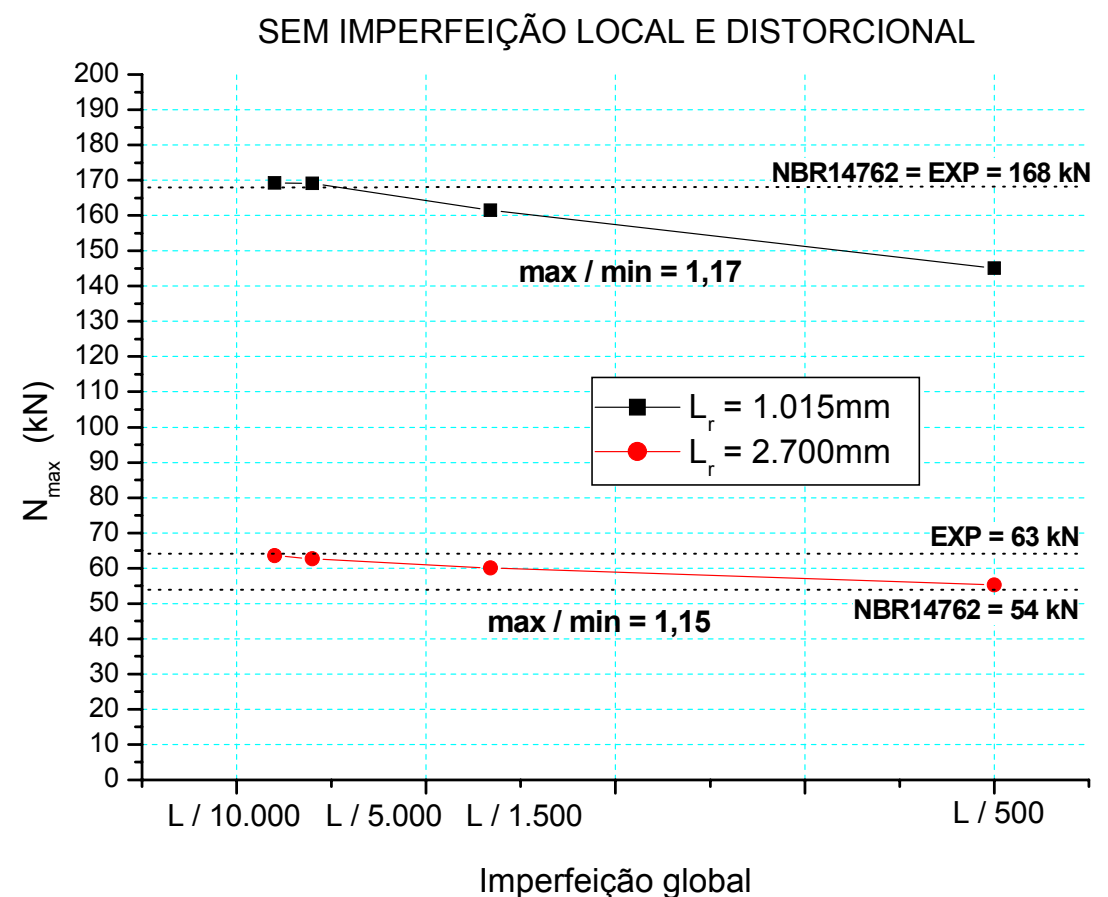

Figura 6.19 Análise de sensibilidade às imperfeições globais: Ue 125×50×25×2,38

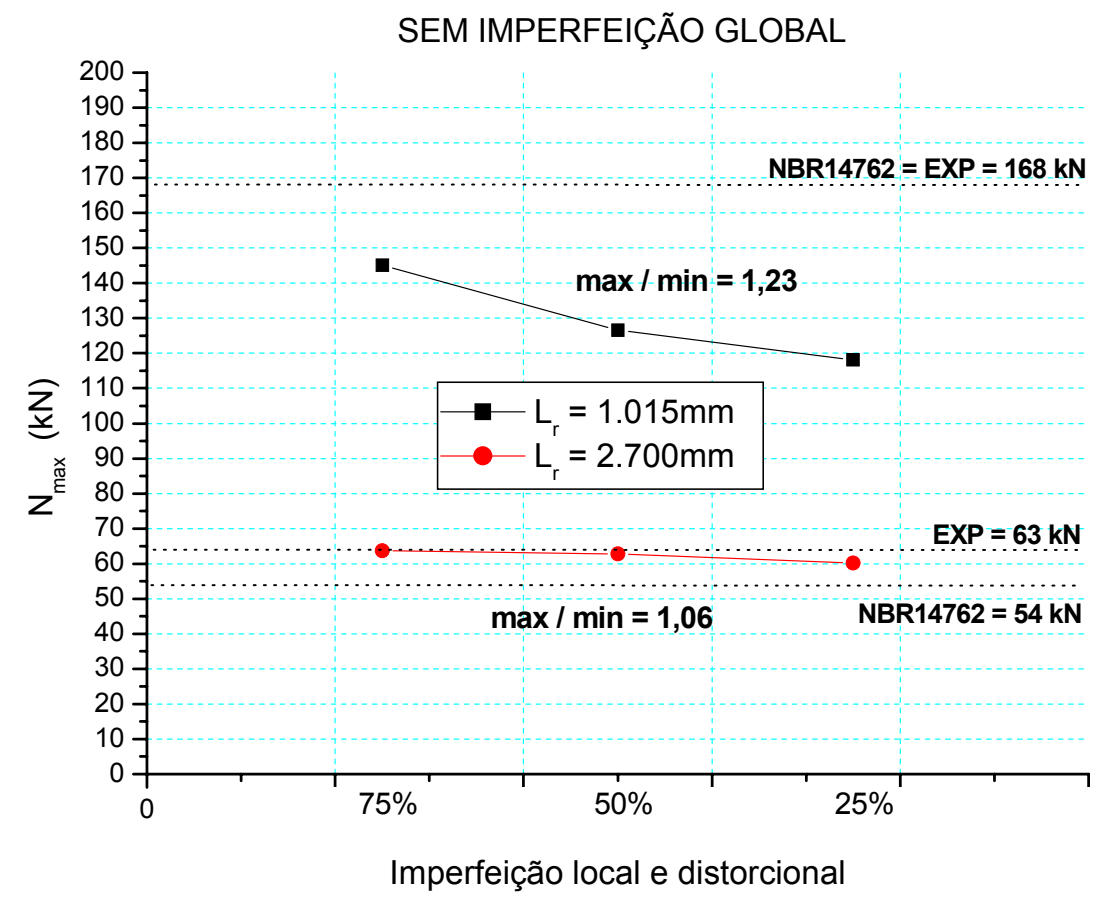

Figura 6.20 Análise de sensibilidade aos modos local e distorcional: Ue 125×50×25×2,38 


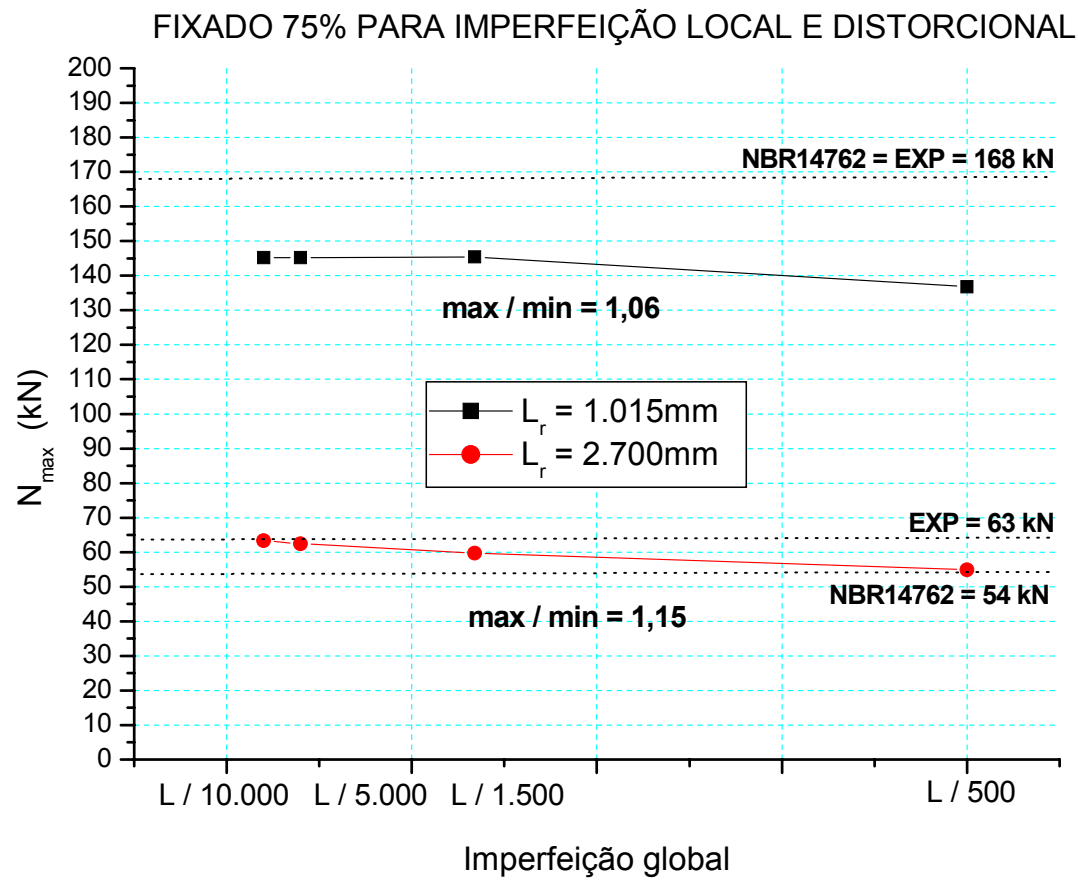

Figura 6.21 Análise de sensibilidade considerando todas as imperfeições para quantil $75 \%$ :

Ue $125 \times 50 \times 25 \times 2,38$

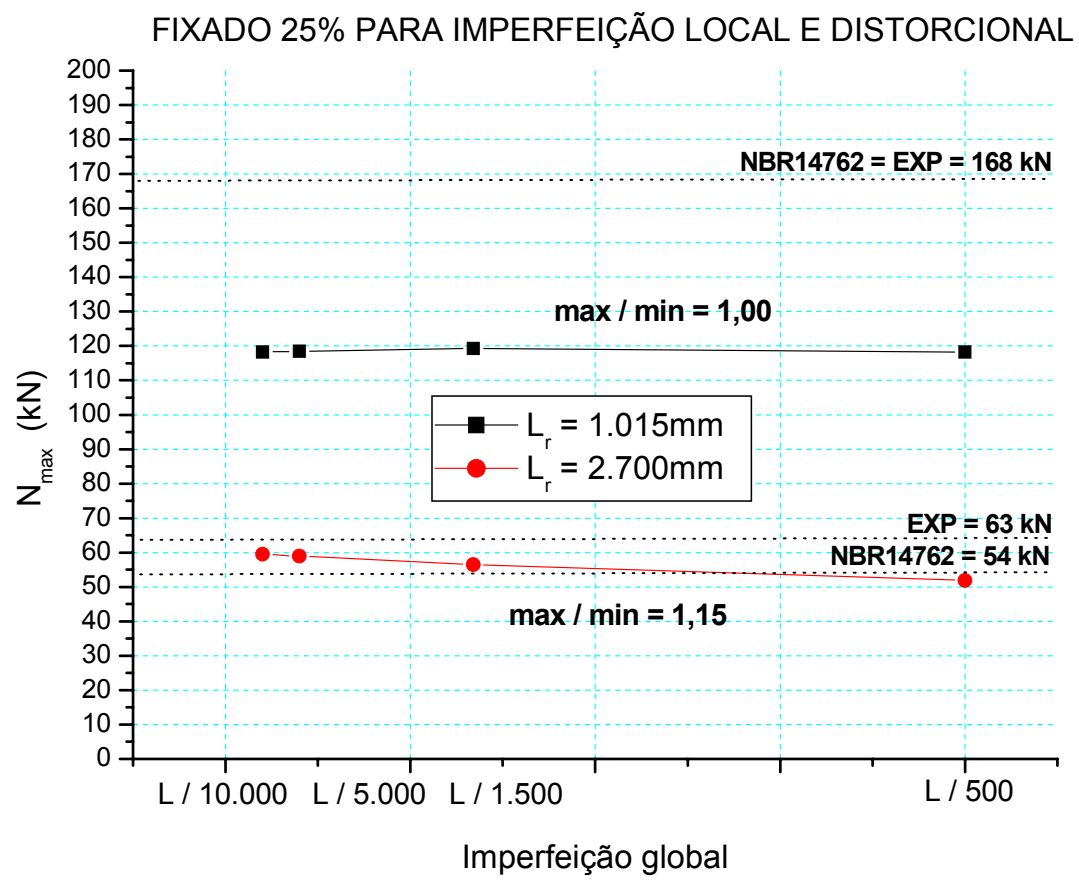

Figura 6.22 Análise de sensibilidade considerando todas as imperfeições para quantil 25\%:

Ue $125 \times 50 \times 25 \times 2,38$ 
Tabela 6.3 Imperfeição geométrica global obtida por minimização de erros com base em imperfeições medidas no laboratório

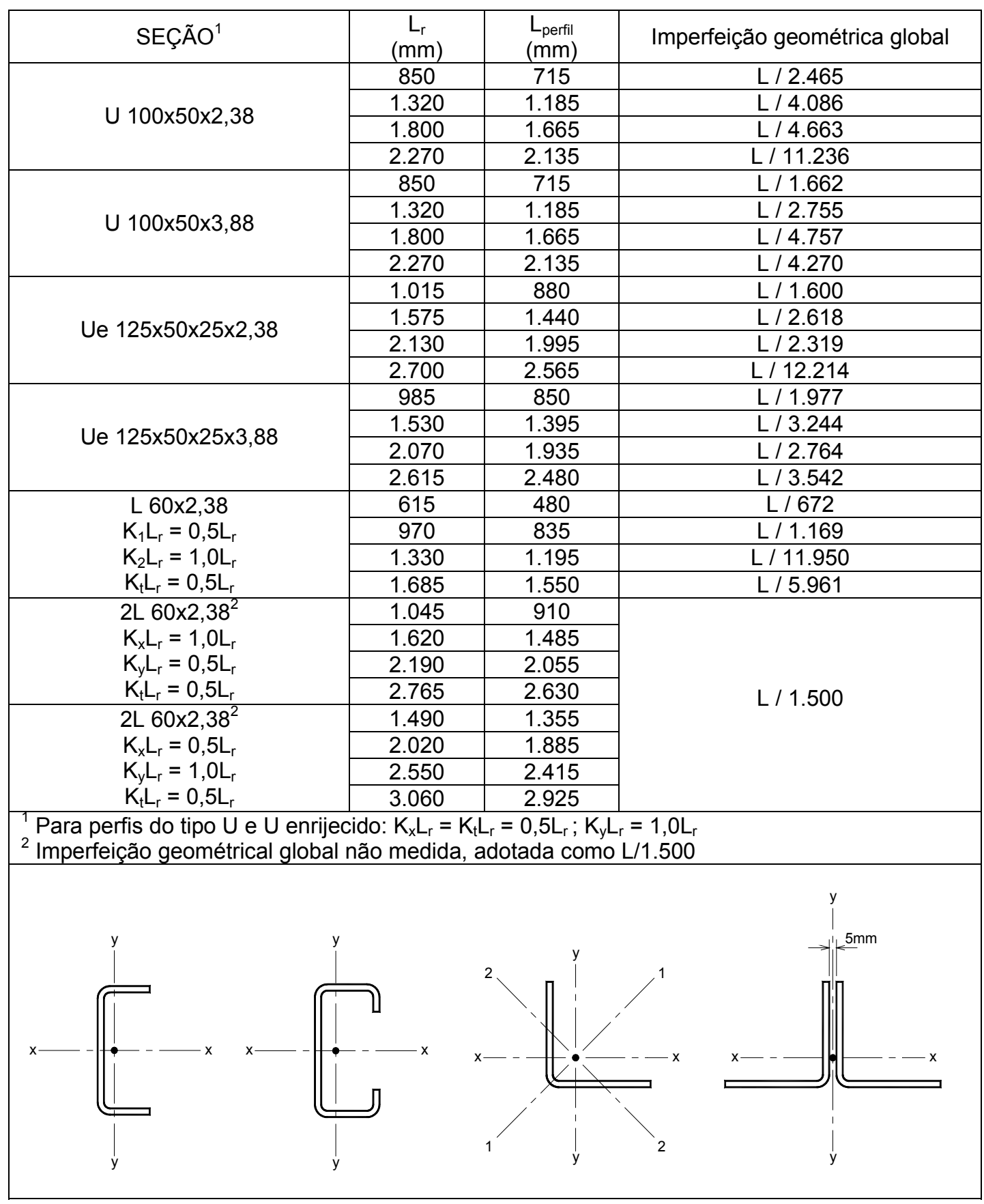

\subsubsection{Tensões residuais}

Tensões residuais, como já comentado, é um dos assuntos que ainda não é consenso quanto à inserção nos modelos numéricos, principalmente em decorrência da escassez de trabalhos nesse tema.

Portanto, muitas vezes tais tensões são negligenciadas nos modelos, ou o diagrama tensão-deformação do modelo é modificado para se tentar considerá-las de modo aproximado, 
mesmo porque já foi explicado que o valor das tensões residuais é geralmente baixo, sendo um pouco maior para perfis oriundos de mesas de roletes (lembrando que os perfis deste trabalho são oriundos de prensas).

Com base nos trabalhos relatados na revisão bibliográfica, principalmente em SCHAFER (1997), a análise da influência das tensões residuais na resistência das barras foi estabelecida da seguinte forma:

- $\quad$ Tensões de membrana: foram ignoradas, por seu valor ser muito baixo para perfis oriundos de prensas (perfis do presente trabalho) e pelo fato de não se ter considerado o aumento de $f_{y}$ nos cantos da seção, região onde a tensão de encruamento é maior devido ao trabalho a frio. Entretanto, mesmo se fosse considerado o aumento de $f_{y}$, e consequentemente a tensão residual, os resultados não seriam muito diferentes pois estes dois fatores praticamente se compensam;

- $\quad$ Tensões de flexão: Por serem um pouco mais elevadas que as de membrana, foram consideradas as tensões residuais médias para toda a seção transversal, variando os valores nas mesas e almas, conforme ilustrado na Figura 2.4 para perfis oriundos de prensa. Entretanto, ignorou-se o aumento na região dos cantos $\left(0,33 . f_{y}\right)$, pelo fato de não se ter considerado o aumento de $\mathrm{f}_{\mathrm{y}}$ nestas regiões.

Estes valores de tensão residual de flexão foram então estabelecidos como arquivo de entrada no programa Ansys. Pelo fato do elemento de casca SHELL 181, utilizado para as barras, possuir 5 pontos de integração ao longo da espessura, em todos os elementos das barras esse gradiente simétrico foi aplicado com seu devido valor de tensão, sendo tração na parte externa e compressão na parte interna com relação à superfície dos perfis, e com o valor nulo no centro da espessura dos elementos. Além disso, é importante relatar que essas tensões foram aplicadas no Ansys como $S_{y}$, pois são tensões residuais longitudinais das barras, ou seja, na direção do comprimento das barras.

Para se tornar viável, e de certa forma simples, a inserção destas tensões residuais nos modelos, foi elaborado um programa na plataforma MatLab, específico para cada tipo de seção transversal. Esse programa MatLab gera o arquivo de entrada ISTRESS.IST a ser lido nos padrões do Ansys, e se tem com isso a barra com as tensões residuais. Esse arquivo de entrada é apresentado a seguir em $\mathrm{kN} / \mathrm{cm}^{2}$ para 3 elementos somente para o caso de perfis com $\mathrm{f}_{\mathrm{y}}=37,5 \mathrm{kN} / \mathrm{cm}^{2}$ (obviamente segue o mesmo padrão para os milhares de elementos da malha das barrras). 


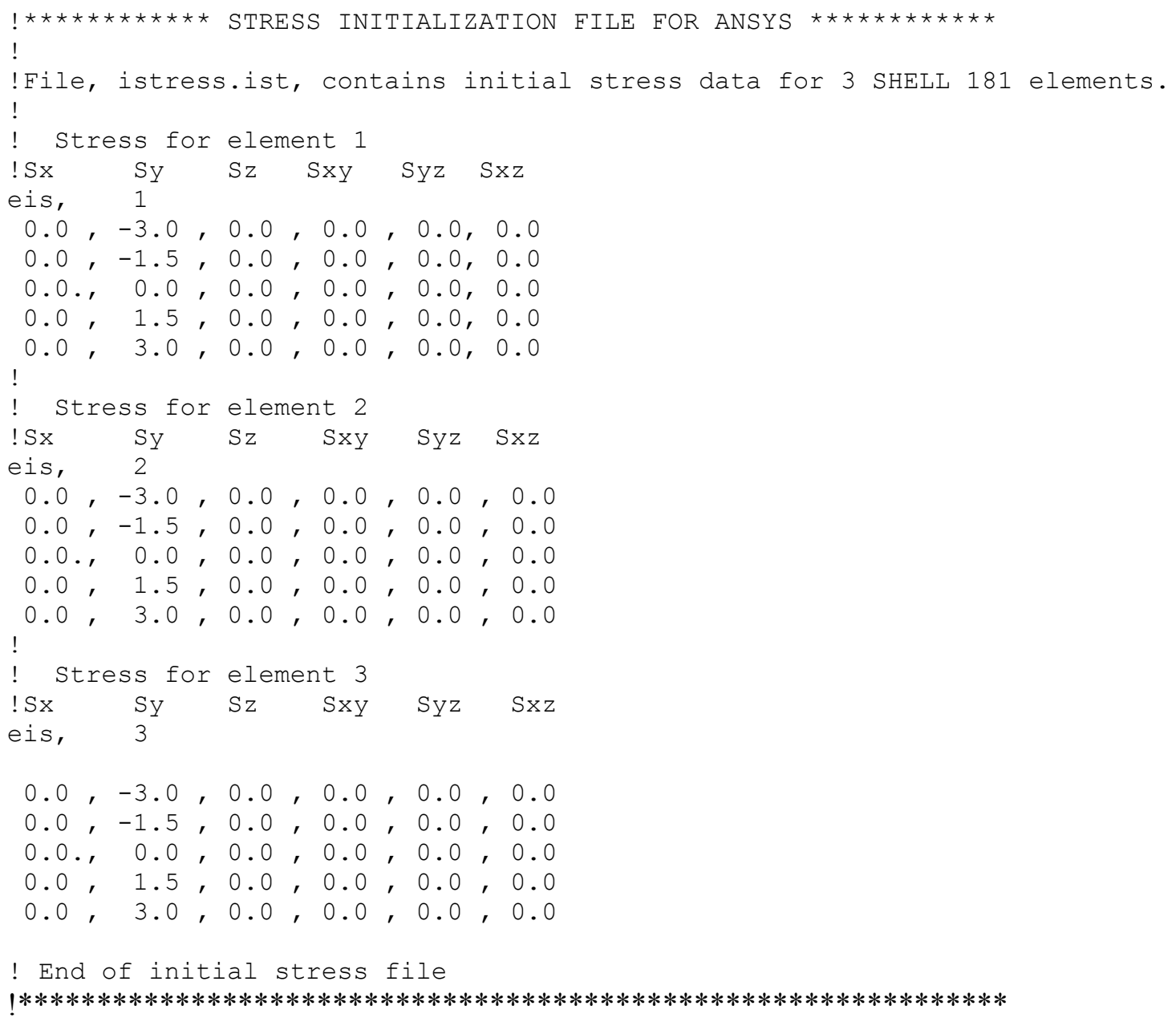

Algumas análises não-lineares foram então realizadas com a aplicação destes panoramas de tensões residuais, além de consideração de não-linearidade física (modelo reológico) e geométrica (imperfeições geométricas iniciais).

Uma observação interessante é que dependendo do sentido para o qual a barra se deforma quando da análise de autovalor (os quais são utilizados para compor as imperfeições geométricas das barras) as tensões residuais podem contribuir para uma resistência maior ou menor da barra, quando a comparação é feita com modelos sem tensões residuais. Isto ocorre pelo fato da superposição das tensões residuais aliviar ou aumentar as tensões existentes dependendo da deformada da barra.

Pôde-se concluir que as forças máximas (resistência das barras) praticamente não se alteram comparando-se as análises das barras sem e com tensões residuais, isto pelo fato destas tensões residuais serem pequenas, especialmente para perfis oriundos de prensas, como já mencionado. Por outro lado, comparando-se os modelos sem e com tensões residuais, para um mesmo nível de força de compressão atuante (um passo de carga qualquer escolhido ao longo do incremento de carregamento), existe obviamente a constatação nos modelos 
numéricos de um panorama sutilmente diferente quanto a distribuição de tensões e deformações nos elementos das barras.

Entende-se que mesmo se fosse inserida a tensão de membrana, e com isso também o aumento de $f_{y}$ nos cantos, as resistências das barras ainda assim não mudariam significativamente, pois estes valores são pequenos e de certo modo se compensariam, como também já mencionado.

Após estas verificações e conclusões obtidas destas análises prévias optou-se por não se utilizar nenhum tipo de tensão residual nos modelos deste trabalho, ficando a análise numérica restrita às imperfeições geométricas e modelo reológico (a ser explicado a seguir) coerentes .

\subsubsection{Modelo reológico}

Inicialmente, é importante alertar que os valores do diagrama tensão-deformação obtidos dos ensaios de caracterização do aço (curva azul escuro na Figura 6.23, na qual se deprezou o trecho descendente para tensões abaixo de $85 \%$ da tensão máxima) são valores que sempre se referem à área inicial dos corpos-de-prova utilizados no ensaio de tração, ou seja, sem considerar a estricção. Este valores são denominados convencionais (engineering values) e são apresentados também na curva laranja da Figura 6.23, agora já se fazendo a seleção de trechos multi-lineares em vez de se utilizar a infinidade de pontos oriundos do ensaio, para que seja viável a utilização de tal diagrama nos programas de análise numérica.

Entretanto, programas em elementos finitos que fazem análise não-linear para grandes deformações, como Ansys e Abaqus, utilizam rotinas criadas para pares tensão-deformação denominados de valores corrigidos (true values). Estes valores corrigidos são ilustrados pela curva verde na Figura 6.23, após conversão da curva laranja conforme expressões (6.1) e (6.2). Essa conversão leva em consideração, por exemplo, a estricção da seção durante o ensaio de tração, o que é mais correto, e com isso a curva tensão-deformação é sempre crescente.

Para análises em regime de pequenas deformações, as curvas geradas por estes dois conjuntos de valores (convencional ou corrigido) são muito próximas. Porém, quando a análise entra em regime de grandes deformações, as duas curvas do modelo reológico se distanciam implicando em respostas diferentes do modelo.

Para as análises não-lineares deste presente trabalho, mesmo se trabalhando com tensões máximas, i.e., referentes ao instante em que se atinge a resistência máxima das barras, baixas (normalmente abaixo de $f_{y}$ ), como será mostrado a seguir no item 6.3 via tensões de von Mises, e portanto no âmbito das deformações baixas, utilizou-se a conversão 
dos valores de caracterização convencionais para os corrigidos para que fosse utilizado o procedimento mais correto.

É importante dizer também que os modelos reológicos foram sempre inseridos no programa Ansys na opção: Material models - Structural - Nonlinear - Inelastic - Rate Independent - Isotropic Hardening Plasticity - Mises Plasticity - Multilinear.

$$
\begin{aligned}
& \varepsilon_{t}=\ln \left(1+\varepsilon_{e}\right) \\
& \sigma_{t}=\sigma_{e}\left(1+\varepsilon_{e}\right)
\end{aligned}
$$

onde:

$\varepsilon_{t}$ : deformação corrigida (true);

$\sigma_{t}$ : tensão corrigida (true);

$\varepsilon_{\mathrm{e}}$ : deformação convencional (engineering);

$\sigma_{e}:$ tensão convencional (engineering);

Tensão $\left(\mathrm{kN} / \mathrm{cm}^{2}\right)$ x Deformação $(\mu \mathrm{e})$ - MÉDIA

azul escuro: resultado do ensaio de caracterização

laranja: Valores convencionais (ENGINEERING stress/strain) verde: Valores corrigidos (TRUE stress/strain, utilizados no Ansys)

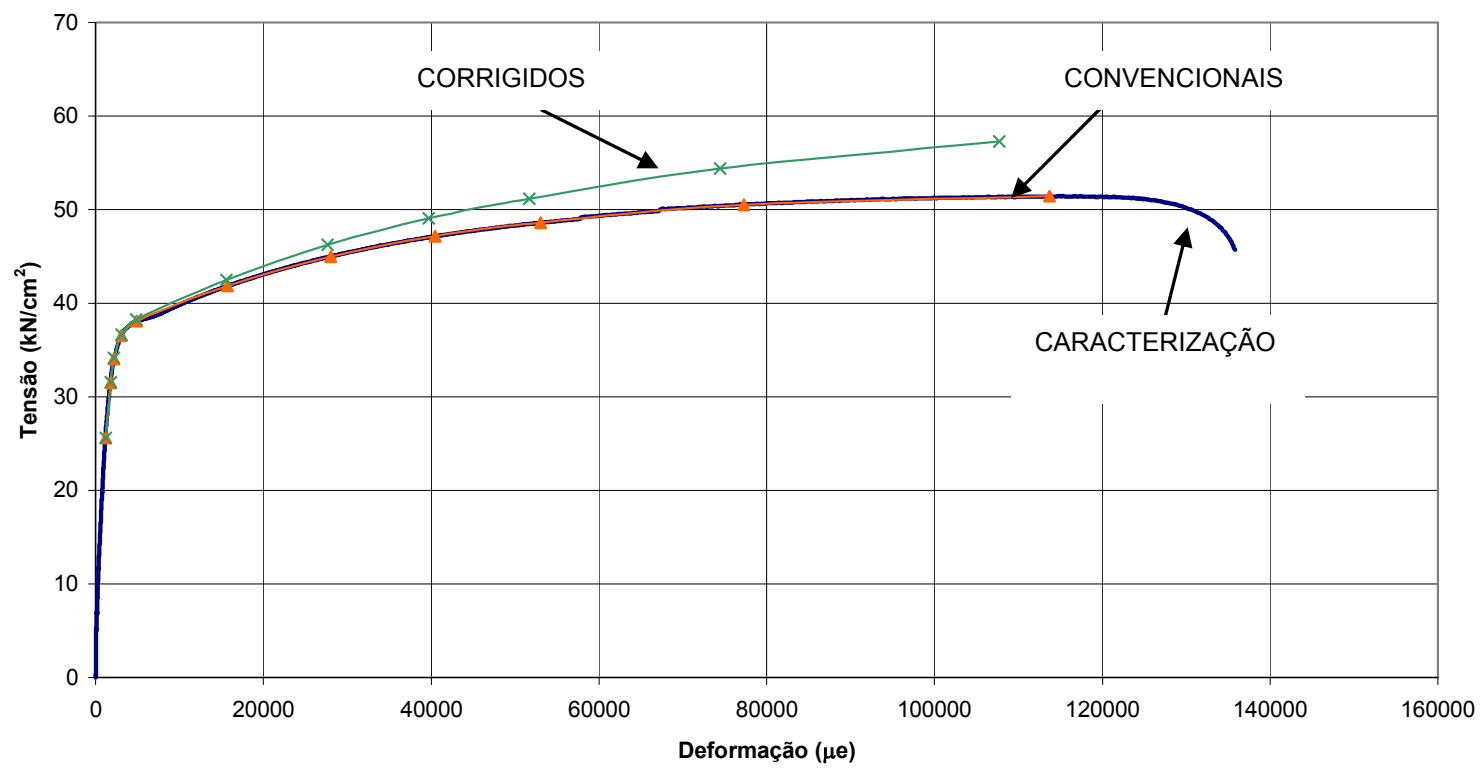

Figura 6.23 Exemplo de modelo reológico: valores corrigidos e valores convencionais

Vale ressaltar que, inicialmente, várias análises não-lineares geométricas foram realizadas variando-se o modelo reológico (não-linearidade física, i.e., do material), para que se 
averiguasse qual o modelo reológico mais satisfatório a ser utilizado nos modelos numéricos. Nessas análises prévias foi utilizado, por exemplo, o modelo reológico aproximado trilinear a seguir, ilustrado na Figura 6.24. Percebeu-se que este modelo pode ser considerado como uma aproximação satisfatória quando não se dispõe de resultados de ensaios de caracterização - ainda que deva ser avaliado com cuidado dependendo da análise em questão, vide Figura 6.25 - pois os resultados de resistência das barras (força máxima atingida) dos modelos numéricos foram próximos aos valores provenientes da análise experimental.

Entretanto, como os resultados da caracterização do aço estavam disponíveis, naturalmente foram adotadas curvas tensão-deformação ajustadas (valores corrigidos), adotando para cada perfil a média dos resultados dos corpos-de-prova.

Ressalta-se, por fim, que os valores do par tensão-deformação (já convertidos para true values) e as curvas respectivas utilizados no Ansys para todas as seções transversais analisadas são apresentados no apêndice deste trabalho.

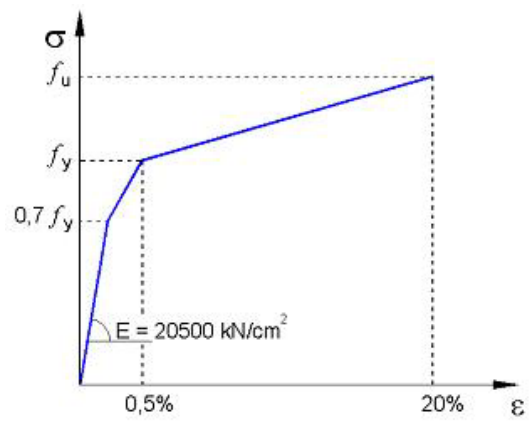

Figura 6.24 Gráfico tensão-deformação: não-linearidade física

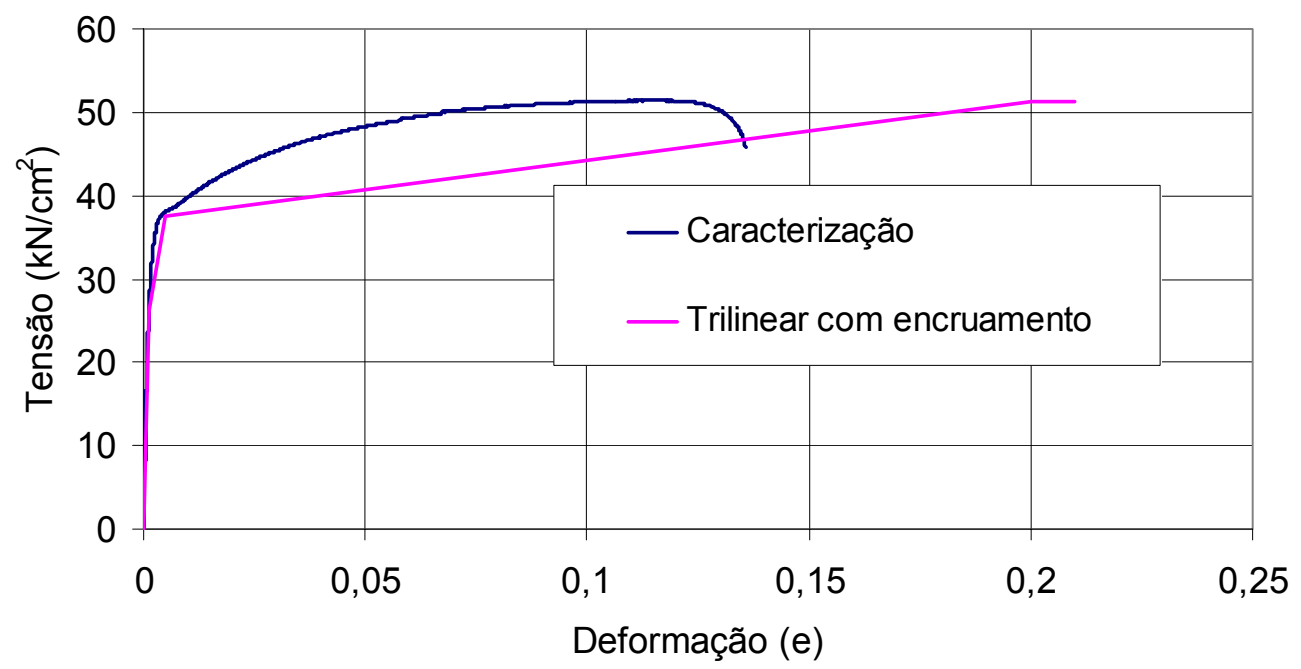

Figura 6.25 Curva tensão-deformação: caracterização versus aproximação trilinear 


\subsubsection{Parâmetros da análise não-linear geométrica}

É importante também citar que para a não-linearidade geométrica foi utilizado neste trabalho para o programa Ansys o método de solução Newton-Raphson Full, com critério de convergência de deslocamento com tolerância de 0,001.

\subsection{Resultados da análise numérica}

Aqui são apresentados e discutidos os resultados da análise numérica deste trabalho. Entretanto, as comparações com valores previstos por normas, procedimentos alternativos e análise experimental serão apresentadas no capítulo seguinte, de análise e discussão de resultados.

Os resultados da análise numérica são referentes a duas fases:

- Por meio do programa CUFSM (faixas finitas), via uma análise geral de estabilidade elástica, apresentada na Tabela 6.4. Tais resultados foram utilizados tanto para avaliação das imperfeições geométricas iniciais (referente ao procedimento explicado de minimização de erros) como para a utilização do Método da Resistência Direta (MRD);

- Por meio do programa ANSYS (elementos finitos), inicialmente via uma análise de autovalor, apresentada na Tabela 6.5, a qual é utilizada também tanto como uma opção para a utilização do Método da Resistência Direta (MRD) como para a obtenção das imperfeições geométricas iniciais das barras, e em seguida via uma análise não-linear física e geométrica, apresentada na Tabela 6.6. 
Tabela 6.4 Análise geral de estabilidade elástica via faixas finitas - CUFSM

\begin{tabular}{|c|c|c|}
\hline \multirow{2}{*}{ PERFIL } & Instabilidade local & Instabilidade distorcional \\
\hline & $\mathbf{N}_{\ell}(\mathbf{k N})$ & $\mathbf{N}_{\text {dist }}(\mathrm{kN})$ \\
\hline U $100 \times 50 \times 2,38$ & 144 & $\mathrm{NC}$ \\
\hline U $100 \times 50 \times 3,88$ & 632 & NC \\
\hline Ue $125 \times 50 \times 25 \times 2,38$ & 241 & 350 \\
\hline Ue $125 \times 50 \times 25 \times 3,88$ & 1041 & 973 \\
\hline L 60x2,38 - 480mm & 36 & NC \\
\hline L 60x2,38 - 835mm & 34 & NC \\
\hline $\mathrm{L} 60 \times 2,38-1.195 \mathrm{~mm}$ & 33 & $\mathrm{NC}$ \\
\hline L 60x2,38 - 1.550mm & 31 & NC \\
\hline 2L 60x2,38 - 910mm & 69 & NC \\
\hline $2 \mathrm{~L} 60 \times 2,38-1.355 \mathrm{~mm}$ & 67 & $\mathrm{NC}$ \\
\hline $2 \mathrm{~L} 60 \times 2,38-1.485 \mathrm{~mm}$ & 66 & NC \\
\hline $2 \mathrm{~L} 60 \times 2,38-1.885 \mathrm{~mm}$ & 64 & NC \\
\hline $2 \mathrm{~L} 60 \times 2,38-2.055 \mathrm{~mm}$ & 62 & NC \\
\hline 2L $60 \times 2,38-2.415 \mathrm{~mm}$ & 58 & NC \\
\hline $2 \mathrm{~L} 60 \times 2,38-2.630 \mathrm{~mm}$ & 55 & NC \\
\hline $2 \mathrm{~L} 60 \times 2,38-2.925 \mathrm{~mm}$ & 55 & NC \\
\hline \multicolumn{3}{|c|}{$\begin{array}{l}\text { NC: Não caracterizado } \\
\text { Para as cantoneiras simples e duplas, o modo local é coincidente com o modo global (torsional) - o que } \\
\text { será explicado em detalhes no item } 7.1 \text { - e se obteve do programa um valor elástico para cada } \\
\text { comprimento de barra pelo fato destes perfis não apresentarem ponto de mínimo na curva de resultados } \\
\text { do CUFSM (vide Figura } 6.4 \text { ), o que será melhor explicado no item de análise e discussão dos } \\
\text { resultados para o caso das cantoneiras simples. }\end{array}$} \\
\hline
\end{tabular}

É interessante apresentar neste momento a Figura 6.26, que ilustra o valor de resistência máxima (peak load) via análise não-linear realizada no Ansys para uma barra genérica, a fim de esclarecer como foi feita a obtenção de tais valores para todas as barras (ver Tabela 6.6).

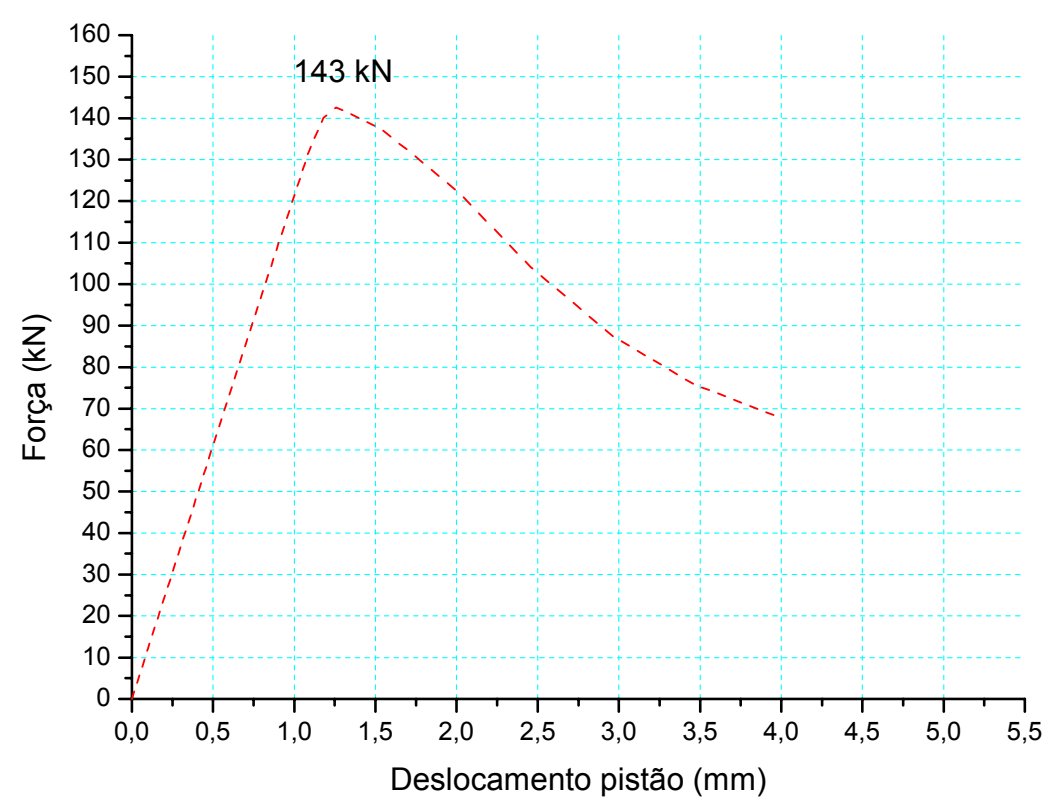

Figura 6.26 Resistência máxima via Ansys: perfil tipo U 100x50×3,88mm $\left(L_{r}=1.320 \mathrm{~mm}\right)$ 
Tabela 6.5 Análise de autovalor via elementos finitos - ANSYS

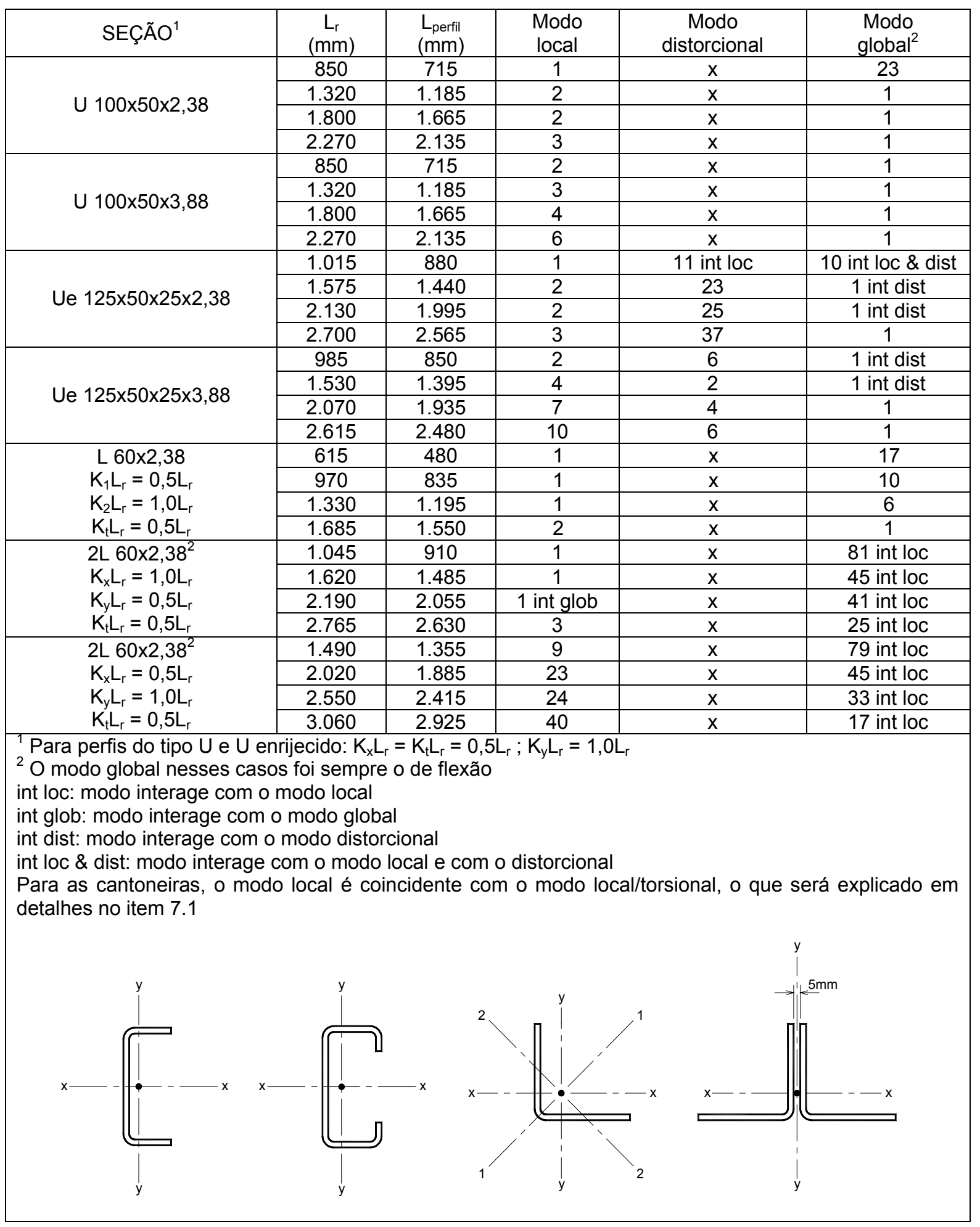


Pôde-se perceber da análise de autovalor apresentada na Tabela 6.5 que:

- para os perfis do tipo $U$ e $U$ enrijecido, o modo global de flexão foi crítico, com exceção de duas barras de menor comprimento em que prevaleceu o modo local. O modo distorcional não foi crítico para nenhuma barra;

- para as cantoneiras simples e duplas, o modo crítico dominante, por outro lado, foi o modo local/torsional, com exceção de duas barras de maior comprimento em que ocorreu o modo global de flexão;

Para que o leitor tenha uma idéia melhor quanto aos resultados numéricos, o que pode ser conseguido utilizando-se uma apresentação de resultados mais ilustrativa, o panorama de tensões de von Mises obtido da análise não-linear realizada via programa Ansys é apresentado a seguir para algumas barras. Este panorama é apresentado somente para 1 barra de cada tipo de seção transversal analisada, pois entendeu-se não haver necessidade de apresentá-lo para todas as barras analisadas.

Pode-se verificar que na região dos elementos sólidos que compõem o dispositivo de extremidade (rótula) as tensões são muito baixas como esperado (regiões em azul nas figuras) por esta ser uma região robusta frente à barra. Além disso, nos modelos numéricos, as regiões de tensão máxima (em vermelho nas figuras) ficam normalmente abaixo da resistência ao escoamento que é $\mathrm{f}_{\mathrm{y}}=37,5 \mathrm{kN} / \mathrm{cm}^{2}$ para os perfis de $t=2,38 \mathrm{~mm}$ e $\mathrm{f}_{\mathrm{y}}=28,8 \mathrm{kN} / \mathrm{cm}^{2}$ para os perfis de $t=3,88 \mathrm{~mm}$. Portanto, nos modelos numéricos, os perfis de paredes finas podem atingir sua resistência máxima para valores de tensão abaixo da resistência ao escoamento devido a problemas de instabilidade. Entretanto, na análise experimental, regiões de plastificação foram verificadas nas barras no instante em que se atingiu a resistência máxima, e esta diferença se explica devido a condições inerentes ao material que são difíceis de serem simuladas nos modelos numéricos nesses casos.

Por exemplo, a Figura 6.27 ilustra o panorama de tensões de von Mises para o perfil $U$ $100 \times 50 \times 2,38 \mathrm{~mm}\left(\mathrm{~L}_{r}=850 \mathrm{~mm}\right)$ - FEM $25 \%$ no instante em que a barra atinge a resistência máxima de $72 \mathrm{kN}$ (ver Tabela 6.6), ou seja, é observado pouco modo global de flexão - mesmo porque a barra é curta - com ocorrência mais pronunciada de instabilidade localizada nas almas e em especial nas mesas. A tensão máxima ocorre devido à instabilidade em regiões das mesas (em vermelho na figura) e atinge $28,9 \mathrm{kN} / \mathrm{cm}^{2}$, abaixo da resistência ao escoamento que é $\mathrm{f}_{\mathrm{y}}=37,5 \mathrm{kN} / \mathrm{cm}^{2}$. 
Tabela 6.6 Análise não-linear via elementos finitos - ANSYS

\begin{tabular}{|c|c|c|c|c|c|c|}
\hline SEÇÃO ${ }^{1}$ & $\begin{array}{c}\mathrm{L}_{\mathrm{r}} \\
(\mathrm{mm})\end{array}$ & $\begin{array}{l}\mathrm{L}_{\text {perfil }} \\
(\mathrm{mm})\end{array}$ & $\begin{array}{c}\text { FEM } \\
75 \% \\
\mathrm{~N}_{\text {FEM }}(\mathrm{kN})^{3}\end{array}$ & $\begin{array}{c}\text { FEM } \\
25 \% \\
\mathrm{~N}_{\mathrm{FEM}}(\mathrm{kN})^{3}\end{array}$ & $\begin{array}{c}\text { Modo } \\
\text { Falha } \\
75 \%\end{array}$ & $\begin{array}{c}\text { Modo } \\
\text { Falha } \\
25 \%\end{array}$ \\
\hline \multirow{4}{*}{ U $100 \times 50 \times 2,38$} & 850 & 715 & 109 & 72 & $\mathrm{LM}, \mathrm{LA}, \mathrm{F}^{*}$ & LM, LA, $F^{*}$ \\
\hline & 1.320 & 1.185 & 114 & 60 & LM, LA*, $F^{*}$ & LM, LA ${ }^{*}, F$ \\
\hline & 1.800 & 1.665 & 69 & 43 & $\mathrm{~F}, \mathrm{LM}^{*}$ & $\mathrm{~F}, \mathrm{LM}, \mathrm{LA}^{*}$ \\
\hline & 2.270 & 2.135 & 42 & 32 & $F, L M, L^{*}$ & $\mathrm{~F}, \mathrm{LM}, \mathrm{LA}^{*}$ \\
\hline \multirow{4}{*}{ U $100 \times 50 \times 3,88$} & 850 & 715 & 201 & 145 & LM & $\mathrm{LM}, \mathrm{F}^{*}$ \\
\hline & 1.320 & 1.185 & 143 & 113 & $\mathrm{~F}^{*}, \mathrm{LM}^{*}$ & $\mathrm{~F}, \mathrm{LM}$ \\
\hline & 1.800 & 1.665 & 101 & 73 & $\mathrm{~F}, \mathrm{LM}^{*}$ & $\mathrm{~F}, \mathrm{LM}$ \\
\hline & 2.270 & 2.135 & 66 & 55 & $\mathrm{~F}, \mathrm{LM}^{*}$ & $F, L M$ \\
\hline \multirow{4}{*}{ Ue $125 \times 50 \times 25 \times 2,38$} & 1.015 & 880 & 145 & 119 & $\mathrm{~F}, \mathrm{D}+$ & $\mathrm{F}, \mathrm{D}+$ \\
\hline & 1.575 & 1.440 & 129 & 105 & $F^{*}, D+, L M$ & $F, D+, L A$ \\
\hline & 2.130 & 1.995 & 91 & 80 & $\mathrm{~F}, \mathrm{D}+, \mathrm{LA}^{*}$ & $F, D, L A$ \\
\hline & 2.700 & 2.565 & 63 & 60 & $\mathrm{~F}, \mathrm{LA}^{*}$ & $\mathrm{~F}, \mathrm{D}+, \mathrm{LA}$ \\
\hline \multirow{4}{*}{ Ue $125 \times 50 \times 25 \times 3,88$} & 985 & 850 & 220 & 175 & $F^{*}, D+^{*}$ & $F, D, L A$ \\
\hline & 1.530 & 1.395 & 220 & 184 & $F, D, L A$ & $F, D, L A$ \\
\hline & 2.070 & 1.935 & 140 & 133 & $F, D, L A$ & $F, D, L A$ \\
\hline & 2.615 & 2.480 & 97 & 93 & $\mathrm{~F}, \mathrm{D}+, \mathrm{LA}+, \mathrm{LM}$ & $\mathrm{F}, \mathrm{D}+, \mathrm{LA}+, \mathrm{LM}$ \\
\hline \multirow{4}{*}{$\begin{aligned} \mathrm{L} 60 \times 2,38 \\
\mathrm{~K}_{1} \mathrm{~L}_{\mathrm{r}}=0,5 \mathrm{~L}_{\mathrm{r}} \\
\mathrm{K}_{2} \mathrm{~L}_{\mathrm{r}}=1,0 \mathrm{~L}_{\mathrm{r}} \\
\mathrm{K}_{\mathrm{t}} \mathrm{L}_{\mathrm{r}}=0,5 \mathrm{~L}_{\mathrm{r}}\end{aligned}$} & 615 & 480 & 31 & 26 & $\mathrm{~L} / \mathrm{T}$ & $\mathrm{L} / \mathrm{T}$ \\
\hline & 970 & 835 & 28 & 25 & $\mathrm{~L} / \mathrm{T}$ & $\mathrm{L} / \mathrm{T}$ \\
\hline & 1.330 & 1.195 & 26 & 23 & $\mathrm{~L} / \mathrm{T}$ & $\mathrm{L} / \mathrm{T}$ \\
\hline & 1.685 & 1.550 & 23 & 20 & $\mathrm{~L} / \mathrm{T}$ & $\mathrm{F}, \mathrm{L} / \mathrm{T}$ \\
\hline \multirow{4}{*}{$\begin{array}{l}2 \mathrm{~L} 60 \times 2,38^{2} \\
\mathrm{~K}_{\mathrm{x}} \mathrm{L}_{\mathrm{r}}=1,0 \mathrm{~L}_{\mathrm{r}} \\
\mathrm{K}_{\mathrm{y}} \mathrm{L}_{\mathrm{r}}=0,5 \mathrm{~L}_{\mathrm{r}} \\
\mathrm{K}_{\mathrm{t}} \mathrm{L}_{\mathrm{r}}=0,5 \mathrm{~L}_{\mathrm{r}}\end{array}$} & 1.045 & 910 & 90 & 87 & $\mathrm{~F}^{*}, \mathrm{~L} / \mathrm{T}$ & $\mathrm{F}^{*}, \mathrm{~L} / \mathrm{T}$ \\
\hline & 1.620 & 1.485 & 78 & 76 & $\mathrm{~F}^{*}, \mathrm{~L} / \mathrm{T}$ & $\mathrm{F}^{*}, \mathrm{~L} / \mathrm{T}$ \\
\hline & 2.190 & 2.055 & 66 & 63 & $\mathrm{~F}^{*}, \mathrm{~L} / \mathrm{T}$ & $\mathrm{F}^{*}, \mathrm{~L} / \mathrm{T}$ \\
\hline & 2.765 & 2.630 & 56 & 53 & $\mathrm{~F}^{*}, \mathrm{~L} / \mathrm{T}$ & $\mathrm{F}^{*}, \mathrm{~L} / \mathrm{T}$ \\
\hline \multirow{4}{*}{$\begin{array}{l}2 \mathrm{~L} 60 \times 2,38^{2} \\
\mathrm{~K}_{\mathrm{x}} \mathrm{L}_{\mathrm{r}}=0,5 \mathrm{~L}_{\mathrm{r}} \\
\mathrm{K}_{\mathrm{y}} \mathrm{L}_{\mathrm{r}}=1,0 \mathrm{~L}_{\mathrm{r}} \\
\mathrm{K}_{\mathrm{t}} \mathrm{L}_{\mathrm{r}}=0,5 \mathrm{~L}_{\mathrm{r}}\end{array}$} & 1.490 & 1.355 & 91 & 88 & $\mathrm{~F}^{*}, \mathrm{~L} / \mathrm{T}$ & $\mathrm{F}^{*}, \mathrm{~L} / \mathrm{T}$ \\
\hline & 2.020 & 1.885 & 78 & 69 & $\mathrm{~F}, \mathrm{~L} / \mathrm{T}$ & $\mathrm{F}, \mathrm{L} / \mathrm{T}$ \\
\hline & 2.550 & 2.415 & 61 & 53 & $\mathrm{~F}, \mathrm{~L} / \mathrm{T}$ & $\mathrm{F}, \mathrm{L} / \mathrm{T}$ \\
\hline & 3.060 & 2.925 & 50 & 42 & $\bar{F}, \mathrm{~L} / \mathrm{T}$ & $\mathrm{F}, \mathrm{L} / \mathrm{T}$ \\
\hline \multicolumn{7}{|c|}{$\begin{array}{l}\text { Para perfis do tipo } U \text { e } U \text { enrijecido: } \mathrm{K}_{\mathrm{x}} \mathrm{L}_{\mathrm{r}}=\mathrm{K}_{\mathrm{t}} \mathrm{L}_{\mathrm{r}}=0,5 \mathrm{~L}_{\mathrm{r}} ; \mathrm{K}_{\mathrm{y}} \mathrm{L}_{\mathrm{r}}=1,0 \mathrm{~L}_{\mathrm{r}} \\
2 \text { Imperfeição geométrica global não medida, adotada como } \mathrm{L} / 1.500 \\
{ }^{3} \text { Resistência máxima } \\
{ }^{4} \text { vide legenda abaixo: } \\
{ }^{*} \text { indica modo pouco pronunciado; } \\
+ \text { indica modo consequente da deformada causada por outro modo de ocorrência prévia; } \\
\text { F: modo global de flexão; } \\
\text { D+: distorção consequente da deformada causada por outro modo; } \\
\text { LM: instabilidade local da mesa; } \\
\text { LA: instabilidade local da alma; } \\
\text { L/T: instabilidade local/torsional (denominação a ser explicada em detalhes no item } 7.1 \text { ); }\end{array}$} \\
\hline
\end{tabular}

A Figura 6.28 ilustra também o panorama de tensões de von Mises, agora para a cantoneira $60 \times 2,38 \mathrm{~mm}\left(L_{r}=970 \mathrm{~mm}\right)$ - FEM $25 \%$, no instante em que a barra atinge a resistência máxima de $25 \mathrm{kN}$ (ver Tabela 6.6), sendo observado modo local/torsional. Neste caso, a tensão máxima devido à flexo-torção (regiões em vermelho na figura) e atinge $31,7 \mathrm{kN} / \mathrm{cm}^{2}$, também abaixo da resistência ao escoamento que é $\mathrm{f}_{\mathrm{y}}=37,5 \mathrm{kN} / \mathrm{cm}^{2}$. 


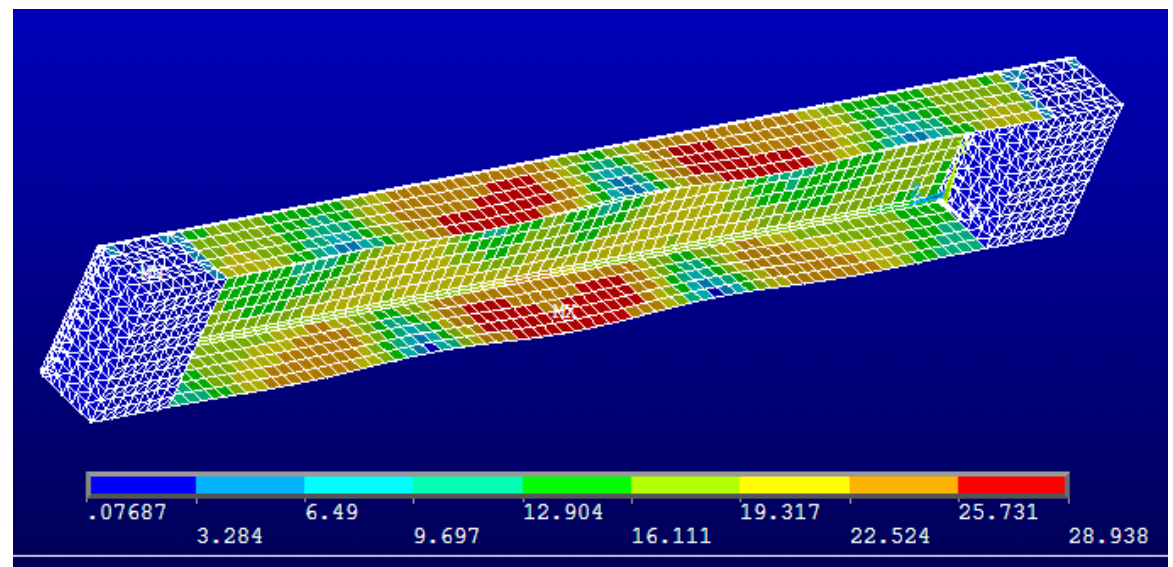

Figura 6.27 Tensões de von Mises: perfil U 100x50x2,38 $\left(L_{r}=850 \mathrm{~mm}\right)$ - FEM 25\%
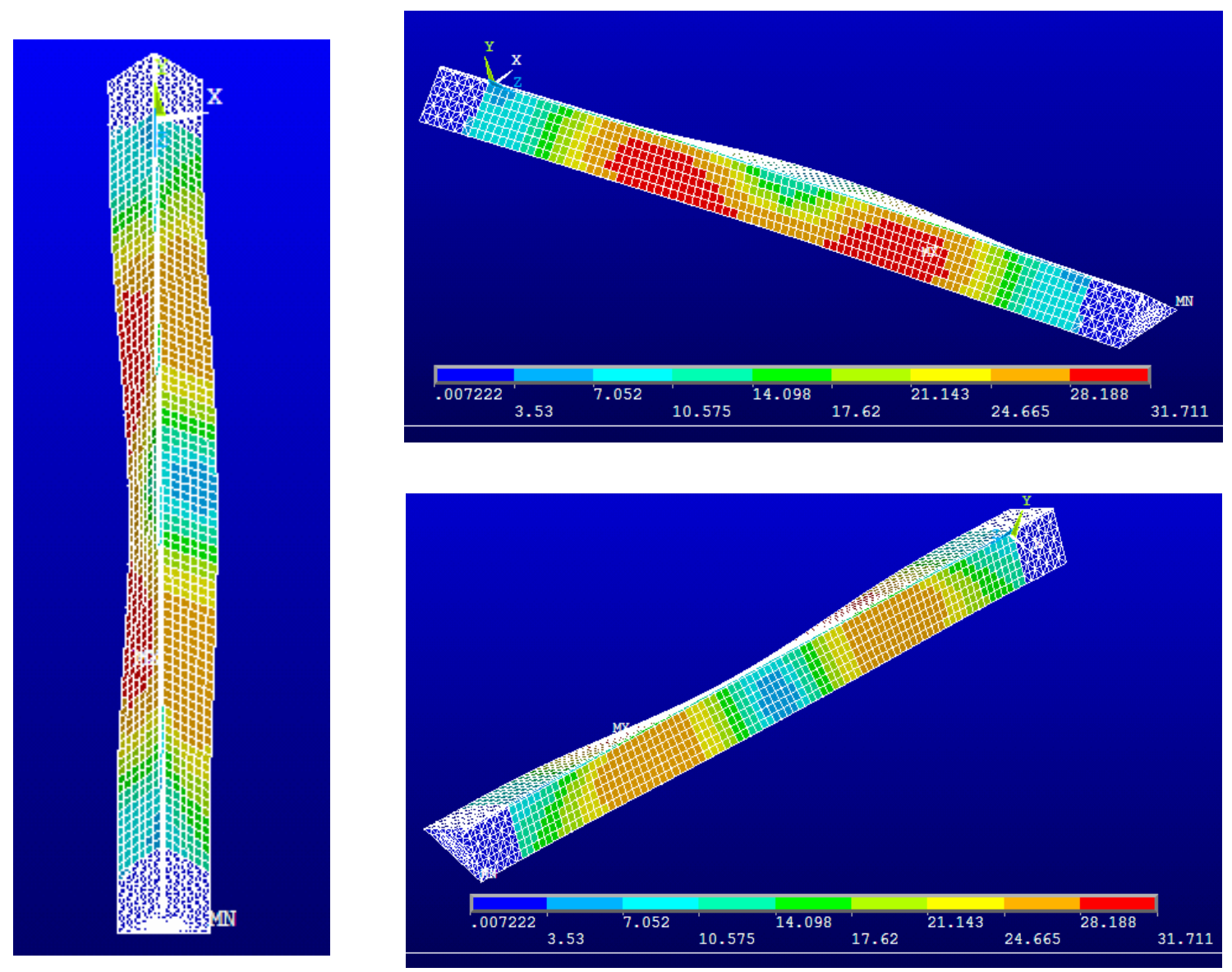

Figura 6.28 Tensões de von Mises: cantoneira 60x2,38 $\left(L_{r}=970 \mathrm{~mm}\right)$ - FEM 25\%

A Figura 6.29 ilustra agora tanto o panorama de deslocamento dos nós como o de tensões de von Mises para o perfil Ue $125 \times 50 \times 25 \times 3,88 \mathrm{~mm}\left(L_{r}=2.615 \mathrm{~mm}\right)-$ FEM $25 \%$ no instante em que a barra atinge a resistência máxima de $93 \mathrm{kN}$. Entretanto, neste caso se escolheu para apresentar tal panorama um perfil com a espessura de $3,88 \mathrm{~mm}$, teoricamente 
menos sujeito às instabilidades localizadas do que o de 2,38mm. Foi observado modo global de flexão em torno do eixo de menor inércia, distorção (que pode se consequência da flexão), e instabilidades localizadas na alma e mesa (ver Tabela 6.6). A tensão máxima (regiões em vermelho na figura) atinge $25 \mathrm{kN} / \mathrm{cm}^{2}$, também abaixo da resistência ao escoamento que é $f_{y}=28,8 \mathrm{kN} / \mathrm{cm}^{2}$ para perfis de $t=3,88 \mathrm{~mm}$.
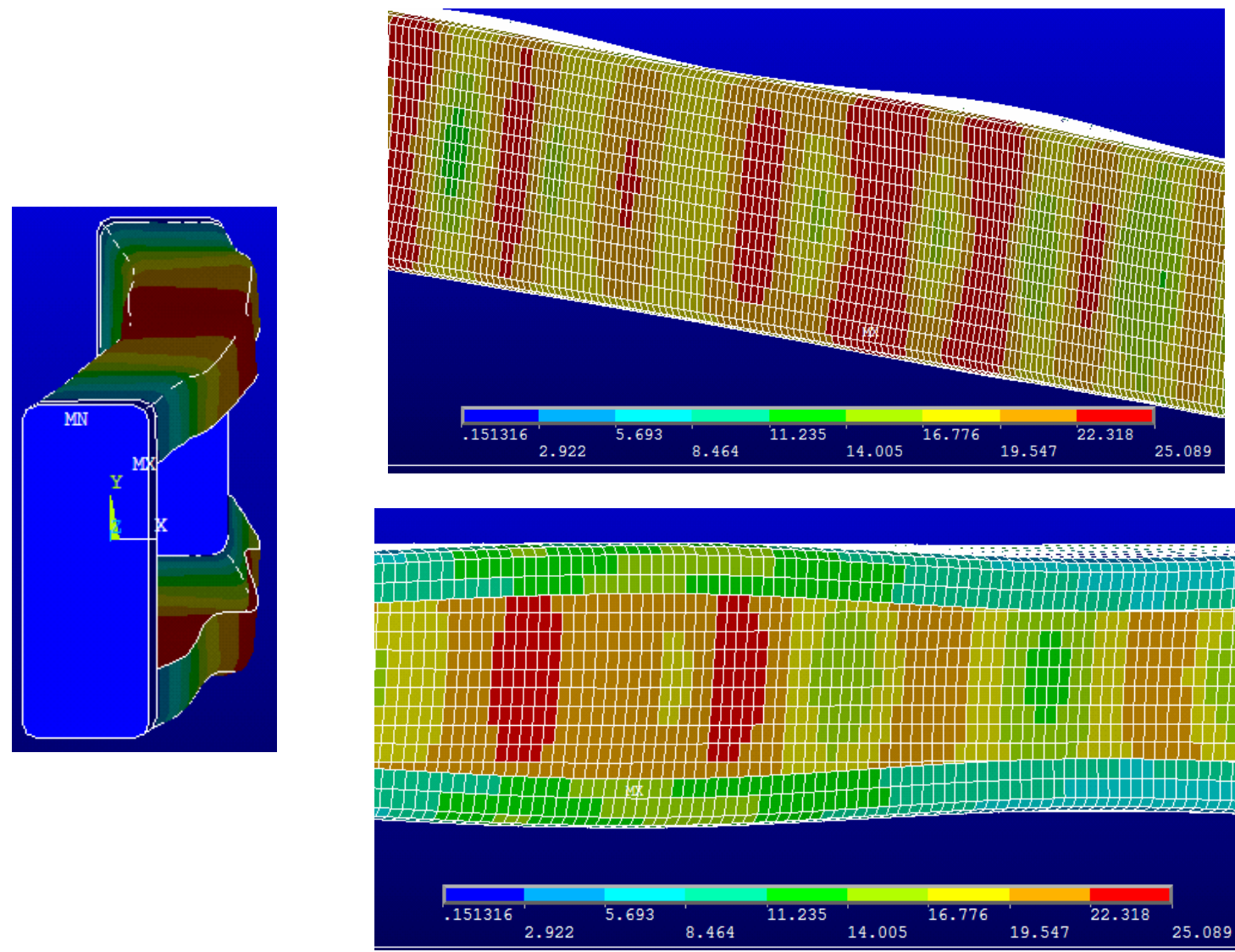

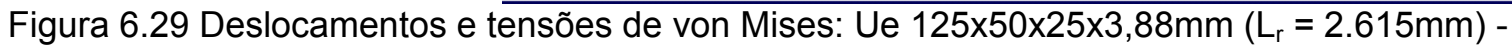
FEM $25 \%$

Finalmente, para a cantoneira dupla, a Figura 6.30 ilustra o panorama de tensões de von Mises para a barra denominada $2 \mathrm{~L} 60 \times 2,38 \mathrm{~mm}\left(L_{r}=2.020 \mathrm{~mm}\right)$ - FEM $75 \%$, para o caso com rótula utilizada de modo a haver flexão em torno do eixo de maior inércia, no instante em que a barra atinge a resistência máxima de $78 \mathrm{kN}$. Foi observado modo global de flexão em torno do eixo de maior inércia e instabilidades localizadas nas abas (ver Tabela 6.6), sendo que estes modos observados podem se confundir como modo local/torsional, observado na análise experimental. A tensão máxima (regiões em vermelho na figura) e atinge $34,9 \mathrm{kN} / \mathrm{cm}^{2}$, também abaixo da resistência ao escoamento que é $\mathrm{f}_{\mathrm{y}}=37,5 \mathrm{kN} / \mathrm{cm}^{2}$. 

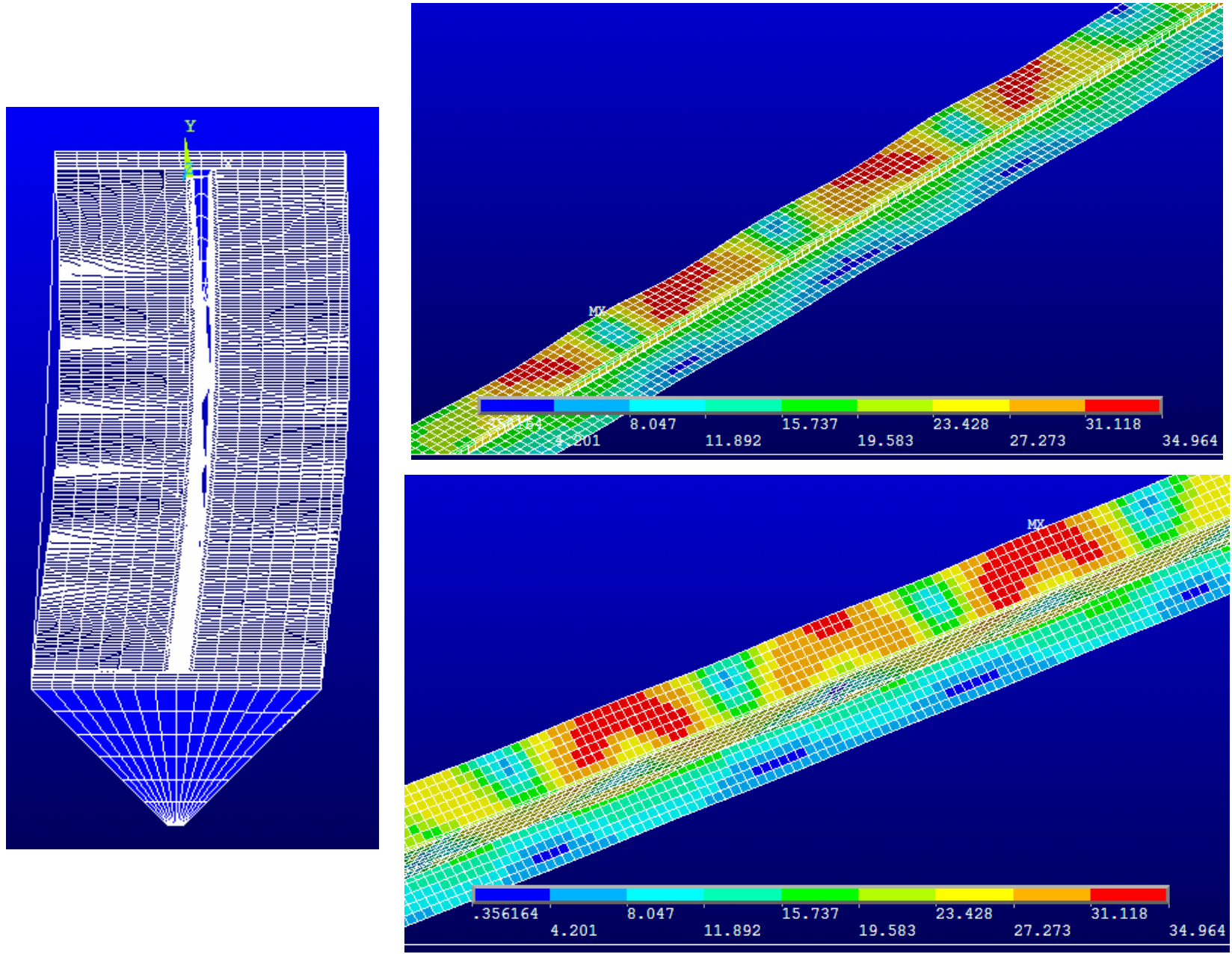

Figura 6.30 Deslocamentos e tensões de von Mises: $2 \mathrm{~L} 60 \times 2,38 \mathrm{~mm}\left(\mathrm{~L}_{r}=2.020 \mathrm{~mm}\right)-\mathrm{FEM} 75 \%$ 


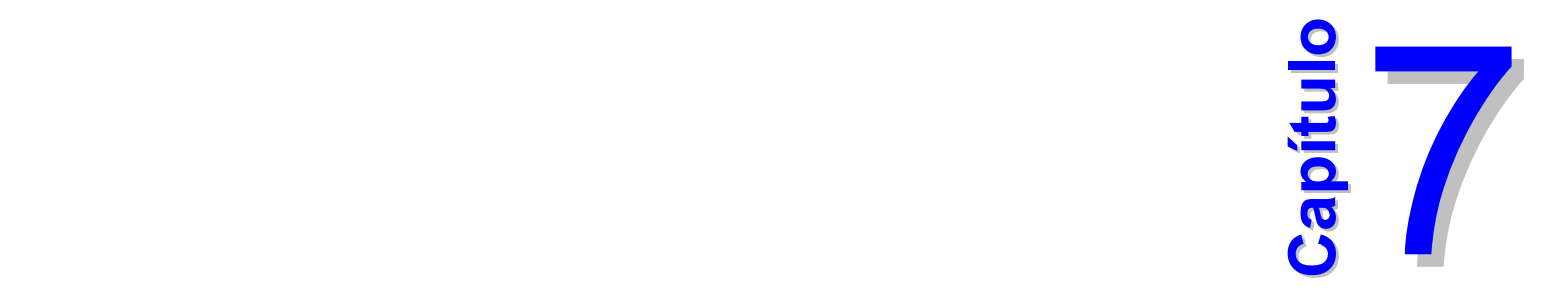

\section{ANÁLISE E DISCUSSÃO DOS RESULTADOS}

Neste capítulo são analisados e discutidos os resultados desta tese. Um item exclusivo (7.1) é dedicado às cantoneiras simples, por se ter percebido no decorrer deste trabalho aspectos interessantes quanto ao comportamento deste tipo de perfil, que apesar de possuir seção transversal simples, ainda gera dúvidas entre pesquisadores de todo o mundo.

\subsection{Cantoneiras simples}

Após se analisar as cantoneiras por procedimentos numéricos e experimentais, percebeu-se que apesar de possuir seção transversal simples comparando-se com outros tipos de perfis, ainda geram dúvidas quanto ao procedimento de cálculo a respeito dos modos de instabilidade, interações entre eles, e considerações que devem ser analisadas. Visto isso, entendeu-se importante uma abordagem deste tipo de perfil neste item exclusivo, ainda que vários trabalhos abordem o tema, como YOUNG (2003, 2004), PRABHU (1982), e também o trabalho muito interessante de RASMUSSEN (2003) que apresenta resultados de ensaios de POPOVIC et al. (1999) e WILHOITE et al. (1984).

É importante relatar inicialmente que cantoneiras esbeltas podem apresentar dois tipos de instabilidade: local de chapa/global por torção (teoricamente o modo global é o por flexotorção) e também global por flexão. Entretanto, a maneira como isso é tratado - especialmente a coincidência entre os modos de instabilidade local de chapa e global por torção - ainda é uma questão aberta quanto aos procedimentos de cálculo.

Por exemplo, é apresentada uma análise de estabilidade elástica de uma cantoneira $60 \times 60 \times 2,38 \mathrm{~mm}$ submetida à compressão utilizando-se o programa CUFSM. Dois modos são observados na Figura 7.1. As linhas cheias representam o modo crítico. O modo identificado na figura como local/torsional (local/global por torção) não é usualmente verificado em análises de 
outros tipos de seções transversais pois (a) não existe um mínimo em função do comprimento de meia-onda (b) os modos de flambagem local e global por torção são coincidentes (c) o modo de flambagem por distorção não é identificado.

Vale dizer desde já que o modo local/global por torção é denominado neste trabalho de local/torsional pois a análise de estabilidade elástica indica uma coincidência entre o modo local (chapa) e o modo global por torção. Estes dois modos são matematicamente coincidentes para cantoneiras de abas iguais de espessura constante submetidas à compressão, conforme apresentado explicitamente em RASMUSSEN (2003). Este fato causa confusão nos pesquisadores quanto à possível consideração "duplicada" nos procedimentos de cálculo deste modo local/torsional. Isto por este modo poder ser considerado como um modo local e também como um modo global, além da possível interação entre eles.

A partir deste fato, RASMUSSEN (2003) propõe um procedimento que (i) sugere a consideração da flexo-compressão, devido ao deslocamento do centróide da seção efetiva em relação à seção bruta.

Vale dizer que uma justificativa comum na literatura para se ignorar a flambagem global por torção - caso (i) acima - é que esse modo já é considerado na flambagem local por meio do cálculo da área efetiva, entendendo-se que esses dois modos de fato podem ser aceitos como coincidentes. Entretanto, deve-se atentar ao fato de que para cantoneiras com abas mais espessas não ocorre a redução da área efetiva, e esse modo global por torção não seria então considerado.

Para se entender melhor como os modos de instabilidade relativos a uma análise elástica para uma cantoneira podem ou não interagir, é interessante entender como esses modos local/torsional e global por flexão podem ocorrer quando mais de uma meia onda ocorre em um determinado comprimento de barra $\mathrm{L}$.

Considere-se, por exemplo a força crítica para uma barra de $3000 \mathrm{~mm}$ na Figura 7.2. O menor valor da força crítica está associado ao modo global por flexão para $m=1$; o segundo ao modo local/torsional para $m=1$; a partir do terceiro modo (até o sétimo) aparecem modos local/torsional para $m>1$ para valores próximos de força crítica. Esse platô de valores de força crítica para diferentes valores de $m$ é uma característica de flambagem local. 


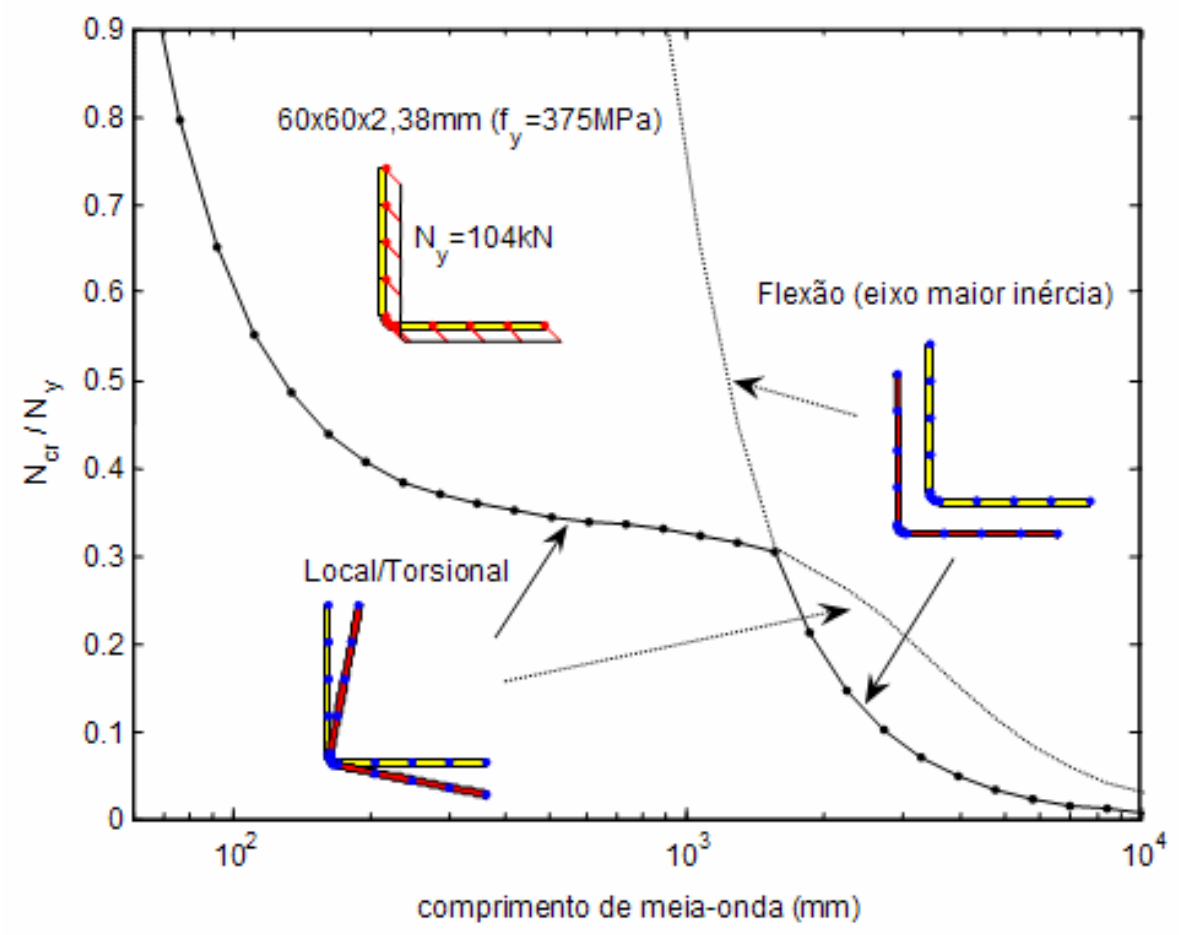

Figura 7.1 Análise de estabilidade elástica via CUFSM: cantoneira submetida à compressão

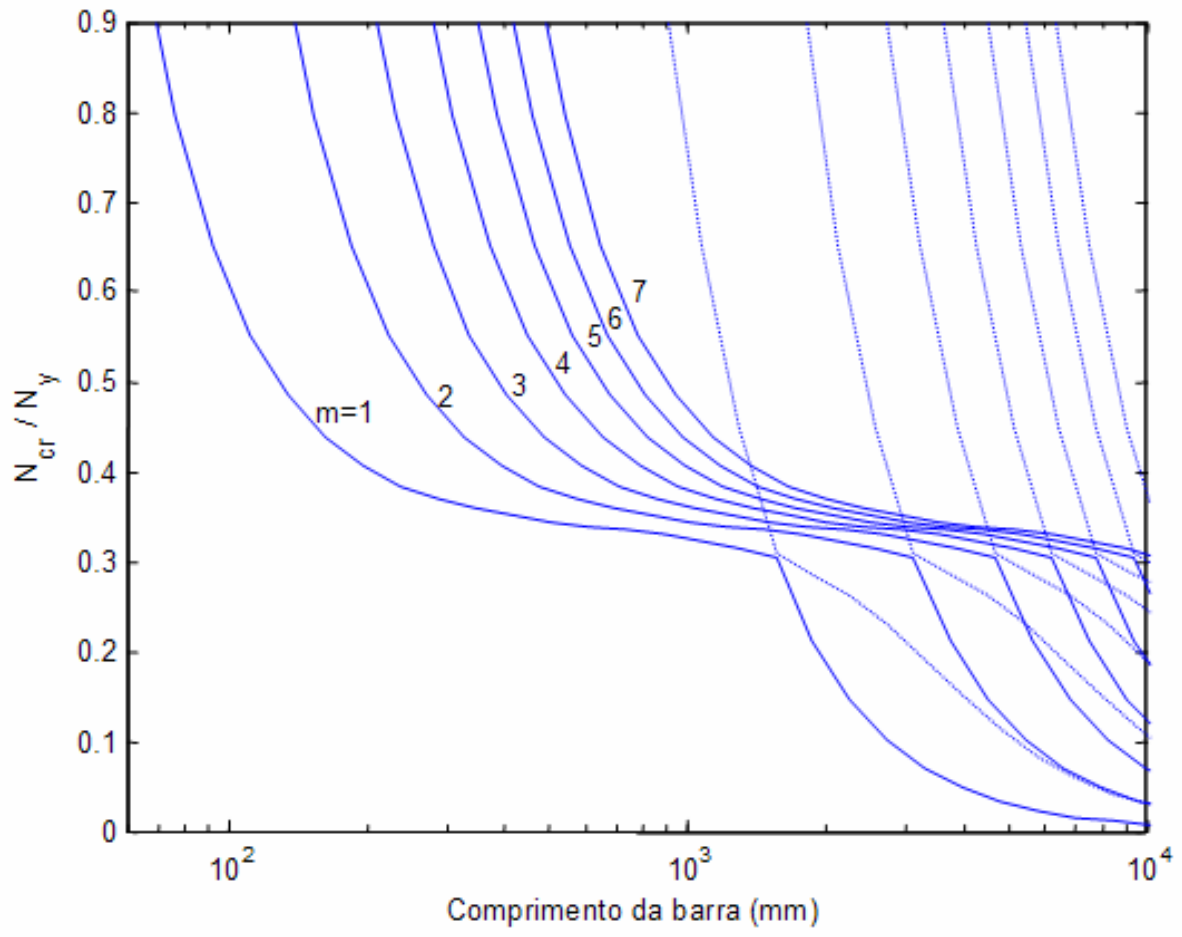

Figura 7.2 Análise via faixas finitas mostrando $m$ meias-ondas em função do comprimento 
Os trabalhos de YOUNG (2003) e YOUNG (2004) apresentam resultados de análise experimental para cantoneiras simples submetidas à compressão centrada. Relatam que a norma norte-americana de 2001 e a australiana de 1996 para perfis de aço formados a frio são muito conservadoras, especialmente porque os procedimentos destas normas quanto às resistências ao modo global de torção e de flexo-torção resultam em valores muito baixos, não condizendo com a realidade dos ensaios por ele realizados.

Isto ocorre, segundo o próprio Young, pois os valores de força normal elástica de flambagem por torção e por flexo-torção fornecidos pelas normas são muito inferiores aos relativos à flexão, conduzindo a resistência da barra a um valor muito inferior aos ensaios.

Como ilustração para este fato relatado tem-se a Figura 7.3 (apresentada para dois lotes de ensaios), caso em que o modo de flexo-torção (praticamente invariável em função do comprimento da barra) comanda o dimensionamento pelos procedimentos normativos com uma força resistente muito inferior aos ensaios e também ao modo de flexão.

Tal fato conduziu à consideração por Young somente do modo de flexão para o cálculo da resistência das barras, o que será discutido, e contestado, logo adiante.
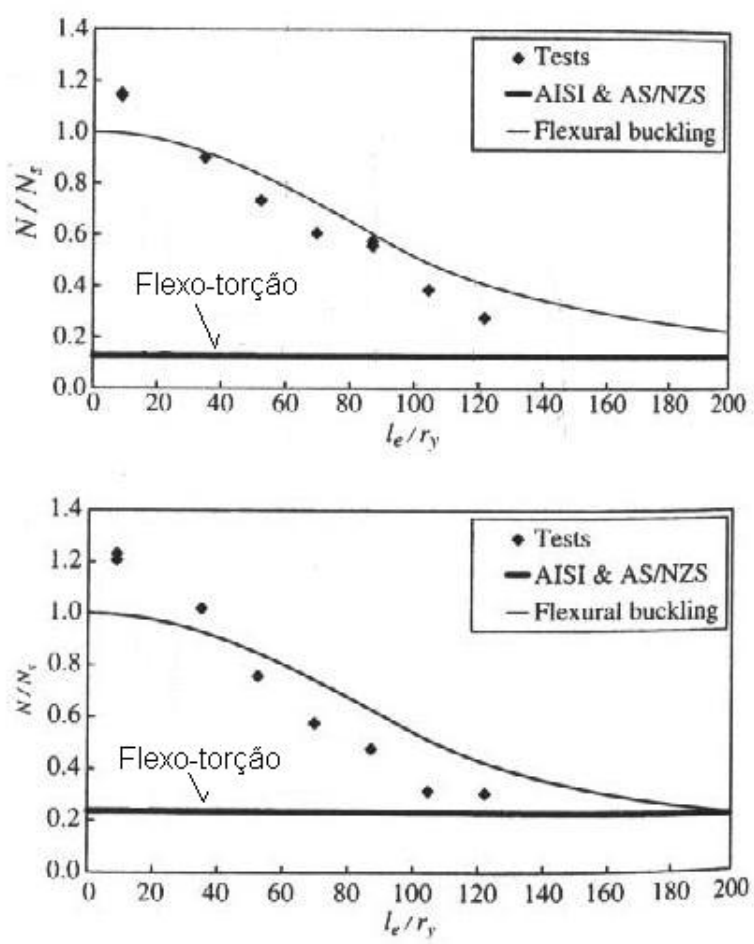

Figura 7.3 Comparação: resistência entre ensaios e procedimentos normativos [YOUNG (2003)]

Entretanto, neste presente trabalho de doutorado, cantoneiras foram analisadas utilizando-se a NBR 14762:2001 e o NAS:2004, e os resultados previstos de resistência foram comparados com os resultados dos ensaios. Pôde-se perceber que o modo dominante foi o de 
flexo-torção. Para estas seções monossimétricas, sendo o eixo 1 o principal de maior inércia, o valor de $\mathrm{N}_{\mathrm{e} 1 \mathrm{t}}$ é o valor que comanda quando comparado a $\mathrm{N}_{\mathrm{e} 2}$, com exceção do caso da barra de maior comprimento aqui analisada.

Isto mostra que o modo de flexo-torção deve sim ser considerado na análise, e não somente o modo de flexão. Portanto, se opõe à idéia de se negligenciar para o valor da resistência o modo de flexo-torção, por tal fato ser muito "conservador", como relatado no trabalho de YOUNG (2003).

A partir desses fatos, na tentativa de se entender melhor esse comportamento das cantoneiras, e imaginando-se que a desconsideração do modo global de flexo-torção para o procedimento de cálculo seria contrário à segurança, foram realizadas neste trabalho algumas análises, apresentadas a seguir.

Um conjunto de figuras (Figura 7.4 até a Figura 7.6) é apresentado, relativo a cantoneiras submetidas à compressão centrada sob o conceito de cálculo de larguras efetivas das normas vigentes, mas sem a consideração da mudança de posição do centróide da seção efetiva em relação à seção bruta, ou seja, sem se considerar a flexo-compressão, considerando, portanto, compressão centrada.

A resistência das barras nessas figuras é portanto calculada com base na (i) no modo global apropriado (somente flexão ou o mínimo entre flexo-torção e flexão), e (ii) uma área efetiva calculada com base na tensão associada ao modo global assumido com crítico na análise. Nessas figuras, tais curvas são comparadas com os resultados dos ensaios realizados neste trabalho para cantoneiras simples e duplas.

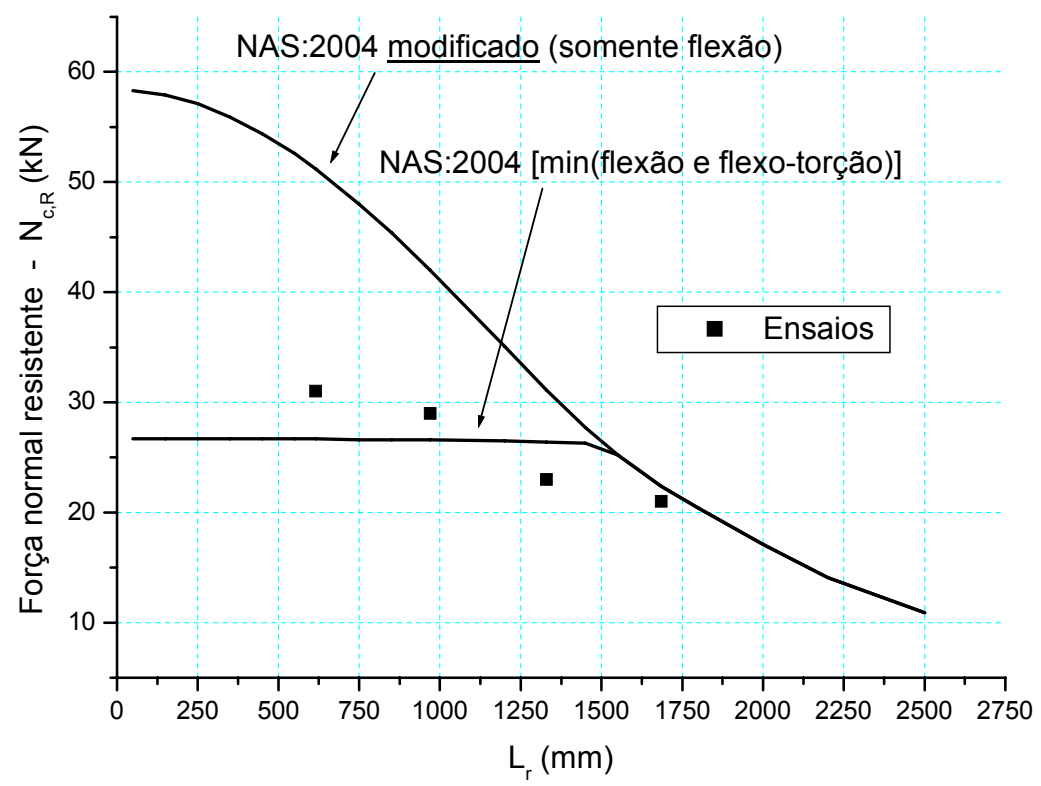

Figura 7.4 Cantoneira simples: ensaios versus NAS (2004) 


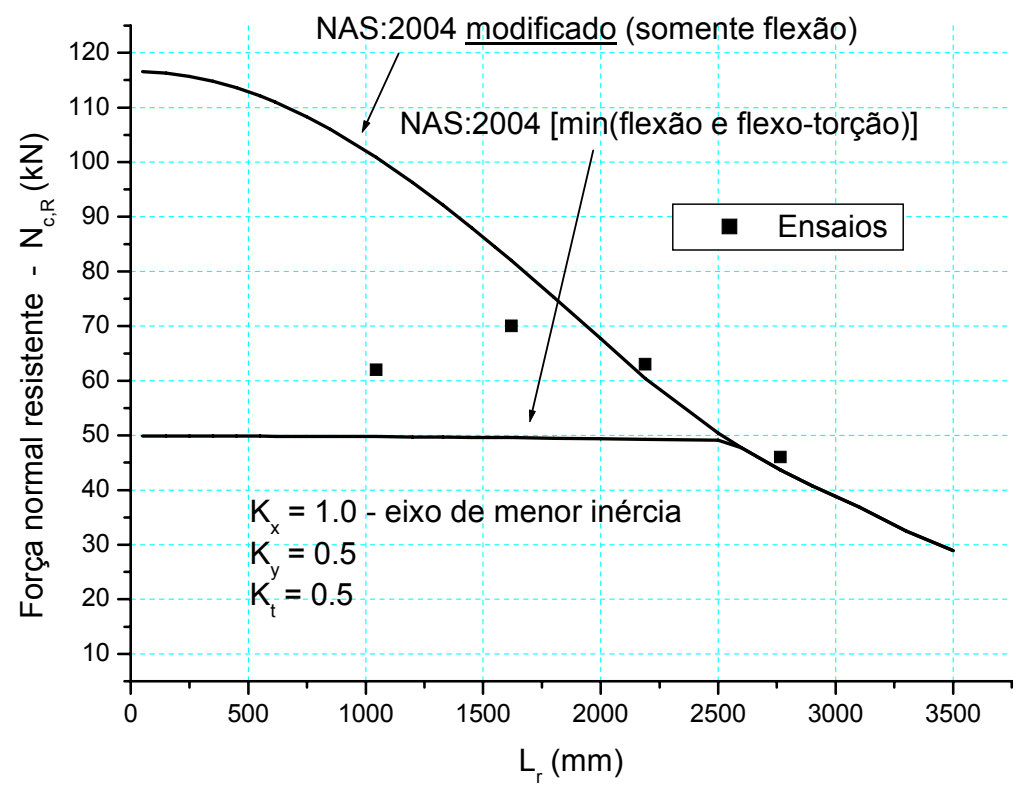

Figura 7.5 Cantoneira dupla com rótula para flexão em torno do eixo de menor inércia: ensaios versus NAS (2004)

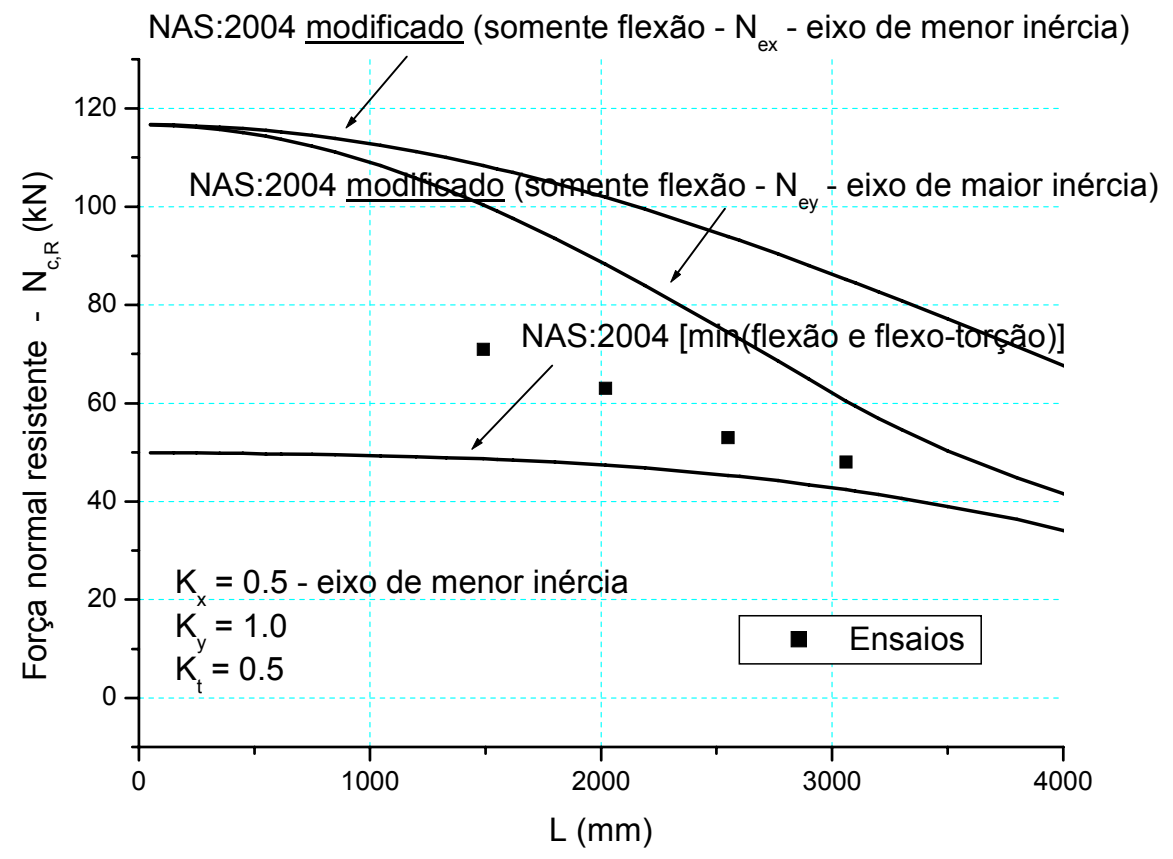

Figura 7.6 Cantoneira dupla com rótula para flexão em torno do eixo de maior inércia: ensaios versus NAS (2004)

Da análise do conjunto de figuras apresentado (Figura 7.4 até Figura 7.6), pode-se perceber que ignorar o modo global de flexo-torção em cantoneiras submetidas à compressão é contrário à segurança. Entretanto, cabe salientar que as conclusões não são definitivas uma 
vez que, se por um lado esse procedimento de cálculo conservadoramente inclui o modo global de flexo-torção, por outro, contrário à segurança, ignora o deslocamento do centróide da seção efetiva.

Finalmente, como já discutido quanto à Figura 7.2, evidências existem de que o modo local/torsional pode ser definido tanto como um modo local quanto como um modo global de torção, e com isso o fato de se ignorar ou não o modo global por torção nos procedimentos de cálculo merece atenção e cuidado.

\subsubsection{Comparação com o Método da Resistência Direta}

O Método da Resistência Direta (MRD) não foi previamente calibrado para cantoneiras, como pode ser observado na norma norte-americana NAS (2004) e no DSM Design Guide (AISI 2006).

Para as cantoneiras, como já explicado, perdura a dúvida quanto a se considerar no MRD o modo local/torsional obtido da análise elástica - por exemplo via CUFSM - como modo local, global ou ambos. Recomendações atuais do DSM Design Guide (AISI 2006) sugerem que se assuma a última opção, assim como se concluiu neste trabalho de doutorado e se apresentou no item anterior.

É aqui apresentada também uma opção inovadora, considerando-se que o modo local/torsional da análise elástica é o distorcional para o MRD, o que não é inconsistente se forem admitidos enrijecedores relativamente pequenos adicionados à cantoneira.

Recentemente, RASMUSSEN (2003) estendeu seu trabalho sobre cantoneiras para incluir o procedimento do MRD. Ignora o modo global de flexo-torção e explicitamente considera a excentricidade, fazendo então uma análise de flexo-compressão mesmo para barras submetidas à compressão centrada. Este procedimento de viga-coluna (flexão composta) é consistente com o MRD, e analisa a cantoneira sujeita à tensões de compressão e flexão, indicando que as excentricidades aumentam a resistência da barra quando próximas à junção das abas e a reduzem quando próximas à extremidade livre das abas.

Após essas explicações iniciais, são apresentadas aqui simulações do MRD para cantoneiras simples submetidas à compresão centrada, sendo que os efeitos explícitos da excentricidade são ignorados. Seis opções $(a-f)$ são consideradas, como detalhado na Tabela 7.1. Vale ressaltar que as expressões do MRD são as mesmas do Apêndice 1 da NAS (2004), mas aqui muitas outras opções do MRD são propostas e analisadas, inclusive quanto à adoção de $\mathrm{N}_{\mathrm{cr}}$ para as análises do método.

As opções $\underline{b}$ e $\underline{c}$ seguem as recomendações de Rasmussen e alguns outros pesquisadores, ignorando o modo local/torsional $(\mathrm{L} / \mathrm{T})$ como um modo global. A Tabela 7.2 mostra que essa idéia é razoável comparando-se com os resultados experimentais de Wilhoite 
e Popovic - apresentados em RASMUSSEN (2003) - enquanto que a comparação com os resultados oriundos dos ensaios deste doutorado mostra tal idéia como não conservadora (contrária à segurança).

As opções $\underline{a}$, $\underline{e}$ e $\underline{f}$ tratam o modo $L / T$ tanto como modo local (de chapa) quanto como modo global por torção. A opção a é a original proposta do método. As opções a e e têm sido recomendadas pelo recente guia do MRD conforme DSM Design Guide (AISI 2006). As opções $\underline{\mathrm{a}}$, $\underline{\mathrm{e}}$ e $\underline{\mathrm{f}}$ da Tabela 7.2 apresentam boa concordância quando comparadas aos ensaios realizados neste doutorado, enquanto indicam valores conservadores quando comparadas aos resultados de Wilhoite e Popovic. A opção f é interessante por ser simples, pois para o modo local do MRD, L/T é tomado somente para um comprimento (em que L/T=F), ou seja, menor valor da curva do modo $L / T$, a qual não apresenta mínimo bem definido, vide Figura 7.1, e permite fácil uso em projetos, sendo que os resultdos ficaram ligeiramente a favor da segurança quando comparados com a análise experimental deste presente trabalho.

Tabela 7.1 Opções para aplicação do MRD ${ }^{1}$

\begin{tabular}{|c|c|c|c|c|c|c|c|}
\hline MODO & & a & b & c & d & e & f \\
\hline Global & $\mathrm{N}_{\text {cre }}$ & $\begin{array}{c}\min \\
(\mathrm{L} / \mathrm{T}, \mathrm{F})\end{array}$ & $\mathrm{F}$ & $\mathrm{F}$ & $\begin{array}{c}\min \\
(\mathrm{L} / \mathrm{T}, \mathrm{F})\end{array}$ & $\begin{array}{c}\min \\
(\mathrm{L} / \mathrm{T}, \mathrm{F})\end{array}$ & $\begin{array}{c}\min \\
(\mathrm{L} / \mathrm{T}, \mathrm{F})\end{array}$ \\
\hline Local & $\mathrm{N}_{\text {cre }}$ & $\mathrm{L} / \mathrm{T}$ & $\mathrm{L} / \mathrm{T}$ & $\mathrm{L} / \mathrm{T}$ & - & $\mathrm{L} / \mathrm{T}$ & $\mathrm{L} / \mathrm{T}^{*}$ \\
\hline Distorcional & $\mathrm{N}_{\text {crd }}$ & - & - & $\mathrm{L} / \mathrm{T}$ & - & $\mathrm{L} / \mathrm{T}$ & - \\
\hline
\end{tabular}

Tabela 7.2 Opções do MRD comparadas com resultados de ensaios

Relação: experimental / previsão MRD

\begin{tabular}{|c|c|cccccc|}
\hline & & a & b & c & d & e & f \\
\hline \multirow{2}{*}{ Wilhoite } & média & 1,27 & 1,04 & 1,04 & 1,14 & 1,27 & 1,32 \\
& desv. padrão & 0,12 & 0,18 & 0,17 & 0,10 & 0,12 & 0,14 \\
\hline \multirow{2}{*}{ Popovic } & média & 1,18 & 0,93 & 0,95 & 1,06 & 1,18 & 1,23 \\
& desv. padrão & 0,26 & 0,16 & 0,16 & 0,22 & 0,26 & 0,28 \\
\multirow{2}{*}{ Chodraui et al. (2006a) } & média & 1,00 & 0,76 & 0,78 & 0,91 & 1,00 & 1,04 \\
& desv. padrão & 0,09 & 0,21 & 0,19 & 0,10 & 0,09 & 0,10 \\
\hline
\end{tabular}

A variação dos resultados relativos aos 3 autores citados na Tabela 7.2 é analisada e comparada com algumas opções do MRD na Figura 7.7. Pode-se verificar que os resultados de Popovic geralmente seguem uma curva "rebaixada" da flambagem por flexão, enquanto que os de Wilhoite não indicam uma tendência bem definida. Os resultados dos ensaios deste trabalho de doutorado mostram uma maior proximidade com a curva associada à consideração do modo local/torsional como global no MRD (opção f no caso). Isto sugere a necessidade de se realizar 
mais ensaios e análises numéricas detalhadas a fim de melhor esclarecer o procedimento de cálculo mais correto para cantoneiras.

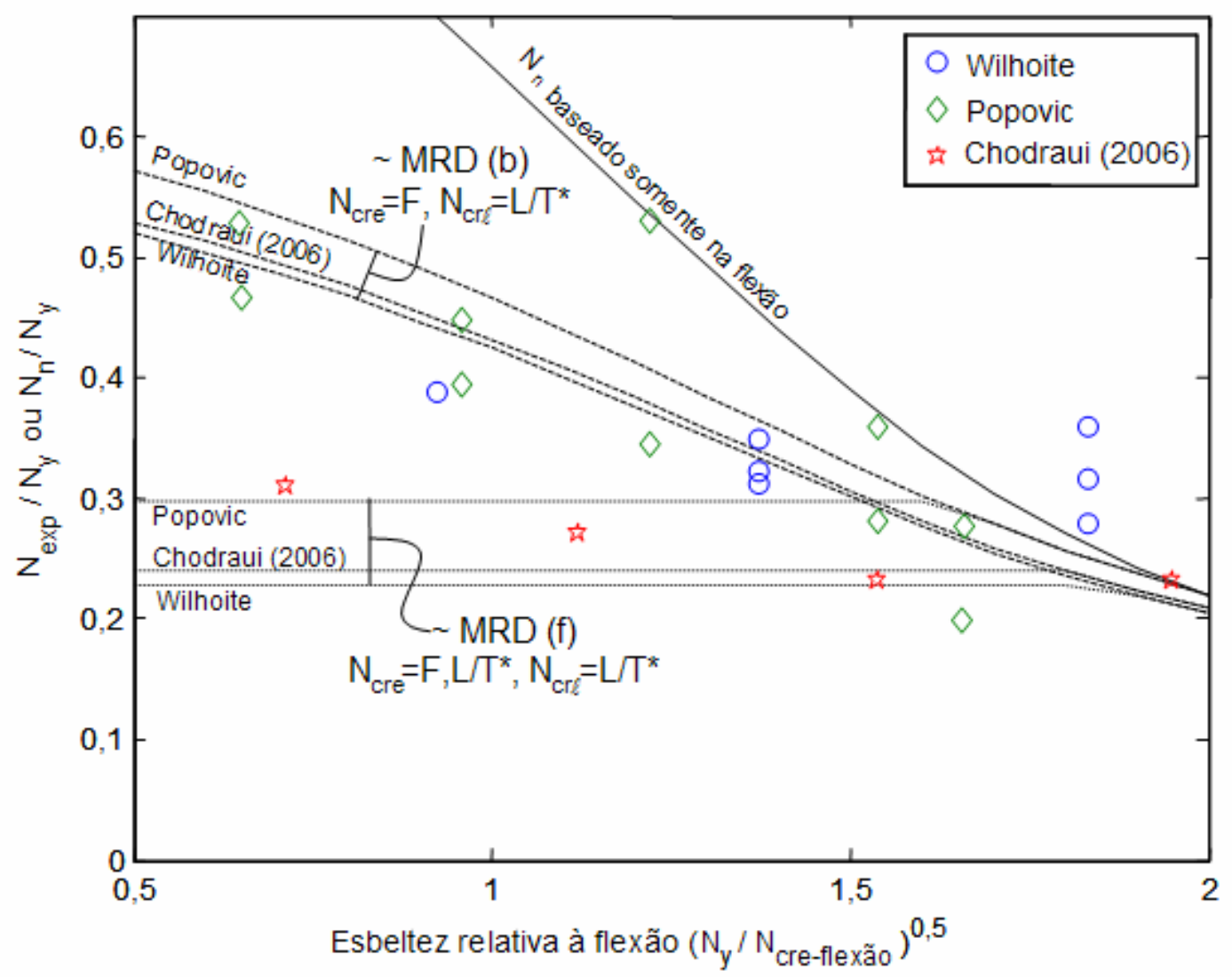

Nota: DSM: Direct Strength Method, ou MRD: Método da Resistência Direta Figura 7.7 Comparação: ensaios versus previsões de resistência

\subsubsection{Análises adicionais}

Análises adicionais em elementos finitos para cantoneiras submetidas à compressão foram realizadas neste trabalho em conjunto com o professor Benjamin W. Schafer, com o intuito de se explorar possíveis interações entre modos de instabilidade e também a sensibilidade às imperfeições geométricas.

Os modelos foram desenvolvidos no programa ABAQUS, adotando extremidades articuladas e empenamento livre, elementos de casca S9R5, e incluindo não-linearidade geométrica e do material na forma de critério de von Mises com encruamento isótropo e curva tensão-deformação simplificada com encruamento $\left(f_{y}=345 \mathrm{MPa}\right)$.

Para uma cantoneira L60x4,76 com comprimento $1.000 \mathrm{~mm}$, a Figura 7.8 apresenta os valores da força normal máxima (peak load) em função do número de meias-onda $m$ ao longo do comprimento da barra, associado ao modo local/torsional. Foi admitida imperfeição global 
de flexão com amplitude $\mathrm{L} / 500$ (falha por flexão) e amplitude $\mathrm{d} / \mathrm{t}=0,64$ para $\mathrm{o}$ modo local/torsional. Com base na Figura 7.8 pode-se observar que o modo local/torsional pode interagir com o modo global de flexão, porém tal interação só é desfavorável quando o comprimento de meia-onda do modo local/torsional é pequeno (valores mais elevados de $m$ ) e assim, a configuração deformada de torção é repetida várias vezes ao longo do comprimento.

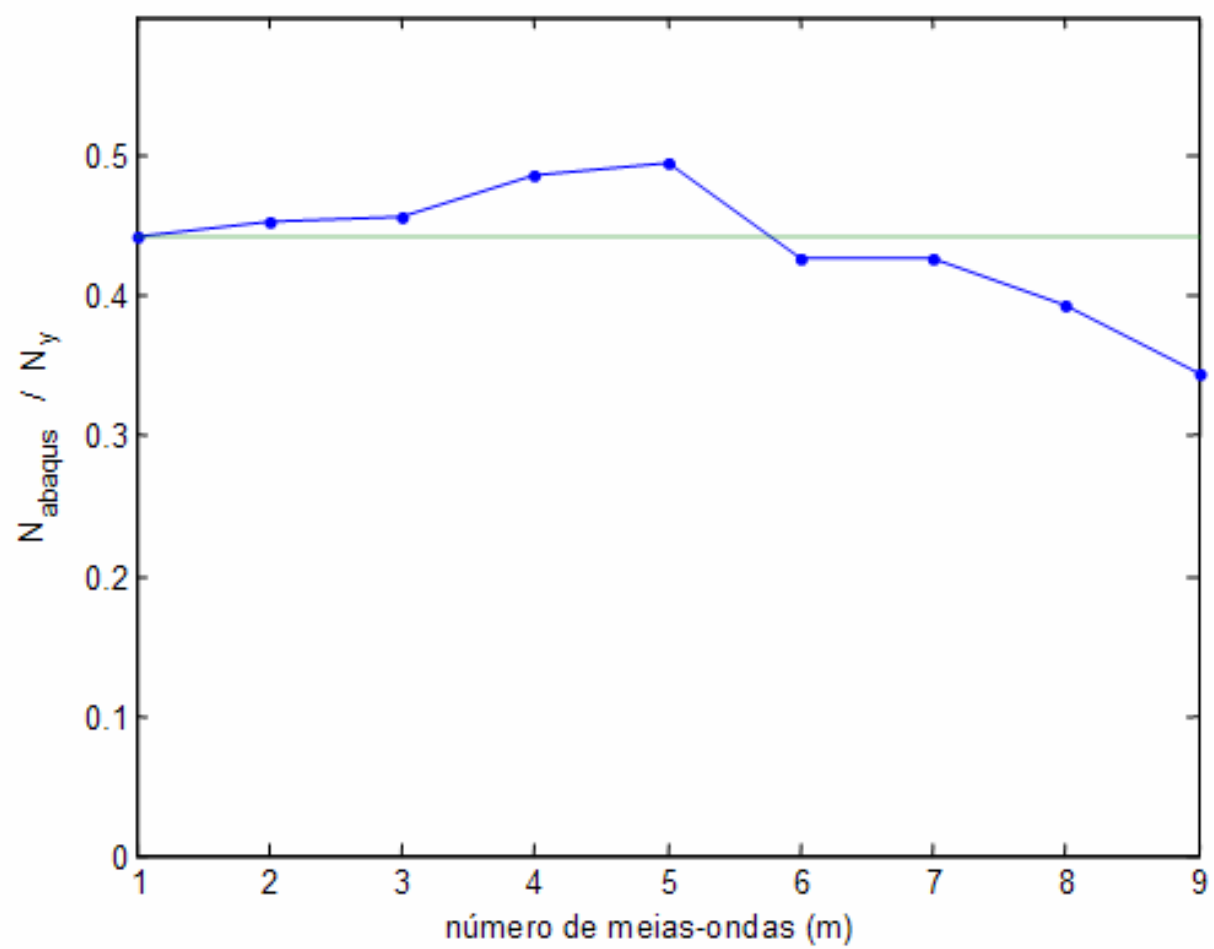

Figura 7.8 Imperfeições globais de flexão e local/torsional com $m$ meias-ondas

O estudo foi complementado analisando-se uma cantoneira $L 60 \times 2,38 \mathrm{~mm}$, com o objetivo de investigar possíveis interações entre o modo local-chapa e global-torsional, isto é, a sensibilidade da resposta em relação à imperfeição local-torsional com uma única meia-onda $(m=1)$ e local-torsional com múltiplas meias-ondas ao longo do comprimento $(m>1)$. Nesse caso, o comprimento da cantoneira foi reduzido para $L=615 \mathrm{~mm}$, de maneira que o modo global crítico (mais baixo) correspondesse ao modo torsional e não por flexão ( $L=970 \mathrm{~mm}$ também foi analisado apresentando resultados similares). Os resultados estão apresentados na Figura 7.9, onde pode-se observar que a força normal máxima diminui à medida que aumenta o número de meias-ondas associado ao modo local/torsional, demonstrando uma interação definida.

Mesmo diante da limitação desse estudo, os resultados indicam que (i) o modo local/torsional interage com o modo global de flexão (como já esperado), e (ii) o modo local/torsional interage com ele próprio, e para diferentes comprimentos de meias-ondas, é 
possível e desfavorável. Essas conclusões reforçam a hipótese que a instabilidade local/torsional deve ser considerada como modo local de chapa e também como modo globaltorsional nos procedimentos de cálculo, como enfatizado neste presente trabalho de doutorado.

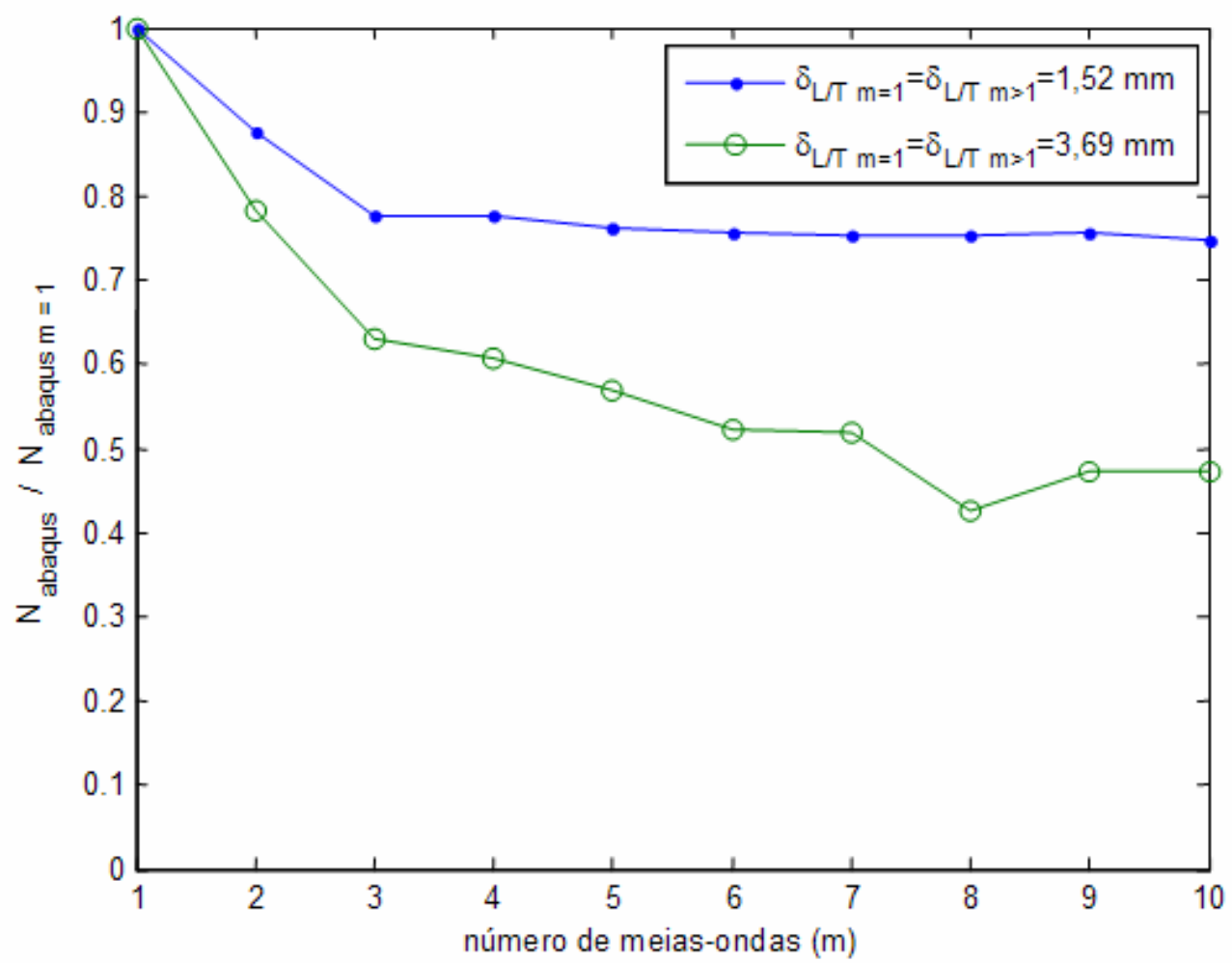

Figura 7.9 Imperfeições globais de torção $(m=1)$ e local/torsional com $m>1$ meias-ondas

\subsection{Discussão dos resultados em geral}

Após a discussão dos resultados para o caso particular das cantoneiras, são aqui realizadas análises e discussões dos resultados obtidos neste trabalho como um todo (todas as barras analisadas), a fim de também fundamentarem o capítulo de conclusões a seguir.

Inicialmente, pode-se dizer que os modelos numéricos em elementos finitos mostraramse confiáveis tanto quanto aos valores obtidos de resistência máxima quanto à configuração deformada das barras. Além disso, a estratégia proposta quanto à inserção das imperfeições geométricas iniciais, modelo reológico e a não inclusão de tensões residuais se mostrou adequada e serve de base para novos trabalhos.

Adicionalmente, quanto à comparação entre os modelos em elementos finitos e a análise experimental, no que se refere às configurações deformadas das barras no momento em que se atinge a resistência máxima, percebeu-se que: 
- Para os perfis do tipo $U$, mais modos foram verificados nos modelos em elementos finitos (modos locais), além dos verificados nos ensaios;

- O mesmo ocorreu para os perfis do tipo Ue, neste caso em particular atenção especial para o aparecimento do modo distorcional nos modelos em elementos finitos, o que é justificado pelo fato da prévia inserção deste modo na superposição de modos de instabilidade quando da aplicação das imperfeições geométricas iniciais;

- Para as cantoneiras simples os modos coincidiram integralmente, sendo predominantemente local/torsional para ambas as análises;

- Para as cantoneiras duplas, verificou-se o modo local/torsional na maioria das barras ensaiadas, enquanto que se obteve a superposição entre o modo global de flexão e o local/torsional nos modelos em elementos finitos, o que na verdade pode ser confundido com flexo-torção em alguns casos;

Para que o leitor veja uma ilustração da coincidência entre a análise experimental e os modelos em elementos finitos, a Figura 7.10 ilustra o modo local/torsional para a cantoneira simples, evidenciando a semelhança entre a deformada da barra após o ensaio e o resultado fornecido pelo modelo numérico via análise não-linear em elementos finitos.

Algumas figuras são apresentadas agora a fim de ilustrar a comparação entre a análise experimental e os modelos numéricos quanto ao gráfico força versus deslocamento do pistão. Entendeu-se não haver a necessidade de se apresentar este gráfico para todas as barras analisadas, pois o comportamento é similar. Pode ser visto que, mesmo com a ocorrência de uma acomodação inicial da barra no sistema de ensaio, o comportamento da barra é muito próximo ao fornecido pelo modelo numérico. A Figura 7.11 ilustra a comparação para um perfil do tipo $U$, enquanto que a Figura 7.12 e a Figura 7.13 ilustram para uma cantoneira simples e para um perfil do tipo $U$ enrijecido, respectivamente. 


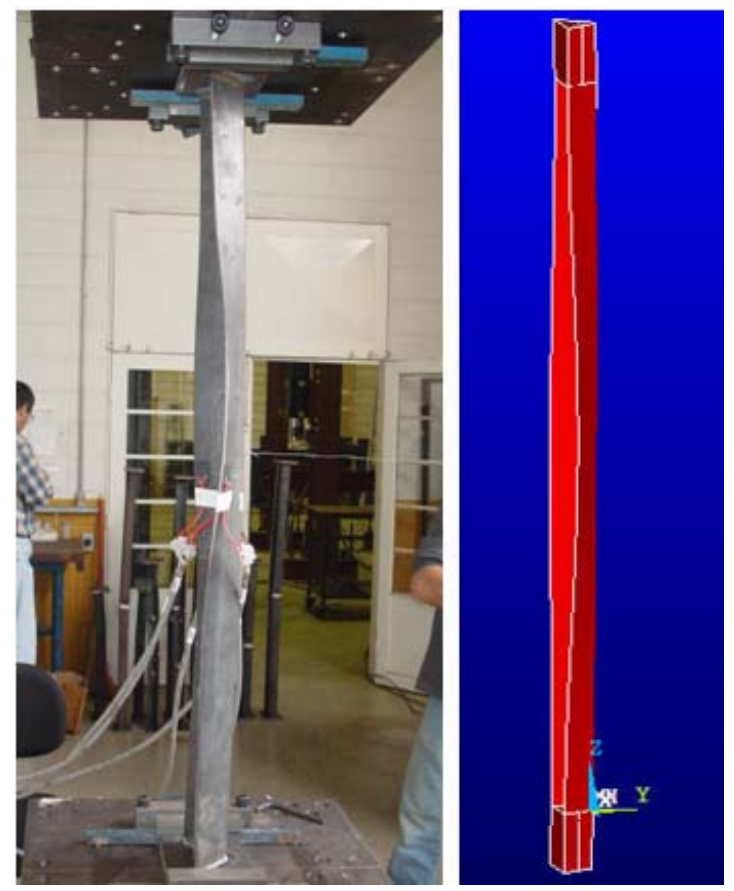

Figura 7.10 Ensaio versus Ansys: modo local/torsional para cantoneira $60 \times 2,38 \mathrm{~mm}$

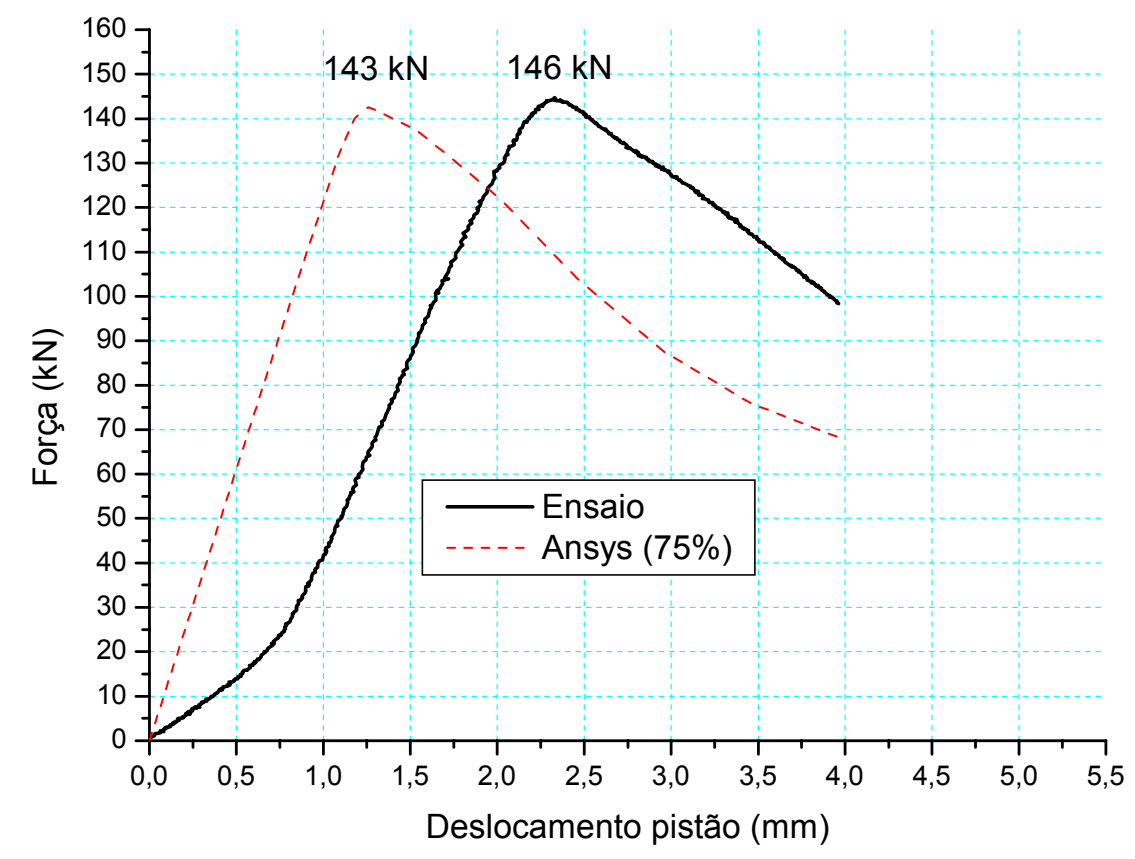

Figura 7.11 Ensaio versus Ansys: perfil tipo $U 100 \times 50 \times 3,88 \mathrm{~mm}\left(\mathrm{~L}_{r}=1.320 \mathrm{~mm}\right)$ 


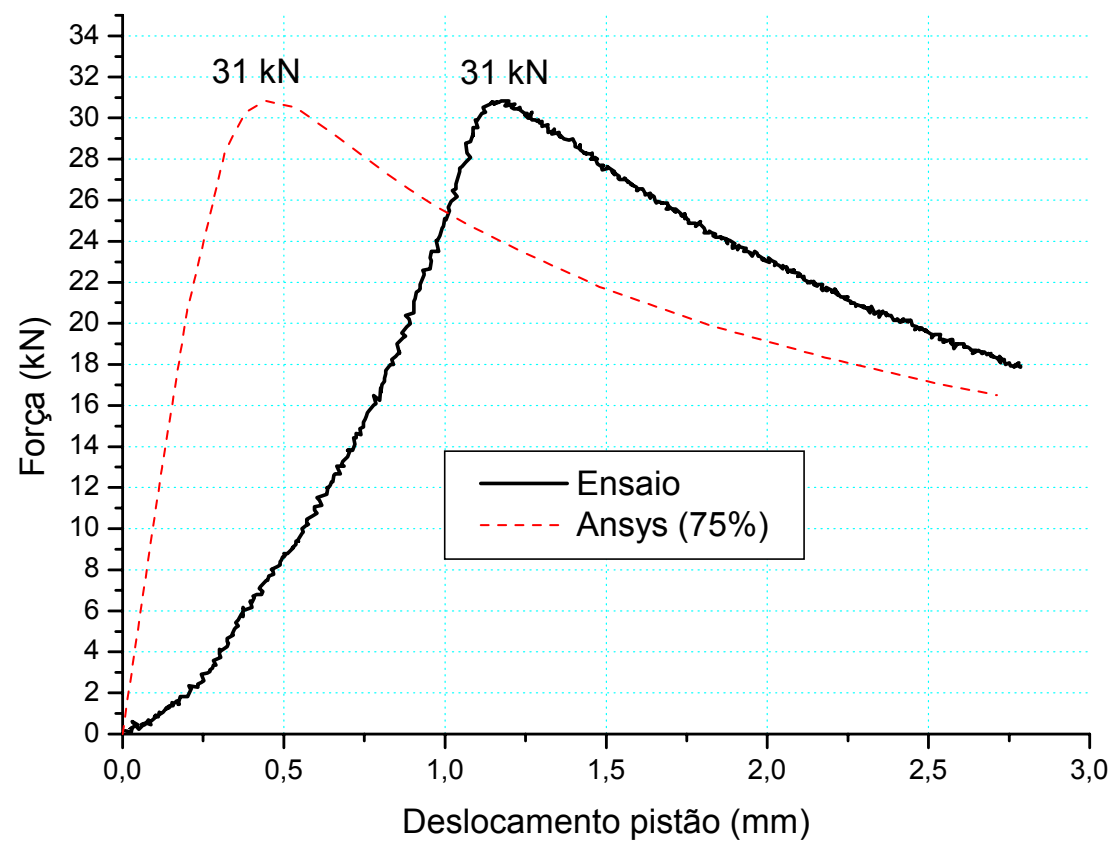

Figura 7.12 Ensaio versus Ansys: perfil tipo $L 60 \times 2,38 \mathrm{~mm}\left(L_{r}=615 \mathrm{~mm}\right)$

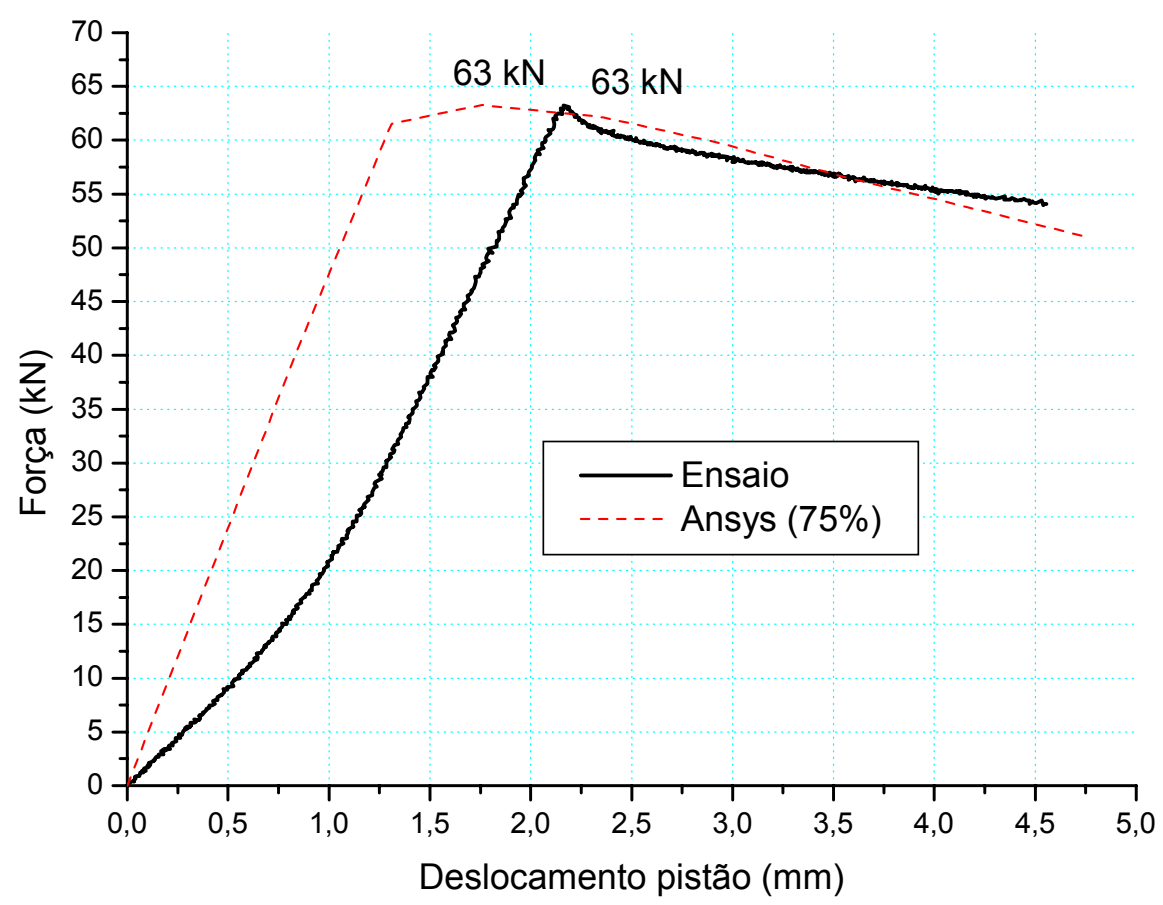

Figura 7.13 Ensaio versus Ansys: perfil tipo Ue $125 \times 50 \times 25 \times 2,38 \mathrm{~mm}\left(L_{r}=2.700 \mathrm{~mm}\right)$

Um aspecto também interessante, apresentado e comentado no capítulo dos resultados da análise numérica, é relativo aos panoramas de tensão de von Mises. Foram apresentados para uma barra para cada tipo de seção transversal, no instante em que a barra atinge a resistência máxima. Tais resultados ilustram os modos de falha apresentados na Tabela 6.6. 
Além disso, pôde-se verificar que na região dos elementos sólidos que compõem a rótula as tensões são muito baixas como esperado, e a tensão máxima (regiões em vermelho nas figuras em questão) foi inferior à resistência ao escoamento, que é $\mathrm{f}_{\mathrm{y}}=37,5 \mathrm{kN} / \mathrm{cm}^{2}$ para os perfis de espessura $t=2,38 \mathrm{~mm}$, e $f_{y}=28,8 \mathrm{kN} / \mathrm{cm}^{2}$ para os perfis de espessura $t=3,88 \mathrm{~mm}$. Portanto, nos modelos numéricos, os perfis de paredes finas podem atingir sua resistência máxima para valores de tensão abaixo da resistência ao escoamento devido a problemas de instabilidade. Entretanto, na análise experimental, regiões de plastificação foram verificadas nas barras no instante em que se atingiu a resistência máxima, e esta diferença se explica devido a condições inerentes ao material que são difíceis de serem simuladas nos modelos numéricos nesses casos.

A Tabela 7.3 apresenta os valores da resistência máxima e a comparação para os diversos tipos de análises para todas as barras. As análises estatísticas são apresentadas nesta tabela em duas etapas, pois para as cantoneiras duplas os resultados de ensaio se aproximaram mais do quantil de $25 \%$ de imperfeições geométricas iniciais do modelo numérico (maiores imperfeições), diferentemente do que aconteceu para os outros tipos de perfis, em que os resultados de ensaio que se aproximaram mais do quantil de $75 \%$ (menores imperfeições).

Quanto à comparação entre os resultados de resistência máxima dos ensaios e das normas (experimental / norma), constatou-se que: para os perfis do tipo $U$, Ue e para as cantoneiras simples, os resultados dos ensaios são muito próximos dos previstos pelas normas, mas houve uma aproximação maior dos ensaios, em termos médios, com a norma americana (NAS:2004), que possui curva única, sendo média de 1,01 com variação de 0,79 a 1,23, enquanto que comparando-se com a NBR 14762:2001 obteve-se média de 1,10 com variação de 0,82 a 1,35; para as cantoneiras duplas, a comparação com as duas normas apresentou valor semelhante de média e desvio padrão, mas tais valores previstos pelas normas não resultaram tão próximos aos resultados dos ensaios (valores da análise experimental, em média, $25 \%$ superiores aos previstos pelas normas, com variação de 1,05 a 1,46 comparando-se à NAS:2004, e de 1,12 a 1,42 comparando-se à NBR 14762:2001).

Como já comentado, quanto à comparação entre os resultados dos ensaios e dos modelos numéricos, para os perfis do tipo $U$, Ue e para as cantoneiras simples, os resultados dos ensaios são também próximos dos previstos pelos modelos, constatada uma aproximação maior com o panorama de $75 \%$, ou seja, menores imperfeições geométricas iniciais, enquanto que para as cantoneiras duplas foi constatada uma aproximação maior com o panorama de $25 \%$, ou seja, maiores imperfeições geométricas iniciais. Entende-se que para as cantoneiras duplas o fato de se soldar os dois perfis a uma única chapa de topo procurando-se alinhá-los, aliado à utilização de presilhas, fez com que maiores imperfeições iniciais fossem instaladas nas barras. 
Para o caso das cantoneiras simples e duplas, essa semelhança de resultados de resistência máxima dos ensaios realizados neste trabalho de doutorado com as normas e modelos numéricos - fato que contradiz portanto o que sugerem alguns pesquisadores - dá suporte à questão de que a idéia desses pesquisadores de se negligenciar o modo de flexotorção no cálculo deste tipo de perfil parece não ser a mais correta como já explicado.

O conjunto de gráficos apresentado da Figura 7.14 até a Figura 7.17 é uma opção de visualização dos resultados das análises numéricas frente aos resultados dos procedimentos normativos. Observa-se que a retirada das cantoneiras duplas destes gráficos conduz a um melhor ajuste do conjunto de resultados experimentais às curvas normativas.

Alguns gráficos são apresentados, comparando-se os resultados de resistência máxima dos ensaios realizados neste trabalho com os previstos por normas (NBR 14762:2001, que adota as mesmas curvas de resistência do Eurocode, bem como NAS:2004).

Portanto, como análises comparativas das resistências máximas verificadas nos ensaios com as previstas pelas normas, apresentam-se a Figura 7.18 e a Figura 7.19, que relacionam os resultados dos ensaios com valores previstos pela NBR 14762:2001 e pelo NAS:2004 respectivamente.

Pode ser visto que embora as curvas das normas tenham sido elaboradas para perfis soldados e laminados, é razoável utilizá-las para os formados a frio. Além disso, a curva b da norma brasileira praticamente cobre todos os casos, e uma sugestão é adotá-la como única para todos os perfis de aço formados a frio em vez da utilização das múltiplas curvas como é feito atualmente, o que é justificável pela pequena influência das tensões residuais nos perfis formados a frio e pelo panorama semelhante de impefeições geométricas nos perfis usuais. Em síntese, no contexto dos perfis de aço, pode-se entender que os formados a frio (pelo menos os usuais) constituem uma única família de perfis. Vale salientar que não se colocou no mesmo gráfico as curvas da norma brasileira e americana pois o cálculo de $\lambda_{0}$ é feito de forma diferente, $\lambda_{c} \neq \lambda_{0}$ se $A_{\text {ef }} \neq A$.

Para se entender melhor a idéia proposta neste trabalho em virtude dos resultados encontrados, quanto a se utilizar a curva b como única para todos os perfis de aço formados a frio, independente da seção transversal e do eixo de flexão como é recomendado atualmente, foi realizada a análise apresentada na Tabela 7.4.

A Tabela 7.4 apresenta, portanto, os resultados obtidos nos ensaios, os previstos pela norma NBR 14762:2001, e também, utilizando-se a mesma norma, mas com a proposição de uma curva b única. Comparações são realizadas e se pode constatar que, mesmo sendo uma pequena diferença, a modificação proposta neste trabalho faz com que os resultados previstos se aproximem mais dos ensaios (média de 1,11 utilizando-se a curva b única contra 1,14 para utilização da norma atual, curvas $\underline{b}$ e $\underline{\mathrm{c}}$ no caso). 
Tese de Doutorado - Gustavo Monteiro de Barros Chodraui

Tabela 7.3 Comparação: resultados das barras (NBR 14762:2001, NAS:2004, análise experimental e numérica)

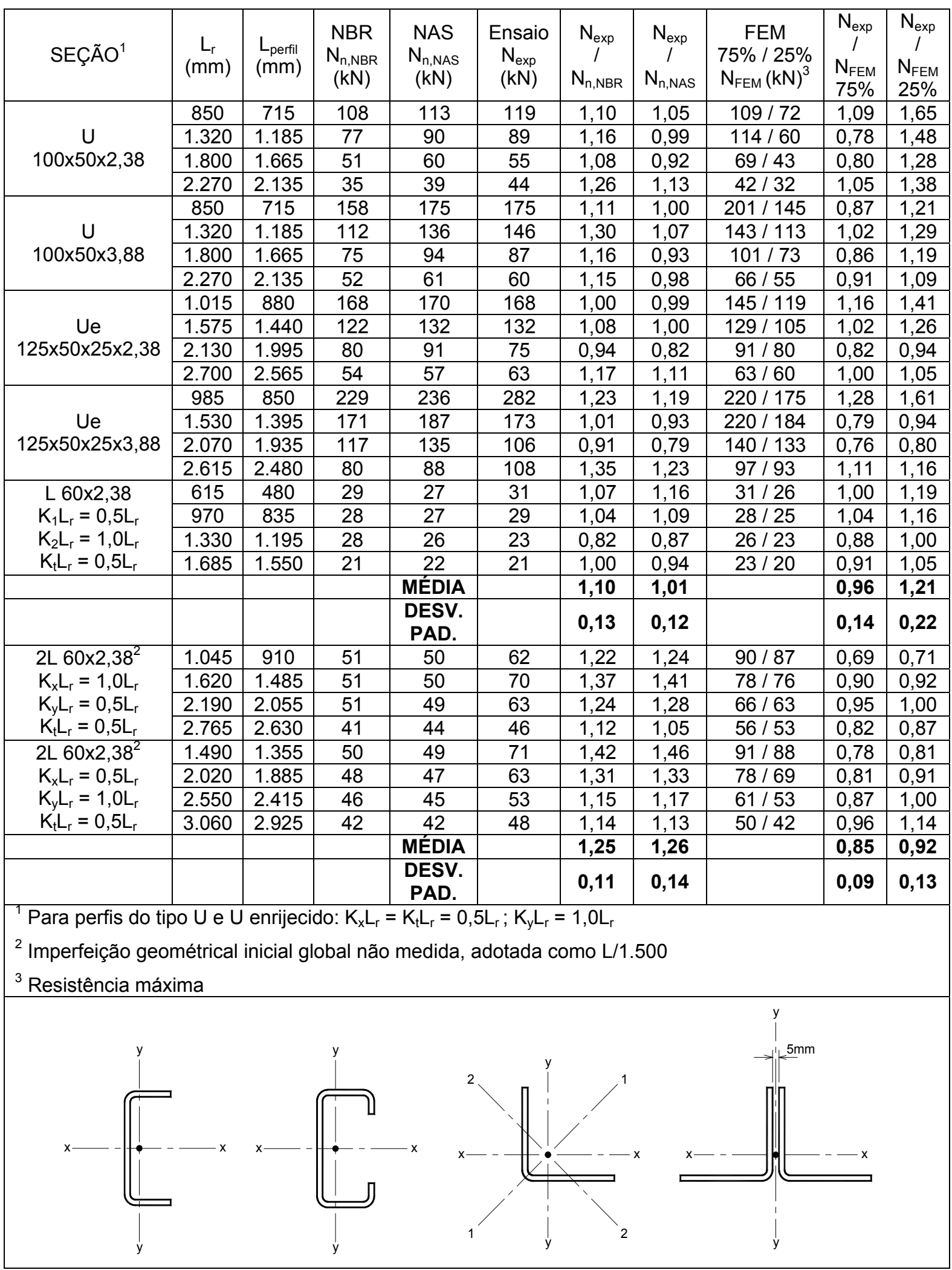




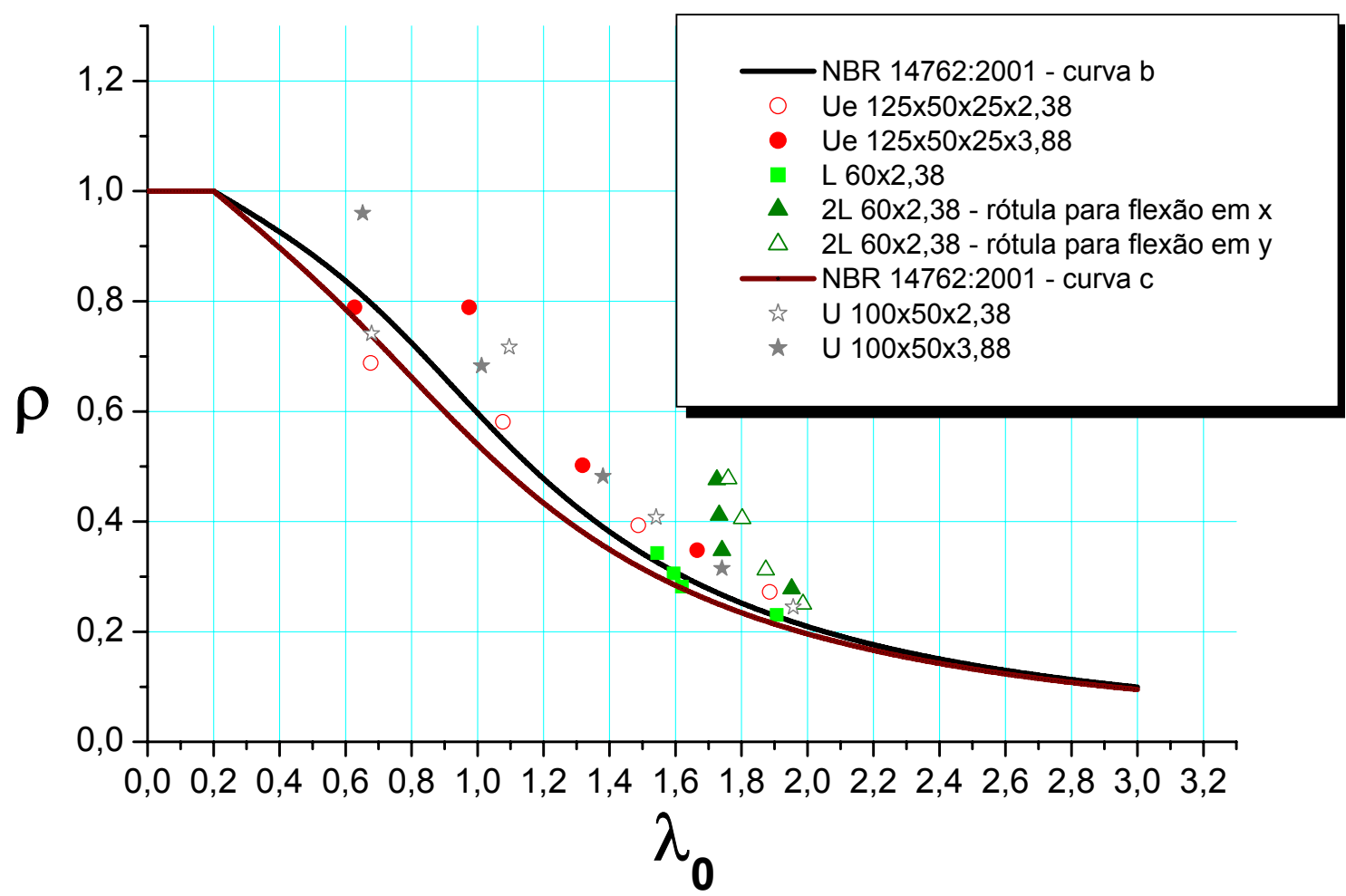

Figura 7.14 NBR 14762:2001 e numérico 75\%

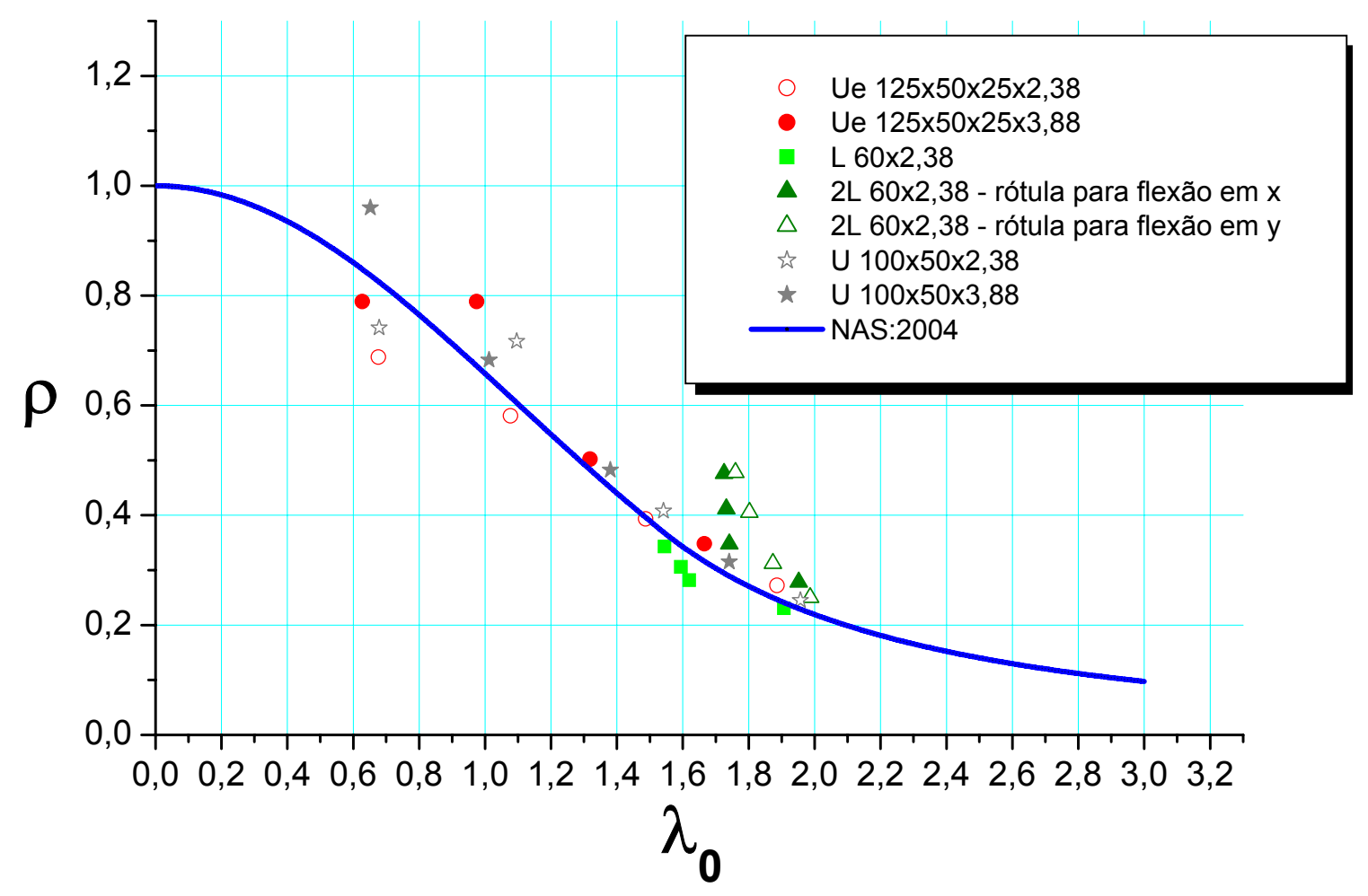

Figura 7.15 NAS:2004 e numérico 75\% 


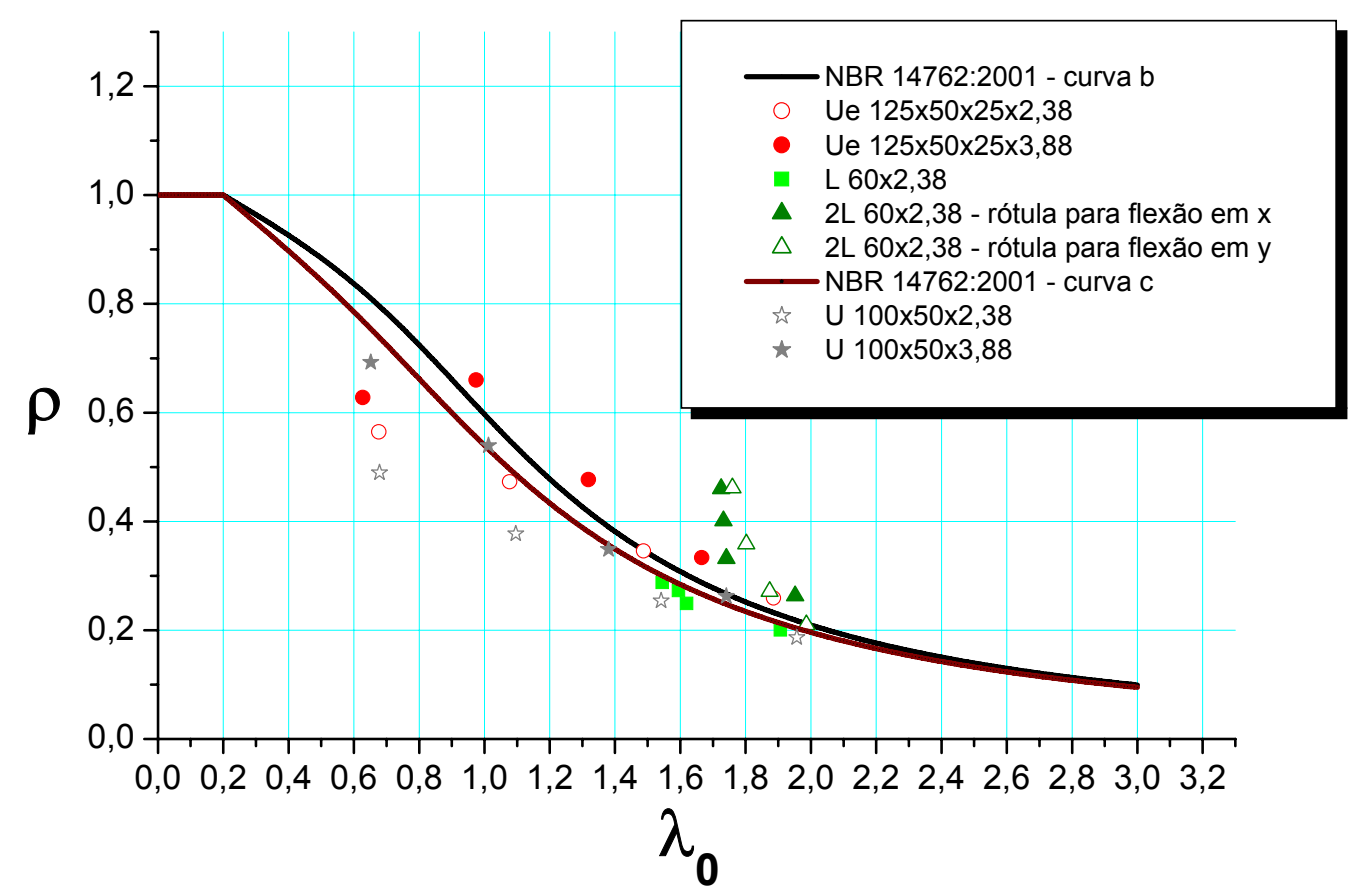

Figura 7.16 NBR 14762:2001 e numérico 25\%

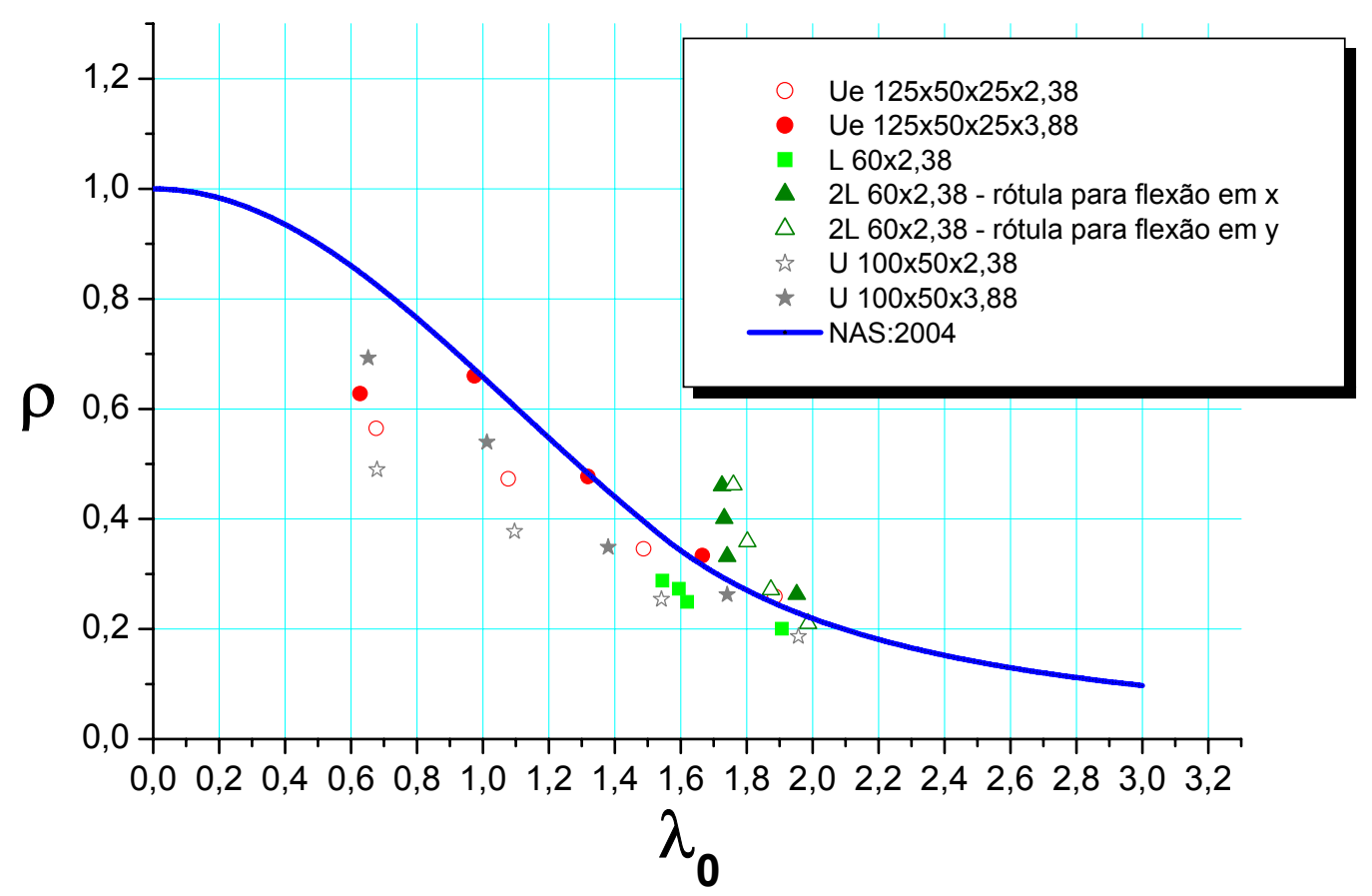

Figura 7.17 NAS:2004 e numérico 25\% 


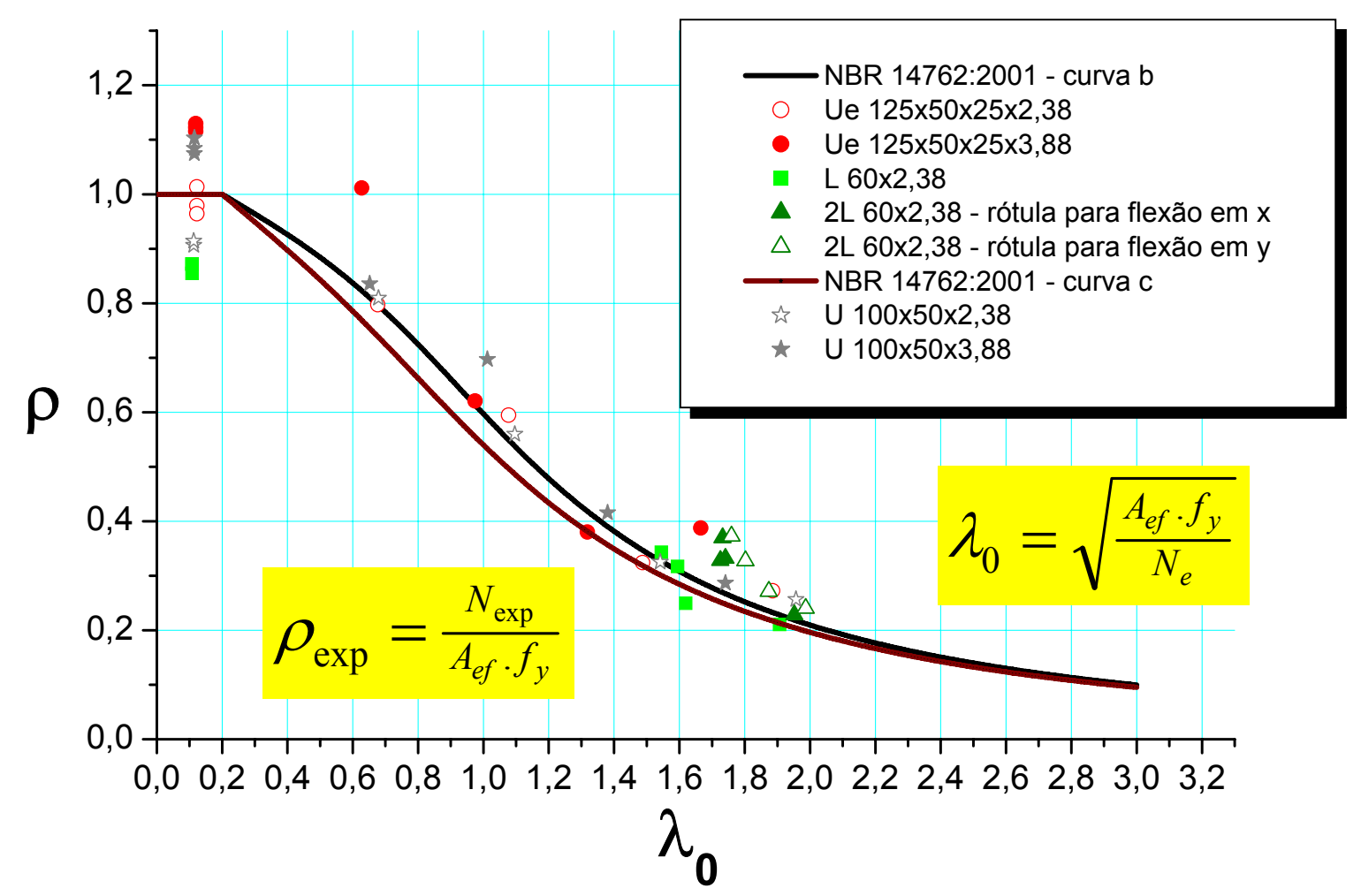

Figura 7.18 NBR 14762:2001 e ensaios

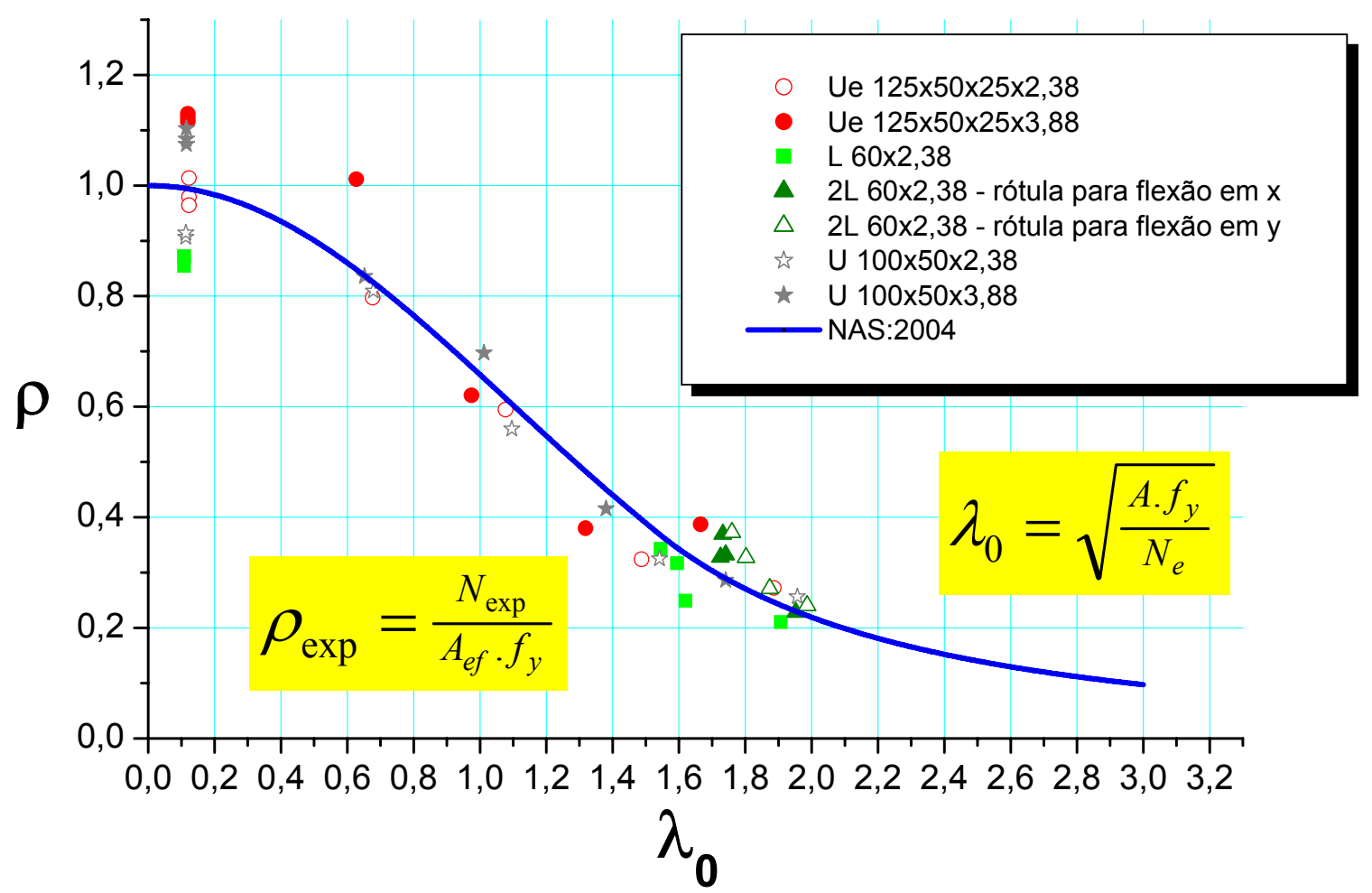

Figura 7.19 NAS:2004 e ensaios 
Tabela 7.4 Verificação de utilização de curva única tipo b

\begin{tabular}{|c|c|c|c|c|c|c|c|}
\hline SEÇÃO & $\begin{array}{c}\text { NBR } \\
14762: 2001 \\
N_{n, N B R}(k N)\end{array}$ & $\begin{array}{c}\text { Curva } \\
\text { NBR } \\
\text { 14762:2001 } \\
\text { original }\end{array}$ & $\begin{array}{l}\text { Ensaio } \\
\qquad N_{\exp } \\
(k N)\end{array}$ & $\begin{array}{c}N_{\exp } \\
\quad{ }_{n, N B R}^{\prime}\end{array}$ & $\begin{array}{c}\text { NBR } \\
\text { 14762:2001 } \\
\text { MOD } \\
N_{n, \text { NBR }}(k N)\end{array}$ & $\begin{array}{c}\text { Curva } \\
\text { NBR 14762:2001 } \\
\text { MOD } \\
\text { (sempre curva b) }\end{array}$ & $\begin{array}{c}N_{\exp } \\
N_{n, N B R}^{\prime} \\
M O D\end{array}$ \\
\hline \multirow{4}{*}{$\underset{100 \times 50 \times 2,38}{U}$} & 108 & c & 119 & 1,10 & 115 & b & 1,04 \\
\hline & 77 & $\mathrm{c}$ & 89 & 1,16 & 85 & $\mathrm{~b}$ & 1,05 \\
\hline & 51 & $\mathrm{c}$ & 55 & 1,08 & 55 & $\mathrm{~b}$ & 1,00 \\
\hline & 35 & $\mathrm{c}$ & 44 & 1,26 & 37 & $\mathrm{~b}$ & 1,18 \\
\hline \multirow{4}{*}{$\underset{100 \times 50 \times 3,88}{U}$} & 158 & $\mathrm{c}$ & 175 & 1,11 & 170 & b & 1,03 \\
\hline & 112 & c & 146 & 1,30 & 123 & $b$ & 1,18 \\
\hline & 75 & $\mathrm{c}$ & 87 & 1,16 & 82 & $\mathrm{~b}$ & 1,07 \\
\hline & 52 & $\mathrm{c}$ & 60 & 1,15 & 56 & $\mathrm{~b}$ & 1,07 \\
\hline \multirow{4}{*}{$\begin{array}{c}\mathrm{Ue} \\
125 \times 50 \times 25 \times 2,38\end{array}$} & 168 & $b$ & 168 & 1,00 & 168 & $\mathrm{~b}$ & 1,00 \\
\hline & 122 & b & 132 & 1,08 & 122 & b & 1,08 \\
\hline & 80 & $b$ & 75 & 0,94 & 80 & $b$ & 0,94 \\
\hline & 54 & $\mathrm{~b}$ & 63 & 1,17 & 54 & $\mathrm{~b}$ & 1,17 \\
\hline \multirow{4}{*}{$\begin{array}{c}\mathrm{Ue} \\
125 \times 50 \times 25 \times 3,88\end{array}$} & 229 & $b$ & 282 & 1,23 & 229 & b & 1,23 \\
\hline & 171 & b & 173 & 1,01 & 171 & b & 1,01 \\
\hline & 117 & $\mathrm{~b}$ & 106 & 0,91 & 117 & $\mathrm{~b}$ & 0,91 \\
\hline & 80 & $b$ & 108 & 1,35 & 80 & $\mathrm{~b}$ & 1,35 \\
\hline \multirow{4}{*}{$\begin{array}{c}\mathrm{L} \\
60 \times 2,38\end{array}$} & 29 & $\mathrm{~b}$ & 31 & 1,07 & 29 & $\mathrm{~b}$ & 1,07 \\
\hline & 28 & $b$ & 29 & 1,04 & 28 & $\mathrm{~b}$ & 1,04 \\
\hline & 28 & $\mathrm{~b}$ & 23 & 0,82 & 28 & $\mathrm{~b}$ & 0,82 \\
\hline & 21 & $\mathrm{c}$ & 21 & 1,00 & 23 & $b$ & 0,93 \\
\hline \multirow{4}{*}{$\begin{array}{c}2 \mathrm{~L} \\
60 \times 2,38-x\end{array}$} & 51 & $b$ & 62 & 1,22 & 51 & $\mathrm{~b}$ & 1,22 \\
\hline & 51 & $b$ & 70 & 1,37 & 51 & $b$ & 1,37 \\
\hline & 51 & $b$ & 63 & 1,24 & 51 & $\mathrm{~b}$ & 1,24 \\
\hline & 41 & c & 46 & 1,12 & 44 & b & 1,05 \\
\hline \multirow{4}{*}{$\begin{array}{c}2 \mathrm{~L} \\
60 \times 2,38-y\end{array}$} & 50 & $\mathrm{~b}$ & 71 & 1,42 & 50 & $\mathrm{~b}$ & 1,42 \\
\hline & 48 & $b$ & 63 & 1,31 & 48 & $b$ & 1,31 \\
\hline & 46 & $b$ & 53 & 1,15 & 46 & $b$ & 1,15 \\
\hline & 42 & $b$ & 48 & 1,14 & 42 & $b$ & 1,14 \\
\hline MÉDIA & & & & 1,14 & & & 1,11 \\
\hline DESV. PAD. & & & & 0,14 & & & 0,15 \\
\hline
\end{tabular}

\subsubsection{Comparação com o Método da Resistência Direta}

Algumas análises quanto ao Método da Resistência Direta (MRD) são aqui apresentadas, para todas as barras analisadas neste trabalho (perfis do tipo $U$, Ue, cantoneira simples e dupla). Para a curva de resistência do MRD referente ao modo de instabilidade global, duas opções são apresentadas, curva única do NAS:2004 (portanto, MRD como proposto) e uma opção alternativa, utilizando-se as múltiplas curvas da NBR 14762:2001 (mesmas curvas do Eurocode 3 -1.3:1996), a fim de verificar a viabilidade da utilização da norma brasileira em conjunto com o MRD. 
Deve-se atentar ao fato do índice de esbeltez das curvas de resistência à compressão da norma brasileira NBR 14762:2001 e o calculado pelo MRD serem calculados de maneira diferente, pois o referente à norma brasileira considera a área efetiva em seu cálculo. Portanto, as curvas de resistência destes dois procedimentos não podem ser simplesmente colocadas no mesmo gráfico a fim de comparação (a menos que $A_{\text {ef }}=A$, como já explicado), e se isso ocorrer, pelo menos o eixo do índice de esbeltez dever ser duplo (um para cada procedimento).

Vale ressaltar que para a análise geral de estabilidade elástica prévia, necessária à utilização do MRD (explicado anteriormente), além de análises manuais, ou outras numéricas, por exemplo, tanto o programa via faixas finitas CUFSM quanto uma análise de autovalor, utilizando-se, por exemplo, o programa via elementos finitos Ansys, pode ser utilizada. Estas duas últimas análises foram realizadas, e os resultados ficaram praticamente idênticos.

As comparações são realizadas entre os resultados dos ensaios e as duas possibilidades do MRD, como apresentado na Tabela 7.5. Pode-se perceber uma opção interessante $\left(\mathrm{N}_{\mathrm{MRD}, \mathrm{NBR}}\right)$, segundo a qual as múltiplas curvas de resistência da NBR 14762:2001 são adotadas para a determinação de $\mathrm{N}_{\mathrm{g}}$ no Método da Resistência Direta, em vez do uso da curva única da NAS:2004. Entretanto, a opção original do MRD ainda apresentou resultados em termos médios mais próximos dos ensaios (média de 1,07 contra 1,17 para o caso das múltiplas curvas).

Ainda quanto a Tabela 7.5, em particular para o caso das seções pré-qualificadas para utilização do MRD, ou seja, perfis do tipo $U$ e $U$ enrijecido, a comparação dos ensaios com o MRD com a utilização da curva da NAS:2004 (seria o método fechado, como foi proposto)

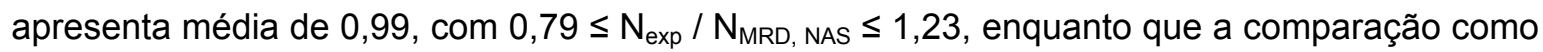
o MRD utilizando-se as múltiplas curvas apresenta média de 1,12, com $0,91 \leq \mathrm{N}_{\text {exp }} / \mathrm{N}_{\mathrm{MRD}, \mathrm{NBR}} \leq 1,35$.

Pode ser verificado na Figura 7.20, para as seções pré-qualificadas do MRD, que dentre as três análises da figura, o procedimento do MRD com a curva do NAS:2004 (método fechado, como foi proposto) fornece os resultados mais próximos aos ensaios, sendo isto um fato interessante e encorajador quanto à proposta do MRD, por ser um método novo o prático. Portanto, em termos médios, a análise experimental ficou mais próxima do MRD com curva do NAS:2004 do que via procedimento fechado da NBR 14762:2001.

Vale lembrar que a NBR 14762:2001 utiliza o procedimento das larguras efetivas, enquanto que o MRD analisa a seção transversal como um todo - interação explícita entre os elementos - e utiliza a área bruta para a análise, além de utilizarem curvas de resistência diferentes. Além disso, vale relatar que o MRD (utilizando-se as múltiplas curvas da NBR) apresenta os mesmos valores, na maioria dos casos, aos referentes à utilização do procedimento completo da norma NBR 14762:2001, pois nos casos em que a instabilidade global é a crítica a curva utilizada nesses dois procedimentos é exatamente a mesma. 
Tabela 7.5 Barras analisadas: ensaio versus Método da Resistência Direta

\begin{tabular}{|c|c|c|c|c|c|c|c|}
\hline SEÇÃO ${ }^{1}$ & $\begin{array}{c}\mathrm{L}_{\mathrm{r}} \\
(\mathrm{mm})\end{array}$ & $\begin{array}{l}\mathrm{L}_{\text {perfil }} \\
(\mathrm{mm})\end{array}$ & $\begin{array}{c}\text { MRD } \\
\text { curva } \\
\text { NAS:2004 } \\
\text { N }_{\text {MRD,NAS }} \\
(k N)\end{array}$ & $\begin{array}{c}\text { MRD } \\
\text { curva } \\
\text { NBR 14762:2001 } \\
N_{\text {MRD,NBR }} \\
(\mathrm{kN})\end{array}$ & $\begin{array}{l}\text { Ensaio } \\
N_{\exp } \\
(\mathrm{kN})\end{array}$ & $\begin{array}{c}\mathrm{N}_{\exp } \\
/ \\
\mathrm{N}_{\mathrm{MRD}, \mathrm{NAS}}\end{array}$ & $\begin{array}{c}\mathrm{N}_{\exp } \\
/ \\
\mathrm{N}_{\mathrm{MRD}, \mathrm{NBR}}\end{array}$ \\
\hline \multirow{4}{*}{ U 100x50x2,38 } & 850 & 715 & 119 & 109 & 119 & 1,00 & 1,09 \\
\hline & 1.320 & 1.185 & 96 & 80 & 89 & 0,93 & 1,12 \\
\hline & 1.800 & 1.665 & 62 & 51 & 55 & 0,88 & 1,08 \\
\hline & 2.270 & 2.135 & 39 & 35 & 44 & 1,12 & 1,26 \\
\hline \multirow{4}{*}{ U 100x50×3,88 } & 850 & 715 & 175 & 158 & 175 & 1,00 & 1,11 \\
\hline & 1.320 & 1.185 & 136 & 112 & 146 & 1,07 & 1,31 \\
\hline & 1.800 & 1.665 & 94 & 75 & 87 & 0,92 & 1,17 \\
\hline & 2.270 & 2.135 & 61 & 52 & 60 & 0,99 & 1,16 \\
\hline \multirow{4}{*}{ Ue $125 \times 50 \times 25 \times 2,38$} & 1.015 & 880 & 173 & 168 & 168 & 0,97 & 1,00 \\
\hline & 1.575 & 1.440 & 139 & 124 & 132 & 0,95 & 1,07 \\
\hline & 2.130 & 1.995 & 92 & 80 & 75 & 0,82 & 0,93 \\
\hline & 2.700 & 2.565 & 57 & 54 & 63 & 1,10 & 1,17 \\
\hline \multirow{4}{*}{ Ue $125 \times 50 \times 25 \times 3,88$} & 985 & 850 & 236 & 229 & 282 & 1,19 & 1,23 \\
\hline & 1.530 & 1.395 & 187 & 171 & 173 & 0,92 & 1,01 \\
\hline & 2.070 & 1.935 & 135 & 117 & 106 & 0,79 & 0,91 \\
\hline & 2.615 & 2.480 & 88 & 80 & 108 & 1,23 & 1,35 \\
\hline \multirow{4}{*}{$\begin{aligned} \mathrm{L} 60 \times 2,38 \\
\mathrm{~K}_{1} \mathrm{~L}_{\mathrm{r}}=0,5 \mathrm{~L}_{\mathrm{r}} \\
\mathrm{K}_{2} \mathrm{~L}_{\mathrm{r}}=1,0 \mathrm{~L}_{\mathrm{r}} \\
\mathrm{K}_{\mathrm{t}} \mathrm{L}_{\mathrm{r}}=0,5 \mathrm{~L}_{\mathrm{r}}\end{aligned}$} & 615 & 480 & 29 & 27 & 31 & 1,07 & 1,14 \\
\hline & 970 & 835 & 28 & 26 & 29 & 1,05 & 1,12 \\
\hline & 1.330 & 1.195 & 27 & 25 & 23 & 0,86 & 0,91 \\
\hline & 1.685 & 1.550 & 22 & 21 & 21 & 0,94 & 1,02 \\
\hline \multirow{4}{*}{$\begin{array}{l}2 \mathrm{~L} 60 \times 2,38 \\
\mathrm{~K}_{\mathrm{x}} \mathrm{L}_{\mathrm{r}}=1,0 \mathrm{~L}_{\mathrm{r}} \\
\mathrm{K}_{\mathrm{y}} \mathrm{L}_{\mathrm{r}}=0,5 \mathrm{~L}_{\mathrm{r}} \\
\mathrm{K}_{\mathrm{t}} \mathrm{L}_{\mathrm{r}}=0,5 \mathrm{~L}_{\mathrm{r}}\end{array}$} & 1.045 & 910 & 51 & 48 & 62 & 1,22 & 1,28 \\
\hline & 1.620 & 1.485 & 50 & 48 & 70 & 1,40 & 1,47 \\
\hline & 2.190 & 2.055 & 49 & 46 & 63 & 1,30 & 1,36 \\
\hline & 2.765 & 2.630 & 42 & 39 & 46 & 1,10 & 1,19 \\
\hline \multirow{4}{*}{$\begin{array}{l}2 \mathrm{~L} 60 \times 2,38 \\
\mathrm{~K}_{\mathrm{x}} \mathrm{L}_{\mathrm{r}}=0,5 \mathrm{~L}_{\mathrm{r}} \\
\mathrm{K}_{\mathrm{y}} \mathrm{L}_{\mathrm{r}}=1,0 \mathrm{~L}_{\mathrm{r}} \\
\mathrm{K}_{\mathrm{t}} \mathrm{L}_{\mathrm{r}}=0,5 \mathrm{~L}_{\mathrm{r}}\end{array}$} & 1.490 & 1.355 & 49 & 47 & 71 & 1,44 & 1,51 \\
\hline & 2.020 & 1.885 & 47 & 45 & 63 & 1,34 & 1,39 \\
\hline & 2.550 & 2.415 & 44 & 42 & 53 & 1,21 & 1,25 \\
\hline & 3.060 & 2.925 & 41 & 39 & 48 & 1,18 & 1,22 \\
\hline \multirow{2}{*}{\multicolumn{5}{|c|}{ Somente perfis U e U enrijecidos (pré-qualificados MRD) }} & MÉDIA & 0,99 & 1,12 \\
\hline & & & & & DESV. PAD. & 0,12 & 0,13 \\
\hline \multirow{2}{*}{\multicolumn{5}{|c|}{ Somente cantoneiras simples e duplas }} & MÉDIA & 1,18 & 1,24 \\
\hline & & & & & DESV. PAD. & 0,18 & 0,18 \\
\hline \multirow{2}{*}{\multicolumn{5}{|c|}{ Todos os perfis }} & MÉDIA & 1,07 & 1,17 \\
\hline & & & & & DESV. PAD. & 0,17 & 0,16 \\
\hline
\end{tabular}




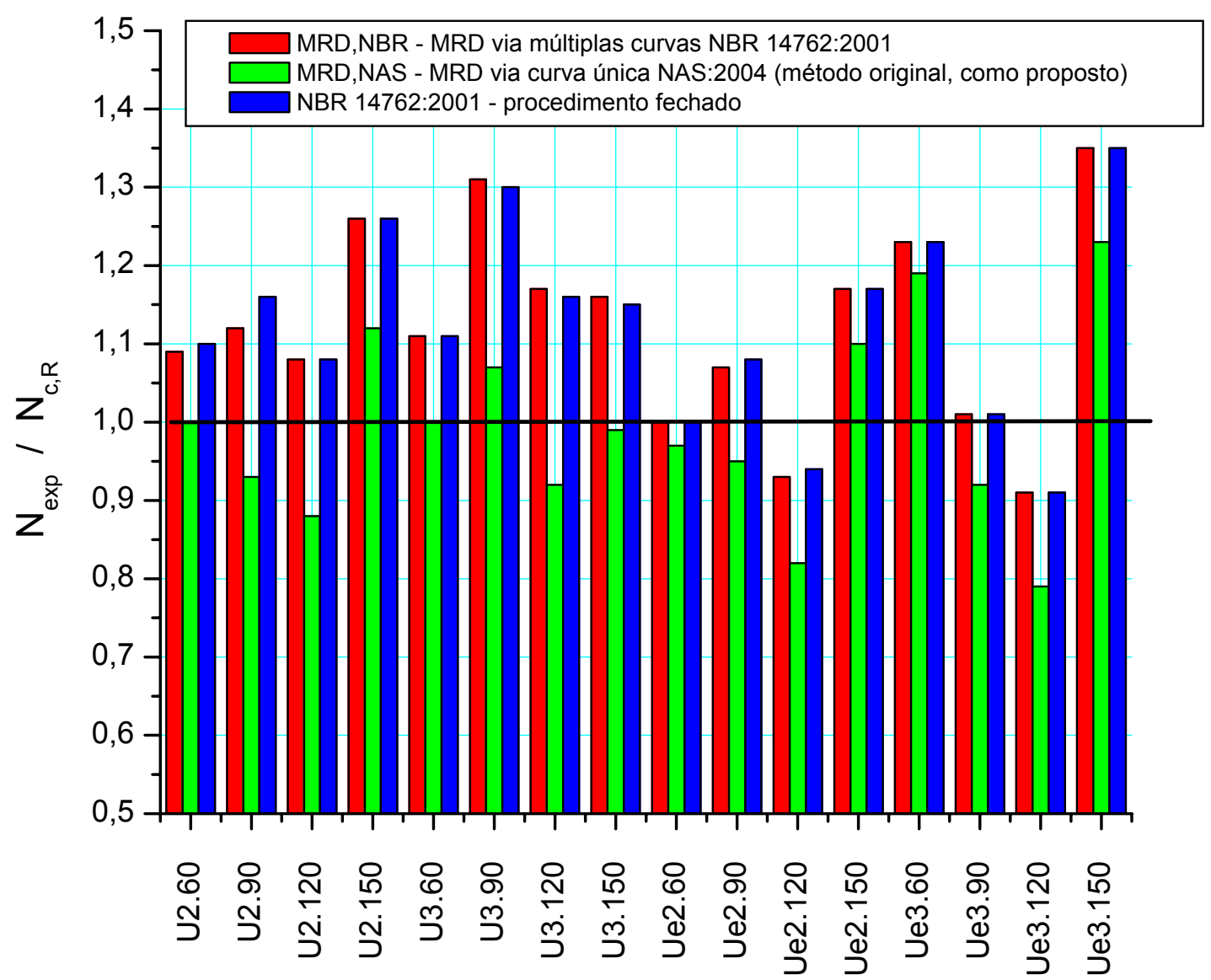

Figura 7.20 Seções pré-qualificadas para uso do MRD: resistência via MRD e ensaios

Como discussão final, a Figura 7.21 apresenta uma análise comparativa entre procedimentos de cálculo quanto à resistência máxima para as barras analisadas neste trabalho. As duas primeiras tabelas desta figura já foram apresentadas (de um modo até mais completo, com todos os valores) e analisadas. Quanto às duas últimas tabelas desta figura, analisando-se, em termos médios, a utilização do procedimento via larguras efetivas com o $M R D$, percebe-se que os resultados são praticamente idênticos, desde que se utilize a mesma curva (curva única do NAS:2004 ou múltiplas curvas da NBR 14762:2001) para os dois casos em questão. 


\begin{tabular}{|c|cc|c|}
\cline { 3 - 4 } \multicolumn{1}{c|}{} & \multicolumn{2}{c|}{ EXPERIMENTAL / PROCEDIMENTO } \\
\cline { 2 - 4 } \multicolumn{2}{c|}{} & \multicolumn{2}{c|}{ LARGURAS EFETIVAS } \\
\hline \multicolumn{2}{|c|}{ SEÇÃO } & NBR 14762:2001 & NAS:2004 \\
\hline \multirow{2}{*}{ U, Ue, L } & MÉDIA & 1,1 & 1,01 \\
\cline { 2 - 4 } & DESV. PAD. & 0,13 & 0,12 \\
\hline \multirow{2}{*}{$2 \mathrm{~L}$} & MÉDIA & 1,25 & 1,26 \\
\cline { 2 - 4 } & DESV. PAD. & 0,11 & 0,14 \\
\hline
\end{tabular}

\begin{tabular}{|c|c|c|c|}
\hline & \multicolumn{2}{|c|}{ EXPERIMENTAL / PROCEDIMENTO } \\
\hline & & \multicolumn{2}{|c|}{ MRD } \\
\hline \multicolumn{2}{|c|}{ SEÇÂO } & MRD,NBR & MRD, NAS \\
\hline \multirow{2}{*}{$\mathrm{U}, \mathrm{Ue}$} & MÉDIA & 1,12 & 0,99 \\
\hline & DESV. PAD. & 0,13 & 0,12 \\
\hline \multirow{2}{*}{$\mathrm{L}, 2 \mathrm{~L}$} & MÉDIA & 1,24 & 1,18 \\
\hline & DESV. PAD. & 0,18 & 0,18 \\
\hline \multirow{2}{*}{ TODAS } & MÉDIA & 1,17 & 1,07 \\
\hline & DESV. PAD. & 0,16 & 0,17 \\
\hline
\end{tabular}

\begin{tabular}{|c|c|c|c|}
\hline \multirow{2}{*}{\multicolumn{2}{|c|}{$\frac{\text { PRÉ-QUALIFICADAS }}{\text { SEÇÂOO }}$}} & \multicolumn{2}{|c|}{ EXPERIMENTAL / PROCEDIMENTO } \\
\hline & & MRD,NAS & NAS:2004 \\
\hline \multirow{2}{*}{ U, Ue } & MÉDIA & 0,99 & 1,01 \\
\hline & DESV. PAD. & 0,12 & 0,12 \\
\hline
\end{tabular}

\begin{tabular}{|c|c|c|c|}
\hline \multirow{2}{*}{\multicolumn{2}{|c|}{$\frac{\text { PRÉ-QUALIFICADAS }}{\text { SEÇÃO }}$}} & \multicolumn{2}{|c|}{ EXPERIMENTAL / PROCEDIMENTO } \\
\hline & & $M$ MRD,NBR $_{\text {, }}$ & NBR 14762:2001 \\
\hline \multirow{2}{*}{$\mathrm{U}$, Ue } & MÉDIA & 1,12 & 1,13 \\
\hline & DESV. PAD. & 0,13 & 0,12 \\
\hline
\end{tabular}

Figura 7.21 Análise comparativa entre procedimentos 
Tese de Doutorado - Gustavo Monteiro de Barros Chodraui 


\section{CONCLUSÕES}

As pesquisas mais recentes sobre compressão e análise de curvas de resistência têm sido na área dos perfis formados a frio, sendo que tais curvas de resistência à compressão para a análise de resistência máxima de barras são calibradas por análise experimental e numérica, considerando-se - embora ainda não haja um consenso sobre tais aspectos imperfeições geométricas iniciais, tensões residuais (se relevantes), modelo reológico apropriado, etc.

O Eurocode utiliza as múltiplas curvas, o mesmo ocorrendo com a NBR 8800:1986 (em revisão) e NBR 14762:2001. Entretanto, nos Estados Unidos, mesmo com recomendação do SSRC quanto à adoção das múltiplas curvas, o AISC e AISI ainda adotam curva única, mantendo uma tradição de edições anteriores.

Foram realizados cálculos de resistência para diversas barras constituídas por perfis de aço formados a frio submetidas à compressão (perfis do tipo $U, U$ enrijecido, cantoneira simples e dupla), para índice de esbeltez na menor inércia na faixa de 60, 90, 120 e 150, via procedimentos de normas - tanto utilizando-se a NBR 14762:2001, que adota as mesmas curvas de resistência do Eurocode 3 1.3:1996, bem como utilizando-se a NAS:2004 - e via procedimento do Método da Resistência Direta (MRD). Além disso, foi realizada uma análise experimental e numérica (faixas finitas e elementos finitos).

Sobre a análise experimental, os resultados confirmaram a adequação das curvas de resistência da NBR 14762:2001, mas também apontam para o emprego de uma curva única (curva b, por exemplo), o que é justificável pela pequena influência das tensões residuais nos perfis formados a frio, e pelo panorama semelhante de imperfeições geométricas nos perfis usuais. Em síntese, no contexto dos perfis de aço, pode-se entender que os formados a frio (pelo menos os usuais) constituem uma única família de perfis, o que já foi relatado na revisão bibliográfica deste trabalho, vide WENG \& PEKÖZ (1990). 
Quanto à comparação entre os resultados de resistência máxima dos ensaios e das normas (experimental / norma), constatou-se que:

- Para os perfis do tipo U, U enrijecido e para as cantoneiras simples, os resultados dos ensaios são muito próximos dos previstos pelas normas. Entretanto, houve uma aproximação maior dos ensaios, em termos médios, com a norma americana (NAS:2004), que possui curva única, obtendo-se média de 1,01 com variação de 0,79 a 1,23. Comparando-se com a NBR 14762:2001, obteve-se média de 1,10 com variação de 0,82 a 1,35;

- Para as cantoneiras duplas, a comparação com as duas normas apresentou valor semelhante de média e desvio padrão, mas os valores previstos pelas normas não resultaram tão próximos aos resultados dos ensaios (valores da análise experimental, em média, 25\% superiores aos previstos pelas normas, com variação de 1,05 a 1,46 comparando-se à NAS:2004, e de 1,12 a 1,42 comparando-se à NBR 14762:2001).

Comparações foram realizadas entre os resultados da análise experimental e as duas possibilidades do Método da Resistência Direta (MRD), como apresentado na Tabela 7.5. Pode-se perceber uma opção interessante $\left(\mathrm{N}_{\mathrm{MRD}, \mathrm{NBR}}\right)$, ou seja, múltiplas curvas de resistência da NBR 14762:2001 adotadas para a determinação de $\mathrm{N}_{\mathrm{g}}$ no MRD, em vez do uso da curva única da NAS:2004 ( $\left.\mathrm{N}_{\text {MRD,NAS }}\right)$. Entretanto, a opção original do MRD (N $\mathrm{N}_{\text {MRD,NAS }}$ ) ainda apresentou resultados em termos médios mais próximos dos ensaios (média de 1,07 contra 1,17 para o caso das múltiplas curvas).

Para as seções pré-qualificadas para uso do Método da Resistência Direta (MRD), os resultados experimentais ficaram em média, mais próximos dos resultados via procedimento do MRD original, ou seja, via curva única do NAS:2004 ( $\left.\mathrm{N}_{\mathrm{MRD}, N A S}\right)$, do que dos resultados via procedimento fechado da NBR 14762:2001, o que pode ser observado na Figura 7.20. Isto é um fato encorajador quanto à proposta do MRD, por ser este um método novo o prático. $A$ comparação dos ensaios com o $N_{M R D, N A S}$ apresenta média de 0,99 , com $0,79 \leq N_{\exp } / N_{M R D, N A S} \leq$ 1,23, enquanto que a comparação como o $\mathrm{N}_{\mathrm{MRD}, \mathrm{NBR}}$ apresenta média de 1,12, com $0,91 \leq \mathrm{N}_{\text {exp }} / \mathrm{N}_{\mathrm{MRD}, \mathrm{NBR}} \leq 1,35$.

Os ensaios de cantoneiras realizados neste presente trabalho mostraram que o modo de flexo-torção (denominado para esses casos de local/torsional, como explicado no item 7.1) realmente comandou. Entende-se, portanto, ser incorreta a idéia de alguns autores de se considerar o menor valor da força normal de flambagem elástica como somente o referente à flexão, negligenciando-se o modo de flexo-torção.

Quanto aos ensaios das barras curtas (stub columns), salienta-se que mesmo não tendo sido realizada a usinagem das extremidades das barras, os procedimentos 
tomados - procurou-se ter o cuidado de garantir a planicidade da seção transversal das extremidades das barras e também a perpendicularidade do plano da seção transversal das extemidades com o eixo da barra - conduziram a bons resultados, vide Tabela 5.11.

Ressalta-se, ainda quanto às barras curtas (stub columns), que as imperfeições geométricas iniciais exercem influência nos resultados, pois os perfis com paredes mais esbeltas aparecem abaixo dos mais compactos na Figura 7.18 e na Figura 7.19. Além desse fato, essa questão também é influenciada pelo tipo de colapso verificado nos ensaios, que é diferente comparando-se os perfis mais esbeltos com os mais compactos.

Sobre a análise numérica, a estratégia desenvolvida e proposta neste trabalho para as imperfeições geométricas iniciais, para as tensões residuais (a estratégia para a inserção destas nos modelos numéricos é interessante, embora se tenha decidido, após análises prévias, não utilizá-las) e para o modelo reológico se mostrou como uma importante contribuição à construção dos modelos numéricos para se representar o comportamento de barras constituídas por perfis de aço formados a frio submetidas à compressão, pois os resultados dos modelos numéricos ficaram próximos dos experimentais.

Quanto às imperfeições geométricas iniciais, a estratégia proposta foi se fazer superposição dos modos, utilizando para as amplitudes do modo local e distorcional os valores do tipo 1 e/ou tipo 2, respectivamente, propostas por SCHAFER \& PEKÖZ (1998), selecionadas para os quantis de $75 \%$ e $25 \%$ de probabilidade de excedência. Para o modo global, valores de d/t por meio da minimização de erros, com exceção das cantoneiras duplas, para as quais as imperfeições iniciais não foram medidas em laboratório e portanto adotou-se o valor da senóide proposta por Young com amplitude de L/1.500. Melhores resultados entenda-se mais próximos dos resultados dos ensaios - foram obtidos para o quantil de $75 \%$ (menores imperfeições) para os perfis do tipo $U, U$ enrijecido e cantoneiras simples, enquanto que para as cantoneiras duplas o quantil de 25\% (maiores imperfeições) se mostrou mais adequado.

Ainda quanto às imperfeições geométricas iniciais, entende-se como correto se adotar para o modo global a senóide proposta por Young, com a magnitude das imperfeições seguindo os valores usuais de L / 1.500 (curvas $P$ do SSRC) e L / 1.000 (curvas Européias). Isto é muito útil, mesmo porque os valores medidos de imperfeições apresentam grande variabilidade na literatura mesmo após a tentativa de se fazer o ajuste realizado via minimização de erros, como apresentado na Tabela 6.3. Além disso, é uma opção quando não houver disponível a medição de imperfeições geométricas como a deste trabalho para possibilitar tal procedimento de ajuste.

Foi realizada também uma análise de sensibilidade quanto às imperfeições geométricas iniciais a fim de se estudar o impacto destas na resistência das barras. Observou-se que as 
barras são mais sensíveis às imperfeições localizadas (local e distorcional). Obviamente, para as barras de maior comprimento, a imperfeição global tem uma influência considerável.

Quanto às tensões residuais, as de membrana são muito pequenas nos perfis formados a frio, um pouco mais pronunciadas nas regiões dos cantos. Devem ser modeladas nestas regiões se o aumento de $f_{y}$ devido ao trabalho a frio também for incluído nos modelos. Entretanto, por estes valores praticamente se compensarem, sua inserção não acarreta diferença significativa na resistência das barras, sendo que portanto não foram utilizadas nos modelos numéricos deste trabalho.

Com relação às tensões residuais de flexão, estas também apresentam valores pequenos comparados a $f_{y}$ dos aços comumente utilizados nas construções, ainda mais nos perfis oriundos de prensas (utilizados neste trabalho), mas foram adotadas em análises prévias aqui realizadas conforme dados de SCHAFER \& PEKÖZ (1998). Após tais análises prévias, verificou-se não serem significativas na resistência das barras, e portanto as tensões residuais não foram utilizadas nos modelos deste trabalho.

Quanto aos modelos reológicos utilizados na análise numérica, como os resultados da caracterização do aço estavam disponíveis, foram adotadas curvas tensão-deformação ajustadas (valores corrigidos, true values), adotando para cada perfil a média dos resultados dos corpos-de-prova, procedimento que se mostrou adequado.

Ainda quanto a análise numérica, um aspecto também interessante, apresentado e comentado no capítulo dos resultados da análise numérica, é relativo aos panoramas de tensão de von Mises. Pôde-se verificar que a tensão máxima (regiões em vermelho nas figuras em questão) foi inferior à resistência ao escoamento. Portanto, nos modelos numéricos, os perfis de paredes finas podem atingir sua resistência máxima para valores de tensão abaixo da resistência ao escoamento devido a problemas de instabilidade. Entretanto, na análise experimental, regiões de plastificação foram verificadas nas barras no instante em que se atingiu a resistência máxima, e esta diferença se explica devido a condições inerentes ao material que são difíceis de serem simuladas nos modelos numéricos nesses casos.

Quanto ao estudo das cantoneiras formadas a frio, de abas iguais, submetidas à compressão centrada, caso ainda pouco analisado na literatura, algumas conclusões são apresentadas:

- Apresentam dois modos de instabilidade: local/torsional e global por flexão. A coincidência entre o modo local de chapa e o global por torção dificulta a interpretação dos resultados da análise de estabilidade elástica, a aplicação imediata do MRD, e consequentemente a definição do procedimento de cálculo para obtenção da força normal resistente; 
- Foram realizadas análises numéricas adicionais, onde se pôde perceber, por exemplo, que considerando-se a possibilidade de imperfeição geométrica com múltiplas meias-ondas $(m)$ ao longo do comprimento da barra, o modo local/torsional pode ser considerado tanto como um modo local de chapa $(m>1)$ quanto um modo global por torção $(m=1)$;

- Resultados dos ensaios em cantoneiras simples e duplas realizados neste trabalho foram apresentados, assim como a comparação destes com resultados obtidos pelo método das larguras efetivas e pelo Método da Resistência Direta (MRD). Entende-se que a idéia de se ignorar o modo local/torsional como um modo global pode resultar contra a segurança. Resumindo, os resultados dos ensaios realizados neste trabalho se aproximam do que é sugerido pelo guia do MRD, denominado DSM Design Guide (AISI 2006), mas contradizem resultados de ensaios realizados por alguns pesquisadores, e portanto isto indica a necessidade de maior investigação sobre o tema;

- O modo local/torsional pode interagir com o modo global de flexão, porém tal interação só é desfavorável quando o comprimento de meia-onda do modo local/torsional é pequeno (valores mais elevados de $m$ ), e assim a configuração deformada de torção é repetida várias vezes ao longo do comprimento (Figura 7.8);

- Quanto à sensibilidade da resposta das barras em relação à imperfeição local/torsional com uma única meia-onda $(m=1)$ e local/torsional com múltiplas meias-ondas ao longo do comprimento $(m>1)$, a força normal máxima diminui à medida que aumenta o número de meias-ondas associado ao modo local/torsional, demonstrando uma interação definida (Figura 7.9);

- Entende-se que um procedimento de cálculo correto - embora os estudos aqui realizados indiquem a necessidade de maior investigação sobre o tema, devido à controvérsias com outros pesquisadores - seja empregando larguras efetivas ou o MRD, consiste em tratar o modo local/torsional como modo local de chapa e também como modo global por torção;

- Foram apresentadas opções $(a-f)$ do Método da Resistência Direta (MRD) para cantoneiras simples submetidas à compresão centrada, vide Tabela 7.1. As opções $\underline{a}$, $\underline{e}$ e $\underline{f}$ tratam o modo L/T tanto como modo local de chapa quanto modo global por torção, o que parece ser o mais correto, como já relatado. A opção a é a original proposta do método. As opções a e e têm sido recomendadas pelo recente guia do MRD, vide DSM Design Guide (AISI 2006). Os resultados dos ensaios deste trabalho de doutorado mostram uma maior proximidade com a curva associada à opção a e e . A opção f é interessante, por ser simples, 
pois $L / T$ para o modo local do MRD é tomado somente para um comprimento (em que $L / T=F$ ), ou seja, menor valor da curva do modo L/T, a qual não apresenta mínimo bem definido, vide Figura 7.1, e permite fácil uso em projetos, sendo que os resultados ficaram ligeiramente a favor da segurança.

Como sugestões para trabalhos futuros, a seguir são registradas algumas propostas:

$\checkmark$ maior aprofundamento na análise experimental e numérica com relação às cantoneiras, por se ter percebido que este tipo de perfil apresenta comportamento distinto dos demais, prevendo-se, por exemplo, casos de compressão excêntrica e também cantoneiras com enrijecedor de borda;

$\checkmark$ mais análises numéricas via elementos finitos, extrapolando-se os quantis de probabilidade de excedência obtidos de SCHAFER \& PEKÖZ (1998), em especial para as cantoneiras duplas, as quais indicaram que valores de resistência mais próximos dos ensaios possivelmente serão conseguidos com quantis acima de 25\% (maiores imperfeições);

$\checkmark$ análises numéricas computando-se também as tensões residuais de membrana (e o aumento de $\mathrm{f}_{\mathrm{y}}$ nos cantos do perfil) somadas às tensões residuais de flexão, para que se possa verificar se a inserção do panorama completo de tensões residuais e aumento de $f_{y}$ realmente não é relevante para os resultados dos modelos numéricos quanto à resistência máxima dos perfis de aço formados a frio;

$\checkmark \quad$ Análise mais aprofundada do ECBL e sua viabilidade de aplicação como procedimento normativo. 


\section{BIBLIOGRAFIA}

AMERICAN INSTITUTE OF STEEL CONSTRUCTION (1989). Manual of steel construction. Allowabe Stress Design Specification for Structural Steel Buildings $9^{\text {th }}$.ed., Chicago, USA.

AMERICAN INSTITUTE OF STEEL CONSTRUCTION (1999). Manual of steel construction. Load and Resistance Factor Design Specification for Structural Steel Buildings, Chicago, USA.

AMERICAN IRON AND STEEL INSTITUTE (1940). Reports of research at Cornell University on light gage cold-formed steel structural members - Index and Synopses. Washington: AISI.

AMERICAN IRON AND STEEL INSTITUTE (1986). Cold-Formed Steel Design Manual. Washington: AISI.

AMERICAN IRON AND STEEL INSTITUTE (1996). Cold-Formed Steel Design Manual. Washington: AISI.

AMERICAN IRON AND STEEL INSTITUTE (2001). North American Specification for the Design of Cold-Formed Steel Structural Members. Washington: AISI.

AMERICAN IRON AND STEEL INSTITUTE (2004). Appendix 1 - Design of cold-formed steel structural members using the direct strength method. North American Specification for the Design of Cold-Formed Steel Structural Members. Washington: AISI.

AMERICAN IRON AND STEEL INSTITUTE (2006). Direct Strength Method Design Guide. American Iron and Steel Institute, Washington, DC. (Approved, to be published in 2006). 
AMERICAN SOCIETY FOR TESTING AND MATERIALS (1992). ASTM A370: Standard test methods for tension testing of metalic materials (metric). Philadelphia.

ANSYS (1995). Structural nonlinearities: user's guide for revision 5.1. Houston. v.1.

ASSOCIAÇÃO BRASILEIRA DE NORMAS TÉCNICAS (1967). NB-143 - Dimensionamento de estruturas de aço constituídas por perfís formados a frio. Rio de Janeiro.

ASSOCIAÇÃO BRASILEIRA DE NORMAS TÉCNICAS (1986). NBR-8800 - Projeto e execução de estruturas de aço. Rio de Janeiro.

ASSOCIAÇÃO BRASILEIRA DE NORMAS TÉCNICAS (1998). NM 144-2: Requisitos gerais para produtos laminados planos de aço-carbono e aço baixa liga e alta resistência. Parte 2 Produzidos em laminadores de tiras a quente.

ASSOCIAÇÃO BRASILEIRA DE NORMAS TÉCNICAS (2001). NBR 14762: Dimensionamento de estruturas de aço constituídas por perfis formados a frio. Rio de Janeiro: ABNT.NM 1442:1998

ASSOCIAÇÃO BRASILEIRA DE NORMAS TÉCNICAS (2003). NBR 6355: Perfis estruturais de aço formados a frio. Rio de Janeiro: ABNT.

AUSTRALIAN/NEW ZEALAND STANDARD (1996). AS/NZS 4600:1996: Cold-formed steel structures.

BADAWY ABU-SENA, A.B.; CHAPMAN, J.C.; DAVIDSON, P.C. (2001). Interaction between critical torsional flexural and lip buckling in channel sections. Journal of Constructional Steel Research, v.57, p.925-944.

BALLIO, G.; MAZZOLANI, F. M. (1983). Theory and design of steel structures. London, Chapman nad Hall.

BASU, P. K.; AKHTAR, M. N. (1992). Interactive and local bucling of thin-walled members. Journal of Thin-Walled Structures, vol.12, p.335-352.

BATISTA, E. M. (1986). Essais de profils $E$ et $U$ en acier plies a froid. Universite de Liege, Laboratoire de Stabilite des Constructions, Raport n. 157. 
BATISTA, E. M. (1988). Ėtude de la stabilité des profils à parois minces et section ouverte de types $U$ et $C$. Thesis presented to the University of Liege, Belgium, in partial fulfillment of requirements for the degree od Doctor of Sciences.

BATISTA, E. M. (2000). Reliability and Progress in design Codes, in Proceedings of the Third Int. Conference on Coupled Instabilities in Metal Structures CIMS'2000, Ed. Camotim, D; Dubina, D. e Rondal, J., Imperial College Press, Lisboa, 661-671.

BATISTA, E. M. et al. (2000). Estudos dos modos de instabilidade local de placa e distorcional em perfis de chapa dobrada de aço. In: JORNADAS SUDAMERICANAS DE INGENIERIA ESTRUCTURAL, 29., Punta Del Este, Uruguay, nov. 2000. Memorias. 14p.

BATISTA, E. M. et al. (2001). Curso paralelo de perfis formados a frio. In: SEMINÁRIO INTERNACIONAL O USO DE ESTRUTURAS METÁLICAS NA CONSTRUÇÃO CIVIL, 4. I CONGRESSO INTERNACIONAL DA CONSTRUÇÃO METÁLICA, 1., nov. 2001, São Paulo.

BATISTA, E. M. et al. (2002). Stability analysis of cold-formed members: finite element and finite strip method results. In: INT. COLLOQUIUM. Budapest, 2002. 8p.

BATISTA, E. M.; CAMOTIM, D.; PROLA, L. C.; VAZQUEZ, E. (1998). On the stability and strength of steel columns affected by distortional buckling. Journal of Constructional Steel Research, v.46, n.1-3, p.129-131.

BATISTA, E. M.; RODRIGUES, F. C. (1994). Buckling curve for cold-formed compressed members. Journal of Constructional Steel Research, v.28, p.121-136.

BEEDLE, L. S. (1991). Stability of metal structures $-A$ world view. $2^{\text {nd }}$ ed.

BERNARD, E. S.; BRIDGE, R. Q.; COLEMAN, R. (1999). Measurement and assessment of geometric imperfections in thin-walled panels. Thin Walled Structures, v.33, p. 103-126.

BIJLAARD, P.P.; FISCHER, G.P. (1952). Interaction of column and local buckling in compression members. NACA Technical Note, 2640.

BJORHOVDE, R. (1972). Deterministic and probabilistic approaches to the strength of steel columns. PhD Dissertation, Lehigh University, PA. 
BJORHOVDE, R. (2004). Development and use of high performance steel. Journal of Constructional Steel Research, v.60, p.393-400.

BLEICH, F. (1952). Buckling strength of metal structures. New York: McGraw-Hill Book. 508p.

BRADFORD, M. A. (1999). Elastic distortional buckling of tee-section cantilevers. Thin Walled Structures, v.33, p. 3-17.

BRADFORD, M. A. (2000). Strength of compact steel beams with partial restraint. Journal of Constructional Steel Research, v.53, p.183-200.

BRITISH STANDARDS INSTITUTION (1987). BS 5950 - Structural use of steelwork in building. Part 5: Code of pratice for design of cold-formed sections. London.

BUDIANSKY, B. (1974) apud GIONCU, V. (1994). Theory of buckling and postbuckling behaviour of elastic structures. In: Advances in Applied Mechanics, ed. Chia-Shum Yih, v.14, Academic Press, New York, USA, pp.1-65.

BULSON, P. S. (1967). Local stability and strength of structural sections, in thin walled structures. New York, John Wiley and Sons.

CANADIAN STANDARDS ASSOCIATION (1984) CAN3-S136-M84: Cold-formed steel structural members. Toronto: CSA.

CANADIAN STANDARDS ASSOCIATION (1989) CAN3-S136-M89: Cold-formed steel structural members. Toronto: CSA.

COHEN, J.M. (1987). Local buckling behavior of plate elements. Department of Structural Engineering Report, Cornell University, Ithaca, New York.

COSTA FERREIRA, C.M.; RONDAL, J. (1986). Influence of flexural residual stresses on the stability of compresses angles. In: Hajdin N, Sekulovic M, editors. Proceedings of International Conference on the Steel Structures - Recent Research Advances, Budvs, Yugoslavia, $28^{\text {th }}$ September $-1^{\text {st }}$ October, vol. I, pp. 147-56.

CHAJES, A.; FANG, P.J. ; WINTER, G. (1966). Torsional-flexural buckling, elastic and inelastic, of cold-formed fhin-walled columns. Cornell University, Engineering Research Bulletin 66-1. 
CHAJES, A.; WINTER, G. (1965). Torsional-flexural buckling of thin-walled members. Journal of the Structural Division, ASCE, v. 91.

CHEUNG, Y. K. (1976). Finite strip method in structural analysis. New York, Pergamon Press.

CHILVER, A. H. (1953). The Stability and Strength of Thin-Walled Steel Struts. The Engineer, pp. 180-183.

CHILVER, A. H. (1967) apud GIONCU, V. (1994). Coupled modes in elastic buckling. J. Mech. Phys. Solids, v.15, pp. 15-28.

CHODRAUI, G. M. B. (2003). Flambagem por distorção da seção transversal em perfis de aço formados a frio submetidos à compressão centrada e à flexão. São Carlos. 173p. Dissertação (Mestrado) - Escola de Engenharia de São Carlos, Universidade de São Paulo.

CHODRAUI, G. M. B. et al. (2002). Flambagem por distorção da seção transversal em perfis de aço formados a frio submetidos à compressão centrada e à flexão. In: CONGRESSO INTERNACIONAL DA CONSTRUÇÃO METÁLICA, 2. - II CICOM, São Paulo, Brasil, nov. 2002.

CHODRAUI, G. M. B. et al. (2003). Flambagem por distorção em perfis de aço formados a frio. In: XXIV Iberian Latin-American Congress on Computational Methods in Engineering, Ouro Preto, Brasil, out. 2003.

CHODRAUI, G. M. B. et al. (2003). Flambagem por distorção em perfis de aço formados a frio In: 7o. CONGRESSO DE MECÂNICA APLICADA E COMPUTACIONAL, 2003, Évora. Universidade de Évora / APMTAC, 2003. v.1. p.427-436.

CHODRAUI, G. M. B. et al. (2004)a. Dimensionamento de perfis de aço formados a frio com base no Método da Resistência Direta. In: Jornadas Sud-Americanas de Ingeniería Estructural, Mendoza, Argentina, maio, 2004.

CHODRAUI, G. M. B. et al. (2004)b. Distortional buckling of cold-formed steel members. In: LaBOUBE, R.A.; YU, W.W. (Ed.). Recent research and developments in cold-formed steel design and construction (17th International Specialty Conference on Cold-Formed Steel Structures, Orlando, USA, Nov. 4-5, Rolla, University of Missouri-Rolla, p.71-84. 
CHODRAUI, G. M. B. et al. (2004)c. Flambagem por distorção em perfis de aço formados a frio. In: Jornadas Sud-Americanas de Ingeniería Estructural, Mendoza, Argentina, maio 2004.

CHODRAUI, G. M. B. et al. (2006)a. Cold-formed steel angles under axial compression. In: LaBOUBE, R.A.; YU, W.W. (Ed.). Recent research and developments in cold-formed steel design and construction (18th International Specialty Conference on Cold-Formed Steel Structures, Orlando, USA, Oct. 26-27, Rolla, University of Missouri-Rolla (a ser publicado).

CHODRAUI, G. M. B. et al. (2006)b. Distortional buckling of cold-formed steel members. Journal of Structural Engineering (ASCE), vol. 132, n.4, p.636-639.

DAT, D. T. (1980). The strength of cold-formed steel columns. PhD. Thesis, Cornell University, Ithaca, New York.

DAVIDS, A. J.;HANCOCK, G. J. (1985). The strength of long length I-section columns fabricated from slender plates. Civil Engineering Transactions, p.347-352.

DAVIES, J. M. (2000). Recent research advances in cold-formed steel structures. Journal of Constructional Steel Research, v.55, p.267-288.

DAVIES, J. M.; JIANG, C. (1996). Design of thin-walled columns for distortional buckling, Proc. of the $2^{\text {nd }}$ Int. Conference on Coupled Instabilities in Metal Structures, Imperial College Press, Liege, Belgium.

DAVIES, J. M.; JIANG, C. (1998). Design for distortional buckling. Journal of Constructional Steel Research, v.46, n.1-3, p.174-175.

DAVIES, J. M.; KESTI, J. (1999). Local and distortional buckling of thin-walled short columns. Thin Walled Structures, v.34, p. 115-134.

DAVIES, J. M.; LEACH, P. (1994). First-order generalised beam theory. Journal of Constructional Steel Research, 31 (2-3), p.187-220.

DAVIES, J. M.; LEACH, P. (1994). Second-order generalised beam theory. Journal of Construction Steel Research, 31 (2-3), p.221-241. 
DAVIES, J. M.; VOUTAY, P. A. (1994). Analysis of cassete sections in compression. Advances in Steel Structures, ICASS'02, v. 1, p.401-408.

DESMOND, T. P.; PEKÖZ, T. ; WINTER, G. (1981). Edge stiffeners for thin-walled members. Journal of the Structural Division, ASCE, v.107, no. ST2, p. 329-353.

DEWOLF, J. T.; PEKÖZ, T.; WINTER, G. (1974). Local and overral bucking of cold-formed members. Journal of Structures Division, ASCE, vol.100, n.10, 2017-2036.

DOUTY, R. T. (1962). A design approach to the strength of laterally unbraced compression flange. Engineering Experiment Station, Cornell University. (Bulletin 37).

DUBINA, D. (1990). A new approach to the interaction of local and overall buckling in thinwalled cold-formed compressed members - Final Report. Proceedings of $4^{\text {th }}$ Int. Coll. On Stability on Steel Structures, Budapest, April 25-27, pp.412-419.

DUBINA, D. (1993). Coupled instabilities in thin-walled structures: erosion coefficient approach in overall-local buckling interaction. Commision of the European Communities, Cooperation in Science and Technology with Central and Eastern European Countries Research Report, Ref ERB 3510PL922443, Liège.

DUBINA, D. (1998). Part VI: Interactive buckling analysis of thin-walled cold-formed steel members via critical load erosion theory in Coupled Instabilities in Metal Structures, edited by J. Rondal, Springer-Verlag, pp.291-344.

DUBINA, D. (2001). The ECBL approach for interactive buckling of thin-walled steel members. Steel \& Composite Structures, v.1, n.1, p.75-96.

DUBINA, D. et al. (1995). Interactive buckling of cold-formed thin-walled member. In: INTERNATIONAL CONFERENCE ICSSD'95 - STRUCTURAL STABILITY AND DESIGN, Sydney, Australia, 1995. Proceedings. Rotterdam: A.A. Balkema. p. 49-54.

DUBINA, D. et al. (1996). Recent interactive buckling approachs for cold-formed thin-walled members. In: CONFERENCE ON COUPLED INSTABILITIES IN METAL STRUCTURES, $2^{\text {nd }}$, Liege, Belgium. Proceedings. 
DUBINA, D. et al. (1997). Numerical modelling of instability phenomena of thin-walled steel members. Proceedings of $5^{\text {th }}$ International Coloquium on Stability and Ductility of Steel Structures - SDSS'97, Nagoya, Japan, July 29-31, vol.2, pp.755-767.

DUBINA, D. et al. (1998). Recent research on stability analysis of thin-walled cold-formed steel members. Journal of Constructional Steel Research, vol. 46, n. 1-3, p.172-173.

DUBINA, D. et al. (2000). Timisoara Steel Structures Stability Research School: relevant contribuitions. Journal of Constructional Steel Research, vol. 55, p.343-354.

DUBINA, D.; GEORGESCU, M. (1994). Interactive buckling curves for thin-walled sections. Thin-Walled Structures, v.20, n.1-4, p.189-201.

DUBINA, D., UNGUREANU, V. (2000). Elastic-plastic interactive buckling of thin-walled steel members. In: Structural Stability Research Counsil Annual Technical \& Meeting, July 24-26, Memphis, USA.

DUBINA, D., UNGUREANU, V. (2000). Elastic-plastic interactive buckling of thin-walled steel compression members. In: $15^{\text {th }}$ International Specialty Conference on Cold-Formed Steel Structures, October 19-20, 2000, St. Louis, Missouri, USA.

DUBINA, D., UNGUREANU, V. (2002a). Effect of imperfections on numerical simulation of instability behaviour of cold-formed steel members. Thin-Walled Structures, vol. 40, p.239-262.

DUBINA, D., UNGUREANU, V. (2002b). Local-Overall and Distortional-Overall interactive buckling of thin-walled members. In: EUROPEAN CONFERENCE ON STEEL STRUCTURES, 3rd, Coimbra, Portugal, 2002. Proceedings. Guimarães: CMM / Universidade de Coimbra.

ELLIFRITT, D.; GLOVER, B.; HREN, J. (1997). Distortional buckling of channels and zees not attached to sheathing. Report for the American Iron and Steel Institute, Washington D. C.

European Convention for Constructional Steelwork - ECCS (1987). European Recommendations for the Design of Light Gauge Steel Members. Brussels.

EUROPEAN COMMITTEE FOR STANDARDIZATION (1996). ENV 1993-1-3: Eurocode 3: Design of steel structures. Part 1.3: General rules. Supplementary rules for cold-formed thin gauge members and sheeting. Brussels. 
FLESERIU, E.; DUBINA, D. (1986). Experimental investigations concerning the thin-walled coldformed bars, subjected to centric and eccentric compression. Proceedings: Second Regional Colloquium on Stability of Steel Structures. September 25-26, Hungary.

FRUCHTENGARTEN, J. (1995) Sobre a estabilidade de perfis de seção aberta. Tese (Doutorado) - Escola Politécnica, Universidade de São Paulo, São Paulo.

GALAMBOS, T.V. (1998). Guide to stability design criteria for metal structures. New York: John Wiley \& Sons. 911 p. $4^{\text {th }}$ ed.

GAYLORD, E. H. Jr; et al. (1992). Design of steel structures. McGRAW-HILL International editions. $3^{\text {rd }}$ ed.

GEORGESCU, M. (1998). Instability problems by thin-walled cold-formed steel members. The Politehnica University of Timisoara - PhD Thesis.

GEORGESCU, M.; DUBINA, D. (1999). E.C.B.L. and Eurocode 3 Annex Z based calibration procedure for buckling curves of compression steel members. Proceedings of $6^{\text {th }}$ International Colloquium on Stability and Ductility of Steel Structures - SDSS'99, Timisoara, September 9-11, pp.501-510.

GIONCU, V. (1994). General Report: General Theory of Coupled Instabilities. Thin-Walled Structures. v.19, n.2-4, p. 81-127.

GUO Y. L.; FUKUMOTO Y. (1996). Theoretical study of ultimate load of locally buckled stub columns loaded eccentrically. Journal of Construction Steel Research, v.38, n.3, p.239-255.

HANCOCK, G. J. (1997). Light gauge construction. Progress in Structural Engineering and Materials, v.1, n.1, p.25-30, Sept.

HANCOCK, G. J. (2003). Cold-formed steel structures - Review article. Journal of Constructional Steel Research, v.59, p.473-487.

HANCOCK, G. J.; DAVIDS, A. J.; KEY, P. W.; RASMUSSEN, K. J. R. (1987). Strength tests of thin-walled high tensile steel columns. Steel Structures - Advances, Design and Construction. Elsevier Applied Science. 
HANCOCK, G. J.; KWON Y.B.; BERNARD, E.S. (1994). Strength design curves for thin walled sections undergoing distortional buckling. Journal of Construction Steel Research, v.31, p.169186.

HANCOCK, G. J.; LAU, S. C. W. (1987). Distortional buckling formulas for channel columns. Journal of Structural Engineering, ASCE, v.125, n.2, p.118-127, February.

HANCOCK, G. J.; MURRAY, T. M.; ELLIFRITT, D. S. (2001). Cold-formed steel structures to the AISI specification. New York: Marcel Dekker.

HANCOCK, G. J.; ROGERS, C. A. (1998). Design of cold formed steel structures of high strength steel. Journal of Constructional Steel Research, v.46, n.1-3, p.167-168.

HANCOCK, G.J.; KWON, Y.B.; BERNARD, E.S. (1994). Strength design curves for thin-walled sections undergoing distortional buckling. Journal of Constructional Steel Research, v.31, n.2-3, p.169-186.

HANCOCK, G.J.; YANG, D.; ROGERS, C.A. (2003). Stability and ductility of thin high strength G550 steel members and connections. Thin-Walled Structures, v.41, p.149-166.

HO, D. (1972) apud GIONCU, V. (1994). The influence of imperfections on systems with coincident buckling loads. Int. J. Nonlinear Mech., v.1, pp.311-21.

HO, D. (1974) apud GIONCU, V. (1994). Buckling load of nonlinear systems with multiple eigenvalues. Int. J. Solids Struct., v.10, pp.1315-30.

HUBER, A. W.; BEEDLE, L. S. (1992). Residual stress and compressive strength of steel. Welding Journal, v.33, n.12, p.589s-614s.

HUNT, G. W. (1982) apud GIONCU, V. (1994). Symmetries of elastic buckling. Eng. Struct., v.4(13), 21-8.

HUNT, G. W. (1983) apud GIONCU, V. (1994). Elastic stability in structural mechanics and applied mathematics. In Collapse: The Buckling of Structures in Theory and Practice, ed. J. M. T. Thompson \& G. W. Hunt. Cambridge University Press, pp.125-48. 
HUNT, G. W. (1986) apud GIONCU, V. (1994). Hidden (a)symmetries of elastic and plastic bifurcation. Appl. Mech. Rev., v.39, 1165-86.

JAVARONI, C. E. (1993). Perfis de aço formados a frio por dobramento de chapa fina Fundamentos teóricos para o dimensionamento. São Carlos. 213p. Dissertação (Mestrado) Escola de Engenharia de São Carlos, Universidade de São Paulo.

JOHNS, K. C. (1972) apud GIONCU, V. (1994). Simultaneous buckling in symmetric structural systems. J. Eng. Mech. Div., EM4, pp.835-49.

JOHNS, K. C. (1974) apud GIONCU, V. (1994). Imperfection sensitivity of coincident buckling systems. Int. J. Nonlinear Mech., v.9, pp.1-21.

JOHNS, K. C. (1976) apud GIONCU, V. (1994). Some statistical aspects of coupled buckling structures. In: Buckling of Structures. ed. B. Budiansky. Springer Verlag, Berlin, pp.199-207.

JOHNS, K. C.; CHILVER, A. H. (1971) apud GIONCU, V. (1994). Multiple path generation at coincident branching points. Int. J. Mech. Sci., v.13, pp.899-910.

KALA, Z. (2004). Sensitivity of load-carrying capacity of a thin-walled steel member to the initial curvature shape of its axis. Fourth International Conference on Thin-Walled Structures. ThinWalled Structures - Advances in Research, Design and Manufacturing Technology.

KALYANARAMAN, V. (1979). Local buckling of cold-formed steel members. PhD. Thesis, Cornell University, Cornell, U.S.A.

KALYANARAMAN, V.; PEKÖZ, T.; WINTER, G. (1977). Unstiffened compression elements. Journal of the Structural Division, ASCE, v.103, no.ST9, Proc. paper 13197, p.1833-1848, September.

KARREN, K. W.; WINTER, G. (1967). Effects of cold-forming on light-gage steel members. Journal of the Structural Division, ASCE, v.93.

KEMP, L. et al. (1995) Structural behavior of cold-formed profiles with emphasis on the Zetaprofile. Journal of Constructional Steel Research, v.34, p.207-224. 
KENNEDY, J.B.; MURTY K.S. (1982). Buckling of angles: state of art. Journal of the Structural Division, ASCE, v.108.

KESTI, J.; DAVIES, J. M. (1999). Local and distortional buckling of thin-walled short columns. Thin Walled Structures, v.34, p.115-134.

KLIPPSTEIN, K. H. (1986). Discussion of criteria for connection spacing in cold-formed steel by M. Yener. Journal of the Structural Enginnering. vol. 112, Dec. 1986.

KOITER, W. T. (1945) apud GIONCU, V. (1994). Over de stabiliteit van het elastisch evenwicht. $\mathrm{PhD}$ Thesis, H.J. Paris, Amsterdam, the Netherlands. English translation as NASDA TTF10,833, 1957 and AFFDL Report TR 70-25, 1970 (in Dutch).

KOITER W. T.; SKALOUD, M. (1962) apud GIONCU, V. (1994). Interventions. In: Comportement Postcritique des Plaques Utilisées en Constriction Metallique, Liège, Belgium. Mem. Soc. R., tom VIII, v.5, 64-8, 103-4.

KWON, Y. B.; HANCOCK, G. J. (1991). Strength tests of cold-formed channel sections undergoing local and distortional buckling. Research Report no. R640, University of Sydney, Sydney.

KWON, Y. B.; HANCOCK, G. J. (1992). Strength tests of cold-formed channel sections undergoing local and distortional buckling. Journal of Structural Engineering, ASCE, 117(2), 1786-1803.

KWON, Y. B.; HANCOCK, G. J. (1992). Tests of cold-formed channels with local and distortional buckling. Journal of Structural Engineering, ASCE, v.118, n.7, p.1786-1803.

LaBOUBE, R. A.; YU, W. W (1978). Structural behavior of beam webs subjected to bending stress. Civil Engineering Study Structural Series, 78-1, Departament of Civil Engineering, University of missouri-Rolla, Rolla, Missouri.

LaBOUBE, R. A.; YU, W. W (2000). Recent research and developments in cold-formed steel design and construction $\left(15^{\text {th }}\right.$ International Specialty Conference on Cold-Formed Steel Structures, St. Louis, USA, October 19-20). Department of Civil Engineering, University of Missouri-Rolla, 2000. p.149-168. 
LAIER, J. E. (1988). Introdução à estabilidade das estruturas (flambagem). 50p. Escola de Engenharia de São Carlos, Universidade de São Paulo. São Carlos (SP).

LANDOLFO, R.; DI LORENZO, G.; PORTIOLI, F. (2004). On the caracterization of the material properties for cold-formed steel members. Fourth International Conference on Thin-Walled Structures. Thin-Walled Structures - Advances in Research, Design and Manufacturing Technology.

LAU, C.S.W. (1988). Distortional buckling of thin walled columns. PhD Thesis, University of Sydney.

LAU, S.C.W.; HANCOCK G.J. (1987). Distortional buckling formulas for channel columns. Journal of Structural Engineering, ASCE, 113(5), 1063-1078.

LAU, S.C.W.; HANCOCK, G.J. (1990). Inelastic buckling of channel columns in the distortional modes thin-allowed structures. Journal of Structural Engineering, ASCE, p.59-84.

LECCE, M.; RASMUSSEN, K. (2004). Experimental investigations of distortional buckling of cold-formed stainless steel sections. In: LaBOUBE, R.A.; YU, W.-W. (Ed.). Recent research and developments in cold-formed steel design and construction $\left(17^{\text {th }}\right.$ International Specialty Conference on Cold-Formed Steel Structures, Orlando, USA, Nov. 4-5, 2004). Rolla, University of Missouri-Rolla, 2004. p.383-398.

LOUGHLAN, J. (1979). Mode interaction in lipped channel columns under concentric or eccentric loading. PhD. Thesis. University of Strathclyde. Glasgow.

LOUGHLAN, J.; RHODES, J.(1980). The interactive buckling of lipped channel columns under concentric or eccentric loading. In: INTERNATIONAL CONFERENCE ON THIN-WALLED STRUCTURES, University of Strathclyde, Glasgow. Proceedings.

LU, T. J.; TIAN, Y. S. (2004). Minimum weight of cold-formed steel sections under compression. Thin Walled Structures, v.42, p. 515-532.

LU, W. (2000). Neural network model for distortional buckling behaviour of cold-formed steel compression members. Thesis for Degree of Licentiate of Science in Technology. 
MACKERLE, J. (1996). Finite element and boundary element analyses of beams and thinwalled structures - A bibliography (1994-1995). Finite Elements in Analysis and Design. v.23, p.77-89.

MACKERLE, J. (1997). Stability problems analysed by finite element and boundary element techniques - A bibliography (1994-1996). Finite Elements in Analysis and Design, v.26, p.337353.

MADUGULA, M. K. S.; PRABHU, T. S.; TEMPLE, M. C. (1983). Ultimate strength of concentrically loaded cold-formed angles. Canadian Journal of Civil Engineering, 10, 60-68.

MALITE, M. et al. (1999). Algumas considerações sobre a nova norma brasileira de dimensionamento de estruturas de aço constituídas por perfis formados a frio [CD-ROM]. In: SEMINÁRIO INTERNACIONAL O USO DE ESTRUTURAS METÁLICAS NA CONSTRUÇÃO CIVIL, 2., Belo Horizonte, nov. 1999. Belo Horizonte: SME - Sociedade Mineira de Engenheiros. $7 p$.

MALITE, M.; SÁLES, J.J. (1993). Estruturas de aço constituídas por perfis de chapa dobrada: dimensionamento de barras. São Carlos: EESC-USP. 97p.

MAQUOI, R. et al. (2002). Effect of initial imperfections in numerical simulations of collapse behaviour of stiffened plates under compression. In: Eurosteel, Coimbra, Portugal.

MAQUOI, R.; MASSONNET, C. (1976) apud GIONCU, V. (1994). Interaction between local plate buckling and overall buckling in thin-walled compression members. Theories and Experiments. In: Buckling of Structures, ed. B. Budiansky. IUTAM Symp.,Springer Verlag, Berlin, 1976, pp.117-32.

MAQUOI, R.; RONDAL, J. (1978). Mise en equation des novellas courbes européennes de flambement. Construction Métallique, n.1, Paris.

MAQUOI, R.; RONDAL, J. (1979). Formulations d' Airton-Perry pour flambement de barres métalliques. Construction Métallique, n.4, Paris.

MERWE, P. V.; BERG, G. J. V.; COETSEE, J. S. (1990). The behaviour of stainless steel lipped channel axially loaded compression members. 1990 Annual Technical Session Proceedings Structural Stability Research Council. 
MILLER, T. H.; PEKÖZ, T. (1994). Load-eccentricity effects on cold-formed steel lipped-channel columns. Journal of Structural Engineering, ASCE, 120(3), 805-823.

MOLDOVAN, A. (1994). Compression tests on cold-formed steel columns with monosymmetrical section. Thin-Walled Structures, v.20, n.1-4, 241-252.

MOREYARA, M. E. (1993). The behavior of cold-formed lipped channels under bending. M.S. Thesis, Cornell University, Ithaca, New York.

MULLIGAN, G. P. (1983). The influence of local buckling on the structural behavior of singlysymetric cold-formed steel columns. PhD. Thesis. Cornell University, Ithaca, NY.

MULLIGAN, G. P.; PEKÖZ, T. (1983). The influence of local buckling on the structural behavior of singly-symetric cold-formed steel column. Cornell University, Department of structural engineering.

MULLIGAN, G. P.; PEKÖZ, T. (1984). Locally buckled thin-walled columns. Journal of Structures Division, ASCE, vol.110, n.11, 2635-2654.

MURRAY, N. W.; KHOO, P. S. (1981). Some basic plastic mechanisms in the local buckling of thin-walled steel structures. Internation Journal of Mechanical Science, 23(12), pp.703-713.

MURTY, K. S.; PRABHU, T.S.; TEMPLE, M.C. (1982). Ultimate strength of concentrically loaded cold-formed angles. In: ANNUAL TECHNICAL SESSION OF THE STRUCTURAL RESEARCH COUNCIL. Proceedings.

NAGAHAMA, K. J. (2003). Análise de estabilidade local em perfis de seção aberta em aço e em resina reforçada com fibra de vidro. Rio de Janeiro. 160p. Tese (Doutorado) - COPPE, Universidade Federal do Rio de Janeiro.

NARAYANAN, S.; MAHENDRAN, M. (2003). Ultimate capacity of innovative cold-formed steel columns. Journal of Constructional Steel Research, v.59, p.489-508. 
NARAYANAN, S.; MAHENDRAN, M. (2002) apud RANAWAKA, T.; MAHENDRAN, M. (2004). Design of cold-formed steel compression members subject to distortional buckling at elevated temperatures. In: LaBOUBE, R.A.; YU, W.-W. (Ed.). Recent research and developments in cold-formed steel design and construction $\left(17^{\text {th }}\right.$ International Specialty Conference on ColdFormed Steel Structures, Orlando, USA, Nov. 4-5, 2004). Rolla, University of Missouri-Rolla, 2004. p.225-240.

NETHERCOT, D. A. (2000). Frame Structures: Global performance, static and stability behaviour - General Report. Journal of Constructional Steel Research, v.55, p.109-124.

NORTH AMERICAN SPECIFICATION (2004). Supplement 2004 to the North American Specification for the Design of Cold-Formed Steel Structural Members: Appendix 1, Design of Cold-Formed Steel Structural Members Using Direct Strength Method. American Iron and Steel Institute, Washington, D.C.

OUTINEN, J. (2000). Profiled steel sheeting. In: SEMINAR ON STEEL STRUCTURES: DESIGN OF COLD-FORMED STEEL STRUCTURES, Helsinki University of Technology, Laboratory of Steel Structures, Publications 15, Expoo 2000. p.1-13.

PANDEY, M. D.; SHERBOUNE, A. N. (1989). Unified v. integrated approaches in lateraltorsional buckling of beams. The Structural Engineer, v.67, p.245-249, July, 1989.

PAULA, G. D. (1994). Alguns aspectos da fundamentação teórica e dimensionamento de elementos comprimidos de aço. São Carlos. 225p. Dissertação (Mestrado) - Escola de Engenharia de São Carlos, Universidade de São Paulo.

PAULA, G. D. (2002). Estudo teórico-experimental de elementos comprimidos de aço: Ênfase em perfis soldados. São Carlos. 178p. Tese (Doutorado) - Escola de Engenharia de São Carlos, Universidade de São Paulo.

PEKÖZ, T. (1986). Development of a unified approach to the design of cold-formed steel members. American Iron and Steel Institute, Research report SG 86-4.

PEKÖZ, T. (1987). Development of a unified approach to the design of cold-formed steel members. American Iron and Steel Institute, Research report CF 87-1. 
PEKÖZ, T. et al. (2003). The finite element method for thin-walled members - applications. Thin Walled Structures, v.41, p.191-206.

PEKÖZ, T., DRACKY, M. (1997). Experimental model research and testing of thin-walled structures. Proceedings of the International Conference - Academy of Sciences of the Czech Republic.

PEKÖZ, T.; SCHAFER, B. W. (1998). Computational modeling of cold-formed steel: characterizing geometric imperfections and residual stresses. Journal of Constructional Steel Research, v.47, p.193-210.

PEKÖZ, T.; WENG, T. T. (1988). Compression tests of cold-formed steel columns. Ninth International Specialty Conference on Cold-Formed Steel Structures - Recent Research and Developments in Cold-Formed Steel Design and Construction, University of Missouri-Rolla,v.9.

PEKÖZ, T.; WINTER, G. (1969). Torsional-flexural buckling of thin-walled sections under eccentric load. Journal of the Structural Division, ASCE, v.95, n.ST5, p.941-963.

PÉREZ, S. V. S. (2003). Análise experimental da instabilidade distorcional em perfis de paredes finas e seção aberta, sob força de compressão excêntrica. Rio de Janeiro. 152p. Tese (Doutorado) - COPPE, Universidade Federal do Rio de Janeiro.

PERTTOLA, H. (2000). Numerical analysis for thin-walled structures. In: SEMINAR ON STEEL STRUCTURES: DESIGN OF COLD-FORMED STEEL STRUCTURES, Helsinki University of Technology, Laboratory of Steel Structures, Publications 15, Expoo 2000. p.45-64.

PFLÜGER, A. Von (1961). Thin-walled compression members. Hanover, Publications of Technische Hochschule.

PHUNG, N.; YU, W. W. (1978). Structural behavior of longitudinally reinforced beam webs. Civil Engineering Study Structural Series, Departament of Civil Engineering, 78-6, University of Missouri-Rolla.

POLYZOIS, D.; CHARNVARNICHBORIKARN, P. (1993). Web-flange interaction in cold-formed steel Z-section columns. Journal of Structural Engineering, ASCE, 119(9), 2607-2628. 
POPOVIC, D.; HANCOCK, G. J.; RASMUSSEN, K.J.R (1999). Axial Compression Tests of Cold-Formed Angles. Journal of Structural Engineering, American Society of Engineers. 125 (5): 515-523.

Projeto e execução de estruturas de aço e de estruturas mistas aço-concreto de edifícios (Abril 2006). Texto base para revisão da NBR 8800. Belo Horizonte. Obs: o texto-base para revisão está disponível no endereço www.dees.ufmg.br/fakury.

QUISPE, L.; HANCOCK, G. J. (2002). Direct strength method for the design purlins. In: $16^{\text {th }}$ International Specialty Conference on Recent Research and Developments in Cold-Formed Steel Design and Construction, pp. 561-572, October, Orlando, Florida, USA.

RACHID, M. (1983). Instabilidade de barras de seção delgada. Escola de engenharia de São Carlos, Universidade de São Paulo. São Carlos (SP).

RACHID, M.; MORI, D. D. (1993). Instabilidade: flambagem de barras de seção delgada por torção e flexão. Escola de engenharia de São Carlos, Universidade de São Paulo. São Carlos $(\mathrm{SP})$.

RACHID, M.; MORI, D. D. (2000). Instabilidade: Conceitos - Aplicação na flambagem por flexão. Escola de engenharia de São Carlos, Universidade de São Paulo. São Carlos (SP).

RASMUSSEN, K. J. R. (2003). Design of Angle Columns with Locally Unstable Legs. Department of Civil Engineering, Research Report No. R830, University of Sydney. Australia.

RASMUSSEN, K. J. R.; HANCOCK, G. J. (1988). Geometric imperfections in plated structures subject to interaction between buckling modes. Thin-Walled Structures, 6(6):433-452.

RASMUSSEN, K. J. R.; HANCOCK, G. J. (1993). The flexural behaviour of fixed-ended channel section columns. Thin-Walled Structures, 17(1):45-63.

RASMUSSEN, K. J. R.; RONDAL, J. (1997). Strength curves for metal columns. Journal of Structural Engineering, Am Soc Civil Eng, 123(6):721-8.

RASMUSSEN, K. J. R.; RONDAL, J. (1998). A unified approach to column design. Journal of Constructional Steel Research, v.46, n.1-3, p. 127-128. 
RASMUSSEN, K. J. R.; YOUNG, B. (1999). Behaviour of cold-formed singly symetric columns. Thin Walled Structures, v.33, p. 83-102.

RASMUSSEN, K. J. R.; YOUNG, B. (2000). Inelastic bifurcation of cold-formed singly symmetric columns. Thin Walled Structures, v.36, p. 213-230.

REIS, A.; CAMOTIM, D. (2001). Estabilidade estrutural. Lisboa, Portugal: McGRAW-HILL de Portugal. 470p.

RHODES, J. (1991). Some interesting phenomena which can occur in light gauge steel members. In: INTERNATIONAL CONFERENCE ON STEEL AND ALUMINIUM STRUCTURES, ICSAS 91, Singapore, May. Proceedings.

RHODES, J. (1997). Research into thin-walled structures at the University of Strathclyde - a brief history. Thin Walled Structures, v.28, n.3/4, p. 201-212.

RHODES, J. (2004). Postbuckling behaviour and interaction of different modes in thin-walled members. Fourth International Conference on Thin-Walled Structures. Thin-Walled Structures Advances in Research, Design and Manufacturing Technology.

RODRIGUES, F.C. (1993) Estudo teórico-experimental de perfis de chapa dobrada submetidos à compressão. Tese (Doutorado) - Universidade Federal do Rio de Janeiro, COPPE, Rio de Janeiro.

ROGERS, C. A. (1995). Interaction buckling of flange, edge stiffener and web of C-sections in bending. M.S. Thesis, University of Waterloo, Ontario, Canada.

ROGERS, C.A.; HANCOCK, G.J. (1998). Behaviour of thin G550 sheet steel bolted connections. In: INTERNATIONAL SPECIALTY CONFERENCE ON COLD-FORMED STEEL STRUCTURES, 14., St.Louis, Missouri, U.S.A., October 15-16, 1998. Proceedings.Rolla, University of Missouri.

ROGERS, C.A.; SCHUSTER, R.M. (1995). Interaction buckling of flange, edge stiffener and web of C-sections in bending, research into cold-formed steel. Ontario, University of Waterloo, Department of Civil Engineering, Final report of CSSBI/IRAP project. 
RONDAL, J. (1992). Determination theoretique des contraintes residuelles dans les elements en acier profiles a froid. Ce travail a recu le prix N.V. BEKAERT S.A.. Octroye par le Fonds National de la Recherche Scientifique.

RONDAL, J. (2000). Cold-formed steel members and structures. General report. Journal of Constructional Steel Research, v.55, n.1-3, p.155-158.

RONDAL, J.; MAQUOI, R. (1979). Formulation d'Ayrton-Perry pour le flambement des barres métalliques. Construction Métallique, 4, pp.41-53.

RUSCH, A.; LINDNER, J. (2001). Remarks to the direct strength method. Thin Walled Structures, v.39, n. 9, p. 807-820.

SCHAFER, B. W. (1997). Cold-Formed Steel Behavior and Design: Analytical and Numerical Modeling of Elements and Members with Longitudinal Stiffeners. PhD. Dissertation, Cornell University, Ithaca.

SCHAFER, B. W. (2001). Finite Strip Analysis of Thin-walled Members. In: CU-FSM: Cornell University - Finite Strip Method.

SCHAFER, B. W. (2001). Thin-walled column design considering local, distortional and euler buckling. Proceedings: Structural Stability Research Council - Annual Technical Session and Meeting.

SCHAFER, B. W. (2002). Progress on the direct strength method. In: $16^{\text {th }}$ international Specialty Conference on Recent Research and Developments in Cold-Formed Steel Design and Construction, pp. 647-662, October, Orlando, Florida, USA.

SCHAFER, B. W. (2006). Design Guide for Direct Strength Method (DSM). American Iron and Steel Institute - Committee on Specifications for the Design of Cold-Formed Steel Structural Members, January, 2006.

SCHAFER, B. W.; PEKÖZ, T. (1998). Computational modeling of cold-formed steel: characterizing geometric imperfections and residual stresses. Journal of Constructional Steel Research, v.47, p.193-210, January. 
SCHARDT, R. (1994). Lateral torsional and distortional buckling of channel and hat sections. Journal of Construction Steel Research, p.243-265.

SCHARDT, R.; SCHRADE, W. (1982). Kaltprofil-Pfetten. Institut für statik, technische Hochschule Darmstad, Bericht Nr.1, Darmstadt.

SCHUSTER, R. M. (1992). Testing of perforated C-stud sections in bending. Report for the Canadian Sheet Steel Building Institute, University of Waterloo, Waterloo Ontario.

SEAH, L. K.; RODHES, J. (1993). Simplified buckling analysis of plate with coumpond edge stiffeners. Journal of Engineering Mechanics, v.119, n.1, p.19-38.

SHAN, M.; LABOUBE, R. A.; YU, W. W. (1994). Behavior of web elements with openings subjected to bending, shear and the combination of bending and shear. Civil Engineering Study Structural Series, 94-2, Departament of Civil Engineering, University of Missouri-Rolla, Rolla, Missouri.

SHANLEY, F. R. (1947). Inelastic column theory. Journal of Aeronautical Science, v. 14.

SILVESTRE, N. (2005). Teoria Generalizada de Vigas: Novas Formulações, Implementação Numérica e Aplicações. Lisboa. Tese (Doutorado) - Departamento de Engenharia Civil e Arquitectura (DECivil), Instituto Superior Técnico.

SILVESTRE, N.; CAMOTIM, D. (2002a). First-order generalised beam theory for arbitrary orthotropic materials. Thin-Walled Structures, Elsevier 40 (9) 755-789.

SILVESTRE, N.; CAMOTIM, D. (2002b). Second-order generalised beam theory for arbitrary orthotropic materials. Thin-Walled Structures, Elsevier, 40 (9) 791-820.

SILVESTRE, N.; CAMOTIM, D. (2003). Nonlinear Generalized Beam Theory for Cold-formed Steel Members. International Journal of Structural Stability and Dynamics. 3 (4) 461-490.

SILVESTRE, N.; CAMOTIM, D. (2004) Towards an Efficient Design Against Distortional Buckling: Formulae for $\mathrm{C}$ and Z-Section Cold-Formed Steel Members. Proceedings of Structural Stability Research Council (SSRC) 2004 Annual Stability Conference, Long Beach, pp. 239263, March 24-27, 2004. 
SIVAKUMARAN, K. S.; ABDEL-RAHMAN, N. (1998). A finite element analysis model for the behaviour of cold-formed steel members. Thin Walled Structures, v.31, p. 305-324.

SHARP, M. L. (1966). Longitudinal stiffeners for compression members. Journal of Structural Division, ASCE, 92 (ST5), p.187-211.

SRIDHARAN, S. (1982). A finite strip analysis of locally buckled plate structures subject to nonuniform compression. Engineering Structures, v. 4.

SRIDHARAN, S. (1982). A semi-analytical method for the post-local-torsional buckling analysis of prismatic plate structures. International Journal for Numerical Methods in Engineering, v.18.

SRIDHARAN, S.; BENITO, R. (1982). Interactive buckling in thin-walled columns. In: INTERNATIONAL SPECIALTY CONFERENCE ON COLD-FORMED STEEL STRUCTURES, $6^{\text {th }}$, University of Missouri. Proceedings.

SRIDHARAN, S.; GALAMBOS T.V. (1981). Finite strip analysis of postbuckling behavior of plate structures some recent results. In: ANNUAL TECHNICAL SESSION OF THE STRUCTURAL STABILITY RESEARCH COUNCIL. Proceedings.

SRIDHARAN, S.; GRAVES-SMIT, T.R. (1981). Postbuckling analysis with finite strip. Journal of the Engineering Mechanics Division, ASCE, v. 107.

STIEMER, S. F. (2000). Design of compression members - Column Design. CAN/CSA-S16.194.

SUPPLE, W. J. (1967) apud GIONCU, V. (1994). Coupled branching configurations in the elastic buckling of symmetric structural systems. Int. J. Mech. Sci., v.9, pp.97-112.

SUPPLE, W. J. (1968) apud GIONCU, V. (1994). On the change in buckle pattern in elastic structures. Int. J. Mech. Sci., v.10, pp.737-45.

SUPPLE, W. J. (1969) apud GIONCU, V. (1994). Initial post-buckling behaviour of a class of elastic structural systems. Int. J. Non-Linear Mech., v.4, pp.23-36.

TIAN, Y. S.; LU, T. J. (2004). Minimun Weight of cold-formed steel sections under compression. Thin Walled Structures, v.42, p. 515-532. 
TIMOSHENKO, S. P.; GERE, J. M. (1961). Theory of elastic stability. 2.ed. New York: McGrawHill. 541p.

THOM, R. (1972) apud GIONCU, V. (1994). Stabilite Structurelle et Morphogenese. Benjamin, Reading, UK.

THOMASSON, P. (1978). Thin-walled C-shaped panels in axial compression. Swedish Council for Building Research. D1:1978, Stockholm, Sweden.

THOMPSON, J. M. T.; HUNT, G. W. (1971) apud GIONCU, V. (1994). A theory for the numerical analysis of compound branching. ZAMP, v.22, 1001.

THOMPSON, J. M. T.; HUNT, G. W. (1973) apud GIONCU, V. (1994). A general theory of elastic stability. Wiley, London, UK.

TONEFF, J. P.; STEIMER, S. F.; OSTERRIEDER, P. (1987). Local and overral buckling in thinwalled beams and columns. Journal of Structures Division, ASCE, vol.113, n.4, p.769-786.

UNGUREANU, V.; DUBINA, D. (2003). Recent research advances on ECBL approach. Part 1: Plastic-elastic interactive buckling of cold-formed steel sections. Thin-Walled Structures, article in press.

UNGUREANU, V.; DUBINA, D. (2004). Post-elastic strength and ductility of cold-formed steel sections. Fourth International Conference on Thin-Walled Structures. Thin-Walled Structures Advances in Research, Design and Manufacturing Technology.

VAN der NEUT, A. (1969) apud GIONCU, V. (1994). The interaction of local buckling and column failure of thin-walled compression members. $12^{\text {th }}$ Int. Congr. of Applied Mechanics, Stanford. Springer Verlag, Berlin, pp.389-99.

VAN der NEUT, A. (1973) apud GIONCU, V. (1994). The sensitivity of thin-walled compression members to column axis imperfections. Int. J. Solids Struct., n.9, pp.999-1011.

VAZQUEZ, E. G. (1998). Estudo do comportamento pós-crítico de paredes esbeltas de perfis metálicos. Dissertação (Mestrado) - COPPE/UFRJ, Rio de Janeiro. 
VAZQUEZ, E. G. (2002). Análise teórica e experimental da instabilidade torcional de perfis formados a frio sob compressão centrada. Tese (Doutorado) - COPPE/UFRJ, Rio de Janeiro.

VENANCI, V. (2005). Resistência de vigas-colunas formadas por perfis de aço de chapa dobrada, com base no método da resistência direta. Rio de Janeiro. 174p. Dissertação (Mestrado) - COPPE, Universidade Federal do Rio de Janeiro.

VLASOV, V.Z.(1961). Thin-walled elastic beams. 2.ed. Jerusalem, Israel Program for Scientific Translations.

VON KARMAN, T.; SECHLER, E. E.; DONNELL, L. H. (1932). The strength of thin plates in compression. Transactions, American Society of Mechanical Engineers, v.54, p.53-57, June.

WALKER, A. C. (1975) apud YANG, D.; HANCOCK, G. J. (2004). Design and analysis of coldformed sections. International Textbook Company Limited.

WANG, S. T.; BLANDFORD, G. E. (1978). Stability analysis of local buckling frames. In: INTERNATIONAL SPECIALTY CONFERENCE ON COLD-FORMED STEEL STRUCTURES, $4^{\text {th }}$, University of Missouri, June. Proceedings.

WANG, S. T.; PAO, H. Y. (1980). Lateral bracing of locally buckled columns. In: INTERNATIONAL SPECIALTY CONFERENCE ON COLD-FORMED STEEL STRUCTURES, $5^{\text {th }}$, University of Missouri. Proceedings.

WANG, S. T.; PAO, H. Y.(1980). Stability analysis of locally buckled singly symmetric columns. Int. Conf. on Thin-Walled Structures. University of Strathclyde.

WANG, S.T.; PAO, H.Y.(1982). Stability analysis of locally singly symmetric columns, in thinwalled structures. In: INTERNATIONAL SPECIALTY CONFERENCE ON COLD-FORMED STEEL STRUCTURES, $6^{\text {th }}$, University of Missouri. Proceedings.

WANG, S.T.; TIEN, Y.L. (1973). Post-local buckling behavior of thin-walled columns. In: SPECIALTY CONFERENCE ON COLD-FORMED STEEL STRUCTURES, $2^{\text {nd }}$, University of Missouri, October. Proceedings.

WENG, C.C. (1991). Effect of residual stress on cold-formed steel column strength. Journal of Structural Engineering, ASCE, v.117, n.6, p.1622-1640. 
WENG, C.C.; LIN, C.P. (1992). Study of the maximum strength of cold-formed steel columns. Journal of Structural Engineering, ASCE, v.118, n.1, p.128-146.

WENG, S. T.; PAO, H. Y. (1990) Torsional-flexural buckling of locally buckled columns. Computers and Structures, v.11, p.127-136.

WENG, C.C.; PEKÖZ, T. (1990) Residual stresses in cold-formed steel members. Journal of Structural Engineering, ASCE, v.116, n.6, p.1230-1246, May.

WILHOIT, G.; ZANDONINI, R.; ZAVELLANI, A. (1984). Behavior and strength of angles in compression: an experimental investigation. ASCE Annual Convention and Structures Congress.

WILLIS, C. T.; WALLACE, B. (1990). Behavior of cold-formed steel purlins under gravity loading. Journal of Structural Engineering, ASCE, 116(8).

WINTER, G. (1959). Cold-formed, light-gauge steel construction. Journal of the Structural Engineering, ASCE, v.85, n.ST9, p.151-173, November.

WINTER, G. (1940). Tests on Light Studs of Cold-Formed Steel. Third Progress Report. Cornell University.

WINTER, G. (1947). Strength of thin steel compression flanges. Transactions, ASCE, v.112, p.527-554.

YANG, D.; HANCOCK, G. J. (2004). Numerical simulations of high strength steel box-shaped columns. In: LaBOUBE, R.A.; YU, W.-W. (Ed.). Recent research and developments in coldformed steel design and construction $\left(17^{\text {th }}\right.$ International Specialty Conference on Cold-Formed Steel Structures, Orlando, USA, Nov. 4-5, 2004). Rolla, University of Missouri-Rolla, 2004. p.241-264.

YOUNG, B. (1997). The behaviour of cold-formed channel columns, PhD. Thesis, University of Sydney, Australia.

YOUNG, B. (2003). Tests of cold-formed steel plain angle columns. Advances in Structures, ASSCCA'03, ed. Hancock et al., v.1, p. 295-301. 
YOUNG, B. (2004). Concentrically loaded compression members of thin-walled lipped angles. Fourth International Conference on Thin-Walled Structures. Thin-Walled Structures - Advances in Research, Design and Manufacturing Technology.

YOUNG, B. (2004). Design of channel columns with inclined edge stiffeners. Journal of Constructional Steel Research, v.60, p. 183-197.

YOUNG, B. (2004). Tests and Design of Fixed-Ended Cold-Formed Steel Plain Angle Columns. Journal of Structural Engineering, 130(12), 1931-1940.

YOUNG, B.; RASMUSSEN, KIM J. R. (1997). Design of cold-formed singly symmetric compression members. Departament of Civil Engineering, Research Report no. R759, University of Sydney.

YOUNG, B.; RASMUSSEN, KIM J. R. (2000). Inelastic bifurcation of cold-formed singly symmetric columns. Thin Walled Structures, v.36, p. 213-230.

YU, W. W. (2000). Cold-formed steel design. New York: John Wiley \& Sons. 756p. 


\section{APÊNDICE}

A sequência dos apêndices é a seguinte:

Apêndice A - Modelos reológicos (true values): Ansys

Apêndice B - Imperfeições geométricas medidas no laboratório

Apêndice C - Ensaios das barras curtas (stub columns)

Apêndice D - Ensaios das barras longas

Apêndice E - Resultados do programa CUFSM

Apêndice F - Expressões: flexo-compressão

O apêndice A apresenta os valores e curvas do par tensão-deformação (já convertidos para valores corrigidos, true values) para todas as seções analisadas, e que foram utilizados no Ansys como modelo reológico.

O apêndice B apresenta os resultados das medições das imperfeições geométricas realizadas no laboratório.

Os apêndices C (análise experimental das barras curtas, stub columns, portanto sem utilização das rótulas) e D (análise experimental das barras longas, com a utilização das rótulas) ilustram para cada barra ensaiada uma figura com 4 itens: foto da configuração deformada ao final do ensaio, diagrama força $x$ deslocamento do pistão, diagrama força $x$ deslocamento dos transdutores e diagrama força $x$ deformação dos extensômetros. Para 0 caso das stub columns em particular, de cada 3 ensaios (repetiu-se 3 vezes o ensaio de cada seção) somente em 1 se utilizou extensômetros e transdutores de deslocamento.

Os transdutores de deslocamento e os extensômetros foram posicionados no meio do comprimento das barras. O posicionamento na seção transversal tanto dos transdutores de 
deslocamento como dos extensômetros é apresentado a seguir, e serve de legenda para todas as figuras do apêndice. A direção das flechas (1 e 2) indicativas dos transdutores nas figuras indica deslocamento positivo nos gráficos a serem apresentados nos apêndices.

$O$ apêndice $E$ apresenta os resultados da análise de estabilidade elástica via programa CUFSM para todas as seções transversais analisadas neste trabalho.

Por fim, o apêndice F apresenta expressões adicionais para utilização em problemas práticos do dia-a-dia com relação ao caso da flexão composta (flexo-compressão).

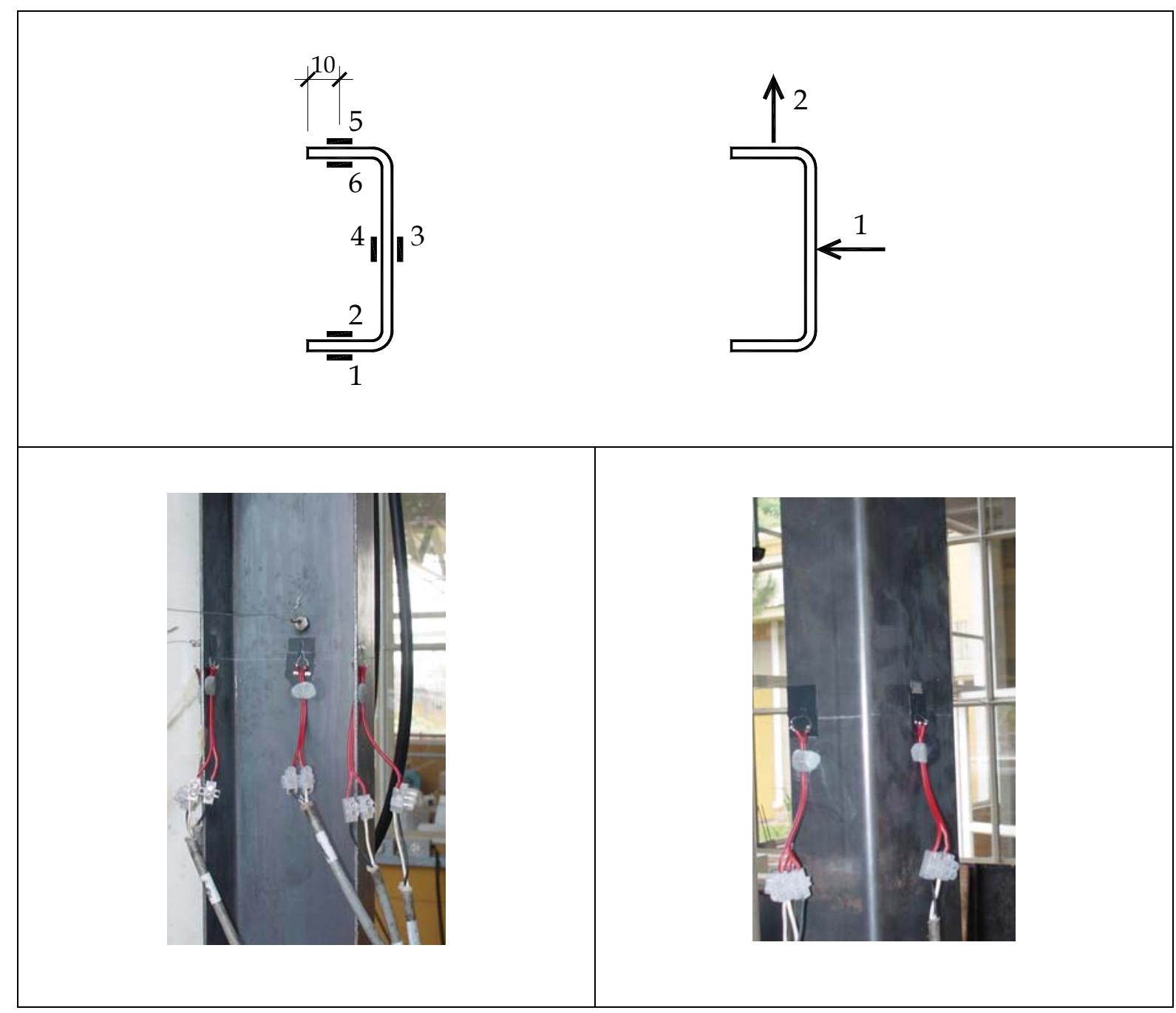

Figura A.0.1 Posição extensômetros e transdutores de deslocamento: perfil U simples 


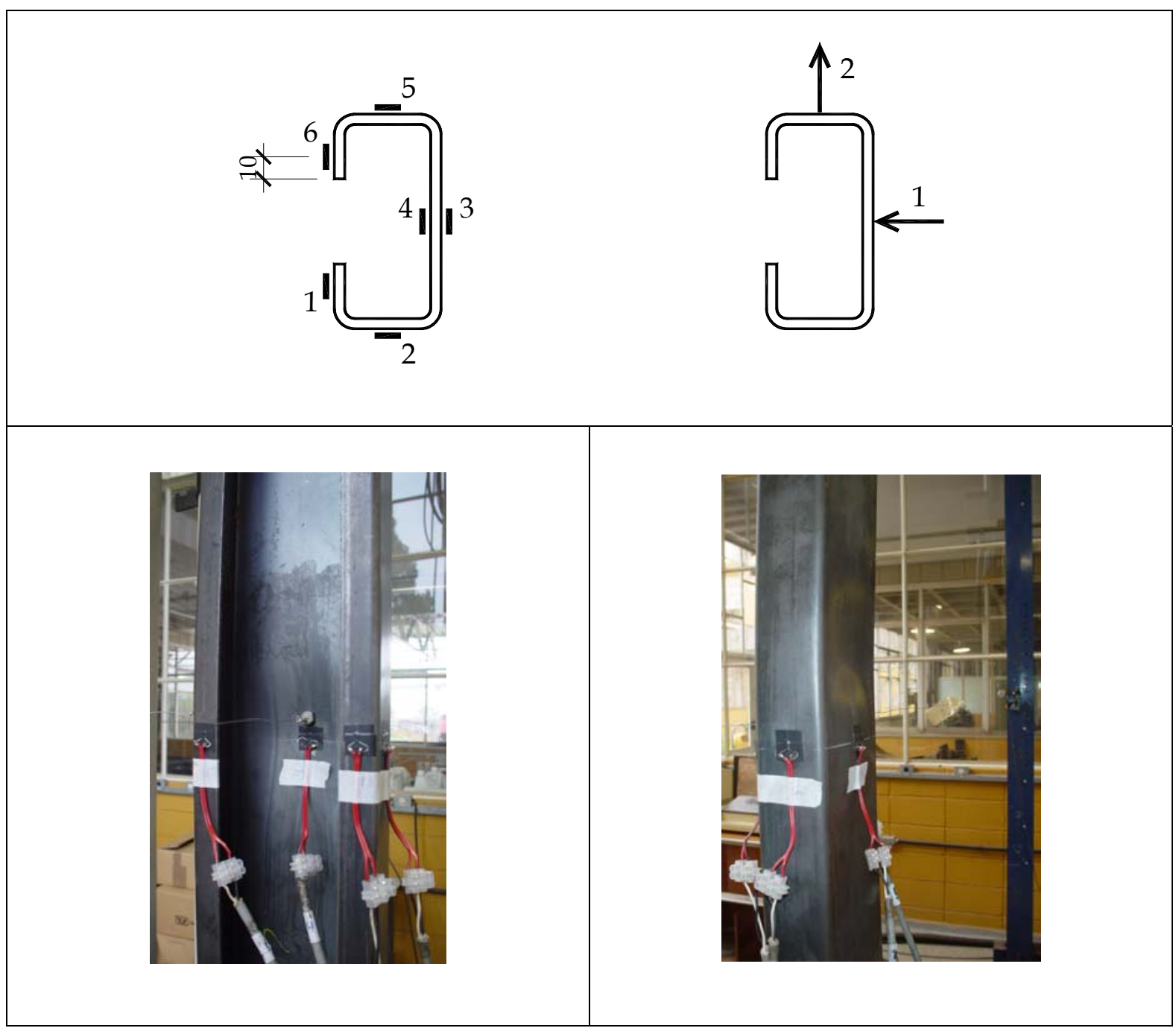

Figura A.0.2 Posição extensômetros e transdutores de deslocamento: perfil U enrijecido 


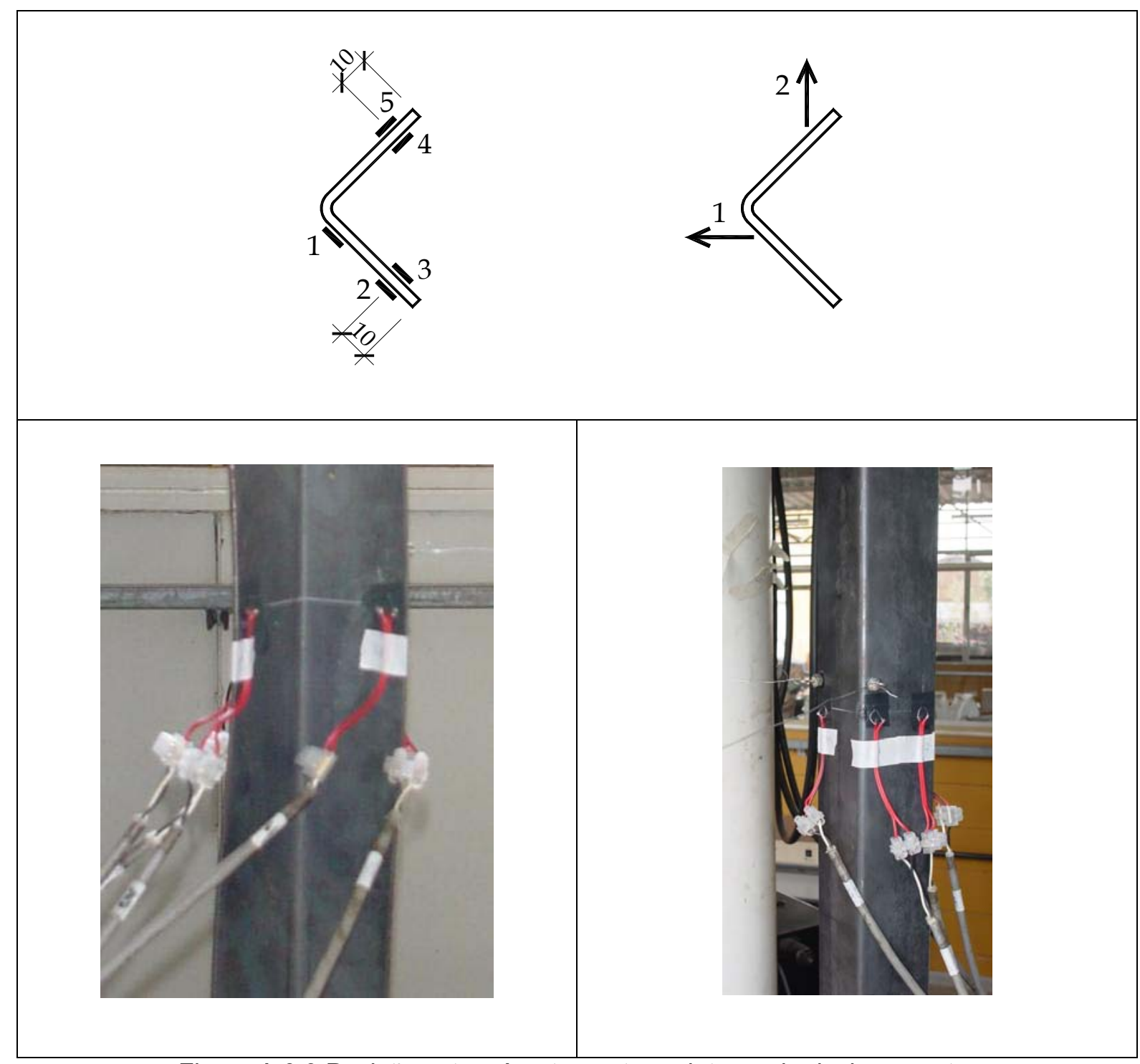

Figura A.0.3 Posição extensômetros e transdutores de deslocamento: perfil Cantoneira simples 


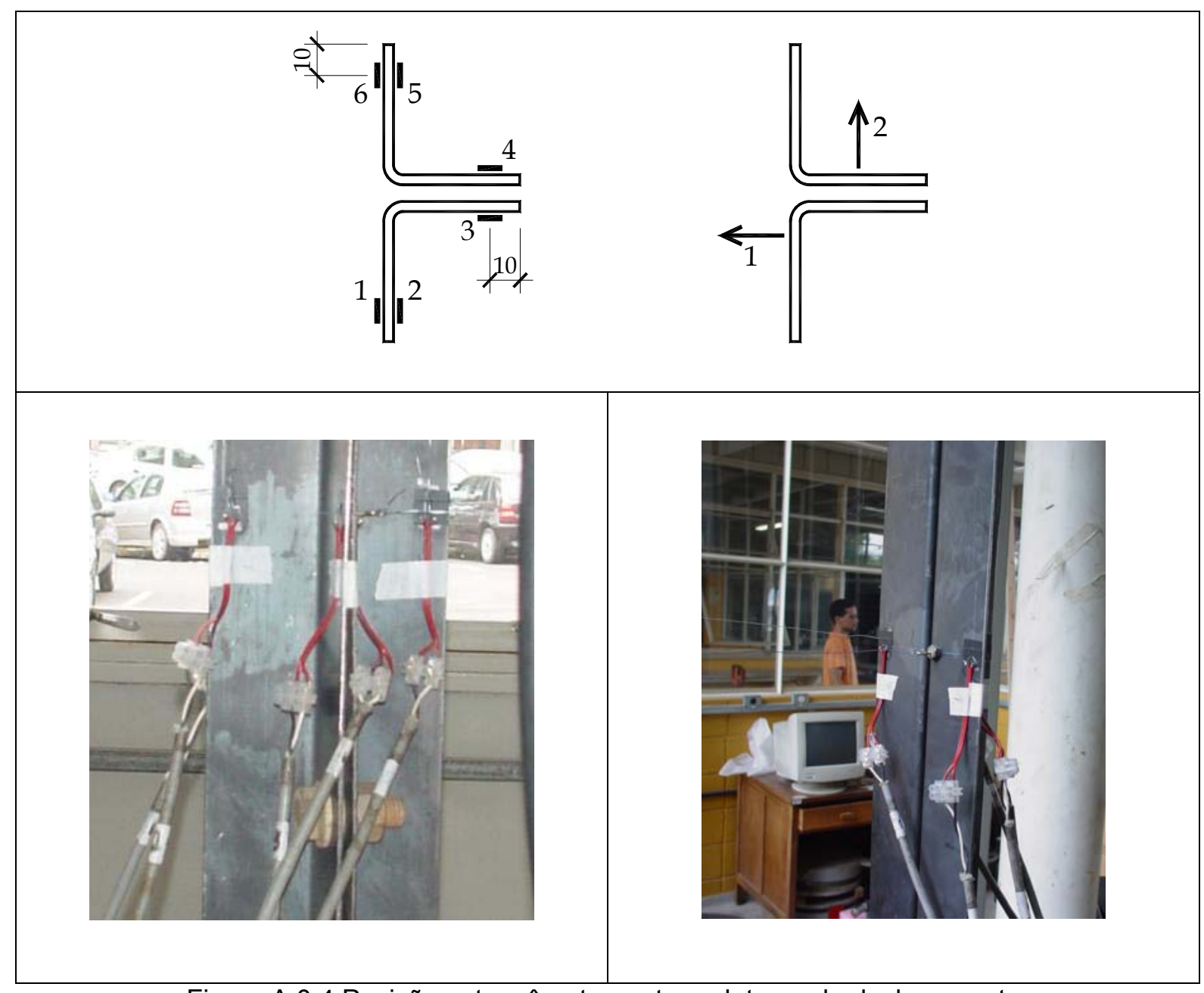

Figura A.0.4 Posição extensômetros e transdutores de deslocamento: perfil Cantoneira dupla - rótula para flexão em " $x$ " 


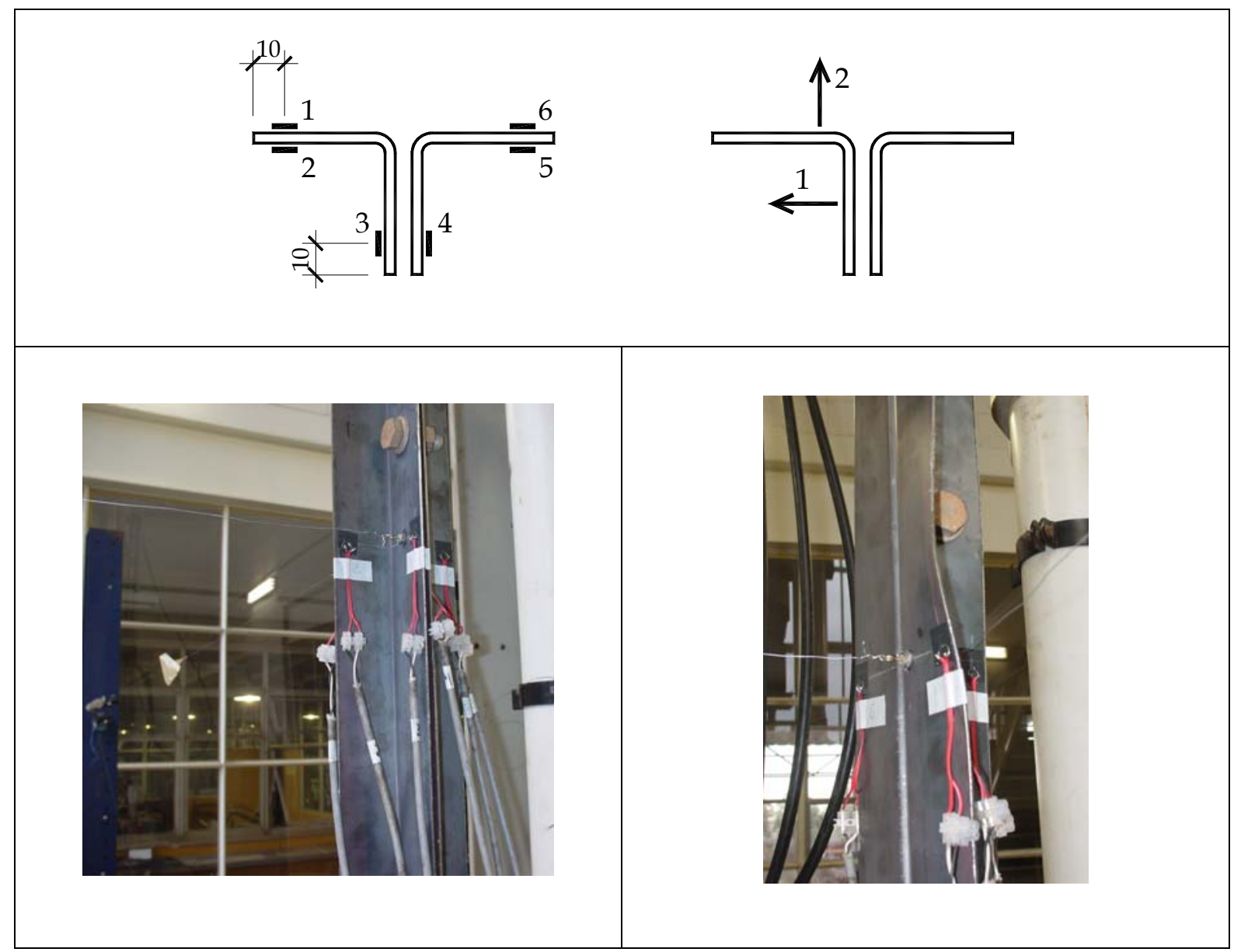

Figura A.0.5 Posição extensômetros e transdutores de deslocamento: perfil Cantoneira dupla - rótula para flexão em "y" 


\section{APÊNDICE A - MODELOS REOLÓGICOS (true values): Ansys PERFIL: cantoneira simples $2,38 \mathrm{~mm}$ e dupla $2,38 \mathrm{~mm}$}

\begin{tabular}{|c|c|}
\hline $\begin{array}{c}\text { Deformação } \\
\text { (ue) }\end{array}$ & $\begin{array}{c}\text { Tensão } \\
\text { (kN/cm }^{\mathbf{2}} \text { ) }\end{array}$ \\
\hline 0,001248001 & 25,63 \\
\hline 0,001774025 & 31,58 \\
\hline 0,00221265 & 34,15 \\
\hline 0,003063064 & 36,67 \\
\hline 0,004857802 & 38,26 \\
\hline 0,015629028 & 42,50 \\
\hline 0,027654466 & 46,25 \\
\hline 0,03971463 & 49,07 \\
\hline 0,051688816 & 51,18 \\
\hline 0,07442635 & 54,41 \\
\hline 0,107727313 & 57,27 \\
\hline
\end{tabular}

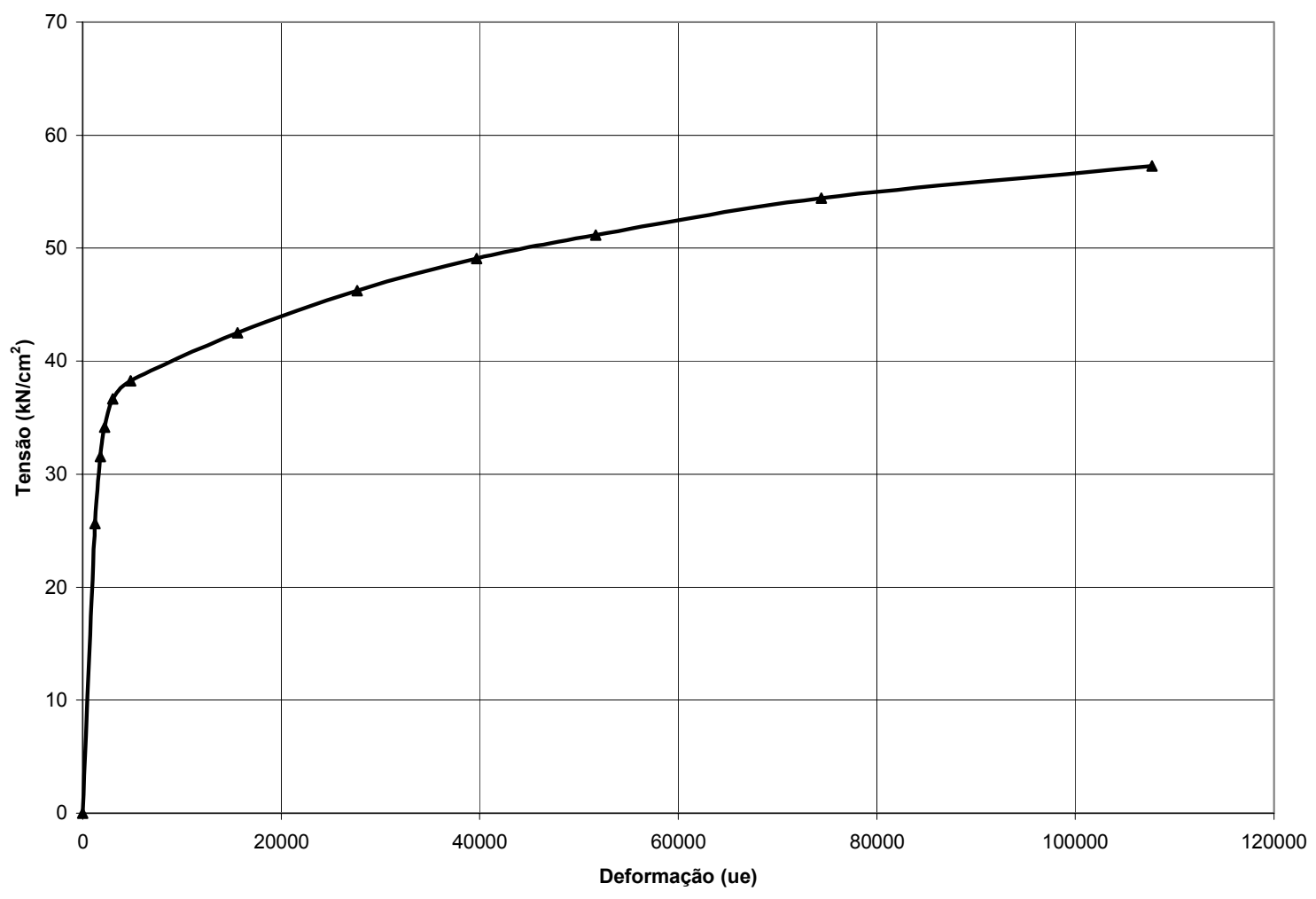

Figura A.1 Modelo reológico: cantoneira simples 2,38mm e dupla 2,38mm 


\section{PERFIL: U simples 2,38mm}

\begin{tabular}{|c|c|}
\hline $\begin{array}{c}\text { Deformação } \\
\text { (ue) }\end{array}$ & $\begin{array}{c}\text { Tensão } \\
\text { (kN/cm }^{2} \text { ) }\end{array}$ \\
\hline 0,001131067 & 23,23 \\
\hline 0,001686271 & 30,21 \\
\hline 0,002364682 & 34,21 \\
\hline 0,003223705 & 36,16 \\
\hline 0,005971071 & 37,45 \\
\hline 0,008966613 & 38,33 \\
\hline 0,010266716 & 38,92 \\
\hline 0,01873971 & 42,30 \\
\hline 0,033327098 & 46,52 \\
\hline 0,055331264 & 50,78 \\
\hline 0,066461671 & 52,37 \\
\hline 0,100936745 & 55,95 \\
\hline 0,135615386 & 58,36 \\
\hline
\end{tabular}

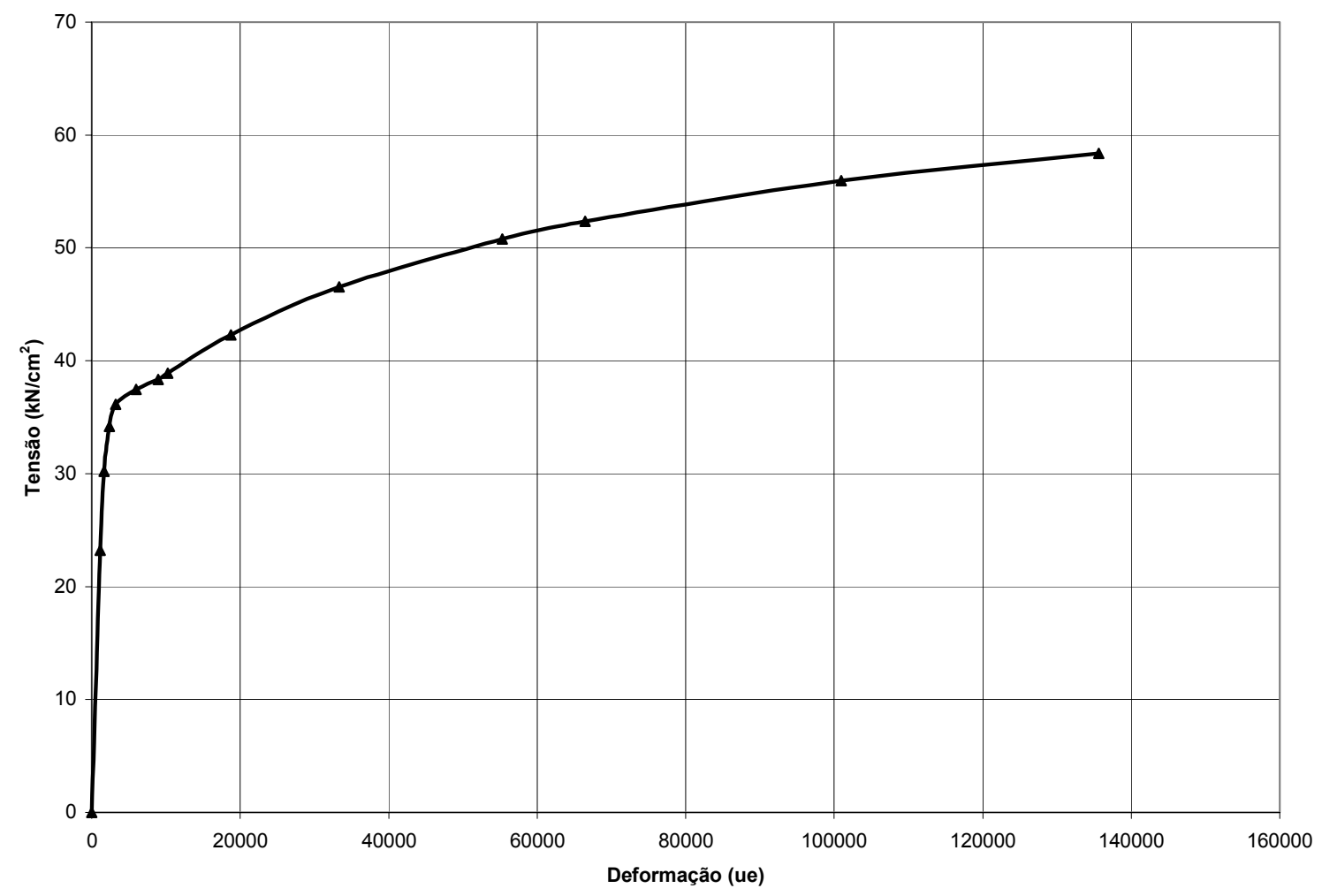

Figura A.2 Modelo reológico: perfil U simples 2,38mm 


\section{PERFIL: U simples $3,88 \mathrm{~mm}$}

\begin{tabular}{|cc|}
\hline $\begin{array}{c}\text { Deformação } \\
\text { (ue) }\end{array}$ & $\begin{array}{c}\text { Tensão } \\
\text { (kN/cm }^{2} \text { ) }\end{array}$ \\
\hline 0,000867916 & 17,82 \\
0,001001565 & 20,31 \\
0,001194726 & 22,56 \\
0,001844232 & 26,73 \\
0,002703688 & 28,48 \\
0,003206175 & 28,93 \\
0,005837197 & 29,78 \\
0,010788527 & 30,72 \\
0,018302287 & 32,98 \\
0,02418842 & 34,51 \\
0,031245017 & 36,11 \\
0,065908832 & 42,09 \\
0,096590572 & 45,46 \\
0,113519143 & 46,91 \\
0,139919611 & 48,83 \\
0,190427504 & 51,75 \\
\hline
\end{tabular}

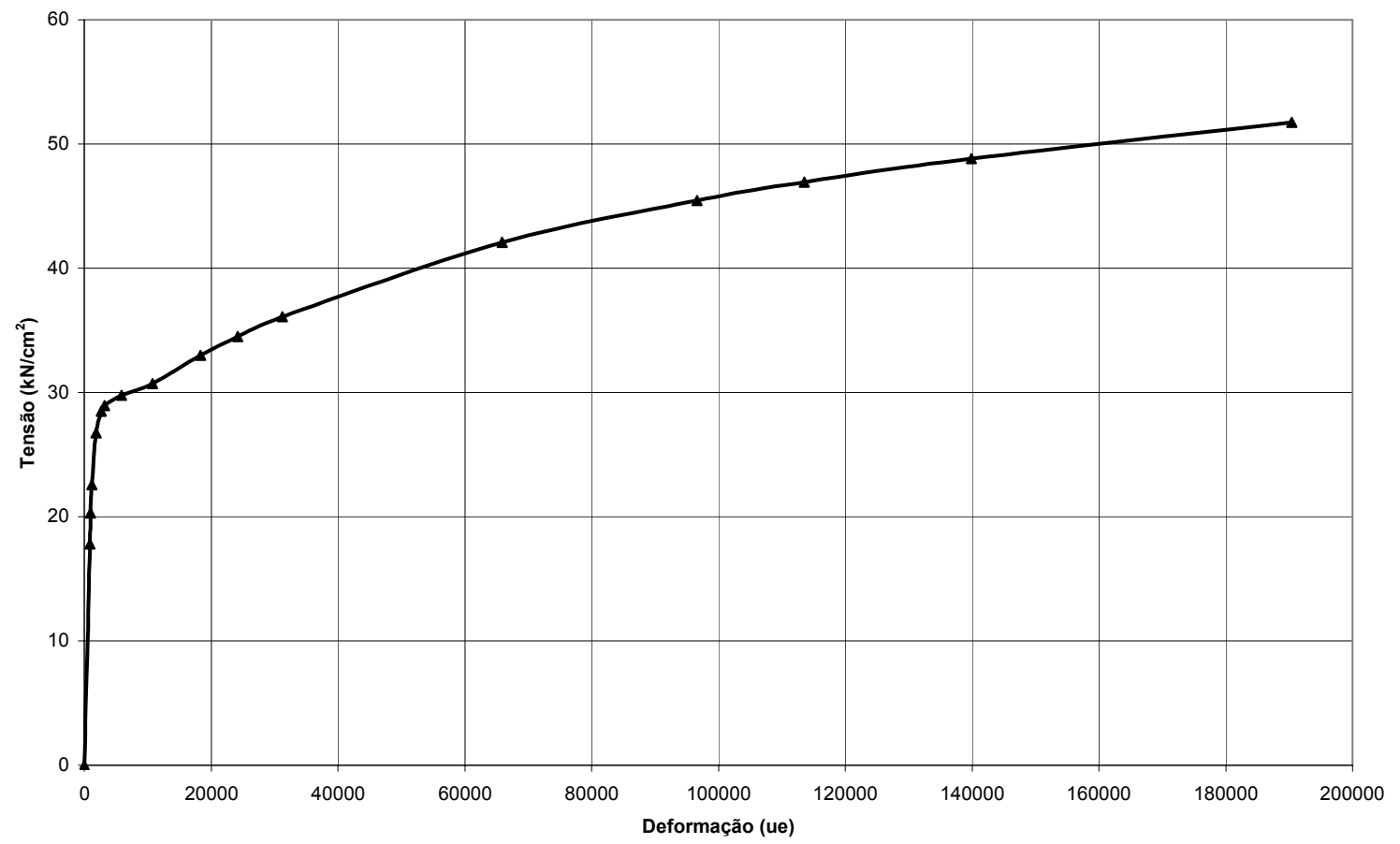

Figura A.3 Modelo reológico: perfil U simples 3,88mm 
Tese de Doutorado - Gustavo Monteiro de Barros Chodraui

\section{PERFIL: U enrijecido 2,38mm}

\begin{tabular}{|cc|}
\hline $\begin{array}{c}\text { Deformação } \\
\text { (ue) }\end{array}$ & $\begin{array}{c}\text { Tensão } \\
\text { (kN/cm }{ }^{2} \text { ) }\end{array}$ \\
\hline 0,001131067 & 23,23 \\
0,001179304 & 24,09 \\
0,00191442 & 30,65 \\
0,002382214 & 34,29 \\
0,00307181 & 37,06 \\
0,003650011 & 37,76 \\
0,006425446 & 38,57 \\
0,007403063 & 38,91 \\
0,015207905 & 42,04 \\
0,021393126 & 44,22 \\
0,033746655 & 47,54 \\
0,049852457 & 50,56 \\
0,071478136 & 53,69 \\
0,13097446 & 58,33 \\
\hline
\end{tabular}

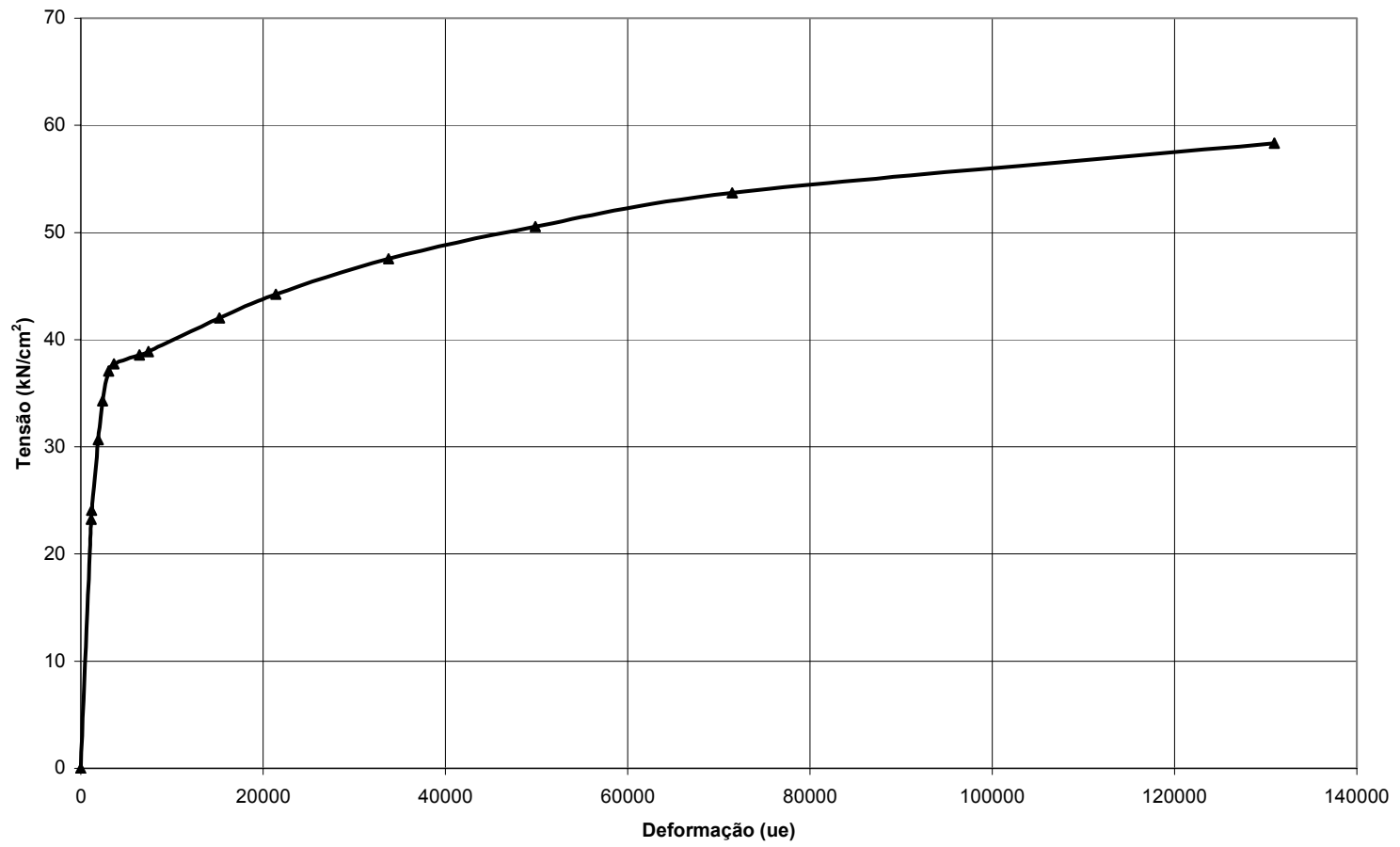

Figura A.4 Modelo reológico: perfil U enrijecido 2,38mm 
Tese de Doutorado - Gustavo Monteiro de Barros Chodraui

\section{PERFIL: U enrijecido $3,88 \mathrm{~mm}$}

\begin{tabular}{|cc|}
\hline $\begin{array}{c}\text { Deformação } \\
\text { (ue) }\end{array}$ & $\begin{array}{c}\text { Tensão } \\
\text { (kN/cm }{ }^{2} \text { ) }\end{array}$ \\
\hline 0,000970748 & 19,93 \\
0,001159621 & 22,71 \\
0,001446393 & 24,87 \\
0,002007996 & 27,12 \\
0,002697838 & 28,42 \\
0,005271813 & 30,07 \\
0,014243676 & 32,45 \\
0,019147903 & 33,81 \\
0,030932357 & 36,59 \\
0,046207785 & 39,43 \\
0,059137713 & 41,48 \\
0,063618098 & 42,32 \\
0,084621746 & 44,70 \\
0,106473097 & 46,71 \\
0,139349104 & 49,11 \\
0,183473116 & 51,68 \\
\hline
\end{tabular}

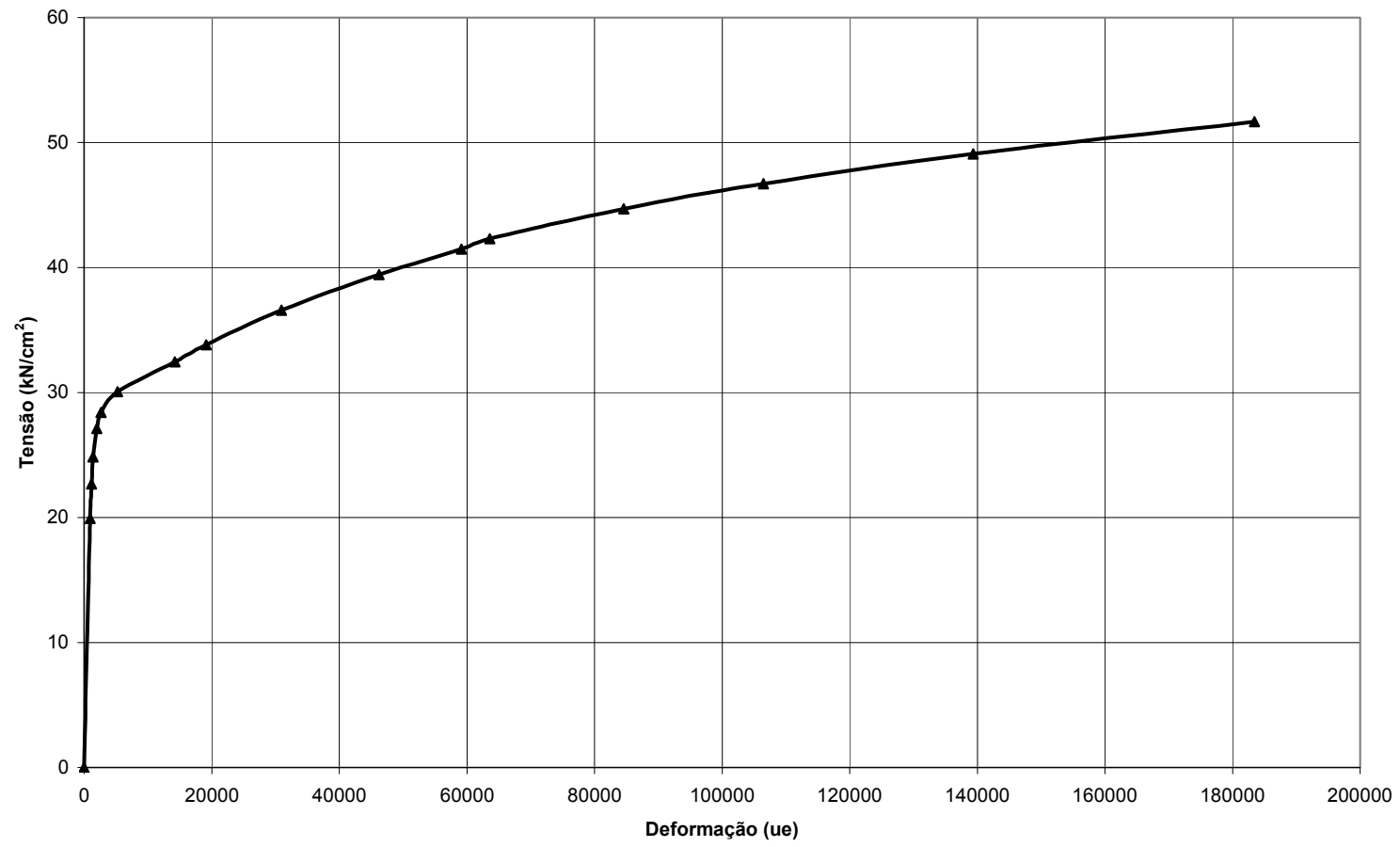

Figura A.5 Modelo reológico: perfil U enrijecido 3,88mm 
Tese de Doutorado - Gustavo Monteiro de Barros Chodraui 


\section{APÊNDICE B - IMPERFEIÇÕES GEOMÉTRICAS MEDIDAS NO LABORATÓRIO}

As tabelas e os gráficos a seguir são baseados na legenda apresentada na Figura B.1. O sinal positivo indica deslocamento no sentido da parte interna do perfil.

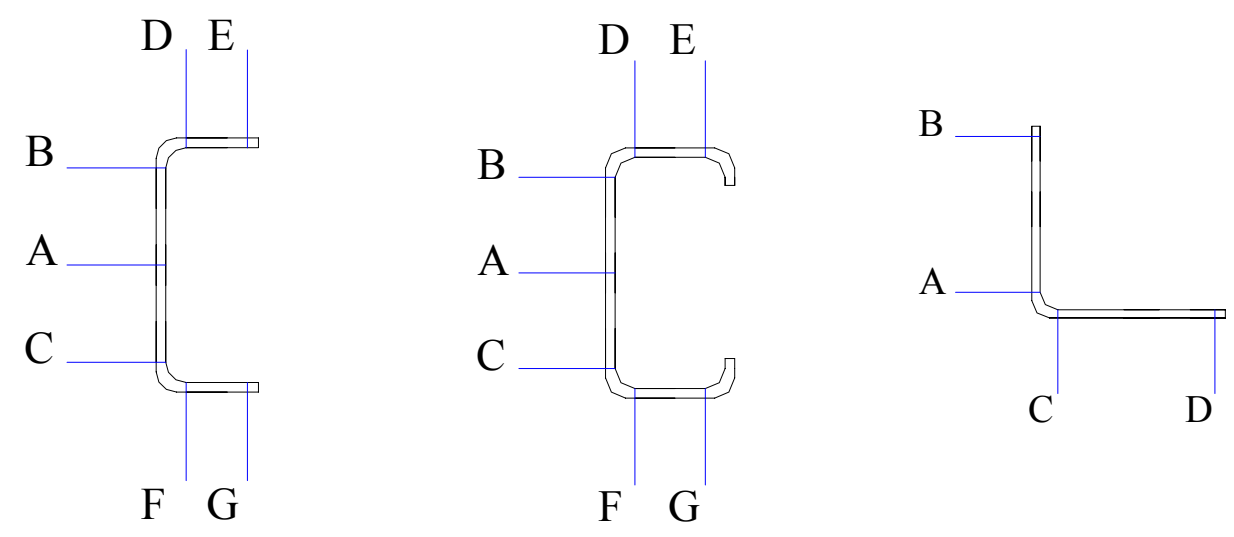

Figura B.1 Posições de medida das imperfeições geométricas

Tabela B.1 Valores das imperfeições iniciais obtidos (mm): U 100x50x2,38 ( $\mathrm{L}=1.665 \mathrm{~mm})$

\begin{tabular}{|c|c|c|c|c|c|c|c|c|}
\hline Perfil & \multirow{2}{*}{$\begin{array}{c}\text { Leitura } \\
\text { ao } \\
\text { longo } \\
\text { da barra } \\
\text { (mm) }\end{array}$} & \multicolumn{7}{|c|}{ Posição na seção transversal - vide Figura B.2 } \\
\hline \multirow{12}{*}{$\begin{array}{c}\mathrm{U} 100 \times 50 \times 2,38 \\
\mathrm{~L}=1.665 \mathrm{~mm}\end{array}$} & & $\stackrel{\mathrm{A}}{(\mathrm{mm})}$ & $\begin{array}{c}B \\
(\mathrm{~mm})\end{array}$ & $\begin{array}{c}\mathrm{C} \\
(\mathrm{mm})\end{array}$ & $\begin{array}{c}\mathrm{D} \\
(\mathrm{mm})\end{array}$ & $\underset{(m m)}{E}$ & $\begin{array}{c}\mathrm{F} \\
(\mathrm{mm})\end{array}$ & $\begin{array}{c}\mathrm{G} \\
(\mathrm{mm})\end{array}$ \\
\hline & 0 & 0,0 & 0,0 & 0,0 & 0,0 & 0,0 & 0,0 & 0,0 \\
\hline & 167 & $-0,4$ & $-0,6$ & $-0,5$ & 0,0 & $-0,2$ & 0,0 & 0,0 \\
\hline & 333 & $-0,6$ & $-0,8$ & $-0,7$ & 0,2 & 0,3 & 0,0 & 0,0 \\
\hline & 500 & $-0,2$ & $-0,3$ & $-0,4$ & 0,4 & 0,7 & 0,1 & 0,1 \\
\hline & 666 & $-0,2$ & $-0,3$ & $-0,4$ & 0,1 & 0,2 & 0,0 & $-0,3$ \\
\hline & 833 & $-0,1$ & $-0,2$ & $-0,3$ & 0,0 & 0,0 & $-0,2$ & $-0,4$ \\
\hline & 999 & 0,0 & $-0,2$ & $-0,3$ & 0,0 & $-0,3$ & 0,0 & 0,0 \\
\hline & 1166 & 0,0 & 0,0 & $-0,3$ & 0,1 & 0,0 & 0,1 & 0,0 \\
\hline & 1332 & 0,0 & 0,0 & $-0,3$ & 0,2 & 0,2 & 0,1 & 0,2 \\
\hline & 1499 & 0,1 & 0,1 & 0,0 & 0,2 & 0,2 & 0,1 & 0,1 \\
\hline & 1665 & 0,0 & 0,0 & 0,0 & 0,0 & 0,0 & 0,0 & 0,0 \\
\hline
\end{tabular}




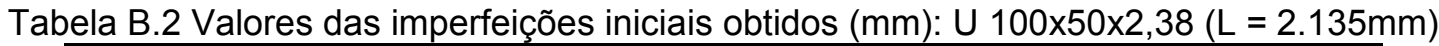

\begin{tabular}{|c|c|c|c|c|c|c|c|c|}
\hline Perfil & \multirow{2}{*}{$\begin{array}{c}\text { Leitura ao } \\
\text { longo da } \\
\text { barra } \\
(\mathrm{mm})\end{array}$} & \multicolumn{7}{|c|}{ Posição na seção transversal - vide Figura B.3 } \\
\hline \multirow{12}{*}{$\begin{array}{c}U 100 \times 50 \times 2,38 \\
L=2.135 \mathrm{~mm}\end{array}$} & & $\begin{array}{c}\mathrm{A} \\
(\mathrm{mm})\end{array}$ & $\begin{array}{c}B \\
(\mathrm{~mm})\end{array}$ & $\underset{(\mathrm{mm})}{\mathrm{C}}$ & $\begin{array}{c}\mathrm{D} \\
(\mathrm{mm})\end{array}$ & $\underset{(\mathrm{mm})}{\mathrm{E}}$ & $\begin{array}{c}\mathrm{F} \\
(\mathrm{mm})\end{array}$ & $\underset{(\mathrm{mm})}{\mathrm{G}}$ \\
\hline & 0 & 0,0 & 0,0 & 0,0 & 0,0 & 0,0 & 0,0 & 0,0 \\
\hline & 214 & 0,0 & 0,2 & $-0,4$ & 0,3 & $-0,2$ & 0,0 & 0,9 \\
\hline & 427 & $-0,3$ & 0,0 & $-0,4$ & 0,3 & $-0,3$ & 0,5 & 1,2 \\
\hline & 641 & $-0,6$ & $-0,2$ & $-0,4$ & 0,2 & $-0,4$ & 0,7 & 1,4 \\
\hline & 854 & $-0,2$ & 0,1 & $-0,2$ & 0,1 & $-0,5$ & 0,8 & 1,4 \\
\hline & 1068 & 0,0 & 0,0 & $-0,2$ & $-0,2$ & $-0,9$ & 0,6 & 0,9 \\
\hline & 1281 & $-0,2$ & $-0,2$ & 0,0 & $-0,1$ & $-1,2$ & 0,8 & 0,9 \\
\hline & 1495 & $-0,1$ & $-0,1$ & 0,0 & 0,1 & $-0,7$ & 1,0 & 0,9 \\
\hline & 1708 & 0,0 & 0,0 & $-0,2$ & 0,2 & $-0,3$ & 0,7 & 0,9 \\
\hline & 1922 & 0,1 & 0,2 & 0,0 & 0,0 & $-0,2$ & 0,4 & 0,9 \\
\hline & 2135 & 0,0 & 0,0 & 0,0 & 0,0 & 0,0 & 0,0 & 0,0 \\
\hline
\end{tabular}

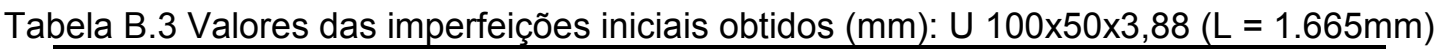

\begin{tabular}{|c|c|c|c|c|c|c|c|c|}
\hline Perfil & \multirow{2}{*}{$\begin{array}{c}\text { Leitura ao } \\
\text { longo da } \\
\text { barra } \\
(\mathrm{mm})\end{array}$} & \multicolumn{7}{|c|}{ Posição na seção transversal - vide Figura B.4 } \\
\hline \multirow{12}{*}{$\begin{array}{c}\text { U } 100 \times 50 \times 3,88 \\
L=1.665 \mathrm{~mm}\end{array}$} & & $\begin{array}{c}\mathrm{A} \\
(\mathrm{mm})\end{array}$ & $\begin{array}{c}B \\
(\mathrm{~mm})\end{array}$ & $\underset{(\mathrm{mm})}{\mathrm{C}}$ & $\begin{array}{c}\mathrm{D} \\
(\mathrm{mm})\end{array}$ & $\underset{(\mathrm{mm})}{\mathrm{E}}$ & $\underset{(\mathrm{mm})}{\mathrm{F}}$ & $\begin{array}{c}\mathrm{G} \\
(\mathrm{mm})\end{array}$ \\
\hline & 0 & 0,0 & 0,0 & 0,0 & 0,0 & 0,0 & 0,0 & 0,0 \\
\hline & 167 & $-0,2$ & $-0,4$ & 0,0 & 0,1 & 0,0 & 0,0 & $-0,4$ \\
\hline & 333 & $-0,5$ & $-0,6$ & $-0,1$ & 0,1 & $-0,1$ & 0,1 & $-0,5$ \\
\hline & 500 & $-0,2$ & $-0,2$ & 0,0 & 0,2 & $-0,1$ & 0,3 & $-0,3$ \\
\hline & 666 & $-0,3$ & $-0,3$ & $-0,2$ & 0,2 & 0,2 & 0,2 & $-0,3$ \\
\hline & 833 & $-0,3$ & $-0,4$ & $-0,2$ & 0,3 & 0,4 & 0,2 & $-0,2$ \\
\hline & 999 & $-0,3$ & $-0,4$ & $-0,2$ & 0,4 & 0,0 & 0,3 & $-0,4$ \\
\hline & 1166 & $-0,3$ & $-0,3$ & $-0,2$ & 0,0 & $-0,3$ & 0,3 & $-0,2$ \\
\hline & 1332 & $-0,3$ & $-0,3$ & $-0,6$ & 0,0 & $-0,2$ & 0,3 & 0,0 \\
\hline & 1499 & 0,0 & 0,0 & $-0,2$ & 0,0 & $-0,1$ & 0,3 & 0,1 \\
\hline & 1665 & 0,0 & 0,0 & 0,0 & 0,0 & 0,0 & 0,0 & 0,0 \\
\hline
\end{tabular}

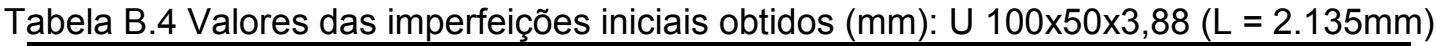

\begin{tabular}{|c|c|c|c|c|c|c|c|c|}
\hline Perfil & \multirow{2}{*}{$\begin{array}{c}\text { Leitura ao } \\
\text { longo da } \\
\text { barra } \\
(\mathrm{mm})\end{array}$} & \multicolumn{7}{|c|}{ Posição na seção transversal - vide Figura B.5 } \\
\hline \multirow{12}{*}{$\begin{array}{c}U 100 \times 50 \times 3,88 \\
L=2.135 \mathrm{~mm}\end{array}$} & & $\begin{array}{c}\mathrm{A} \\
(\mathrm{mm})\end{array}$ & $\begin{array}{c}B \\
(\mathrm{~mm})\end{array}$ & $\underset{(\mathrm{mm})}{\mathrm{C}}$ & $\begin{array}{c}\mathrm{D} \\
(\mathrm{mm})\end{array}$ & $\underset{(\mathrm{mm})}{\mathrm{E}}$ & $\underset{(\mathrm{mm})}{\mathrm{F}}$ & $\begin{array}{c}\mathrm{G} \\
(\mathrm{mm})\end{array}$ \\
\hline & 0 & 0,0 & 0,0 & 0,0 & 0,0 & 0,0 & 0,0 & 0,0 \\
\hline & 214 & 0,1 & 0,5 & $-0,3$ & $-0,4$ & $-0,6$ & $-0,1$ & $-0,2$ \\
\hline & 427 & 0,0 & 0,3 & $-0,6$ & $-0,4$ & $-0,9$ & 0,0 & $-0,4$ \\
\hline & 641 & 0,3 & 1,0 & $-0,4$ & 0,0 & $-0,3$ & 0,4 & 0,1 \\
\hline & 854 & 0,2 & 0,7 & $-0,4$ & 0,0 & $-0,7$ & 0,4 & $-0,2$ \\
\hline & 1068 & 0,4 & 1,2 & $-0,3$ & 0,1 & $-0,1$ & 0,5 & 0,2 \\
\hline & 1281 & 0,5 & 1,5 & $-0,5$ & 0,5 & 0,5 & 0,8 & 0,8 \\
\hline & 1495 & 1,0 & 1,7 & 0,0 & 0,5 & 0,0 & 0,9 & 0,4 \\
\hline & 1708 & 0,8 & 1,4 & 0,1 & 0,4 & 0,0 & 0,7 & 0,4 \\
\hline & 1922 & 0,5 & 0,6 & 0,2 & 0,2 & 0,0 & 0,4 & 0,1 \\
\hline & 2135 & 0,0 & 0,0 & 0,0 & 0,0 & 0,0 & 0,0 & 0,0 \\
\hline
\end{tabular}


Tese de Doutorado - Gustavo Monteiro de Barros Chodraui

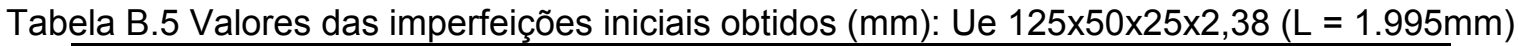

\begin{tabular}{|c|c|c|c|c|c|c|c|c|}
\hline Perfil & \multirow{2}{*}{$\begin{array}{c}\text { Leitura ao } \\
\text { longo da } \\
\text { barra } \\
(\mathrm{mm}) \\
\end{array}$} & \multicolumn{7}{|c|}{ Posição na seção transversal - vide Figura B.6 } \\
\hline \multirow{12}{*}{$\begin{array}{l}\text { Ue } 125 \times 50 \times 25 \times 2,38 \\
L=1.995 \mathrm{~mm}\end{array}$} & & $\underset{(\mathrm{mm})}{\mathrm{A}}$ & $\begin{array}{c}\text { B } \\
(\mathrm{mm})\end{array}$ & $\underset{(\mathrm{mm})}{\mathrm{C}}$ & $\begin{array}{c}\mathrm{D} \\
(\mathrm{mm})\end{array}$ & $\underset{(\mathrm{mm})}{\mathrm{E}}$ & $\begin{array}{c}\mathrm{F} \\
(\mathrm{mm})\end{array}$ & $\begin{array}{c}\mathrm{G} \\
(\mathrm{mm})\end{array}$ \\
\hline & 0 & 0,0 & 0,0 & 0,0 & 0,0 & 0,0 & 0,0 & 0,0 \\
\hline & 200 & $-0,4$ & $-0,2$ & $-0,6$ & 0,3 & 0,3 & 0,3 & 0,4 \\
\hline & 399 & $-0,9$ & $-0,5$ & $-1,4$ & 0,3 & 0,5 & 0,2 & 0,4 \\
\hline & 599 & $-0,8$ & 0,0 & $-1,5$ & 0,4 & 0,5 & 0,4 & 0,6 \\
\hline & 798 & $-0,9$ & 0,0 & $-1,7$ & 0,2 & 0,2 & 0,1 & 0,3 \\
\hline & 998 & $-0,7$ & 0,2 & $-1,6$ & 0,1 & $\overline{0,1}$ & 0,0 & 0,2 \\
\hline & 1197 & $-0,7$ & 0,2 & $-1,6$ & 0,3 & 0,1 & 0,2 & 0,2 \\
\hline & 1397 & $-0,5$ & 0,3 & $-1,5$ & 0,5 & 0,4 & 0,4 & 0,4 \\
\hline & 1596 & 0,0 & 0,6 & $-1,0$ & 0,7 & 0,7 & 0,6 & 0,8 \\
\hline & 1796 & 0,0 & 0,3 & $-0,5$ & 0,5 & 0,6 & 0,2 & 0,6 \\
\hline & 1995 & 0,0 & 0,0 & 0,0 & 0,0 & 0,0 & 0,0 & 0,0 \\
\hline
\end{tabular}

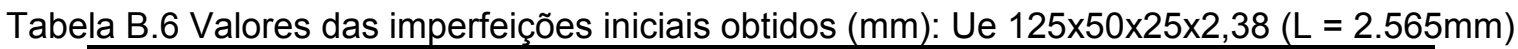

\begin{tabular}{|c|c|c|c|c|c|c|c|c|}
\hline Perfil & \multirow{2}{*}{$\begin{array}{l}\text { Leitura } \\
\text { ao longo } \\
\text { da barra } \\
(\mathrm{mm})\end{array}$} & \multicolumn{7}{|c|}{ Posição na seção transversal - vide Figura B.7 } \\
\hline \multirow{12}{*}{$\begin{array}{c}\text { Ue } 125 \times 50 \times 25 \times 2,38 \\
L=2.565 \mathrm{~mm}\end{array}$} & & $\begin{array}{c}\mathrm{A} \\
(\mathrm{mm})\end{array}$ & $\begin{array}{c}B \\
(\mathrm{~mm})\end{array}$ & $\underset{(\mathrm{mm})}{\mathrm{C}}$ & $\begin{array}{c}\mathrm{D} \\
(\mathrm{mm})\end{array}$ & $\underset{(\mathrm{mm})}{\mathrm{E}}$ & $\begin{array}{c}\mathrm{F} \\
(\mathrm{mm})\end{array}$ & $\begin{array}{c}\mathrm{G} \\
(\mathrm{mm})\end{array}$ \\
\hline & 0 & 0,0 & 0,0 & 0,0 & 0,0 & 0,0 & 0,0 & 0,0 \\
\hline & 257 & 0,4 & 0,1 & $-1,0$ & $-0,2$ & 0,0 & $-0,2$ & 0,1 \\
\hline & 513 & 0,0 & 0,2 & $-1,0$ & $-0,4$ & $-0,6$ & $-0,3$ & $-0,1$ \\
\hline & 770 & $-0,4$ & 0,4 & $-1,5$ & 0,0 & $-0,1$ & 0,0 & $-0,1$ \\
\hline & 1026 & $-0,4$ & 0,5 & $-1,5$ & 0,0 & $-0,2$ & 0,0 & 0,0 \\
\hline & 1283 & 0,0 & 1,2 & $-1,1$ & $-0,1$ & $-0,3$ & 0,2 & 0,1 \\
\hline & 1539 & 0,1 & 1,4 & $-1,0$ & 0,2 & 0,0 & 0,4 & 0,4 \\
\hline & 1796 & 0,1 & 0,9 & $-0,7$ & 0,7 & 0,5 & 0,5 & 0,4 \\
\hline & 2052 & $-0,3$ & 0,3 & $-0,8$ & 0,3 & 0,3 & 0,2 & 0,1 \\
\hline & 2309 & 0,0 & 0,0 & $-0,2$ & 0,0 & 0,0 & 0,0 & 0,0 \\
\hline & 2565 & 0,0 & 0,0 & 0,0 & 0,0 & 0,0 & 0,0 & 0,0 \\
\hline
\end{tabular}

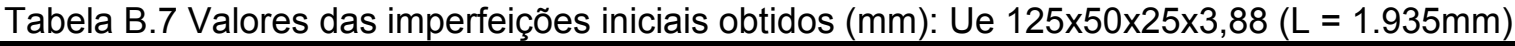

\begin{tabular}{|c|c|c|c|c|c|c|c|c|}
\hline Perfil & $\begin{array}{c}\text { Leitura } \\
\text { ao longo } \\
\text { da barra } \\
(\mathrm{mm})\end{array}$ & $\begin{array}{c}\mathrm{F} \\
(\mathrm{mm})\end{array}$ & $\begin{array}{c}\mathrm{B} \\
(\mathrm{mm})\end{array}$ & $\begin{array}{c}\mathrm{C} \\
(\mathrm{mm})\end{array}$ & $\begin{array}{c}\mathrm{D} \\
(\mathrm{mm})\end{array}$ & $\begin{array}{c}\mathrm{E} \\
(\mathrm{mm})\end{array}$ & $\begin{array}{c}\mathrm{F} \\
(\mathrm{mm})\end{array}$ & $\begin{array}{c}\mathrm{G} \\
(\mathrm{mm})\end{array}$ \\
\hline & 0 & 0,0 & 0,0 & 0,0 & 0,0 & 0,0 & 0,0 & 0,0 \\
\cline { 2 - 9 } & 194 & $-0,6$ & $-0,6$ & $-0,4$ & 0,0 & $-0,3$ & 0,0 & 0,1 \\
\cline { 2 - 9 } & 387 & $-0,9$ & $-0,6$ & $-0,8$ & 0,0 & $-0,5$ & 0,0 & 0,0 \\
\cline { 2 - 9 } & 581 & $-0,8$ & $-0,2$ & $-0,8$ & 0,3 & $-0,2$ & 0,5 & 0,2 \\
\cline { 2 - 9 } & 774 & $-0,8$ & $-0,3$ & $-0,9$ & 0,1 & $-0,4$ & 0,3 & 0,0 \\
\cline { 2 - 9 } & 968 & $-0,8$ & $-0,1$ & $-0,9$ & 0,4 & 0,1 & 0,4 & 0,3 \\
\cline { 2 - 9 } & 1161 & $-0,8$ & 0,0 & $-1,2$ & 0,6 & 0,3 & 0,6 & 0,6 \\
\cline { 2 - 9 } & 1355 & $-0,5$ & 0,0 & $-0,5$ & 0,6 & 0,2 & 0,6 & 0,4 \\
\cline { 2 - 9 } & 1548 & $-0,3$ & 0,3 & $-0,3$ & 0,7 & 0,3 & 0,7 & 0,5 \\
\cline { 2 - 9 } & 1742 & 0,0 & 0,4 & 0,1 & 0,5 & 0,3 & 0,4 & 0,3 \\
\cline { 2 - 9 } & 1935 & 0,0 & 0,0 & 0,0 & 0,0 & 0,0 & 0,0 & 0,0 \\
\hline
\end{tabular}




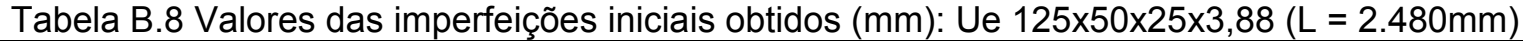

\begin{tabular}{|c|c|c|c|c|c|c|c|c|}
\hline Perfil & \multirow{2}{*}{$\begin{array}{l}\text { Leitura } \\
\text { ao longo } \\
\text { da barra } \\
(\mathrm{mm})\end{array}$} & \multicolumn{7}{|c|}{ Posição na seção transversal - vide Figura B.9 } \\
\hline \multirow{12}{*}{$\begin{array}{l}\text { Ue } 125 \times 50 \times 25 \times 3,88 \\
L=2.480 \mathrm{~mm}\end{array}$} & & $\underset{(\mathrm{mm})}{\mathrm{A}}$ & $\begin{array}{c}\mathrm{B} \\
(\mathrm{mm})\end{array}$ & $\underset{(\mathrm{mm})}{\mathrm{C}}$ & $\underset{(\mathrm{mm})}{\mathrm{D}}$ & $\underset{(\mathrm{mm})}{\mathrm{E}}$ & $\begin{array}{c}\mathrm{F} \\
(\mathrm{mm})\end{array}$ & $\begin{array}{c}\mathrm{G} \\
(\mathrm{mm})\end{array}$ \\
\hline & 0 & 0,0 & 0,0 & 0,0 & 0,0 & 0,0 & 0,0 & 0,0 \\
\hline & 248 & 0,0 & 0,7 & $-0,5$ & $-0,3$ & 0,1 & $-0,2$ & 0,1 \\
\hline & 496 & $-0,3$ & 0,7 & $-1,2$ & 0,0 & 0,1 & $-0,1$ & 0,0 \\
\hline & 744 & 0,0 & 1,2 & $-1,1$ & 0,2 & 0,3 & 0,4 & 0,6 \\
\hline & 992 & $-0,2$ & 0,9 & $-1,2$ & 0,5 & 0,3 & 0,4 & 0,4 \\
\hline & 1240 & 0,1 & 1,2 & $-0,9$ & 1,0 & 1,2 & 0,8 & 1,2 \\
\hline & 1488 & 0,1 & 1,2 & $-1,0$ & 1,3 & 1,4 & 1,0 & 1,6 \\
\hline & 1736 & 0,7 & 1,5 & 0,0 & 1,2 & 1,2 & 1,2 & 1,6 \\
\hline & 1984 & 0,2 & 0,6 & 0,0 & 0,8 & 0,7 & 0,6 & 1,1 \\
\hline & 2232 & 0,2 & 0,2 & 0,2 & 0,3 & 0,2 & 0,1 & 0,6 \\
\hline & 2480 & 0,0 & 0,0 & 0,0 & 0,0 & 0,0 & 0,2 & 0,0 \\
\hline
\end{tabular}

Tabela B.9 Valores das imperfeições iniciais obtidos (mm): $L$ 60x2,38 $(L=1.195 \mathrm{~mm})$

\begin{tabular}{|c|c|c|c|c|c|}
\hline Perfil & \multirow{2}{*}{$\begin{array}{c}\text { Leitura } \\
\text { ao longo } \\
\text { da barra } \\
(\mathrm{mm})\end{array}$} & \multicolumn{5}{|c|}{ Posição na seção transversal - vide Figura } \\
\cline { 2 - 6 } & $\begin{array}{c}\mathrm{A} .10 \\
(\mathrm{~mm})\end{array}$ & $\begin{array}{c}\text { B } \\
(\mathrm{mm})\end{array}$ & $\begin{array}{c}\mathrm{C} \\
(\mathrm{mm})\end{array}$ & $\begin{array}{c}\mathrm{D} \\
(\mathrm{mm})\end{array}$ \\
\cline { 2 - 6 } & 0 & 0,0 & 0,0 & 0,0 & 0,0 \\
\cline { 2 - 6 } & 120 & 0,1 & 0,2 & $-0,4$ & $-1,1$ \\
\cline { 2 - 6 } & 239 & 0,0 & 0,1 & $-0,4$ & $-1,4$ \\
\cline { 2 - 6 } $\mathrm{L} 60 \times 2,38$ & 359 & $-0,1$ & 0,2 & $-0,4$ & $-0,9$ \\
\cline { 2 - 6 } & 478 & 0,0 & 0,3 & $-0,1$ & 0,0 \\
\cline { 2 - 6 } & 598 & $-0,1$ & 0,0 & 0,1 & 0,3 \\
\cline { 2 - 6 } & 717 & $-0,1$ & $-0,3$ & 0,1 & 0,8 \\
\cline { 2 - 6 } & 837 & $-0,2$ & $-0,6$ & 0,1 & 0,9 \\
\cline { 2 - 6 } & 956 & $-0,5$ & $-1,2$ & 0,0 & 0,5 \\
\cline { 2 - 6 } & 1076 & $-0,3$ & $-0,9$ & 0,1 & 0,7 \\
\cline { 2 - 6 } & 1195 & 0,0 & 0,0 & 0,0 & 0,0 \\
\hline
\end{tabular}

Tabela B.10 Valores das imperfeições iniciais obtidos (mm): $L$ 60x2,38 $(L=1.550 \mathrm{~mm})$

\begin{tabular}{|c|c|c|c|c|c|}
\hline Perfil & \multirow{2}{*}{$\begin{array}{c}\text { Leitura } \\
\text { ao longo } \\
\text { da barra } \\
(\mathrm{mm})\end{array}$} & \multicolumn{4}{|c|}{$\begin{array}{c}\text { Posição na seção transversal - vide Figura } \\
\text { B. } 11\end{array}$} \\
\hline \multirow{12}{*}{$\begin{array}{l}L=60 \times 2,38 \\
L=1.550 \mathrm{~mm}\end{array}$} & & $\begin{array}{c}\mathrm{A} \\
(\mathrm{mm})\end{array}$ & $\begin{array}{c}\mathrm{B} \\
(\mathrm{mm})\end{array}$ & $\begin{array}{c}\mathrm{C} \\
(\mathrm{mm}) \\
\end{array}$ & $\begin{array}{c}\mathrm{D} \\
(\mathrm{mm})\end{array}$ \\
\hline & 0 & 0,0 & 0,0 & 0,0 & 0,0 \\
\hline & 155 & $-0,2$ & $-0,7$ & $-0,2$ & $-0,6$ \\
\hline & 310 & $-0,5$ & $-0,9$ & 0,1 & 1,2 \\
\hline & 465 & $-0,6$ & 0,1 & $-0,2$ & 0,9 \\
\hline & 620 & $-0,7$ & 0,5 & 0,0 & 1,4 \\
\hline & 775 & $-0,5$ & 0,6 & 0,0 & 1,9 \\
\hline & 930 & $-0,7$ & 0,2 & 0,1 & 2,0 \\
\hline & 1085 & $-0,7$ & 0,0 & 0,0 & 1,7 \\
\hline & 1240 & $-0,6$ & 0,2 & $-0,2$ & 0,5 \\
\hline & 1395 & $-0,6$ & $-1,5$ & $-0,1$ & 0,2 \\
\hline & 1550 & 0,0 & 0,0 & 0,0 & 0,0 \\
\hline
\end{tabular}


Tabela B.11 Valores das imperfeições iniciais obtidos $(\mathrm{mm}): \mathrm{L} 60 \times 2,38(\mathrm{~L}=2.630 \mathrm{~mm})$

\begin{tabular}{|c|c|c|c|c|c|}
\hline Perfil & $\begin{array}{c}\text { Leitura } \\
\text { ao longo } \\
\text { da barra } \\
(\mathrm{mm})\end{array}$ & \multicolumn{4}{|c|}{ Posição na seção transversal - vide Figura B.12 } \\
\cline { 2 - 6 } & $\begin{array}{c}\mathrm{A} \\
\mathrm{mm})\end{array}$ & $\begin{array}{c}\mathrm{B} \\
(\mathrm{mm})\end{array}$ & $\begin{array}{c}\mathrm{C} \\
(\mathrm{mm})\end{array}$ & $\begin{array}{c}\mathrm{D} \\
(\mathrm{mm})\end{array}$ \\
\cline { 2 - 6 } & 0 & 0,0 & 0,0 & 0,0 & 0,0 \\
\cline { 2 - 6 } & 263 & 0,5 & 0,4 & 0,0 & 1,2 \\
\cline { 2 - 6 } $\mathrm{L} 60 \times 2,38$ & 526 & 0,8 & 1,5 & 0,1 & 1,1 \\
\cline { 2 - 6 } & 789 & 1,0 & 2,5 & 0,5 & 2,3 \\
\cline { 2 - 6 } & 1052 & 1,0 & 1,4 & 0,2 & 0,7 \\
\cline { 2 - 6 } & 1315 & 0,7 & $-0,7$ & 0,0 & $-0,5$ \\
\cline { 2 - 6 } & 1578 & 1,2 & 0,7 & 0,7 & 1,9 \\
\cline { 2 - 6 } & 1841 & 1,6 & 2,5 & 1,1 & 3,0 \\
\cline { 2 - 6 } & 2104 & 0,7 & 1,1 & 0,0 & 1,2 \\
\cline { 2 - 6 } & 2367 & 0,2 & $-0,2$ & $-0,4$ & $-0,2$ \\
\cline { 2 - 6 } & 2630 & 0,0 & 0,0 & 0,0 & 0,0 \\
\hline
\end{tabular}

Tabela B.12 Valores das imperfeições iniciais obtidos (mm): $L$ 60x2,38 $(L=2.925 \mathrm{~mm})$

\begin{tabular}{|c|c|c|c|c|c|}
\hline Perfil & $\begin{array}{c}\text { Leitura } \\
\text { ao longo } \\
\text { da barra } \\
(\mathrm{mm})\end{array}$ & \multicolumn{4}{|c|}{ Posição na seção transversal - vide Figura B.13 } \\
\cline { 2 - 6 } & $\begin{array}{c}\mathrm{A} \\
\mathrm{mm})\end{array}$ & $\begin{array}{c}\mathrm{B} \\
(\mathrm{mm})\end{array}$ & $\begin{array}{c}\mathrm{C} \\
(\mathrm{mm})\end{array}$ & $\begin{array}{c}\mathrm{D} \\
(\mathrm{mm})\end{array}$ \\
\cline { 2 - 6 } & 0 & 0,0 & 0,0 & 0,0 & 0,0 \\
\cline { 2 - 6 } & 293 & 0,4 & 0,7 & 0,0 & $-0,7$ \\
\cline { 2 - 6 } $\mathrm{L} 60 \times 2,38$ & 585 & 0,4 & 1,0 & 0,4 & 1,3 \\
\cline { 2 - 6 } $\mathrm{L}=2.925 \mathrm{~mm}$ & 878 & 0,1 & 0,3 & 0,6 & 1,7 \\
\cline { 2 - 6 } & 1170 & 0,9 & 3,4 & 0,5 & 0,8 \\
\cline { 2 - 6 } & 1463 & 0,9 & 2,3 & 0,9 & 1,3 \\
\cline { 2 - 6 } & 1755 & 1,0 & 1,9 & 1,4 & 2,9 \\
\cline { 2 - 6 } & 2048 & 0,5 & 2,2 & 0,6 & 0,1 \\
\cline { 2 - 6 } & 2340 & 0,0 & 1,2 & 0,1 & $-0,4$ \\
\cline { 2 - 6 } & 2633 & $-0,3$ & $-0,9$ & 0,0 & 0,0 \\
\cline { 2 - 6 } & 2925 & 0,0 & 0,0 & 0,0 & 0,0 \\
\hline
\end{tabular}

Os gráficos a seguir ilustram as tabelas apresentadas. 


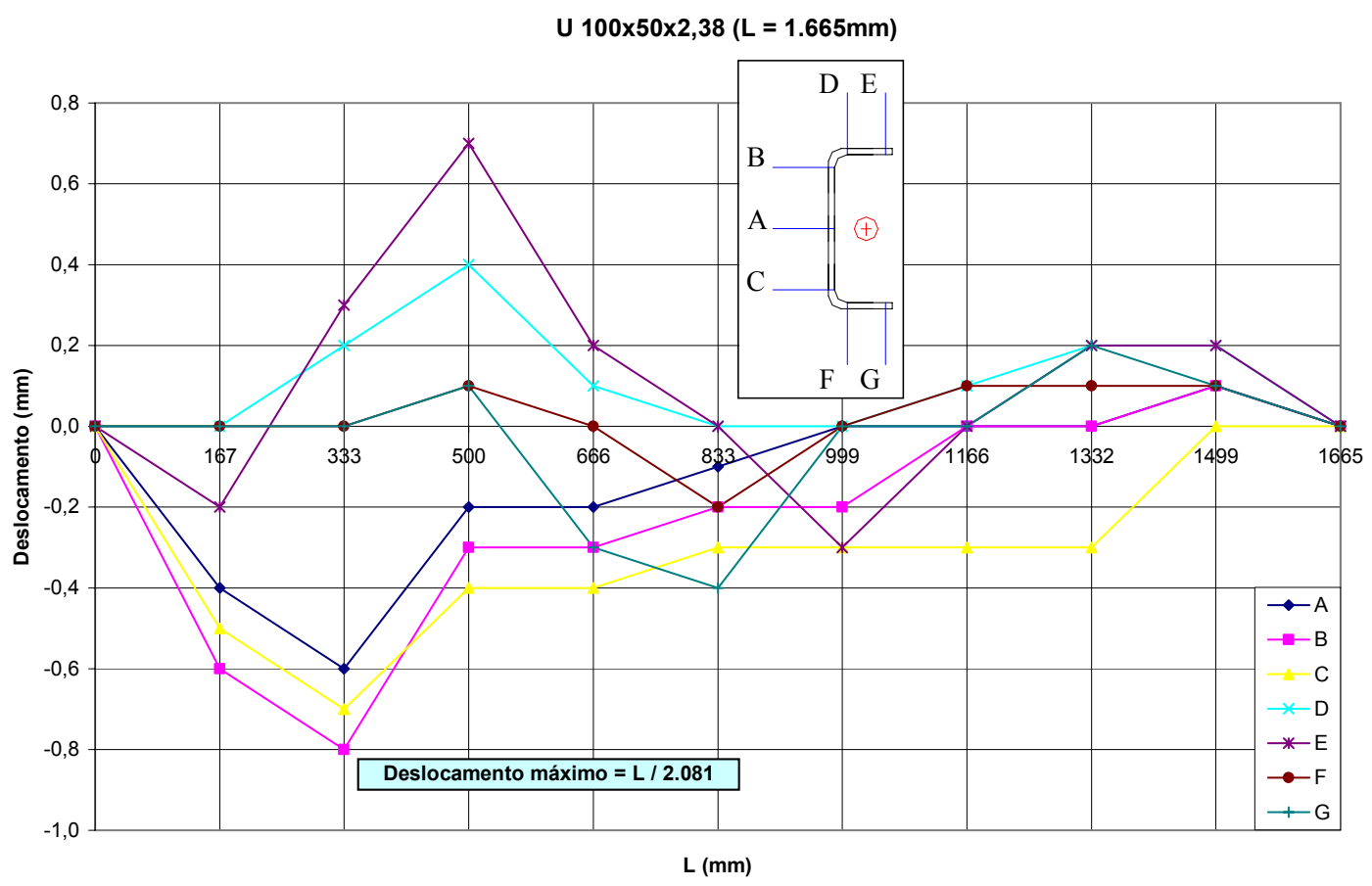

Figura B.2 Imperfeição inicial geométrica - perfil U 100x50×2,38mm $(L=1.665 \mathrm{~mm})$

U $100 \times 50 \times 2,38(L=2.135 \mathrm{~mm})$

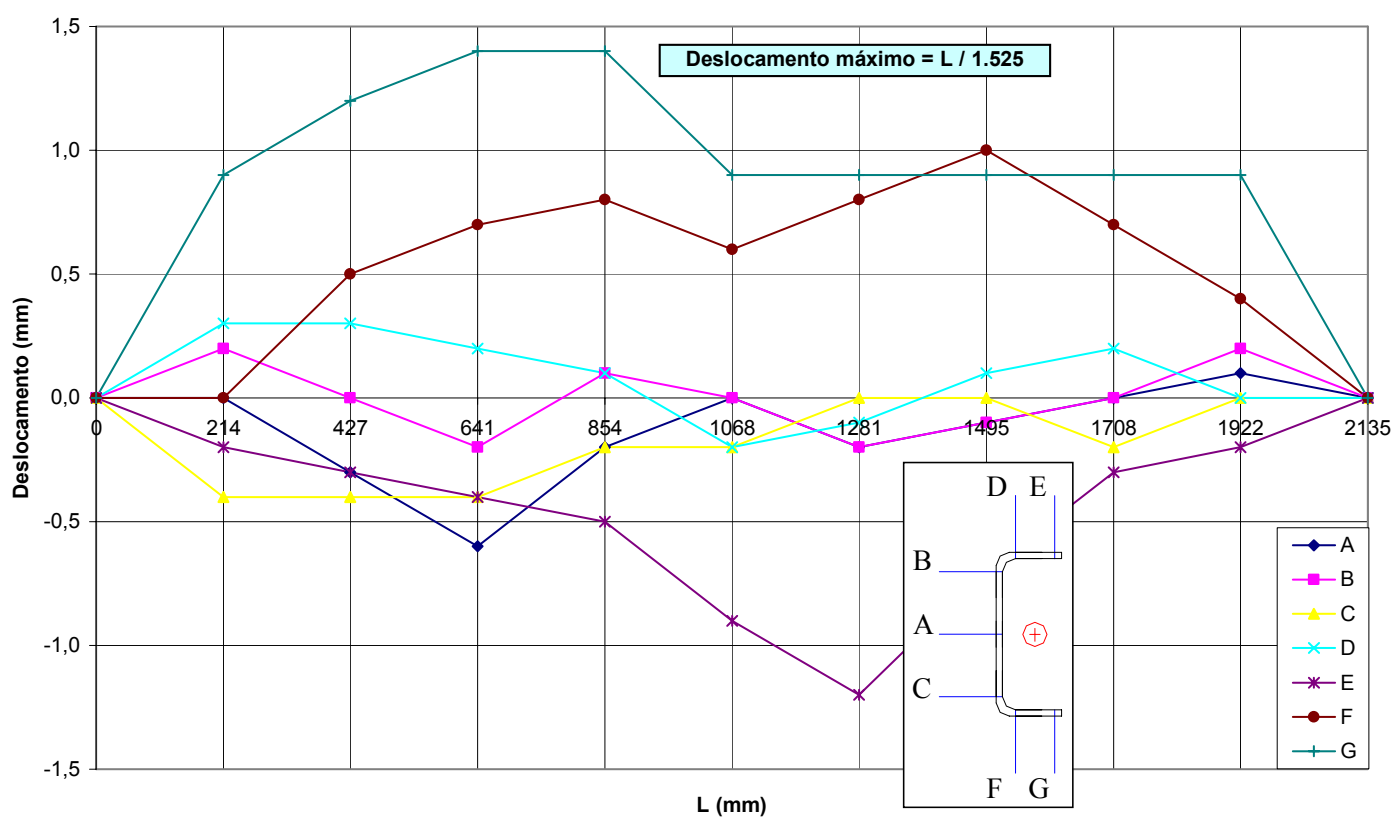

Figura B.3 Imperfeição inicial geométrica - perfil U 100x50x2,38mm ( $L=2.135 \mathrm{~mm})$ 


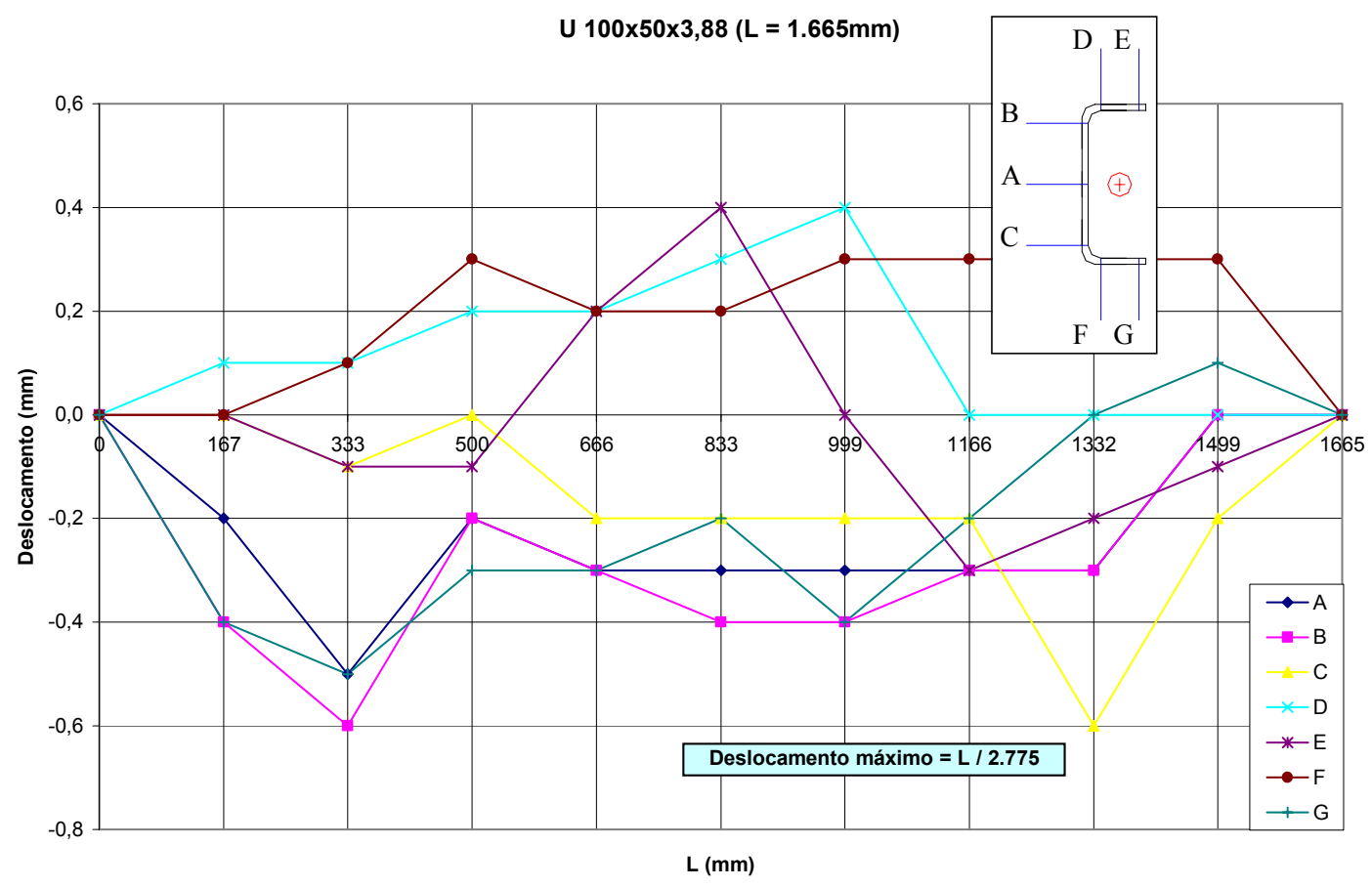

Figura B.4 Imperfeição inicial geométrica - perfil U 100x50×3,88mm $(L=1.665 \mathrm{~mm})$

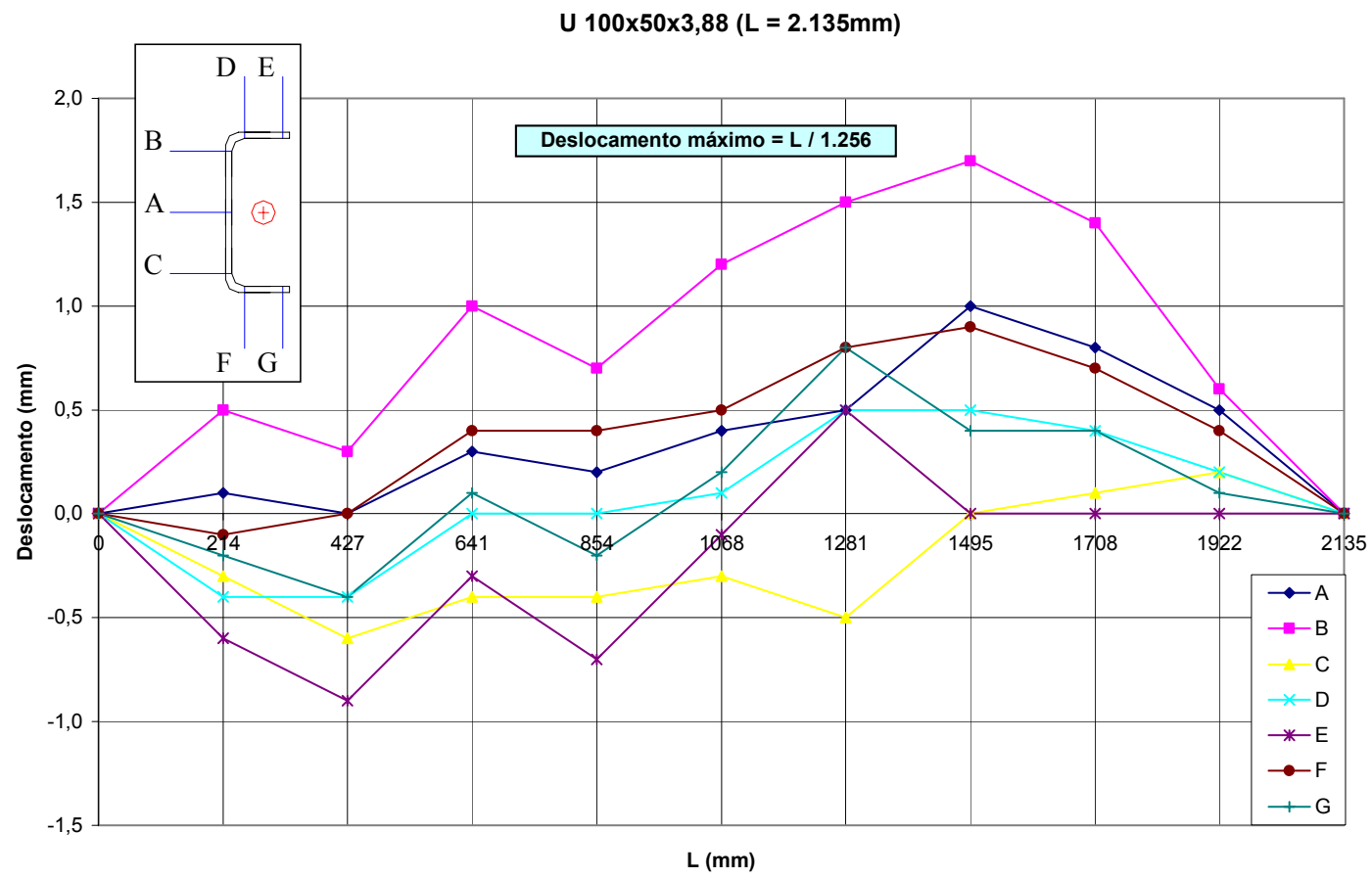

Figura B.5 Imperfeição inicial geométrica - perfil U 100×50×3,88mm $(L=2.135 \mathrm{~mm})$ 
Ue $125 \times 50 \times 25 \times 2,38(L=1.995 \mathrm{~mm})$

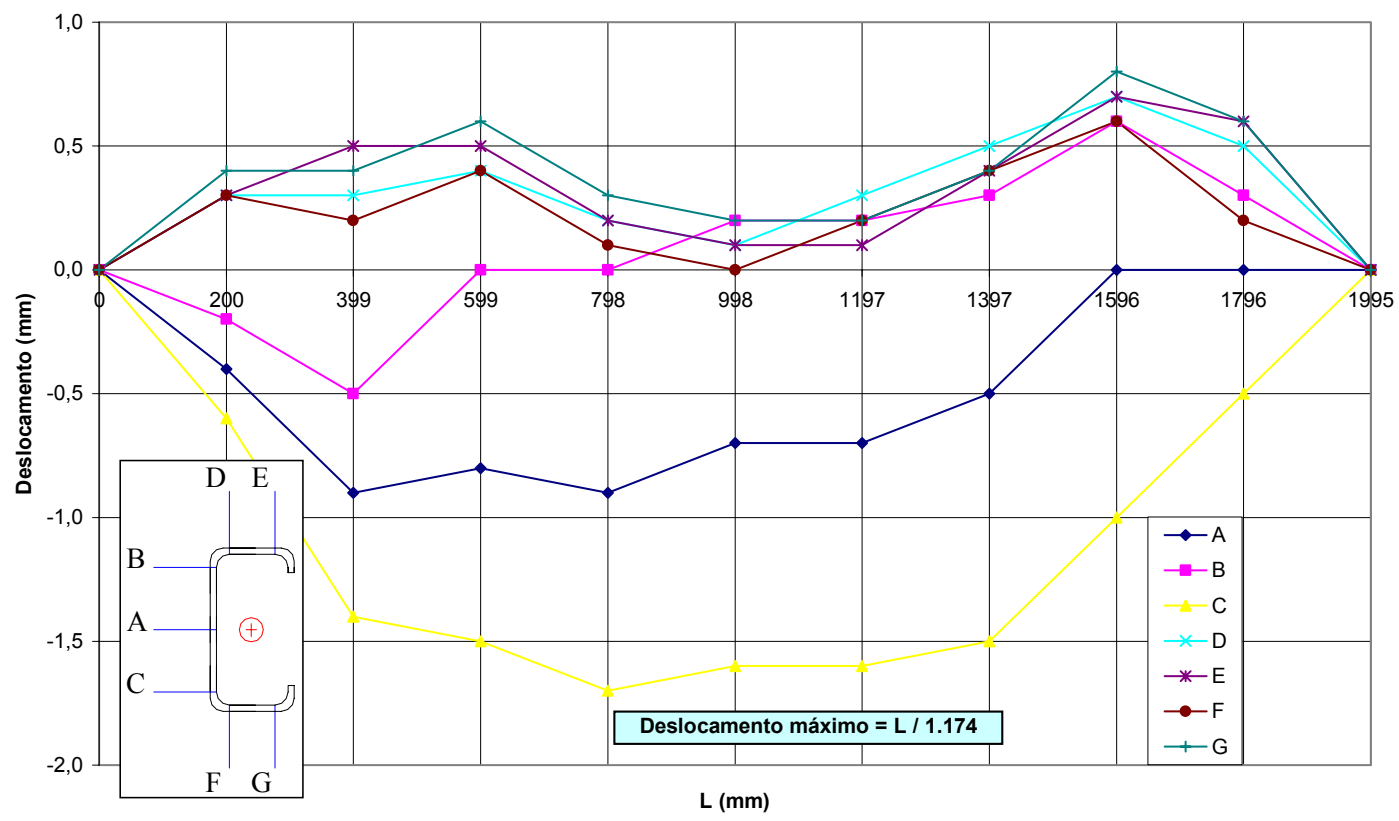

Figura B.6 Imperfeição inicial geométrica - perfil Ue 125×50×25x2,38mm ( $\mathrm{L}=1.995 \mathrm{~mm})$

Ue $125 \times 50 \times 25 \times 2,38(L=2.565 \mathrm{~mm})$

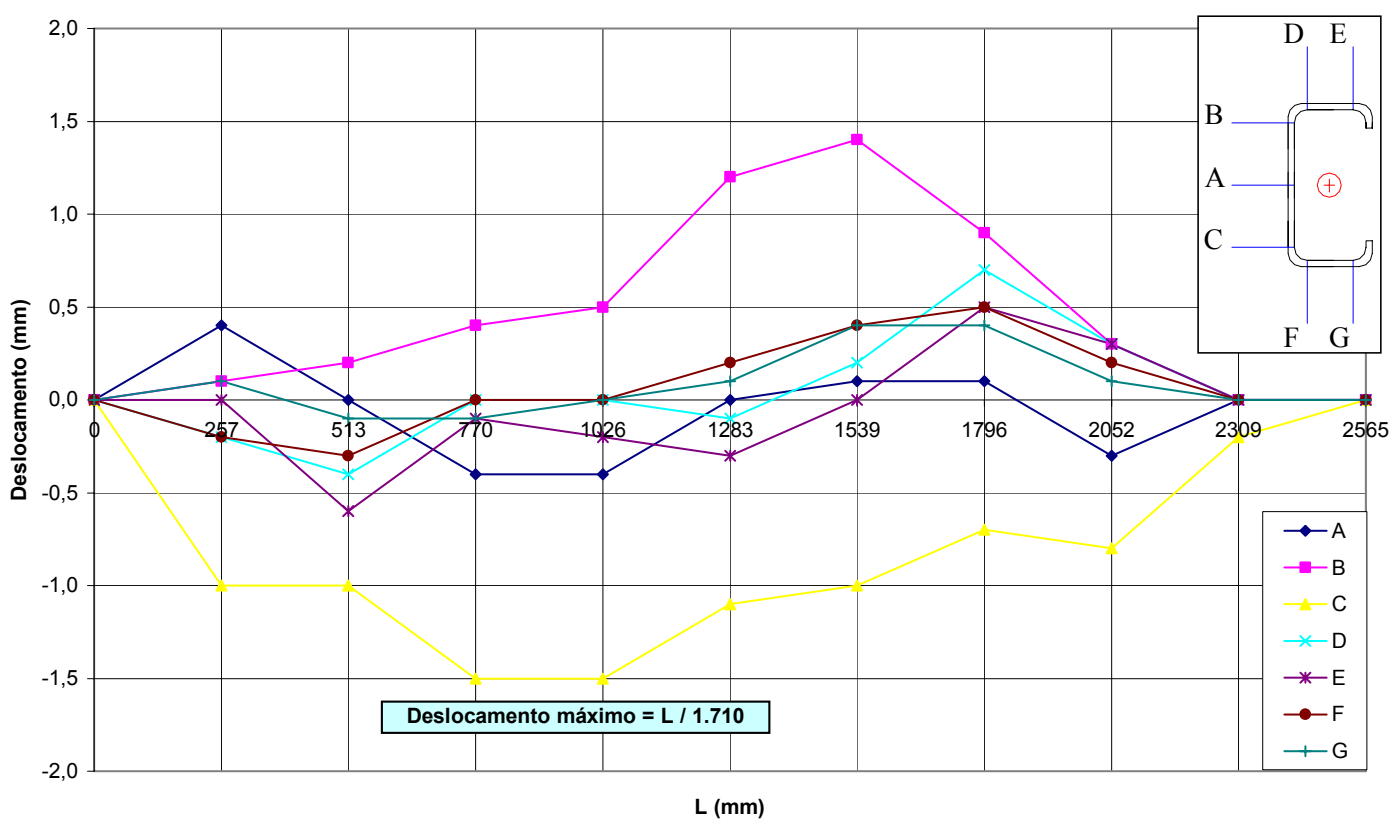

Figura B.7 Imperfeição inicial geométrica - perfil Ue 125x50×25x2,38mm ( $L=2.565 \mathrm{~mm})$ 


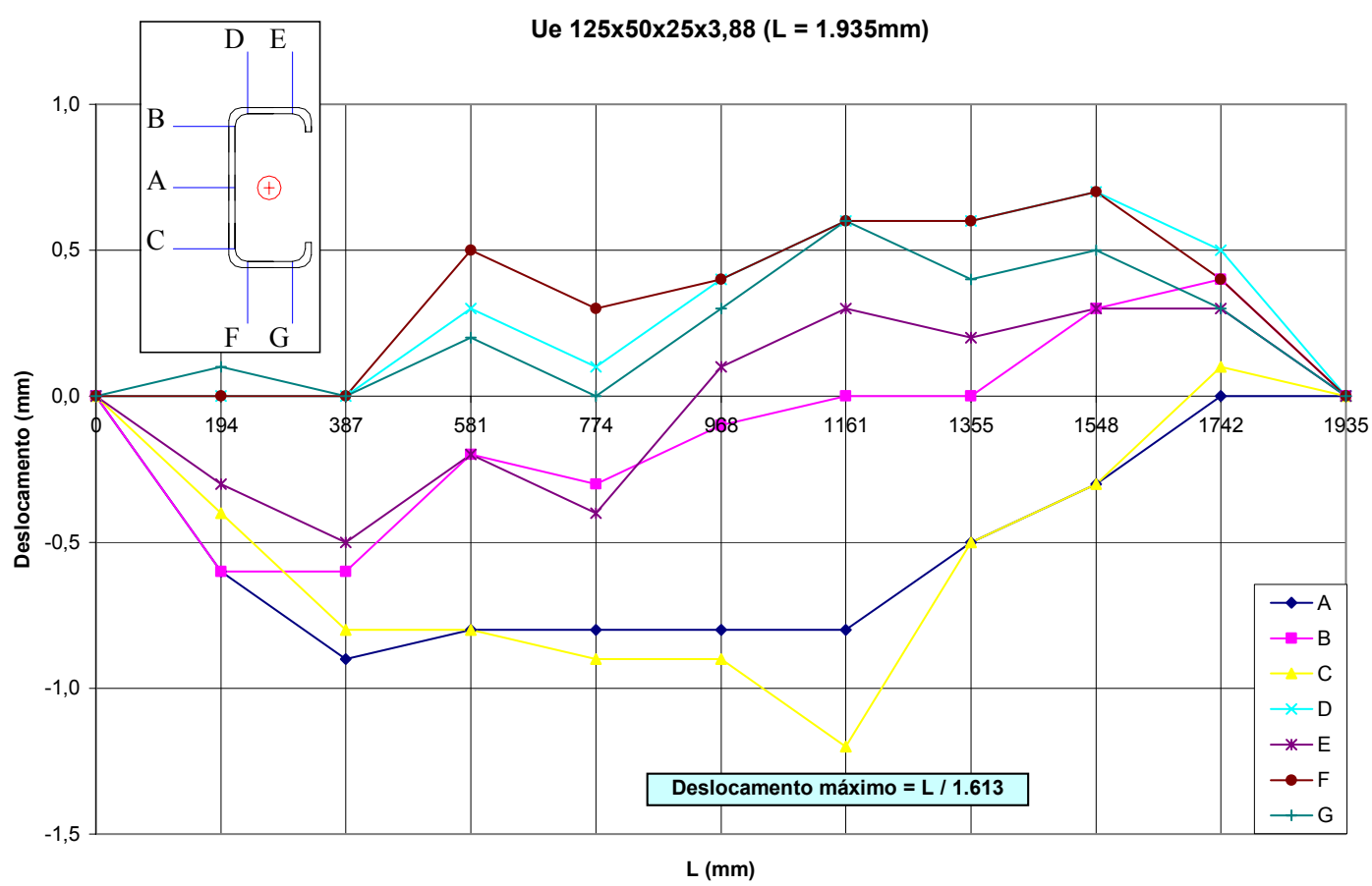

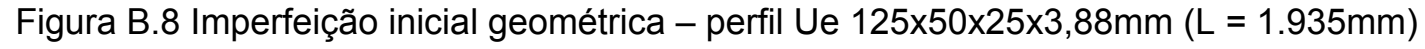

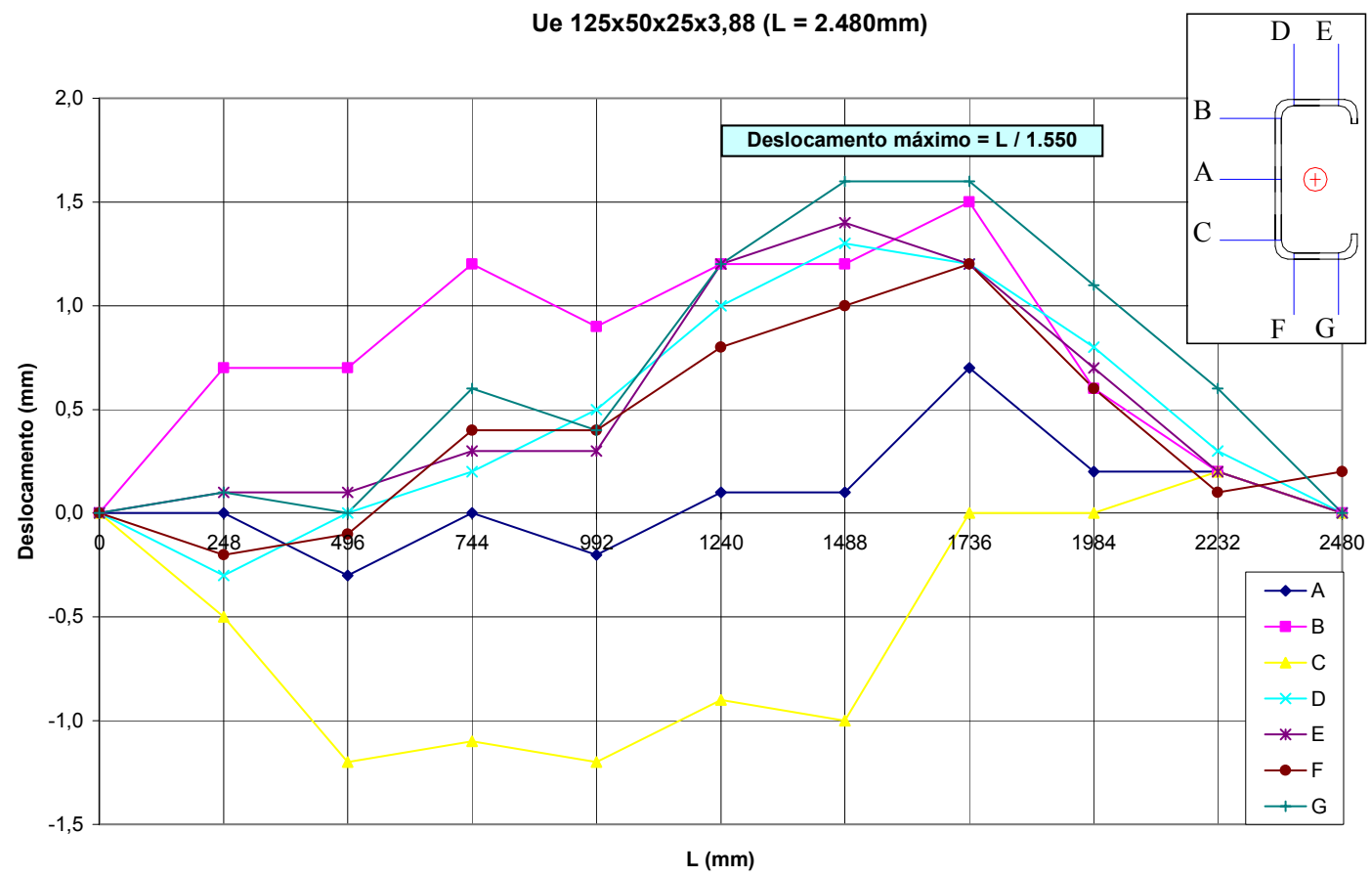

Figura B.9 Imperfeição inicial geométrica - perfil Ue 125x50×25×3,88mm ( $L=2.480 \mathrm{~mm})$ 
$L$ 60x2,38 $(L=1.195 \mathrm{~mm})$

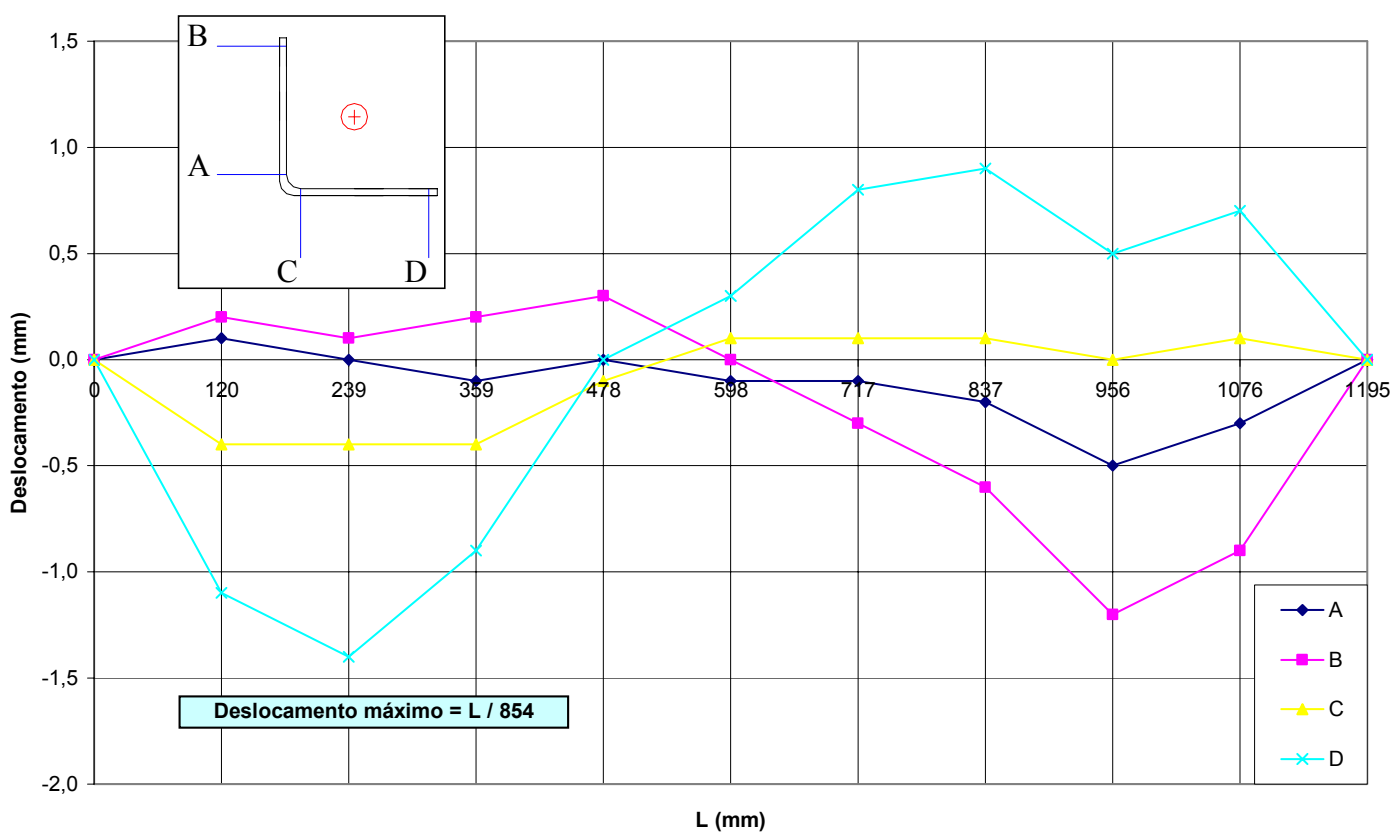

Figura B.10 Imperfeição inicial geométrica - perfil L 60x2,38mm $(L=1.195 \mathrm{~mm})$

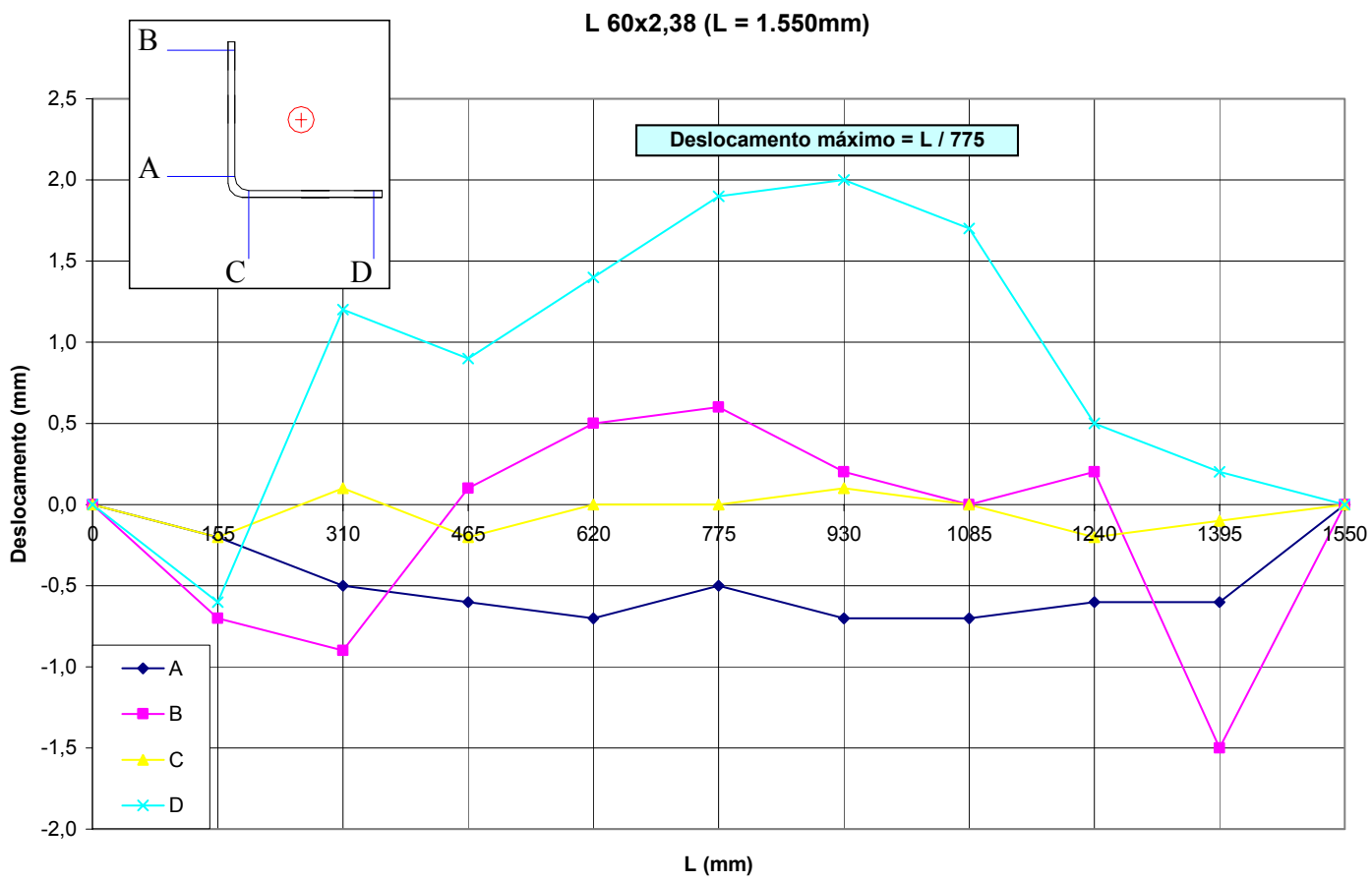

Figura B.11 Imperfeição inicial geométrica - perfil $L$ 60x2,38mm $(L=1.550 \mathrm{~mm})$ 
$L$ 60x2,38 $(\mathrm{L}=2.630 \mathrm{~mm})$

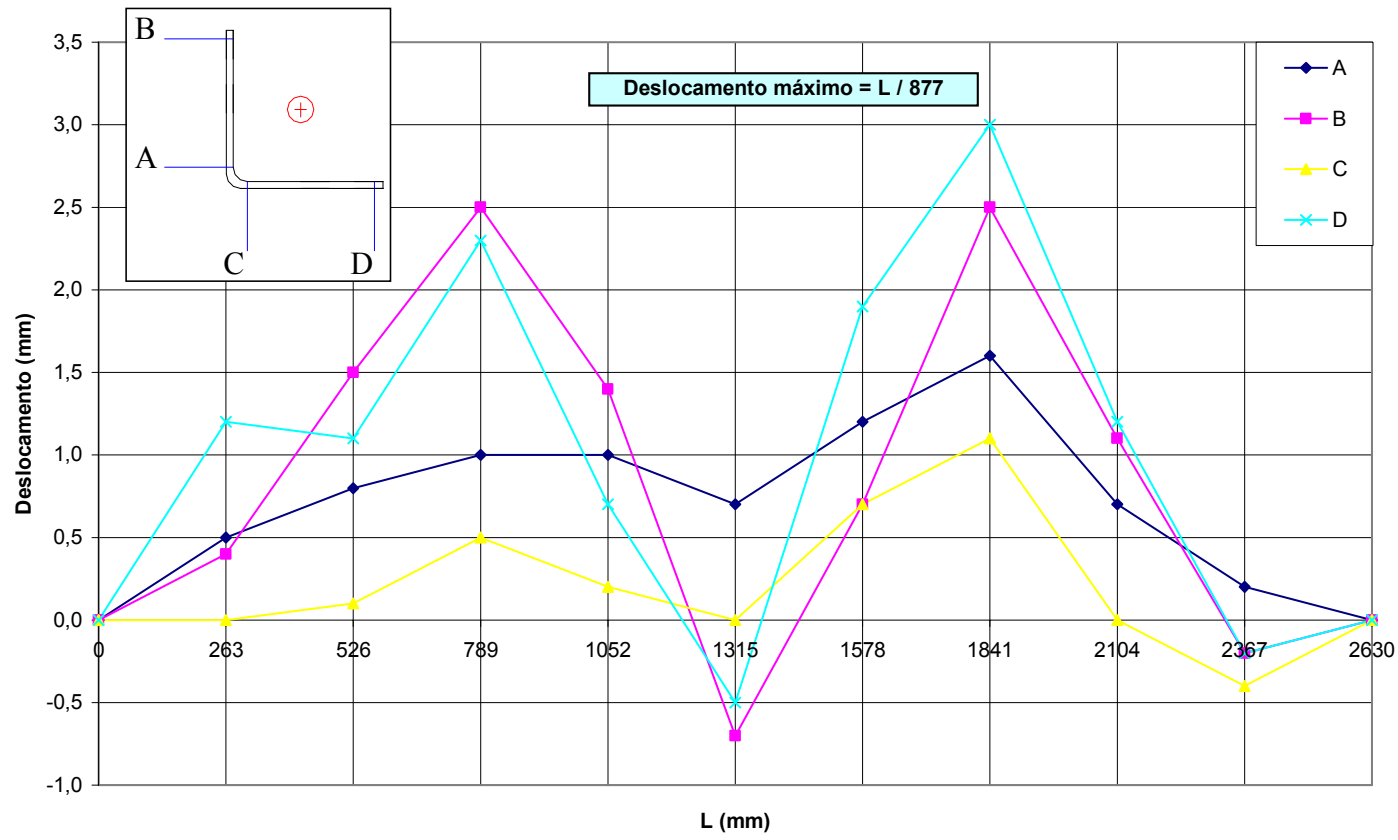

Figura B.12 Imperfeição inicial geométrica - perfil $L$ 60x2,38mm $(L=2.630 \mathrm{~mm})$

$L 60 \times 2,38(L=2.925 \mathrm{~mm})$

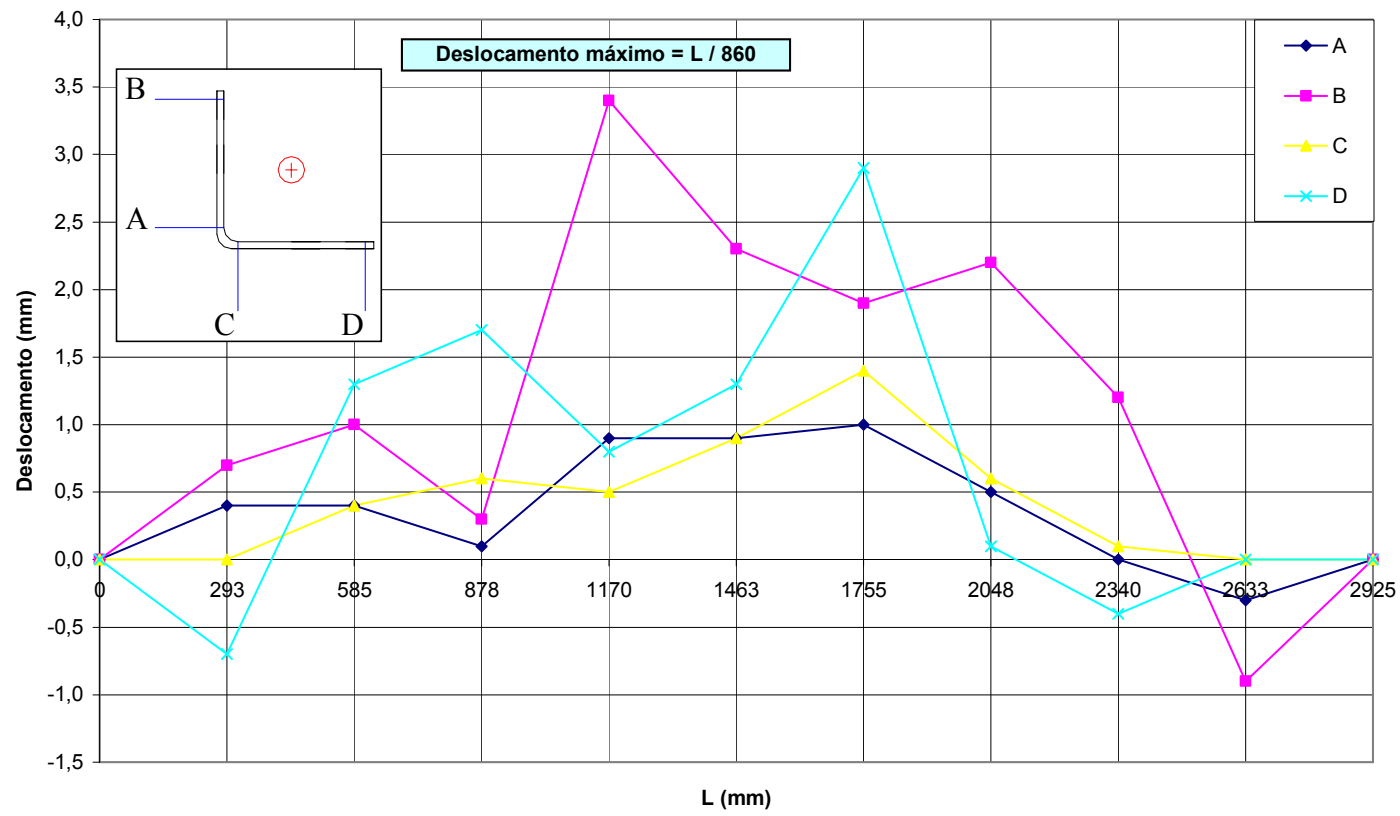

Figura B.13 Imperfeição inicial geométrica - perfil $L$ 60x2,38mm $(L=2.925 \mathrm{~mm})$ 
Tese de Doutorado - Gustavo Monteiro de Barros Chodraui 


\section{APÊNDICE C - ENSAIOS DAS BARRAS CURTAS (STUB COLUMNS)}
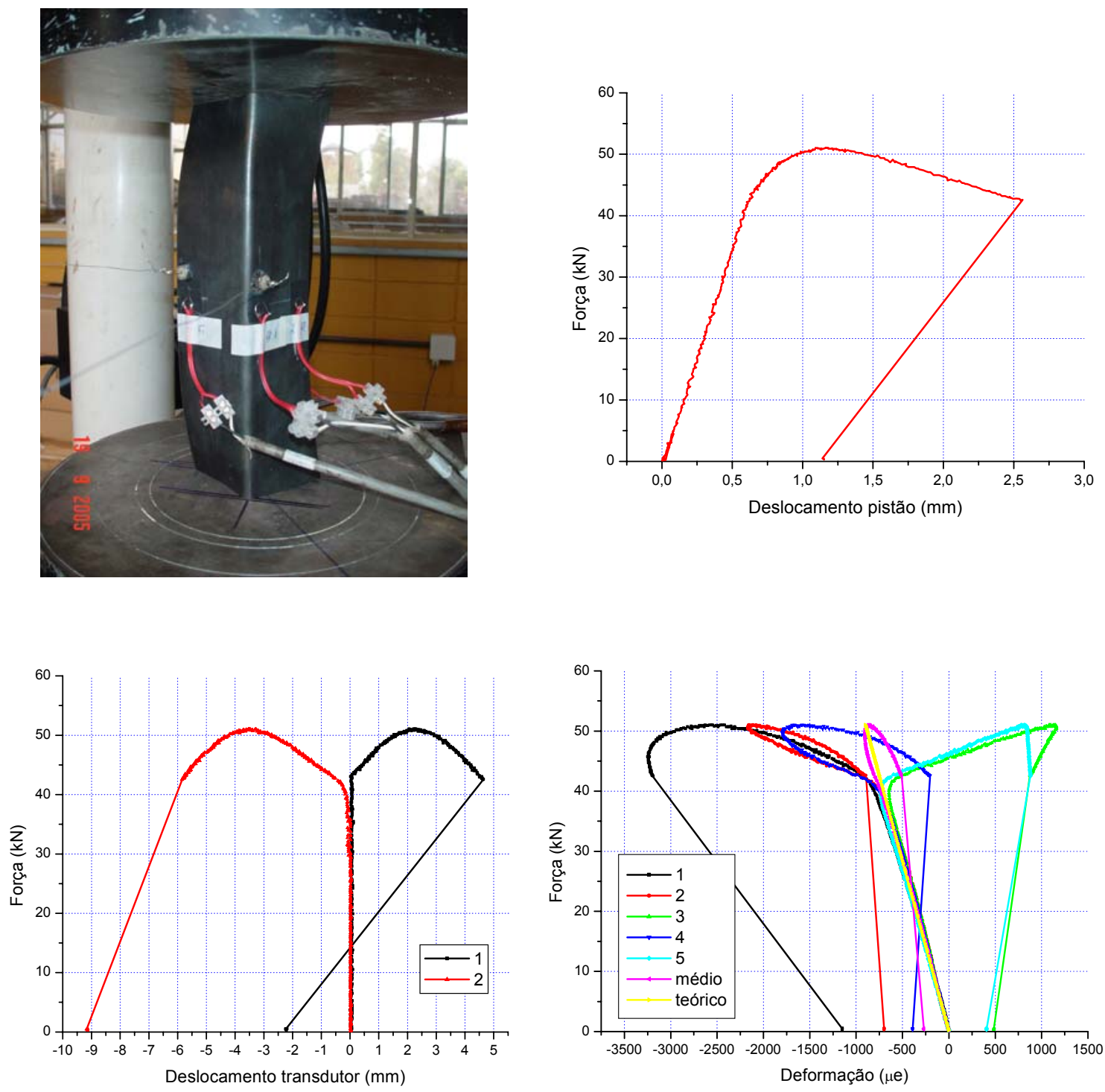

Figura C.1 "Stub column": L2.C 

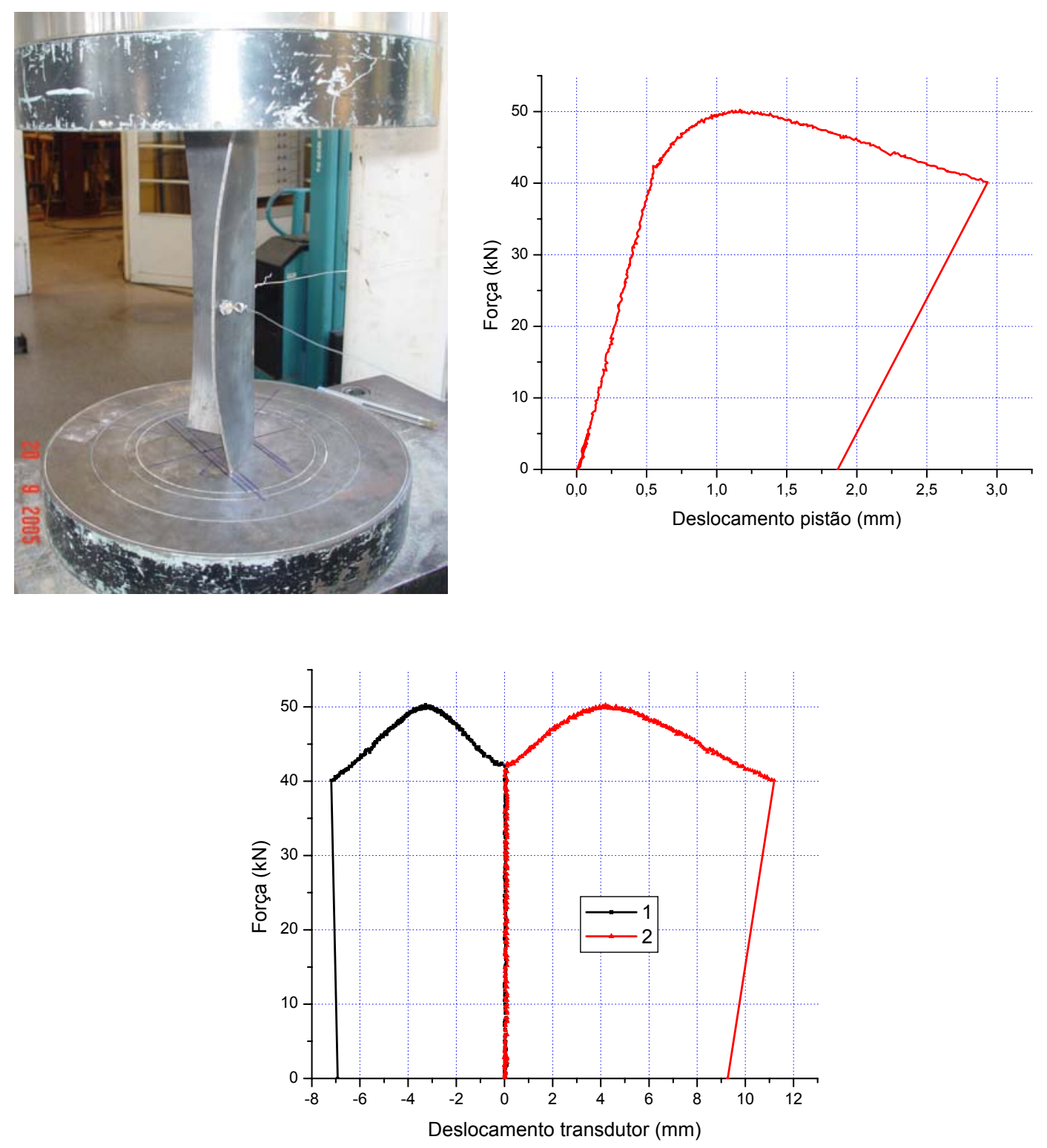

Figura C.2 "Stub column": L2.c2 

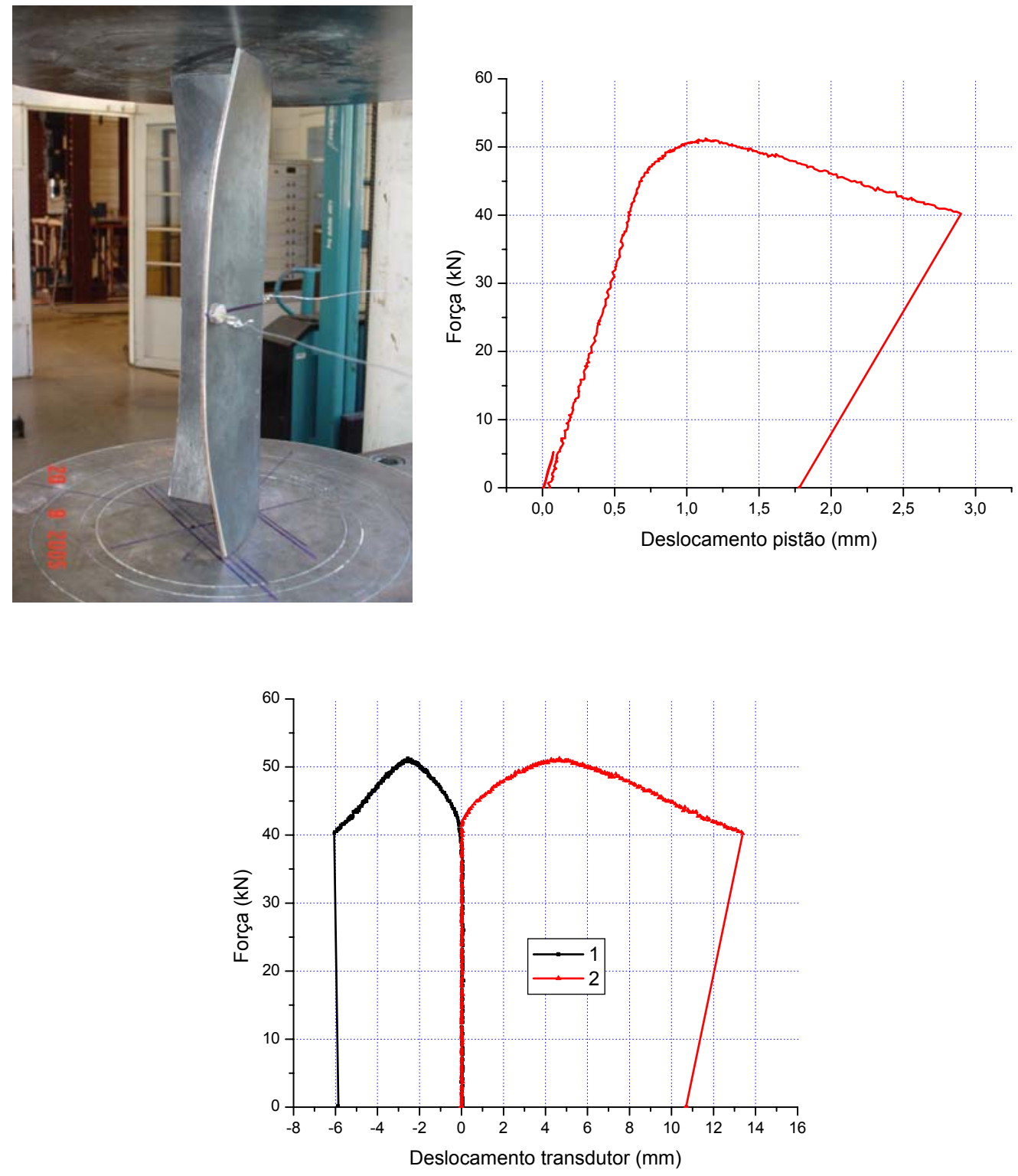

Figura C.3 "Stub column": L2.c3 

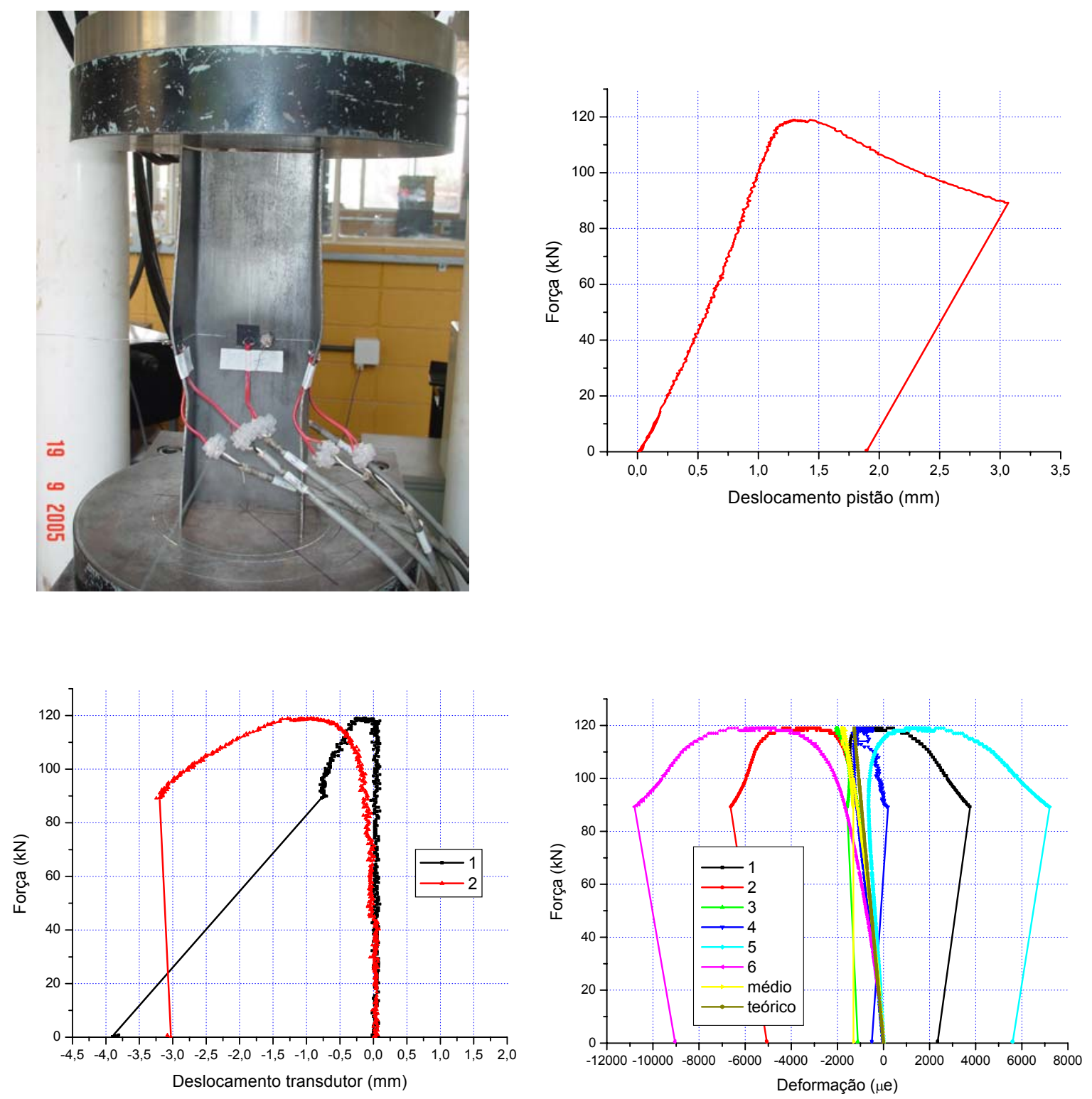

Figura C.4 "Stub column": U2.c 

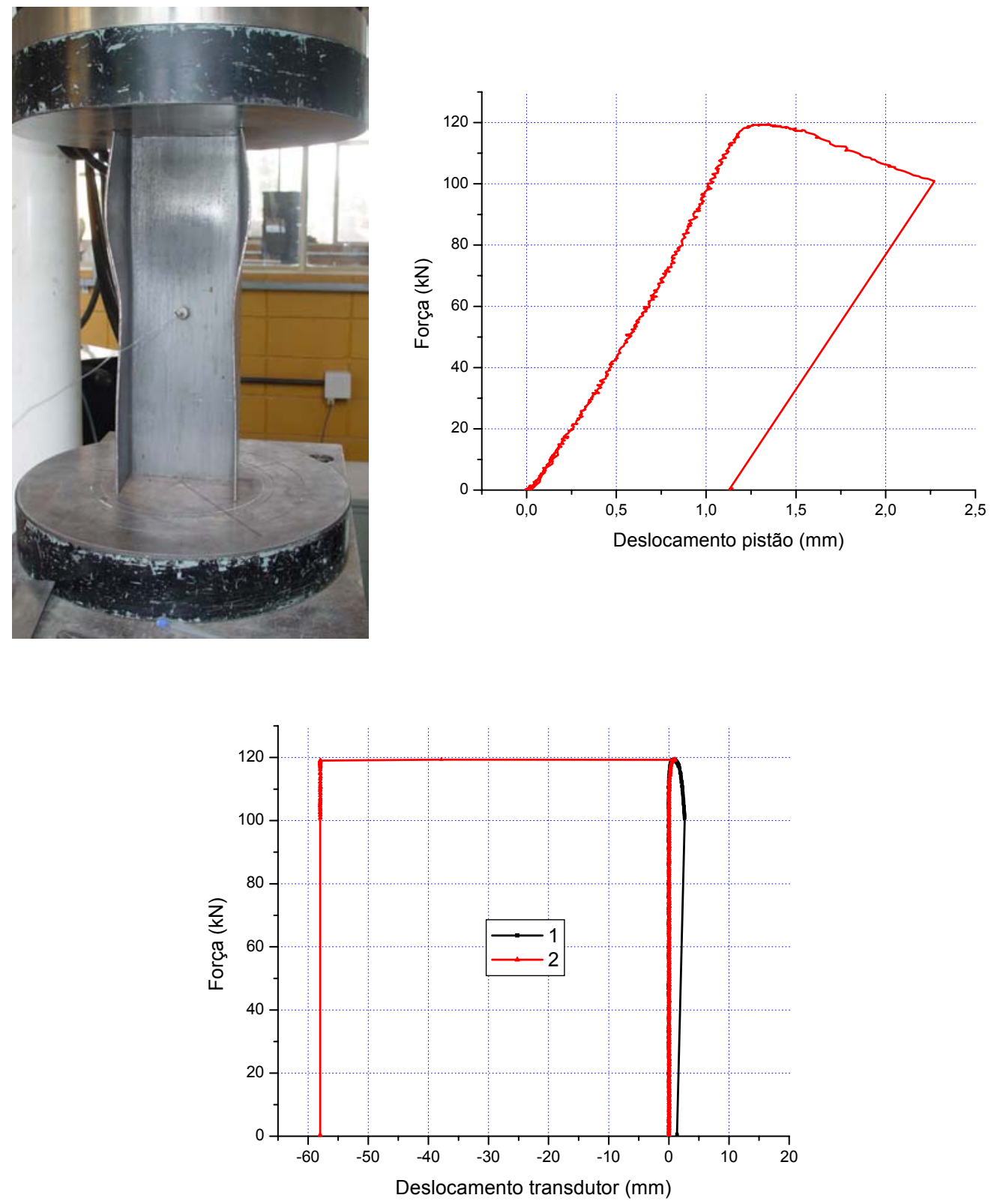

Figura C.5 "Stub column": U2.c2 

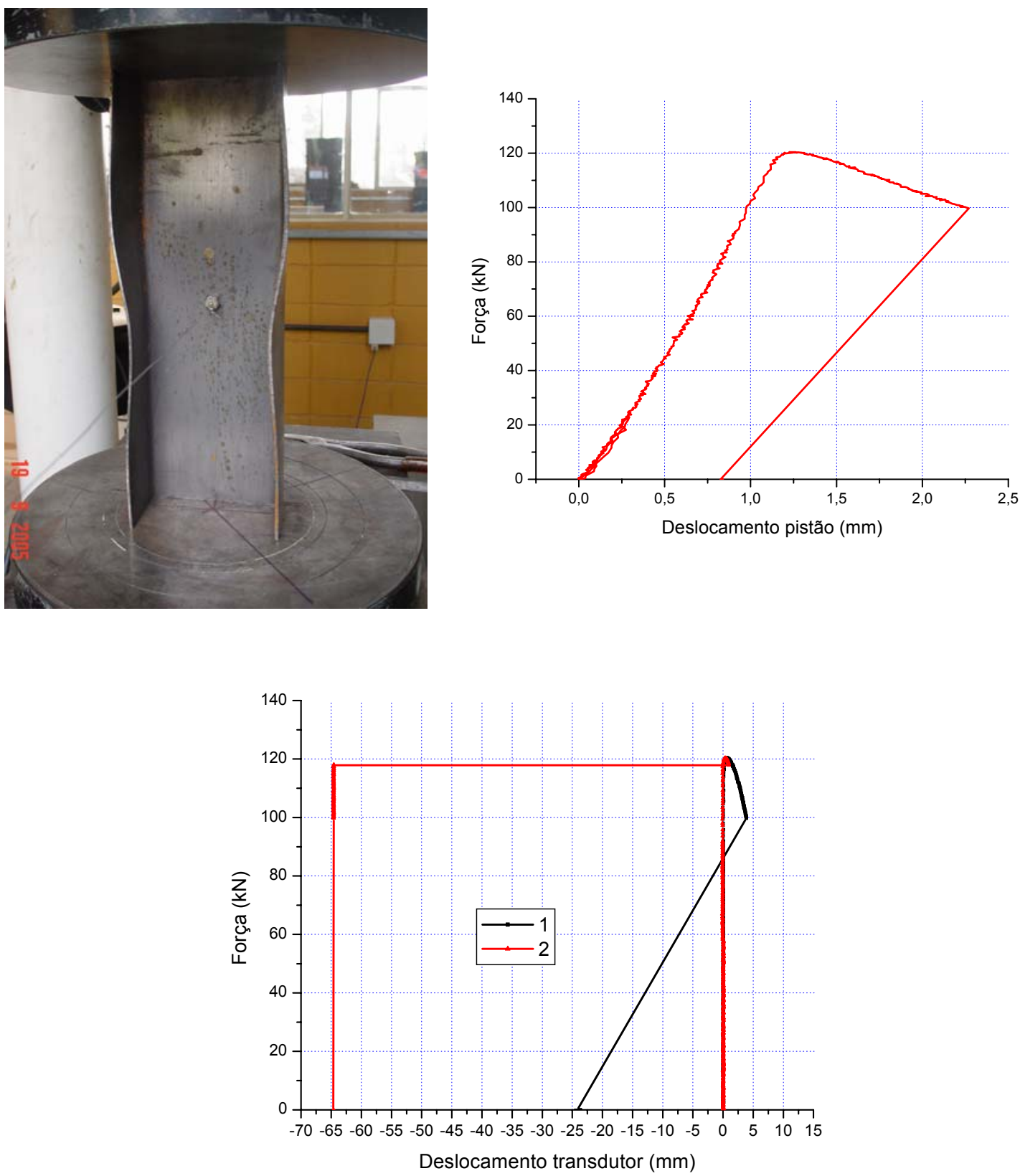

Figura C.6 "Stub column": U2.c3 

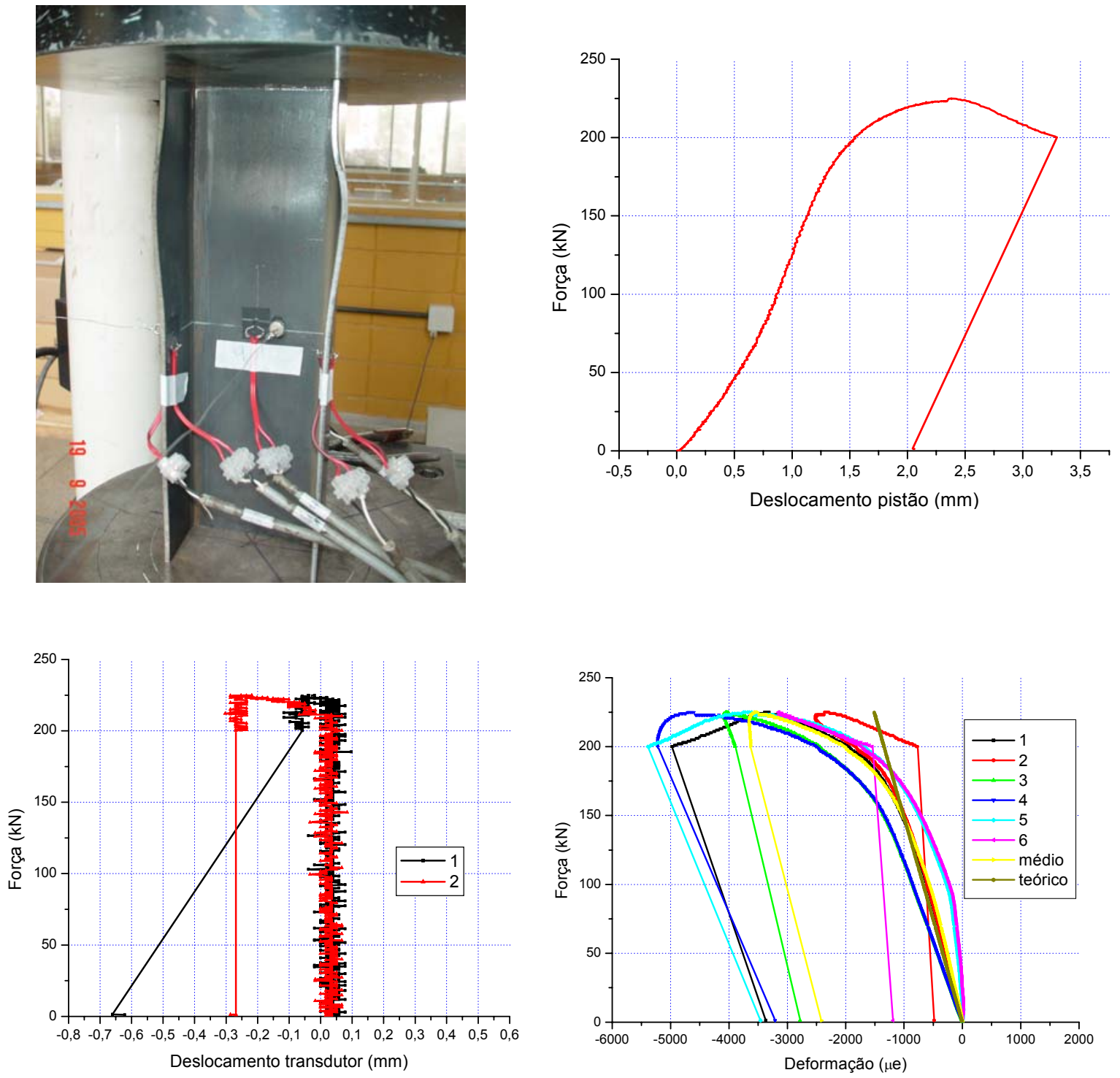

Figura C.7 "Stub column": U3.c 

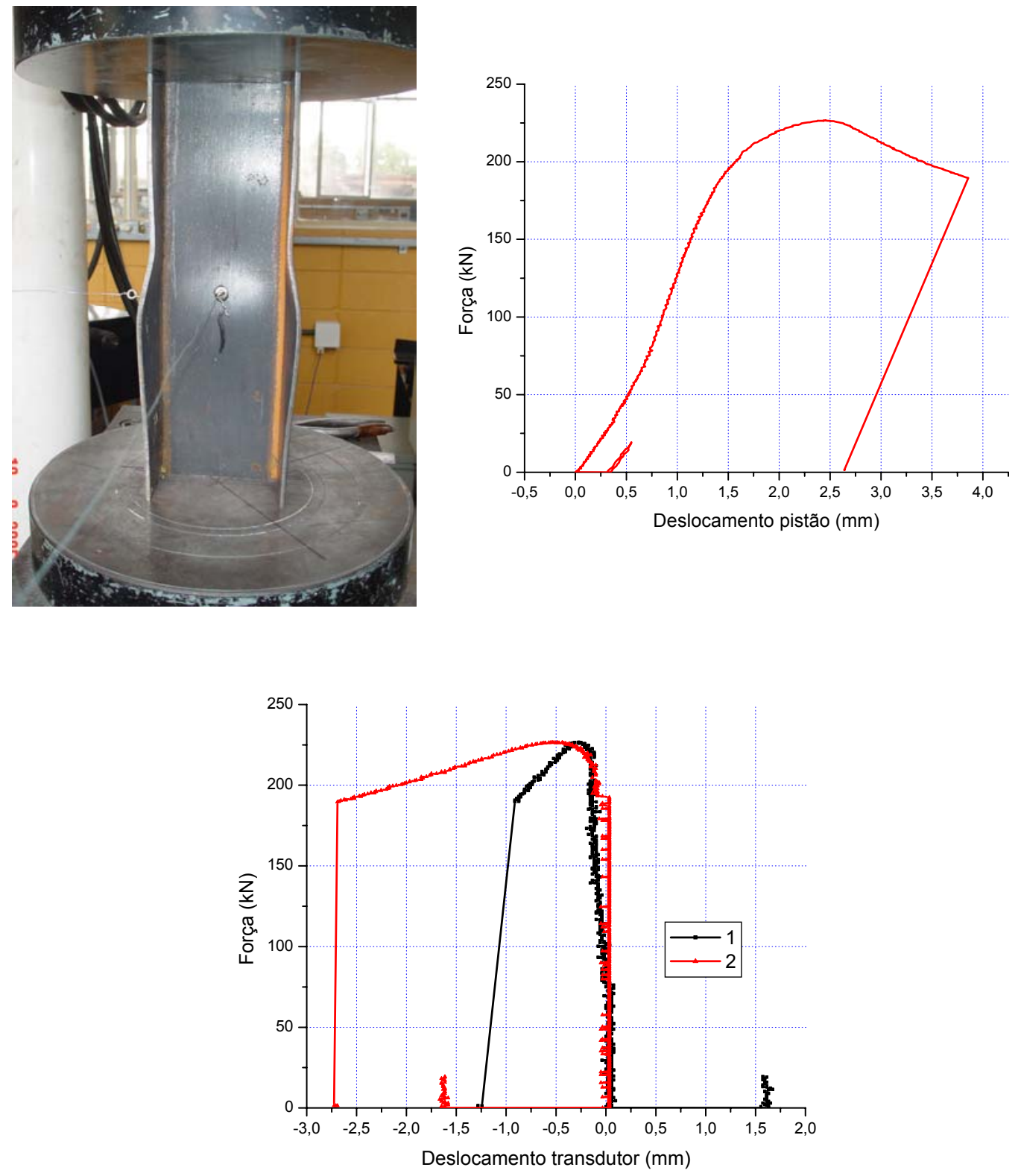

Figura C.8 "Stub column": U3.c2 

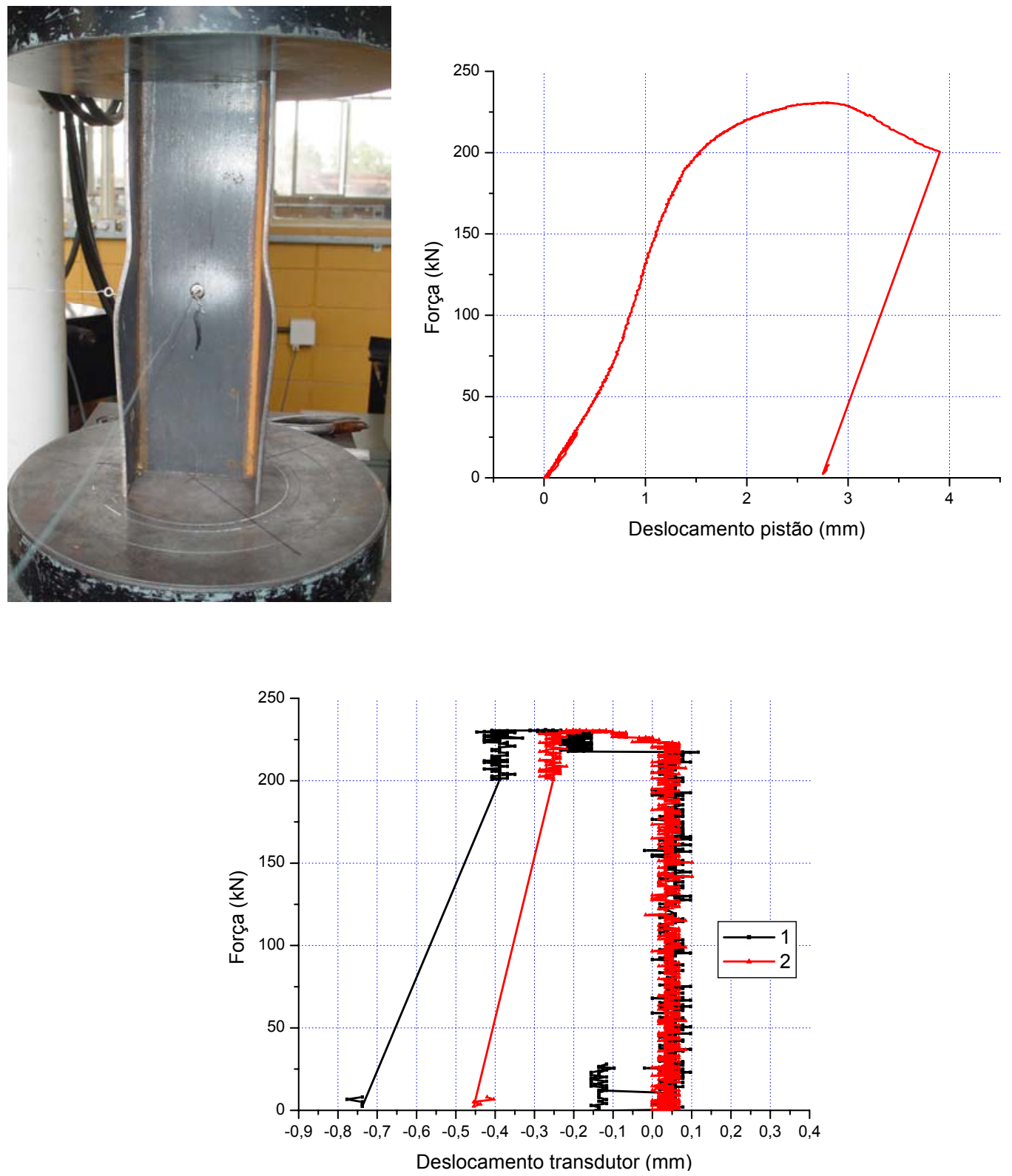

Figura C.9 "Stub column": U3.c3 

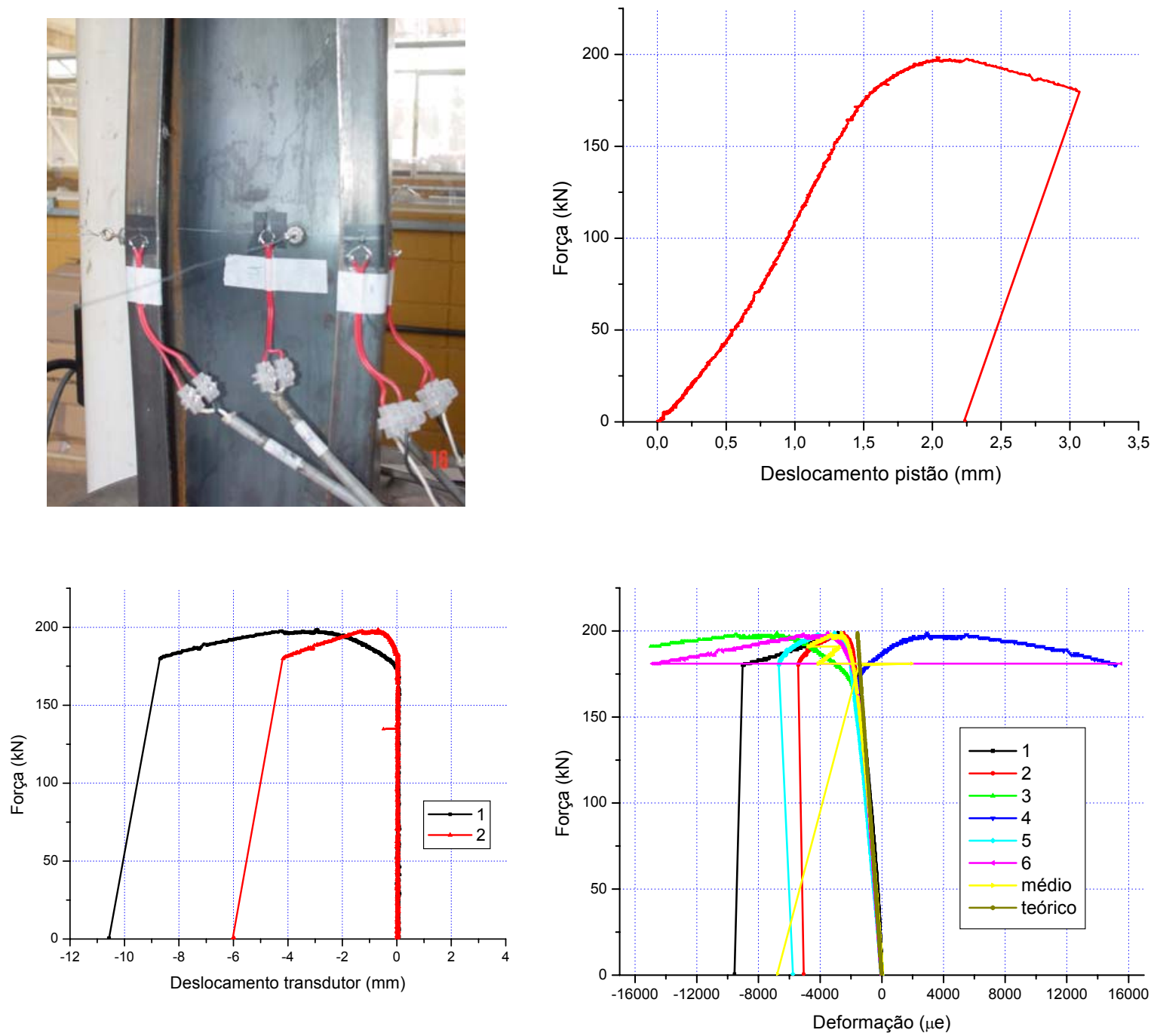

Figura C.10 "Stub column": Ue2.c 

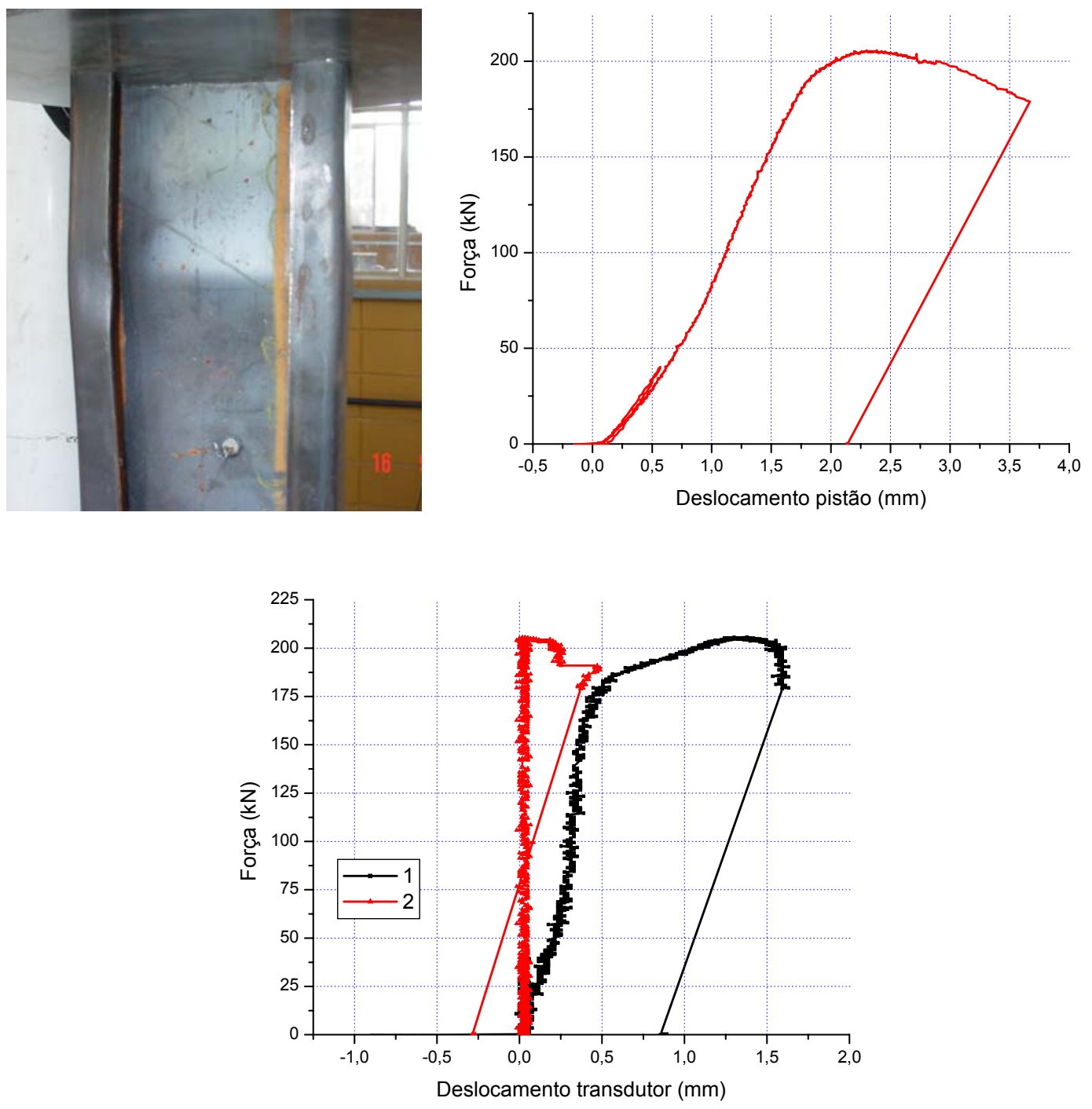

Figura C.11 "Stub column": Ue2.c2 

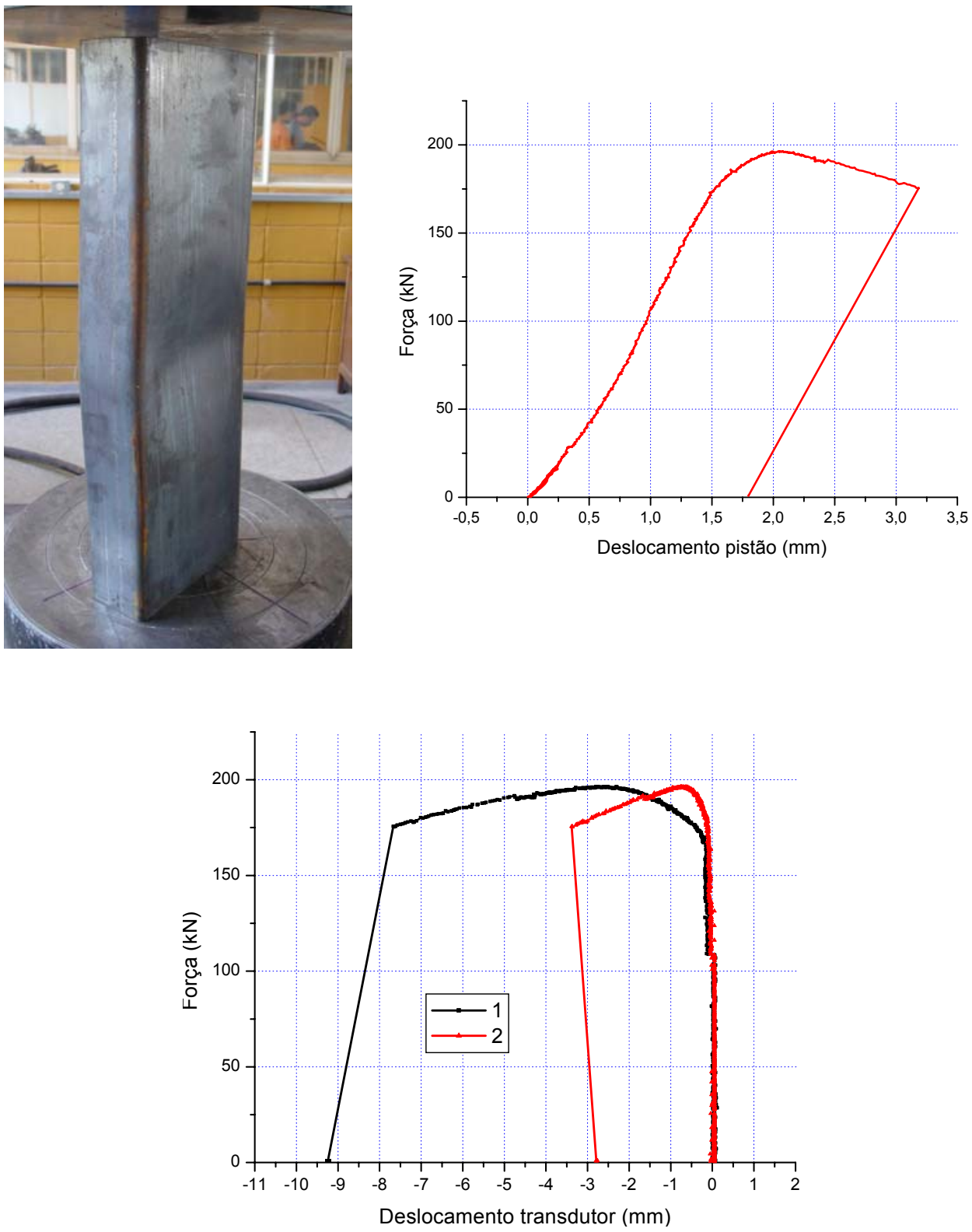

Figura C.12 "Stub column": Ue2.c3 

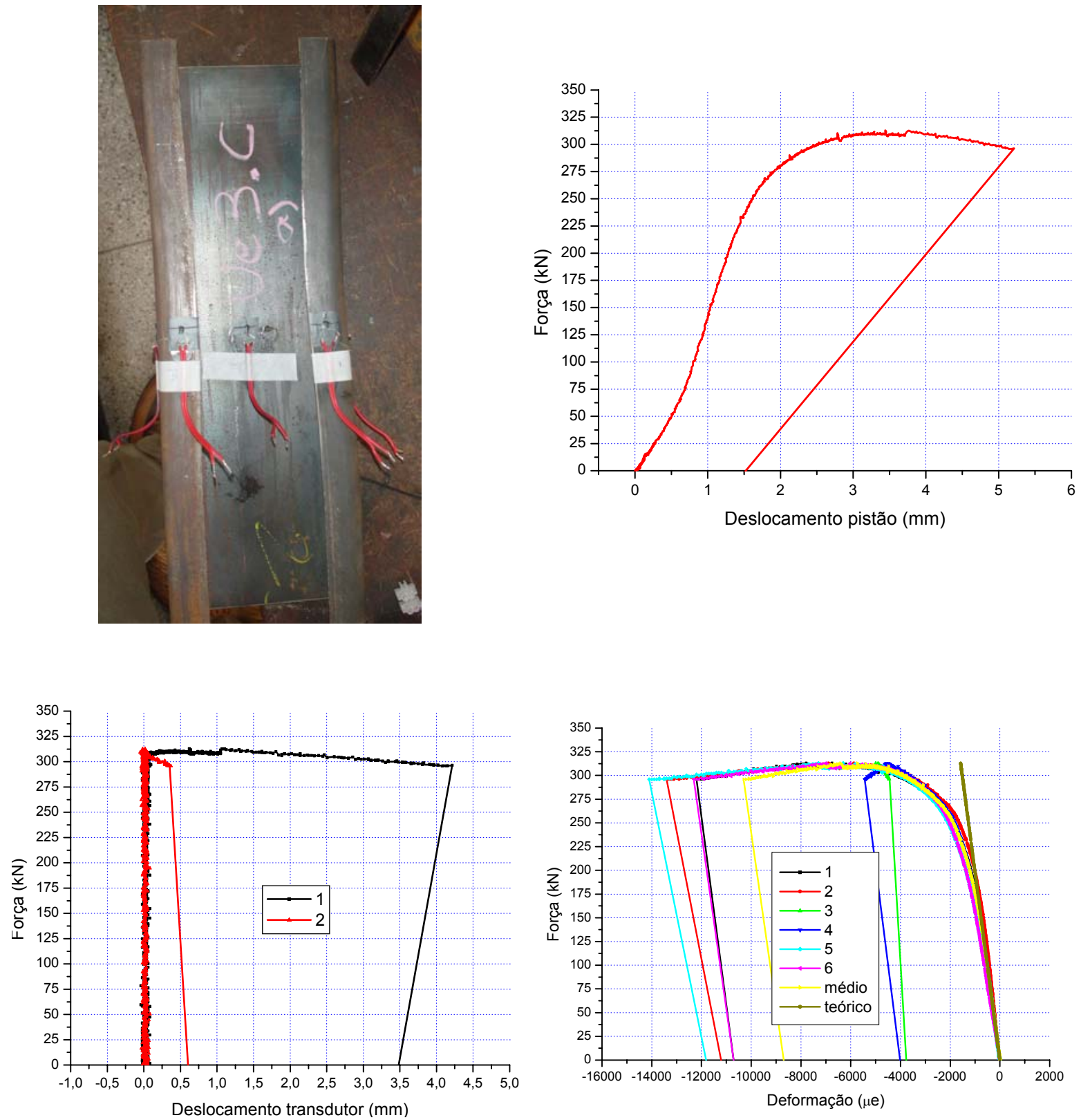

Figura C.13 "Stub column": Ue3.c 

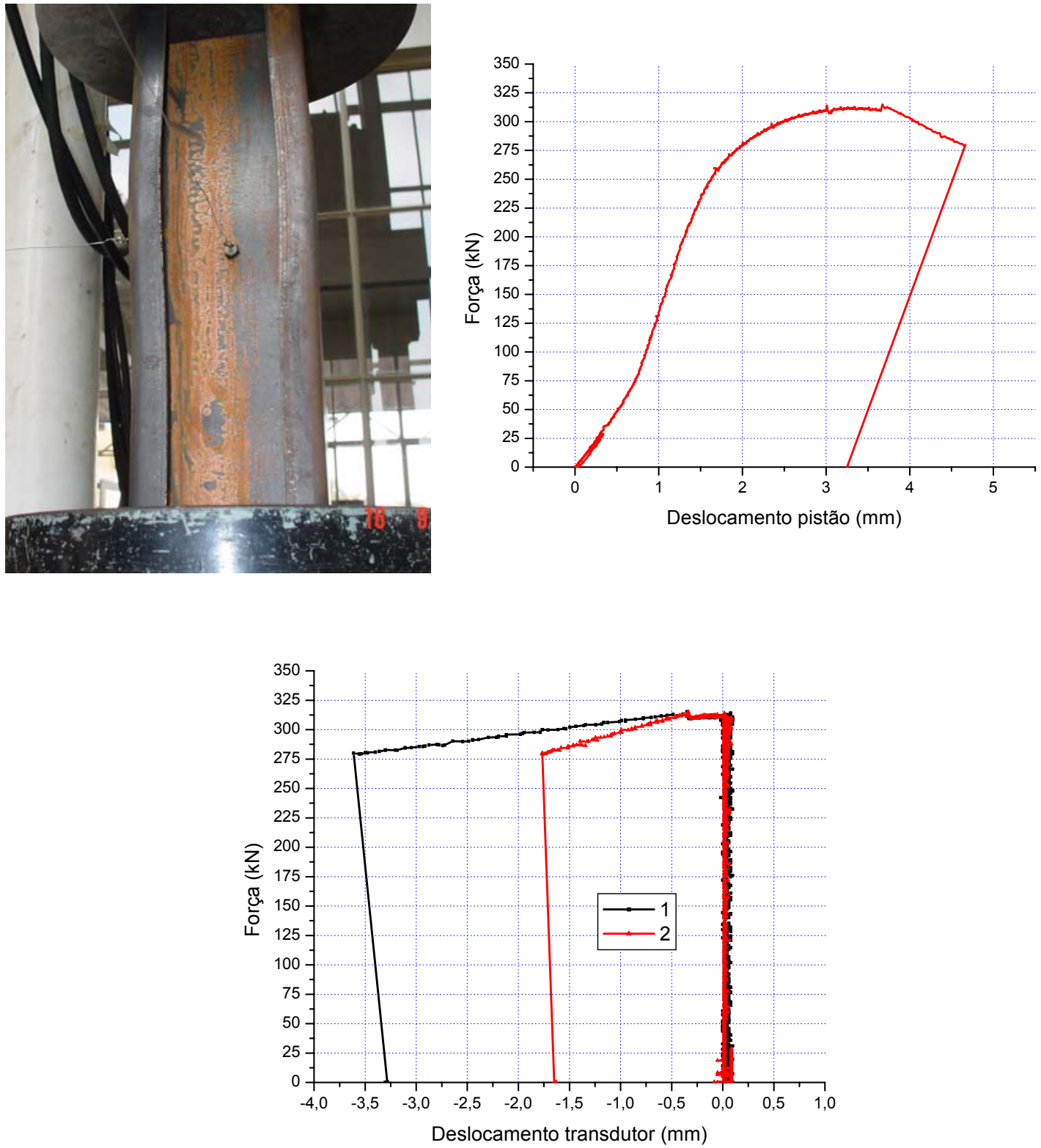

Figura C.14 "Stub column": Ue3.c2 

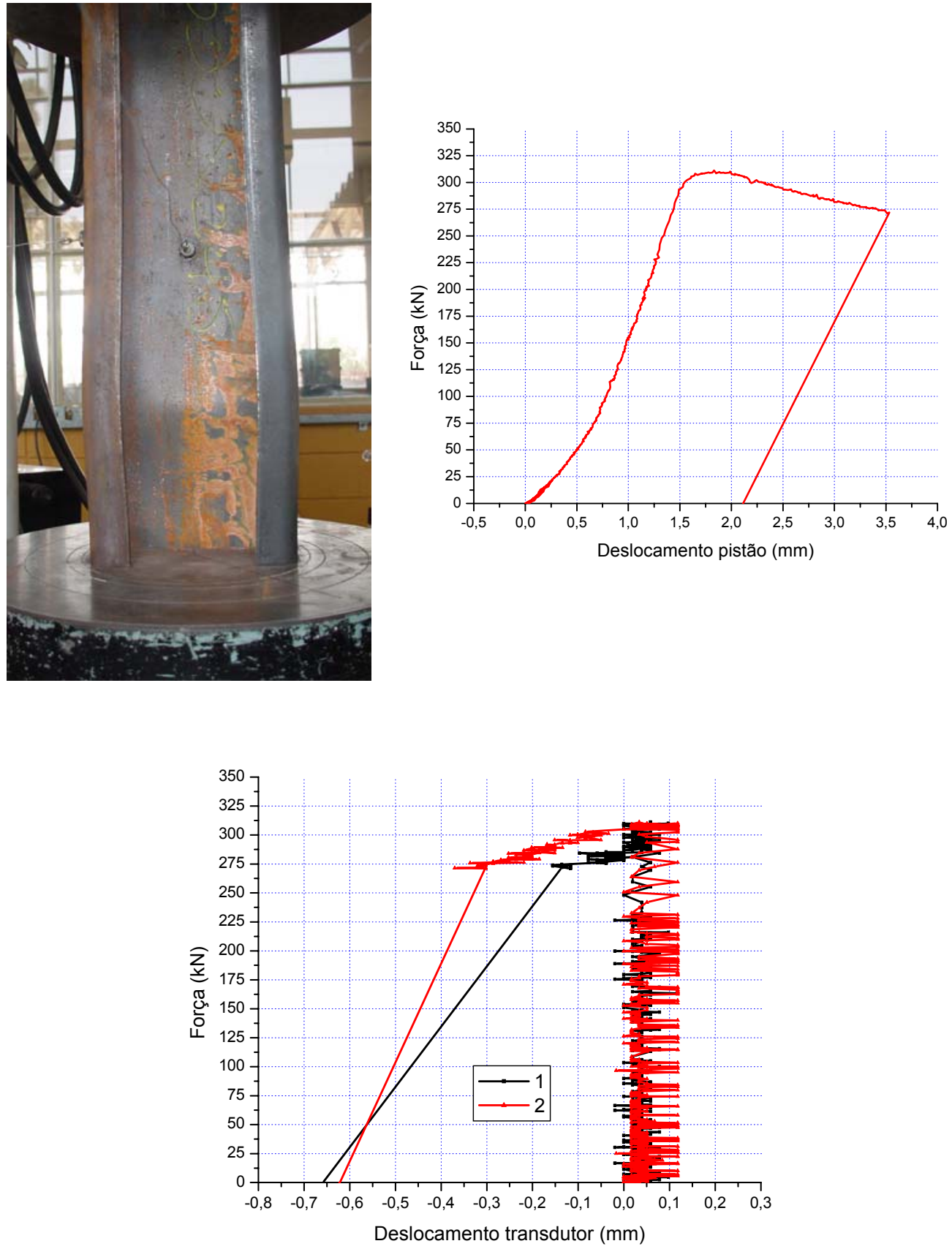

Figura C.15 "Stub column": Ue3.c3 
Tese de Doutorado - Gustavo Monteiro de Barros Chodraui 


\section{APÊNDICE D.1 - ENSAIOS DAS BARRAS LONGAS}

\section{PERFIL: U simples}
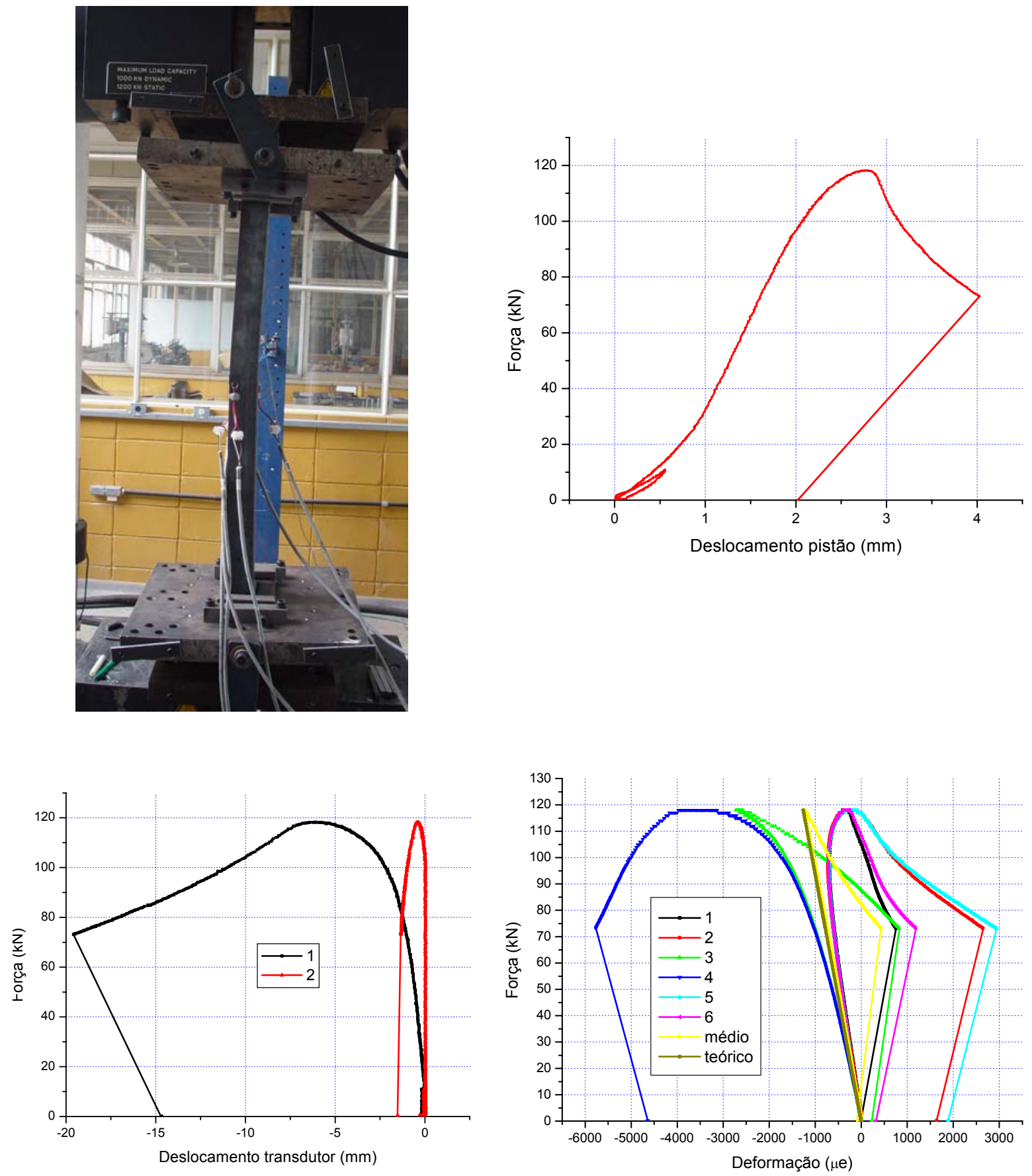

Figura D.1.1 Barras submetidas à compressão: U2.60 

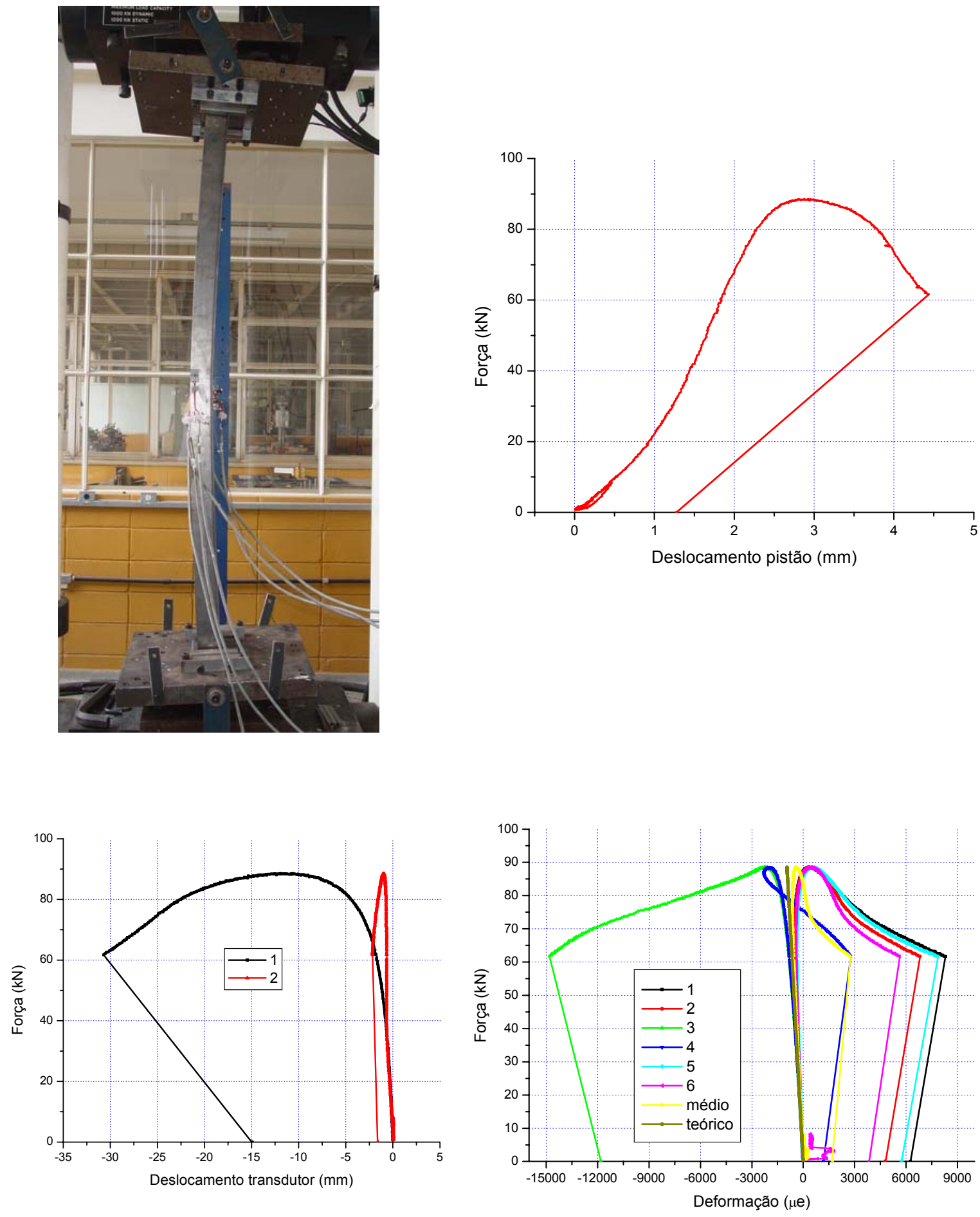

Figura D.1.2 Barras submetidas à compressão: U2.90 

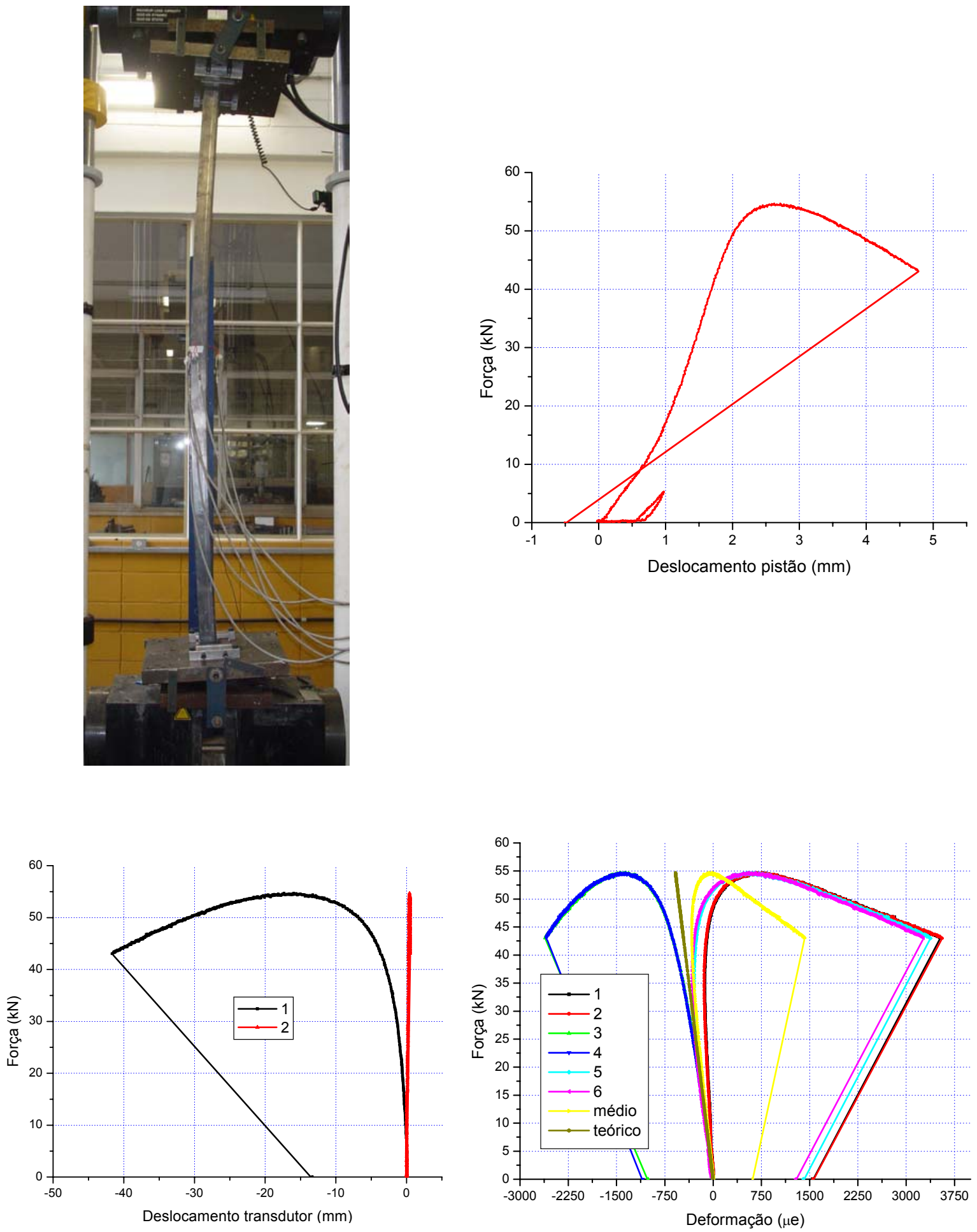

Figura D.1.3 Barras submetidas à compressão: U2.120 

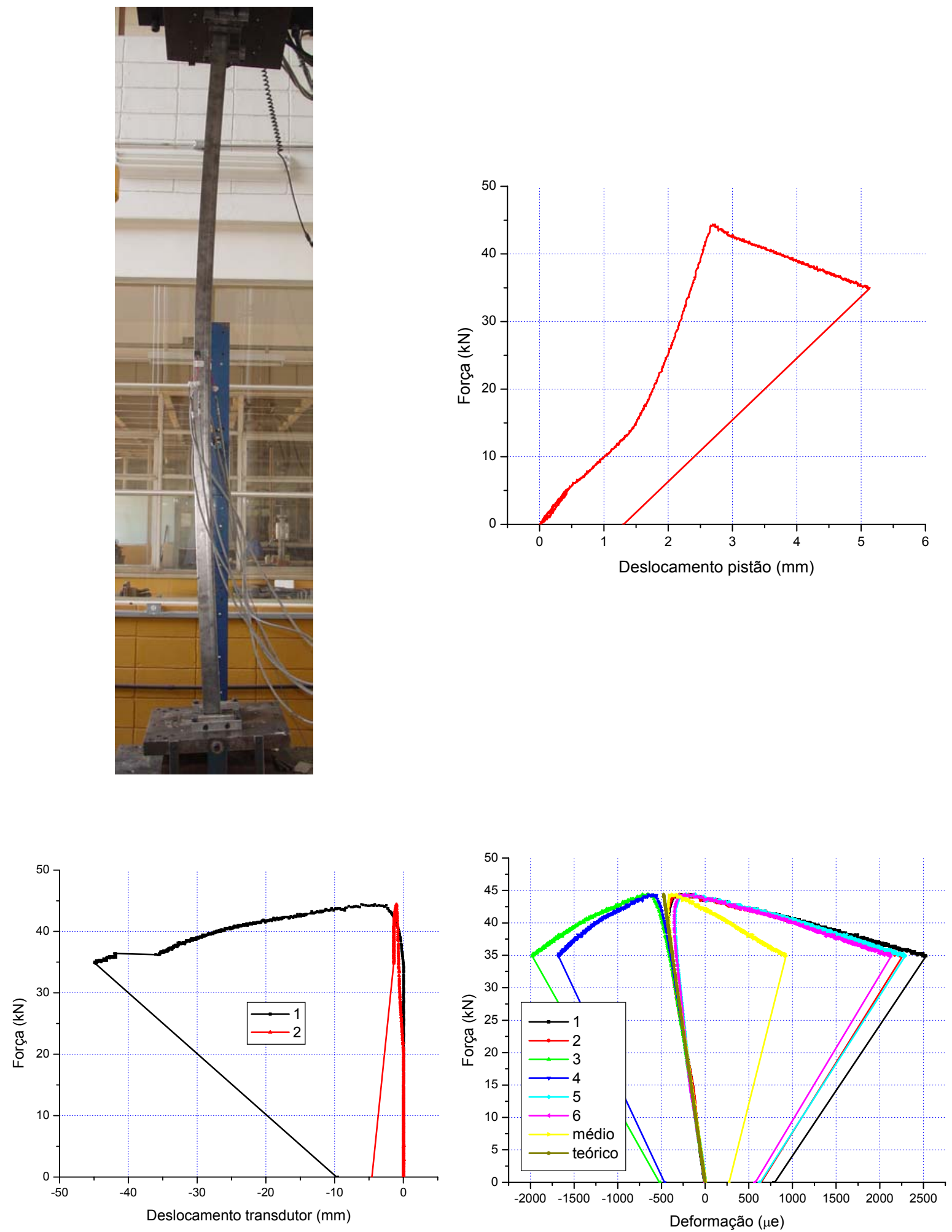

Figura D.1.4 Barras submetidas à compressão: U2.150 

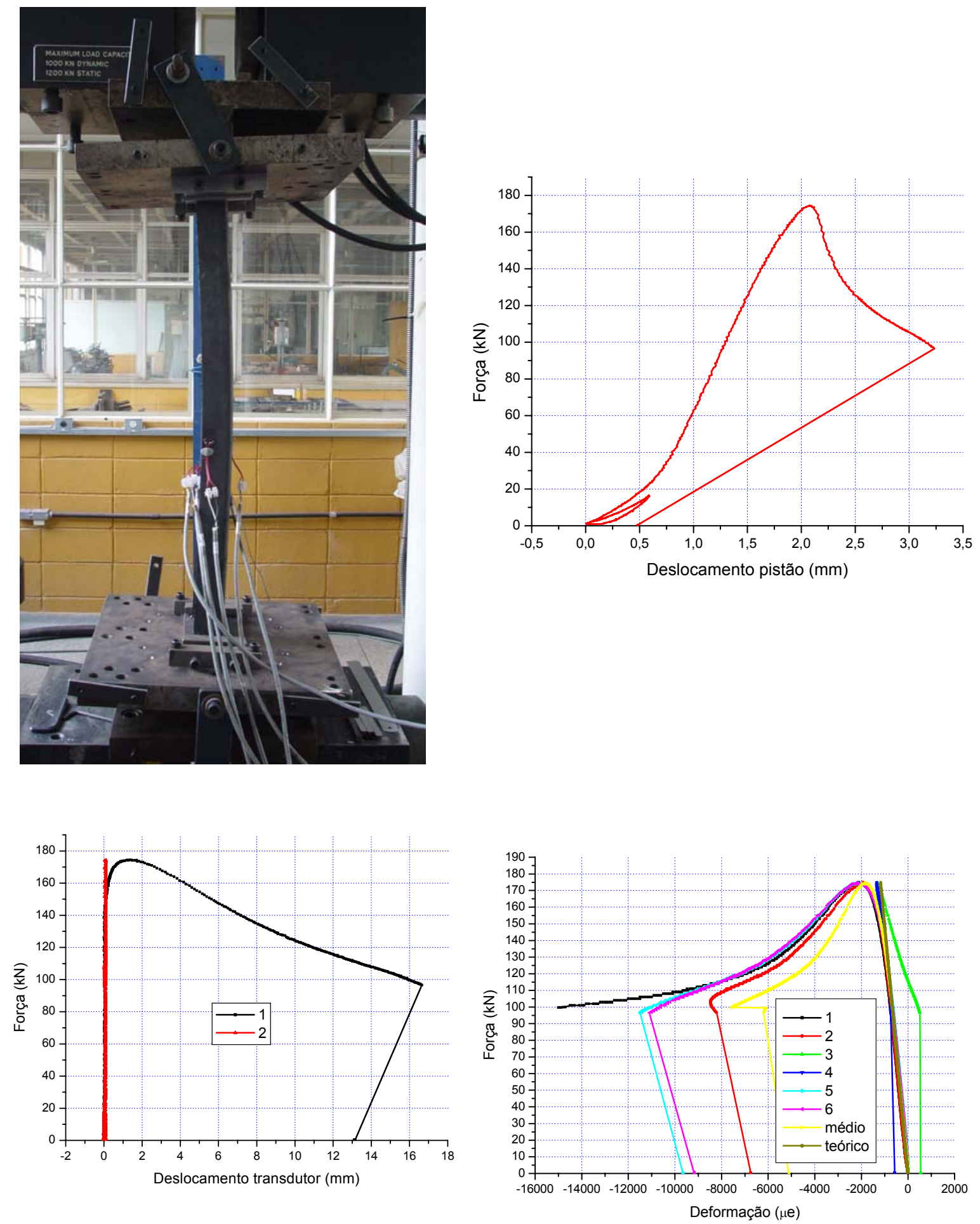

Figura D.1.5 Barras submetidas à compressão: U3.60 

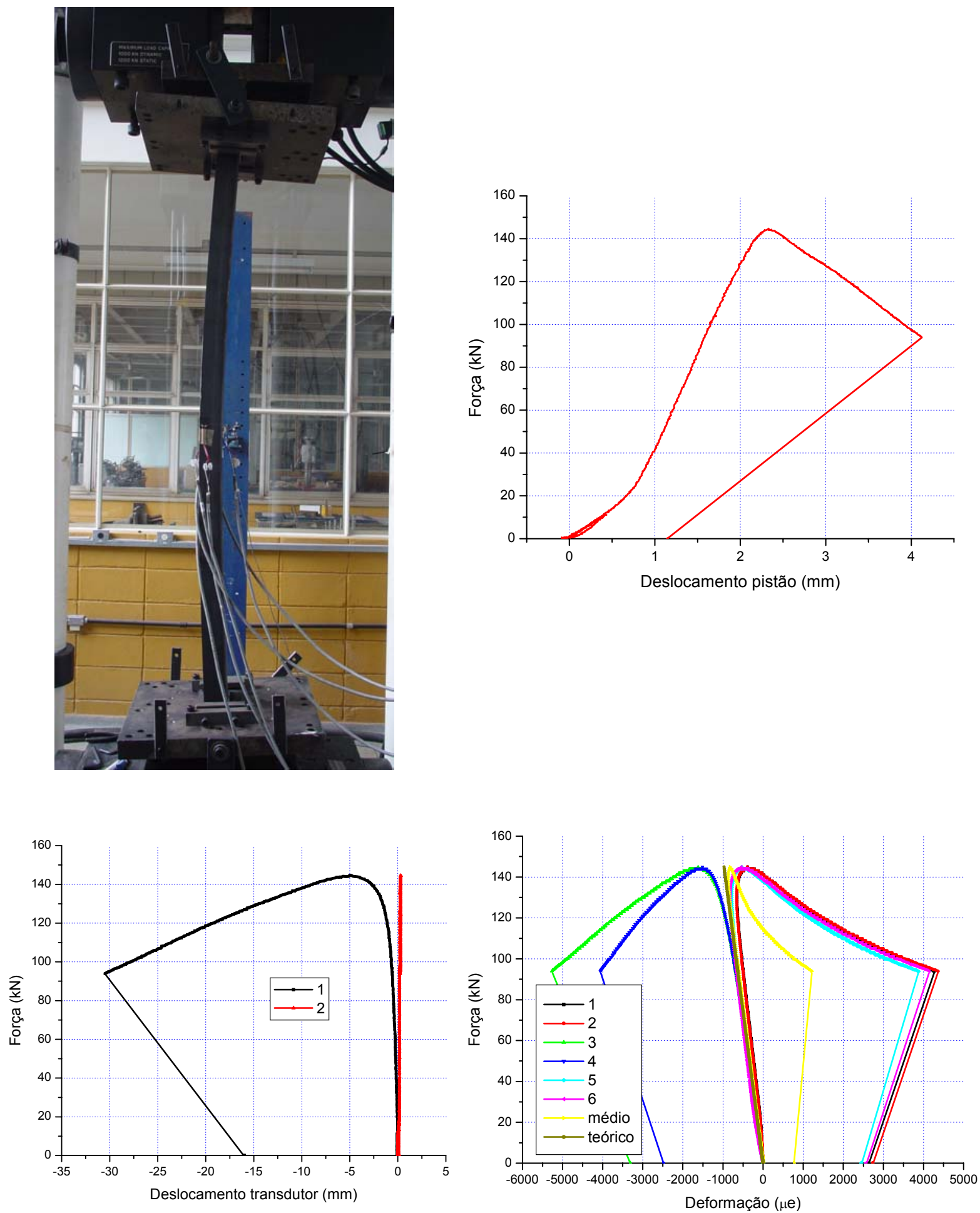

Figura D.1.6 Barras submetidas à compressão: U3.90 

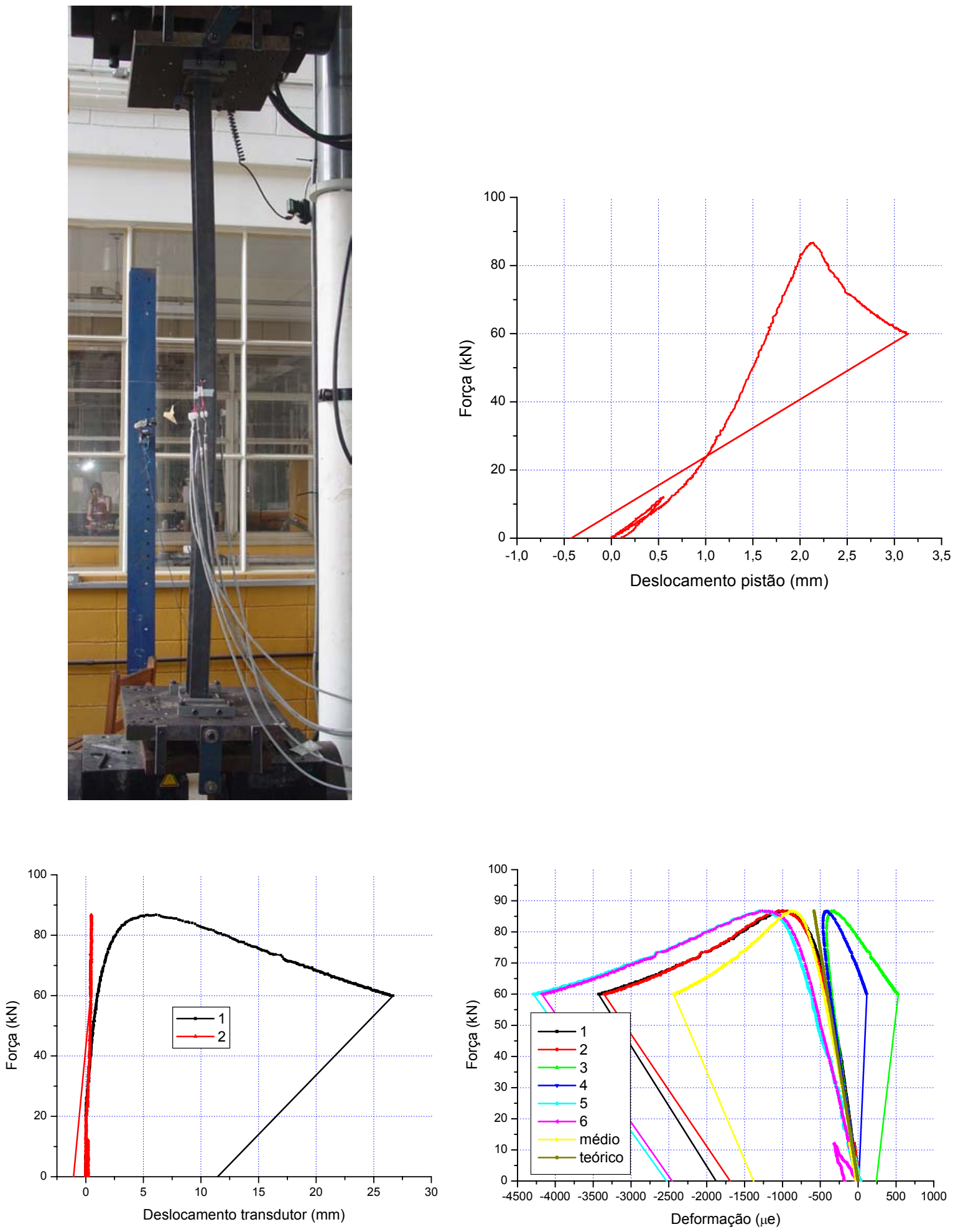

Figura D.1.7 Barras submetidas à compressão: U3.120 

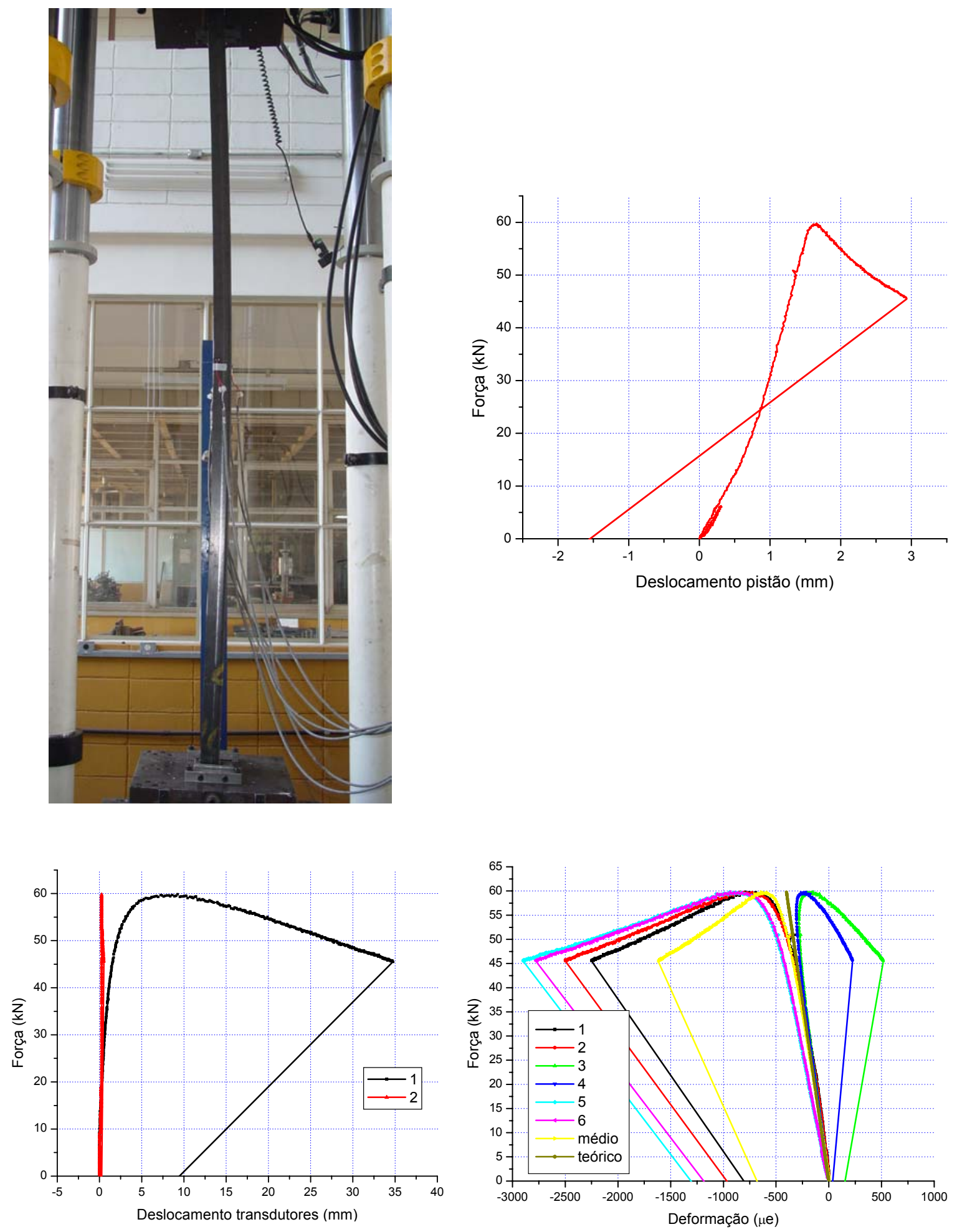

Figura D.1.8 Barras submetidas à compressão: U3.150 


\section{APÊNDICE D.2 - ENSAIOS DAS BARRAS LONGAS}

\section{PERFIL: U enrijecido}
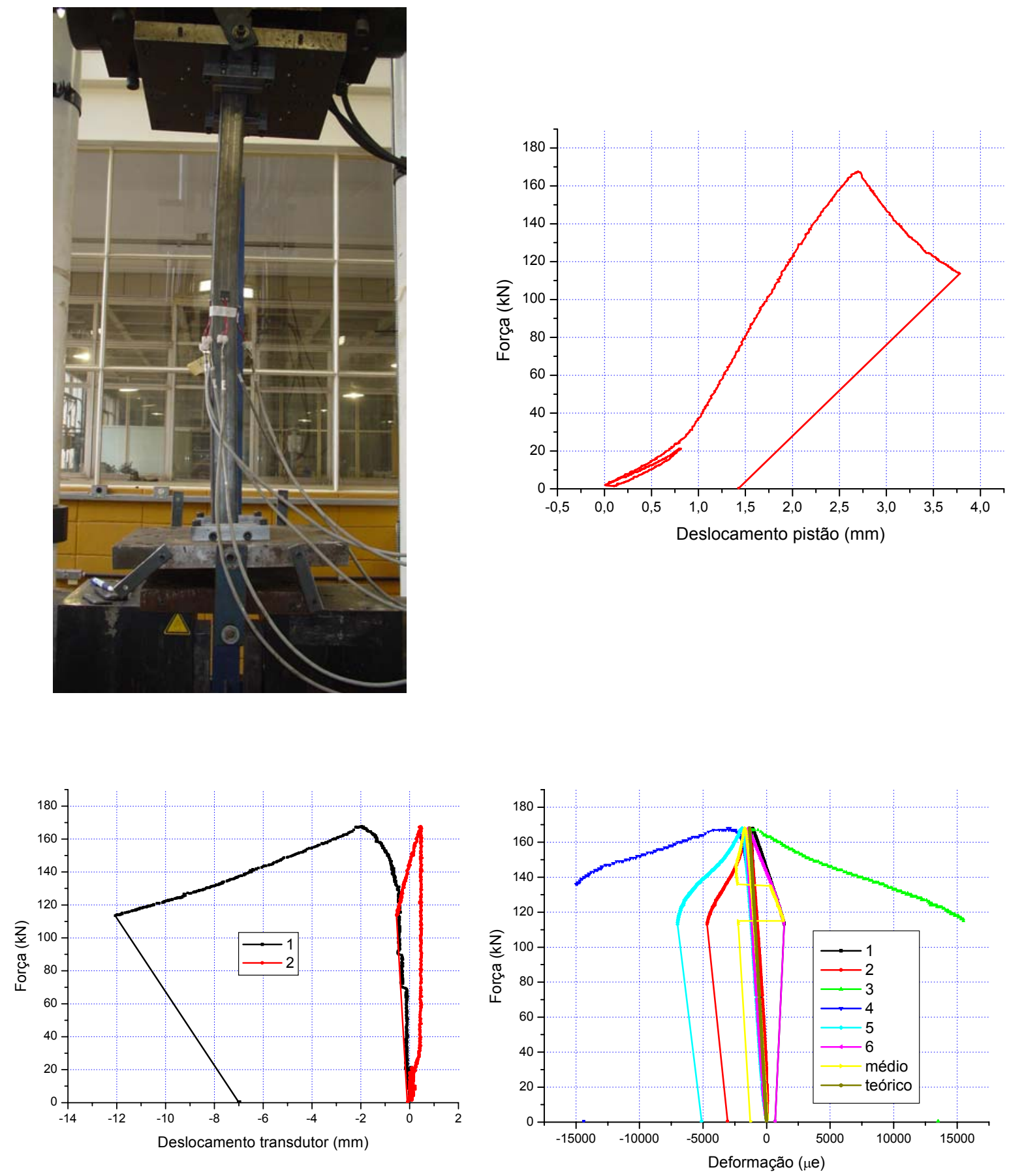

Figura D.2.1 Barras submetidas à compressão: Ue2.60 

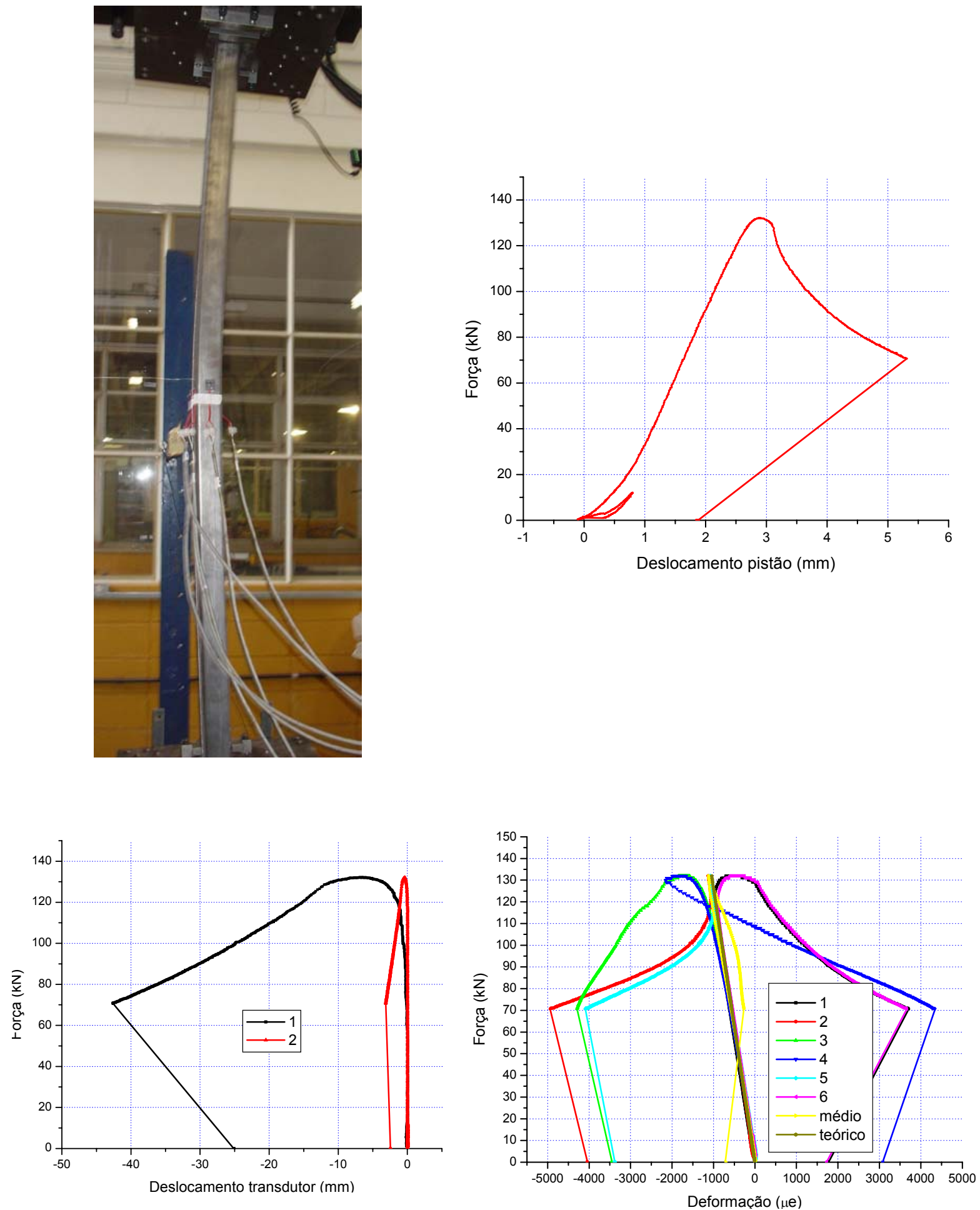

Figura D.2.2 Barras submetidas à compressão: Ue2.90 

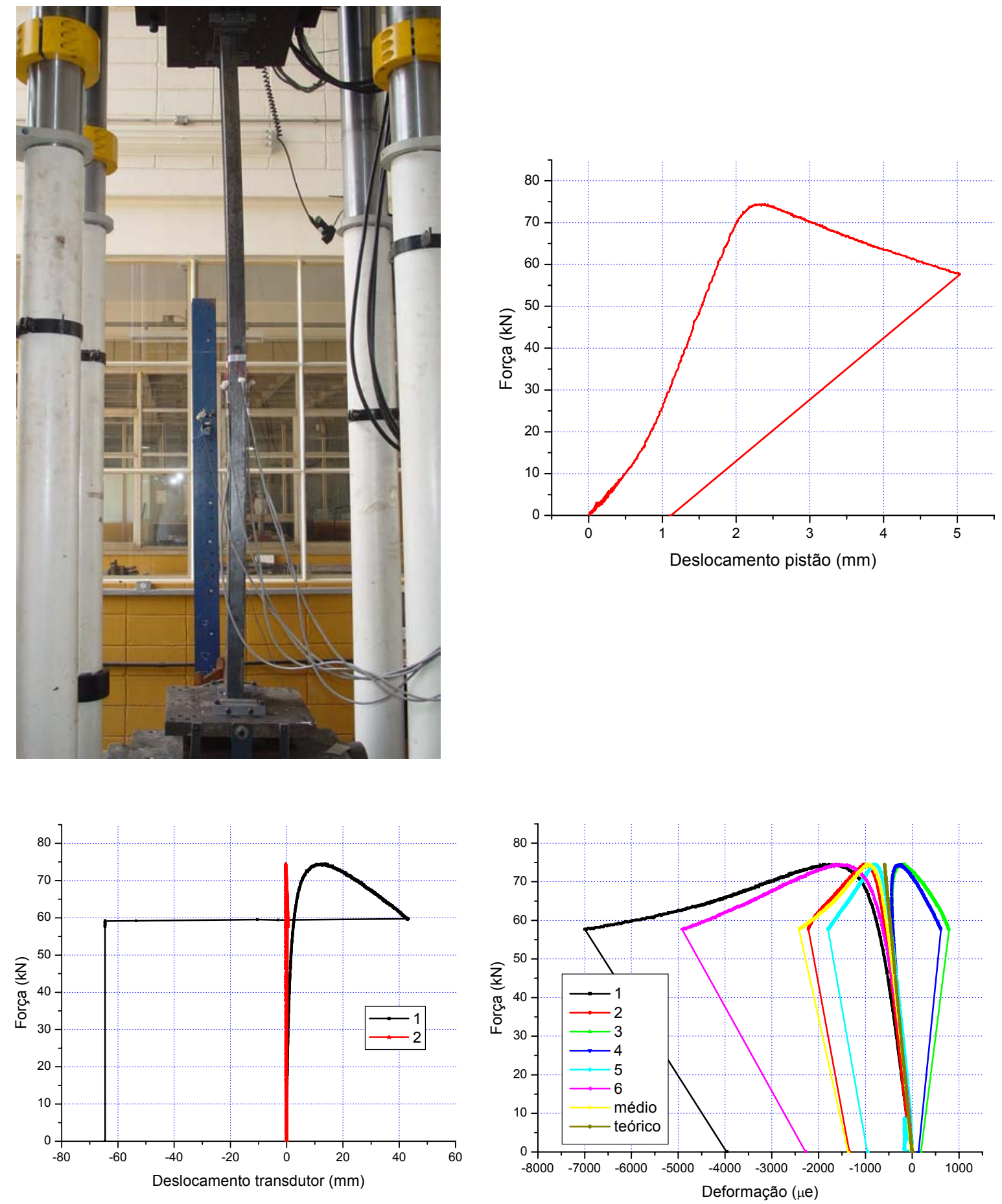

Figura D.2.3 Barras submetidas à compressão: Ue2.120 

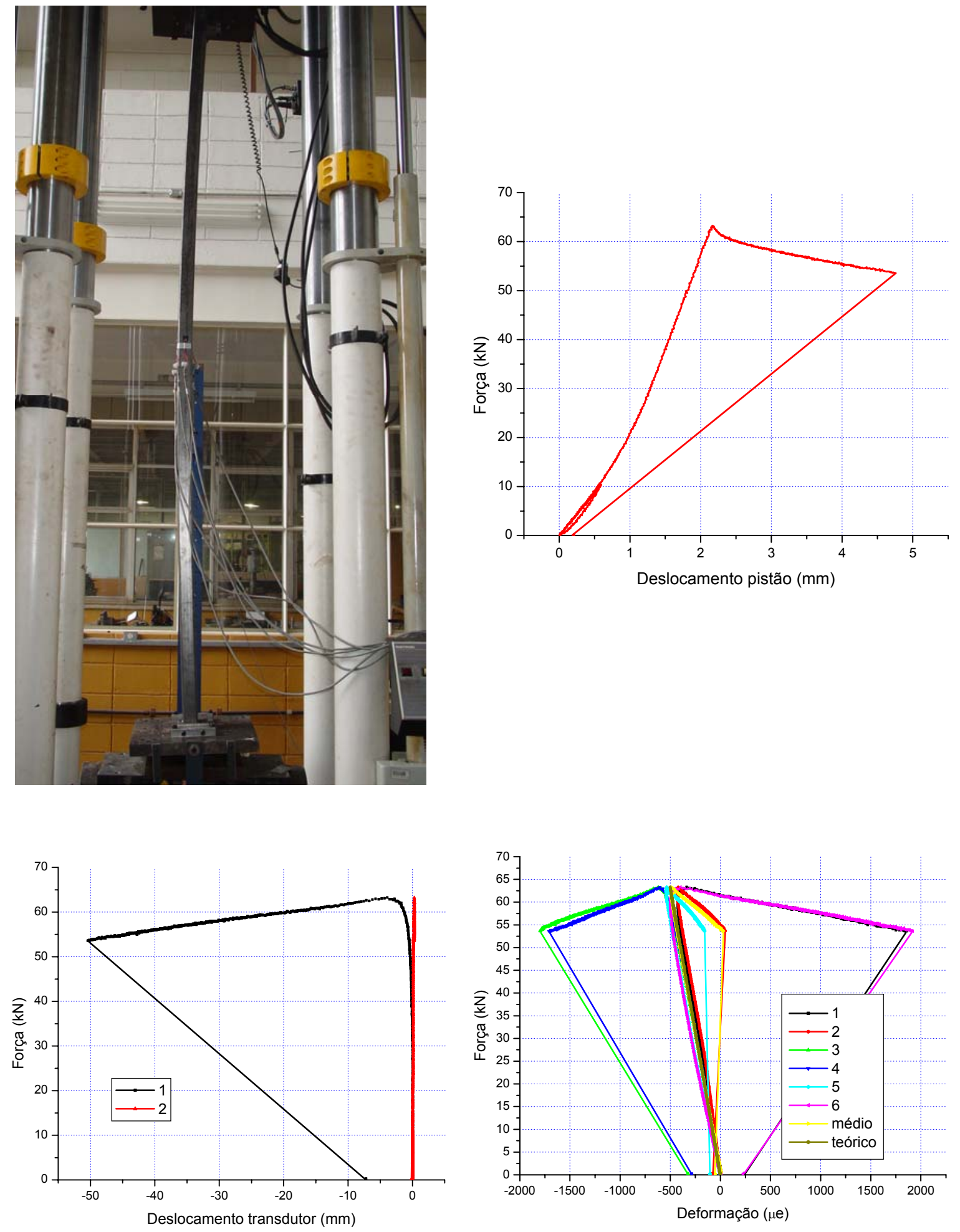

Figura D.2.4 Barras submetidas à compressão: Ue2.150 

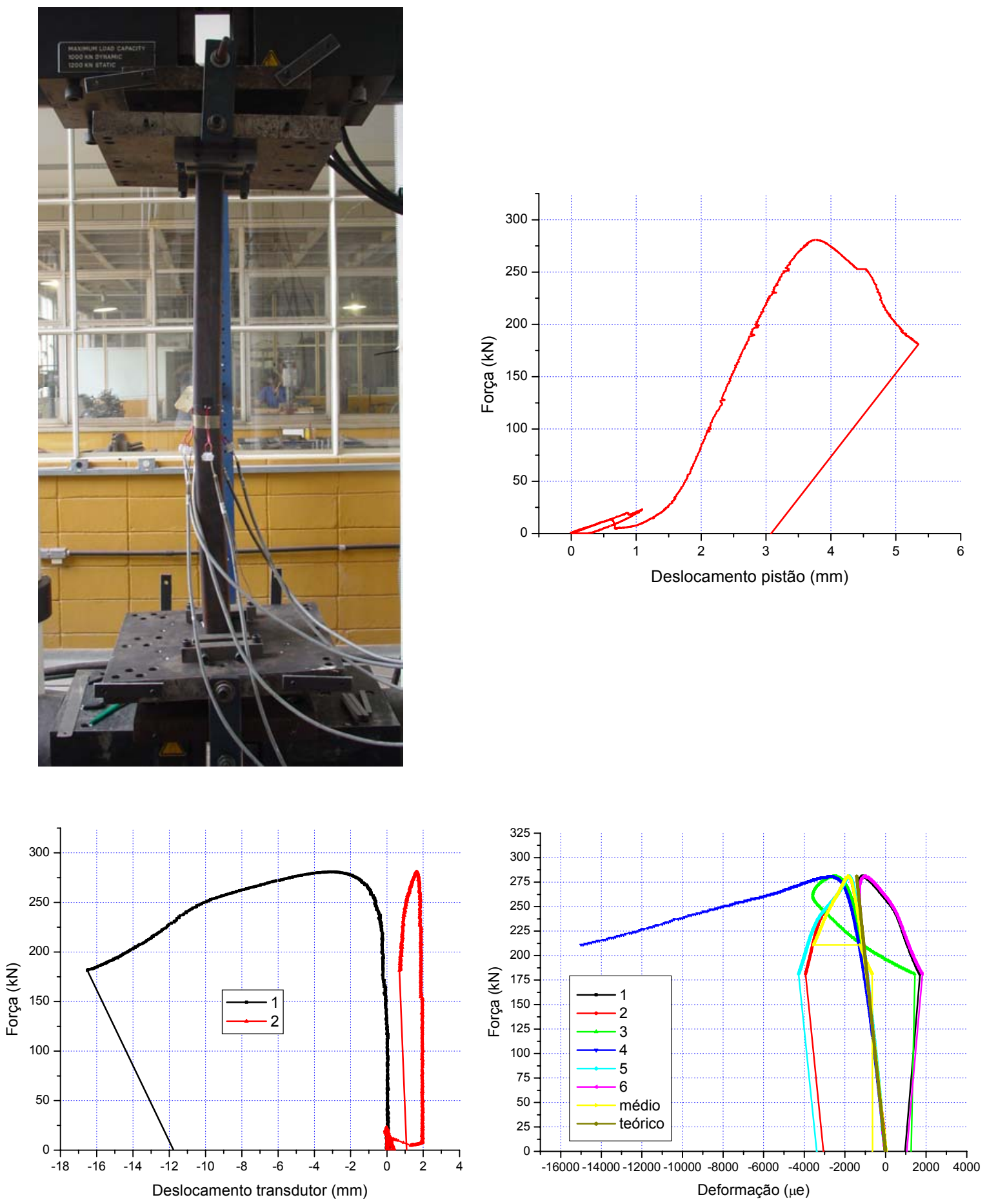

Figura D.2.5 Barras submetidas à compressão: Ue3.60 

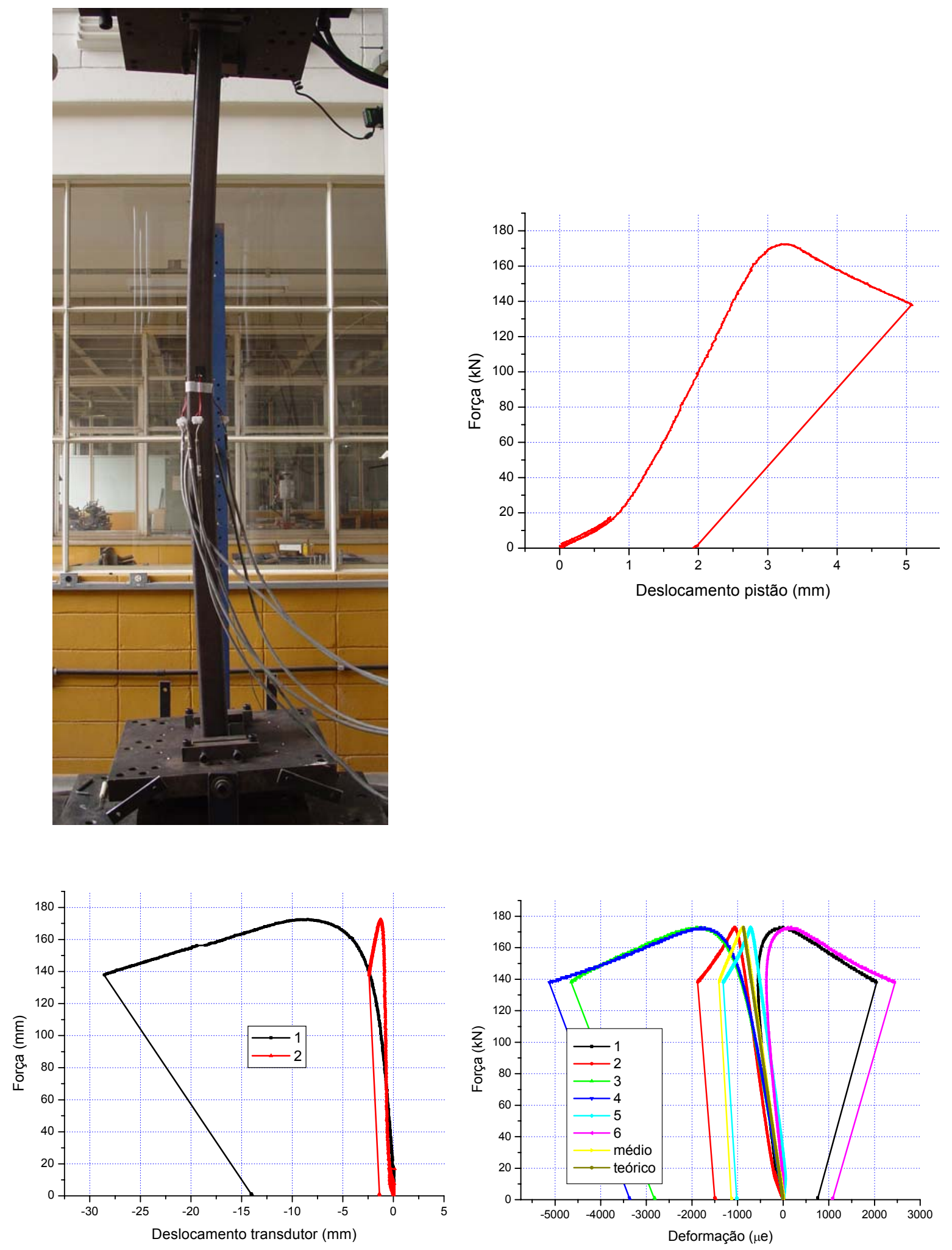

Figura D.2.6 Barras submetidas à compressão: Ue3.90 

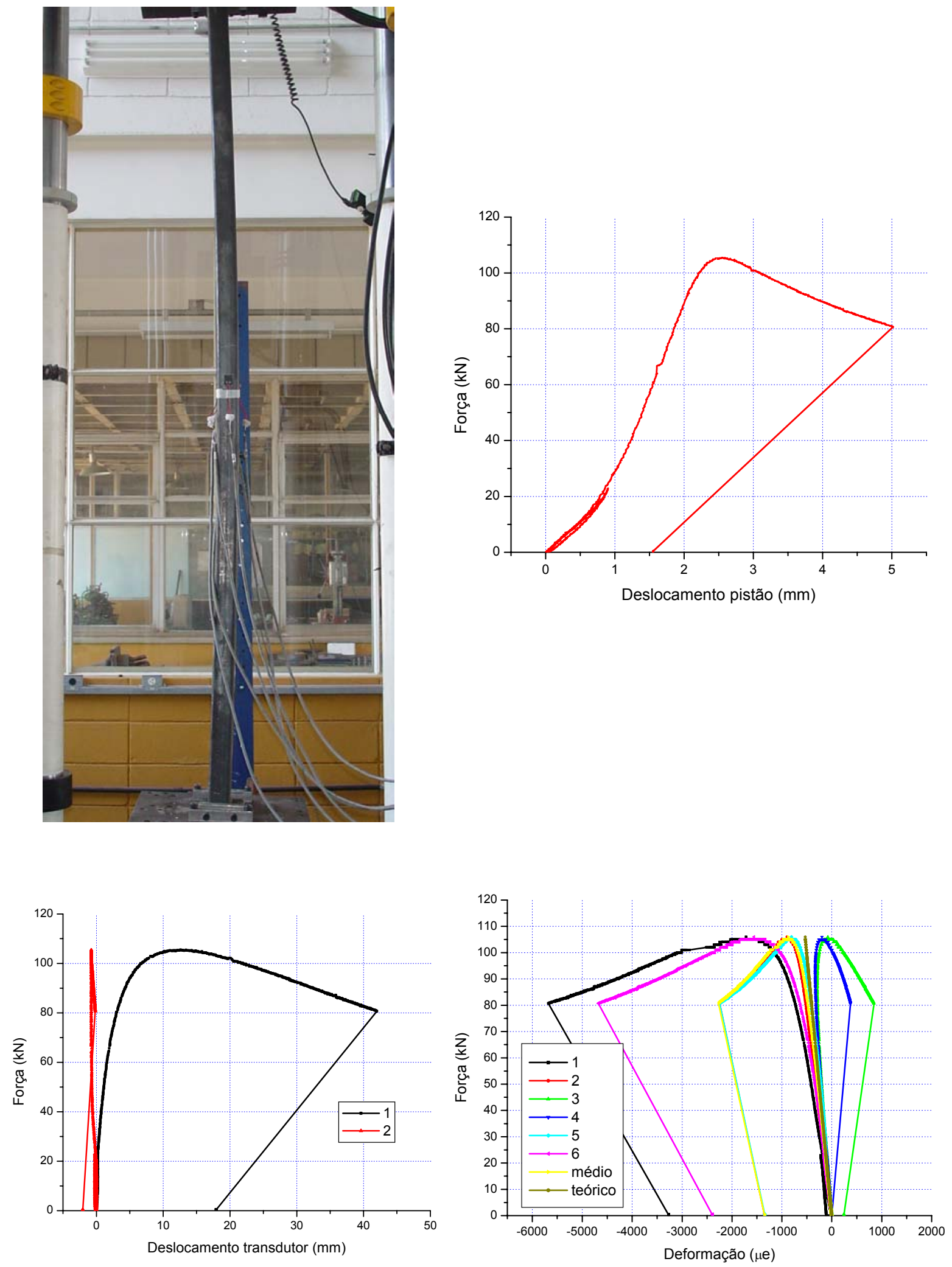

Figura D.2.7 Barras submetidas à compressão: Ue3.120 

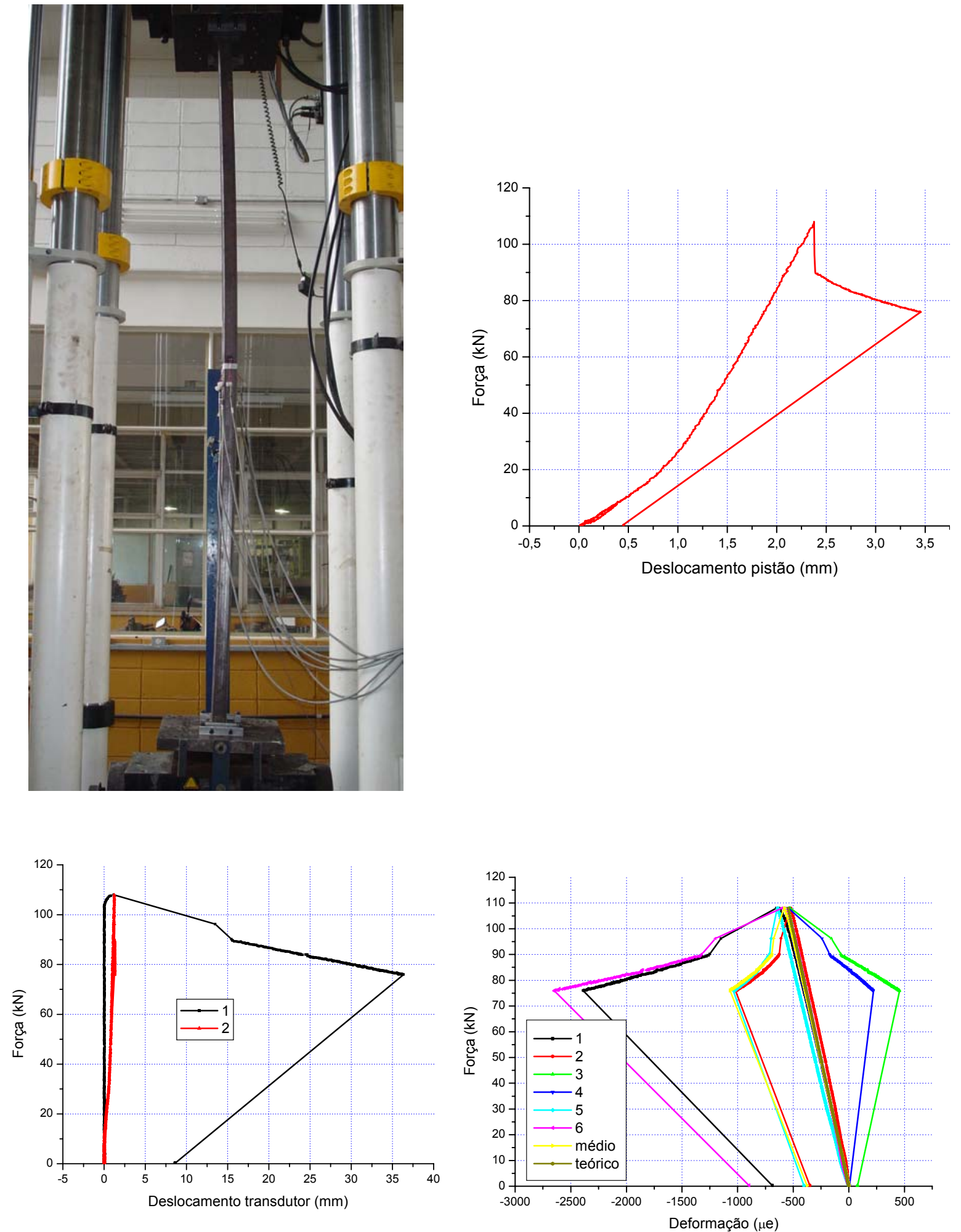

Figura D.2.8 Barras submetidas à compressão: Ue3.150 


\section{APÊNDICE D.3 - ENSAIOS DAS BARRAS LONGAS}

\section{PERFIL: Cantoneira simples}
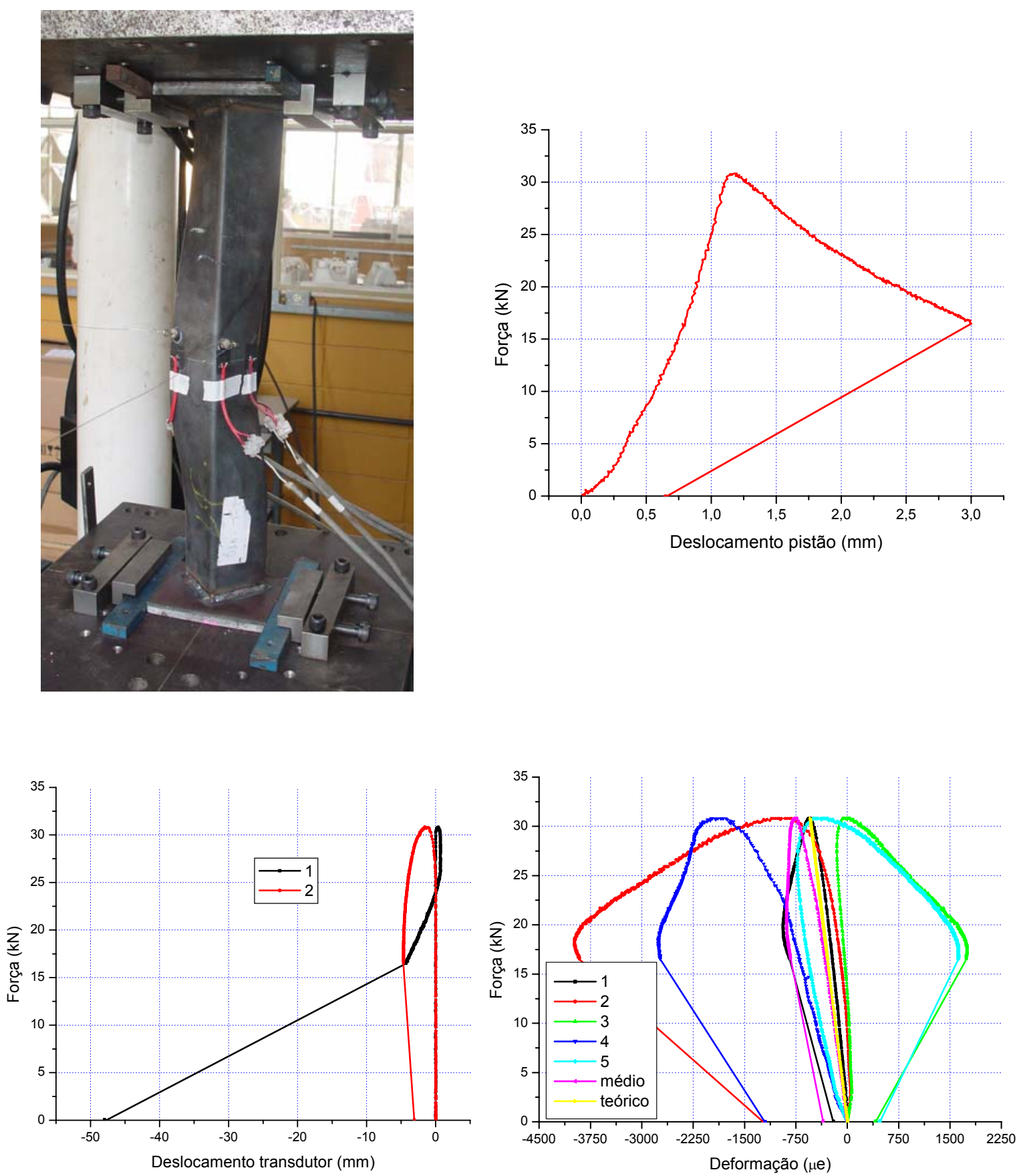

Figura D.3.1 Barras submetidas à compressão: L2.60 

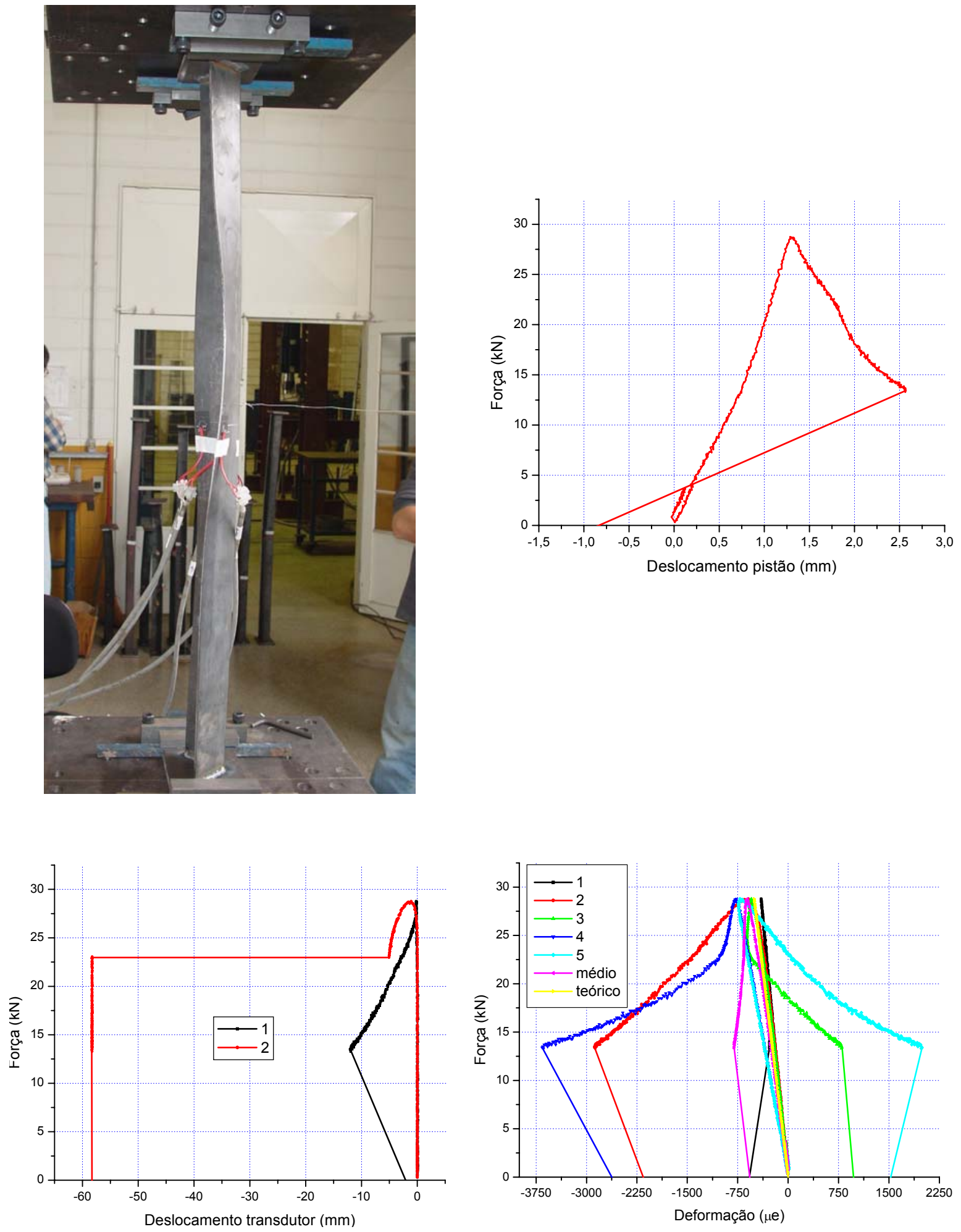

Figura D.3.2 Barras submetidas à compressão: L2.90 

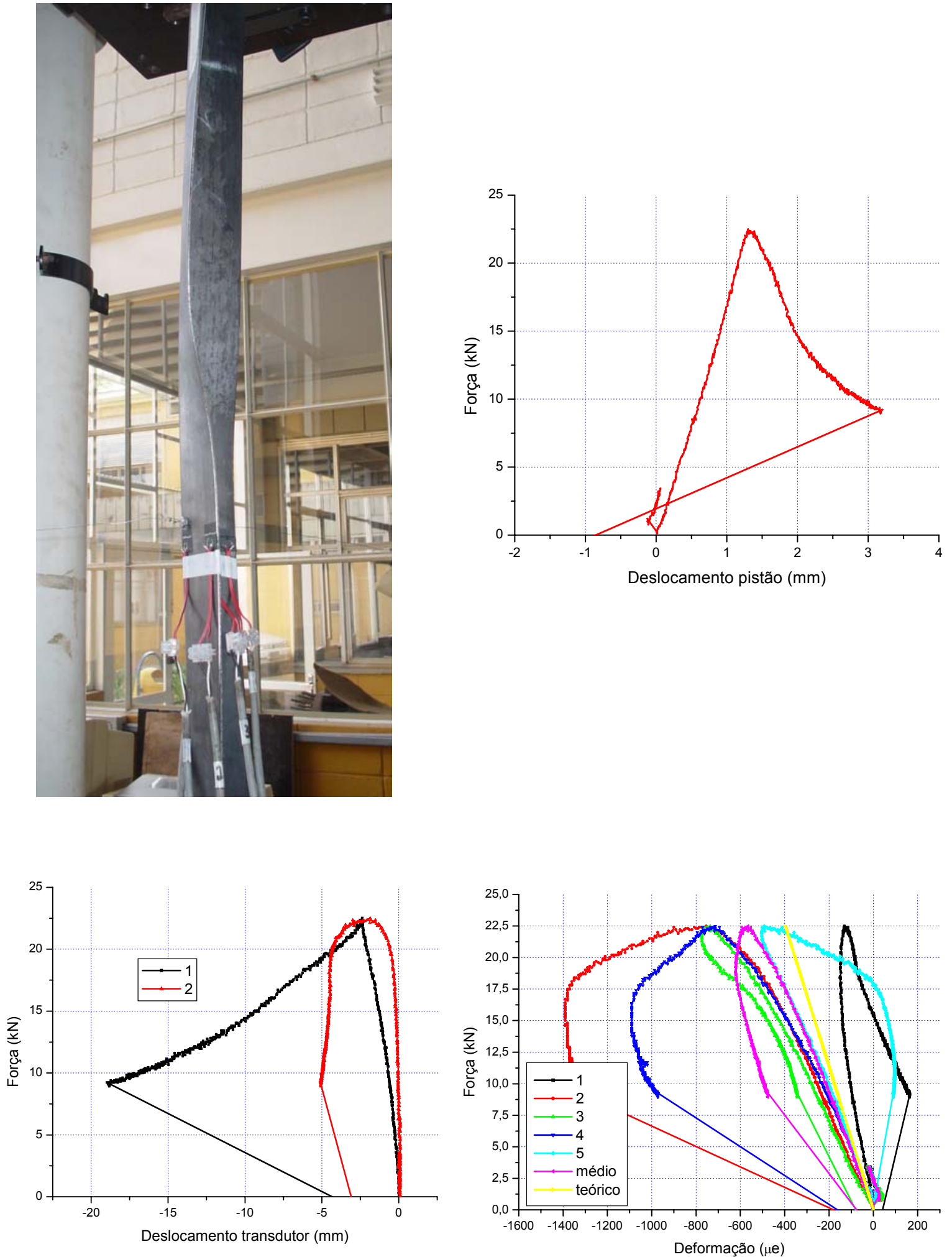

Figura D.3.3 Barras submetidas à compressão: L2.120 

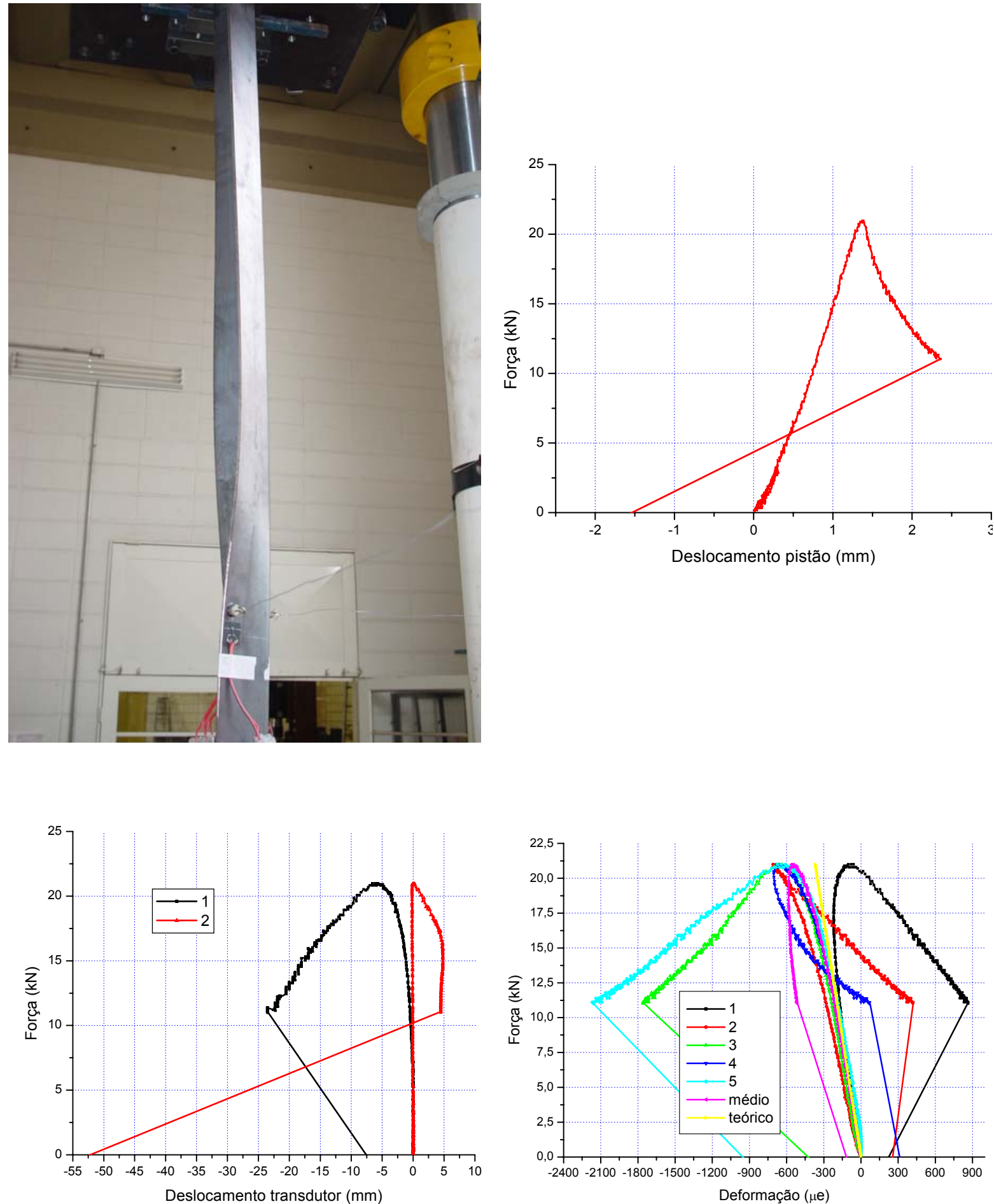

Figura D.3.4 Barras submetidas à compressão: L2.150 


\section{APÊNDICE D.4 - ENSAIOS DAS BARRAS LONGAS}

\section{PERFIL: Cantoneira dupla - rótula para flexão em " $x$ "}
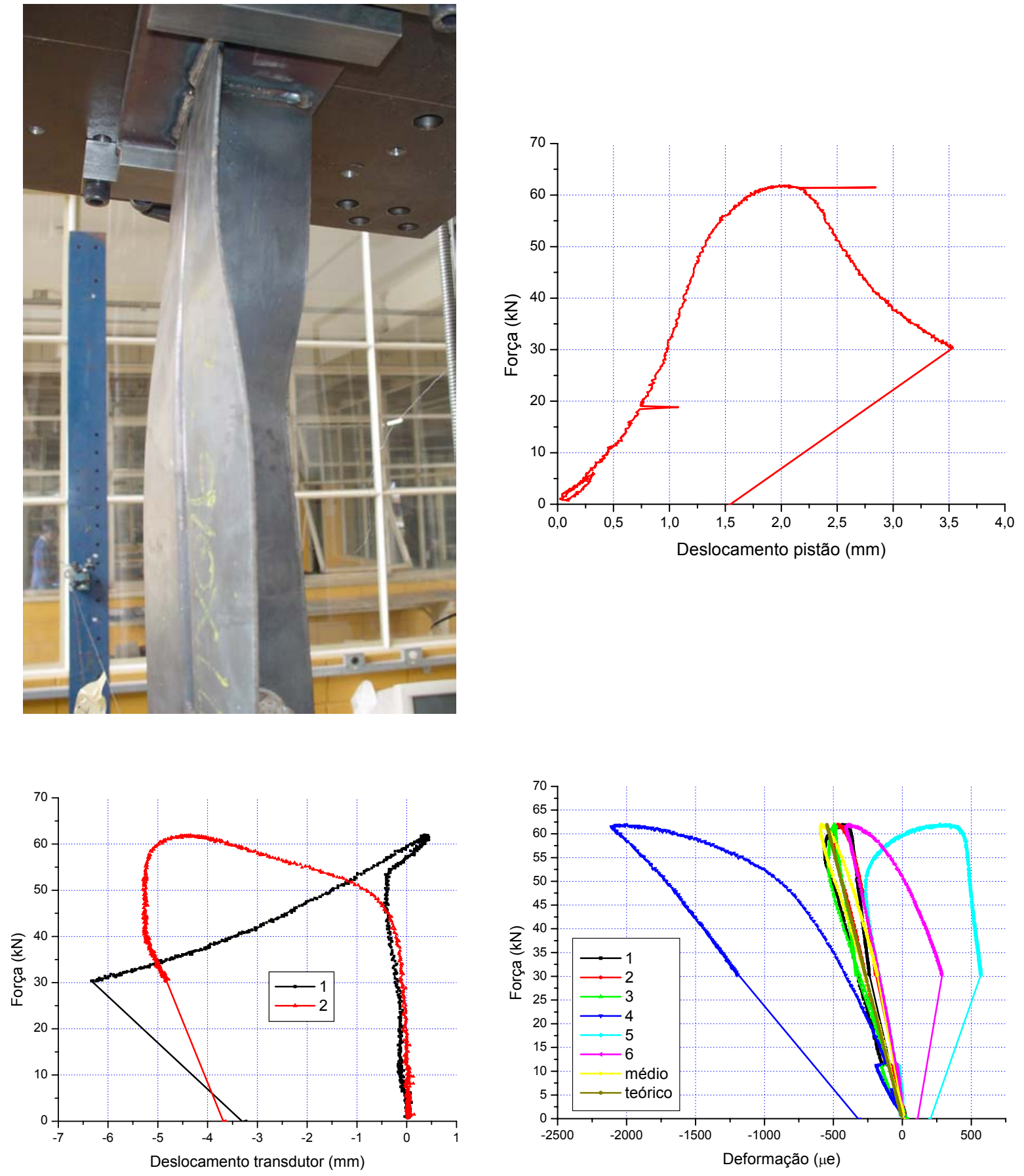

Figura D.4.1 Barras submetidas à compressão: 2L2.60-X 

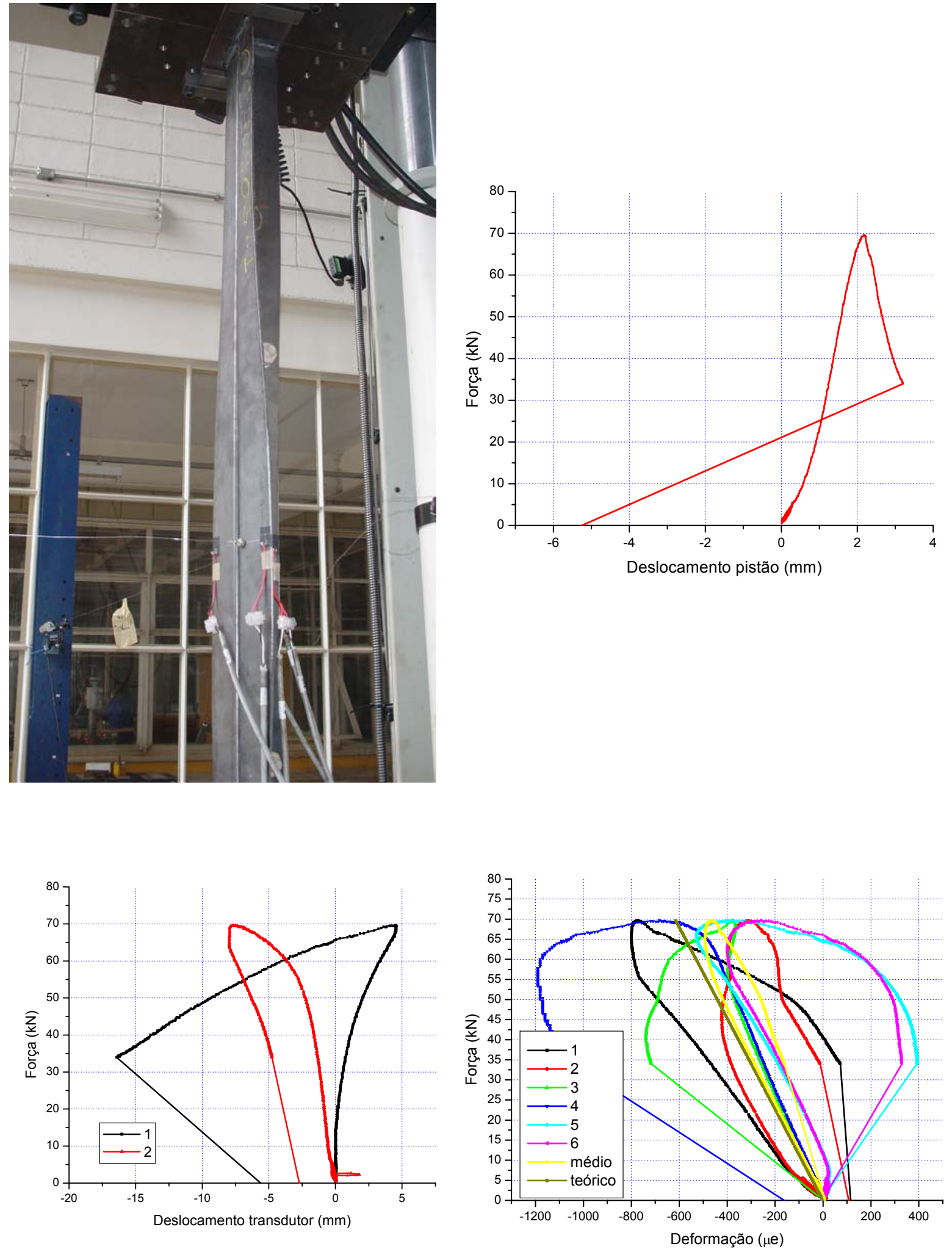

Figura D.4.2 Barras submetidas à compressão: 2L2.90-X 

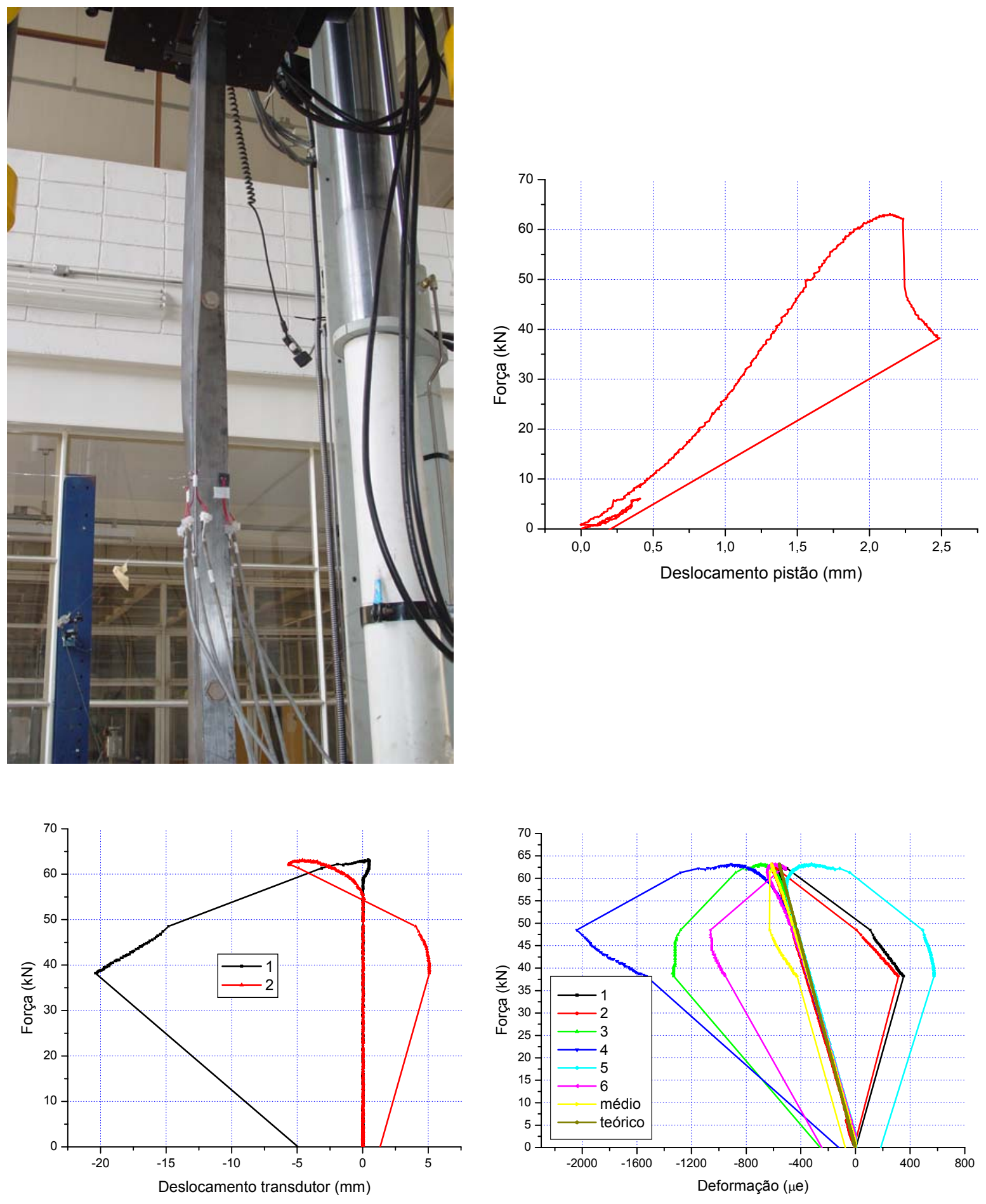

Figura D.4.3 Barras submetidas à compressão: 2L2.120-x 

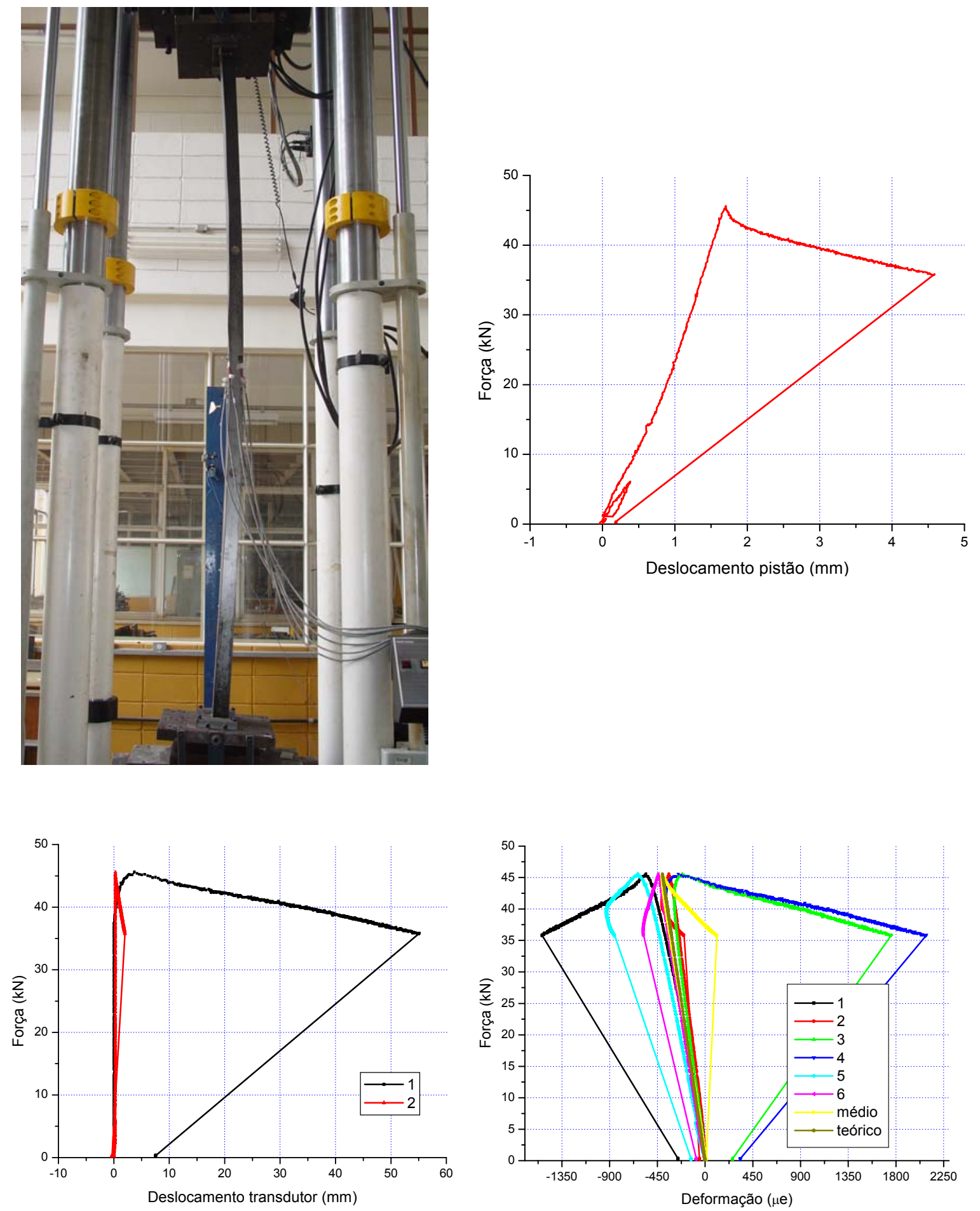

Figura D.4.4 Barras submetidas à compressão: 2L2.150-X 


\section{APÊNDICE D.5 - ENSAIOS DAS BARRAS LONGAS}

\section{PERFIL: Cantoneira dupla - rótula para flexão em "y"}
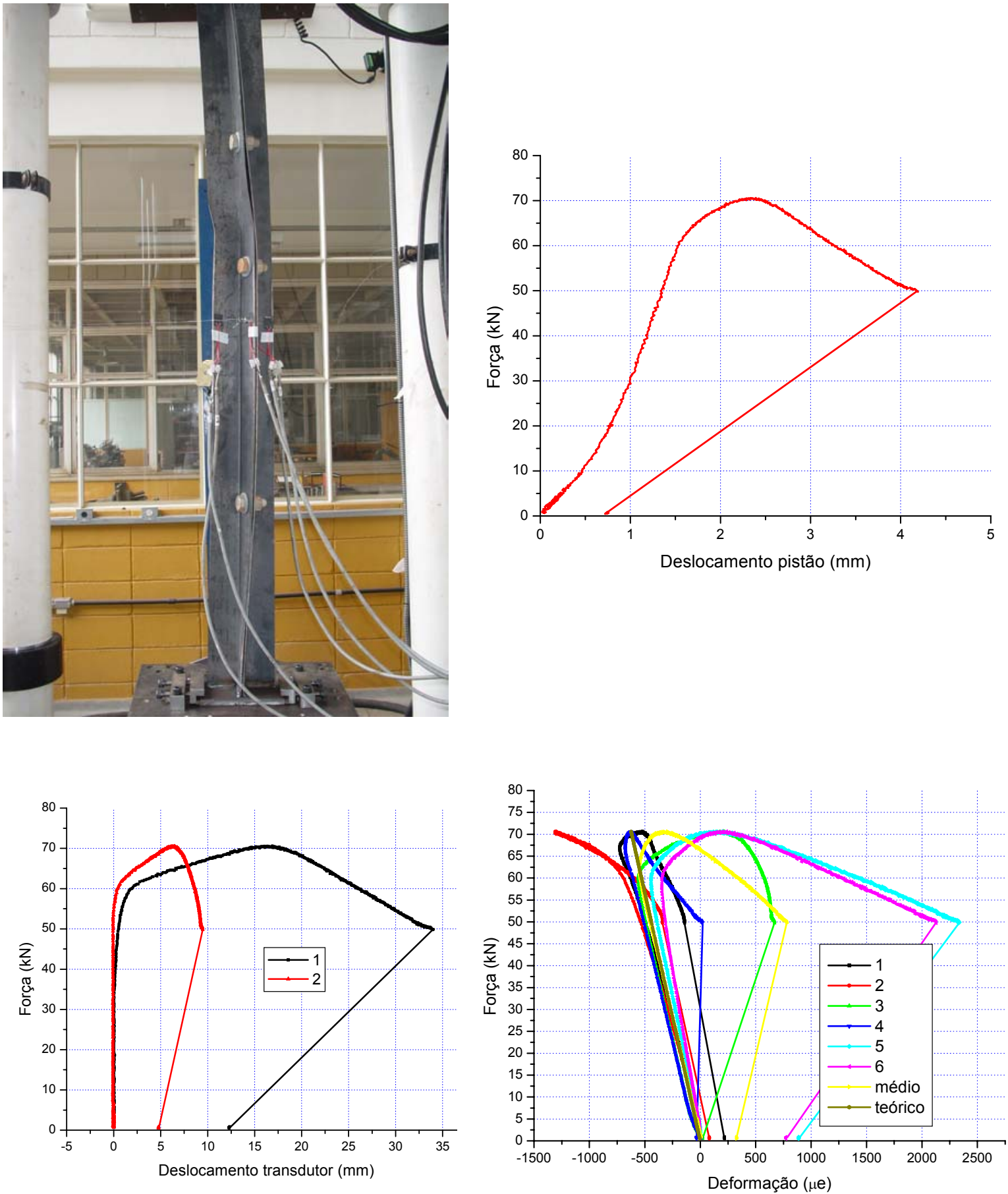

Figura D.5.1 Barras submetidas à compressão: 2L2.60-y 

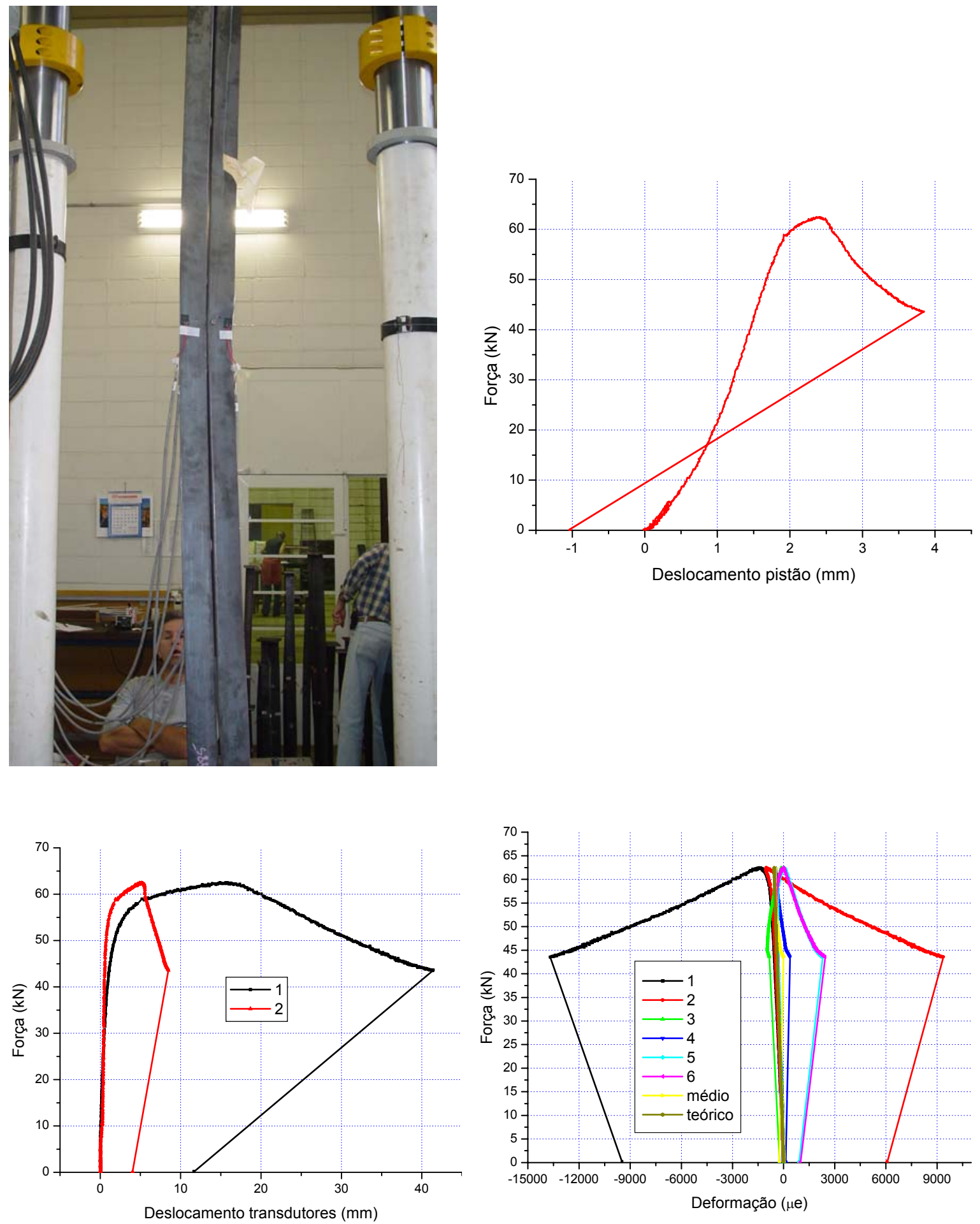

Figura D.5.2 Barras submetidas à compressão: 2L2.90-y 

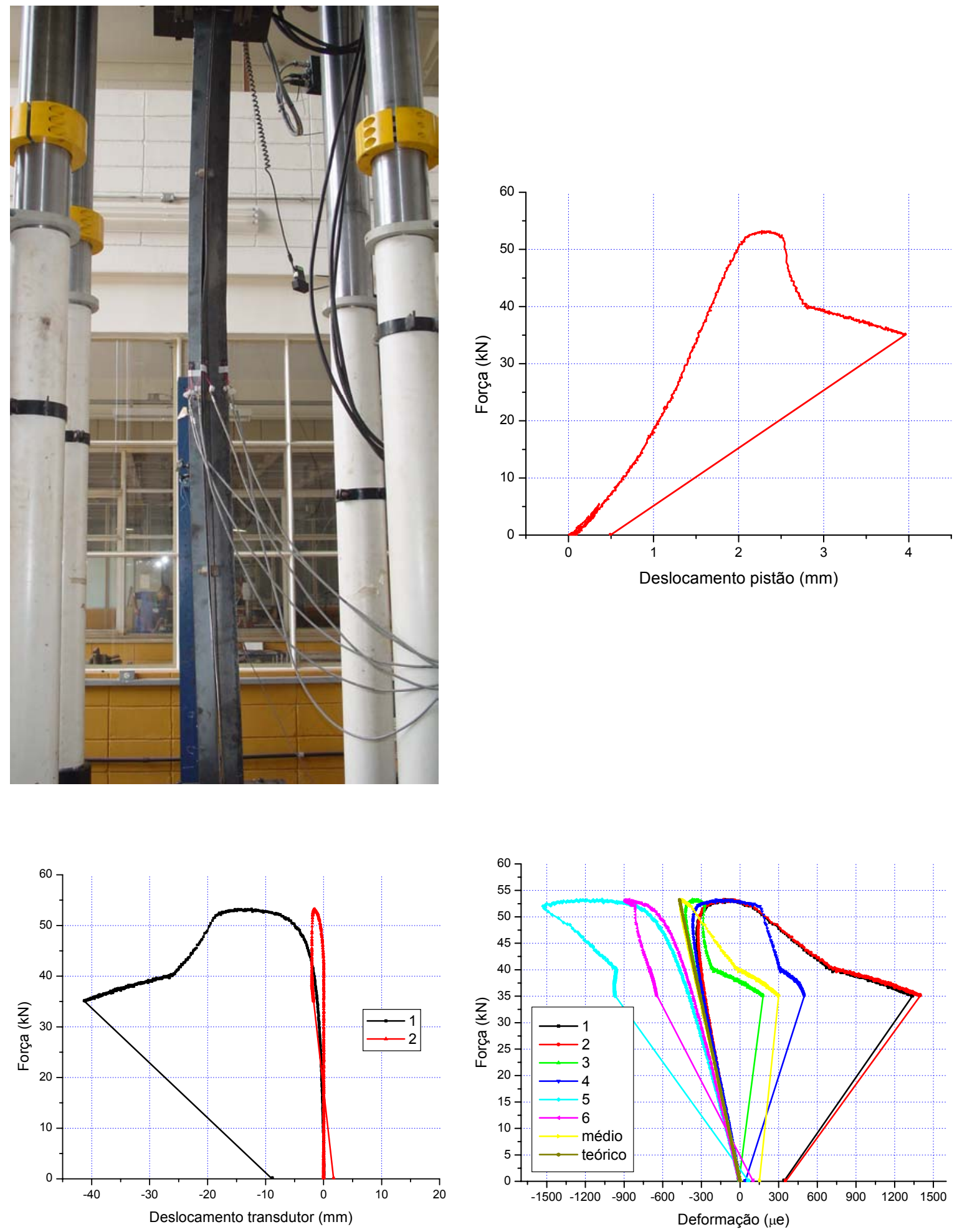

Figura D.5.3 Barras submetidas à compressão: 2L2.120-y 

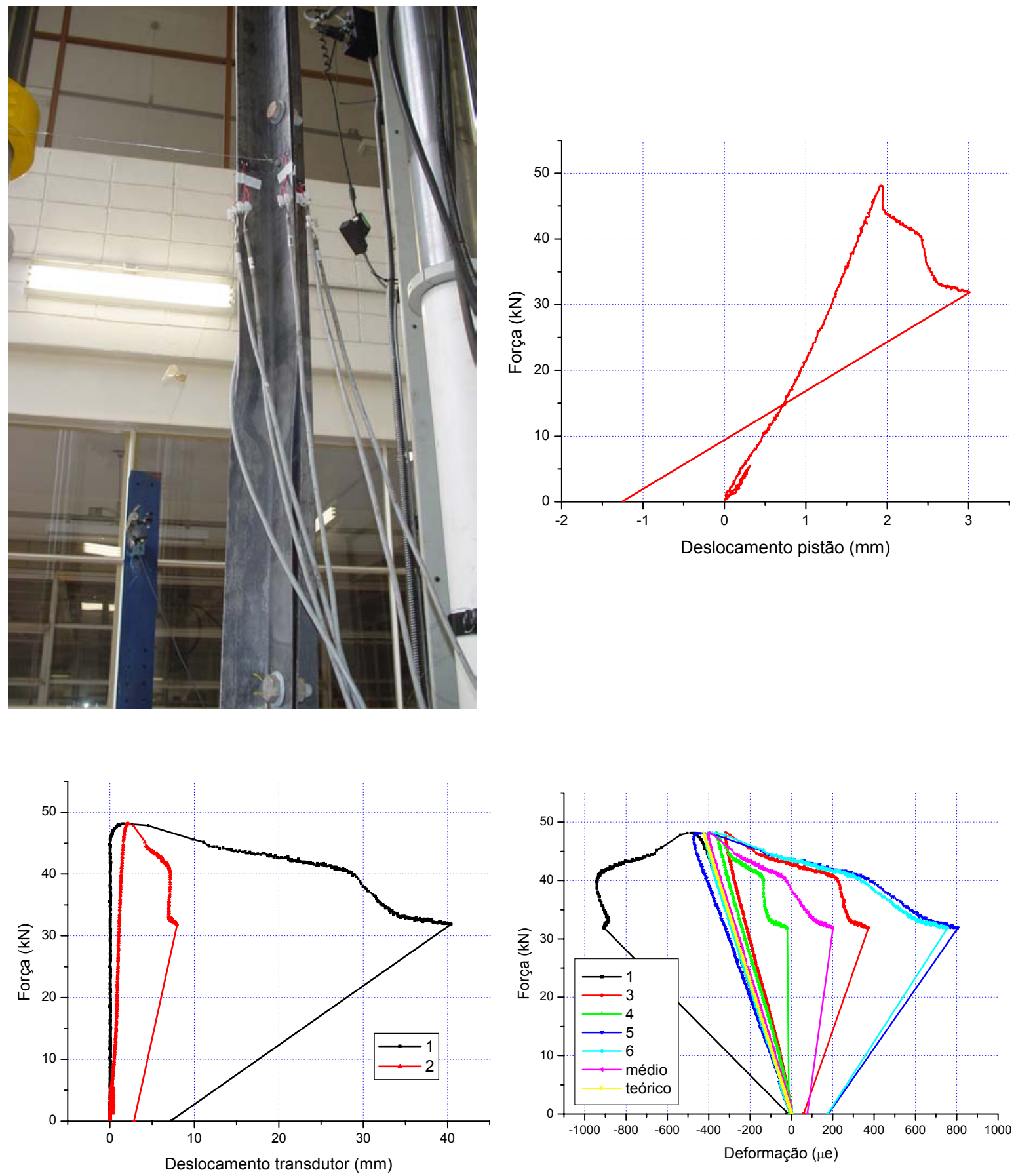

Figura D.5.4 Barras submetidas à compressão: 2L2.150-y 


\section{APÊNDICE E - RESULTADOS DO PROGRAMA CUFSM}

Este apêndice apresenta figuras com os resultados das análises de estabilidade elástica pelo método das faixas finitas via programa CUFSM para todas as seções transversais analisadas nesta Tese. As deformadas das seções transversais ilustradas nestas figuras correspondem aos pontos destacados nas curvas.

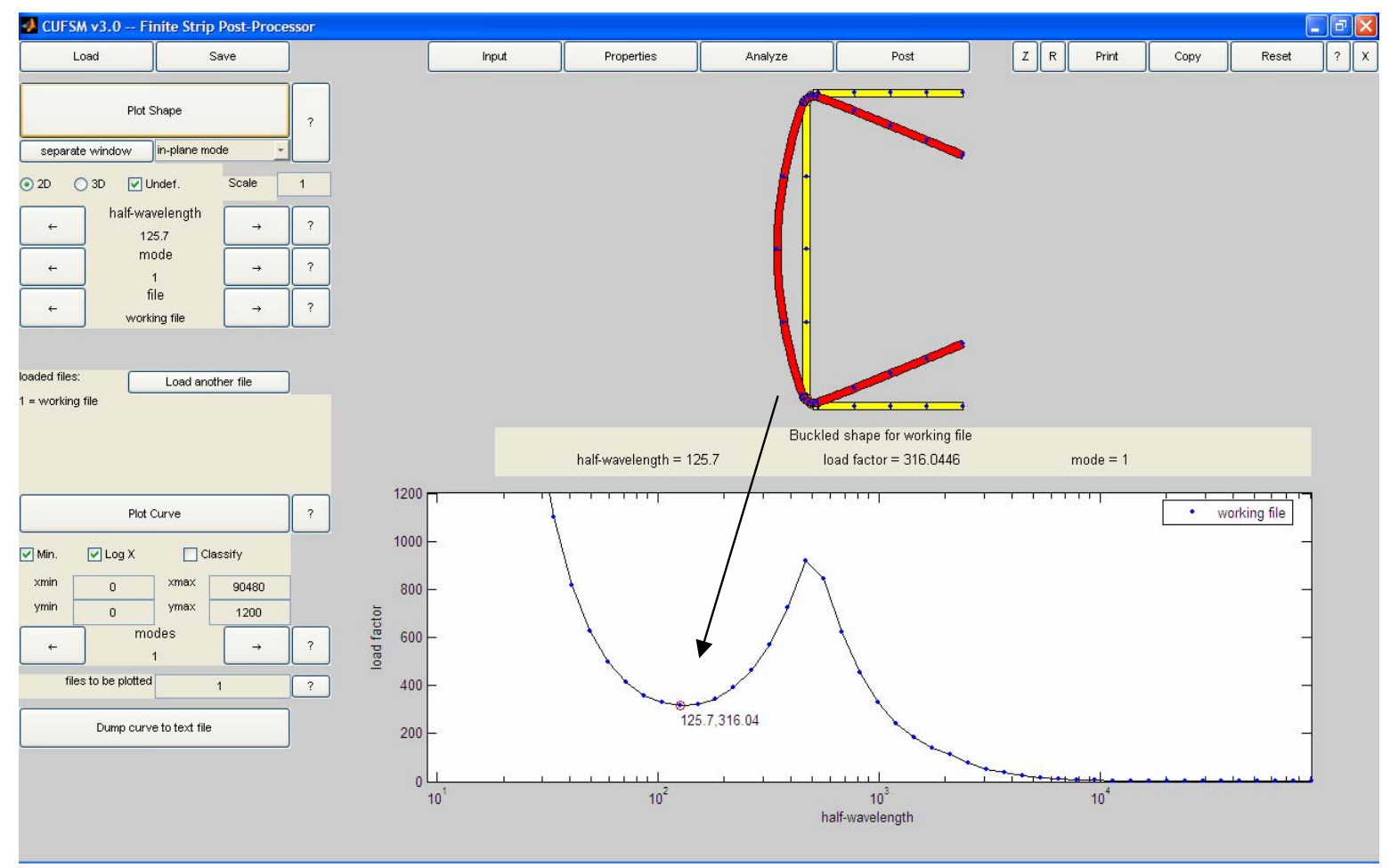

Figura E.1 Resultado da análise via CUFSM: perfil U $(\mathrm{t}=2,38 \mathrm{~mm})$ 


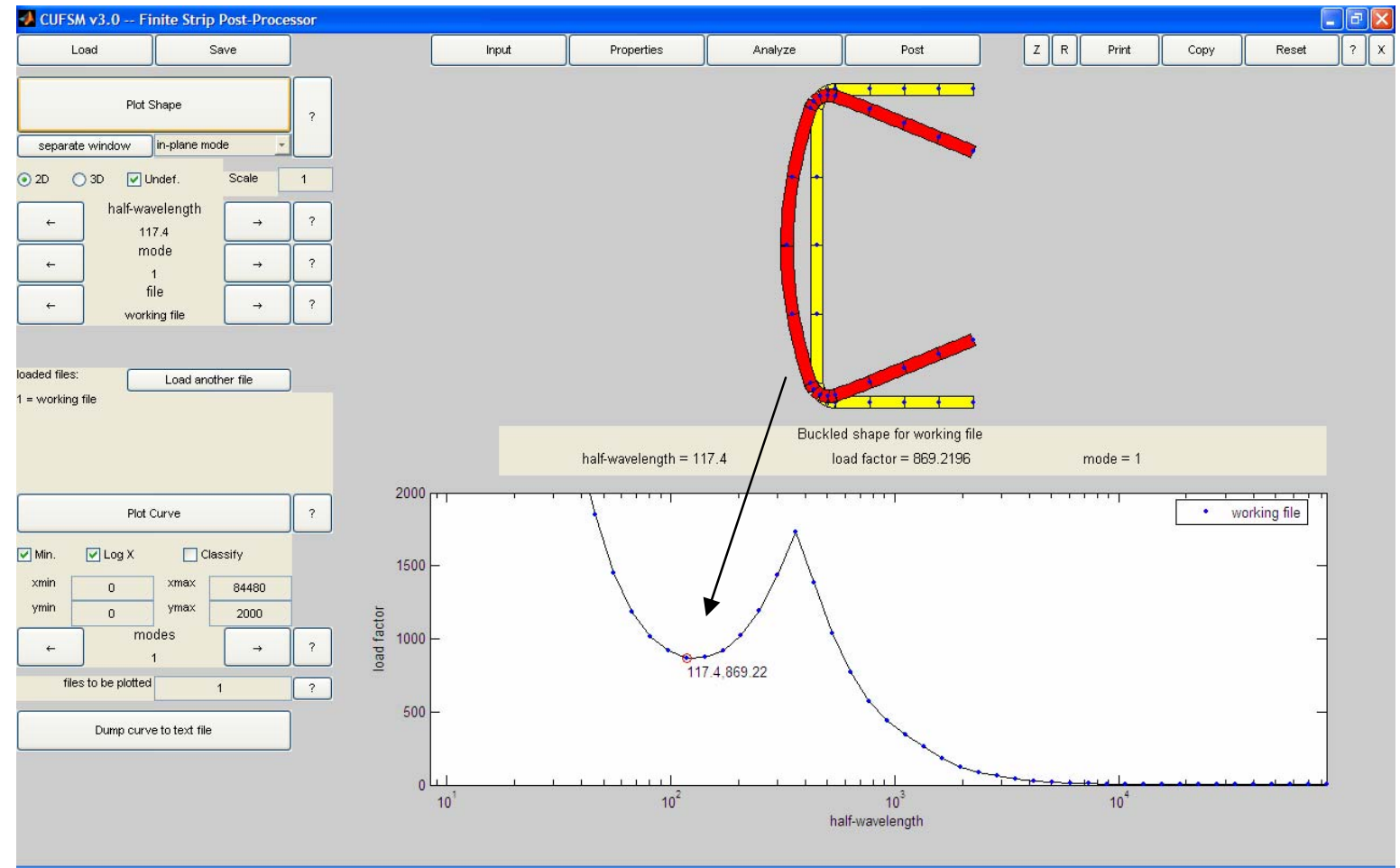

Figura E.2 Resultado da análise via CUFSM: perfil U $(\mathrm{t}=3,88 \mathrm{~mm})$

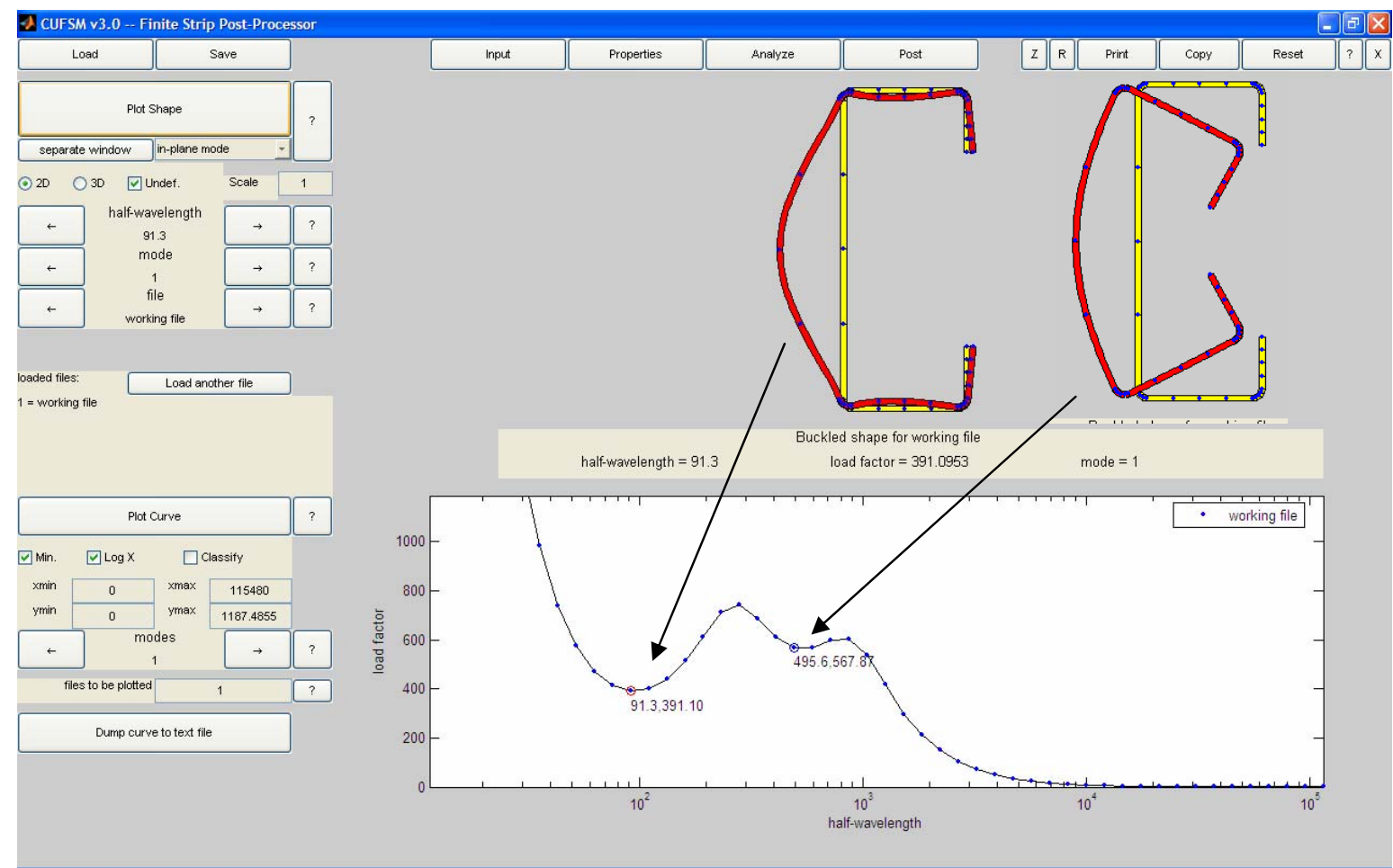

Figura E.3 Resultado da análise via CUFSM: perfil Ue $(\mathrm{t}=2,38 \mathrm{~mm})$ 


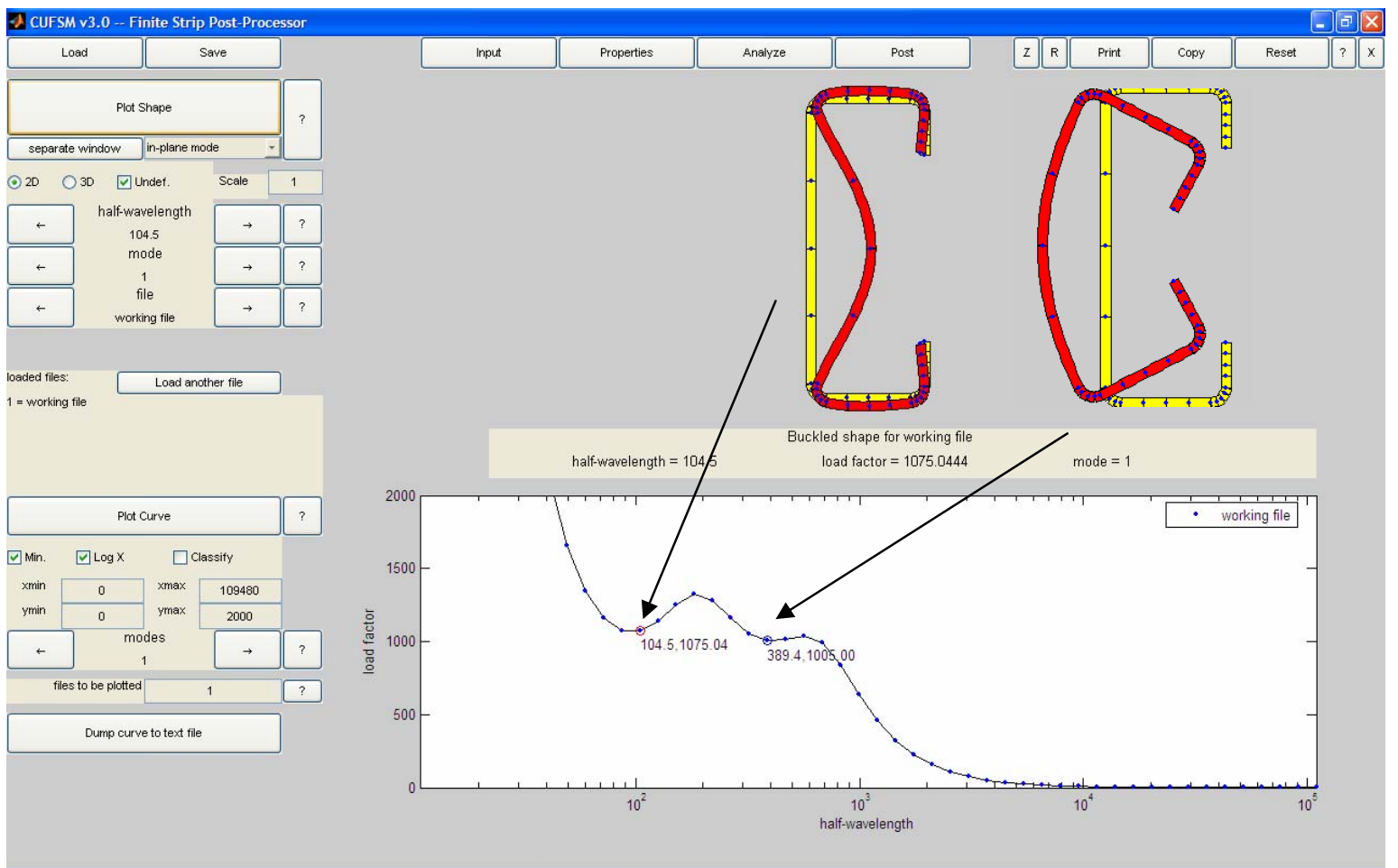

Figura E.4 Resultado da análise via CUFSM: perfil Ue $(\mathrm{t}=3,88 \mathrm{~mm})$

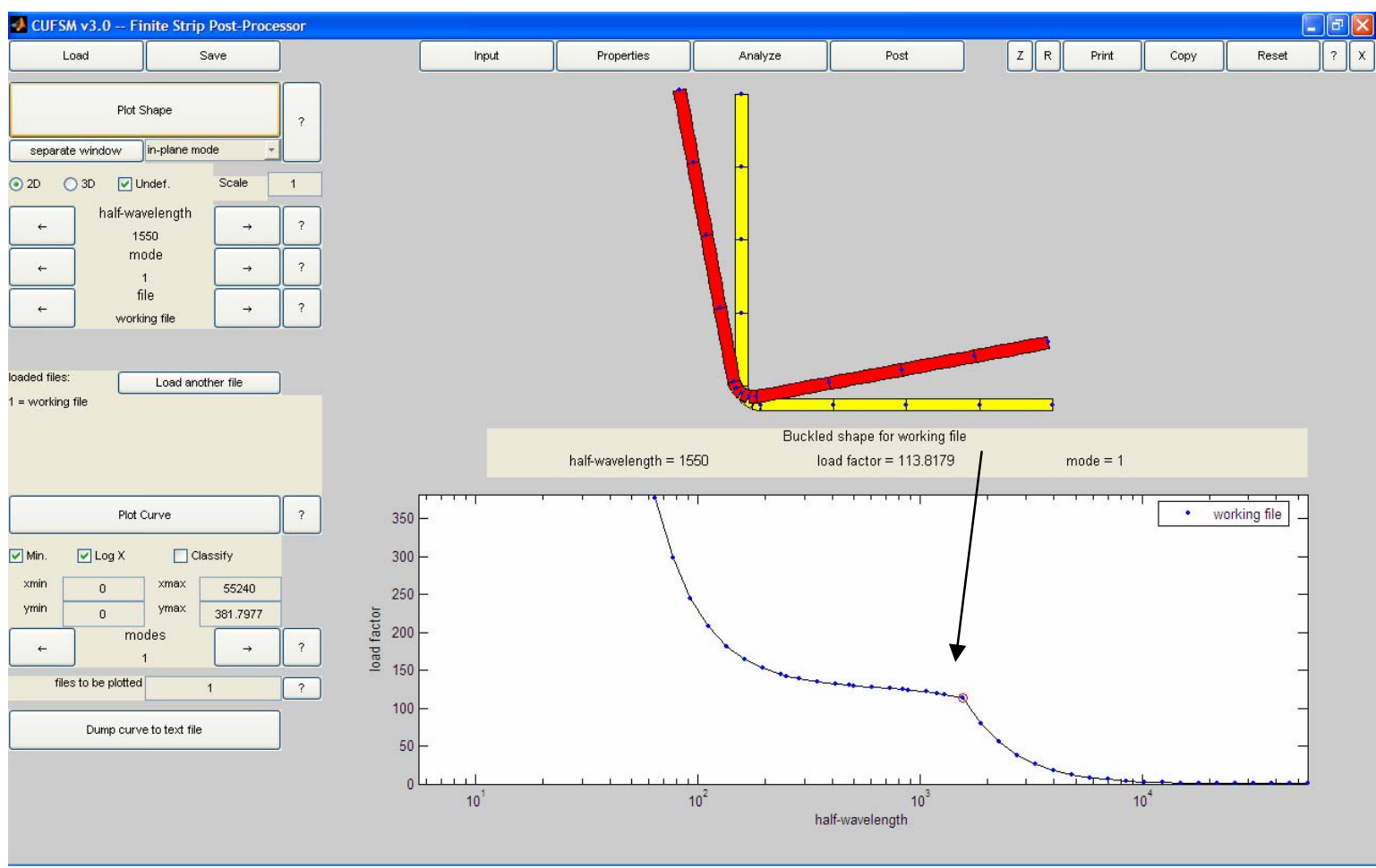

Figura E.5 Resultado da análise via CUFSM: cantoneira simples $(\mathrm{t}=2,38 \mathrm{~mm})$ 


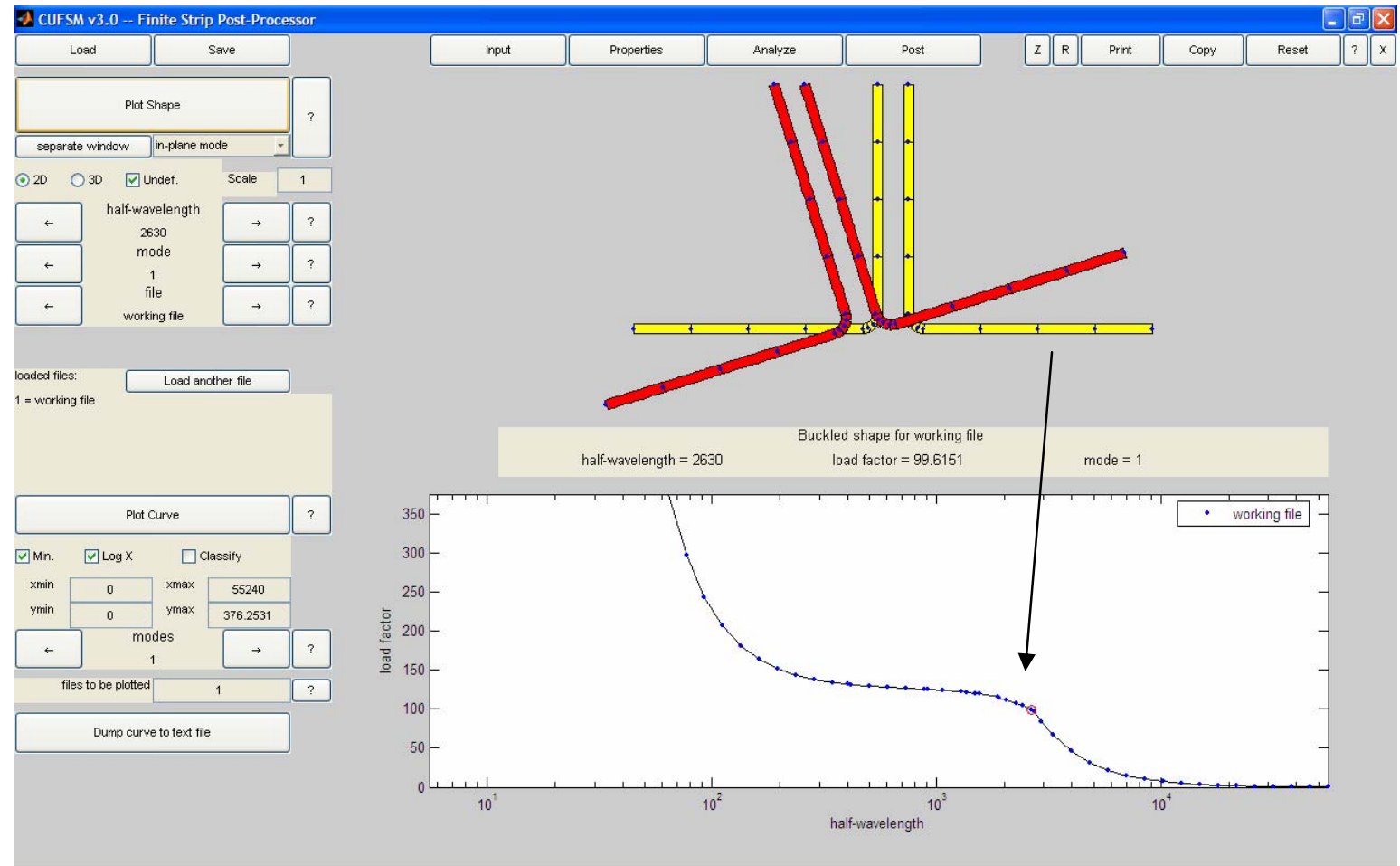

Figura E.6 Resultado da análise via CUFSM: cantoneira dupla $(\mathrm{t}=2,38 \mathrm{~mm})$ (utilizado acoplamento dos nós na metade da altura de uma das abas para simular presilhas) 


\section{APÊNDICE F - EXPRESSÕES: FLEXO-COMPRESSÃO}

Complementando-se o item da Tese relativo a problemas de segunda espécie, STIEMER (2000) apresenta expressões da norma canadense CAN/CSA-S16.1-94 para os casos a), b) e c) apresentados a seguir. Entende-se que estas expressões possam ser úteis para resolução rápida de casos práticos.

\section{a) Barra com imperfeição inicial:}

Uma barra submetida à compressão, com imperfeição inicial assumida como um arco de meio seno, pode ter o panorama de deslocamentos transversais durante o carregamento apresentado pela expressão (F.1). Esta expressão remete à expressão clássica de Young, apresentada no corpo da Tese.

$$
y(x)=-\left(\frac{1}{1-\frac{N}{N_{e}}}\right) v_{0} \cos \frac{\pi x}{L}
$$

Sendo:

$\mathrm{v}_{0}$ : deslocamento (imperfeição) inicial no meio do vão $L$ da barra;

$\mathrm{N}$ : força normal de compressão atuante na barra;

$\mathrm{N}_{\mathrm{e}}$ : força normal de flambagem elástica.

A tensão máxima $\sigma_{c}$ ocorrerá no meio do vão, ou seja, L/2, para um deslocamento $y_{c}$ conforme expressão (F.2), sendo representada pela expressão (F.3).

$$
\begin{aligned}
& y_{c}=-\left(\frac{1}{1-\frac{N}{N_{e}}}\right) v_{0} \\
& \sigma_{c}=\frac{N}{A}\left[1+\left(\frac{1}{1-\frac{N}{N_{e}}}\right)\left(\frac{e \bar{y}}{r^{2}}\right)\right]
\end{aligned}
$$

Sendo:

$\bar{y}$ : distância, na seção transversal, entre a fibra e o centro de gravidade; 
A: área bruta da seção transversal da barra;

r: raio de giração.

\section{b) Barra com força excêntrica:}

A tensão máxima de uma barra submetida à ação de uma força de compressão excêntrica conduz à fórmula secante (F.4).

$$
\sigma_{c}=\frac{N}{A}\left\lfloor 1+\left(\frac{e^{\prime} \bar{y}}{r^{2}}\right) \sec \left(\frac{\pi}{2} \sqrt{\frac{N}{N_{e}}}\right)\right\rfloor
$$

Sendo:

e': excentricidade do ponto de aplicação da força em relação ao centro de gravidade;

c) Barra (biapoiada) com imperfeição inicial e força excêntrica:

Neste caso, a solução para o deslocamento no meio do vão pode ser desenvolvida em uma série como expressa a seguir em (F.5).

$$
y_{c}=e\left(1+\frac{1}{2}\left(\frac{\pi}{4}\right) \frac{N}{N_{e}}+\frac{5}{24}\left(\frac{\pi^{4}}{16}\right) \frac{N^{2}}{N_{e}^{2}}+\ldots\right)+e^{\prime}\left(1+\frac{5}{12}\left(\frac{\pi^{2}}{4}\right) \frac{N}{N_{e}}+\frac{61}{360}\left(\frac{\pi^{4}}{16}\right) \frac{N^{2}}{N_{e}^{2}}+\ldots\right)
$$

Para o caso de $\mathrm{N} / \mathrm{N}_{\mathrm{e}}<0,2$, tem-se que (F.5) pode ser aproximada pela expressão (F.6):

$$
y_{c}=\left(e+e^{\prime}\right)\left(1+\frac{3}{2} \frac{N}{N_{e}}\right)
$$

A expressão (F.7) pode ser utilizada para o cálculo da tensão máxima no meio do vão.

$$
\sigma_{c}=\frac{N}{A}\left[1+\left(1+\frac{3}{2} \frac{N}{N_{e}}\right) \frac{\bar{y}}{r^{2}}\left(e+e^{\prime}\right)\right]
$$

